Universidade de São Paulo

Instituto de Astronomia, Geofísica e Ciências Atmosféricas

Departamento de Meteorologia

Isidro Metódio Tuleni Johanes Ihadua

\title{
Análise microfísica de sistemas precipitantes no leste de são Paulo por meio de radares meteorológicos polarimétricos
}

São Paulo 
Isidro Metódio Tuleni Johanes Ihadua

\section{Análise microfísica de sistemas precipitantes no leste de são Paulo por meio de radares meteorológicos polarimétricos}

Tese apresentada ao Departamento de Meteorologia do Instituto de Astronomia, Geofísica e Ciências Atmosféricas da Universidade de São Paulo como requisito parcial para a obtenção do título de Doutor em Ciências.

Área de Concentração: Meteorologia Orientador: Prof. Dr. Augusto José Pereira Filho

Versão Corrigida. O original encontra-se disponível na Unidade

São Paulo 
Aos meus pais, DEDICO! 


\section{Agradecimentos}

Ao meu orientador, Prof ${ }^{0}$ Dr. Augusto José Pereira Filho, pela recepção, amizade construída, pelos conhecimentos científicos e de vida transmitidos, pela confiança em mim depositada, pelo incomensurável amadurecimento acadêmico que me proporcionou, por todos os momentos de descontração e seriedade nesses anos juntos. O senhor fez toda a diferença nessa missão. Minha eterna gratidão.

À Coordenação de Aperfeiçoamento de Pessoal de Nível Superior "CAPES"e ao Conselho Nacional de Desenvolvimento Científico e Tecnológico "CNPq"pelo apoio financeiro.

Ao pesquisador Dr. Timothy Lang (Atmospheric Measurements, Marshall Space Flight Center NASA) pelos ficheiros referenciados nos códigos disponíveis na plataforma CSURadarTools.

Ao MSc Kleber Lopes da Rocha Filho (Departamento de Águas e Energia Elétrica) pela concessão dos dados do radar SPOL de São Paulo.

Ao Dr. Thiago Biscaro (CPTEC/INPE) pela conversão dos dados SPOL.

Aos Dr. Diogo Nunes da Silva Ramos, José Luís Flores Rojas Ivon e Wilson da Silva Júnior pelo apoio computacional.

Aos meus amigos colegas João Maria de Souza Afonso, Nayara Arroxelas dos Santos, Eleazar chuchon angulode, Jorge Rosas Santana, Carolina Bitencour Bernardes, Yusvelis Maribel Barzaga Ramirez, Marcos Figueiredo Salviano, Darsys Aguero Morell, entre outros, foram pessoas que direta ou indiretamente, fizeram a minha caminhada não cessar durante o doutorado.

A todo o corpo docente do Departamento de Ciências Atmosféricas pela transmissão do conhecimento. A todos os técnicos e funcionários do DCA pelos socorros prestados. 
"O que sabemos é uma gota, o que ignoramos é um oceano"

Isaac Newton

"A ciência opera na fronteira entre conhecimento e ignorância. Não temos medo de admitir o que não sabemos. Não há vergonha nisso. A única vergonha é achar que temos todas as respostas" Neil deGrasse Tyson

"O mais importante é nunca parar de questionar. A curiosidade tem uma razão para existir... Nunca perca sua sagrada curiosidade."

Albert Einstein 


\section{Resumo}

Este trabalho teve como tema de estudo análise microfísica dos sistemas precipitantes atuantes sobre a Região Leste de São Paulo (RLSP) com ênfase na Região Metropolitana de São Paulo (RMSP). São discutidas nesta tese questões relacionadas ao impacto da urbanização nos processos microfísicos de sistemas precipitantes associados a sistemas de escala sinótica, mesoescala e escala local. Entre as questões abordadas estão o impacto da ilha de calor urbano (ICU) e o adensamento urbano verticalizado na microfísica, dinâmica e termodinâmica, e distribuição das precipitações e chuvas mais intensas durante a evolução espaço-temporal dos eventos de brisa marítima (BM) e convecções isoladas (CIs), e bandas dispersas $(\mathrm{BDs})$ induzidas por frente fria $(\mathrm{FF})$ com e sem fumaça de incêndios na Amazônia. A metodologia proposta para a realização do projeto compreende cinco componentes: classificação de hidrometeoros com a lógica fuzzy, cálculos do diâmetro da gota de chuva, da massa de água líquida e massa de água sólida e da taxa de chuva a partir das variáveis polarimétricas medidas com radares meteorológicos de dupla polarização banda $\mathrm{X}$ e banda $\mathrm{S}$ e dados de radiossondagens. Os resultados da classificação de hidrometeoros são comparados com as medidas observadas dos radares meteorológicos Doppler. Os resultados mostram que as variações microfísicas das proporções de mistura de diferentes hidrometeoros e os parâmetros dinâmicos e termodinâmicos associados às células convectivas, influenciaram na produção de chuva forte. Os resultados também indicaram que a urbanização impacta na formação da precipitação, massa de água líquida e massa de água sólida, profundidade e duração longa das células convectivas (CIs) e tempestade induzida por combinações de BM, FF e ICU que se formam na RMSP. As CIs se formam no centro geométrico da RMSP, geralmente induzidas por rotação ciclônica que as tornam mais profundas e de duração longa, percorrendo longas distâncias sobre regiões de aden- 
samento urbano da RMSP. Os resultados mostraram que os eventos que atuam na RMSP, dependem de processos microfísicos de nuvem mista (água e gelo) acima da isoterma $0^{\circ} \mathrm{C}$ para produção de chuva forte. Observou-se que o processo de descongelamento das pedras de granizo inicia quando precipitam a partir da isoterma $0^{\circ} \mathrm{C}$ que transformam-se em gotas grandes já a partir da isoterma $0^{\circ} \mathrm{C}$. A quantidade de pedras de granizo diminui e a quantidade de gotas grandes aumenta paulatinamente, à medida que estes hidrometeoros precipitam da base da isoterma $0^{\circ} \mathrm{C}$ para temperaturas $>0^{\circ} \mathrm{C}$ para as regiões inferiores das células convectivas. Notou-se que quando a CI é induzida por rotação ciclônica, uma porção das pedras granizo precipita intacta até à superfície, enquanto outra porção é terraformada em gotas grandes pelo processo de descongelamento. Quando a CI é induzida por convergência na superfície, descongela toda a quantidade de pedras de granizo que transforma-se em gotas grandes ao precipitar até à superfície. Os resultados mostraram que a tempestade induzida por combinações de BM, FF e ICU, resulta da integração de disparos de várias células convectivas secundárias intensas no centro geométrico da RMSP. A ICU induz fortes convergências entre os fluxos de noroeste e os fluxos da BM, retardando o deslocamento da frente de BM e da tempestade para fora do centro geométrico da RMSP, que influenciou na maior produção de granizo na área da tempestade acima da isoterma $0^{\circ} \mathrm{C}$ sobre o centro da cidade de São Paulo do que nas outras áreas da tempestade. Os resultados mostraram que a fumaça de incêndios na Amazônia, influenciou na redução do tamanho das gotas e na supressão generalizada da chuva das BDs induzidas por FF sobre a RMSP durante o Inverno de 2019. As BDs sem presença de fumaça produziram chuva generalizada, e com algumas células que produziram pedras de granizo e graupel nos núcleos acima da isoterma $0^{\circ} \mathrm{C}$ e gotas grandes na base da isoterma $0^{\circ} \mathrm{C}$ durante o Verão de 2019. Estes importantes processos microfísico, dinâmico e termodinâmico dentro das CIs e da tempestade resultante da integração das células convectivas secundárias induzidas por combinações de BM, FF e ICU, devem ser tidos em conta no esquema de parametrização dos modelos de nuvem, bem como a dinâmica e termodinâmica associada as piscinas frias na superfície, que são importantíssimos para a previsão, principalmente de curtíssimo prazo de perigo de precipitação de granizo e de chuvas fortes.

Palavras-chave: Radar, polarimetria, classificação de hidrometeoros, célula convectiva, rotação ciclônica, granizo. 


\section{Abstract}

This work is concerned with microphysical analysis of the precipitating systems on the Eastern Region of São Paulo (RLSP) with emphasis on the Metropolitan Area of São Paulo (RMSP). This manuscript deals with issues related to the impact of urbanisation on the microphysical processes of precipitating systems associated with synoptic, mesoscale, and local scale systems. Among the issues addressed are the impact of the urban heat island (ICU) and the vertical urban density in microphysics, dynamics and thermodynamics, and distribution of rainfall and more intense rainfall during the space-time evolution of sea breeze (BM) events and isolated convections (ICs), and scattered bands (BDs) induced by the cold front (FF) with and without smoke from fires in the Amazon. The proposed methodology for carrying out the project comprises five components: classification of hydrometeors with fuzzy logic, calculations of the diameter of the raindrop, of the liquid water mass and solid water mass, and the rain rate from the polarimetric variables measured with X-band and S-band dual-polarization weather radars and radiosonde data. The results of the hydrometeor classification are compared with the observed measurements of the Doppler weather radars. The results show that the microphysical variations of the mixing ratios of different hydrometeors and the dynamic and thermodynamic parameters associated with the convective cells influenced the production of heavy rain. The results also indicated that urbanization impacts the formation of precipitation, liquid water mass and solid water mass, depth and long duration of convective cells (ICs), and storm-induced by combinations of BM, FF, and ICU that form in the RMSP. ICs are formed in the geometric centre of the RMSP, generally induced by cyclonic rotation that makes them deeper and long-lasting, covering long distances over dense urban regions of in the RMSP. The results showed that the events that act in the RMSP, depend on mixed cloud microphysical 
processes (water and ice) above the $0^{\circ} \mathrm{C}$ isotherm to produce heavy rain. It was observed that the process of defrosting the hailstones starts when they precipitate from the $0^{\circ} \mathrm{C}$ isotherm which transforms into large drops already from the $0^{\circ} \mathrm{C}$ isotherm. The amount of hailstones decreases and the amount of large drops gradually increases, as these hydrometeors precipitate from the base of the $0^{\circ} \mathrm{C}$ isotherm for temperatures greater than $0^{\circ} \mathrm{C}$ for the lower regions of the convective cells. It was noted that when IC is induced by cyclonic rotation, a portion of the hailstones precipitates to the surface intact, while another portion is transformed into large drops by the thawing process. When IC is induced by convergence on the surface, it thaws the entire amount of hailstones that turn into large drops when it precipitates to the surface. The results showed that the storm-induced by combinations of $\mathrm{BM}, \mathrm{FF}$, and ICU, results from the integration of trigger from several intense secondary convective cells in the geometric centre of the RMSP. The ICU induces strong convergences between northwest flows and BM flows, delaying the displacement of the BM front and the storm out of the RMSP geometric centre, which influenced the greater hail production in the storm area above the $0^{\circ} \mathrm{C}$ isotherm over the city centre of São Paulo than in other areas of the storm. The results showed that the smoke from fires in the Amazon influenced the reduction in the size of the droplets and the generalised suppression of rain of the BDs induced by FF over the RMSP during the 2019 winter. The BDs without smoke produced generalised rain, and with some cells that produced hailstones and graupel in the nuclei above the $0^{\circ} \mathrm{C}$ isotherm and large drops at the base of the $0^{\circ} \mathrm{C}$ isotherm during the 2019 summer. These important microphysical, dynamic, and thermodynamic processes within ICs and the storm resulting from the integration of secondary convective cells induced by combinations of BM, FF, and ICU, must be taken into account in the parameterization scheme of the cloud models, as well as the dynamics and thermodynamics associated with cold pools on the surface, which are very important for the forecast, mainly very short-term risk of precipitation of hail and heavy rains.

Keywords: Radar, polarimetry, classification of hydrometeors, convective cell, cyclonic rotation, hail. 


\section{Lista de Figuras}

1.1 Esquema do funcionamento dos processos microfísicos envolvidos na formação da precipitação em nuvens convectivas. Fonte: Holton et al. (2003) . . . .

1.2 Região Metropolitana de são Paulo (RMSP). O contorno com amarelo é a fronteira política da RMSP. Os contornos cor laranja são as fronteiras políticas dos municípios dentro da RMSP. A área cinzenta é adensamento urbano. A cor azul é o oceano. Fonte: Adaptada de Google Earth. . . . . .

1.3 (a) Esquemas de uma condição sinóptica típica associada ao desenvolvimento de convecção profunda sobre a RMSP causada por intensa brisa marítima, circulação de ilhas de calor urbana e frente fria. (b) Diagrama esquemático de uma seção transversal de ventos e nebulosidade para um desenvolvimento típico de convecção profunda sobre a RMSP, causada pela brisa do marítima, vento de noroeste e ilha de calor urbana. Fonte: Vemado e Pereira Filho (2016) . . . . . . . . . . . . . . . .

1.4 (a) Espalhamento Rayleigh, tamanho de hidrometeoro $<\lambda / 10$, não depende do ângulo incidente, sofre espalhamento isotrópico. (b) Espalhamento de Mie, tamanho de hidrometeoro $>\lambda / 10$, depende do ângulo incidente, espalhamento não-isotrópico. (c) Espalhamento óptico, dependência do ângulo aumenta com hidrometeoro maior . . . . . . . . . . . . . .

1.5 Secção transversal de retroespalhamento $\sigma_{b}$ para hidrometeoros esféricos e não-esféricos (a). Secção transversal de retroespalhamento $\sigma_{b}$ para hidrometeoros esféricos e não-esféricos de radar banda $\mathrm{X}(3.21 \mathrm{~cm})$, radar banda $\mathrm{C}$ $(5.5 \mathrm{~cm})$ e radar banda $\mathrm{S}(10 \mathrm{~cm})(\mathrm{b})$. Fontes: Oziel et al. (2017) e Doviak

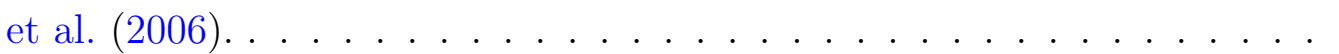


2.1 Exemplo de PPI e CAPPI. Um CAPPI é obtido através de uma selecção de intervalos em vários PPIs para criar uma imagem $2 \mathrm{D}$ da varredura do volume. Fonte: Fabry (2015). . . . . . . . . . . . . . . .

2.2 Área de vigilância da MXPOL na Região Metropolitana de São Paulo. A Cruz e o triângulo indicam a localização da MXPOL e do Disdrometro JW no Parque Estadual Fontes do Ipiranga (PEFI), respectivamente. As áreas verde e amarela são as cidades de São Paulo e Barueri, respectivamente. Fonte: Pereira Filho et al. (2007). . . . . . . . . . . . . . . . . . . 66

2.3 Área de vigilância da SPOL no Leste do Estado de São Paulo. O ponto azul indica a localização do SPOL, instalado na barragem de Ponte Nova, localizada na cabeceira do rio Tietê. . . . . . . . . . . . .

2.4 Refletividade diferencial $\left(\mathrm{Z}_{D R}\right.$ para diferentes tamanhos e orientação de hidrometeoros. Fonte: www.eol.ucar.edu. Acessado em 10 de Dezembro de

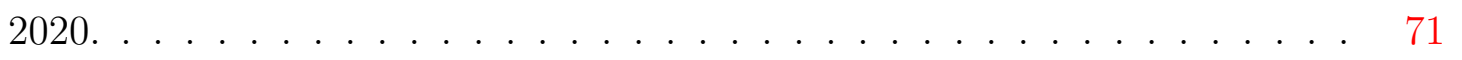

2.5 Interação das ondas electromagnéticas polarizadas horizontalmente (cor cinza) e verticalmente (cor laranja) com as gotas de chuva. Na primeira coluna ambas as ondas estão em fases. Na segunda coluna, a passagem por muitas gotas grandes faz com que a onda electromagnética polarizada horizontalmente abrande mais do que a onda electromagnética polarizada verticalmente; já não está em fase. Na terceira coluna, a diferença de fase é preservada à medida que ambas as ondas electromagnéticas polarizadas saem da chuva. Na quarta coluna, o encontro de mais gotas grandes faz com que a diferença de fase volte a aumentar. Fonte: www.eol.ucar.edu. Acessado em 10 de Dezembro de 2020 . . . . . . . . . . . . . . . . . . . . . . . . 72

2.6 Variação nos valores de $\mathrm{K}_{D P}$ para diferentes tamanhos e tipos de hidrometeoros. Fonte: Rauber e Nesbitt (2018). . . . . . . . . . . . . . . . . 73 
2.7 Sistema fuzzy para a classificação de hidrometeoros para as variáveis polarimétricas $1=\mathrm{Z}_{H}, 2=\mathrm{Z}_{D R}, 3=\rho_{h v}, 4=\mathrm{K}_{D P}, 5=$ dados da temperatura obtida por uma radiossondagem. $\mathrm{MBF}_{n_{m}}, n$ seria o número correspondente a variável polarimétrica e $m$ seria o número do tipo de hidrometeoro (1=chuvisco, $2=$ chuva, ..., etc). $\operatorname{Ps}_{n_{m}}$ corresponde a Fuzzificação. $\operatorname{Rs}_{n}$ representa as regras de inferência. MAX representa o valor máximo das regras de inferência. Fonte: adaptada de Rauber e Nesbitt (2018), apud Liu e Chan-

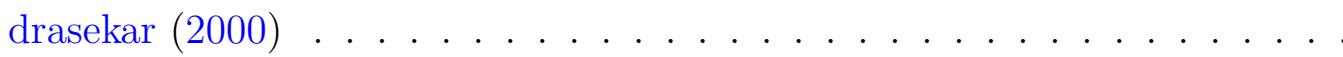

2.8 Simulações T matriz de uma gota de chuva. (a) para reflectividade na polarização horizontal e (b) para atenuação diferencial versus diâmetro equivalente à gota na banda $\mathrm{S}$ (verde) e na banda X (vermelho). Fonte: Rauber e Nesbitt (2018). . . . . . . . . . . . . . . . . .

3.1 Análise sinótica da tempestade através de imagens de satélite ocorrido no dia 11 de Janeiro de 2010 . . . . . . . . . . . . . . . . . . . .

3.2 (a) Campo de pressão reduzido ao nível do mar (hPa); (b) campo de movimento vertical e altura geopotencial (gpm); (c) Campo de vento (m.s ${ }^{-1}$ ) a $10 \mathrm{~m}$ e umidade (\%) a $2 \mathrm{~m}$ acima da superfície; e (d) CAPE $\left(\mathrm{J} \mathrm{kg}^{-1}\right)$, obtido a partir da análise de modelo de circulação global-GFS do evento ocorrido no 11 de janeiro de 2010. A faixa de isóbaras é de 1 hPa. Cores frias/quentes indicam valores mais baixos/mais altos. A faixa de isolinhas geopotenciais é de 20 gpm e a barra de cores indica a velocidade vertical em $\mathrm{Pa} \mathrm{s}^{-1}$. As setas indicam a magnitude do vento e a barra de cores indica a umidade. A escala de cores indica os valores do CAPE. Contornos geopolíticos, latitudes, longitudes e tempos são indicados . . . . . . . . . 
3.3 (a) PPI de elevação $0.6^{\circ}$ da velocidade radial do radar MXPOL de 11 de Janeiro de 2010 às 2025 UTC do sistema de convecção induzida por brisa marítima e vento de noroeste sobre o centro geométrico da RMSP. (b) corte vertical do perfil de temperatura e umidade relativa do ECMWF dentro de uma coluna com resolução de $12.5 \mathrm{~km}^{2}$, fixo na longitude $47^{\circ} 60^{\prime} \mathrm{W}$ e variando entre latitudes $22^{\circ} 25^{\prime} \mathrm{S}$ a $24^{\circ} 95^{\prime} \mathrm{S}$ do dia 11 de Janeiro de 2010 às 1800 UTC. A escala de core indica a velocidade $\left(\mathrm{m} \mathrm{s}^{-1}\right)$ de alvos que se aproxima (azul) e se afasta (vermelho) do MXPOL. O ponto preto no centro indica posição do radar meteorológico MXPOL (23 $32.2^{\prime}$ S; $46^{\circ} 52.8^{\prime} \mathrm{W}$ ) em Barueri, São Paulo. Circunferências concêntricas estão espaçadas a cada 25 km. Longitudes, latitudes, contornos dos municípios são indicados. A escala de cores representa a umidade (\%). As setas representam a magnitude do

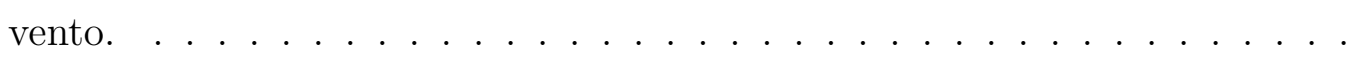

3.4 PPI de elevação $0.6^{\circ}$ da refletividade $\left(\mathrm{Z}_{H}\right)$ do radar MXPOL (a) às 1757 UTC, (b) 1850 UTC, (c) 1940 UTC e (d) 2025 UTC do sistema de convecção induzida por brisa marítima e vento de noroeste sobre o centro geométrico da RMSP no dia 11 de Janeiro de 2010. A escala de cores indica a refletividade (dBZ). Circunferências concêntricas estão espaçadas a cada $25 \mathrm{~km}$. O radar meteorológico MXPOL está centro da menor circunferência concêntrica $\left(23^{\circ}\right.$ 32.2'S; 46 52.8'W) em Barueri, São Paulo. Longitudes, latitudes, contornos dos municípios são indicados. As setas pretas indicam a frente de brisa marítima representada pela linha fina de refletividade. . . . . . . . . .

3.5 Idem Fig. 3.4, mas (a) às 2040 UTC, (b) 2050 UTC, (c) 2115 UTC e (d) 2135 UTC. A linha fina de refletividade na área destacada representa a frente de rajada da tempestade. . . . . . . . . . . . . . . . . . 92 
3.6 PPI de elevação 9.0 $0^{\circ}$ do radar MXPOL no dia 11 de Janeiro de 2010 às 2027 UTC, (a) refletividade $\left(\mathrm{Z}_{H}\right)$, (b) refletividade diferencial $\left(\mathrm{Z}_{Z D}\right)$, (c) fase diferencial específica $\left(\mathrm{K}_{K D}\right)$ e $(\mathrm{d})$ coeficiente de correlação. As escalas de cores indica a refletividade (dBZ), refletividade diferencial (dB), fase diferencial específica $\left({ }^{\circ} \mathrm{km}^{-1}\right)$ e coeficiente de correlação (sem unidade) . Circunferências concêntricas estão espaçadas a cada $25 \mathrm{~km}$. O radar meteorológico MXPOL está centro da menor circunferência concêntrica $\left(23^{\circ}\right.$ 32.2'S; 46 52.8'W) em Barueri, São Paulo. Longitudes, latitudes, contornos dos municípios são indicados. . . . . . . . . . . . . . . .

3.7 PPI de elevação 9.0 $0^{\circ}$ do radar MXPOL no dia 11 de Janeiro de 2010 às 2027 UTC, (a) massa de água líquida $\left(\mathrm{g} \mathrm{m}^{-3}\right)$, (b) massa de água sólida $\left(\mathrm{g} \mathrm{m}^{-3}\right)$, (c) diâmetro da gota da chuva $(\mathrm{mm})$ e (d) classificação de hidrometeoros. As escalas de cores estão indicados. Ademais escala de cores apresenta as 10 classificações dos hidrometeoros: Gota de água, Granizo, Graupel AD, Graupel BD, Gelo vertical, Neve molhada, Agregado, Cristal de gelo, Chuva e Chuvisco. Circunferências concêntricas estão espaçadas a cada 25 km. O radar meteorológico MXPOL está centro da menor circunferência

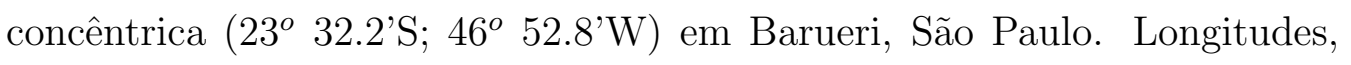
latitudes, contornos dos municípios são indicados. . . . . . . . . . .

3.8 PPI de elevação 9.0 do radar MXPOL no dia 11 de Janeiro de 2010 às 2032 UTC, (a) classificação de hidrometeoros, (b) refletividade $\left(Z_{H}\right)$, (c) massa de água líquida $\left(\mathrm{g} \mathrm{m}^{-3}\right)$, (d) massa de água sólida $\left(\mathrm{g} \mathrm{m}^{-3}\right)$, (e) diâmetro da gota da chuva $(\mathrm{mm})$ e $(\mathrm{f})$ refletividade diferencial $\left(\mathrm{Z}_{D R}\right)$. A escala de cores apresenta as 10 classificações dos hidrometeoros: Gota de água, Granizo, Graupel AD, Graupel BD, Gelo vertical, Neve molhada, Agregado, Cristal de gelo, Chuva e Chuvisco. Ademais escalas de cores estão indicados. Circunferências concêntricas estão espaçadas a cada $25 \mathrm{~km}$. O radar meteorológico MXPOL está centro da menor circunferência concêntrica $\left(23^{\circ}\right.$ 32.2'S; 46 52.8'W) em Barueri, São Paulo. Longitudes, latitudes, contornos dos municípios são indicados. 
3.9 PPIs de elevações $0.6^{\circ}, 2.0^{\circ}$ e $3.0^{\circ}$ do radar MXPOL no dia 11 de Janeiro de 2010 entre 2055 a 2056 UTC, (a) refletividade $\left(\mathrm{Z}_{H}\right)$, (b) classificação de hidrometeoros, (c) refletividade $\left(\mathrm{Z}_{H}\right)$, (d) classificação de hidrometeoros, (e) refletividade $\left(\mathrm{Z}_{H}\right)$ e (f) classificação de hidrometeoros. A escala de cores apresenta as 10 classificações dos hidrometeoros: Gota de água, Granizo, Graupel AD, Graupel BD, Gelo vertical, Neve molhada, Agregado, Cristal de gelo, Chuva e Chuvisco. A escala de cores indica a refletividade (dBZ). Circunferências concêntricas estão espaçadas a cada $25 \mathrm{~km}$. O radar meteorológico MXPOL está centro da menor circunferência concêntrica ( $23^{\circ}$ 32.2'S; 46 52.8'W) em Barueri, São Paulo. Longitudes, latitudes, contornos dos municípios são indicados. . . . . . . . . . . . . . . . .

3.10 PPIs de elevações $0.6^{\circ}, 2.0^{\circ}$ e $3.0^{\circ}$ do radar MXPOL no dia 11 de Janeiro de 2010 entre 2055 a 2056 UTC, (a) refletividade diferencial $\left(\mathrm{Z}_{D R}\right)$, (b) refletividade diferencial $\left(\mathrm{Z}_{D R}\right)$, (c) refletividade diferencial $\left(\mathrm{Z}_{D R}\right)$ e $(\mathrm{d})$ método de chuva. A escala de cores indica a refletividade diferencial (dB). A escala de cores apresenta os 5 métodos de chuva: R(kdp, Zdr), R(Kdp), R(Z, Zdr), $\mathrm{R}(\mathrm{Z})$ e $\mathrm{R}($ Zrain). Circunferências concêntricas estão espaçadas a cada 25 km. O radar meteorológico MXPOL está centro da menor circunferência concêntrica (23 32.2’S; $46^{\circ} 52.8^{\prime} \mathrm{W}$ ) em Barueri, São Paulo. Longitudes, latitudes, contornos dos municípios são indicados. . . . . . . . . . . . . . 101

3.11 (a) Evolução temporal do número total de tamanhos de gotas com diâmetros entre 0,359 e 5,373 mm e, (b) medição da distribuição de tamanho de gotas feitas por um disdrômetro de impacto Joss-Waldvogel no dia 11 Janeiro de 2010 no PEFI da cidade de São Paulo (Fig. 2.2). Números de gotas integrados a cada 5 minutos indicados na escala de cores. Fonte: Pereira Filho et al. (2013) . . . . . . . . . . . . . . . . . . . 105

3.12 Perfis verticais da massa de água (a, b, c, d) e massa de água sólida gelo (e, f, g, h) nos núcleos das células secundária e célula integradas, no núcleo da extremidade sul da tempestade às 2025 UTC, às 2030 UTC e às 2055 UTC, respectivamente, do dia 11 de Janeiro de 2010 . . . . . . . . . . . . . 106 
3.13 Perfis verticais da refletividade horizontal (a, b, c) e refletividade diferencial(e, f, g) nos núcleos das células secundária e integradas, no núcleo da extremidade sul da tempestade às 2025 UTC, às 2030 UTC e às 2055 UTC, respectivamente, no dia 11 de Janeiro de 2010 . . . . . . . . . . . . . . . . 108

3.14 Perfis do diâmetro da gota de chuva no núcleo da célula secundária (a), no núcleo das células integradas (b) e no núcleo da extremidade sul da tempestade (c) às 2025 UTC, às 2030 UTC e às 2055 UTC, respectivamente, do dia 11 de Janeiro de 2010

3.15 Imagens do satélite GOES 10 no canal infravermelho da Amárica do Sul entr $-20^{\circ}$ e $-35^{\circ}$ de latitude e entre $-60^{\circ} \mathrm{S}$ e $-30^{\circ}$ de longitude (a) às 1800 UTC e (b) às 2100 UTC de 18 de maio de 2014. Contornos geográficos dos estados do Brasil e dos países da Argentina, Uruguai e Paraguai são indicados nas imagens. Fonte: DSA-CPTEC.INPE, 2020 . . . . . . . . . . . .

3.16 (a) Campo de pressão reduzido ao nível do mar (hPa); (b) campo de movimento vertical e altura geopotencial (gpm); (c) Campo de vento (m.s ${ }^{-1}$ ) a $10 \mathrm{~m}$ e umidade (\%) a $2 \mathrm{~m}$ acima da superfície e (d) CAPE $\left(\mathrm{J} \mathrm{kg}^{-1}\right)$ do GFS às 1800 UTC do dia dia 18 de Maio de 2014. A faixa de isóbaras é de $1 \mathrm{hPa}$. Cores frias/quentes indicam valores mais baixos/mais altos. A faixa de isolinhas geopotenciais é de 20 gpm e a barra de cores indica a velocidade vertical em $\mathrm{Pa} \mathrm{s}^{-1}$. As setas indicam a magnitude do vento e a barra de cores indica a umidade. A escala de cores indica os valores do CAPE. Contornos geopolíticos dos estados do Brasil e dos países da Argentina e Paraguai, latitudes, longitudes e horários e datas são indicados nos campos. 111

3.17 Perfis verticais da temperatura do ar $\left({ }^{\circ} \mathrm{C}\right)$, temperatura do ponto do orvalho $\left({ }^{\circ} \mathrm{C}\right)$, velocidade (nós) e direção do vento $\left(^{\circ}\right)$ no Aeroporto Campo de Marte $\left(-23^{\circ} 30^{\prime} 31^{\prime \prime} \mathrm{S},-46^{\circ} 38^{\prime} 15^{\prime \prime} \mathrm{W}\right)$, (a) às 1200 UTC do 18 UTC e (b) à 0000 UTC do dia 19 de maio de 2014. A RMSP, as latitude e longitudes são indicados nos mapas, indicados nos cantos superiores direito dos perfis, e o ponto preto indica a localização de lançamento das sondagens. Fonte: weather.uwyo.edu. Acessada em 14 de julho de 2019 
3.18 Campos da velocidade radial do radar SPOL, (a) PPI de elevação 0.5 ${ }^{\circ}$, (b) PPI de elevação $1.5^{\circ}$, (c) PPI de elevação $2.8^{\circ}$ e (d) PPI de elevação $4.7^{\circ}$ entre às 1900 e 1901 UTC de 18 de Maio de 2014. A escala de core indica a velocidade $\left(\mathrm{m} \mathrm{s}^{-1}\right)$ de alvos que se aproxima (azul) e se afasta (vermelho) do SPOL. O ponto preto no centro indica posição do radar meteorológico SPOL na cabeceira da Bacia do Alto Tietê. Circunferências concêntricas estão espaçadas a cada $50 \mathrm{~km}$. Longitudes, latitudes, contornos dos municípios são indicados. . . . . . . . . . . . . . . . . . . . . . . . . . 114

3.19 Esquema ilustrativo de tempestade severa (convecção isolada-CI) em diferentes estágios de desenvolvimento. (a) estágio sob influência de corrente ascendente. (b) estágio sob influência de correntes ascendente e descendente. (c) estágio inicial sob influência de rotação ciclônica. (d) tempestade severa sob influência de rotação ciclônica. A seta azul-escuro indica a direção de propagação da CI. As setas brancas indicam o gradiente de vento (cisalhamento). As setas vermelhas dentro da nuvem indicam a corrente ascendente. As setas azul-escuro dentro da nuvem indicam a corrente descendente. Fonte: www.bom.gov.au. Acessada em 23 de Outubro de 2020. 115

3.20 Idem Fig. 3.18, mas às 1945 UTC. . . . . . . . . . . . . . . . . . . . . 116

3.21 PPI de ângulo de elevação de $0.5^{\circ}$ da refletividade $\left(\mathrm{Z}_{H}\right)$ do radar SPOL (a) às 1755 UTC, (b) 1815 UTC, (c) 1830 UTC, (d) 1845 UTC, (e) 1910 UTC, (f) 1925 UTC, (g) 1935 UTC e (h) 1945 UTC do dia 18 de Maio de 2014. A escala de cores indica a refletividade (dBZ). Circunferências concêntricas estão espaçadas a cada $50 \mathrm{~km}$. O radar meteorológico SPOL está centro da menor circunferência concêntrica. Longitudes, latitudes, contornos dos municípios são indicados. . . . . . . . . . . . . . . . . . . . . . . . 118

3.22 Idem Fig. 3.21, mas para Refletividade diferencial $\left(\mathrm{Z}_{D R}\right) \ldots$. . . . . . . . . 119

3.23 Idem Fig. 3.21, mas para fase diferencial específica $\left(\mathrm{K}_{D P}\right)$. . . . . . . . . . 120 3.24 Idem Fig. 3.21, mas para coeficiente de correlação (sem unidade). . . . . . 121 
3.25 PPI de ângulo de elevação de $0.5^{\circ}$ da refletividade $\left(\mathrm{Z}_{H}\right)$ do radar SPOL (a) às 1950 UTC, (b) 1955 UTC, (c) 2035 UTC, (d) 2040 UTC, (e) 2055 UTC, (f) 2100 UTC, (g) 2120 UTC e (h) 2145 UTC do dia 18 de Maio de 2014. A escala de cores indica a refletividade (dBZ). Circunferências concêntricas estão espaçadas a cada $25 \mathrm{~km}$. O radar meteorológico SPOL está centro da menor circunferência concêntrica, a direita das figuras. Longitudes, latitudes, contornos dos municípios são indicados. . . . . . . . . . . . . . . 123

3.26 Idem Fig. 3.25, mas para Refletividade diferencial $\left(\mathrm{Z}_{D R}\right)$. . . . . . . . . . . 124

3.27 Idem Fig. 3.25, mas para fase diferencial específica $\left(\mathrm{K}_{D P}\right)$. . . . . . . . . . 125

3.28 Idem Fig. 3.25, mas para coeficiente de correlação (sem unidade). . . . . . 126

3.29 PPIs de ângulo de elevação de $0.5^{\circ}$ (a), $1.5^{\circ}$ (b), $2.8^{\circ}$ (c) e $4.7^{\circ}$ (d) da classificação de hidrometeoros do radar SPOL no dia 18 de Maio de 2014, às 1910 UTC. A escala de cores apresenta as 10 classificações dos hidrometeoros: Gota de água, Granizo, Graupel AD, Graupel BD, Gelo vertical, Neve molhada, Agregado, Cristal de gelo, Chuva e Chuvisco. Circunferências concêntricas estão espaçadas a cada $25 \mathrm{~km}$. O radar meteorológico SPOL está centro da menor circunferência concêntrica. Longitudes, latitudes, contornos dos municípios de São Paulo são indicados. . . . . . . . . . . . . . . 129

3.30 Idem Fig. 3.29, mas às 1940 UTC . . . . . . . . . . . . . . . . . . . . . 130

3.31 Imagens de recolha da camada de gelo no dia seguinte após a passagem da tempestade sobre a zona oeste do município de São paulo, centro geométrico da RMSP (a) e (b). Pedras de granizo com bolhas de ar dentro das mesmas (c) e (d). Crédito: Augusto José Pereira Filho. . . . . . . . . . . . . . . . . 131

3.32 Idem Fig. 3.29, mas às 2000 UTC. . . . . . . . . . . . . . . . . . . 132

3.33 PPIs de ângulo de elevação de $0.5^{\circ}$ (a), 1.5 (b), $2.8^{\circ}$ (c), $4.7^{\circ}$ (d) e $7.3^{\circ}$ (e) da classificação de hidrometeoros do radar SPOL no dia 18 de Maio de 2014, às 2015 UTC. A escala de cores apresenta as 10 classificações dos hidrometeoros: Gota de água, Granizo, Graupel AD, Graupel BD, Gelo vertical, Neve molhada, Agregado, Cristal de gelo, Chuva e Chuvisco. Circunferências concêntricas estão espaçadas a cada $25 \mathrm{~km}$. O radar meteorológico SPOL está centro da menor circunferência concêntrica. Longitudes, latitudes, contornos dos municípios de São Paulo são indicados. 
3.34 PPI de ângulo de elevação de 0.5 do radar SPOL às 1900 UTC (a), às 1940 UTC (b), às 2000 UTC (c) e às 2015 UTC (d) dos métodos de chuva do dia 18 de Maio de 2014. A escala de cores apresenta os 4 métodos de chuva: $\mathrm{R}\left(\mathrm{K}_{D P}\right), \mathrm{R}\left(\mathrm{K}_{D P}, \mathrm{Z}_{D R}\right), \mathrm{R}\left(\mathrm{Z}, \mathrm{Z}_{D R}\right), \mathrm{R}(\mathrm{Z}) \mathrm{R}\left(\mathrm{K}_{D P}\right), \mathrm{R}\left(\mathrm{K}_{D P}, \mathrm{Z}_{D R}\right), \mathrm{R}\left(\mathrm{Z}, \mathrm{Z}_{D R}\right)$, $\mathrm{R}(\mathrm{Z})$ e R(rain) . . . . . . . . . . . . . . . . . . . . . 135

3.35 PPIs de ângulo de elevação de 0.5 do radar SPOL às 1900 UTC (a), às 1940 UTC (b), às 2000 UTC (c) e às 2015 UTC (d) da massa de água sólida ( $\mathrm{g} \mathrm{m}^{-3}$ ) do dia 18 de Maio de 2014,. As escalas de cores estão indicados. Circunferências concêntricas estão espaçadas a cada $25 \mathrm{~km}$. O radar meteorológico SPOL está centro da menor circunferência concêntrica. Longitudes, latitudes, contornos dos municípios são indicados. . . . . . . . . . . . 136

3.36 Idem Fig. 3.44, mas para massa de água sólida. . . . . . . . . . . . . . . 137

3.37 PPI de ângulo de elevação de $0.5^{\circ}$ do radar SPOL às 2025 UTC (a), às 2035 UTC (b), às 2045 UTC (c) e às 2055 UTC (d) da classificação dos hidrometeoros presentes na CI do dia 18 de maio de 2014. A escala apresenta as 10 classificações dos hidrometeoros: Gota de água, Granizo, Graupel AD, Graupel BD, Gelo vertical, Neve molhada, Agregados, Cristais de gelo, Chuva e Chuvisco. Circunferências concêntricas estão espaçadas a cada $25 \mathrm{~km}$. O radar meteorológico SPOL está centro da menor circunferência concêntrica. Longitudes, latitudes, contornos dos municípios são indicados. 138

3.38 Idem Fig. 3.37, mas para $7.3^{\circ}$ de elevação . . . . . . . . . . . . . . . . . 139

3.39 Idem Fig. 3.37, mas para método de chuva. . . . . . . . . . . . . . . . . 140

3.40 PPI de ângulo de elevação de 0.5 do radar SPOL às 1900 UTC (a), às 1940 UTC (b), às 2000 UTC (c) e 2015 UTC (d) da classificação dos hidrometeoros presentes quase linha de instabilidade formada sobre a região rural do dia 18 de maio de 2014. A escala apresenta as 10 classificações dos hidrometeoros: Gota de água, Granizo, Graupel AD, Graupel BD, Gelo vertical, Neve molhada, Agregados, Cristais de gelo, Chuva e Chuvisco. Circunferências concêntricas estão espaçadas a cada $25 \mathrm{~km}$. O radar meteorológico SPOL está centro da menor circunferência concêntrica. Longitudes, latitudes, contornos dos municípios são indicados. . . . . . . . . . . . . . . . . . 141

3.41 Idem Fig. 3.40, mas para PPI de elevação $2.8^{\circ}$. . . . . . . . . . . . . . . . 142 
3.42 Idem Fig. 3.40 para o método de chuva. . . . . . . . . . . . . . . . . . . . 143

3.43 Idem Fig. 3.40, mas para gotas de chuva. . . . . . . . . . . . . . . . . . . 144

3.44 Idem Fig. 3.40, mas para a massa de água líquida. . . . . . . . . . . . . . 145

3.45 Idem Fig. 3.40, mas para a massa de água sólida. . . . . . . . . . . . . . . 146

3.46 PPI de ângulo de elevação de 0.5º do radar SPOL às 1910 UTC (a), às 1940 UTC (b), às 2000 UTC (c) e às 2015 UTC (d) da da taxa de chuva da CI de origem urbana. A escala de cor indica a taxa de chuva $\left(\mathrm{mm} \mathrm{h}^{-1}\right)$ do 18 de Maio de 2018. Circunferências concêntricas estão espaçadas a cada $25 \mathrm{~km}$. O radar meteorológico SPOL está centro da menor circunferência concêntrica. Longitudes, latitudes, contornos dos municípios são indicados.

3.47 Perfis verticais da massa de água (a, b, c, d) e massa de gelo (e, f, g, h) no núcleo da CI, durante a evolução espaço-temporal às 1900 UTC, 1940 UTC, 2000 UTC e 2015 UTC, respectivamente, do dia 18 de Maio de 2014. . . . 150

3.48 Perfis verticais da refletividade horizontal (a, b, c, d) e refletividade diferencial(e, f, g, h) no núcleo da CI, durante a evolução espaço-temporal às 1900 UTC, 1940 UTC, 2000 UTC e 2015 UTC, respectivamente, do dia 18 de Maio de 2014.

3.49 Perfis verticais do diâmetro da gota de chuva no núcleo da CI, durante a evolução espaço-temporal (a) às 1900 UTC, (b) às 1940 UTC, (c) às 2000 UTC e (d) às 2015 UTC do dia 18 de Maio de 2014 . . . . . . . . . . . . . 152

3.50 Imagens do satélite GOES 12 no canal infravermelho (a) 1600 UTC, (b) 1730 UTC, (c) 2000 UTC e (d) 2100 UTC de 24 de Janeiro de 2016. A RMSP destacada no quadrado vermelho. Fonte: DSA-CPTEC.INPE, 2020

3.51 Perfil vertical da temperatura do $\operatorname{ar}\left({ }^{\circ} \mathrm{C}\right)$, temperatura do ponto do orvalho $\left({ }^{\circ} \mathrm{C}\right)$, velocidade (nós) e direção do vento $\left(^{\circ}\right)$ no Aeroporto Campo de Marte (-230 30' 31"S, $\left.-46^{\circ} 38^{\prime} 15^{\prime} \mathrm{W}\right)$, onde a) 1200 UTC do dia 18 de maio de 2014 e b) 0000 UTC do dia 24 de Janeiro de 2016. Fonte: University of Wyoming 
3.52 PPI de ângulo de elevação da velocidade radial do radar SPOL às 1705 UTC (a) $1.0^{\circ}$, (b) $1.6^{\circ}$, (c) $2.4^{\circ}$, (d) $3.2^{\circ}$, (e) $4.2^{\circ}$, (f) $5.50^{\circ}$ do dia 24 de Janeiro de 2016. A escala de cores indica a velocidade radial $\left(\mathrm{m} \mathrm{s}^{-1}\right)$. As cores azul e vermelho representam o conjunto de hidrometeoros que se aproxima e se afasta do radar SPOL. Circunferências concêntricas estão espaçadas a cada $50 \mathrm{~km}$. O ponto preto indica a localização do radar meteorológico SPOL, no centro da menor circunferência concêntrica. Longitudes, latitudes, contornos dos municípios são indicados. . . . . . . . . . . . . 155

3.53 PPI de ângulo de elevação de $1.0^{\circ}$ da refletividade $\left(\mathrm{Z}_{H}\right)$ do radar SPOL às $1510 \operatorname{UTC}(\mathrm{a}), 1540 \operatorname{UTC}(\mathrm{b}), 1715 \operatorname{UTC}$ (c), 1745 UTC (d), 1805 UTC (e) e 1945 UTC (f) do dia 24 de Janeiro de 2016. A escala de cores indica a refletividade (dBZ). Circunferências concêntricas estão espaçadas a cada $25 \mathrm{~km}$. O radar meteorológico SPOL está centro da menor circunferência concêntrica. Longitudes, latitudes, contornos dos municípios são indicados. 156

3.54 Idem Fig. 3.53, mas para coeficiente de correlação (sem unidade). . . . . . 157

3.55 Idem Fig. 3.53, mas para refletividade diferencial $\left(\mathrm{Z}_{D R}\right)$. . . . . . . . 158

3.56 Idem Fig. 3.53, mas para fase diferencial especifica $\left(\mathrm{Z}_{D P}\right)$. . . . . . . . . . 159

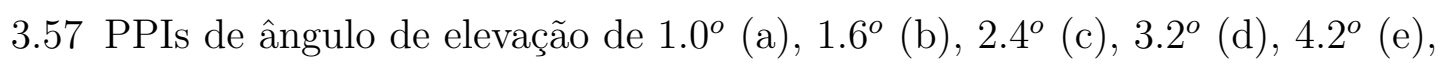
$5.5^{\circ}$ (f), $6.9^{\circ}$ (g) e $8.6^{\circ}$ (h) da classificação de hidrometeoros do radar SPOL no dia 24 de Janeiro de 2016, às 1705 UTC. A escala de cores apresenta as 10 classificações dos hidrometeoros: Gota de água, Granizo, Graupel AD, Graupel BD, Gelo vertical, Neve molhada, Agregado, Cristal de gelo, Chuva e Chuvisco. Circunferências concêntricas estão espaçadas a cada 25 km. O radar meteorológico SPOL está centro da menor circunferência concêntrica. Longitudes, latitudes, contornos dos municípios de São Paulo são indicados. 160

3.58 PPIs de ângulo de elevação de $1.0^{\circ}$ do radar SPOL às 1705 UTC, (a) massa de água líquida, (b) diâmetro da gota de chuva, (c) método de chuva, e (d) taxa de chuva no dia 24 de Janeiro de 2016. As escalas de cores estão indicadas. Circunferências concêntricas estão espaçadas a cada $25 \mathrm{~km}$. O radar meteorológico SPOL está centro da menor circunferência concêntrica. Longitudes, latitudes, contornos dos municípios de São Paulo são indicados. 161 
3.59 Imagens do satélite GOES 16 (a) 1600 UTC, (b) 1730 UTC, (c) 2000 UTC e (d) 2100 UTC de 24 de Janeiro de 2019. A escala de cores represta a temperatura do topo da nuvem. A RMSP destacada no quadrado vermelho. Fonte: DSA-CPTEC.INPE, 2020. . . . . . . . . . . . . . . . . 164

3.60 (a) Campo de pressão reduzido ao nível do mar (hPa); (b) campo de movimento vertical e altura geopotencial (gpm); (c) Campo de vento (m.s $\left.\mathrm{s}^{-1}\right)$ em 10 m e umidade (\%) em 2 m acima da superfície; e (d) CAPE $\left(\mathrm{J} \mathrm{kg}^{-1}\right)$ obtido a partir GFS do dia 29 de Janeiro de 2019. A faixa de isóbaras é de $1 \mathrm{hPa}$. Cores frias/quentes indicam valores mais baixos/mais altos. A faixa de isolinhas geopotenciais é de 20 gpm e a barra de cores indica a velocidade vertical em $\mathrm{Pa} \mathrm{s}^{-1}$. As setas indicam a magnitude do vento e a barra de cores indica a umidade. A escala de cores indica os valores do CAPE. Contornos geopolíticos, latitudes, longitudes e tempos são indicados

3.61 Perfis verticais da temperatura do ar $\left({ }^{\circ} \mathrm{C}\right)$, temperatura do ponto do orvalho $\left({ }^{\circ} \mathrm{C}\right)$, velocidade (nós) e direção do vento $\left(^{\circ}\right)$ no Aeroporto Campo de Marte $\left(-23^{\circ} 30^{\prime} 31^{\prime \prime} \mathrm{S},-46^{\circ} 38^{\prime} 15^{\prime} \mathrm{W}\right)$, (a) às 1200 UTC do dia 29 e (b) à 0000 UTC do dia 30 de Janeiro de 2019. A RMSP, as latitude e longitudes são indicados nos mapas, estão indicados nos cantos superiores direito dos perfis, o ponto preto indica a localização de lançamento das sondagens. Fonte: weather.uwyo.edu. Acessada em 14 de julho de 2019.

3.62 PPIs de ângulo de elevação de $1.0^{\circ}$ da velocidade radial do radar SPOL às 1700 UTC (a), às 1755 UTC (b), às 1805 UTC (c), às 1845 UTC (d), às 1855 UTC (d) e às 1910 UTC (e) do dia 29 de Janeiro de 2019. A escala de core indica a velocidade $\left(\mathrm{m} \mathrm{s}^{-1}\right)$ de alvos que se aproxima (azul) e se afasta (vermelho) do SPOL. O ponto preto no centro indica posição do radar meteorológico SPOL, na cabeceira da Bacia do Alto Tietê. Circunferências concêntricas estão espaçadas a cada $50 \mathrm{~km}$. Longitudes, latitudes, contornos dos municípios são indicados. 
3.63 Campos da velocidade radial do radar SPOL nos PPIs de ângulo de elevação de $1.0^{\circ}(\mathrm{a}), 1.6^{\circ}$ (b), $2.4^{\circ}$ (c), $3.2^{\circ}$ (d), $4.2^{\circ}$ (e), $5.5^{\circ}$ (f), $6.9^{\circ}$ (g) e 8.6.2 (h) entre às 1845 e 1848 UTC do dia 29 de Janeiro de 2019. A escala de core indica a velocidade $\left(\mathrm{m} \mathrm{s}^{-1}\right)$ de alvos que se aproxima (azul) e se afasta (vermelho) do SPOL. O ponto preto no centro indica posição do radar meteorológico SPOL, na cabeceira da Bacia do Alto Tietê. Circunferências concêntricas estão espaçadas a cada $50 \mathrm{~km}$. Longitudes, latitudes, contornos dos municípios são indicados. . . . . . . . . . . . . . . . . 168

3.64 PPI de ângulo de elevação de $1.0^{\circ}$ da refletividade $\left(\mathrm{Z}_{H}\right)$ do radar SPOL às $1630 \operatorname{UTC}(\mathrm{a}), 1700 \operatorname{UTC}(\mathrm{b}), 1730 \operatorname{UTC}$ (c), 1755 UTC (d), 1805 UTC (e), 1845 UTC (f), 1855 UTC (g) e 1905 UTC (h) do dia 29 de Janeiro de 2019. A escala de cores indica a refletividade (dBZ). Circunferências concêntricas estão espaçadas a cada $25 \mathrm{~km}$ até aos $100 \mathrm{~km}$ e espaçadas a cada $50 \mathrm{~km}$ até aos $200 \mathrm{~km}$. O radar meteorológico SPOL está centro da menor circunferência concêntrica. Longitudes, latitudes, contornos dos municípios são indicados. . . . . . . . . . . . . . . . . . . 170

3.65 Idem Fig. 3.64, mas para refletividade diferencial. A escala de cores indica refletividade diferencial $(\mathrm{dB}) . \ldots \ldots \ldots$. . . . . . . . . . . . 171

3.66 Idem Fig. 3.64, mas para fase diferencial específica. A escala de cores indica a fase diferencial específica $\left({ }^{o} \mathrm{~km}^{-1}\right) \ldots \ldots \ldots \ldots$. . . . . . . . . . 172

3.67 Idem Fig. 3.64, mas para coeficiente de correlação. A escala de cores indica o coeficiente de correlação (sem unidade) . . . . . . . . . . . . . . 173

3.68 PPI de ângulo de elevação de $1.0^{\circ}$ da refletividade $\left(\mathrm{Z}_{H}\right)$ do radar SPOL às 1915 UTC (a), 1930 UTC (b), 1940 UTC (c), 1950 UTC (d) do dia 29 de Janeiro de 2019. A escala de cores indica a refletividade (dBZ). Circunferências concêntricas estão espaçadas a cada $25 \mathrm{~km}$ até aos $100 \mathrm{~km}$ e espaçadas a cada $50 \mathrm{~km}$ até aos $200 \mathrm{~km}$. O radar meteorológico SPOL está centro da menor circunferência concêntrica. Longitudes, latitudes, contornos dos municípios são indicados. . . . . . . . . . . . . . . . . . . 174

3.69 Idem Fig. 3.68, mas para refletividade diferencial. A escala de cores indica refletividade diferencial $(\mathrm{dB}) . \ldots \ldots \ldots \ldots$. . . . . . . . . . 175 
3.70 Idem Fig. 3.68, mas para fase diferencial específica. A escala de cores indica a fase diferencial específica $\left({ }^{o} \mathrm{~km}^{-1}\right) \ldots \ldots \ldots \ldots \ldots$

3.71 Idem Fig. 3.68, mas para coeficiente de correlação. A escala de cores indica o coeficiente de correlação (sem unidade). . . . . . . . . . . . . . . . 177

3.72 PPIs de ângulo de elevação de $1.0^{\circ}$ (a), $1.6^{\circ}$ (b), $2.4^{\circ}$ (c), 3.2 $(\mathrm{d}), 4.2^{\circ}$ (e) e $5.5^{\circ}$ (f) da classificação de hidrometeoros do radar SPOL no dia 29 de Janeiro de 2019, às 1700 UTC. A escala de cores apresenta as 10 classificações dos hidrometeoros: Gota de água, Granizo, Graupel AD, Graupel BD, Gelo vertical, Neve molhada, Agregado, Cristal de gelo, Chuva e Chuvisco. Circunferências concêntricas estão espaçadas a cada $25 \mathrm{~km}$. O radar meteorológico SPOL está centro da menor circunferência concêntrica. Longitudes, latitudes, contornos dos municípios de São Paulo são indicados. . 178

3.73 PPIs de ângulo de elevação de $1.0^{\circ}$ (a), 1.6 $6^{\circ}$ (b), $2.4^{\circ}$ (c), 3.2 ${ }^{\circ}$ (d), 4.2 $2^{\circ}$ (e), $5.5^{\circ}$ (f), $6.9^{\circ}$ (g) e $8.6^{\circ}$ (h) da classificação de hidrometeoros do radar SPOL no dia 29 de Janeiro de 2019, às 1755 UTC. A escala de cores apresenta as 10 classificações dos hidrometeoros: Gota de água, Granizo, Graupel AD, Graupel BD, Gelo vertical, Neve molhada, Agregado, Cristal de gelo, Chuva e Chuvisco. Circunferências concêntricas estão espaçadas a cada $25 \mathrm{~km}$. O radar meteorológico SPOL está centro da menor circunferência concêntrica. Longitudes, latitudes, contornos dos municípios de São Paulo são indicados. 179

3.74 PPIs de ângulo de elevação de $1.0^{\circ}$ (a), $1.6^{\circ}$ (b), $2.4^{\circ}$ (c), 3.2 $2^{\circ}$ (d), $4.2^{\circ}$ (e) $6.9^{\circ}$ (f) da classificação de hidrometeoros do radar SPOL no dia 29 de Janeiro de 2019, às 1805 UTC. A escala de cores apresenta as 10 classificações dos hidrometeoros: Gota de água, Granizo, Graupel AD, Graupel BD, Gelo vertical, Neve molhada, Agregado, Cristal de gelo, Chuva e Chuvisco. Circunferências concêntricas estão espaçadas a cada $25 \mathrm{~km}$. O radar meteorológico SPOL está centro da menor circunferência concêntrica. Longitudes, latitudes, contornos dos municípios de São Paulo são indicados. . . 181 
3.75 PPIs de ângulo de elevação de $1.0^{\circ}$ (a), 1.6 $6^{\circ}$ (b), 2.4 (c), 3.2 $2^{\circ}$ (d), $4.2^{\circ}$ (e), $5.5^{\circ}$ (f), $6.9^{\circ}$ (g) e $8.6^{\circ}$ (h) da classificação de hidrometeoros do radar SPOL no dia 29 de Janeiro de 2019, às 1840 UTC. A escala de cores apresenta as 10 classificações dos hidrometeoros: Gota de água, Granizo, Graupel AD, Graupel BD, Gelo vertical, Neve molhada, Agregado, Cristal de gelo, Chuva e Chuvisco. Circunferências concêntricas estão espaçadas a cada $25 \mathrm{~km}$. O radar meteorológico SPOL está centro da menor circunferência concêntrica. Longitudes, latitudes, contornos dos municípios de São Paulo são indicados. 182

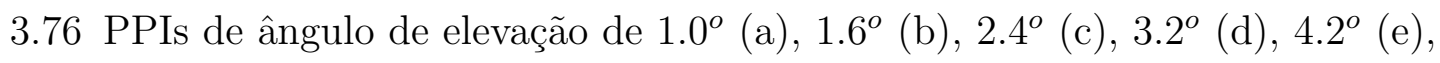
$5.5^{\circ}$ (f), $6.9^{\circ}$ (g) e $8.6^{\circ}$ (h) da classificação de hidrometeoros do radar SPOL no dia 29 de Janeiro de 2019, às 1855 UTC. A escala de cores apresenta as 10 classificações dos hidrometeoros: Gota de água, Granizo, Graupel AD, Graupel BD, Gelo vertical, Neve molhada, Agregado, Cristal de gelo, Chuva e Chuvisco. Circunferências concêntricas estão espaçadas a cada $25 \mathrm{~km}$. O radar meteorológico SPOL está centro da menor circunferência concêntrica. Longitudes, latitudes, contornos dos municípios de São Paulo são indicados. 184

3.77 PPIs de ângulo de elevação de $1.0^{\circ}$ (a), 1.6 $6^{\circ}$ (b), $2.4^{\circ}$ (c), 3.2 $2^{\circ}$ (d), $4.2^{\circ}$ (e), $5.5^{\circ}$ (f), $6.9^{\circ}$ (g) e $8.6^{\circ}$ (h) da classificação de hidrometeoros do radar SPOL no dia 29 de Janeiro de 2019, às 1910 UTC. A escala de cores apresenta as 10 classificações dos hidrometeoros: Gota de água, Granizo, Graupel AD, Graupel BD, Gelo vertical, Neve molhada, Agregado, Cristal de gelo, Chuva e Chuvisco. Circunferências concêntricas estão espaçadas a cada 25 km. O radar meteorológico SPOL está centro da menor circunferência concêntrica. Longitudes, latitudes, contornos dos municípios de São Paulo são indicados. 185

3.78 PPIs de ângulo de elevação de $1.0^{\circ}$ (a), 1.6 $6^{\circ}$ (b), $2.4^{\circ}$ (c), 3.2 $2^{\circ}$ (d), $4.2^{\circ}$ (e), $5.5^{\circ}$ (f), $6.9^{\circ}$ (g) e $8.6^{\circ}$ (h) da classificação de hidrometeoros do radar SPOL no dia 29 de Janeiro de 2019, às 1930 UTC. A escala de cores apresenta as 10 classificações dos hidrometeoros: Gota de água, Granizo, Graupel AD, Graupel BD, Gelo vertical, Neve molhada, Agregado, Cristal de gelo, Chuva e Chuvisco. Circunferências concêntricas estão espaçadas a cada $25 \mathrm{~km}$. O radar meteorológico SPOL está centro da menor circunferência concêntrica. Longitudes, latitudes, contornos dos municípios de São Paulo são indicados. 187 
3.79 PPIs de ângulo de elevação de $1.0^{\circ}$ do radar SPOL para o método de chuva às 1700 UTC (a), às 1755 UTC (b), às 1805 UTC (c), às 1840 UTC (d), às 1855 UTC (e), às 1910 UTC (f), e 1930 UTC (g) do dia 29 de Janeiro de 2019. A escala de cores indica a relação $\mathrm{R}\left(\mathrm{mm} \mathrm{h}^{-1}\right)$ com as variáveis polarimétricas. Circunferências concêntricas estão espaçadas a cada $25 \mathrm{~km}$. O radar meteorológico SPOL está centro da menor circunferência concêntrica. Longitudes, latitudes, contornos dos municípios de São Paulo são indicados. 188

3.80 PPIs de ângulo de elevação de $1.0^{\circ}$ do radar SPOL para a taxa de chuva às 1700 UTC (a), às 1755 UTC (b), às 1805 UTC (c), às 1840 UTC 9d), às 1855 UTC (e), às 1910 UTC (f), e 1930 UTC (g) do dia 29 de Janeiro de 2019. A escala de cores indica a taxa de chuva $\left(\mathrm{mm} \mathrm{h}^{-1}\right)$. Circunferências concêntricas estão espaçadas a cada $25 \mathrm{~km}$. O radar meteorológico SPOL está centro da menor circunferência concêntrica. Longitudes, latitudes, contornos dos municípios de São Paulo são indicados. . . . . . . . . . . . . . . 190

3.81 Perfis verticais da massa de água (a, b, c) e massa de gelo (d, e, f) no núcleo da CI às 1700 UTC, 1805 UTC e 1815 UTC, respectivamente, no dia 29 de Janeiro de 2019 . . . . . . . . . . . . . . . . . . . . . .

3.82 Perfis verticais da refletividade horizontal (a, b, c) e refletividade diferencial(d, e, f) no núcleo da CI às 1700 UTC, 1805 UTC e 1815 UTC, respectivamente, no dia 29 de Janeiro de 2019

3.83 Perfis verticais do diâmetro da gota de chuva no núcleo da CI (a) às 1700 UTC, (b) às 1805 UTC e (c) às 1815 UTC do dia 29 de Janeiro de 2019.

3.84 Imagens GOES16 - Canal $_{16}$ (13.30 microns) da banda de nebulosidade associada a frente fria ocorrido às 1440 UTC (a), 1715 UTC (b), 1750 UTC (c) e 1800 UTC (d) dia 19 de Agosto de 2019. A escala de cores indica temperatura no topo da nuvem em graus célcius. . . . . . . . . . . . 196

3.85 Análise sinótica e termodinâmica do sistema precipitante através de análises de GFS e radiossondagem ocorrido no dia 19 de Agosto de 2019 . . . . . . 198 
3.86 Perfis verticais da temperatura do ar $\left({ }^{\circ} \mathrm{C}\right)$, temperatura do ponto do orvalho $\left({ }^{\circ} \mathrm{C}\right)$, velocidade (nós) e direção do vento $\left({ }^{o}\right)$ no Aeroporto Campo de Marte $\left(-23^{\circ} 30^{\prime} 31^{\prime} \mathrm{S},-46^{\circ} 38^{\prime} 15^{\prime} \mathrm{W}\right)$, (a) às $1200 \mathrm{UTC}$ do dia 19 e (b) à 0000 UTC do dia 20 de Agosto de 2019. A RMSP, as latitude e longitudes são indicados nos mapas, estão indicados nos cantos superiores direito dos perfis, o ponto preto indica a localização de lançamento das sondagens. Fonte: weather.uwyo.edu. Acessada em 22 de julho de 2020 . . . . . . . . . . 199

3.87 Campos da velocidade radial do radar SPOL no PPI de ângulo de elevação $1.0^{\circ}$, (a) às 1345 UTC, (b) às 1420 UTC, (c) às 1535 UTC, (d) às 1605 UTC, (e) às 1730 UTC, (f) às 1810 UTC, (g) às 1830 UTC e (h) às 2100 UTC do dia 19 de Agosto de 2019. A escala de core indica a velocidade ( $\mathrm{m} \mathrm{s}^{-1}$ ) de alvos que se aproxima (azul) e se afasta (vermelho) do SPOL. O ponto preto no centro indica posição do radar meteorológico SPOL, na cabeceira da Bacia do Alto Tietê. Circunferências concêntricas estão espaçadas a cada $25 \mathrm{~km}$. Longitudes, latitudes, contornos dos municípios são indicados. . . . 200

3.88 Campos da refletividade $\left(\mathrm{Z}_{H}\right)$ do radar SPOL no PPI de ângulo de elevação $1.0^{\circ}$, (a) às $1345 \mathrm{UTC}$, (b) $1420 \mathrm{UTC}$, (c) $1450 \mathrm{UTC}$, (d) $1535 \mathrm{UTC}$, (e) 1605 UTC, (f) 1705 UTC, (g) 1730 UTC e (h) 1755 UTC do dia 19 de Agosto de 2019. A escala de cores indica a refletividade (dBZ). O círculos concêntricos estão espaçadas a cada $25 \mathrm{~km}$ até aos $100 \mathrm{~km}, 50 \mathrm{~km}$ entre 100 e $150 \mathrm{~km}$ e, novamente $24 \mathrm{~km}$ entre 150 e $200 \mathrm{~km}$. O radar meteorológico SPOL está centro da menor circunferência concêntrica. Longitudes, latitudes, contornos dos municípios são indicados. . . . . . . . . . . . . . . 202

3.89 Idem Fig. 3.88, mas para refletividade diferencial. A escala de cores indica

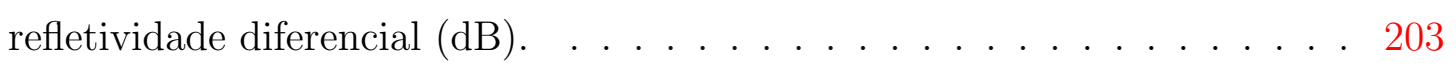

3.90 Idem Fig. 3.88, mas para fase diferencial específica. A escala de cores indica fase diferencial específica $\left({ }^{o} \mathrm{~km}^{-1}\right) \ldots \ldots \ldots$. . . . . . . . . . . . 204

3.91 Idem Fig. 3.88, mas para coeficiente de correlação. A escala de cores indica coeficiente de correlação (sem unidade) . . . . . . . . . . . . . 205 
3.92 Campos da refletividade $\left(\mathrm{Z}_{H}\right)$ do radar SPOL no PPI de ângulo de elevação $1.0^{\circ}$, (a) às $1800 \mathrm{UTC}$, (b) $1810 \mathrm{UTC}$, (c) $1830 \mathrm{UTC}$, (d) $1945 \mathrm{UTC}$, (e) 2010 UTC e (f) 2100 UTC do dia 19 de Agosto de 2019. A escala de cores indica a refletividade (dBZ). O círculos concêntricos estão espaçadas a cada $25 \mathrm{~km}$ até aos $100 \mathrm{~km}, 50 \mathrm{~km}$ entre 100 e $150 \mathrm{~km}$ e, novamente $24 \mathrm{~km}$ entre 150 e 200 km. O radar meteorológico SPOL está centro da menor circunferência concêntrica. Longitudes, latitudes, contornos dos municípios são indicados.

3.93 Idem Fig. 3.92, mas para refletividade diferencial. A escala de cores indica refletividade diferencial $(\mathrm{dB}) . \ldots \ldots$. . . . . . . . . . . . . 208

3.94 Idem Fig. 3.92, mas para fase diferencial específica. A escala de cores indica fase diferencial específica $\left({ }^{o} \mathrm{~km}^{-1}\right) \ldots \ldots \ldots$. . . . . . . . . . . . 209

3.95 Idem Fig. 3.92, mas para coeficiente de correlação. A escala de cores indica coeficiente de correlação (sem unidade) . . . . . . . . . . . . . . . 210

3.96 PPI de ângulo de elevação de $1.0^{\circ}$ às 1430 UTC (a), 1435 UTC (b), 1440 UTC (c) e 1450 UTC (d) do dia 19 de Agosto de 2019, apresentando a classificação dos hidrometeoros presentes na tempestade. A escala apresenta as 10 classificações dos hidrometeoros: Gota de água, Granizo, Graupel AD, Graupel BD, Gelo vertical, Neve molhada, Agregados, Cristais de gelo, Chuva e Chuvisco . . . . . . . . . . . . . . . . . . . . 212

3.97 PPI de ângulo de elevação de $1.0^{\circ}$ às 1830 UTC (a), 1845 UTC (b), 2010 UTC (c) e 2100 UTC (c) do dia 19 de Agosto de 2019, apresentando a classificação dos hidrometeoros presentes na tempestade. A escala apresenta as 10 classificações dos hidrometeoros: Gota de água, Granizo, Graupel AD, Graupel BD, Gelo vertical, Neve molhada, Agregados, Cristais de gelo, Chuva e Chuvisco. . . . . . . . . . . . . . . . . . . . . 213

3.98 PPIs de ângulos de elevação de $1.0^{\circ}$ (a), 2.4 $(\mathrm{b}), 3.2^{\circ}$ (c) e $4.2^{\circ}$ (d) de classificação de hidrometeoros, às 1755 UTC do dia 19 de Agosto de 2019. A escala de cores indica os hidrometeoros identificados. . . . . . . . . . . . 214 


\section{Lista de Tabelas}

2.1 Características técnicas do sistema do radar meteorológico MXPOL . . . . 67

2.2 Características técnicas do sistema do radar meteorológico SPOL . . . . 69

2.3 Parâmetros da função beta dos limiares de reflectividade $\mathrm{Z}_{H}(\mathrm{dBZ})$, reflectividade diferencial $\mathrm{Z}_{D R}(\mathrm{~dB})$, reflectividade diferencial específica $\mathrm{K}_{D P}{ }^{o}$ $\mathrm{km}^{-1}$ ), coeficiente de correlação $\rho_{H V}$ e altitude do MXPOL para os dez tipos de hidrometeoros. Fonte: Lang et al. (2019). . . . . . . . . . . . . . .

2.4 Parâmetros da função beta dos limiares de reflectividade $\mathrm{Z}_{H}$ (dBZ), reflectividade diferencial $\mathrm{Z}_{D R}(\mathrm{~dB})$, reflectividade diferencial específica $\mathrm{K}_{D P}{ }^{\circ}$ $\mathrm{km}^{-1}$ ), coeficiente de correlação $\rho_{H V}$ e altitude do SPOL para os dez tipos de hidrometeoros. Fonte: Lang et al. (2019). . . . . . . . . . . . . . . . . . 79

2.5 Tipos de hidrometeoros correspondentes aos limiares de reflectividade $\mathrm{Z}_{H}$ $(\mathrm{dBZ})$, reflectividade diferencial $\mathrm{Z}_{D R}(\mathrm{~dB})$, reflectividade diferencial específica $\mathrm{K}_{D P}\left({ }^{o} \mathrm{~km}^{-1}\right)$, coeficiente de correlação $\rho_{H V}$ e altitude do MXPOL. Fonte: Rauber e Nesbitt (2018). . . . . . . . . . . . . . . . .

2.6 Tipos de hidrometeoros correspondentes aos limiares de reflectividade $\mathrm{Z}_{H}$ (dBZ), reflectividade diferencial $\mathrm{Z}_{D R}(\mathrm{~dB})$, reflectividade diferencial específica $\mathrm{K}_{D P}\left({ }^{o} \mathrm{~km}^{-1}\right)$, coeficiente de correlação $\rho_{H V}$ e altitude do SPOL. Fonre: Rauber e Nesbitt (2018). . . . . . . . . . . . . . . . . . . . . 80

2.7 Cálculos de taxa de chuva de radar polarimétrico . . . . . . . . . . . 84 
3.1 Resumo de tipos de hidrometeoros identificados nos núcleos das células secundárias acima da isoterma $0^{\circ} \mathrm{C}$, abaixo da isoterma $0^{\circ} \mathrm{C}$, dentro da isoterma $0^{\circ} \mathrm{C}$ e provavelmente atingindo a superfície durante a evolução espaçotemporal sobre o centro geométrico da RMSP entre 1950 e 2135 UTC do dia 11 de Janeiro de 2010 com os dados do radar MXPOL. . . . . . . . . . 103

3.2 Resumo de tipos de hidrometeoros identificados no núcleo da CI acima da isoterma $0^{\circ} \mathrm{C}$, abaixo da isoterma $0^{\circ} \mathrm{C}$, dentro da isoterma $0^{\circ} \mathrm{C}$ e provavelmente atingindo a superfície durante a evolução espaço-temporal sobre o centro geométrico da RMSP entre entre 1825 e 2105 UTC do dia 18 de Maio de 2014 com os dados do radar SPOL. . . . . . . . . . . . . . . . . . 148

3.3 Resumo de tipos de hidrometeoros identificados nos núcleos das BDs acima da isoterma $0^{\circ} \mathrm{C}$, abaixo da isoterma $0^{\circ} \mathrm{C}$, dentro da isoterma $0^{\circ} \mathrm{C}$ e provavelmente atingindo a superfície durante a evolução espaço-temporal sobre o LSP entre 1640 e 1850 UTC do dia 24 de Janeiro de 2016 com os dados do radar SPOL . . . . . . . . . . . . . . . . . . . . 163

3.4 Resumo de tipos de hidrometeoros identificados no núcleo da CI acima da isoterma $0^{\circ} \mathrm{C}$, abaixo da isoterma $0^{\circ} \mathrm{C}$, dentro da isoterma $0^{\circ} \mathrm{C}$ e provavelmente atingindo a superfície durante a evolução espaço-temporal sobre o centro geométrico da RMSP entre entre 1700 e 2005 UTC do dia 29 de Janeiro de 2019 com os dados do radar SPOL. . . . . . . . . . . . . . . . . 191 


\section{Sumário}

1. Introdução . . . . . . . . . . . . . . . . . . . . . . . 39

1.1 Motivação e Objetivos . . . . . . . . . . . . . . . . . . 39

1.2 Revisão Bibliográfica . . . . . . . . . . . . . . . . . . . . . . . . 41

1.2.1 Nuvens e precipitações . . . . . . . . . . . . . . . . . . . . . 41

1.2.2 Microfísica da nuvem quente e da nuvem mista . . . . . . . . . . 43

1.2.3 Características dos sistemas precipitantes na Região Metropolitana de São Paulo (RMSP) . . . . . . . . . . . . . . . . . . . . . 46

1.2.3.1 Combinações de circulações Locais e sinóticas . . . . . . . 50

1.2.4 Radar meteorológico . . . . . . . . . . . . . . . 52

1.2.4.1 Equação de radar para alvos meteorológicos à distância 52

1.2.4.2 Espalhamento . . . . . . . . . . . . . . 56

1.2.4.3 Espalhamento Rayleigh e Mie . . . . . . . . . . 56

1.2.4.4 Atenuação . . . . . . . . . . . . . . . 57

1.2.5 Classificação de hidrometeoros . . . . . . . . . . . . . . . . . . . . . 59

1.2.6 Algoritmos de identificação de hidrometeoros para radares de banda

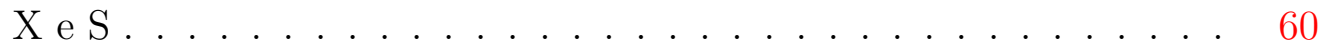

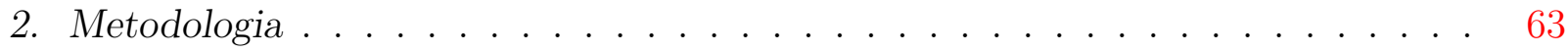

2.1 Radares Meteorológicos dupla polarização Doppler . . . . . . . . . . . . . . 64

2.1.1 Variáveis polarimétricas . . . . . . . . . . . . . . . 69

2.2 Análise sinótica . . . . . . . . . . . . . . . . . 74

2.3 Análise Termodinâmica . . . . . . . . . . . . . . . . . . . . . . . 74

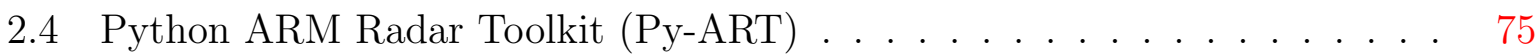


2.5 Classificação de hidrometeoros . . . . . . . . . . . . . . . . . . 75

2.6 Cálculo da massa de água líquida, massa de água sólida e diâmetro médio

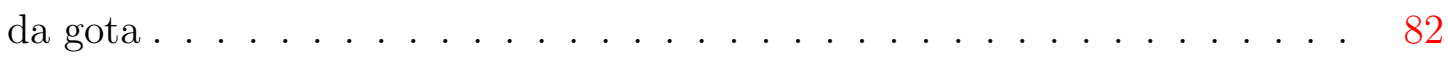

2.7 Estimativa da taxa de chuva . . . . . . . . . . . . . . . . . . 83

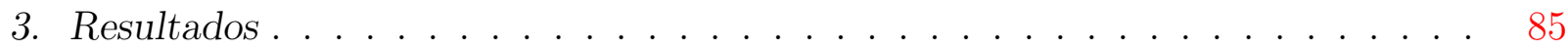

3.1 Tempestade Induzida pelo Sistema de BM, Ilha de calor urbano, Poluição urbana e Sistema pré-frontal no dia 11 de janeiro de 2010 . . . . . . . . . 85

3.1 .1 Análise Sinótica . . . . . . . . . . . . . 86

3.1.2 Análise dinâmica e termodinâmica . . . . . . . . . . . . . . . . 89

3.1.3 Evolução espaço-temporal da tempestade . . . . . . . . . . . . . . . 90

3.1.4 Tipos de hidrometeoros, massas de água líquida e sólida e diâmetro da gota de chuva . . . . . . . . . . . . . . . . . 92

3.1.5 Distribuição de tamanho de gota (DTCs) . . . . . . . . . . . . . . . 104

3.1.6 Perfis verticais . . . . . . . . . . . . . . . . . 105

3.2 Convecção Isolada (CI) associada a um Ciclone Extratropical e Sistema de Alta Pressão no dia 18 de maio de 2014 . . . . . . . . . . . . . . . . . . . 110

3.2.1 Análise Sinótica . . . . . . . . . . . . . . . . . . . . 110

3.2.2 Análises termodinâmica e dinâmica . . . . . . . . . . . . . . . . . . 112

3.2.3 Evolução Espaço-Temporal da CI e da quase-linha de instabilidade 117

3.2.4 Classificação dos hidrometeoros . . . . . . . . . . . . . . . . . . . 127

3.2.5 Perfis verticais . . . . . . . . . . . . . . . . . . . 149

3.3 Bandas dispersas (BDs) induzidas por frente fria no dia 24 de Janeiro de 2016152

3.3.1 Análise sinótica, termodinâmica e dinâmica . . . . . . . . . . . . 152

3.3.2 Evolução espaço-temporal . . . . . . . . . . . . . . . . . . 155

3.3.3 Classificação dos hidrometeoros . . . . . . . . . . . . . . . . . . 159

3.4 Convecção isolada (CI) associada a um sistema de alta pressão no dia 29 de Janeiro de 2019 . . . . . . . . . . . . . . . . . . . . . . . . . . . 164

3.4 .1 Análise sinótica . . . . . . . . . . . . . . . . . . . . 164

3.4.2 Análise termodinâmica e dinâmica . . . . . . . . . . . . 166

3.4.3 Evolução espaço-temporal . . . . . . . . . . . . . . . . . . . . . . 169

3.4.4 Classificação dos hidrometeoros . . . . . . . . . . . . . . . . . . 177 
3.4.5 Perfis verticais . . . . . . . . . . . . . . . . . . 192

3.5 BDs associadas a fumaça de incêndios na Amazônia induzidas por uma FF 196 3.5.1 Análise sinótica . . . . . . . . . . . . . . . . . . . . 196

3.5.2 Análise termodinâmica e dinâmica . . . . . . . . . . . . . . . . . 198

3.5.3 Evolução espaço-temporal . . . . . . . . . . . . . . . . . . . . . . 201

3.5.4 Classificação de hidrometeoros . . . . . . . . . . . . . . . . . . . . . 210

4. Conclusões e Recomendações . . . . . . . . . . . . . . . . . . . . . . . 215

4.1 Conclusões . . . . . . . . . . . . . . . . . . . . . . . 215

4.2 Recomendações . . . . . . . . . . . . . . . . . . . . . . . . . . . . . . . 218

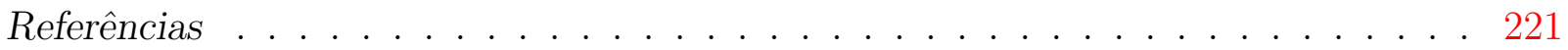


Capítulo 1

\section{Introdução}

\subsection{Motivação e Objetivos}

$\mathrm{Na}$ última década, o aumento da disponibilidade de dados de radares meteorológicos de dupla polarização com alta resolução espacial e temporal, tem permitido grande esforço de pesquisa à microfísica de sistemas convectivos e estratiformes e, suas dinâmicas e termodinâmicas na atmosfera. Estes sistemas estão presentes em todo o globo, mas apresentam processos de formação e desenvolvimento distintos para cada região e na mesma região (Qin et al., 2014). A previsibilidade dos sistemas precipitantes que atingem a Região Metropolitana de São Paulo (RMSP) é um problema significativo, devido o processo complexo de formação. A necessidade de previsão do processo inicial de formação, durante a ocorrência e dissipação de sistemas convectivos tem sido uma meta para os pesquisadores, há algum tempo e até o presente continua sendo um desafio (Qin et al., 2014).

O leste do estado de São Paulo (LSP), com ênfase na RMSP é impactada com frequência por vários eventos meteorológicos. De acordo com Silva et al. (2009), são cinco os principais sistemas que atuam no LSP e esses se distinguem de acordo com suas morfologias: Convecção Isolada (CI), Brisa Marítima (BM), Linhas de Instabilidade (LI), Bandas Dispersas (BD) e Frentes Frias (FF). As células convectivas causadas pela inter-relação de sistemas de escalas distintas (circulação de BM, sistema fronta e ilha de calor urbano), são mais intensas, transferem grandes quantidades de umidade e calor através de correntes ascendentes verticais associadas com flutuabilidade, que podem causar riscos meteorológicos como rajada de vento, relâmpago, granizo, enchentes ou mesmo tornados (García-Ortega et al., 2014). Estudos observacionais, modelagem, dados de superfície, e estimativas por sensoriamento remoto por radares meteorológicos e satélites, foram amplamente realizados 
para o melhor entendimento da dinâmica da interação das BMs e FFs com as circulações locais induzidas pela presença da RMSP. Os processos pelos quais a convecção se inicia e se organiza, foram compreendidos para representar adequadamente o ciclo diurno de precipitação em modelos numéricos (Oliveira et al., 1982; Pereira Filho et al., 2004; Freitas et al., 2007; Vemado e Pereira Filho, 2016; Rojas et al., 2018).

Entretanto, a evolução microfísica dos hidrometeoros dentro dos sistemas convectivos, deve ser analisada para fornecer uma base física para estimar a precipitação por sensoriamento remoto (Nesbitt et al., 2006). Os resultados da análise microfísica com dados de radar meteorológico Doppler pode maximizar a acurácia da previsão de curtíssima prazo. A previsão de precipitação em curtíssima prazo é frequentemente necessária em aplicações meteorológicas e hidrológicas, onde a previsão acurada da precipitação pode ajudar na agricultura, no planeamento de eventos e a amenizar os danos causados pelas cheias.

A classificação de hidrometeoros usando dados de radar polarimétrico fornece informações detalhadas para validar e melhorar parametrizações microfísicas dentro da nuvem. As informações microfísicas são conhecidas por afetar significativamente os modelos numéricos de escala local e meso-escala (Gochis et al., 2002; Wang et al., 2015). Portanto, os efeitos microfísicos são de extrema relevância para entender o comportamento dos episódios convectivos, principalmente eventos convectivos de pequenas dimensões e longas durações (Kraut, 2015).

O conhecimento microfísico de tempestades é imprescindível para previsão, principalmente de curtíssimo prazo, porque nas recentes décadas, danos causados por eventos convectivos parecem terem aumentado por causa das mudanças microclimáticas nas regiões urbanas, devido ações antropogênicas. O impacto dos episódios das convenções severas podem ser minimizados pela previsão acurada, salvando vidas e prevenindo perdas econômicas (Bauer et al., 2015).

Geralmente, as CIs consistem em uma única corretante ascendente, que aumenta rapidamente através do troposfera e produz grandes quantidades de água e gelo. Quando as gotas de chuva e partículas de gelo tornam-se pesadas para a corrente ascendente suportar, começam a precipitar, criando uma corrente descendente que rapidamente substitui a corrente ascendente. Esse evento leva geralmente 30-50 minutos para completar (Houze Jr, 2014). Durante esse período, o sistema provoca tempe severo como vento forte ou granizo que pode ocorrer em curta duração. E raramente verifica-se ocorrência de tornado 
(Houze Jr, 2014).

Entretanto, as CIs que se formam na RMSP, duram mais do que 2h. A RMSP influencia na formação e duração longa da CI? Existem outros mecanismos de estabilidade termodinâmica que influenciam na duração longa das CIs sobre a RMSP? Quais são os hidrometeoros predominantes produzidos durante a evolução espaço-temporal desses eventos sobre a RMSP?

Assim, este trabalho foi motivado pela grande disponibilidade de dados de dois radares polarimétricos Doppler de vários eventos que atuam sobre o LSP, com ênfase sobre a RMSP. A inferência microfísica desses eventos é útil para identificar perigos tais como granizo, transições da chuva para a neve, ou em estudos de processos de nuvens, tais como a compreensão da produção de tipos de hidrometeoros a partir de tempestades convectivas, que pode ser utilizada nas parametrizações microfísicas das nuvens para maior sensibilidade do modelo na previsão de granizo e chuvas fortes. O objetivo geral é analisar a microfísica das CIs, da tempestade induzida pelas combinações da BM, FF e ilha de calor urbano (ICU), e BDs associadas a FFs com e sem fumaça de incêndios na Amazônia a partir de variáveis polarimétricas medidas por radares Doppler de banda X e de banda S na RMSP. Os objetivos específicos:

- Classificar os hidrometeoros por meio do método lógica fuzzy com medidas de variáveis polarimétricas e dados de radiossondagens como dados de entrada;

- Analisar a microfísica, a dinâmica e a termodinâmica durante a evolução espaçotemporal dos sistemas precipitantes a partir do método lógica fuzzy, de medidas polarimétricas, de radiossondagens e do disdrômetro de impacto Joss-Waldvogel;

- Calcular a massa de água líquida, a massa de água sólida, o diâmetro da gota e taxa de chuva durante a evolução espaço-temporal dos sistemas precipitantes a partir de medidas de variáveis polarimétricas e dados de radiossondagens.

\subsection{Revisão Bibliográfica}

\subsubsection{Nuvens e precipitações}

A radiação solar é a condição sinequanone para formação das nuvens. Nuvens e precipitações regulam a radiação solar incidente e o ciclo hidrológico atmosférico, redistribuindo 
água dentro da atmosfera entre diferentes regiões da superfície terrestre (Stephens, 2005). Três mecanismos essenciais estão envolvidos no processo de movimento vertical que produz a condensação e consequentemente formação das nuvens: o empuxo termodinâmico (convecção térmica) devido aquecimento da superfície e convecção; a convergência de umidade em superfície; e o levantamento de parcelas de ar devido efeitos orográfico e frontal (Parker e Andersen, 1988; Barry e Chorley, 2009). A convecção é fundamental no transporte do superávit de calor, umidade e momentum, removendo o excesso de calor da superfície terrestre, que redistribuí pelo ambiente. Este processo inicia próximo à superfície terrestre na forma de termais, colunas de ar menos denso quando comparado ao ar adjacente, que se formam devido aquecimento diurno (Houze Jr, 2014).

A ascensão gradual de ar sobre uma área ampla devido as diferenças de temperaturas entre a superfície e a camada da atmosfera próxima à superfície no entardecer, aumentam os gradientes da temperatura e da pressão, que favorecem por meio de empuxo a ascensão de parcelas de ar, que se expandem, se resfriam e condensam, quando alcança a saturação (Parker e Andersen, 1988). Assim, a convergência próxima à superfície causadas por regiões de baixa pressão atmosférica permite que fluxos de ar de direções diferentes, possam produzir uma corrente ascendente que pode ser bastante eficiente em produzir nuvens, em especial quando o ar úmido de regiões distintas se encontra, e quando há divergência em níveis superiores da atmosfera. Elevações de terreno (montanhas e edifícios) forçam o ar a subir e condensar. O levantamento orográfico ocorre no continente em regiões montanhosas e também na costa continental em algumas regiões, em que o ar úmido de origem oceânica ao encontrar o continente mais elevado forma nuvens ao longo da costa. No levantamento frontal, fluxos de massas de ar com temperatura e umidade diferentes se encontram, em que as parcelas de ar mais quentes e úmidos ascendem, se resfriam, condensam e produzem nuvens e precipitação (Parker e Andersen, 1988).

Muitos aerossóis atuam como núcleos de condensação de nuvens (CCN) ou núcleos de gelo (IN) que alteram de forma complexa das propriedades microfísicas de nuvens e precipitações (Barry e Chorley, 2009). Pesquisadores sugerem que dependendo das condições meteorológicas, os efeitos dos aerossóis podem desencadear ou restringir a ocorrência de precipitação. Aquecimento e resfriamento latente durante a formação e evaporação de nuvens e precipitações, modificam a circulação atmosférica. No entanto, todos esses processos estão intrinsecamente associados com a microfísica das nuvens (Rosenfeld e Ulbrich, 2003). 


\subsubsection{Microfísica da nuvem quente e da nuvem mista}

As nuvens quente ou mista podem desenvolverem-se em condições atmosféricas instáveis, as gotas podem crescer em concentração e massa suficiente para vencer a força de arrasto aerodinâmico e a gravidade, e posteriormente precipitarem. (Pruppacher e Klett, 1996). As gotas suspensas na atmosfera sofrem processos que levam ao seu aumento em diâmetro, concentração e mudança de estado físico. No estágio inicial, durante os primeiros segundos, as gotas que possuem raio menor que $10 \mu \mathrm{m}$, crescem por condensação e difusão do vapor de água com taxa de crescimento sendo dominada pela supersaturação do ambiente, temperatura e efeito do soluto. As gotas com o raio menor que $50 \mu \mathrm{m}$, ficam suspensas ou precipitam a uma velocidade terminal em que o fluxo de ar ao seu redor pouco as afeta, e ainda se isenta na interação entre os campos de vapor das gotas próximas devido à distância das gotas vizinhas serem da ordem de cem vezes o raio médio das gotas na fase quente da nuvem (Pruppacher e Klett, 1996).

Com o contínuo desenvolvimento vertical da nuvem, devido o resfriamento e expansão da parcelas de ar, a umidade sofre aumento rápido e proporcional a velocidade das correntes ascendentes havendo o aumento do conteúdo de água líquida ( $L W C$-sigla em Inglês) durante o estágio maduro da nuvem. Não obstante da grande disponibilidade de vapor de água nestas condições, o crescimento por difusão do vapor de água, torna-se limitado. Assim, o processo microfísico de colisão-coalescência permite que as gotas continuem crescendo devido à interação entre elas (Barry e Chorley, 2009). As gotas que conseguirem crescer de forma mais eficiente no ambiente pelos processos de condensação e difusão de vapor, adquirem velocidade terminal maior que gotas menores, ao alcançarem um raio de $\sim 50 \mu \mathrm{m}$, se iniciam processos em que gotas maiores ao caírem, coletam gotas menores no caminho. Isto resulta em uma gota maior que a primeira. Entretanto, nem todas as gotas menores são capturadas, pois algumas são expelidas pelo fluxo de ar em volta da gota maior (Rogers e Yau, 1989). Os cristais de gelo depois de formados, crescem à custa do vapor de água fornecido pelas gotas existente no ambiente, em consequência da pressão de vapor de equilíbrio exercida sobre os cristais de gelo ser menor do que a pressão sobre as gotas, este mecanismo denominado Wegener-Bergeron-Findeisen é fundamental para nuvem mista no crescimento dos cristais de gelo à custa das gotas vizinhas (Rogers e Yau, 1989). Korolev (2007) define que a taxa de crescimento por condensação ou evaporação 
das gotículas e partículas de gelo na fase mista de nuvem é proporcional á diferença entre a pressão de vapor do ambiente $(e)$, pressão de vapor sobre a água $\left(e_{s}\right)$ e gelo $\left(e_{i}\right)$ que dependem das condições termodinâmicas, sendo que as correntes ascendentes desempenham o papel primário, quando a velocidade e a umidade das correntes implicam na $e, e_{s}$ e $e_{i}$. Assim, quando $e>e_{s}>e_{i}$ há ocorrência simultânea de crescimento de partículas de gelo e gotículas de d'água. Tal como haver corrente vertical ascendente maior que a velocidade das partículas, ocorre também crescimento simultâneo de gelo e gotículas d'água. Quando também há velocidades verticais próximos de zero, o ar em nuvens de fase mista é subsaturada em relação à água (Korolev e Mazin, 2003). A mistura isobárica de duas parcelas subsaturadas possuem diferentes temperaturas que resulta em elevada umidade relativa. Sob certas condições, a umidade relativa resultante pode exceder a saturação sobre o líquido, proporcionando o crescimento simultâneo das gotículas e das partículas de gelo. Quando $e_{s}>e>e_{i}$ as gotículas d'água evaporam e partículas de gelo crescem por deposição de vapor d'água à custa destas gotículas e, quando $e_{s}>e_{i}>e$, ocorre o processo de evaporação tanto das partículas de gelo e das gotículas d'água (Korolev, 2007).

Além da deposição de vapor para crescimento de cristais de gelo, ocorrem os processos de acreção e agregação. Na acreção, cristais de gelo colidem com gotas de água superresfriadas e ocorre o congelamento das gotas, formando-se o graupel (uma espécie de granizo macio e granular). Na agregação os cristais de gelo formados, colidem e se juntam, devido a uma fina camada de água em derretimento que envolve os cristais, este é o principal processo para produção dos flocos de neve e agregados. A forma dos cristais de gelo depende da temperatura e da pressão de vapor sobre o gelo. Na nuvem existem regiões em que predominam um tipo de geometria dos cristais em função das características da região em que se formam (Pruppacher e Klett, 1996). 


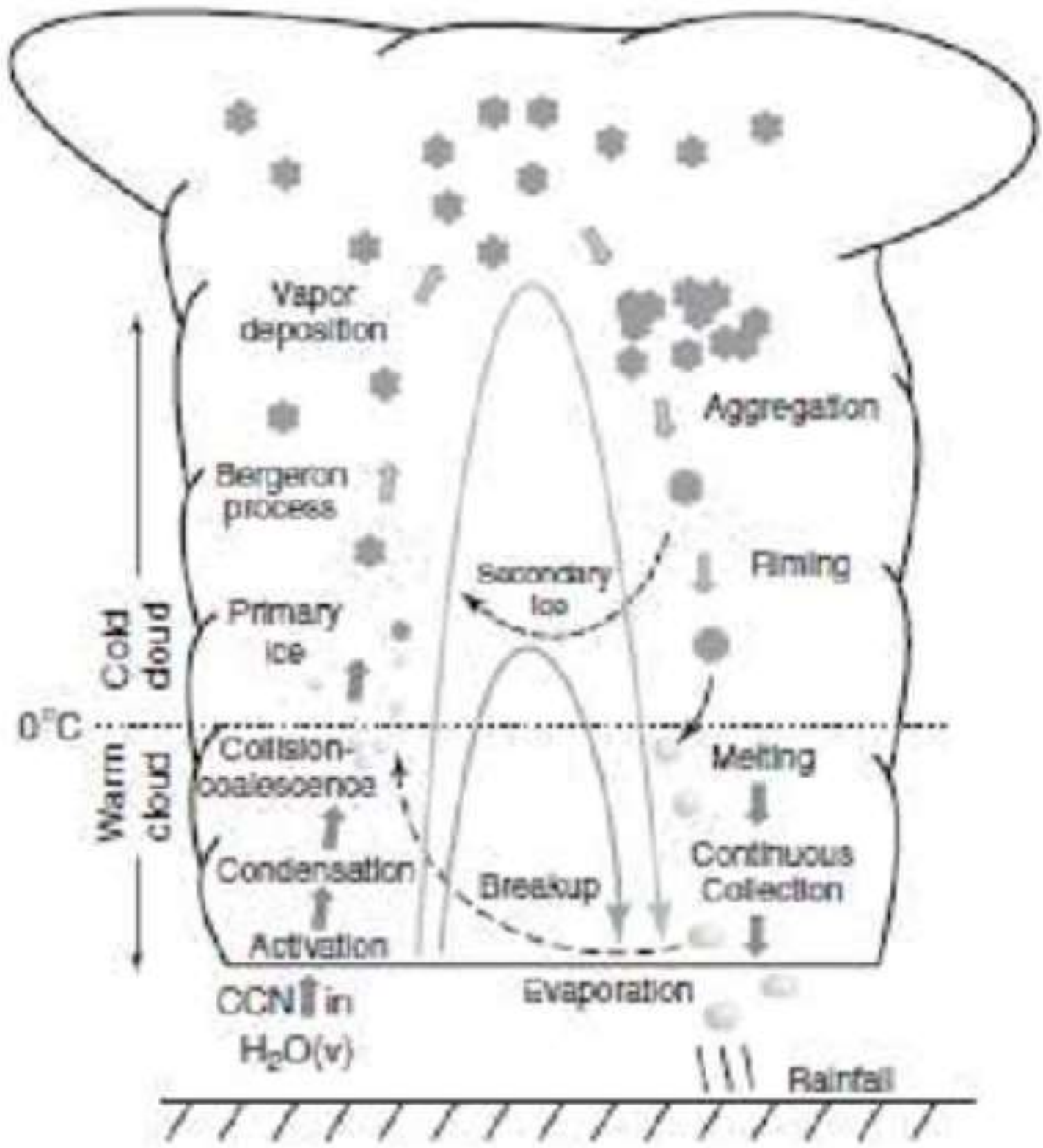

Figura 1.1: Esquema do funcionamento dos processos microfísicos envolvidos na formação da precipitação em nuvens convectivas. Fonte: Holton et al. (2003).

A título de exemplo, a Fig. 1.1 retrata esquematicamente o funcionamento dos processos microfísicos dentro de uma nuvem mista (desenvolvimento vertical). O processo de ativação e crescimento por condensação de nuvem, se inicia com o vapor da água e os núcleos de condensação. A corrente ascendente leva as gotículas para o topo da nuvem e através do processo de colisão e coalescência aumenta o tamanho dessas gotículas. Ultrapassada a isoterma $0^{\circ} \mathrm{C}$, começam a se formar os primeiros cristais de gelo, que continuam a crescer por meio de deposição de vapor pelo processo de Bergeron (Barry e Chorley, 
2009).

Quando alcançam um determinado tamanho, a corrente ascendente não consegue mais carregá-los e mantê-los, estes precipitam e coletam os cristais de gelo ou gotas de água super-resfriadas pelo caminho, e com isso crescer. Se durante esse trajeto os cristais de gelo encontrarem outra corrente ascendente, que consiga levá-los para o alto, a temperaturas negativas, o processo continua como um ciclo até que se forme graupel e depois granizo, que por ser pesado, precipita e atravessa a isoterma $0^{\circ} \mathrm{C}$. O granizo começa a derreter ou não a partir da base da isoterma $0^{\circ} \mathrm{C}$ dependendo das condições atmosféricas. Esse granizo derretido se transforma em gota grande que ao precipitar, se quebra pelo arrasto aerodinâmico, produzindo várias gotas, que coletam gotículas pelo caminho, até precipitar ao solo na forma de chuva e granizo (Houze Jr, 2014; Wang et al., 2015).

\subsubsection{Características dos sistemas precipitantes na Região Metropolitana de São Paulo $(\mathrm{RMSP})$}

A RMSP é uma megalópole composta por 39 cidades no leste do Estado de São Paulo. Esta região está entre as cinco maiores megacidades do planeta, com crescimento urbano intenso e extenso, e atualmente verticalizado (Fig 1.2). A mudança no uso e ocupação do solo ao longo do último século, induziu um ciclo diurno do aquecimento diabático de superfície e uma circulação local com ambiente rico em aerossol que são os principais ingredientes de formação de tempestades severas na RMSP (Pereira Filho, 2000; Pereira Filho et al., 2004). A Fig. 1.2 mostra uma imagem de satélite da RMSP e arredores. É notável o contraste de cores entre a superfície da RMSP (acastanhado), rural (esverdeado) e seu ambiente oceânico (azulado).

Além disso, a RMSP está dentro de uma topografia complexa variando entre 650 me 1200 m. A RMSP está a cerca de 50 km da linha costeira do Oceano Atlântico (Fig 1.2). Entre as duas regiões há a Serra do Mar de $700 \mathrm{~m}$ de altura. Sua direção SW-NE, no estado de São Paulo, induz a circulação térmica direta com ventos sudeste, adicionando velocidade à circulação diurna da brisa marítima em direção à RMSP. Esse ar mais frio e úmido misturado com ar mais quente e seco da RMSP, resulta em convecção profunda (Pereira Filho et al., 2007). A frente da brisa marítima avança em direção à RMSP, onde a rugosidade da superfície e a ilha de calor urbano (ICU) aumentam a convergência de umidade e o movimento ascendente, respectivamente (Vemado e Pereira Filho, 2016; 
Rojas et al., 2018).

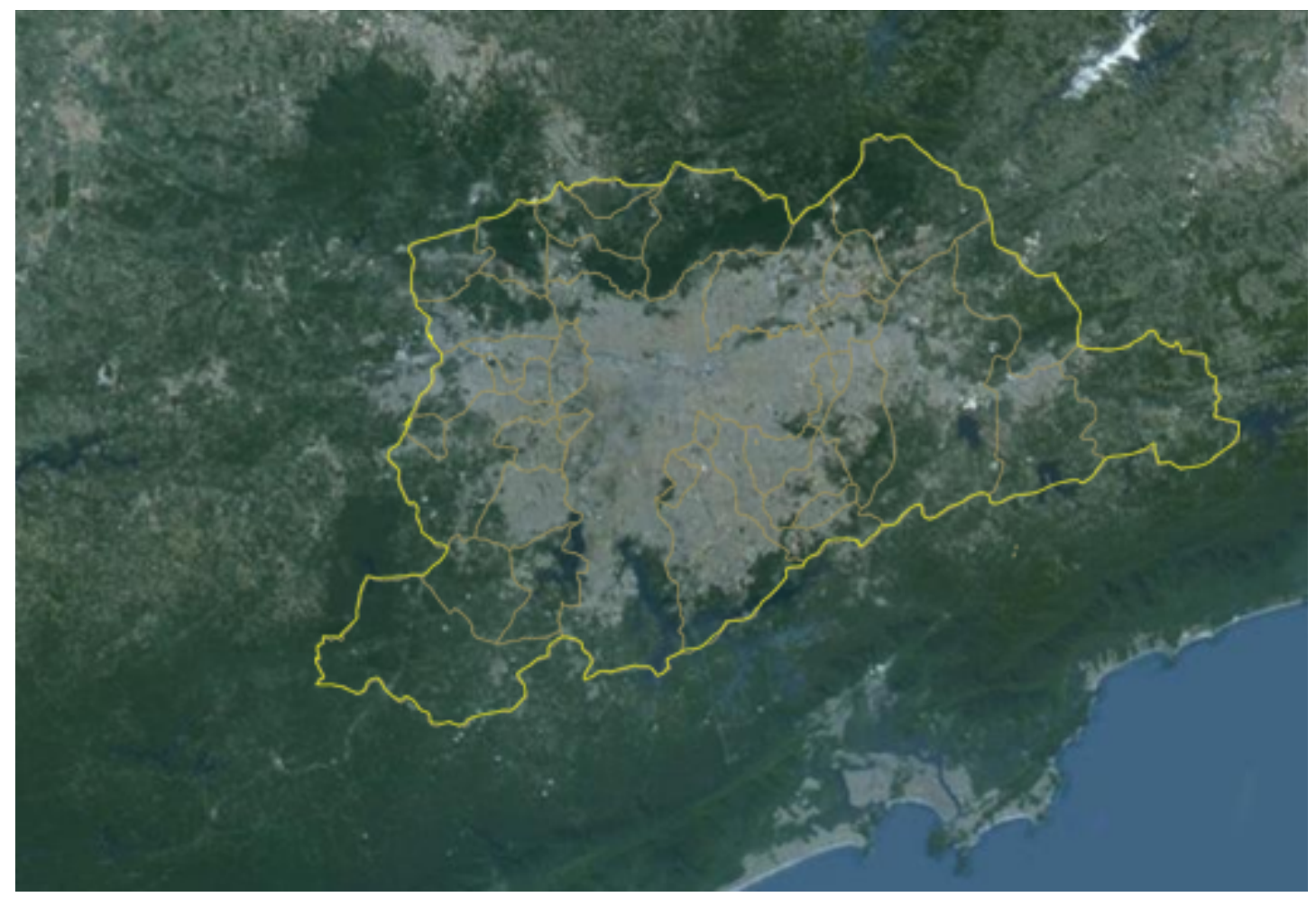

Figura 1.2: Região Metropolitana de são Paulo (RMSP). O contorno com amarelo é a fronteira política da RMSP. Os contornos cor laranja são as fronteiras políticas dos municípios dentro da RMSP. A área cinzenta é adensamento urbano. A cor azul é o oceano. Fonte: Adaptada de Google Earth.

O balanço de energia na superfície indica que a ilha de calor urbano (ICU) é causada pelo grande armazenamento de calor sensível dentro da área urbana nas primeiras horas do dia e liberado durante a tarde e a noite (Rojas et al., 2018). Frentes de brisas marítima tendem a intensificar o cisalhamento e a vorticidade associada e a convergência de umidade e aerossóis urbano (PEREIRA FILHO et al., 2018), para desencadear células convectivas secundárias ainda mais vigorosas (Hallak, 2007). Quando a frente da brisa do mar e a frente da rajada colidem, há uma redução da estabilidade estática de umidade dando origem a novas células convectivas (Hallak, 2007). A ICU sozinho pode induzir convergência e elevação de baixo nível, mas sobre a RMSP sob condições mais quentes e mais secas e alta quantidade de aerossol, o início da convecção profunda depende da umidade fornecida pelo fluxo da brisa marinha.

Tempestades são intensificadas pela circulação do ICU da RMSP e da brisa marítima sob altos gradientes de temperatura do ar rural e urbano, para induzir uma circulação 
térmica mais forte e profunda no meio da tarde, quando a advecção de umidade da brisa marítima reduz a estabilidade estática úmida, e a convecção profunda se desenvolve com chuvas fortes subsequentes (Pereira Filho et al., 2004; He et al., 2013; Vemado e Pereira Filho, 2016). Sob esses efeitos locais de circulação e aerossol, os processos microfísicos tendem a desempenhar um papel importante na dinâmica e termodinâmica das tempestades na RMSP.

Essas peculiaridades dinâmica e termodinâmica do ambiente urbano e núcleos de condensação de nuvens ( $C C N s$ e núcleos de condensação de gelo (ICNs), também induzem espectros de gotas de chuva distintos. Pereira Filho et al. (2013) mostraram que a alta concentração de aerossol urbano foi um fator que afetou a convecção mais profunda do evento de convecção na RMSP do que o evento formado em ambiente de menor concentração de aerossol. Os perfis verticais indicaram maior refletividade, convecção mais duradoura e maior concentração de gotas de chuva do que as observadas na Floresta Amazônica durante o LBA (Pereira Filho et al., 2013).

O LSP é atingido principalmente por cinco (5) eventos precipitantes, nomeadamente as Convecções isoladas (CIs), a Convecções induzidas por brisas marítima (BM), as linhas de instabilidade (LIs), as bandas dispersas (BDs) e as frentes frias (FFs). Estes eventos são classificados de acordo à morfologia, em eventos convectivos (EC) que dominam na primavera e verão, e em eventos estratiformes (EE) que atuam no Outono e no Inverno (Silva et al., 2009). De acordo com os autores, as CIs e as BM têm maiores picos de atuação entre outubro e março, e as FFs de abril a setembro. As BDs atuam durante todo o ano, e as LIs nos meses de junho e julho.

As CIs geralmente se formam à tarde sem orientação aparente e podem estar ou não, associadas a algum sistema de grande escala, e surgem e se dissipam geralmente próximo do local de formação. As CIs são células convectivas ordinárias sem deslocamento aparente ou de deslocamento muito lento, e sem região preferencial para formação sobre o continente. Eventos de CIs ocorrem preferencialmente entre 13:30 HL e 18:30 HL em função do ciclo do aquecimento diurno. Estas células ocorrem em sua grande maioria no interior do continente, geralmente com deslocamento de oeste para leste. As CIs podem dar origem a áreas de precipitação estratiformes mais extensas na fase de decaimento, do que na fase madura de desenvolvimento (Silva et al., 2009).

As BMs podem dar origem a sistemas precipitantes convectivos e estratiformes. Os 
eventos convectivos induzidos por BM, se deslocam para oeste com características morfológicas semelhantes as das CIs. As BMs desenvolvem-se geralmente entre 14:30 HL e 19:00 HL, e com tendência de formar linhas de células convectivas ao longo da costa, as quais são favorecidas pela Serra do Mar. Estes tipos de sistema alcançam a RMSP, onde normalmente produz precipitação convectiva intensa. Em alguns casos, as BMs dão origem a pequenas bandas ou áreas de precipitação estratiforme com tempo de vida curto (Silva et al., 2009).

As LIs apresentam em sua dianteira células convectivas intensas com área de precipitação estratiforme na sua retaguarda, deslocando-se rapidamente, em torno de 10 a 12 m. $\mathrm{s}^{-1}$. Estas surgem geralmente da fusão de ecos convectivos isolados ou podem estar associados a outros sistemas, em geral à dianteira ou retaguarda de FF. As LIs foram observadas em todos os horários, com predominância entre 15:00 HL e 17 HL, com ciclo de vida entre 4 a 12 horas (Silva et al., 2009). Estas se deslocam para todas as direções, mas preferencialmente de noroeste para sudeste, perpendiculares ou paralelas ao movimento de sistemas frontais (Silva et al., 2009). As BDs não apresentam organização espacial e, geralmente, estão associadas a um sistema de grande escala, tais como frentes estacionárias. Em geral, elas se deslocam de noroeste para sudeste e com chuva estratiforme e convecção embebida nelas. O período de vida destes sistemas pode chegar a até 5 dias. As BDs convectivas de maior longevidade estão, em geral, associadas aos episódios de ZCAS (Silva et al., 2009).

As FFs apresentam faixas de precipitações convectivas ou estratiformes de larguras variáveis com orientações noroeste-sudeste e deslocamento de sudoeste para leste/nordeste. A duração destes sistemas na área de cobertura do radar, varia de algumas horas a mais de 5 dias (estacionárias). A média de deslocamento das FFs pela área de cobertura do radar meteorológico de SP, foi de cerca de 18 horas (Silva et al., 2009). As FFs atuam em todos os meses do ano, porém, são mais convectivas no verão do que no inverno, quando se deslocam com maior velocidade e extensão de chuva estratiforme. Em alguns casos, no verão, estas zonas baroclínicas se tornam estacionárias e recebem aporte de umidade oriundo da região amazônica, que evoluem para ZCAS e, desta forma, produzem bandas de precipitações intensas (Silva et al., 2009).

A morfologia e o tempo de evolução de cada categoria desses eventos dependem da topografia, circulação associada e processos de mistura induzidos pelo aquecimento diurno. 
O tamanho horizontal dos mesmos se mostrou bastante variável. os Núcleos convectivos associados as CIs e as BMs, são os de menores dimensões, seguidos das LIs, FFs e BDs (Silva et al., 2009).

\subsubsection{Combinações de circulações Locais e sinóticas}

As forçantes mecânicas na RMSP são induzidas por edifícios de grande porte, que consistem em obstáculos. As forçantes térmicas são geradas pelo ambiente urbano da RMSP, que possuem fontes antropogênicas de calor. O solo urbano possui propriedades térmicas que favorecem a condução de calor mais rapidamente que na adjacência (áreas rurais), fazendo com que esse ambiente se aqueça mais, e gera circulação termicamente induzida (Freitas et al., 2007).

A brisa marítima é resultante da diferença da capacidade térmica entre o continente e a superfície oceânica (Fisher, 1960). A água possui capacidade térmica maior que a terra, consequentemente se aquece menos com a mesma quantidade de energia. Assim, a terra permanece mais aquecido que a água durante o dia, e gera aquecimento diferencial do ar em contato com essas superfícies, gerando contraste de temperatura. Esse contraste gera gradiente de pressão horizontal, com a pressão mais alta sobre a superfície da água. $\mathrm{O}$ ar frio se desloca em direção ao continente e, por continuidade surge em níveis mais elevados, um deslocamento de ar do continente para oceano, circulação denominada por brisa marítima (Fisher, 1960; Simpson, 1994).

A frente fria é uma circulação sinótica, sendo uma zona de transição onde uma massa de ar fria substitui uma massa de ar quente. O ar na retaguarda de uma frente fria é mais frio e seco que o ar na vanguarda. Quando uma frente fria se move para uma determinada região, desloca o ar mais quente do nível do solo. O ar mais frio e mais denso que o ar quente, empurra o ar quente para a atmosfera. À medida que o ar quente é deslocada, causa uma área de baixa pressão ao longo da frente fria (Holton, 1973). As frentes frias se movem de sudoeste para o nordeste sobre a América do Sul.

Muitos eventos de enchentes na RMSP estão associados com aumento da intensidade da precipitação induzida pela combinação da ICU e da BM, que induzem circulação atmosférica local na camada limite planetária - CLP, ejetando umidade e aerossóis (Pereira Filho e SILVA, 2005; Silva et al., 2009). Segundo Freitas et al. (2007) a ICU da RMSP forma uma forte zona de convergência com aceleração da frente de brisa do mar 
(induzida pela ICU) para o centro da cidade de São Paulo. A presença da região urbana aumenta a velocidade média de propagação da frente da brisa marítima. Além disso, devido à forte zona de convergência no centro da cidade, ICU da RMSP atua para bloquear a brisa marítima sobre a cidade por cerca de duas horas, carregando uma grande quantidade de umidade da superfície para os níveis superiores da atmosfera urbana (Freitas et al., 2007).

A Fig.1.3 mostra um modelo conceitual de combinação de circulações sinópticas e circulações locais.

Na Fig. 1.3a é observada como essas circulações combinadas atuam sobre a RMSP, onde uma frente fria se move sobre o sul do Brasil, que intensifica a circulação de noroeste contra a brisa marítima no meio da tarde, causando convergência profunda (Vemado e Pereira Filho, 2016). Na Fig. 1.3b é observada a secção transversal da convergência profunda causada pela circulação de noroeste contra a BM e associada a ICU sobre o centro geométrico da RMSP, que provoca vários disparos de células convectivas intensas e duradouras.
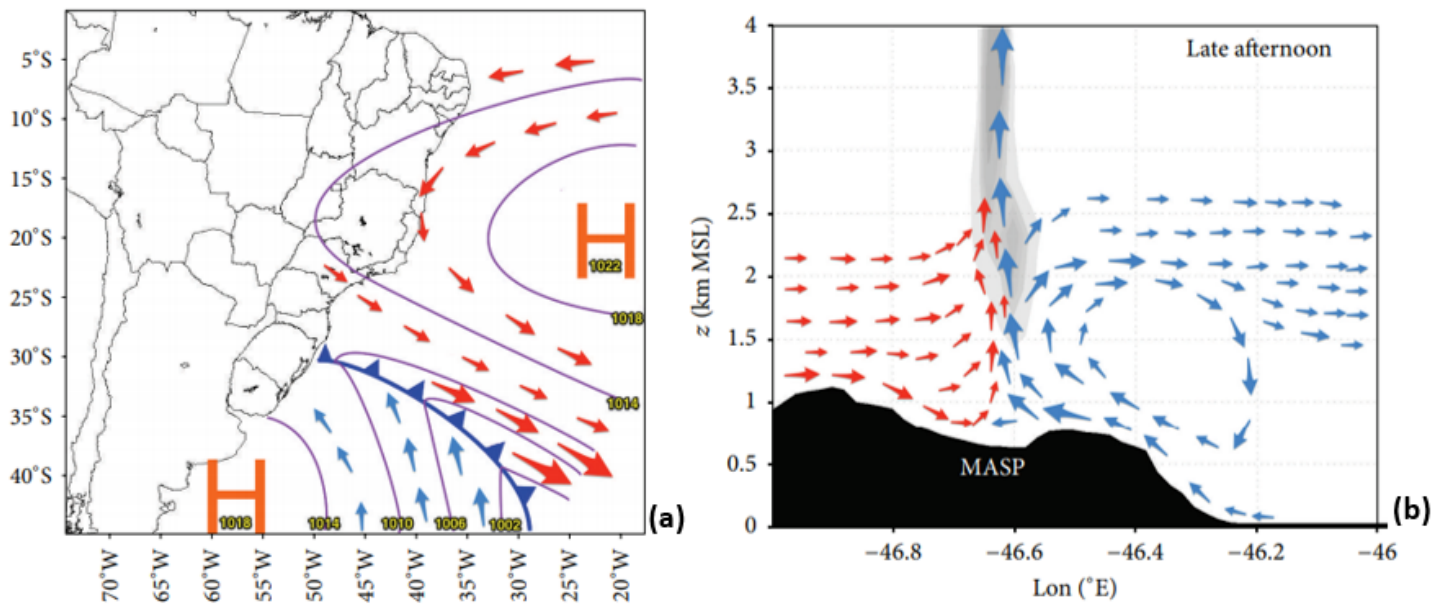

Figura 1.3: (a) Esquemas de uma condição sinóptica típica associada ao desenvolvimento de convecção profunda sobre a RMSP causada por intensa brisa marítima, circulação de ilhas de calor urbana e frente fria. (b) Diagrama esquemático de uma seção transversal de ventos e nebulosidade para um desenvolvimento típico de convecção profunda sobre a RMSP, causada pela brisa do marítima, vento de noroeste e ilha de calor urbana. Fonte: Vemado e Pereira Filho (2016). 


\subsubsection{Radar meteorológico}

O radar (Radio Detection and Ranging) é um dispositivo utilizado como sistema de detecção, localização e caracterização de alvos (hidrometeoros) por meio da transmissão e recepção de ondas eletromagnéticas em micro-ondas, cuja aplicação se dá a fenômenos meteorológicos, no monitoramento e previsão das suas severidades, além da previsão de comportamentos futuros (Rinehart, 1991).

\subsubsection{Equação de radar para alvos meteorológicos à distância}

A energia recebida de alvos meteorológicos distribuídos é derivada de qualquer uma da diversas expressões que são aplicáveis ao radar (Serafin, 1990). Uma delas, com a qual começar, é dada da seguinte forma:

$$
P_{r}=\frac{\beta \sigma}{r^{4}}
$$

Onde

$\beta$ é uma constante dependente dos parâmetros do sistema de radar; $r$ é a distância do alcance do feixe de radar; $\sigma$ é a seção transversal do radar.

É a partir do cálculo do $\sigma$ de alvos meteorológicos que a equação de alcance do radar difere daquela para finalidade de alvos pontuais. Então, $\sigma$ é escrito como:

$$
\sigma=\eta V
$$

Onde

$\eta$ é a refletividade do radar em unidades de área transversal por unidade de volume; $V$ é o volume amostrado pelo radar. O $\eta$ é escrito como:

$$
\eta=\sum_{i=1}^{N} \sigma_{i}
$$

Onde

$N$ é o número de espalhadores por unidade de volume e $\sigma_{i}$ é a seção transversal de retroespalhamento do espalhador $i$. Em geral, os alvos meteorológicos (espalhadores) as- 
sumem diversas formas de variedades de hidrometeoros, i.e, gotículas de água, cristais de gelo, granizo, neve e misturas de hidrometeoros acima da isoterma $0^{\circ} \mathrm{C}$ (Serafin, 1990).

Uma teoria geral foi desenvolvida por Mie (1908) para a energia retro-espalhada por gotas esféricas. Esta energia de retroespalhamento é uma função do comprimento de onda, o índice complexo de refração da partícula, e a razão $2 \pi \alpha / \lambda$, onde $\alpha$ é o raio da partícula esférica e $\lambda$ é o comprimento de onda (Serafin, 1990). Quando a razão é $2 \pi \alpha / \lambda-1$ a aproximação de Rayleigh (Battan, 1973; Serafin, 1990) é aplicada, e $\sigma_{i}$ torna-se

$$
\sigma_{i}=\frac{\pi^{5}}{\lambda^{4}}|K|^{2} D_{i}^{6}
$$

Onde

$D_{i}$ é o diâmetro de cada gota e

$$
|K|^{2}=\left|\frac{m^{2}-1}{m^{2}+2}\right|^{2}
$$

Onde

$m$ é o índice complexo de refração. Em temperaturas entre 0 e $20^{\circ} \mathrm{C}$, para a fase líquida da água e comprimentos de onda em centímetros, tem-se a Eq. 1.6.

$$
|K|^{2} \approx 0.93
$$

E para fase de sólida da água, tem-se a Eq. 1.7.

$$
|K|^{2} \approx 0.197
$$

Assim, a Eq. 1.3 pode ser escrita como:

$$
\eta=\frac{\pi^{5}}{\lambda^{4}}|K|^{2} \sum_{i=1}^{N} D_{i}^{6}
$$

E o fator de refletividade $Z$ do radar é definido como:

$$
Z=\sum_{i=1}^{N} D_{i}^{6}
$$

No uso de radar meteorológico, os diâmetros de gota $D_{i}$ tem sido em milímetros e para considerar a soma em todo volume iluminado de tamanho $1 \mathrm{~m}^{3}$. Por isso, a unidade convencional de $Z$ está em $m m^{6} / m^{3}$. Para partículas de gelo, $D_{i}$ é dado pelo diâmetro da 
gotícula de água, que resultaria se a partícula de gelo derretesse completamente (Serafin, 1990).

Tem sido conveniente tratar a distribuição de tamanho de gota com uma densidade numérica $\mathrm{N}(D)$, em que $\mathrm{N}(D)$ é o número de gotas por unidade de volume, com diâmetros entre $D+d D$ (Serafin, 1990). Assim, Z é dado pela sexta potência da distribuição de tamanho da partícula, pela Eq. 1.10

$$
Z=\int_{0}^{\infty} N(D) D^{6} d D
$$

Se o feixe do radar estiver cheio de partículas espalhadoras, o volume de amostra V é dado aproximadamente pela Eq. 1.11 (Battan, 1973; Serafin, 1990)

$$
\mathrm{V} \approx \frac{\pi \theta \phi r^{2} c \tau}{8}
$$

Onde

$\theta$ e $\phi$ são as larguras de feixe do azimute e da elevação; $C$ é a velocidade da luz; $\tau$ é a largura do pulso do radar.

Substituindo as equações 1.11, 1.2 e 1.8 dentro da equação 1.1, gera a Eq. 1.12.

$$
P_{r}=\frac{\beta \pi}{r^{4}} \frac{\theta \phi r^{2} \mathrm{c} \tau}{8} \frac{\pi^{5}}{\lambda^{4}}|K|^{2} \sum_{i=1}^{N} D_{i}^{6}=\frac{\beta \pi^{6} \theta \phi \mathrm{c} \tau|K|^{2}}{8 \lambda^{4} r^{2}} \mathrm{Z}=\frac{\beta^{\iota} \mathrm{Z}}{r^{2}}
$$

Esta expressão realça que a potência recebida é apenas uma função $\beta$ (uma constante que depende dos parâmetros do sistema de radar), que é proporcional ao fator de refletividade $Z$ e é inversamente proporcional a $r^{2}$ (Serafin, 1990).

A suposição de um ganho uniforme pode levar a erros no cálculo de $Z$, uma vez que o ganho da antena não é uniforme sobre a largura do feixe. Todavia, Probert-Jones (1962) assumiu uma forma gaussiana para o feixe da antena, levando em consideração a não uniformidade do ganho da antena, e derivou a seguinte Eq. para a potência recebida:

$$
P_{r}=\frac{P_{t} G^{2} \lambda^{2} \theta \phi \mathrm{c} \tau}{512(2 \ln 2) \pi^{2} r^{2}} \sum_{i=1}^{N} \sigma_{i}
$$

Onde,

$2 \ln 2$ é a correção devido ao feixe em formato gaussiano. 
Ao relacionar a Eq. 1.8 e a Eq. 1.9, a Eq. 1.13 é escrita em termos do fator de refletividade $Z$ como:

$$
P_{r}=\frac{P_{t} G^{2} \theta \phi \mathrm{c} \tau \pi^{3}|K|^{2} \mathrm{Z}}{512(2 \ln 2) r^{2} \lambda^{2}}
$$

As unidades do fator de reflectividade $Z$ da Eq. 1.14 comumente usadas, são de $m m^{6} / m^{3}$. Como os valores de interesse de $Z$ podem variar ao longo de várias ordens de magnitude, uma escala logarítmica é frequentemente usada (Serafin, 1990), ou seja:

$$
10 \log \mathrm{Z}(d B Z)
$$

A Eq. 1.10 transformada em dBZ, é utilizada para medir o fator de refletividade $Z$, quando o feixe de antena é preenchido por hidrometeoros, sendo válida a aproximação de Rayleigh e com hidrometeoros (dispersores) na fase de gelo ou de água (Serafin, 1990). Mas, nem sempre todas essas condições são satisfeitas, no entanto, tem sido frequente utilizar o termo $Z_{\mathrm{e}}$, o fator de refletividade efetiva, em vez de $Z$. Portanto, quando $Z_{\mathrm{e}}$ é usado, é comumente compreendido que as condições acima são assumidas (Serafin, 1990).

Resumidamente, o funcionamento elementar de um radar meteorológico é o de emitir onda eletromagnética em dada direção e a medida que o feixe atinge alvos na atmosfera, a energia é espalhada pelos alvos e uma parte dessa energia retorna para o radar. A fração de energia retornada é proporcional à secção transversal de retro-espalhamento (Eq. 1.4), que está relacionado ao tamanho do hidrometeoro (Sauvageot, 1992; Raghavan, 2013), ou seja, mede hidrometeoros (chuva, neve, partícula de gelo, graupel, granizo) no espaço detetando-os. Esses hidrometeoros conhecidos de "alvos distribuídos" são simultaneamente iluminados (Eq. 1.8) pelo feixe do radar. O volume que contém esses hidrometeoros, chamados de volume de resolução, dependem da largura do feixe e da duração do pulso da radiação transmitida. Os alvos distribuídos movem-se em relação aos outros com diferentes velocidade de queda, turbulência, vento, potência, (assim como a fase) retornado do volume de resolução centrado em um dado intervalo " $r$ ", que flutua no tempo. A potência instantânea retornada depende do arranjo dos hidrometeoros (dispersores). Assim, uma medida de tempo em mais de 0.01 - 0,1s significa as flutuações (Houze Jr, 2014). Sendo 
que a potência média retornada é dada pela Eq. 1.14.

\subsubsection{Espalhamento}

As ondas eletromagnéticas são interferidas ao incidir sobre os hidrometeoros que provocam a difusão ou dispersão, conhecido como processo físico de espalhamento. Este espalhamento corresponde a uma mudança aleatória da direção de propagação das ondas electromagnéticas devido a sua interação com os elementos na atmosfera. A onda espalhada não é atenuada hipoteticamente, mas sim redirecionada (Rinehart, 1991; Martinez, 2016).

O espalhamento depende fundamentalmente das características físicas dos hidrometeoros, i.e, a forma, o tamanho, a composição, as propriedades elétricas e do comprimento do sinal da onda electromagnética que interage com os hidrometeoros, podendo existir 3 tipos de espalhamento dentro da região de micro-ondas: óptico, Mie e Rayleigh (Martinez, 2016). Entretanto, espalhamento sofre variações físicas, como retroespalhamento e espalhamento frontal.

\subsubsection{Espalhamento Rayleigh e Mie}

A intensidade da onda espalhada é proporcional ao fator quadrado e forma do hidrometeoro $\chi=\frac{2 \pi \alpha_{p}}{\lambda}$, em que $\alpha_{p}$ é o tamanho do hidrometeoro e $\lambda$ é o comprimento de onda incidente. Quando o tamanho da partícula é maior que o $\lambda$, ocorre espalhamento óptico (Fig. 1.4c). Nessas circunstâncias são determinadas as leis clássicas de reflexão, refração e absorção da luz, onde é levada em consideração o ângulo de incidência da onda no hidrometeoro, o índice de refração e as propriedades absorventes do hidrometeoro. Para este caso a luz incidente é totalmente absorvida pelo hidrometeoro (Fukao et al., 2014).

$$
\sigma=\frac{\lambda^{2}}{4 \pi}\left|\sum_{n=1}^{\infty}(-1)^{n}(2 n+1)\left(\alpha_{n}+b_{n}\right)\right|^{2}\left[m^{2}\right]
$$

Onde: $\alpha_{n}$ e $b_{n}$ são os coeficientes de Mie que tem dependência do diâmetro e do complexo índice de refração; 
$n$ é o tamanho do hidrometeoro.

Mas quando os tamanhos dos hidrometeoros são proporcionais ao $\lambda$, ocorre o regime de espalhamento Mie. Neste regime O espalhamento não é igual em todas as direções (Fig. 1.4b), a energia é particionada, parte absorvida e outra parte é espalhada (Fukao et al., 2014). A partir da teoria de espalhamento Mie é considerado que o hidrometeoro absorve e espalha e, a seção transversal de retroespalhamento pode ser expressa na Eq. 1.16.

Quando o $\lambda$ do radar é maior que o diâmetro (D) do hidrometeoro $\left(\frac{\pi D}{\lambda} \ll 1\right)$, temos regime de espalhamento Rayleigh. A seção transversal do hidrometeoro é considerado quase isotrópico (Fig. 1.4a e Eq. 1.4), ou seja, o mesmo espalha energia isotropicamente e retorna a mesma potência para o radar, porque a energia incidente não sofre absorção e, é espalhada em todas as direções (Fukao et al., 2014).

\subsubsection{Atenuação}

A atenuação é causada pela perda potência na propagação do $\lambda$, quando interage com gotículas de nuvem (região rayleigh) e, principalmente gotas de chuva (região Mie), ou seja, quando uma gota de chuva é atingida pelo sinal do radar, a energia é particionada, parte dela é absorvida e outra parte é espalhada, causando atenuação do $\lambda$ e, até extinção (região óptica) dependendo da natureza das condições atmosféricas e da frequência do radar (Fukao et al., 2014).

Quando o diâmetro do hidrometeoros é menor que um décimo do $\lambda$, o espalhamento de luz segue o espalhamento de Rayleigh, onde a luz dispersa é igual em energia (espalhamento isotrópico) e não depende do ângulo de incidência. Para hidrometeoros com o diâmetro maior que um décimo do $\lambda$, o espalhamento de luz segue a teoria de Mie, onde a luz dispersa é desigual (espalhamento não-isotrópico) para a energia incidente e dependente do ângulo de incidência (Fig. 1.4). Assim, maior é atenuação quando ao longo do percurso do sinal do radar coabita uma quantidade maior de hidrometeoros (gotas oblatas) na atmosfera de espalhamento Mie.

A atenuação tem pelo menos dois efeitos negativos nos sinais de radares meteorológicos. Primeiro, devido à atenuação, torna-se difícil, se não impossível, fazer medições quantitativas da energia retro-difundida das gotículas precipitantes, que está em maior alcance 
(e com os mesmos ângulos de azimute e elevação) do que a precipitação mais próxima do radar. Esta incapacidade de medir com precisão a seção transversal de retroespalhamento torna as medições quantitativas das taxas de precipitação mais difíceis (Serafin, 1990).

a)

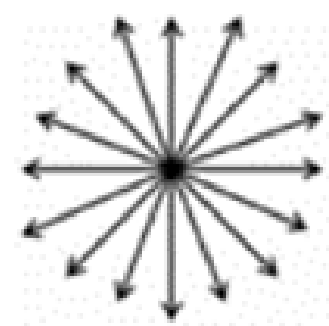

b)

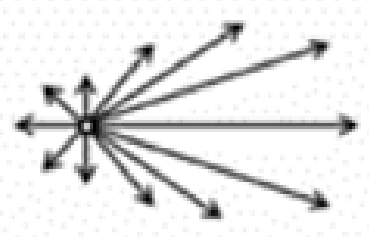

c)

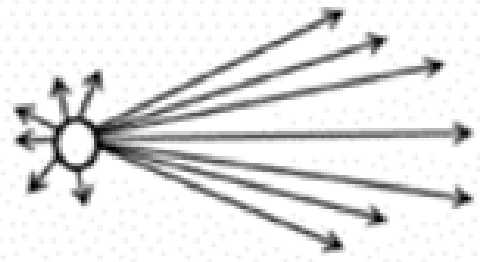

\section{Comprimento de onda $\lambda$ incidente}

Figura 1.4: (a) Espalhamento Rayleigh, tamanho de hidrometeoro $<\lambda / 10$, não depende do ângulo incidente, sofre espalhamento isotrópico. (b) Espalhamento de Mie, tamanho de hidrometeoro $>\lambda / 10$, depende do âgulo incidente, espalhamento não-isotrópico. (c) Espalhamento de Mie, dependência do ângulo aumenta com hidrometeoro maior. Fonte: Bhattacharjee (2016).

Segundo, se a atenuação for causada por um sistema convectivo profundo e de larga extensão, o sinal da célula de precipitante atrás de uma região de forte absorção pode ser totalmente extinto, levando a efeitos potencialmente desastrosos (Serafin, 1990).

Sob estas condições de chuvas fortes e dependendo das $\sigma_{i}, \lambda$ do radar e absorção, maior ou menor gama de hidrometeoros caiem no regime Mie.

A título de exemplo, a Fig. 1.5b ilustra a comparação das $\sigma_{i}$ e do $\lambda$ de radares de banda X $(3.21 \mathrm{~cm})$, de banda $\mathrm{C}(5.5 \mathrm{~cm})$ e de banda $\mathrm{S}(10 \mathrm{~cm})$. Observa-se que maior gama de hidrometeoros que caiem no regime rayleigh no banda $\mathrm{S}$ do que no banda $\mathrm{C}$ e $\mathrm{X}$ e, maior gama de hidrometeoros que caiem no regime Mie nos bandas $\mathrm{X}$ e $\mathrm{C}$ do que no banda S. Assim, tem-se maior atenuação nos radares de banda $\mathrm{X}$ e de banda $\mathrm{C}$ do que no radar de banda $\mathrm{S}$. 

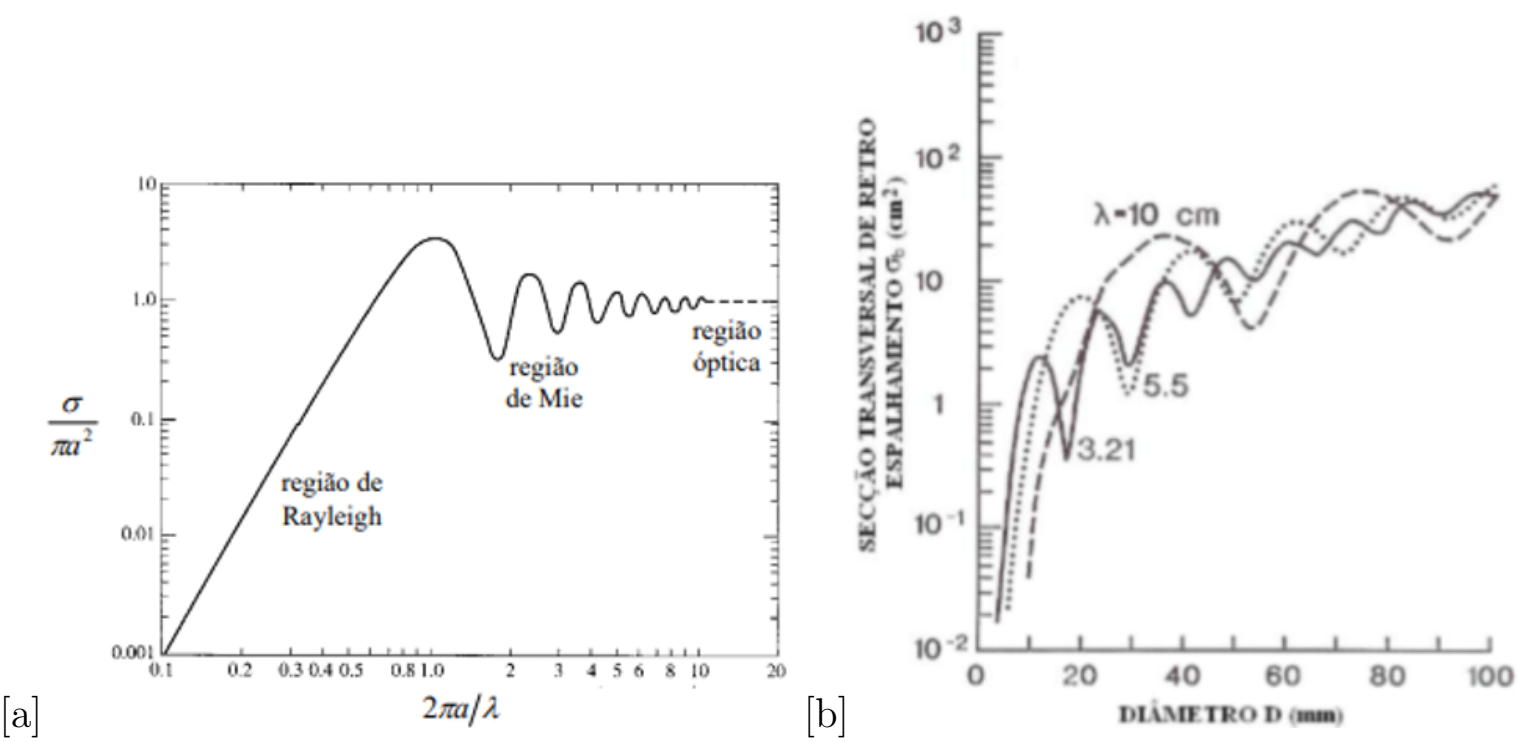

Figura 1.5: Secção transversal de retroespalhamento $\sigma_{b}$ para hidrometeoros esféricos e não-esféricos (a). Secção transversal de retroespalhamento $\sigma_{b}$ para hidrometeoros esféricos e não-esféricos de radar banda $\mathrm{X}(3.21 \mathrm{~cm})$, radar banda $\mathrm{C}(5.5 \mathrm{~cm})$ e radar banda $\mathrm{S}(10 \mathrm{~cm})(\mathrm{b})$. Fontes: Oziel et al. (2017) e Doviak et al. (2006).

Os radares polarimétricos transmitem radiação electromagnética em diversas polarizações, quando os hidrometeoros não são esféricos, a atenuação é distinta para cada polarização. Para radares de dupla polarização, a atenuação é maior na polarização horizontal do que na polarização vertical, quando as gotas são oblatas. Assim, o fator refletividade diferencial do radar terá uma tendência positiva quando a atenuação por gotas de chuva aumenta ou negativa quando a atenuação maior na vertical do que na horizontal (Doviak e Zrnic, 1993; Doviak et al., 2006).

\subsubsection{Classificação de hidrometeoros}

As variáveis polarimétricas juntas descrevem propriedades microfísicas dos hidrometeoros. Assim, é feita a inferência microfísica dos hidrometeoros a partir dessas variáveis. Em geral, usa-se as avariáveis polarimétricas para a classificação de hidrometeoros com várias técnicas e algoritmos existentes atualmente. Os métodos e algoritmos de identificação dos hidrometeoros estão baseados em definir o número e o tipo de classes de hidrometeoros para a identificação. Assim, as variáveis polarimétricas de radares meteorológicos podem ser associadas às classes dos hidrometeoros. Destaca-se as metodologias como a do Bringi 
et al. (1984) na qual usaram a reflectividade $\left(\mathrm{Z}_{H}\right)$ reflectividade diferencial $\left(\mathrm{Z}_{D R}\right)$ pra delimitar as zonas entre granizo e chuva, detecção de granizo e análise de perfis verticais para a classificação de graupel e granizo no centro da tempestade convectiva. Assim como Zrnic et al. (1993) utilizaram a fase diferencial específica $\left(K_{D P}\right)$ e o coeficiente de correlação $\left.\rho_{H V}(0)\right)$ para detectar granizo e as misturas de hidrometeoros em tempestades severas.

\subsubsection{Algoritmos de identificação de hidrometeoros para radares de banda $X$ e $S$}

Algoritmos de classificação de hidrometeoros, foram projetados de várias maneiras, mas o princípio básico é identificar qual tipo de hidrometeoros corresponde melhor às variáveis polarimétricas observadas do radar meteorológico em um local de interesse. A classificação é aplicada em cada gate do radar meteorológico de tal forma que um campo completo de tipos de hidrometeoros é produzido de forma consistente com os dados polarimétricos do radar. O tipo de hidrometeoro pode ser mapeado como um PPI ou um RHI ou examinado em três dimensões para entender onde determinados hidrometeoros estão presentes (Rauber e Nesbitt, 2018).

Os principais algoritmos abordados nas ultimas décadas são baseados no uso de diferentes técnicas (como lógica fuzzy, neuro-fuzzy, simulações teóricas, etc), levando-se me consideração o tipo de radar meteorológico.

Radar meteorológico de banda X apresenta problemas relacionados ao comprimento de onda e tamanho dos hidrometeoros, que influi na transição do regime Rayleigh para regime Mie e a atenuação por chuva, que pode ser um problema para a classificação de hidrometeoros, mas depende também da constante dielétrica. Entretanto, esses efeitos são quase desprezíveis para radares de banda $\mathrm{S}$.

Bringi et al. (1986) progrediram em cálculos da reflectividade horizontal $\left(\mathrm{Z}_{H}\right)$, reflectividade diferencial $\left(\mathrm{Z}_{D R}\right)$, fase diferencial específica $\left(\mathrm{K}_{D P}\right)$ e razão de depolarização linear (LDR), usando o modelo eletromagnético acoplado a um modelo microfísico de derretimento do graupel e detenção de granizo, inicializado com medidas de avião e dados de radiossondagem. Vivekanandan et al. (1999) desenvolveram um algorítimo de classificação de chuva e granizo baseado na teoria de lógica fuzzy, utilizando variáveis polarimétricas como a $\mathrm{Z}_{H}, \mathrm{Z}_{D R}$ e LDR de um radar banda $\mathrm{S}$. Na implementação do algorítimo foi feito o uso de operações matemáticas simples, para o monitoramento da tempestade em tempo real. Este método tem vantagem porque não é afetado de forma negativa pelos erros típicos 
de medição de algumas variáveis de entrada. Straka et al. (2000) usaram um algoritmo baseado na lógica fuzzy para classificação de hidrometeoros a partir dos dado do radar polarimétrico de banda $\mathrm{S}$. As informações foram baseadas em dados observados e de modelagem de assinatura dos hidrometeoros para a identificação de hidrometeoros baseados nas espécies, tamanhos, concentrações e quantidades.

Liu e Chandrasekar (2000) implementaram um algorítimo baseado em lógica fuzzy acoplada a redes neurais. No algoritmo foi usado variáveis polarimétricas de entrada: $\mathrm{Z}_{H}$, $\mathrm{Z}_{D R}, \mathrm{~K}_{D P}, \rho_{H V}(0)$ e LDR e dados de radiossondagem. Os autores obtiveram êxitos com informações de saída do algorítimo com garoa, chuva, neve seca de baixa densidade, cristais secos de alta densidade, neve úmida e derretida, graupel seco e molhado, granizo pequeno e grande, e mistura de chuva e granizo. Fernández-González et al. (2016) usaram um modelo dinâmico e microfísico para a simulação de uma tempestade. Os autores observaram que o resfriamento latente causado por evaporação e fusão (e os efeitos microfísicos que eles induzem), contribuíram para a intensificação da corrente de ar descendente. Interação entre as correntes descendentes de ar frio e as correntes ascendentes de ar quente, resultaram no desenvolvimento de um mecanismo de feedback positivo através de uma circulação dentro da célula convectiva, já o resfriamento latente por sublimação não foi essencial para manter as correntes ascendentes de uma tempestade. Morrison e Milbrandt (2015) desenvolveram um método de parametrização para a modelagem microfísica da fase de gelo. O modelo simulou realisticamente ampla gama das características das partículas em diferentes regiões da linha de instabilidade, comparadas com as partículas de gelo observadas nas linhas de instabilidade. Os testes de sensibilidade mostram que tanto a predição da fração de congelamento da massa e da densidade de congelamento é importante para a simulação da estrutura de linha de instabilidade e precipitação. Dolan e Rutledge (2009) implementaram um algoritmo de identificação de hidrometeoros para radar meteorológico de banda X, baseado em simulações teóricas para diferentes hidrometeoros como primeira etapa. $\mathrm{Na}$ segunda etapa, os resultados das simulações serviram de esquema de identificação com método lógica fuzzy, objectivando a definição de uma função beta $(\beta)$.

Marzano et al. (2010) desenvolveram um modelo interativo bayesiano de classificação de hidrometeoros para radar meteorológico de banda X. O algoritmo desenvolvido foi levado em consideração a correção da atenuação, afim de calcular o conteúdo de água liquida. o resultados mostraram uma melhoria significativa no desempenho da correção de atenuação. 
Sendo que o método pode ser utilizado para radares de banda $\mathrm{X}$ e banda $\mathrm{S}$, o que permite fazer comparações experimentais entre medições em diferentes frequências. Snyder et al. (2010) utilizaram a atenuação para estimar a distribuição tridimensional de hidrometeoros nas tempestades, usando também algoritmo baseado no método lógica fuzzy, para identificar diferentes tipos de hidrometeoros em tempestades para radares meteorológicos de banda X. Kouketsu et al. (2015) implementaram um método de classificação de hidrometeoros baseado em lógica fuzzy para radar polarimétrico de banda X, adequado para observação de hidrometeoros sólidos em ambientes úmidos que produzem pouco ou nenhum granizo. Este método identifica os hidrometeoros a cada ponto de grade de oito categorias: 1) chuvisco, 2) chuva, 3) agregados de neve úmida, 4) agregados de neve seca, 5) cristais de gelo, 6) graupel seco, 7) graupel úmido e 8) mistura de chuva e granizo. O conjunto das funções membros foram definidas com base em estudos anteriores. O método utiliza $\mathrm{Z}_{H}, \mathrm{Z}_{D R}, \mathrm{~K}_{D P}$ e $\rho_{H V}(0)$ como principais entradas e altitude (temperatura).

Um estudo foi realizado por (Mohan et al., 2018), durante a Monção do Nordeste na cidade de Chennai, na costa sudeste da Índia, utilizando o modelo Advanced Research and Weather Research and Forecasting (WRF-ARW). Os autores realizaram simulações para estudar a sensibilidade do modelo às parametrizações da microfísica das nuvens sobre a previsão de chuvas fortes usando informações microfísicas. Os resultados mostram que a microfísica influenciou significativamente a simulação de chuva devido à variação nas proporções de mistura de diferentes hidrometeoros e os parâmetros dinâmicos e termodinâmicos associados, que corroboraram com as observações do radar meteorológico Doppler 
Capítulo 2

\section{Metodologia}

Dados polarimétricos medidos a partir de radares meteorológicos polarimétricos MXPOL e SPOL e dados de radiossondagens foram utilizados como entradas no método lógica fuzzy para a classificação de hidrometeoros. Além disso, utilizou-se dados do disdrômetro de impacto Joss-Waldvogel como complemento na análise do espectro de gotas da tempestade induzida pela combinação de BM, ICU e FF, ocorrido no dia 11 Janeiro de 2010.

Utilizou-se também imagens de satélite Goes-12 na banda infravermelho e Goes 16, dados de reanálises do modelo ECMWF (European Centre for Medium-Range Weather Forecasts) e do modelo GFS (Global Forecast System) para análise sinótica dos eventos.

Total de cinco (5) eventos foram identificados, dos quais 1 evento a partir de medidas polarimétricas do radar MXPOL ocorrido em 2010 e 4 evento a partir de medidas polarimétricas do radar SPOL dos quais 2 eventos ocorridos em 2019 e outros dois eventos em 2014 e 2016. Estes eventos foram classificados de acordo com a morfologia a partir das assinaturas de radar, em eventos convectivos (EC) que dominam na primavera e verão, e em eventos estratiformes (EE) que atuam no Outono e no Inverno, descritos na na secção 1.2.3 (Silva et al., 2009).

As classificações de hidrometeoros e análises microfísicas foram realizadas por meio do método lógica fuzzy com dados de entrada as variáveis polarimétricas e dados de radiossondagens, usando os algorítimo de Lang et al. (2019). Com base nos algoritmos de Lang et al. (2019), também calculou-se massa de água líquida e massa de água sólida, diâmetro da gota de chuva, e estimou-se a taxa de chuva a partir das variáveis polarimétricas dos radares e dados de radiossondagens. 


\subsection{Radares Meteorológicos dupla polarização Doppler}

As principais variáveis polarimétricas medidas por radares meteorológicos de dupla polarização Doppler (Fig. 2.2 e 2.3), são: Refletividade, refletividade diferencial, fase diferencial, fase diferencial específica, coeficiente de correlação, velocidade radial e largura espectral. Através destas variáveis polarimétricas, são obtidas variáveis climáticas como taxas de precipitação, campos de vento em 2D, tipos de hidrometeoros e muitas outras (Pereira Filho, 2000; Pereira Filho et al., 2013). O montante de energia retro-espalhada que chega ao radar apontada a um dado azimute e elevação, é dependente do conteúdo iluminado pelo mesmo. Se o volume não possui hidrometeoros, a energia retro-espalhada é devida às irregularidades no índice refrativo do radar e proporcional ao movimento do ar, sendo chamado de espalhamento Bragg ou ecos de céu claro (Doviak e Zrnic, 1993). O volume radial de todos os espalhadores ao longo do volume de amostra do radar, é dado pelo espectro Doppler (Atlas, 1957). O espectro Doppler é uma distribuição das velocidades radiais dos espalhadores do volume iluminado, ponderada pela potência de retorno. A forma deste espectro é caracterizada pelos seus primeiros três momentos: "sinalto-noise" (S/N), velocidade Doppler (V) e largura espectral (SW). O S/N é o momento zero do espectro Doppler sendo uma medida da potência de retorno do sinal, ou seja, pode-se calcular a refletividade do volume. O primeiro momento do espectro Doppler, é a velocidade média ponderada pela potência espalhadores, chamada de velocidade Doppler (Atlas, 1957). Na presença de hidrometeoros, o espectro Doppler medido é a evolução da velocidade dos hidrometeoros $\left(\mathrm{V}_{T}\right.$, velocidade terminal) e velocidade do ar de $W$, então, a velocidade Doppler $V$ é dada por $V=W-V T$ (Atlas, 1957). O desvio da velocidade ponderada pela potência é o segundo momento do espectro Doppler, chamada de largura espectral, sendo uma medida relacionada diretamente com a turbulência, cisalhamento e distribuição de hidrometeoros no volume amostrado pelo radar (Atlas, 1957).

Os dados recolhidos pelos radares estão em coordenadas esféricas, onde a posição de cada dado é descrito em termos de $(\theta, \phi, r)$, onde $\theta$ é o ângulo de elevação da antena, $\phi$ é o ângulo de rotação no sentido horário da antena em relação ao norte geográfico, chamado ângulo de azimute, e $r$ é a distância entre o radar e o alvo. Os dados recolhidos do radar para uma varredura completa e elevação fixa, é denominada PPI (Plan Position Indicator).

A coleção de PPIs sucessivos de cada radar é um scanner volumétrico. Uma repre- 
sentação bidimensional dos dados volumétricos é obtido por uma gama de seleção de vários PPIs, denominado CAPPI (Posição do Plano de Altitude Constante Indicador). Portanto, um produto CAPPI (Fig. 2.1) é a informação a uma certa altitude, de modo a que todas as elevações podem contribuir para o produto gerado (Fabry, 2015).

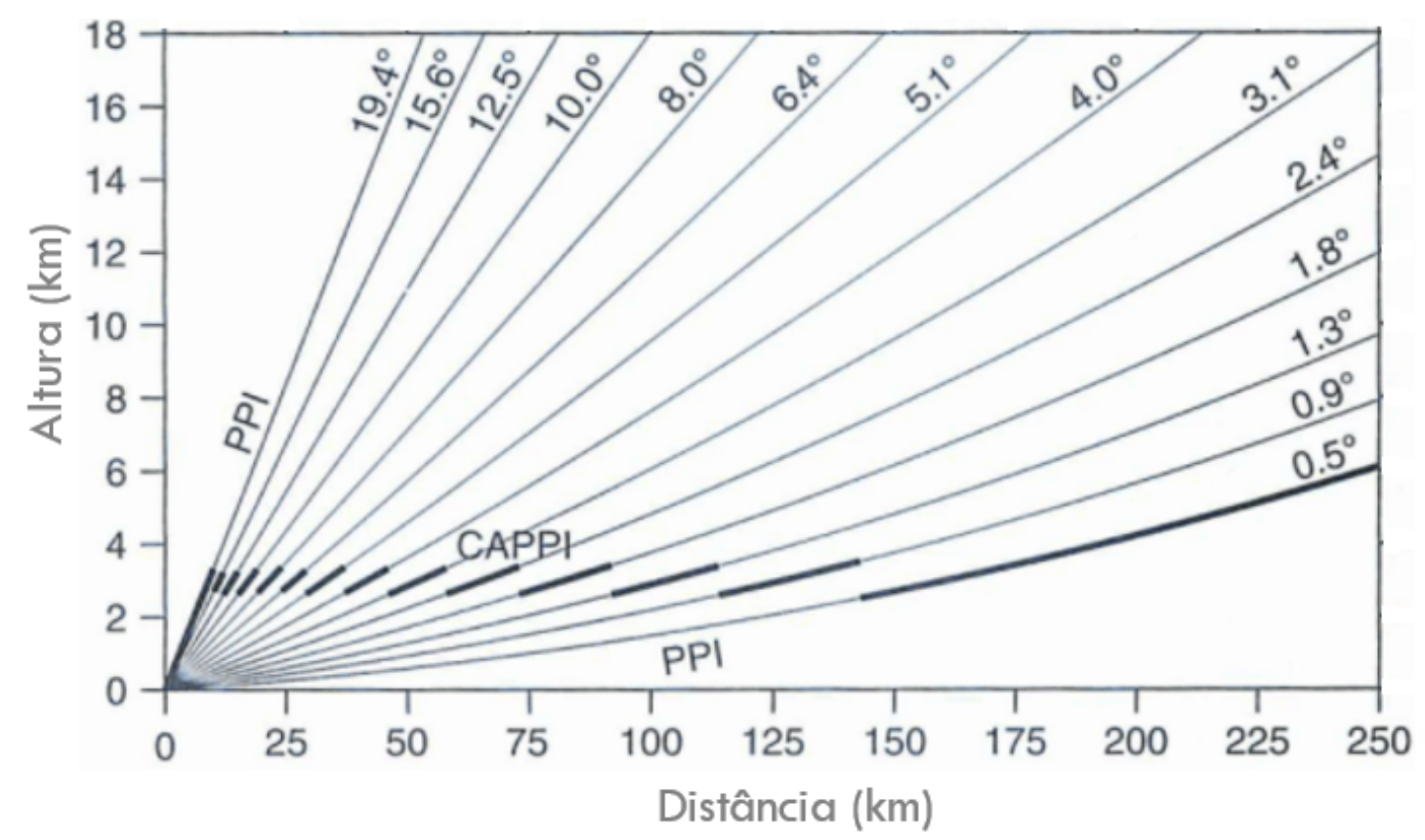

Figura 2.1: Exemplo de PPI e CAPPI. Um CAPPI é obtido através de uma selecção de intervalos em vários PPIs para criar uma imagem $2 \mathrm{D}$ da varredura do volume. Fonte: Fabry (2015).

Neste trabalho, usou-se apenas os PPIs de diferentes ângulos de elevação para a análise microfísica durante a evolução espaço-temporal dos sistemas convectivos precipitantes. Para o MXPOL e SPOL os ângulos mínimos de elevação foram de $0.6^{\circ}$ e $1.0^{\circ}$, respectivamente. As amostras por radial e ângulos máximos de elevação realizados, dependeram da profundidade de cada sistema precipitante.

- Radar meteorológico móvel banda X Doppler de dupla polarização (MXPOL).

O MXPOL (Fig. 2.2) pertencente ao laboratório de Hidrometeorologia (Labhidro) do Departamento de Ciências Atmosféricas do IAG-USP, é um sistema multifuncional com várias inovações tecnológicas para usos como o monitoramento de tempestades severas. Ainda é o primeiro radar meteorológico de gênero atualmente no Brasil a ser utilizado na operação para prover dados polarimétricos de alta resolução espacial (Pereira Filho et al., 2007). Dados do evento ocorrido no 11 de Janeiro de 2010, foram utilizados neste trabalho. 


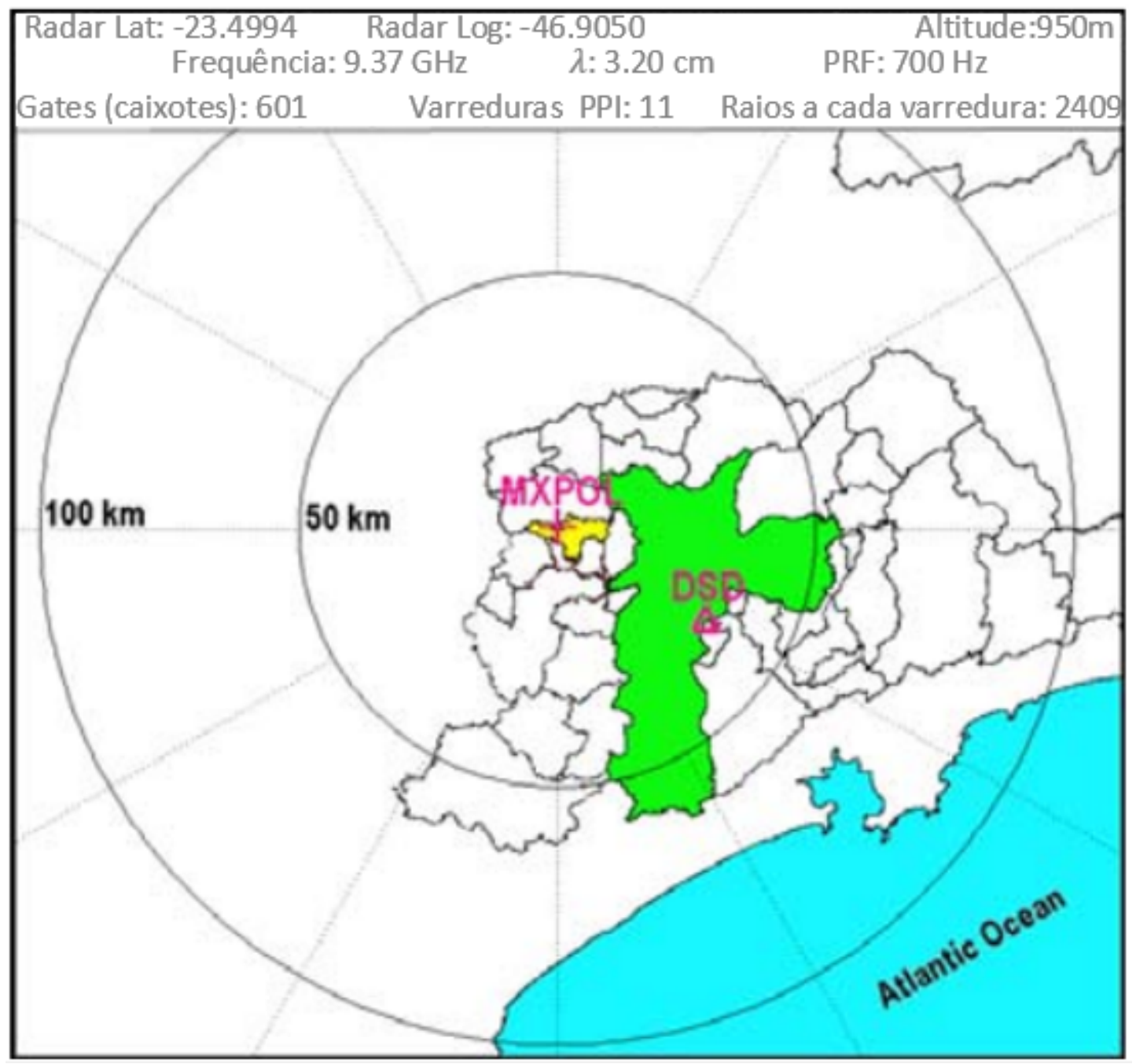

Figura 2.2: Área de vigilância da MXPOL na Região Metropolitana de São Paulo. A Cruz e o triângulo indicam a localização da MXPOL e do Disdrometro JW no Parque Estadual Fontes do Ipiranga (PEFI), respectivamente. As áreas verde e amarela são as cidades de São Paulo e Barueri, respectivamente. Fonte: Pereira Filho et al. (2007).

A antena é controlada pelo RCP8 (radar and antenna control processor) e o processamento de sinais é realizado pelo RVP8 (digital receiver and signal processing). O software IRIS Analysis do SIGMET (Significant Meteorological Information), controla o processador RVP8 e da antena RCP8. Esse software também processa PPI e gera arquivos de dados brutos em tempo integral. As variáveis medidas pelo MXPOL são: refletividade ajustada (DZ) e sem correção (ZT), velocidade radial (VR), largura espectral (SW), refletividade diferencial $\left(\mathrm{Z}_{D R}\right)$, propagação de fase diferencial $\left(\phi_{D P}\right)$, e fase diferencial específica $\left(\mathrm{K}_{D P}\right)$, coeficiente de correlação da magnitude do sinal co-pol H e co-pol V $\left(\rho_{H V}\right)$.

O software está instalado num terceiro processador para melhor desempenho do sistema. 
Os principais produtos são PPI, RHI, CAPPI, ECHO TOPS, chuva acumulada, perfis de refletividade máxima, cortes transversais, previsão de deslocamento de tempestades, trajeto e previsão de tempestades, alertas especiais na tela, água líquida integrada na vertical, velocidade e direção do vento (Ferreira, 2010; Pereira Filho et al., 2007).

O sistema do MXPOL também inclui um caminhão Volvo Diesel de seis cilindros de 180 HP, um gerador de energia elétrica Diesel de 18 KW com autonomia de uma semana, suspensão a ar, sistema de nivelamento automático, Sistema de Posicionamento Global (GPS), linha de Internet via telefone celular e sistema de comunicação banda larga, sistema de posicionamento de antena, medidor e gerador de microondas, e software automático de calibração eletrônica.

Tabela 2.1 - Características técnicas do sistema do radar meteorológico MXPOL. Fonte: adaptada de Pereira Filho et al. (2007).

\begin{tabular}{c|c}
\hline TRANSMISSOR & RECEPTOR \\
\hline Magnetron & Dois canais digitais $(\mathrm{H}, \mathrm{V})$ \\
Freqüência 9,3 a $9,5 \mathrm{GHz}$ & Ruído do radar $<2,5 \mathrm{~dB}$ \\
Potência máxima $80 \mathrm{KW}$ & Alcance Dinâmico $(\mathrm{H}, \mathrm{V})>80 \mathrm{~dB}$ \\
Pulso modulado & Conversor AD de $14 \mathrm{bits}$ \\
PRF $500 \mathrm{~Hz}$ a $5000 \mathrm{~Hz}$ & Oscilador local DAFC \\
Largura do Pulso 0,2 $\mu \mathrm{s} \mathrm{a} 2 \mu \mathrm{s}$ & MDS $(\mathrm{H}, \mathrm{V})-113 \mathrm{dBm} @ 2 \mu \mathrm{s}$ \\
Polarização linear $(\mathrm{H}, \mathrm{V})$ simultâneas & \\
Modulador de estado sólido & \\
Ciclo de trabalho 0,001 & \\
\hline PEDESTAL & REFLETOR \\
\hline Varredura azimutal $0^{0}$ a $360^{0}$ & Parabólico \\
Varredura em elevação $0^{0}$ a $90^{0}$ & Diâmetro $2,44 \mathrm{~m}$ \\
Máxima varredura $36^{0} \mathrm{~s}^{-1}$ & Ganho da Antena $44 \mathrm{~dB}$ \\
Imprecisão de apontamento $<0,1^{0}$ & HPBW @ 3dB $<1,0^{0}$ \\
\hline
\end{tabular}

O sistema do XMPOL foi desenvolvido pela ATMOS SYSTEMS LTDA, uma empresa brasileira de radares. Muitas das partes que compõe o radar foram adquiridas nos EUA (e.g., válvula Magnetron, guias de onda, duplexador, chaveadores e receptores), Alemanha (motores de elevação e azimute, codificadores e anéis deslizantes), Finlândia (refletor e suportes) e Brasil [caminhão e gerador Diesel, ar condicionado, cabine e prateleiras] (Pereira Filho et al., 2007). A Tab. 2.1 mostra as características técnicas do refletor da antena, 
pedestal, transmissor e receptor do MXPOL.

- Radar meteorológico banda S Doppler de dupla polarização (SPOL).

O SPOL está instalado a leste da RMSP (Fig. 2.3), na barragem da Ponte Nova,

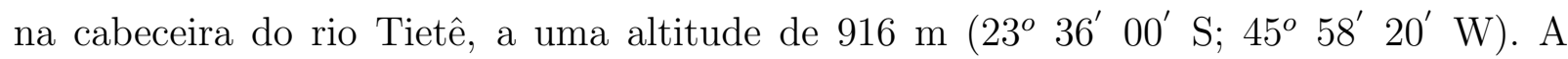
torre metálica que suporta o SPOL, possui 9 metros de altura. O radar pertence ao Departamento de Águas e Energia Elétrica (DAEE) do Estado de São Paulo.

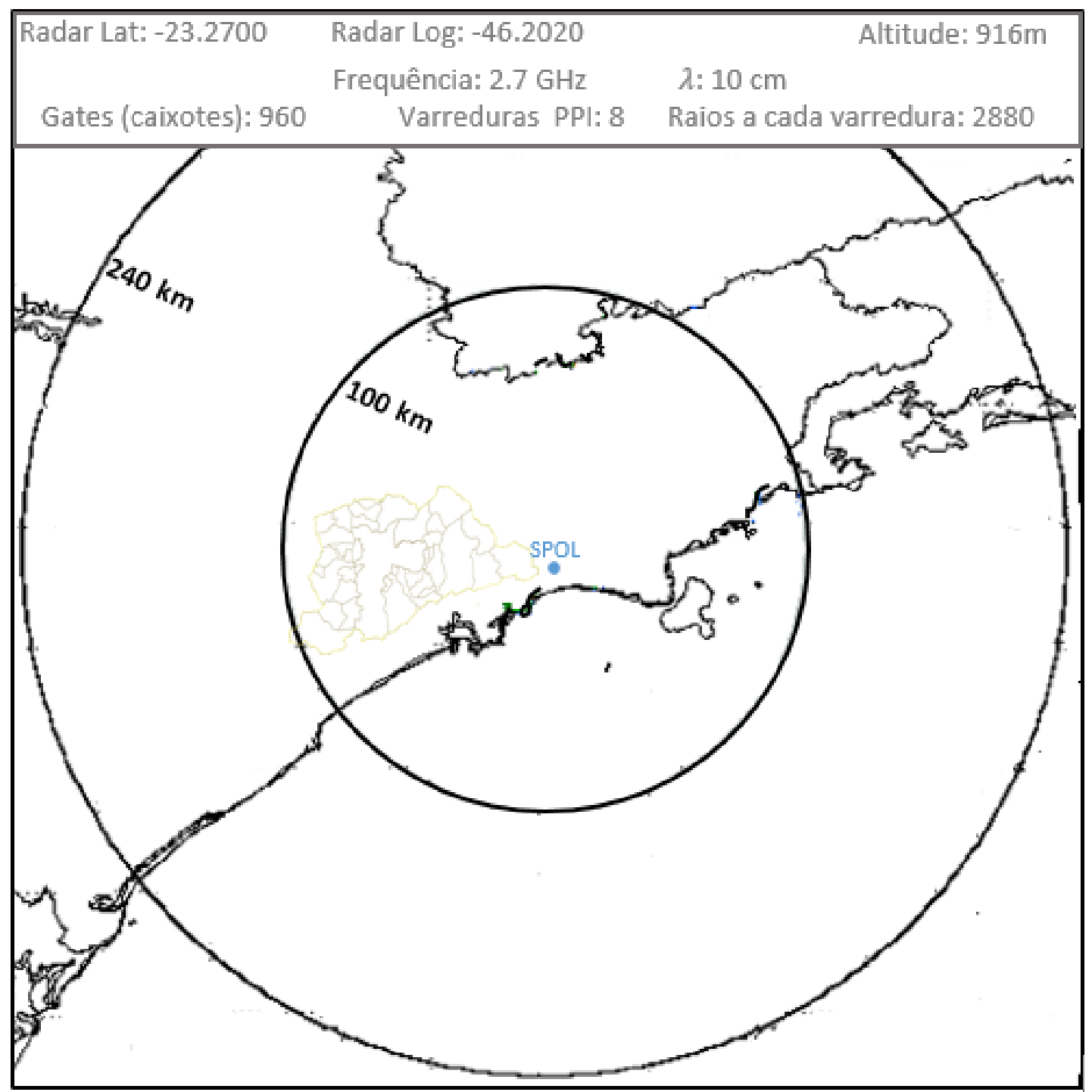

Figura 2.3: Área de vigilância da SPOL no Leste do Estado de São Paulo. O ponto azul indica a localização do SPOL, instalado na barragem de Ponte Nova, localizada na cabeceira do rio Tietê.

O SPOL é utilizado operacionalmente na frequência de aproximadamente $2.7 \mathrm{GHz}$ para a previsão de curtíssimo prazo na RMSP. O mesmo cobre uma área correspondente ao raio 
de $240 \mathrm{~km}$ (Fig. 2.3), e opera num comprimento de onda de $10 \mathrm{~cm}$, com 8 varreduras de PPIs, 2880 raios e 960 gates a cada varredura do ângulo da antena. A área de varredura abrange toda a região leste do Estado do São Paulo, sul dos Estados do Rio de Janeiro e Minas Gerais. Um conjunto de dados deste radar foi disponibilizado pelo DAEE, para o período 2014 e 2019. Dados dos eventos acorridos nos dias 18 de Maio de 2014, 24 de Janeiro de 2016, 29 de Janeiro de 2019 e 19 de Agosto de 2019, foram utilizados neste trabalho. A Tab. 2.2 mostra as características técnicas do refletor da antena, pedestal, transmissor e receptor do SPOL.

Tabela 2.2 - Características técnicas do sistema do radar meteorológico SPOL.

\begin{tabular}{c|c}
\hline TRANSMISSOR & RECEPTOR \\
\hline Magnetron & Dois canais digitais $(\mathrm{H}, \mathrm{V})$ \\
Frequência 2,7 a $2,9 \mathrm{GHz}$ & Ruído do radar $<0.3 \mathrm{~dB}$ \\
Potência máxima $1,000 \mathrm{Kw}$ & Alcance Dinâmico $(\mathrm{H}, \mathrm{V})>90 \mathrm{~dB}$ \\
Pulso modulado & Detecção da reflectividade $<10 \mathrm{~dB}$ a $150 \mathrm{~km}$ \\
PRF $250 \mathrm{~Hz}$ a $2,000 \mathrm{~Hz}$ & Precisão na estimativa da velocidade $-1 \mathrm{~ms}^{-1}$ \\
Largura do Pulso 0.5 a $3.5 \mathrm{~ms}^{-1}$ & Sinal mínimo detectável $(\mathrm{H}, \mathrm{V})-110 \mathrm{~dB}$ \\
Polarização linear $(\mathrm{H}, \mathrm{V})$ simultâneas & Resolução de fases $<1,0^{0}$ \\
& $\mathrm{Z}_{D R}<0.2$ \\
PEDESTAL & Correlação $H V 0.1$ \\
\hline Varredura azimutal $0^{0}$ a $360^{0}$ & REFETOR \\
Varredura em elevação $-5^{0}$ e $+90^{0}$ & Parabólico \\
& Primeiro Lóbulo Lateral $<-25 \mathrm{~dB}$ \\
& Ganho da Antena $45 \mathrm{~dB}$ \\
\hline
\end{tabular}

\subsubsection{Variáveis polarimétricas}

Em radar meteorológico polarimétrico existe quatro (4) propriedades fundamentais das ondas eletromagnéticas: amplitude, fase, frequência e polarização.

Para a precipitação, as características de polarização estão relacionadas aos valores médios e às distribuições de tamanhos, forma, orientação espacial das gotículas dentro do volume de resolução do radar, o estado de fase termodinâmica e o comportamento de queda (Raghavan, 2013). Radar linearmente polarizado transmite e recebe radiação nos planos horizontais e vertical. Assim, as gotas de chuva tendem a tornar-se oblatas à medida que 
aumentam de tamanho, e elas Caem com maior eixo orientado na horizontal.

- Refletividade diferencial $\left(\mathrm{Z}_{D R}\right)$

$\mathrm{O} \mathrm{Z}_{D R}$ é calculada pela razão logarítmica entre a refletividade polarizada horizontal $\left[\mathrm{Z}_{H}\right]$ e refletividade polarizada vertical $\left[\mathrm{Z}_{V}\right]$ (Bringi e Chandrasekar, 2001).

$$
Z_{D R}=10 \log 10\left(\frac{Z_{H}}{Z_{V}}\right)
$$

Este parâmetro pode ser usado para distinguir as partículas de gelo e água, delinear a camada de fusão e, calcular o tamanho médio dos hidrometeoros (Bringi e Chandrasekar, 2001). A Fig. 2.4 mostra o $Z_{D R}$ para diferentes tamanhos e orientação de hidrometeoros. O $\mathrm{Z}_{D R}$ tende a $0 \mathrm{~dB}$ para hidrometeoro esférico (gotícula, granizo pequeno, etc). Para hidrometeoros orientado horizontalmente (chuva, granizo descongelando, etc), o $Z_{D R}$ é > $0 \mathrm{~dB}$. Hidrometeoros orientados verticalmente (cristais de gelo, etc), $\mathrm{Z}_{D R}$ é $<0 \mathrm{~dB}$.

Nota-se que valores positivos de $\mathrm{Z}_{D R}$ indicam a presença de hidrometeoros oblatos, por exemplo, gota de chuva. Os hidrometeoros adquirem o formato oblato à medida que aumentam de tamanho. Estes, à medida que caem, maior é o eixo orientado horizontalmente, variando a polarização horizontal e vertical em diferentes ângulos de elevações. Enquanto valores próximos de zero indicam hidrometeoros aparentemente ou aproximadamente esféricos, por exemplo, gotícula de chuva. Nesta condição, a polarização é a mesma tanto na horizontal e vertical para diferentes ângulos de elevações (Bringi e Chandrasekar, 2001).

Em alguns casos o $\mathrm{Z}_{D R}$ tem valores próximo de zero para o gelo por duas razões: o floco de neve e cristal de gelo oscilam ao caírem sem orientação preferencial, apresentando orientação aleatória de eixo e, o granizo rodopia ao cair sem também orientação preferida de eixo; e estes por apresentarem índice de refração baixo, quando iluminados pelo fixe do radar, produzem ecos fracos de radiação. Mas, na interface gelo-ar existe uma camada quase líquida, este "gelo molhado" que produz eco de radiação (Bringi e Chandrasekar, 2001). 


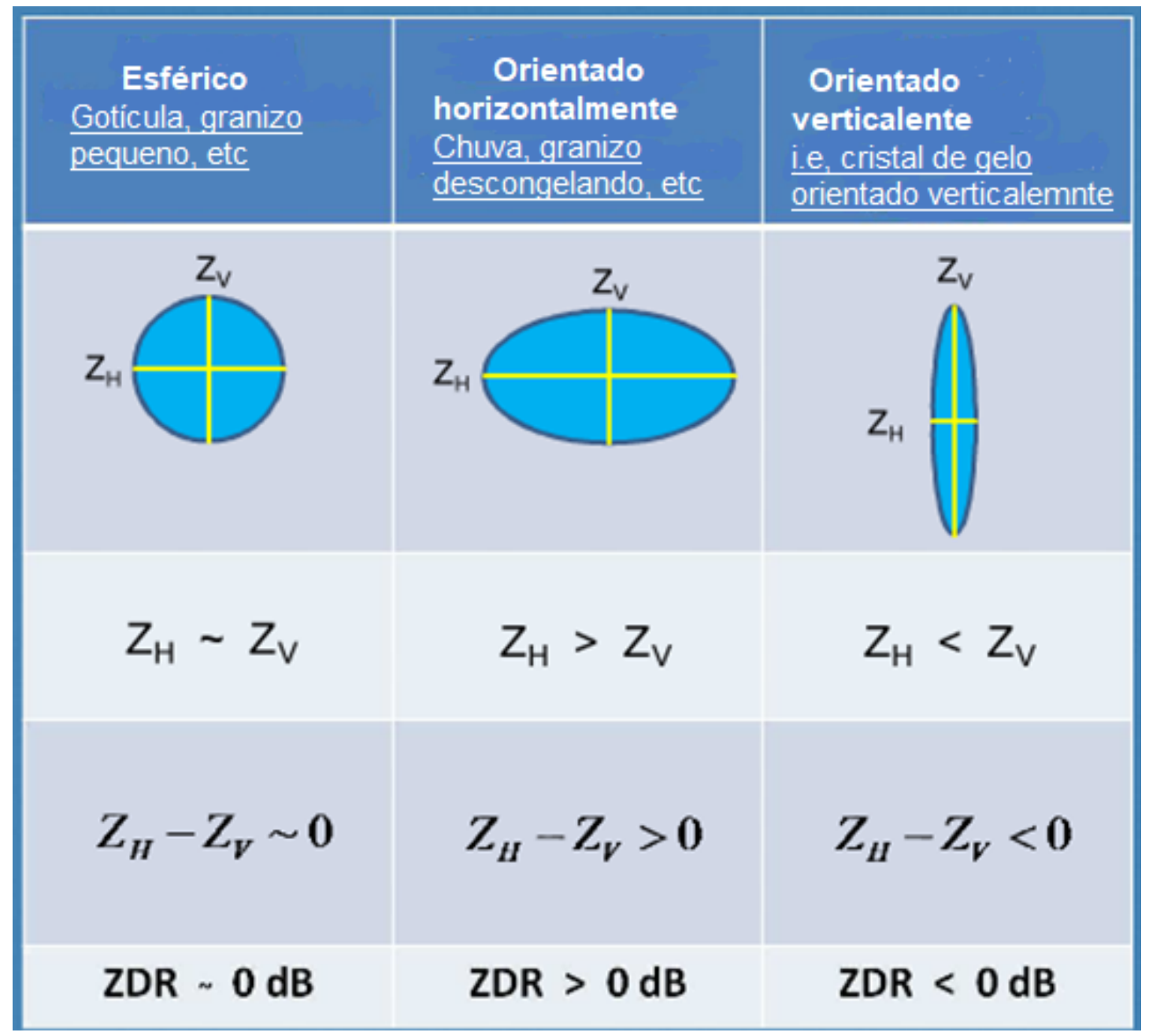

Figura 2.4: Refletividade diferencial $\left(\mathrm{Z}_{D R}\right.$ para diferentes tamanhos e orientação de hidrometeoros. Fonte: www.eol.ucar.edu. Acessado em 10 de Dezembro de 2020.

- Fase diferencial específica $\left(\mathrm{K}_{D P}\right)$

Em um volume compreendido de hidrometeoros horizontalmente orientados, uma onda horizontalmente polarizada tem maior aumento de sua fase e se propaga mais lentamente que uma onda verticalmente polarizada. Devido ao maior comprimento da trajetória da onda através da água líquida, uma onda horizontalmente polarizada experimentará maior atraso na sua fase do que a onda verticalmente polarizada (Fig. 2.5). A diferença de fase $\left(\phi_{D P}\right)$ é definida como mudança comutativa na diferença de fase para viagem completa do pulso. 


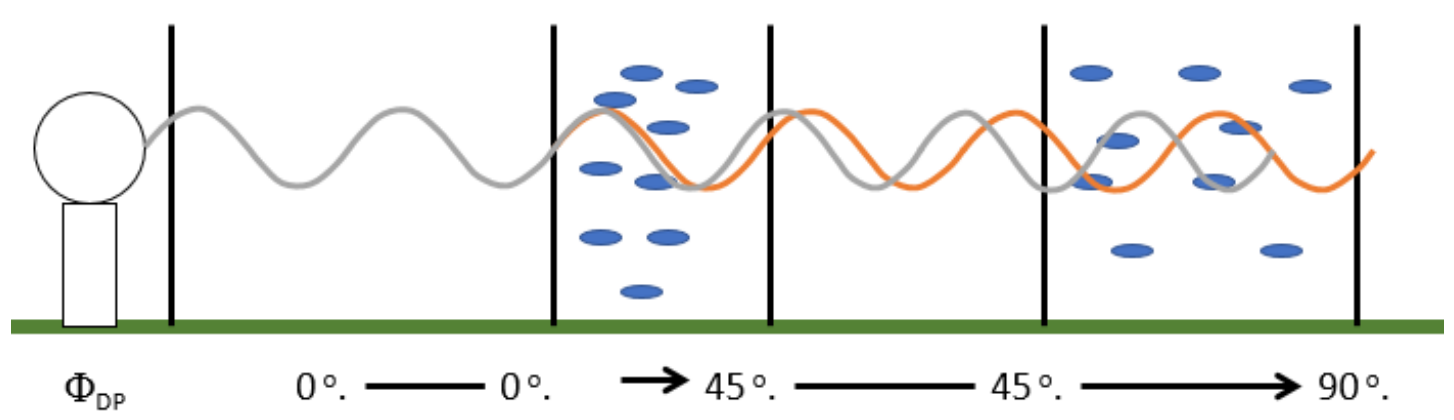

Figura 2.5: Interação das ondas electromagnéticas polarizadas horizontalmente (cor cinza) e verticalmente (cor laranja) com as gotas de chuva. Na primeira coluna ambas as ondas estão em fases. Na segunda coluna, a passagem por muitas gotas grandes faz com que a onda electromagnética polarizada horizontalmente abrande mais do que a onda electromagnética polarizada verticalmente; já não está em fase. Na terceira coluna, a diferença de fase é preservada à medida que ambas as ondas electromagnéticas polarizadas saem da chuva. $\mathrm{Na}$ quarta coluna, o encontro de mais gotas grandes faz com que a diferença de fase volte a aumentar. Fonte: www.eol.ucar.edu. Acessado em 10 de Dezembro de 2020.

O oposto ocorre em um volume compreendido por hidrometeoros verticalmente orientados ou sem preferência de orientação (Bringi e Chandrasekar, 2001). Assim, o $\phi_{D P}$ aumenta de acordo com a Eq. 2.2 (Houze Jr, 2014):

$$
\phi_{D P}=\phi_{H}(r)-\phi_{V}(r)\left(^{o}\right)
$$

A diferença de fase específica $K_{D P}$ é a Variação derivada da fase diferencial e é dada por (Bringi e Chandrasekar, 2001):

$$
K_{D P}=\frac{\phi_{H}\left(r_{2}\right)-\phi_{V}\left(r_{1}\right)}{2\left(r_{2}-r_{1}\right)}\left({ }^{o} m^{-1}\right)
$$

A Fig. 2.6 mostra a variação nos valores de $K_{D P}$ para diferentes tamanhos e tipos de hidrometeoros. $\mathrm{K}_{D P}$ é $>0{ }^{\circ} \mathrm{km}^{-1}$ para gotas oblatas; partículas de gelo orientadas horizontalmente, alta concentração em número; granizo derretido com toro líquido misturado com queda de gotas. 

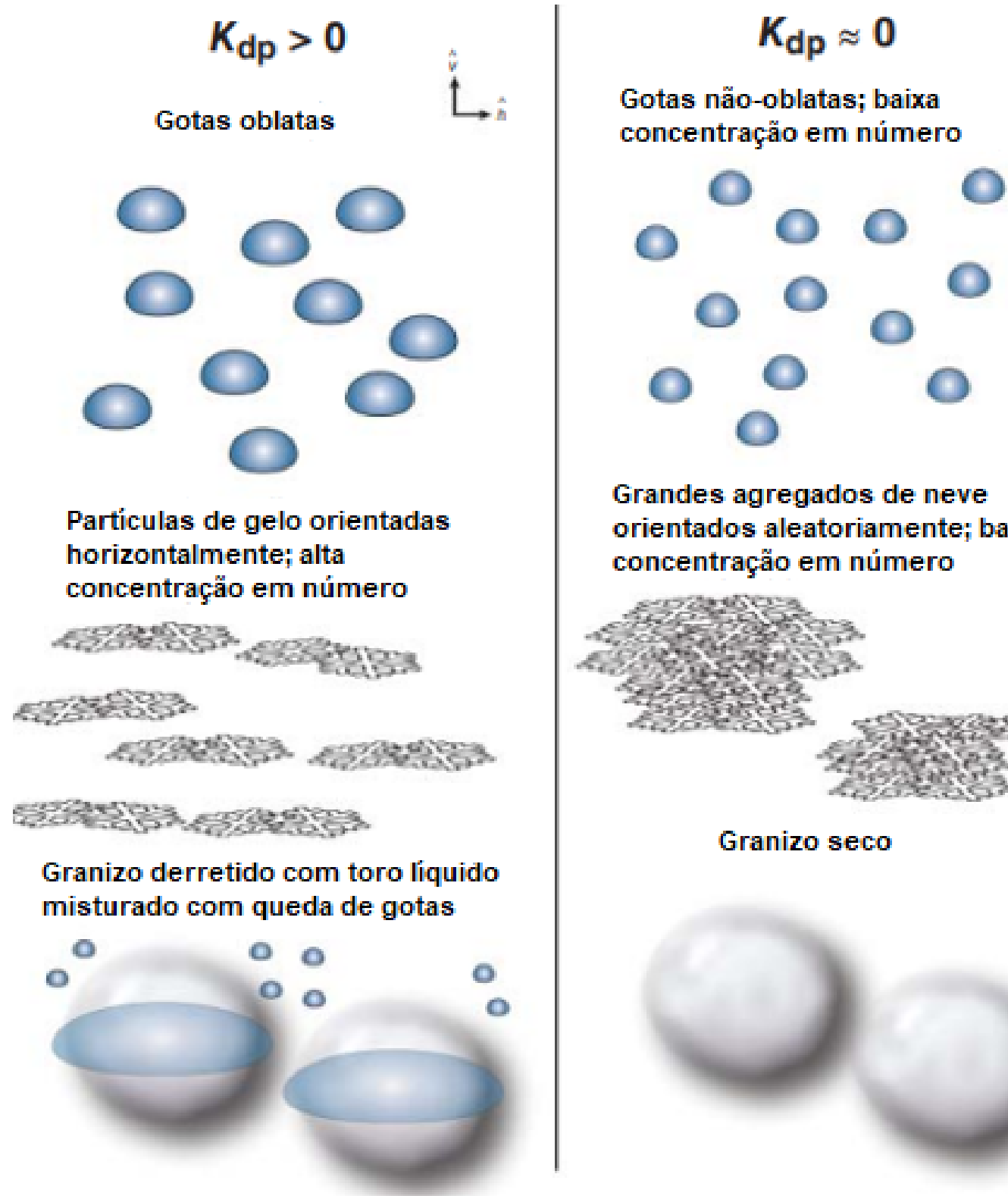

\section{Grandes agregados de neve orientados aleatoriamente; baixa concentração em número}

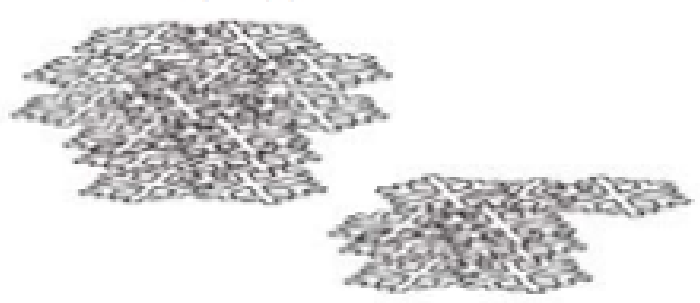

Granizo seco

Figura 2.6: Variação nos valores de $\mathrm{K}_{D P}$ para diferentes tamanhos tipos de hidrometeoros. Fonte: Rauber e Nesbitt (2018).

$\mathrm{K}_{D P}$ tende a $0{ }^{\circ} \mathrm{km}^{-1}$ para gotas não oblatas, baixa concentração me números; grandes agregados de neve orientados aleatoriamente, baixa concentração em número; granizo.

- Coeficiente de correlação $\left(\rho_{H V}(0)\right)$

$\mathrm{O} \rho_{H V}(0)$ descreve as diferenças entre as matrizes de retroespalhamento de ecos de ondas horizontal e verticalmente polarizadas. Esta relação ocorre pois a intensidade da potência retro-espalhada pelo espalhamento Rayleigh depende exclusivamente da dimensão dos hidrometeoros na direção do campo elétrico incidente. Para hidrometeoro esférico a 
correlação medida é próximo de 1. Fisicamente, a de-correlação ocorre se os campos retroespalhados horizontal e verticalmente não variam igualmente. Esta situação pode ocorrer quando as partículas são re-orientadas, há mudança no número de partículas, as partículas estão em degelo e/ou há irregularidades em sua forma, apresentando valores próximo de zero. Assim, esta variável é uma indicadora da região de degelo e outras regiões de fase mista (Bringi e Chandrasekar, 2001).

Esta variável pode ser influenciada por diferenças nas exentricidades, aumento da fase diferencial no espalhamento, orientação e forma de hidrometeoros além de mistura de dois tipos de hidrometeoros, especialmente quando o tamanho de um tipo varia na horizontal e do outro na vertical. Mais detalhes teóricos do desenvolvimento de $\rho_{H V}(0)$ pode ser encontrado em Bringi e Chandrasekar (2001).

\subsection{Análise sinótica}

Utilizaram-se os dados dos modelos do Sistema de Previsão Global dos EUA (GFS) com resolução de 28 km entre pontos da grades e do Centro Europeu de Previsões Meteorológicas de Médio Alcance (ECMWF) com resolução de 12,5 km × 12,5 km nas análises sinóticas dos dias correspondentes aos sistemas precipitantes analisados neste trabalho. Os campos analisados foram: pressão reduzido ao nível do mar (hPa), movimento vertical e geopotencial (gpm) em $700 \mathrm{hPa}$, vento $\left(\mathrm{m} . \mathrm{s}^{-1}\right)$ a $10 \mathrm{~m}$ e umidade (\%) a $2 \mathrm{~m}$ acima da superfície, Energia potencial disponível convectiva-CAPE $\left(\mathrm{J} \mathrm{kg}^{-1}\right)$ e perfil vertical da umidade relativa (\%) e vento. Foram utilizadas imagens GOES-12 no canal infravermelho, disponíveis no site http://satélite.cptec.inpe.br. As imagens de satélite do GOES-12 são disponibilizadas a cada 30 minutos. Estas imagens são obtidas por meio de sensores que medem a radiação de onda longa emitidas pelo topo das nuvens e são processadas digitalmente de modo a realçar os topos com temperatura inferior a $-30^{\circ} \mathrm{C}$. Temperaturas superiores a $-30^{\circ} \mathrm{C}$ estão em degrades entre a cor branca e a preta, onde cor preto indica regiões livres de nuvens que são superfícies continental e oceânica.

\subsection{Análise Termodinâmica}

A análise termodinâmica foi realizada pro meio de diagramas Skew-T. As sondagens são realizadas no aeroporto do Campo de Marte duas vezes ao dia (0000 UTC e 1200 UTC). As 
variáveis medidas para obtenção do diagrama SKEW T, são perfis verticais de temperatura $\left({ }^{\circ} \mathrm{C}\right)$, temperatura do ponto de orvalho $\left({ }^{\circ} \mathrm{C}\right)$, velocidade, direção $\left({ }^{\circ}\right)$ e intensidade do vento $\left(\mathrm{m} \mathrm{s}^{-1}\right)$ e umidade relativa do ar (\%). Também são obtidos nesse conjunto de dados a pressão atmosférica $(\mathrm{hPa})$, altura geopotencial $(\mathrm{m})$, razão de mistura do vapor de água (g $\mathrm{kg}^{-1}$ ), temperatura potencial $(\mathrm{K})$, temperatura potencial virtual $(\mathrm{K})$ e temperatura potencial equivalente $(\mathrm{K})$. Nesse conjunto encontram-se índices de instabilidade de Showalter, de levantamento, total totals, $\mathrm{K}$, energia potencial convectiva disponível [CAPE $\left(\mathrm{J} \mathrm{kg}^{-1}\right)$ ], cálculo da energia potencial convectiva disponível pela temperatura virtual [CAPEV (J $\left.\mathrm{kg}^{-1}\right)$ ], inibição de convecção [CINI $\left(\mathrm{J} \mathrm{kg}^{-1}\right)$ ], inibição de convecção calculada a partir da temperatura virtual [CINIV $\left(\mathrm{J} \mathrm{kg}^{-1}\right)$ ], número de Richardson global (adimensional), água precipitável (mm) e espessura entre 1000 hPa e 500 hPa (mgp).

\subsection{Python ARM Radar Toolkit (Py-ART)}

O Python ARM Radar Toolkit (Py-ART), uma biblioteca de código aberto para trabalhar com dados de radares meteorológicos (Helmus e Collis, 2016). Utilizou-se o Py-ART para ler e visualizar os dados dos radares meteorológicos polarimétricos MXPOL e SPOL, e executar a classificação dos hidrometeoros por meio do método lógica fuzzy, calcular o diâmetro da gota de chuva $\left(\mathrm{D}_{0}\right)$, a massa de água sólida, a massa de água líquida, a taxa de chuva a cada ponto de grade em todos os PPIs e gerar gráficos com os algorítimos disponíveis na plataforma desenvolvido por Lang et al. (2019). Os algorítimos estão disponíveis para comunidade científica para eventuais alterações de interesse que foram adaptados para os metadados dos radares MXPOL e SPOL, usados neste trabalho.

Os algoritmos são implementados em módulos como Scientific Python, incluindo NumPy, SciPy e matplotlib e Cython para realização da interface com as variáveis polarimétricas de radar meteorológico com dados de radiossondagem, etc, e acelerar computacionalmente a execução dos mesmos (Lang et al., 2019).

\subsection{Classificação de hidrometeoros}

Usou-se o algoritmo de identificação de hidrometeoros lógica fuzzy para dados dos radares polarimétricos da banda X e banda $\mathrm{S}$ desenvolvido por Lang et al. (2019). O método lógica fuzzy é uma técnica para sintetizar informação de variáveis polarimétricas 
num algorítimo de classificação de hidrometeoros (Vivekanandan et al., 1991).

Utilizou-se quatro (4) variáveis polarimétricas $\left(\mathrm{Z}_{H} ; \mathrm{Z}_{D R} ; \mathrm{K}_{D P}\right.$ e $\left.\rho_{H V}\right)$ do MXPOL e SPOL e dados locais de altitude (temperatura) para a classificação de hidrometeoros dos sistemas precipitantes por meio de método lógica fuzzy. Os dados de temperatura $\left({ }^{\circ} \mathrm{C}\right)$ e altura Z (m) foram interpolados para cada ponto de grade a cada PPI. Estes dados foram obtidos das radiossondagens do aeródromo Campo de Marte. As interrelações das variáveis polarimétricas e altitude geraram informações de identificação automática dos hidrometeoros representados a cada ponto de grade dos PPIs. A Fig. 2.7 mostra a estrutura implementada do algoritmo lógica fuzzy constituído em quatro etapas (Rauber e Nesbitt, 2018). O algoritmo usa a funções predefinidas associadas para classificar automaticamente os dados de entrada multidimensionais em categorias.

A classificação foi aplicada em cada gate dos radares meteorológicos de tal forma que um campo completo de tipos de hidrometeoros foi produzido de forma consistente principalmente com os dados polarimétricos do radar SPOL. O tipo de hidrometeoro pode ser mapeado como um PPI ou um RHI ou examinado em três dimensões para entender onde determinados hidrometeoros estão presentes (Rauber e Nesbitt, 2018). Neste trabalho optamos por aplicar a classificação dos hidrometeoros em todos os PPIs para análise microfísica durante a evolução espaço-temporal. O método é robusto o suficiente para que seu desempenho não possa ser afetado devido a erro de medição típica em algumas das variáveis de entrada (Vivekanandan et al., 1991; Liu e Chandrasekar, 2000). Este procedimento é confiável para a classificação automática, sendo o mais adequado para a classificação de hidrometeoros (Liu e Chandrasekar, 2000).

As quatro etapas para classificação de hidrometeoros pelo método lógica Fuzzy, são: a) Fuzzificação, b) Inferência, c) Agregação e d) Defuzzificação (Fig. 2.7) (Liu e Chandrasekar, 2000).

\section{a) Fuzzificação}

Na primeira etapa, transforma os dados discretos em conjuntos Fuzzy com o seu correspondente peso. Durante a fuzzificação de cada variável (Fig. 2.7A), todos os hidrometeoros recebem um valor (peso) entre 0 e 1 por meio da função membro, que é o grau com que aquele hidrometeoro está relacionado ao conjunto Fuzzy que ele pertence;

\section{b) Regra de Inferência}

Em um sistema Lógica Fuzzy, esta etapa é usada para descrever a relação entre as 
variáveis Fuzzy de entrada e saída na forma boleana, isto é, se o dado de entrada é $x$, então o dado de saída deve ser y (Liu e Chandrasekar, 2000). O resultado é multiplicado por um peso pré-determinado (Fig. 2.7B), valor esse que é determinado pela sua utilidade na classificação e na acurácia da medida dos campos de entrada;

\section{c) Agregação}

A agregação é usada para determinar todo o espaço Fuzzy a ser analisado. Os valores obtidos pela regra de inferência são então agregados para formar um único valor para cada conjunto Fuzzy, isto é, hidrometeoro ou conjunto de hidrometeoros (Fig. 2.7C);

\section{d) Defuzzificação}

Os dados são transformados para o espaço dimensional (Fig. 2.7D), ou seja, um valor discreto de saída que melhor represente o valor de saída Fuzzy para cada tipo de hidrometeoro, que são: chuvisco, chuva, graupel de alta denisdade, graupel de baixa densidade, neve molhada, agregado, cristal de gelo, gelo vertical, granizo e gota grande.

Este método de classificação que utiliza transições mais suaves nos limites das variáveis polarimétricas observadas para cada tipo de hidrometeoro (Liu e Chandrasekar, 2000; Tessendorf et al., 2005), são representados matematicamente por conjunto das funções membros definidos com base em estudos anteriores através da função beta pela Eq.2.4. Os valores dos três parâmetros para as variáveis polarimétricas do MXPOL estão na Tab. 2.3 e SPOL na Tab. 2.4. Os valores de cada parâmetro para Temperatura são os mesmo para ambos os radares. 


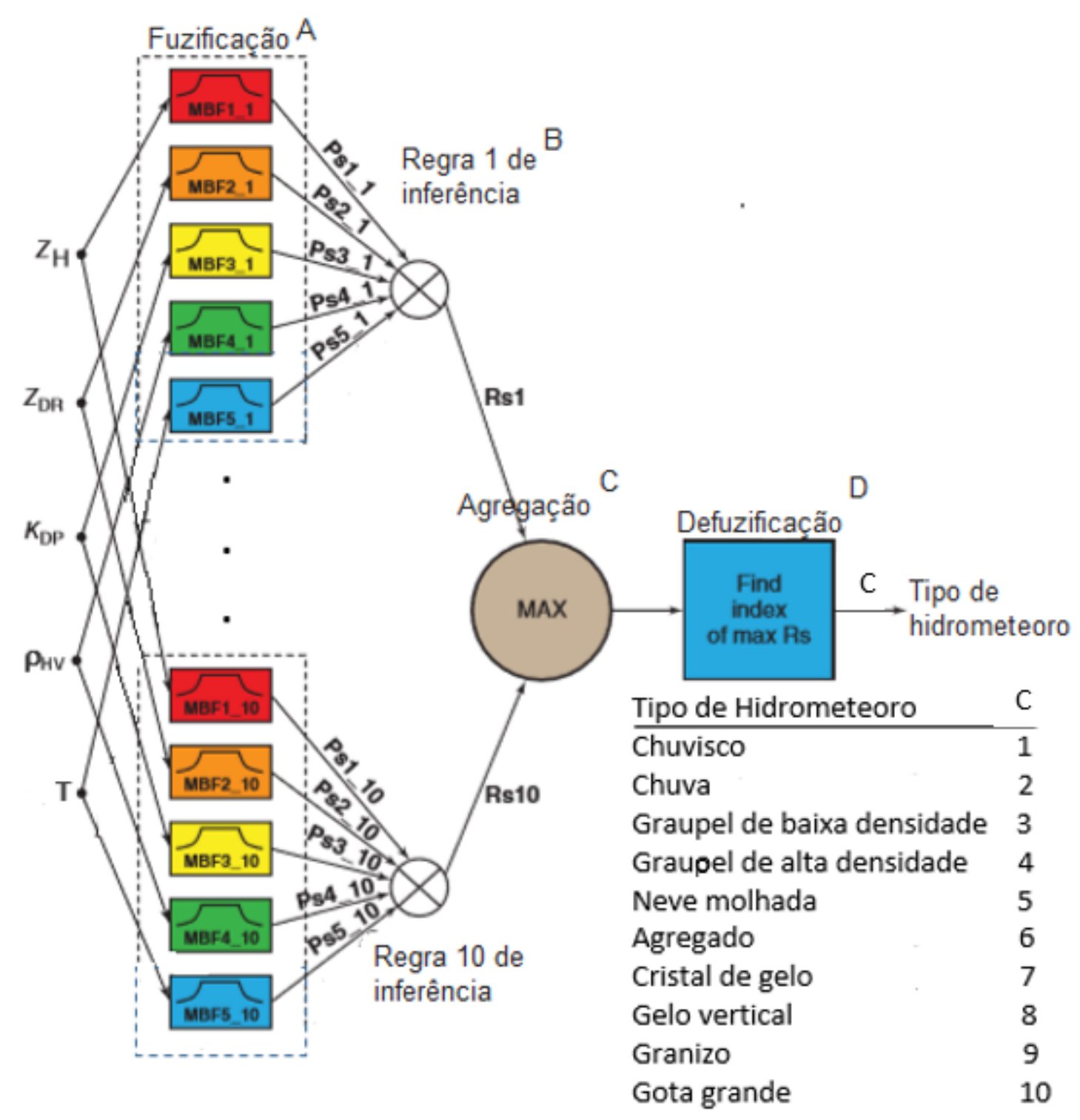

Figura 2.7: Sistema fuzzy para a classificação de hidrometeoros para as variáveis polarimétricas $1=\mathrm{Z}_{H}, 2=\mathrm{Z}_{D R}, 3=\rho_{h v}, 4=\mathrm{K}_{D P}, 5=$ dados da temperatura obtida por uma radiossondagem. $\mathrm{MBF}_{n_{m}}, n$ seria o número correspondente a variável polarimétrica e $m$ seria o número do tipo de hidrometeoro ( $1=$ chuvisco, $2=$ chuva, ..., etc). $\mathrm{Ps}_{n_{m}}$ corresponde a Fuzzificação. $\mathrm{Rs}_{n}$ representa as regras de inferência. MAX representa o valor máximo das regras de inferência. Fonte: adaptada de Rauber e Nesbitt (2018), apud Liu e Chandrasekar (2000).

O conjunto das funções membros (Rauber e Nesbitt, 2018), foram definidas com base em estudos anteriores para radar banda X, implementadas por (Dolan e Rutledge, 2009) e radar banda S implementadas por (Vivekanandan et al., 1991; Liu e Chandrasekar, 2000).

As operações matemáticas envolvidas são simples, lineares, algébricas, e, assim, o processo de classificação de hidrometeoros foi projetado como princípio básico de identificar qual tipo de hidrometeoro corresponde melhor às variáveis polarimétricas dos radares em 
um área de interesse (Vivekanandan et al., 1991; Rauber e Nesbitt, 2018). O conjunto de funções (FB) para refletividade, refletividade deferencial, fase diferencial específica, coeficiente de correlação e temperatura, foram obtidas por meio da Eq. 2.4.

$$
F B=\frac{1}{1+\left[\left(\frac{(x-m)}{a}\right)^{2}\right]^{b}}
$$

onde

$x=$ variavél polarimétrica;

$m=$ centro;

$a=$ largura;

$b=$ inclinação.

Tabela 2.3 - Parâmetros da função beta dos limiares de reflectividade $\mathrm{Z}_{H}$ (dBZ), reflectividade diferencial $\mathrm{Z}_{D R}(\mathrm{~dB})$, reflectividade diferencial específica $\mathrm{K}_{D P}\left({ }^{o} \mathrm{~km}^{-1}\right)$, coeficiente de correlação $\rho_{H V}$ e altitude do MXPOL para os dez tipos de hidrometeoros. Fonte: Lang et al. (2019).

\begin{tabular}{|c|c|c|c|c|c|c|c|c|c|c|c|c|c|c|c|}
\hline \multirow{3}{*}{$\begin{array}{c}\text { Tipo de } \\
\text { hidrometeoro }\end{array}$} & \multicolumn{15}{|c|}{ Funções Membros (MBFs) MXPOL } \\
\hline & \multicolumn{3}{|c|}{ Temperatura } & \multicolumn{3}{|c|}{$K_{D P}$} & \multicolumn{3}{|c|}{$Z_{H}$} & \multicolumn{3}{|c|}{ Rони } & \multicolumn{3}{|c|}{$Z_{D R}$} \\
\hline & $\mathrm{m}$ & $a$ & $\mathrm{~b}$ & $\mathrm{~m}$ & $a$ & $\mathrm{~b}$ & $\mathrm{~m}$ & $a$ & $\mathrm{~b}$ & $\mathrm{~m}$ & $\mathrm{a}$ & $\mathrm{b}$ & $\mathrm{m}$ & $a$ & $\mathrm{~b}$ \\
\hline Chuvisco & 40.000 & 41.000 & 50.000 & 0.03 & 0.03 & 2.000 & 2.0 & 29.0 & 10.00 & 1.000 & 0.015 & 2.000 & 0.45 & 0.45 & 5.0 \\
\hline Chuva & 48.000 & 51.000 & 30.000 & 12.75 & 13.0 & 60.0 & 42.0 & 17.0 & 10.00 & 1.000 & 0.040 & 2.000 & 2.85 & 3.02 & 9.0 \\
\hline Graupel BD & -50.000 & 50.000 & 25.000 & 0.7 & 2.1 & 3.000 & 36.0 & 9.0 & 8.0 & 1.000 & 0.015 & 1.000 & 0.3 & 1.0 & 6.0 \\
\hline Graupel AD & -2.500 & 20.000 & 2.000 & 1.55 & 3.05 & 3.000 & 43.0 & 9.0 & 5.0 & 1.000 & 0.035 & 1.000 & 0.6 & 1.5 & 2.0 \\
\hline Neve molhada & 1.000 & 3.500 & 5.000 & -7.0 & 8.1 & 6.000 & 28.0 & 29.0 & 10.00 & 0.700 & 0.260 & 10.000 & 1.6 & 1.2 & 10.0 \\
\hline Agregados & -25.000 & 26.000 & 15.000 & 0.2 & 0.2 & 1.000 & 16.0 & 17.0 & 15.00 & 0.908 & 0.020 & 3.000 & 0.7 & 0.7 & 7.0 \\
\hline Cristal de gelo & -50.000 & 50.000 & 25.000 & 0.15 & 0.150 & 6.000 & -3.00 & 22.00 & 20.00 & 1.000 & 0.030 & 3.000 & 3.2 & 2.6 & 10.0 \\
\hline Gelo vertical & -50.000 & 50.000 & 25.000 & -0.79 & 0.79 & 3.000 & -3.00 & 22.00 & 20.00 & 0.98 & 0.020 & 3.000 & -0.9 & 1.0 & 10.0 \\
\hline Granizo & 0.000 & 100.000 & 5.000 & 0.5 & 1.5 & 6.000 & 59.0 & 10.3 & 6.0 & 0.970 & 0.150 & 3.000 & 0.12 & 0.5 & 0.8 \\
\hline Gota grande & 48.000 & 51.000 & 30.000 & 3.6 & 3.3 & 6.000 & 56.0 & 9.0 & 10.0 & 0.980 & 0.030 & 3.000 & 4.3 & 2.0 & 8.0 \\
\hline
\end{tabular}

Tabela 2.4 - Parâmetros da função beta dos limiares de reflectividade $\mathrm{Z}_{H}$ (dBZ), reflectividade diferencial $\mathrm{Z}_{D R}(\mathrm{~dB})$, reflectividade diferencial específica $\mathrm{K}_{D P}\left({ }^{o} \mathrm{~km}^{-1}\right)$, coeficiente de correlação $\rho_{H V}$ e altitude do SPOL para os dez tipos de hidrometeoros. Fonte: Lang et al. (2019).

\begin{tabular}{|c|c|c|c|c|c|c|c|c|c|c|c|c|c|c|c|}
\hline \multirow{3}{*}{$\begin{array}{c}\text { Tipo de } \\
\text { hidrometeoro }\end{array}$} & \multicolumn{15}{|c|}{ Funções Membros (MBFs) SPOL } \\
\hline & \multicolumn{3}{|c|}{ Temperatura } & \multicolumn{3}{|c|}{$K_{D P}$} & \multicolumn{3}{|c|}{$Z_{H}$} & \multicolumn{3}{|c|}{ RoHV } & \multicolumn{3}{|c|}{$Z_{D R}$} \\
\hline & $\mathrm{m}$ & $\mathrm{a}$ & $\mathrm{b}$ & $\mathrm{m}$ & $\mathrm{a}$ & $\mathrm{b}$ & $\mathrm{m}$ & $\mathrm{a}$ & $\mathrm{b}$ & $\mathrm{m}$ & $\mathrm{a}$ & $\mathrm{b}$ & $\mathrm{m}$ & $a$ & $\mathrm{~b}$ \\
\hline Chuvisco & 40.000 & 41.000 & 50.000 & 0.010 & 0.010 & 2.000 & 2.00 & 29.00 & 10.00 & 1.000 & 0.015 & 3.000 & 0.35 & 0.35 & 5.00 \\
\hline Chuva & 48.000 & 51.000 & 30.000 & 3.700 & 4.000 & 10.000 & 41.50 & 15.50 & 10.00 & 1.000 & 0.020 & 2.000 & 2.60 & 2.80 & 9.00 \\
\hline Graupel BD & -50.000 & 50.000 & 25.000 & 0.200 & 0.560 & 3.000 & 37.00 & 8.00 & 8.00 & 1.000 & 0.010 & 1.000 & 0.30 & 0.80 & 6.00 \\
\hline Graupel AD & -2.500 & 20.000 & 2.000 & 0.550 & 1.155 & 3.000 & 49.00 & 9.00 & 6.00 & 1.000 & 0.040 & 4.000 & 1.00 & 1.90 & 8.00 \\
\hline Neve molhada & 1.000 & 3.500 & 5.000 & 0.130 & 0.500 & 6.000 & 21.00 & 22.00 & 10.00 & 0.780 & 0.200 & 10.000 & 1.30 & 1.30 & 10.00 \\
\hline Agregados & -25.000 & 26.000 & 15.000 & 0.040 & 0.0500 & 1.000 & 17.00 & 17.00 & 15.00 & 0.998 & 0.020 & 3.000 & 0.60 & 0.60 & 7.00 \\
\hline Cristal de gelo & -50.000 & 50.000 & 25.000 & 0.043 & 0.0430 & 6.000 & -3.00 & 22.00 & 20.00 & 1.000 & 0.020 & 3.000 & 3.20 & 2.80 & 10.00 \\
\hline Gelo vertical & -50.000 & 50.000 & 25.000 & -0.230 & 0.230 & 3.000 & -3.00 & 22.00 & 20.00 & 0.970 & 0.040 & 3.000 & -0.90 & 0.90 & 10.00 \\
\hline Granizo & 0.000 & 100.000 & 5.000 & 0.200 & 0.800 & 6.000 & 58.00 & 12.00 & 10.00 & 0.960 & 0.100 & 3.000 & 0.14 & 0.55 & 8.00 \\
\hline Gota grande & 48.000 & 51.000 & 30.000 & 1.600 & 1.500 & 6.000 & 58.00 & 9.00 & 10.00 & 0.980 & 0.040 & 3.000 & 4.00 & 1.70 & 8.00 \\
\hline
\end{tabular}

Foram examinadas as assinaturas polarimétricas de todos os tipos de hidrometeoros a serem classificados e confrontados os limiares polarimétricos correspondentes a cada tipo de 
hidrometeoro classificado a partir do do método lógica fuzzy. As implementações do método para tomada de decisão de cada tipo de hidrometeoro identificado foram consistentes. A Tab. 2.5 mostra os limiares polarimétricos correspondentes a cada tipo de hidrometeoro classificado por meio do método lógica fuzzy para o MXPOL (Rauber e Nesbitt, 2018). A Tab. 2.6 mostra os limiares polarimétricos correspondentes a cada tipo de hidrometeoro classificado por meio do método lógica fuzzy para o SPOL (Rauber e Nesbitt, 2018).

Tabela 2.5 - Tipos de hidrometeoros correspondentes aos limiares de reflectividade $\mathrm{Z}_{H}$ (dBZ), reflectividade diferencial $\mathrm{Z}_{D R}(\mathrm{~dB})$, reflectividade diferencial específica $\mathrm{K}_{D P}\left({ }^{o} \mathrm{~km}^{-1}\right)$, coeficiente de correlação $\rho_{H V}$ e altitude do MXPOL. Fonte: Rauber e Nesbitt (2018).

\begin{tabular}{|c|c|c|c|c|c|}
\hline \multirow{2}{*}{ Hidrometeoro } & \multicolumn{5}{|c|}{ Variáveis polarimétricas do MXPOL / Altitude } \\
\hline & $\mathrm{Z}_{\mathrm{H}}(\mathrm{dBZ})$ & $Z_{D R}(d B)$ & $K_{D P}\left({ }^{\circ} \mathrm{km}^{-1}\right)$ & ROHV & Temperatura $\left({ }^{\circ} \mathrm{C}\right)$ \\
\hline Chuvisco & 0 a 25 & 0 a 1 & 0 a 0.1 & 0.99 a 1 & $0 \mathrm{a}>45$ \\
\hline Chuva & 24 a 56 & 0.3 a 5.6 & 0.3 a 6 & 0.95 a 0.98 & $0 a>45$ \\
\hline Graupel BD & 28 a 45 & -0.9 a 1.6 & -2 a 2.7 & 0.89 a 0.98 & -50 a -5 \\
\hline Graupel AD & 35 a 52 & -1 a 3.1 & -1.8 a 4.8 & 0.90 a 0.98 & -30 a 20 \\
\hline Neve molhada & 5 a 58 & 0.5 a 2.5 & $<-2$ a 2 & 0.75 a 0.97 & -0.2 a 0.2 \\
\hline Agregados & 2 a 30 & 0.3 a 1.3 & -0.4 a 0.9 & 0.96 a 0.99 & $-50 a-5$ \\
\hline Cristais de gelo & $<0$ a 18 & 0.8 a 5.8 & 0 a 0.3 & 0.96 a 0.98 & $<-50$ a -5 \\
\hline Gelo vertical & $<0$ a 22 & -1.8 a -0.2 & -2 a 0.5 & 0.95 a 0.98 & $<-50$ a -5 \\
\hline Granizo & $50 a>65$ & -0.3 a 0.5 & -0.4 a 1.8 & 0.76 a 1 & -35 a 35 \\
\hline Gota grande & 48 a 68 & 2.8 a 6 & $0.2 a>6.5$ & 0.95 a 0.98 & $0 \mathrm{a}>50$ \\
\hline
\end{tabular}

A refletividade diferencial $\left(\mathrm{Z}_{D R}\right)$ e o perfil vertical de temperatura atuam como papel importante na classificação dos hidrometeoros. Mas outras variáveis polarimétricas foram também fundamentais para identificar mistura de fase líquida e sólida (Vivekanandan et al., 1999).

Tabela 2.6 - Tipos de hidrometeoros correspondentes aos limiares de reflectividade $\mathrm{Z}_{H}$ (dBZ), reflectividade diferencial $\mathrm{Z}_{D R}(\mathrm{~dB})$, reflectividade diferencial específica $\mathrm{K}_{D P}\left({ }^{o} \mathrm{~km}^{-1}\right)$, coeficiente de correlação $\rho_{H V}$ e altitude do SPOL. Fonre: Rauber e Nesbitt (2018).

\begin{tabular}{|c|c|c|c|c|c|}
\hline \multirow{2}{*}{ Hidrometeoro } & \multicolumn{5}{|c|}{ Variáveis polarimétricas do SPOL / Altitude } \\
\hline & $\mathrm{Z}_{\mathrm{H}}(\mathrm{dBZ})$ & $Z_{D R}(d B)$ & $K_{D P}\left({ }^{0} \mathrm{~km}^{-1}\right)$ & ROHV & Temperatura $\left({ }^{\circ} \mathrm{C}\right)$ \\
\hline Chuvisco & 0 a 25 & 0 a 1 & 0 a 0.1 & 0.99 a 1 & $0 \mathrm{a}>45$ \\
\hline Chuva & 25 a 58 & 0.1 a 5.5 & $0.5 a>6$ & 0.98 a 0.99 & $0 \mathrm{a}>45$ \\
\hline Graupel BD & 28 a 45 & -0.8 a 1.3 & -0.8 a 1.8 & 0.97 a 0.98 & -50 a 0 \\
\hline Graupel AD & 39 a 58 & -0.8 a 2.8 & -0.8 a 1.8 & 0.95 a 0.98 & -30 a 20 \\
\hline Neve molhada & 5 a 42 & 0 a 2.5 & -2 a 2.4 & 0.75 a 0.99 & -0.2 a 0.2 \\
\hline Agregados & 3 a 32 & 0.3 a 1 & -0.1 a 0.1 & 0.96 a 0.99 & $-50 a-5$ \\
\hline Cristais de gelo & $<0$ a 18 & 0.8 a 5.8 & 0 a 0.1 & 0.98 a 0.99 & $<-50$ a -5 \\
\hline Gelo vertical & $<0$ a 22 & -1.8 a -0.2 & -1.6 а 0.4 & 0.95 a 0.98 & $<-50$ a -5 \\
\hline Granizo & $48 a>65$ & -0.3 a 0.5 & -0.3 a 0.8 & 0.80 a 1 & -35 a 35 \\
\hline Gota grande & 50 a 68 & 2.8 a 5.7 & 0.7 a 2.7 & 0.93 а 0.97 & 0 a $>50$ \\
\hline
\end{tabular}


A aplicação da lógica fuzzy na classificação de hidrometeoros ao comprimentos de onda electromagnética mais curtos como a do MXPOL encontrou desafios devido a efeitos nãoRayleigh (Fig. 2.8a) e atenuação (Fig. 2.8b). Ambos efeitos negligenciáveis no SPOL (Fig. 2.8). A transição para fora do regime não-Rayleigh depende principalmente do comprimento de onda e do tamanho do hidrometeoro, mas também depende da fase do hidrometeoro resultante das diferentes respostas dielétricas no gelo e na água à radiação incidente (Dolan e Rutledge, 2009). O diâmetro característico para o qual as aproximações de rayleigh podem ser utilizadas, diminui com a diminuição do comprimento de onda do radar, o que resulta numa maior gama de hidrometeoros a cair do regime de não-rayleigh no MXPOL do que no SPOL. Esses efeitos são refletidos na diferença dos limiares polarimétricos para a classificação de alguns hidrometeoros entre os radares MXPOL (Tab. 2.5) e SPOL (Tab. 2.6), em destaque as variáveis polarimétricas $\mathrm{Z}_{D R}$ e $\mathrm{K}_{D P}$ correspondentes a graupel de baixa densidade (BD) e graupel de alta densidade (AD), e $\mathrm{Z}_{H}$ correspondente a granizo e gota grande. A aplicação direta do algorítimo de radar meteorológico banda S poderia levar a uma classificação imprópria de hidrometeoros em comprimento de onda eletromagnética mais curto do radar meteorológico bada X (Dolan e Rutledge, 2009).
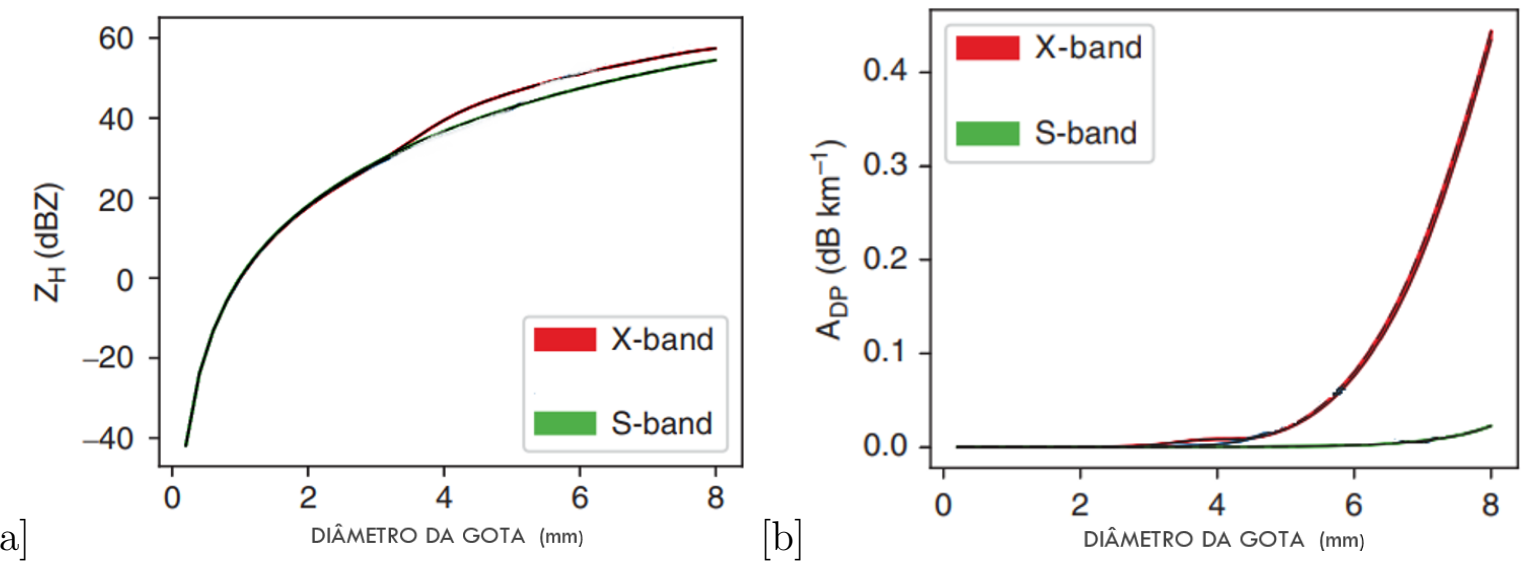

Figura 2.8: Simulações T matriz de uma gota de chuva. (a) para reflectividade na polarização horizontal e (b) para atenuação diferencial versus diâmetro equivalente à gota na banda $\mathrm{S}$ (verde) e na banda $\mathrm{X}$ (vermelho). Fonte: Rauber e Nesbitt (2018).

O radar meteorológico bada $\mathrm{X}$ tem efeito de ressonância de refletividade devido a queda interna de radiação eletromagnética que interferem com a radiação de retroespalhamento (Matrosov et al., 2006; Dolan e Rutledge, 2009). Sendo que, a refletividade do radar banda 
$\mathrm{X}$ é maior do que do radar banda $\mathrm{S}$ com o aumento do diâmetro (Fig. 2.8a), ou seja, o radar banda $\mathrm{X}$ precisa de mais energia para interagir com gotas de chuva de diâmetro maior. A consequência desse efeito a radiação eletromagnética do radar banda $\mathrm{X}$ sofre atenuação significativa do que o radar banda S (Fig. 2.8b).

\subsection{Cálculo da massa de água líquida, massa de água sólida e diâmetro médio da gota}

Foi aplicada a metodologia de Cifelli et al. (2002) para a estimativa da masa de água líquida e massa de água sólida (Lang et al., 2019). A metodologia utiliza diferença de refletividade (ZDP) para calcular a fração das massas de água líquida e gelo precipitantes em níveis de altura especificados, dado $\mathrm{Z}_{H}$ e $\mathrm{Z}_{D R}$ em cada ponto de grade (Carey e Rutledge, 2000). Se o ZDP indicar a presença de precipitação na fase mista, é calculada a massa de água líquida $\left(\mathrm{M}_{w}\right)$ pela relação Z- $\mathrm{M}_{w}$ e massa de gelo $\left(\mathrm{M}_{i}\right)$ pela relação Z-M, calculados a partir das seguintes Equações:

$$
M_{w}=3.34 \times 10^{-3}\left[Z_{H}^{\text {chuva }}\right]^{\frac{4}{7}}\left(\mathrm{gm}^{-3}\right)
$$

Onde $\mathrm{Z}_{H}^{\text {chuva }}$ é em $\mathrm{mm}^{6} \mathrm{~m}^{-3}$ (Ryzhkov e Zrnić, 1995) e

$$
M_{i}=1000 \pi \rho_{i} N_{0}^{\frac{3}{7}}\left(\frac{5.28 X\left(10^{-18}\right) Z_{H}^{g e l o}}{720}\right)^{\frac{4}{7}}\left(\mathrm{gm}^{-3}\right)
$$

Onde $\mathrm{Z}_{H}^{\text {gelo }}$ é em $\mathrm{mm}^{6} \mathrm{~m}^{-3}, \rho_{i}$ é a densidade do gelo $\left(0.917 \mathrm{Kg} \mathrm{m}^{-3}\right)$, e $\mathrm{N}_{0}\left(4 \times 106 \mathrm{~m}^{-4}\right)$ é o parâmetro de interceptação de uma distribuição exponencial inversa para o gelo (Carey e Rutledge, 2000; Cifelli et al., 2002). Se o ZDP indicar presença de água líquida (isso se a diferença entre a refletividade horizontal observada $\left(Z_{H}\right)$ e a refletividade estimada associada a Chuva $\left(\mathrm{Z}_{H}^{\text {chuva }}(\mathrm{ZDP})\right)$ for menor do que o erro padrão $(1,1 \mathrm{~dB})$, assume-se que a reflectividade é dominada pela água líquida e a Eq. 2.7 é utilizada; Além disso, o erro padrão é multiplicado por uma constante, a qual se torna maior (linearmente) com o aumento da distância abaixo da camada de fusão; isto é feito para não limitar a detecção de gelo abaixo da isoterma $0^{\circ} \mathrm{C}$ e, que é mais restritiva em distâncias mais perto do solo, então $\mathrm{M}_{w}$ é calculado a partir da Eq. abaixo.

$$
M_{w}=0.70 \times 10^{-3}\left(Z_{H}^{0.886}\right)\left(\varsigma^{-4.159}\right)\left(\mathrm{gm}^{-3}\right)
$$


Onde $\mathrm{Z}_{H}\left(\mathrm{Z}_{V}\right)$ é a refletividade horizontal observada (no PPI) em $\mathrm{mm}^{6} \mathrm{~m}^{-3}$ (Bringi e Chandrasekar, 2001).

$$
\varsigma=\frac{Z_{H}}{Z_{V}}=10^{\frac{Z_{D R}}{10}}
$$

Onde $\mathrm{Z}_{V}$ é refletividade em determinado PPI para separar as frações de água líquida e água sólida para o $\mathrm{Z}_{H}$.

Se o ZDP indicar a presença de água sólida é utilizada a Eq. $2.6 \mathrm{com} Z_{H}^{\text {gelo }}=Z_{H}^{\text {observado }}$.

Foi aplicada o método de Bringi e Chandrasekar (2001) para o cálculo do diâmetro médio da gota de chuva em níveis de altura especificados, dado $\mathrm{Z}_{D R}$ em cada ponto de grade, por meio da Eq. 2.9 (Lang et al., 2019).

$$
D_{0}=1.619 * Z_{D_{R}}^{(0.485)}
$$

Definiu-se 5 pontos em cada PPI nos núcleos das células convectivas e calculou-se a média dos valores dos pontos. Os perfis verticais resultaram das integrações das médias de cada PPI. Assim, calcou-se os perfis verticais da refletividade, refletividade diferencial, massa de água líquida, massa de água sólida e diâmetro da gota de chuva para análise microfísica durante a queda do hidrometeoro.

\subsection{Estimativa da taxa de chuva}

Os calculados as taxas de chuva em níveis de altura especificados para cada ponto de grade por meio da técnica de otimização com as variáveis polarimétricas $\mathrm{Z}_{H}, \mathrm{ZDR}$ e $\mathrm{K}_{D P}$ (Lang et al., 2019). Os cálculo de taxa de chuva perto da superfície foram escolhidos com base em limiares que maximizam a capacidade de medição de cada variável polarimétrica (Cifelli et al., 2002). O erro padrão da taxa de chuva, minimizou-se combinando as variáveis polarimétricas com as equações para cada estimativa a cada intensidade de precipitação por meio das equações na Tab. 2.7 (Cifelli et al., 2002). 
Tabela 2.7 - Cálculos de taxa de chuva de radar polarimétrico. Fonte: Cifelli et al. (2002).

\begin{tabular}{l|c}
\hline EQUAÇÃO & UNIDADE \\
\hline$(1) \mathrm{R}\left(\mathrm{K}_{D P}, \mathrm{Z}_{D R}\right)=87.6^{*}\left(\mathrm{~K}_{D P}\right)^{(0.934)} *(10)^{\left(0.1 *-1.59 * Z_{D R}\right)}$ & $\mathrm{mm} \mathrm{h}^{-1}$ \\
$\left.(2) \mathrm{R}\left(\mathrm{Z}_{H}, \mathrm{Z}_{D R}\right)=6.70^{*} 10^{-3 *}\left(\mathrm{Z}_{H}\right)^{(0.927)} *(10)^{(0.1 *-3.433} *^{Z}{ }_{D R}\right)$ & $\mathrm{mm} \mathrm{h}^{-1}$ \\
$(3) \mathrm{R}\left(\mathrm{K}_{D P}\right)=53.8^{*}\left(\mathrm{~K}_{D P}\right)^{(0.85)}$ & $\mathrm{mm} \mathrm{h}^{-1}$ \\
$(4) \mathrm{R}\left(\mathrm{Z}_{H}\right)=0.02180^{*}\left(\mathrm{Z}_{H}\right)^{(0.70)}$ & $\mathrm{mm} \mathrm{h}^{-1}$ \\
\hline
\end{tabular}

A Eq. (3) corresponde a precipitação mais intensa, seguida a Eq. (1), Eq. (2) e Eq. (3) para precipitações menos intensas. As variáveis polarimétricas $\mathrm{K}_{D P}$ e $\mathrm{Z}_{D R}$ são ótimas para a estimativa das gotas de chuva e das taxas de chuva (Ihadua et al., 2016).

Na aplicação da metodologia proposta neste trabalho, descartou-se o filtro de artefatos, para não comprometer a detecção da frente de brisa marítima. Se quer foi realizada a correção de atenuação da refletividade que não foi objeto deste trabalho. 
Capítulo 3

\section{Resultados}

\subsection{Tempestade Induzida pelo Sistema de BM, Ilha de calor urbano, Poluição urbana e Sistema pré-frontal no dia 11 de janeiro de 2010}

A Lógica fuzzy foi aplicada usando medidas de entradas do radar MXPOL para obtenção da classificação dos hidrometeoros presentes na tempestade induzida pela frente de BM e influenciada por um sistema frontal e ilha de calor urbano na RMSP que intensificou o evento, causando ventos intensos, chuvas fortes que provocaram inundações repentinas na RMSP, provocando importantes impactos socio-econômicos.

Como descrito na metodologia, utilizou-se dados refletividade horizontal, refletividade diferencial, refletividade diferencial específica, coeficiente de correlação, temperatura e altitude como dados de entrada. Não temos sondagens disponíveis no horário do disparo das células convectivas, a mais próxima é a sondagem das 1200 UTC que foram usadas correspondentes a cada sistema precipitante. A temperatura é uma variável importante por servir como fator determinante na classificação de hidrometeoros que só habitam em regiões de temperaturas a abaixo de $0^{\circ} \mathrm{C}$. Como exemplo, é fisicamente impossível a presença de agregados, graupel de baixa densidade, cristais de gelo e gelo vertical dentro ou abaixo da isoterma $0^{\circ} \mathrm{C}$, já que a partir da temperatura $0^{\circ} \mathrm{C}$ esses hidrometeoros descongelam imediatamente.

O dados na Tab. 2.5 de classificação de hidrometeoros para o MXPOL, foram ajustados por meio de uma revisão bibliográfica do que vem sendo estudado sobre o assunto para radar meteorológico banda X (Dolan e Rutledge, 2009; Marzano et al., 2010; Snyder et al., 2010; Kouketsu et al., 2015). Mas ainda com muitas limitações na classificações de vários tipos de hidrometeoros devido a atenuação do sinal do radar causada por hidrometeoros. 


\subsubsection{Análise Sinótica}

As imagens de satélite na Fig. 3.1 mostram o deslocamento de uma frente fria em direção à região sudeste onde bandas de nublosidade associada à extremidade pré-frontal formou-se sobre estado de São Paulo. À medida que o sistema frontal da FF deslocava-se para região sudeste as bandas de nebulosidade intensificavam-se sobre São paulo. A RMSP não está parcialmente coberta por nuvem associada ao sistema pré-frontal, enquanto que arredores observa-se a cobertura de nuvem rasa (Fig. 3.1a, indicada pela seta vermelha), às 1600 UTC.
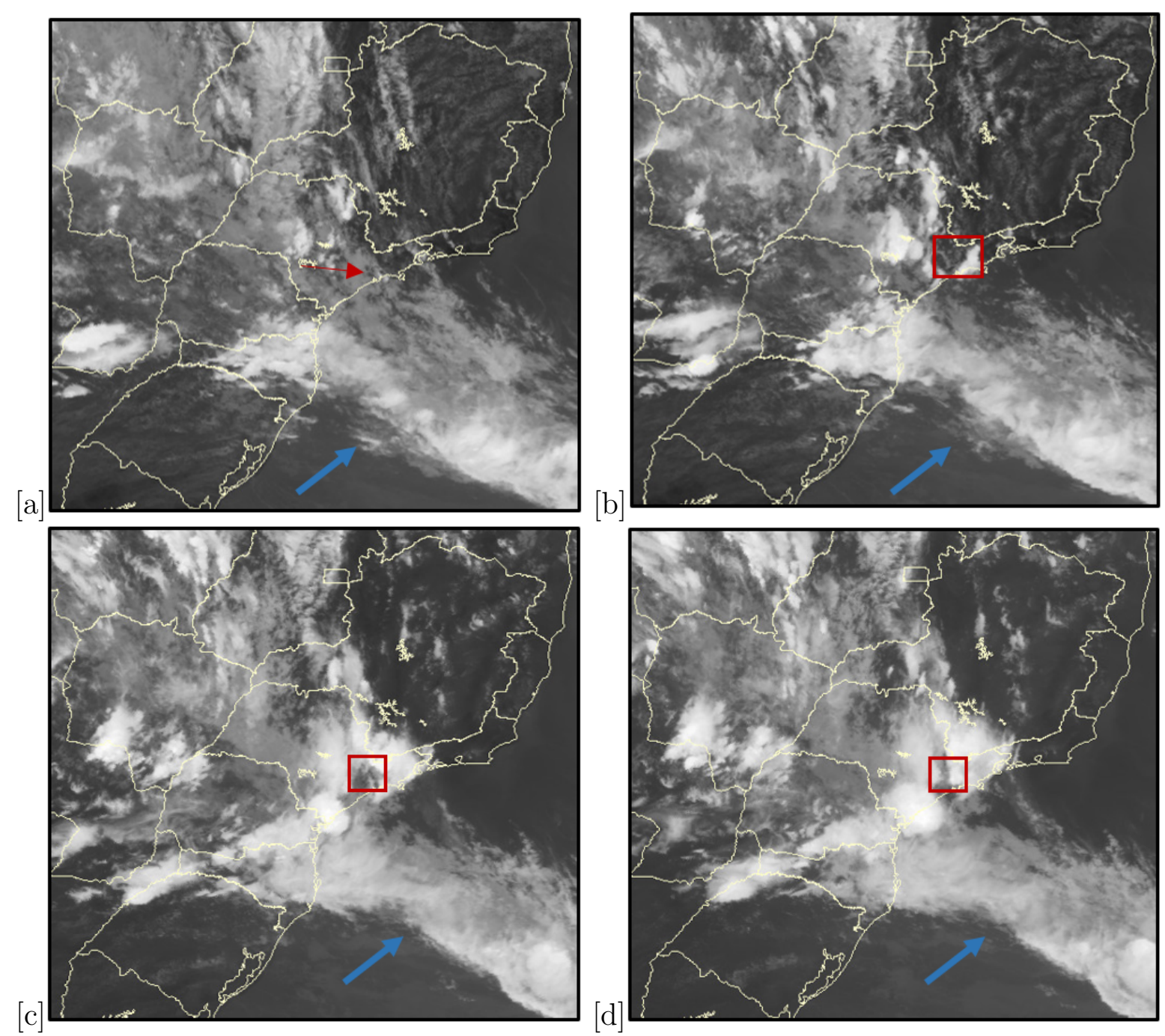

Figura 3.1: Imagens GOES-12 no canal infravermelho (a) 1600 UTC, (b) 1730 UTC, (c) 2000 UTC e (d) 2100 UTC do dia 11 de Janeiro de 2010. A seta azul indica a posição frontal da frente fria. O quadrado vermelho e a seta indicam a RMSP. Fonte: DSA-CPTEC.INPE, 2010. 
No entanto, a Fig. 3.1b mostra uma banda intensa de nebulosidade induzida pela frente de BM (área destacada), propagando-se lentamente em direção à RMSP, às 1730 UTC. A Fig. 3.1c mostra parte da região leste do estado de São Paulo coberta de nuvem intensa, exceto a RMSP onde observa-se nuvem ligeiramente intensa dentro da região cinza, parte sul e parte norte da RMSP, às 2000 UTC. Às 2100 UTC toda região leste e parte do centro da RMSP está coberta de nuvem intensa resultante do disparo das células convectivas quando a frente da BM atingiu o centro da RMSP, interagindo com ilha de calor e poluição urbana. Essas células integraram-se à banda de nebulosidade observada às 1730 UTC, formando uma tempestade ordinária (Fig. 3.1d).

Os dados do GFS foram utilizados para caracterizar a situação sinótica do ambiente em que se desenvolveu a tempestade ordinária induzida pela interação de vários fatores.

A Fig. 3.2a mostra o campo de pressão no nível médio do mar do dia 11 de janeiro de 2010 às 1800 UTC. Observa-se uma crista no interior e um cavado na costa do estado de São Paulo. Na Fig. 3.2b, mostra o campo geopotencial a 700 hPa, onde observa-se uma diminuição do geopotencial no interior do estado de São Paulo, e um aumento do geopotencial nesse nível sobre o costa e litoral do estado de São Paulo associados a crista e ao cavado. Nesse horário há movimentos descendentes no lado oeste da crista na divisa entre os estados de São Paulo e Paraná, e movimentos ascendentes de $0.5 \mathrm{~Pa} \mathrm{~s}^{-1}$ no lado leste da crista e oeste do cavado sobre a RMSP que estende-se sobre o oceano adentro.

O campo de vento a $10 \mathrm{~m}$ e umidade a $2 \mathrm{~m}$ do GFS (Fig. 3.2c), mostra direção predominante do vento de sudeste na costa do estado de São Paulo e umidade de 90\% na divisa entre os dois estados supra citados associada à crista. O campo mostra que a umidade era de de $80 \%$ antes dos disparos de intensas células convectivas sobre a RMSP. 

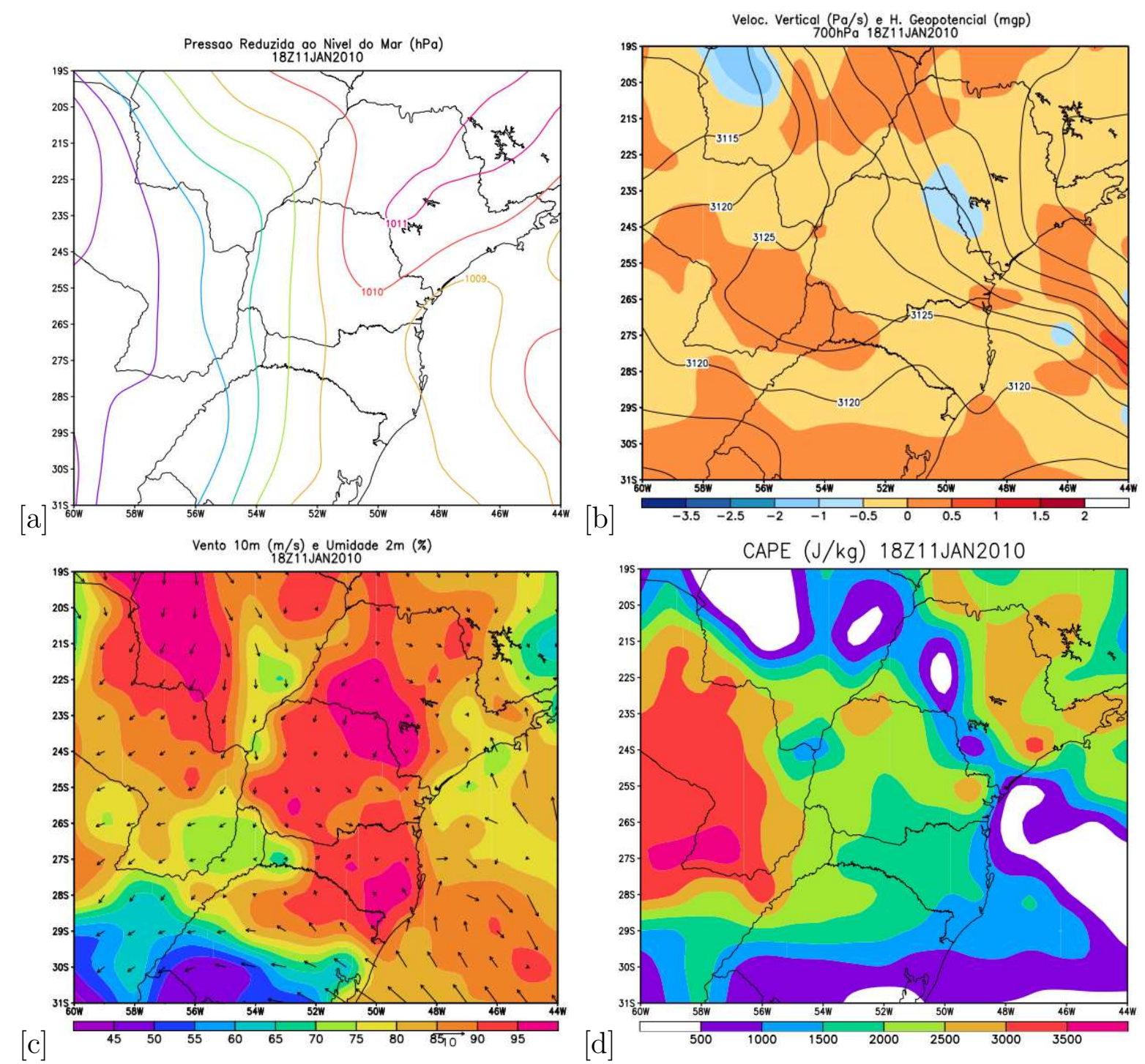

Figura 3.2: (a) Campo de pressão reduzido ao nível do mar (hPa); (b) campo de movimento vertical e altura geopotencial (gpm); (c) Campo de vento $\left(\mathrm{m} . \mathrm{s}^{-1}\right)$ a $10 \mathrm{~m}$ e umidade (\%) a $2 \mathrm{~m}$ acima da superfície; e (d) CAPE $\left(\mathrm{J} \mathrm{kg}^{-1}\right)$, obtido a partir da análise de modelo de circulação global-GFS do evento ocorrido no 11 de janeiro de 2010. A faixa de isóbaras é de $1 \mathrm{hPa}$. Cores frias/quentes indicam valores mais baixos/mais altos. A faixa de isolinhas geopotenciais é de $20 \mathrm{gpm}$ e a barra de cores indica a velocidade vertical em $\mathrm{Pa} \mathrm{s}^{-1}$. As setas indicam a magnitude do vento e a barra de cores indica a umidade. A escala de cores indica os valores do CAPE. Contornos geopolíticos, latitudes, longitudes e tempos são indicados.

A energia potencial disponível para convecção (CAPE) mostra que a região oeste, desde a costa até o extremo norte-noroeste do estado de São Paulo encontrava-se sobre uma área de fraca instabilidade e área de instabilidade sobre a região leste, desde a costa até nortenordeste, principalmente no RMSP onde observa-se valores entre 2500 e $3000 \mathrm{~J} \mathrm{~kg}^{-1}$ às 1800 UTC (Fig. 3.2d). 


\subsubsection{Análise dinâmica e termodinâmica}

A Fig. 3.3a mostra uma assinatura de meso-escala no campo da velocidade radial, onde observa-se uma região de convergência sobre o centro geométrico da RMSP às 2025 UTC, área destacada. Tons vermelho e azul indicam afastamento e aproximação em relação ao radar, respectivamente. A velocidade radial medida dos fluxos é $\sim 7.5 \mathrm{~m} . \mathrm{s}^{-1}$. O fluxo de massa de ar associada a vento do noroeste associado ao jato (tom vermelho), propagou-se contra a frente da BM (tom azul), desencadeando no disparo de várias células convectivas.
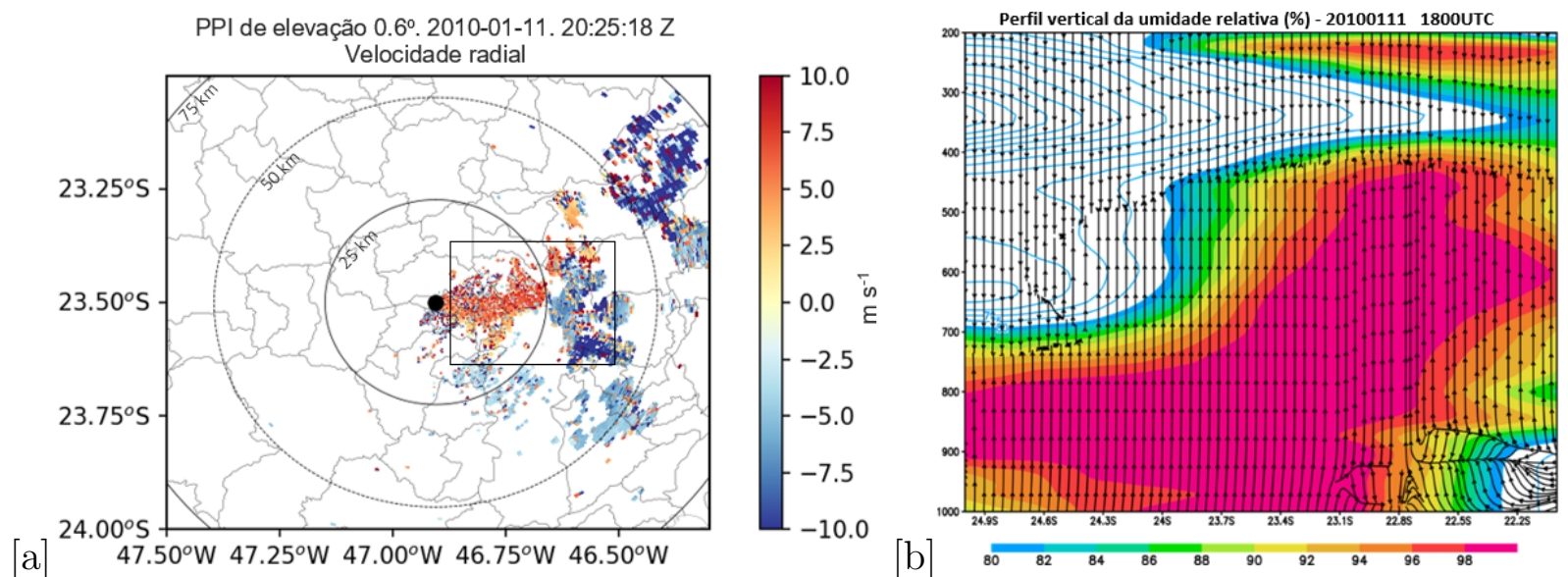

Figura 3.3: (a) PPI de elevação 0.6 $6^{\circ}$ da velocidade radial do radar MXPOL de 11 de Janeiro de 2010 às 2025 UTC do sistema de convecção induzida por brisa marítima e vento de noroeste sobre o centro geométrico da RMSP. (b) corte do perfil vertical da umidade relativa e vento do ECMWF dentro de uma coluna com resolução de $12.5 \mathrm{~km}^{2}$, fixo na longitude $47^{\circ} 60^{\prime} \mathrm{W}$ e variando entre latitudes $22^{\circ} 25^{\prime} \mathrm{S}$ a $24^{\circ} 95^{\prime} \mathrm{S}$ do dia 11 de Janeiro de 2010 às 1800 UTC. A escala de core indica a velocidade ( $\left.\mathrm{m} \mathrm{s}^{-1}\right)$ de alvos que se aproxima (azul) e se afasta (vermelho) do MXPOL. O ponto preto no centro indica posição do radar meteorológico MXPOL (23 32.2'S; 46 ${ }^{\circ}$ 52.8'W) em Barueri, São Paulo. Circunferências concêntricas estão espaçadas a cada $25 \mathrm{~km}$. Longitudes, latitudes, contornos dos municípios são indicados. A escala de cores representa a umidade (\%). As setas representam a magnitude do vento.

A Fig.3.3b mostra o corte do perfil vertical de umidade na longitude $47^{\circ} 60^{\prime} \mathrm{W}$ variando entre latitudes $22^{\circ} 25^{\prime} \mathrm{S}$ a $24^{\circ} 95^{\prime} \mathrm{S}$ entre os extremos sul e norte do município de São Paulo, do dia 11 de janeiro de 2010, às 1800 UTC. Observa-se uma camada de umidade que varia entre 60-90\% até à tropopausa sobre a RMSP durante a passagem da frente de BM. Nota-se um forte entranhamento de massa de ar seco entre 400 e $300 \mathrm{hPa}$. O aquecimento superficial durante o dia e a ejeção de umidade pela frente de BM a tarde e pelo fluxo de noroeste canalizado pelo sistema frontal (Fig.??b), favoreceram para a 
instabilidade atmosférica em um ambiente de fraco cisalhamento do vento. Essas condições termodinâmicas potencializam células convectivas (Houze Jr et al., 1990; Houze Jr, 2014).

\subsubsection{Evolução espaço-temporal da tempestade}

Os dados de radar MXPOL indicaram uma formação típica de tempestade induzida por brisa marítima a partir das 1753 UTC (Fig. 3.4a) e essa foi monitorada até às 2135 UTC do dia 11 de Janeiro de 2010 (Fig. 3.5d), quando passou de sistema convectivo para sistema estratiforme. Durante esse intervalo, primeiro ocorreu o disparo de várias células convectivas. Essas células integraram-se posteriormente, e deslocaram-se no sentido contrário da frente de BM, às 1757 UTC (Fig. 3.4a). A frente da BM (linha fina de refletividade), apresenta orientação de eixo nordeste-sudoeste. Essa frente da BM propagase em direção ao centro geométrico da RMSP (Fig. 3.4a).

A Fig. 3.4b mostra o disparo de uma célula convectiva primária na divisa do extremo leste do município de são Paulo, no azimute $112,5^{\circ}$, com $\mathrm{Z}_{H}$ máxima de $50 \mathrm{dBZ}$, seguida de duas células convectivas primárias menos intensas, às 1850 UTC. Essas células quase integradas, nas áreas destacadas, pragaram-se a leste da RMSP, sentido contrário da frente da BM, às 1940 UTC (Fig. 3.4c). A Fig. 3.4d exibe cinco células convectivas secundárias áreas destacadas, resultantes da interação entre a frente de BM e frente de rajada das células primárias, às 2025 UTC. A célula convectiva secundária (dentro do triângulo) propagou-se e integrou-se às células convectivas primárias dentro do quadrado retângulo, e tornaram-se mais intensas.

A Fig. 3.5a exibe uma célula convectiva resultante da integração das células secundárias. Em destaque a frente de rajada (linha fina de refletividade) na dianteira da tempestade. A tempestade exibe configuração assimétrica,induzida pela convergência intensa dos ventos de noroeste e sudeste sobre o centro geométrico da RMSP, às 2050 UTC (Fig. 3.5b). Nota-se que as duas extremidades da tempestade tendem a deslocar-se mais rápido do que a área central da tempestade (Fig. 3.5b). 

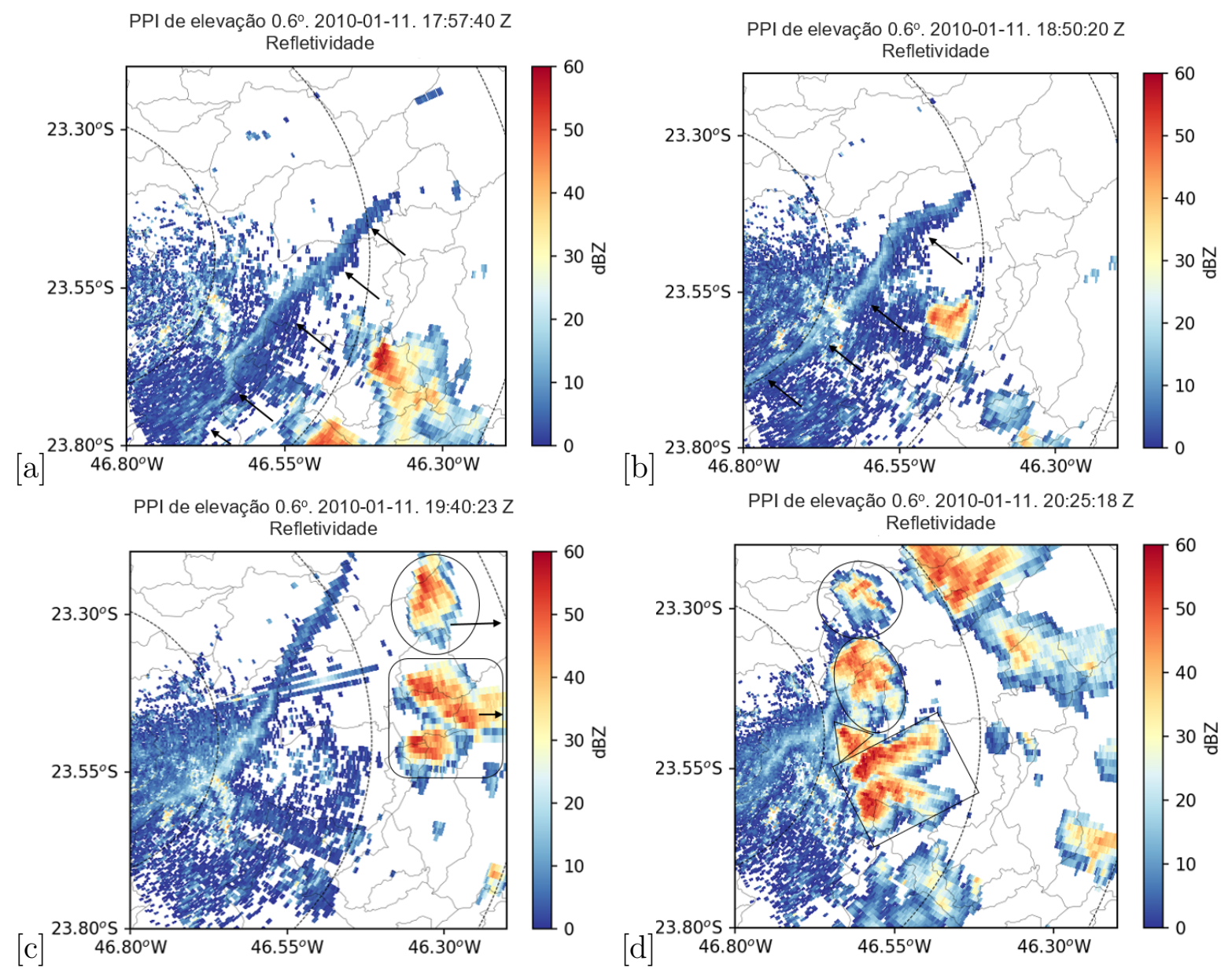

Figura 3.4: PPI de elevação $0.6^{\circ}$ da refletividade $\left(\mathrm{Z}_{H}\right)$ do radar MXPOL (a) às 1757 UTC, (b) 1850 UTC, (c) 1940 UTC e (d) 2025 UTC do sistema de conveç̧ão induzida por brisa marítima e vento de noroeste sobre o centro geométrico da RMSP no dia 11 de Janeiro de 2010. A escala de cores indica a refletividade (dBZ). Circunferências concêntricas estão espaçadas a cada $25 \mathrm{~km}$. O radar meteorológico MXPOL está centro da menor circunferência concêntrica ( $23^{\circ} 32.2^{\prime} \mathrm{S} ; 46^{\circ} 52.8^{\prime} \mathrm{W}$ ) em Barueri, São Paulo. Longitudes, latitudes, contornos dos municípios são indicados. As setas pretas indicam a frente de brisa marítima representada pela linha fina de refletividade.

A Fig. 3.5c exibe a tempestade em estágio de dissipação, às 2115 UTC. Provavelmente a frente da BM propagou-se fora da RMSP, e não há interação com as frentes de rajadas para a retroalimentação da tempestade. Às 2135 UTC, a área convectiva encolheu e a área estratiforme expandiu-se na retaguarda da tempestade (Fig. 3.5d). 

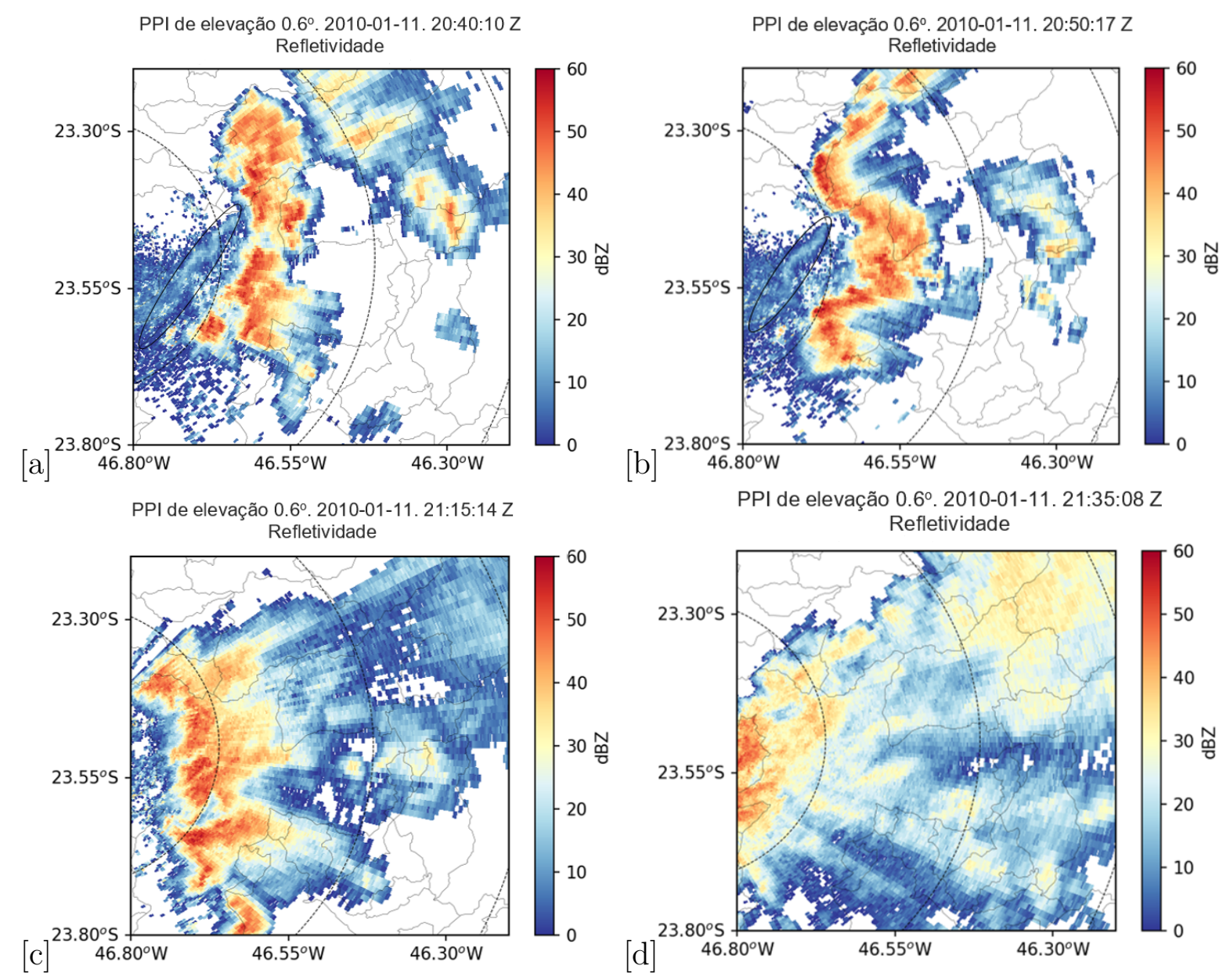

Figura 3.5: Idem Fig. 3.4, mas (a) às 2040 UTC, (b) 2050 UTC, (c) 2115 UTC e (d) 2135 UTC. A linha fina de refletividade na área destacada representa a frente de rajada da tempestade.

3.1.4 Tipos de hidrometeoros, massas de água líquida e sólida e diâmetro da gota de chuva

Foi utilizado dados do radar MXPOL como refletividade, refletividade diferencial, fase diferencial específica e coeficiente de correlação para classificação dos hidrometeoros presentes na tempestade por meio do método lógica fuzzy.

A correção de atenuação não foi objeto deste trabalho. A tempestade objeto de estudo foi analisada a $30 \mathrm{~km}$ de radar MXPOL. O dados do radar MXPOL não foram filtrados, porque perderíamos informações da entrada da frente de brisa BM. A frente de BM está associada a insectos.

A tempestade analisada foi muito intensa que provavelmente causou fortes atenuações 
nas ondas electromagnéticas. Isso influenciou na classificação qualitativa dos hidrometeoros, como granizo e graupel acima da isoterma ${ }^{\circ} \mathrm{C}$, e gota grande abaixo da isoterma ${ }^{o} \mathrm{C}$. Outro aspecto que pode também ter influenciado, são os dados de altitude e temperatura da sondagem das 1200 UTC enquanto que o caso analisado começou no horário das 1700 UTC.

A Fig. 3.6 apresenta os campos de refletividade, refletividade diferencial, fase diferencial específica e coeficiente de correlação acima da isoterma $0^{\circ} \mathrm{C}$, no memento em que a célula convectiva secundária, destacada no oval, propagou-se e quase integrou-se às células convectivas primárias, destacada no quadrado.
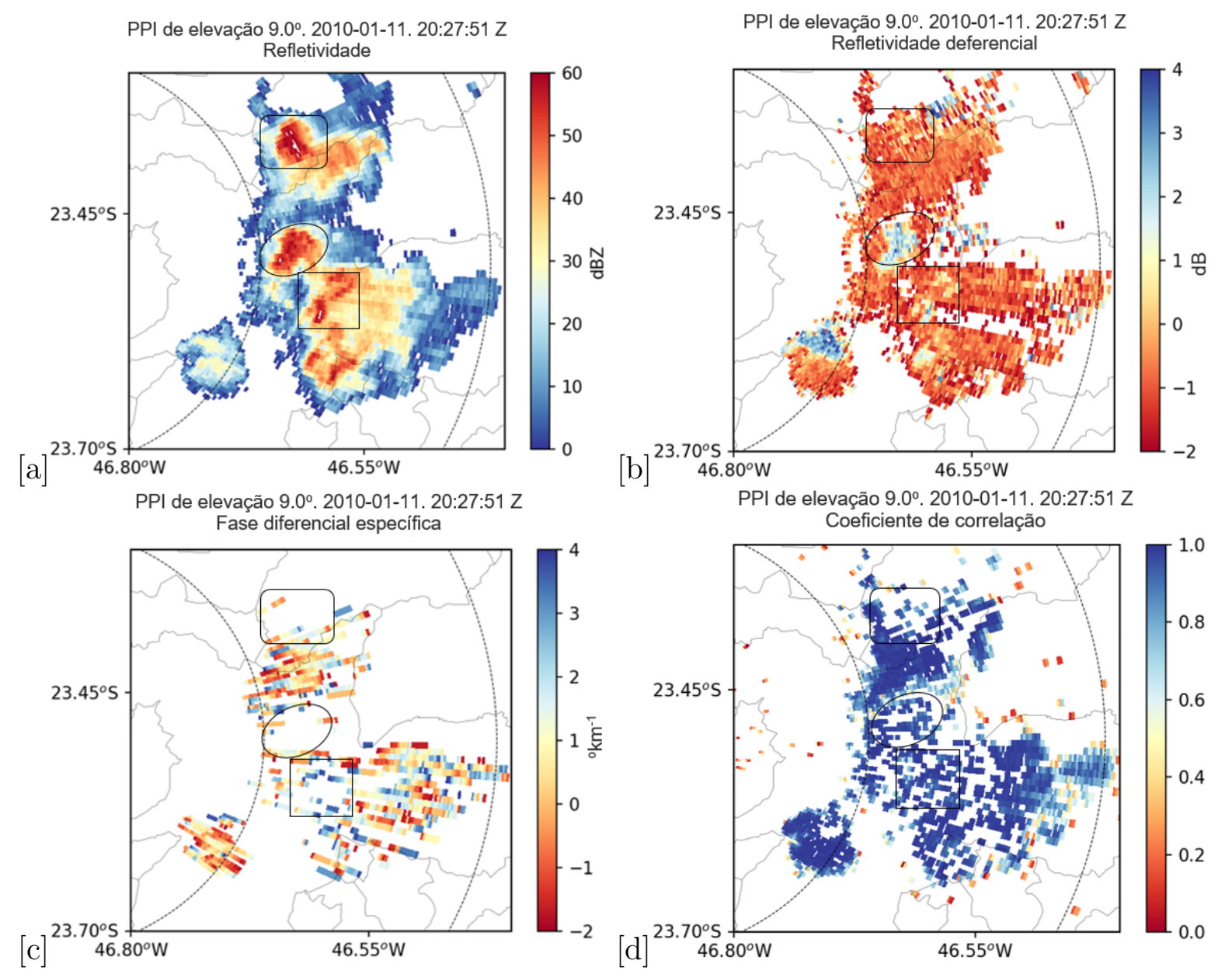

Figura 3.6: PPI de elevação 9.0 $0^{\circ}$ do radar MXPOL no dia 11 de Janeiro de 2010 às 2027 UTC, (a) refletividade $\left(\mathrm{Z}_{H}\right)$, (b) refletividade diferencial $\left(\mathrm{Z}_{Z D}\right)$, (c) fase diferencial específica $\left(\mathrm{K}_{K D}\right)$ e $(\mathrm{d})$ coeficiente de correlação. As escalas de cores indica a refletividade (dBZ), refletividade diferencial (dB), fase diferencial específica $\left({ }^{\circ} \mathrm{km}^{-1}\right)$ e coeficiente de correlação (sem unidade) . Circunferências concêntricas estão espaçadas a cada $25 \mathrm{~km}$. O radar meteorológico MXPOL está centro da menor circunferência concêntrica $\left(23^{\circ} 32.2^{\prime} \mathrm{S}\right.$; $\left.46^{\circ} 52.8^{\prime} \mathrm{W}\right)$ em Barueri, São Paulo. Longitudes, latitudes, contornos dos municípios são indicados. 
Nota-se pelo campo de refletividade diferencial, por ser uma célula convectiva jovem, a célula secundária tem gotas relativamente maiores do que as células primárias destacadas no retângulo redondo e no quadrado (Fig. 3.6b).

Os campos da fase diferencial específica e coeficiente de correlação não apresentam coloração homogenia nas regiões mais intensas das células convectivas (Fig. 3.6c, d). Isso impactou negativamente na classificação dos hidrometeoros.

os campos da massa de água líquida, massa de água sólida, diâmetro da gota de chuva e classificação dos hidrometeoros, estão indicados na Fig. 3.7. Observa-se alta concentração de massa de água líquida e gotas super-resfriadas de maiores diâmetros na célula secundária, destacada no oval (Fig. 3.7a, c), indicativo que essa região estava sob forte corrente ascendente. A água super-refrigerada está associada a correntes ascendentes (Fernández-González et al., 2015).

De acordo com Fernández-González et al. (2016) a nebulosidade associada a célula secundária aparece na retaguarda da tempestade, causada por correntes descendentes em baixos níveis. Porém, neste trabalho a nebulosidade associada a célula secundária é observada na vanguarda da tempestade e essa propagou-se em direção a tempestade que a intensificou. As causas dinâmicas e termodinâmicas associadas a interação da frente de BM que estagnou sobre o centro geométrico da RMSP com frentes de rajadas associadas as correntes descendentes das células primárias, causaram o disparo da célula secundária.

A formação de intensas frentes de rajada está associada a correntes descendentes potencializadas pelo resfriamento latente por evaporação, devido água líquida super arrefecida na região convectiva da tempestade (Lee e Feingold, 2010).

Nota-se que a concentração da massa de água líquida e gotas super-resfriadas é menor nas células primárias, áreas destacadas no quadrado e retângulo redondo (Fig. 3.7a, c). provavelmente, Por serem células mais antigas, a coexistência com cristais de gelo e sua pressão de vapor de baixa saturação, as gotículas super-refrigeradas tendem a evaporar através do mecanismo Bergeron-Findeisen, devido à sua insaturação ambiente (FernándezGonzález et al., 2015). Isso é observado na Fig. 3.7b. Nota-se alta concentração de massa de gelo nas células primárias do que na célula secundária, resultante do crescimento dos cristais de gelo à custa das gotas super-resfriadas evaporadas, ou seja, crescimento por difusão de vapor. Provavelmente, esse processo está na fase inicial na célula secundária.

A Fig. 3.7d indica os hidrometeoros identificados. No geral, observa-se que nas áreas 
destacadas encontra-se granizo. Paradoxalmente, verifica-se baixa quantidade de granizo nas células primárias do que na célula secundária. provavelmente, devido efeitos de espalhamento não Rayleigh, que afeta o radar de band X, bem como os efeitos de ressonância da refletividade devido a queda interna de radiação eletromagnética que interferem com a radiação de retroespalhamento (Ryzhkov e Zrnic, 2005; Matrosov et al., 2006). Isso impactou negativamente na classificação quantitativa e qualitativa dos hidrometeoros. Observa-se chuvisco acima da isoterma $0^{\circ} \mathrm{C}$, regiões de temperaturas $<0^{\circ} \mathrm{C}$, onde esse hidrometeoro é pouco provável de coexistir com cristal de gelo, agregado e gelo vertical (Fig. 3.7d).
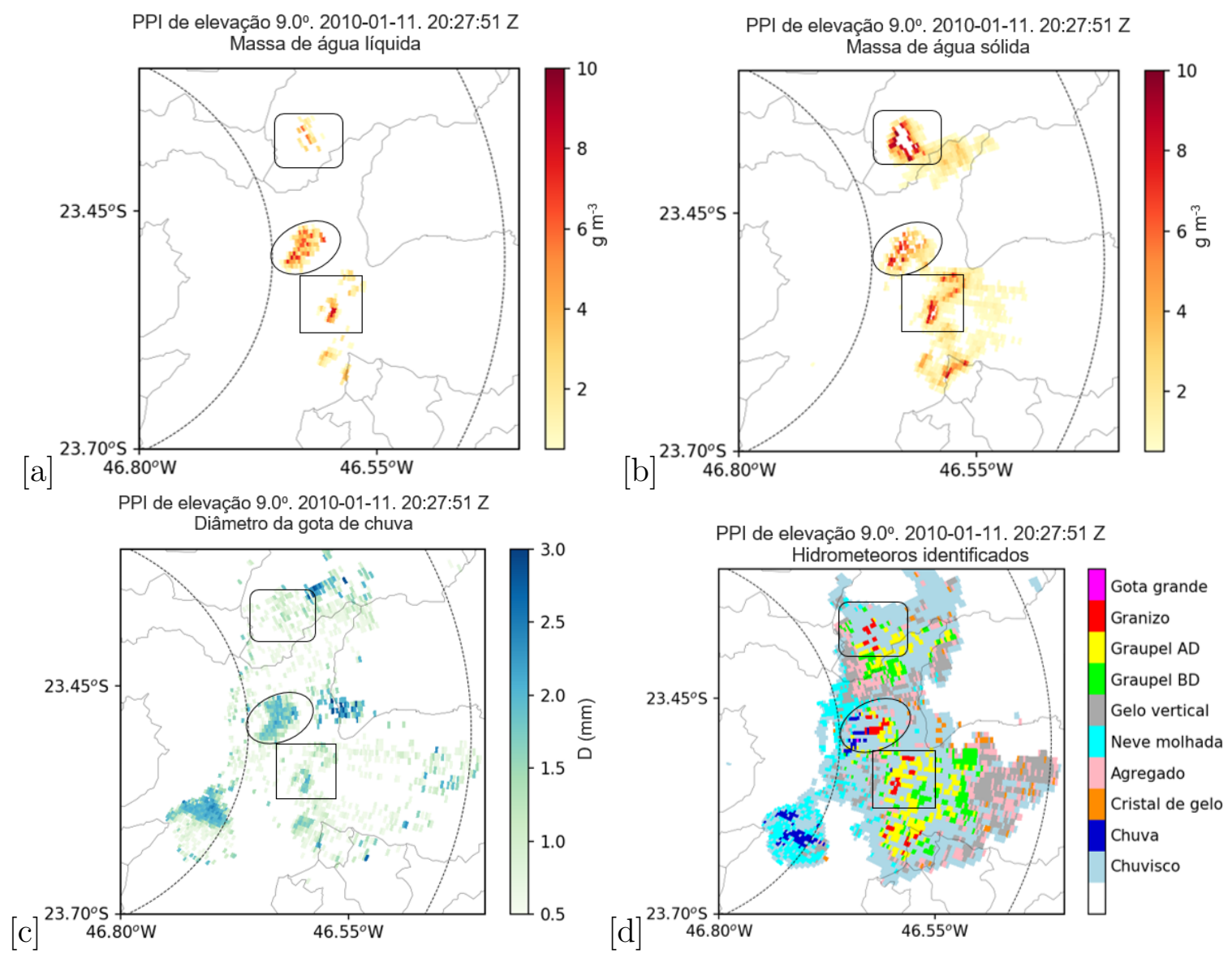

Figura 3.7: PPI de elevação 9.0 do radar MXPOL no dia 11 de Janeiro de 2010 às 2027 UTC, (a) massa de água líquida $\left(\mathrm{g} \mathrm{m}^{-3}\right)$, (b) massa de água sólida $\left(\mathrm{g} \mathrm{m}^{-3}\right)$, (c) diâmetro da gota da chuva $(\mathrm{mm})$ e (d) classificação de hidrometeoros. As escalas de cores estão indicados. Ademais escala de cores apresenta as 10 classificações dos hidrometeoros: Gota de água, Granizo, Graupel AD, Graupel BD, Gelo vertical, Neve molhada, Agregado, Cristal de gelo, Chuva e Chuvisco. Circunferências concêntricas estão espaçadas a cada $25 \mathrm{~km}$. O radar meteorológico MXPOL está centro da menor circunferência concêntrica $\left(23^{\circ} 32.2^{\text {'S }}\right.$; $46^{\circ} 52.8^{\prime} \mathrm{W}$ ) em Barueri, São Paulo. Longitudes, latitudes, contornos dos municípios são indicados. 
Um fato peculiar, as células convectivas que se propagam para o norte-nordeste da RMSP, intensificam-se e produzem quantidade alta de granizo. Observa-se no azimute $45^{\circ}$ a célula primária muito intensa destacada no retângulo redondo na Fig. $3.6 \mathrm{a}, \mathrm{Z}_{H}>55$ e na Fig. 3.7d), supostamente devia existir quantidade alta de granizo acima da isoterma $0^{\circ} \mathrm{C}$, mas, devido a forte atenuação foi classificado pouca quantidade de granizo. Essas peculiaridades de células mais intensas a alta produção de granizo quando se propagam para norte-nordeste da RMSP, foram observadas em outros casos analisados e apresentados neste trabalho.

A célula convectiva secundária provavelmente dominada por fortes correntes ascendentes, área destacada (Fig. 3.8), libera grande quantidade de calor latente durante a condensação, congelamento e deposição de vapor de água das gotas super-resfriadas, que intensifica mais ainda as correntes ascendentes e ejeta alta quantidade de conteúdo de água líquida na parte superior da nuvem (Liu et al., 1997).

Isso possibilita a produção de quantidade alta de de granizo e graupel pelo processo de acreção (riming) acima da isoterma $0^{\circ} \mathrm{C}$ sobre o centro geométrico da RMSP. Esse cenário de aspectos microfísicos apresentado, corrobora com os resultados obtidos por Rojas et al. (2018) que devido à ilha de calor, induz forte convergência sobre o centro da RMSP como observado na Fig. 3.3.

A Fig. 3.8 b mostra campo de $\mathrm{Z}_{H}$ na elevação $9.0^{\circ}$. A célula convectiva secundária continua intenso >55 dBZ da célula, 5 minutos depois, área destacada.

A dinâmica de forte convergência sobre o centro geométrico da RMSP, foi a causa dessa característica microfísica peculiar. Provavelmente, o centro geométrico da RMSP tem sido muito poluído. Isso aumenta a instabilidade e intensifica as correntes ascendentes, que transporta quantidade alta de gotas de água a temperaturas negativas (Fig. 3.8c, e), área destacada. Ambientes poluídos podem favorecer a evolução microfísica devido as correntes ascendentes mais intensas (Khain et al., 2005).

De acordo com Freitas et al. (2007), o efeito da ilha de calor na RMSP acelera a frente de brisa marítima em direção ao centro da RMSP e causa fortes convergências de massas de ar sobre centro da cidade. Esse fator de escala local retarda a propagação da frente da brisa marítima sobre o centro da RMSP por quase 2 horas (Freitas et al., 2007). 

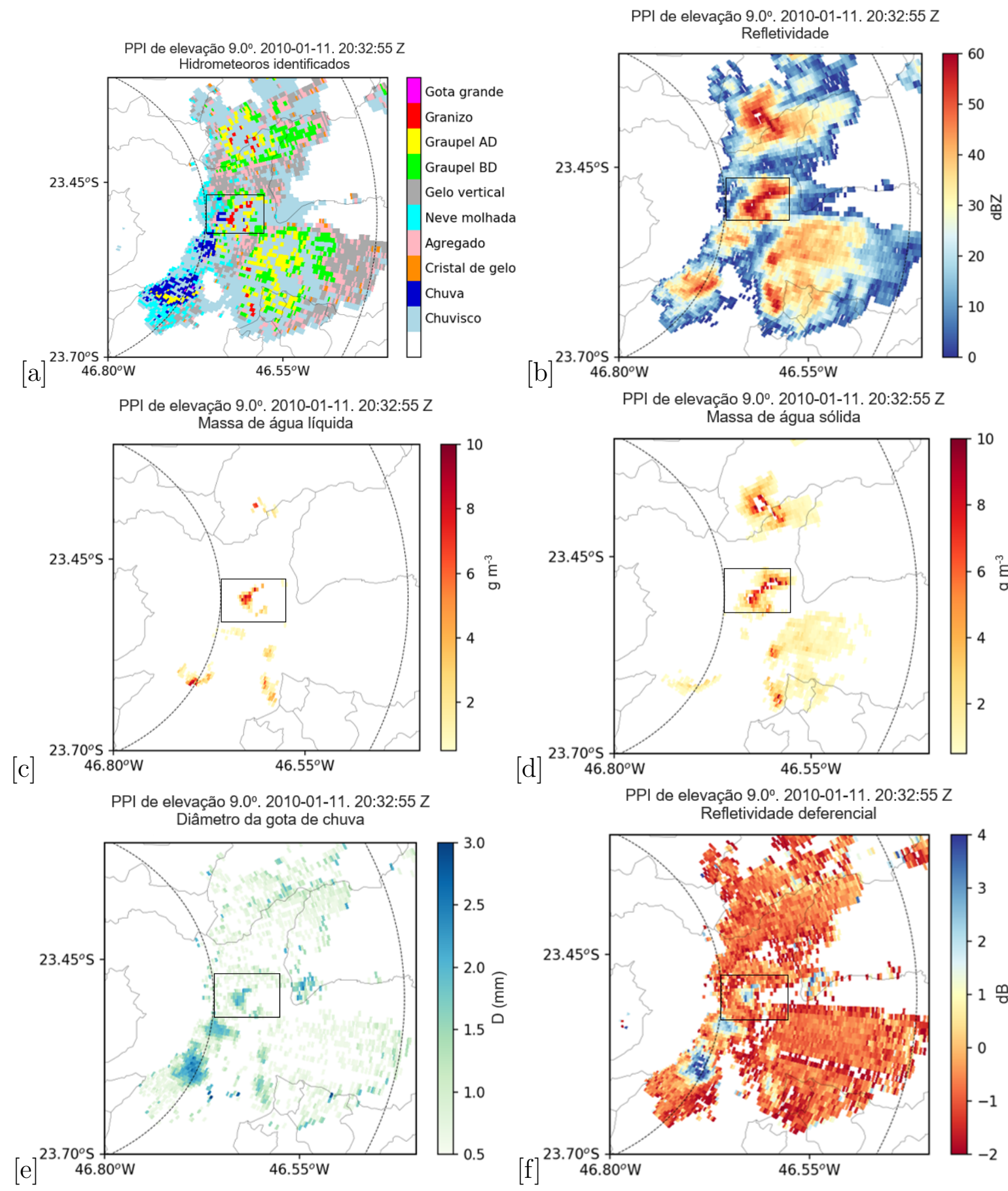

[d] ${ }^{23}$

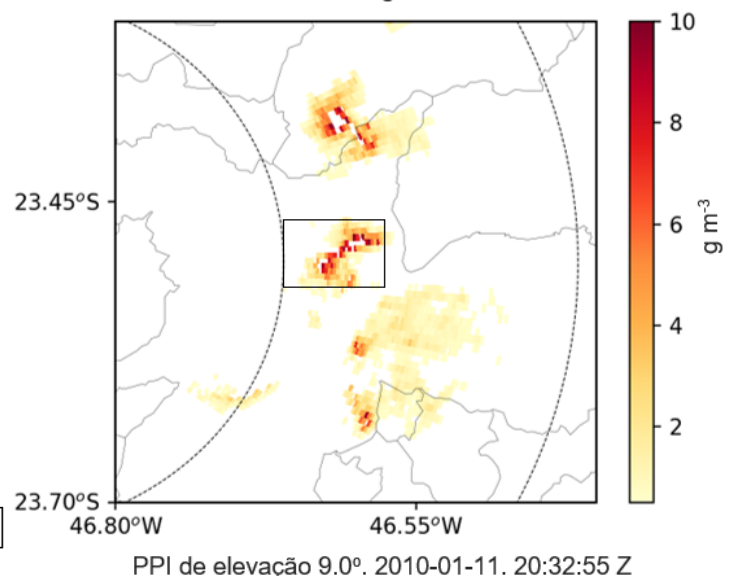
Refletividade deferencial

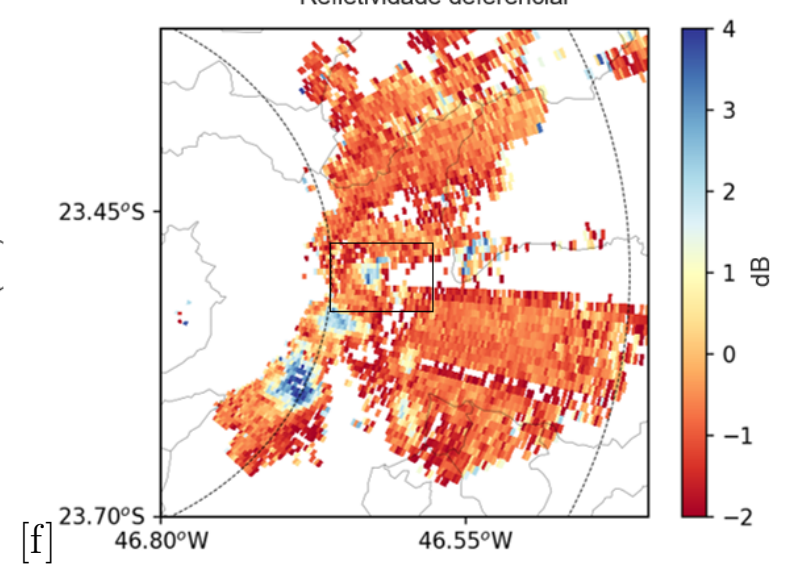

Figura 3.8: PPI de elevação $9.0^{\circ}$ do radar MXPOL no dia 11 de Janeiro de 2010 às 2032 UTC, (a) classificação de hidrometeoros, (b) refletividade $\left(\mathrm{Z}_{H}\right)$, (c) massa de água líquida $\left(\mathrm{g} \mathrm{m}^{-3}\right)$, (d) massa de água sólida $\left(\mathrm{g} \mathrm{m}^{-3}\right)$, (e) diâmetro da gota da chuva $(\mathrm{mm})$ e (f) refletividade diferencial $\left(\mathrm{Z}_{D R}\right)$. A escala de cores apresenta as 10 classificações dos hidrometeoros: Gota de água, Granizo, Graupel AD, Graupel BD, Gelo vertical, Neve molhada, Agregado, Cristal de gelo, Chuva e Chuvisco. Ademais escalas de cores estão indicados. Circunferências concêntricas estão espaçadas a cada $25 \mathrm{~km}$. O radar meteorológico MXPOL está centro da menor circunferência concêntrica ( $23^{\circ} 32.2^{\prime} \mathrm{S} ; 46^{\circ} 52.8^{\prime} \mathrm{W}$ ) em Barueri, São Paulo. Longitudes, latitudes, contornos dos municípios são indicados. 
Essa frente de BM ficou temporariamente estagnada sobre o centro da RMSP, por aproximadamente 2 horas. Posteriormente, propagou-se para fora da RMSP e fora do alcance do radar quando a ilha de calor urbano dissipou-se, tal como observado por Freitas et al. (2007). O efeito disso é observado pelas duas partes das extremidades da tempestade, apresentando as duas extremidades mais salientes e côncava na região do centro da cidade de São Paulo (Fig. 3.9).

Quando a ilha de calor urbano dissipou-se e a frente de brisa marítima propagou-se para da RMSP, a tempestade perdeu a configuração assimétrica e perdendo intensidade. No entanto, a RMSP ainda estava sob chuva misturada a gotas grandes e granizo às 2100 UTU (Tab. 3.1).

Correntes ascendentes persistentemente intensas, são capazes de sustentar grande quantidade de massa de gelo acima da isoterma $0^{\circ} \mathrm{C}$ (Liu et al., 1997). Observa-se que quantidade alta de massa de gelo acima da isoterma $0^{\circ} \mathrm{C}$ na célula secundária, aumentou 5 minutos depois (Fig. 3.8d). Lawson et al. (2015) sugerem que o mecanismo de produção no processo de congelamento de gotículas secundárias na produção de gelo, está nas fortes correntes ascendente que transportam essas gotículas e operam para a formação de núcleos de congelamento.

A consequência disso é a produção de pequenas partículas de gelo colidindo com gotículas super-resfriadas, que produzem um processo em cascata, que resulta em rápido congelamento dessas gotículas dentro da corrente ascendente (Lawson et al., 2015).

A presença de quantidade alta de gotas de água provavelmente super-resfriadas (Fig. 3.8e), área destacada, corrobora com os valores altos de refletividade diferencial (Fig. 3.8f) e quantidade alta de massa de água líquida $\left(\sim 8\right.$ g.m $\left.\mathrm{m}^{-3}\right)$ transportada para parte superior da tempestade (Fig. 3.8c), áreas destacadas. Essas análises mostram que a tempestade estava sob fortes correntes ascendentes. A quantidade alta de massa de água líquida na parte superior da célula secundária (a temperaturas $<0^{\circ} \mathrm{C}$ ), favoreceu o processo de acreção e deposição para a formação de quantidade alta de massa de gelo de $\sim 8$ g.m ${ }^{-3}$ (Fig. 3.8d), área destacada. 


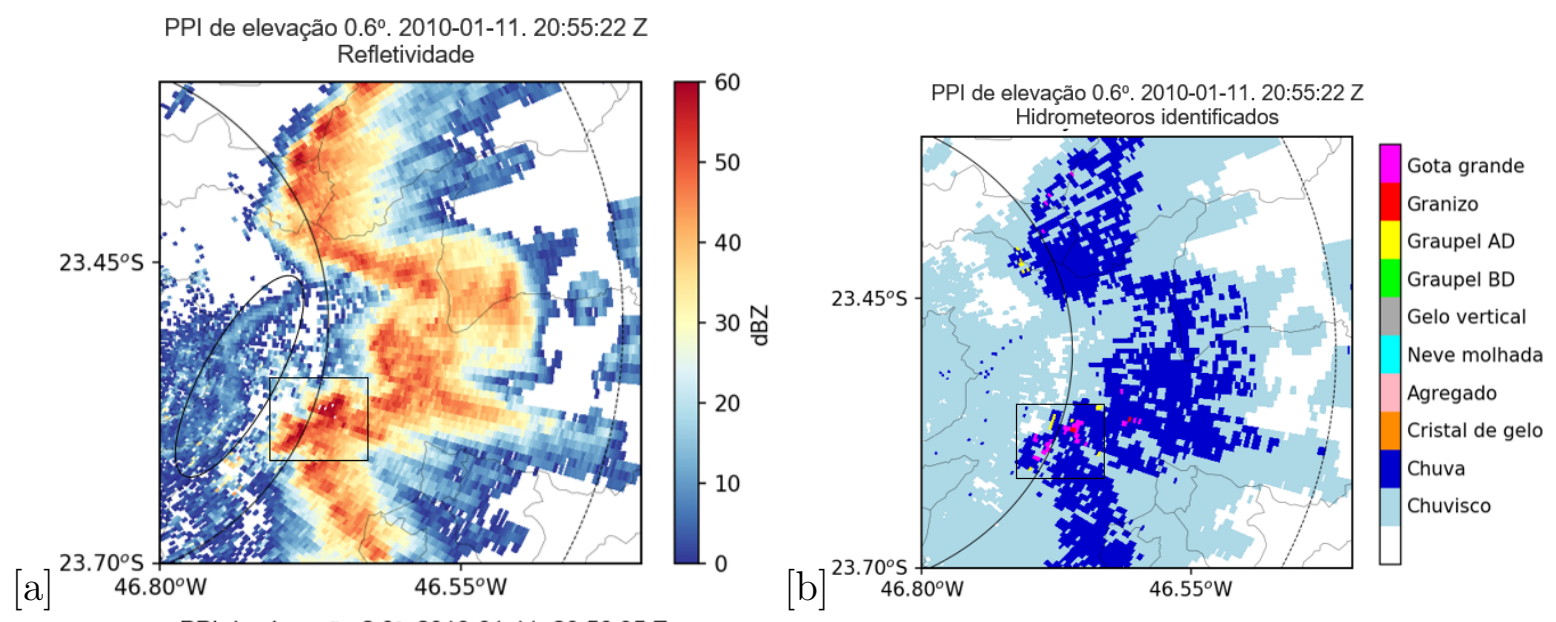

PPI de elevação $2.0^{\circ}$. 2010-01-11. 20:56:05 Z

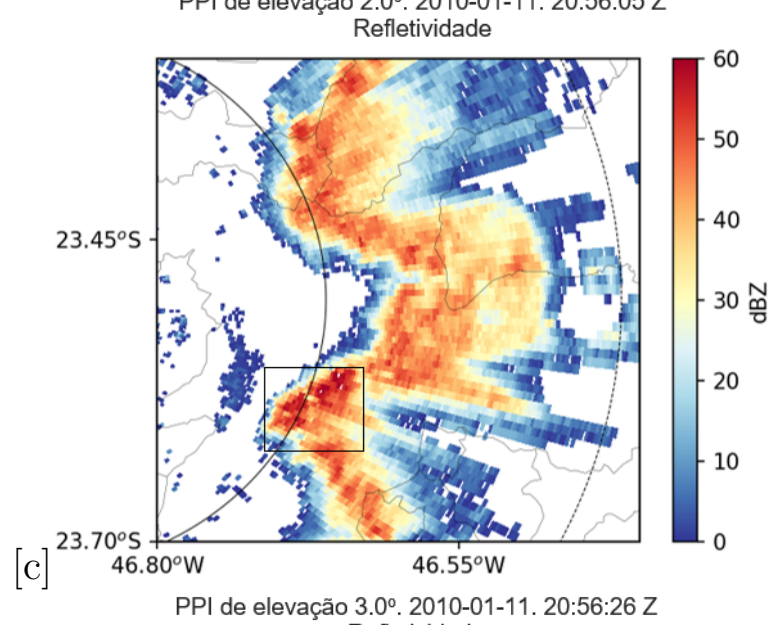

$[\mathrm{d}]^{23.70^{\circ} \mathrm{S}} 46.80^{\circ} \mathrm{W}$

PPI de elevação $2.0^{\circ}$. 2010-01-11. 20:56:05 Z Hidrometeoros identificados
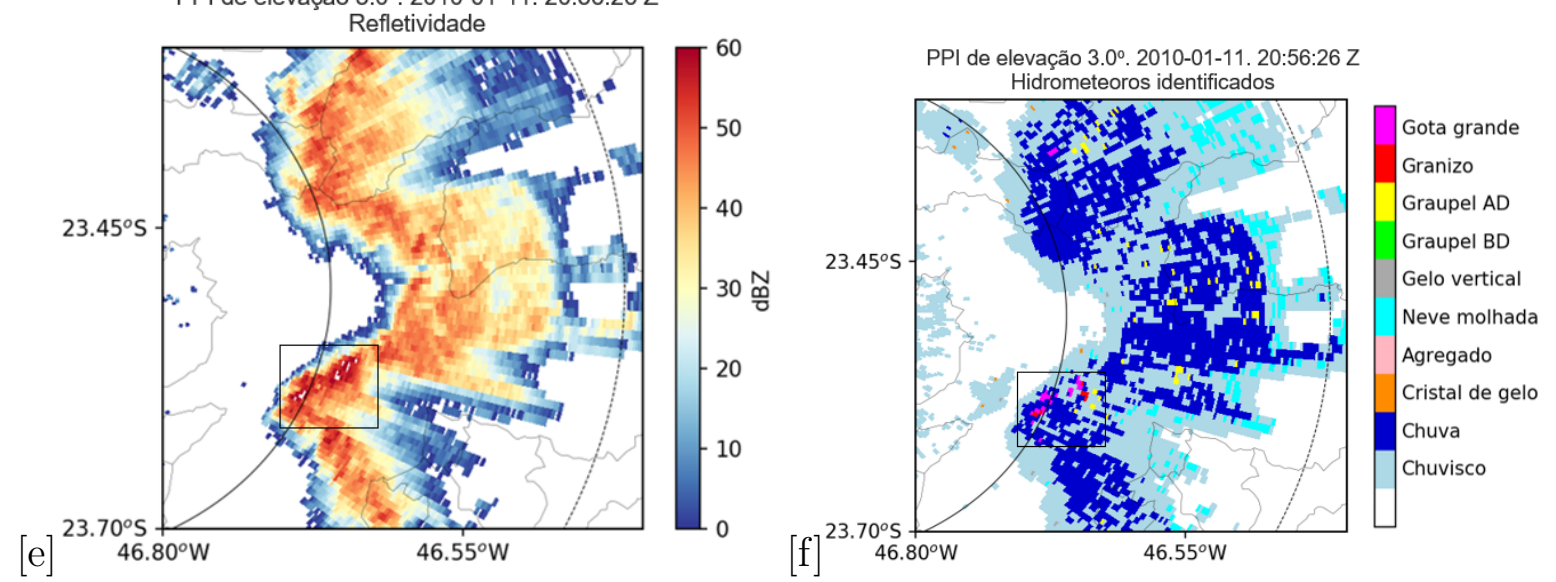

Figura 3.9: PPIs de elevações $0.6^{\circ}, 2.0^{\circ}$ e $3.0^{\circ}$ do radar MXPOL no dia 11 de Janeiro de 2010 entre 2055 a 2056 UTC, (a) refletividade $\left(\mathrm{Z}_{H}\right)$, (b) classificação de hidrometeoros, (c) refletividade $\left(\mathrm{Z}_{H}\right),(\mathrm{d})$ classificação de hidrometeoros, (e) refletividade $\left(\mathrm{Z}_{H}\right)$ e (f) classificação de hidrometeoros. A escala de cores apresenta as 10 classificações dos hidrometeoros: Gota de água, Granizo, Graupel AD, Graupel BD, Gelo vertical, Neve molhada, Agregado, Cristal de gelo, Chuva e Chuvisco. A escala de cores indica a refletividade (dBZ). Circunferências concêntricas estão espaçadas a cada $25 \mathrm{~km}$. O radar meteorológico MXPOL está centro da menor circunferência concêntrica ( $\left.23^{\circ} 32.2^{\prime} \mathrm{S} ; 46^{\circ} 52.8^{\prime} \mathrm{W}\right)$ em Barueri, São Paulo. Longitudes, latitudes, contornos dos municípios são indicados. 
Uma tempestade é intensificada por calor latente realizado e absorvido durante os processos de mudança de fase da água. Em nuvens convectivas mistas (coabitação de água e gelo) ocorrem os processos de derretimento-congelamento e sublimação-deposição, enquanto que em nuvens quentes (só presença água) ocorrem apenas evaporação-condensação (Li et al., 2013).

A Fig. 3.9 mostra a sequência de PPIs nas elevações $0.6^{\circ}, 2.0^{\circ}$ e $3.0^{\circ}$. Nota-se que a tempestade apresenta configuração assimétrica, causada pela intensa convergência sobre o centro geométrico da RMSP de adensamento urbano do que nas áreas adjacentes. A classificação dos hidrometeoros nas Fig. 3.9b, d, f, áreas destacadas, indica chuva misturada a gotas grandes e granizo. Provavelmente, esses hidrometeoros atingem a superfície. Nos campos de $\mathrm{Z}_{H}$, áreas destacadas, apresenta intensidades semelhantes $\sim 55 \mathrm{dBZ}$ nas três elevações (Fig.3.9a,c,e).

A classificação dos hidrometeoros indicados no PPI de elevação $0.6^{\circ}$, área destacada, Fig.3.9b, são os mesmos indicados nos PPIs de elevação $2.0^{\circ}$ e $3.0^{\circ}$, áreas destacadas, Fig. 3.9d, f. Provavelmente, ocorre colapso da mistura de massa de água líquida e massa de água sólida das regiões da superior para as regiões inferiores da nuvem. Nas regões destacadas da tempestade apresentam valores altos de $Z_{D R}>2 \mathrm{~dB}$ correspondente a gotas grandes do que em outras regiões da tempestade (Fig. 3.10). Possivelmente, esteja ocorrendo downburst (explosão), área destacada. Nota-se frente de rajadas indica por uma linha fina de refletividade entre 10 e 20 dBZ, destacada dentro do oval (Fig. 3.9a). Essa frente de rajadas apresenta ligeira curvatura para direita, indicativo que está associada ao talvez downburst (Fig. 3.9a).

O resfriamento latente realizado ou calor latente absorvido durante o congelamento, evaporação e sublimação aumenta negativamente a flutuabilidade, intensificando as correntes descendentes (Li et al., 2013; Liu et al., 1997; Szeto e Stewart, 1997). Estes processos são o causadores de fortes correntes descendentes para a ocorrência de downburst (Fujita e McCarthy, 1990). À medida que o volume mista de massas de água e água sólida precipita da região superior para regiões inferiores da nuvem, arrasta o ar junto, causando corrente descendente de ar. À medida que essa massa mista precipita abaixo da isoterma $0^{\circ} \mathrm{C}$, parte da massa de água sólida descongela, proporcionando a formação de gotas grandes (Rinehart, 2010). 


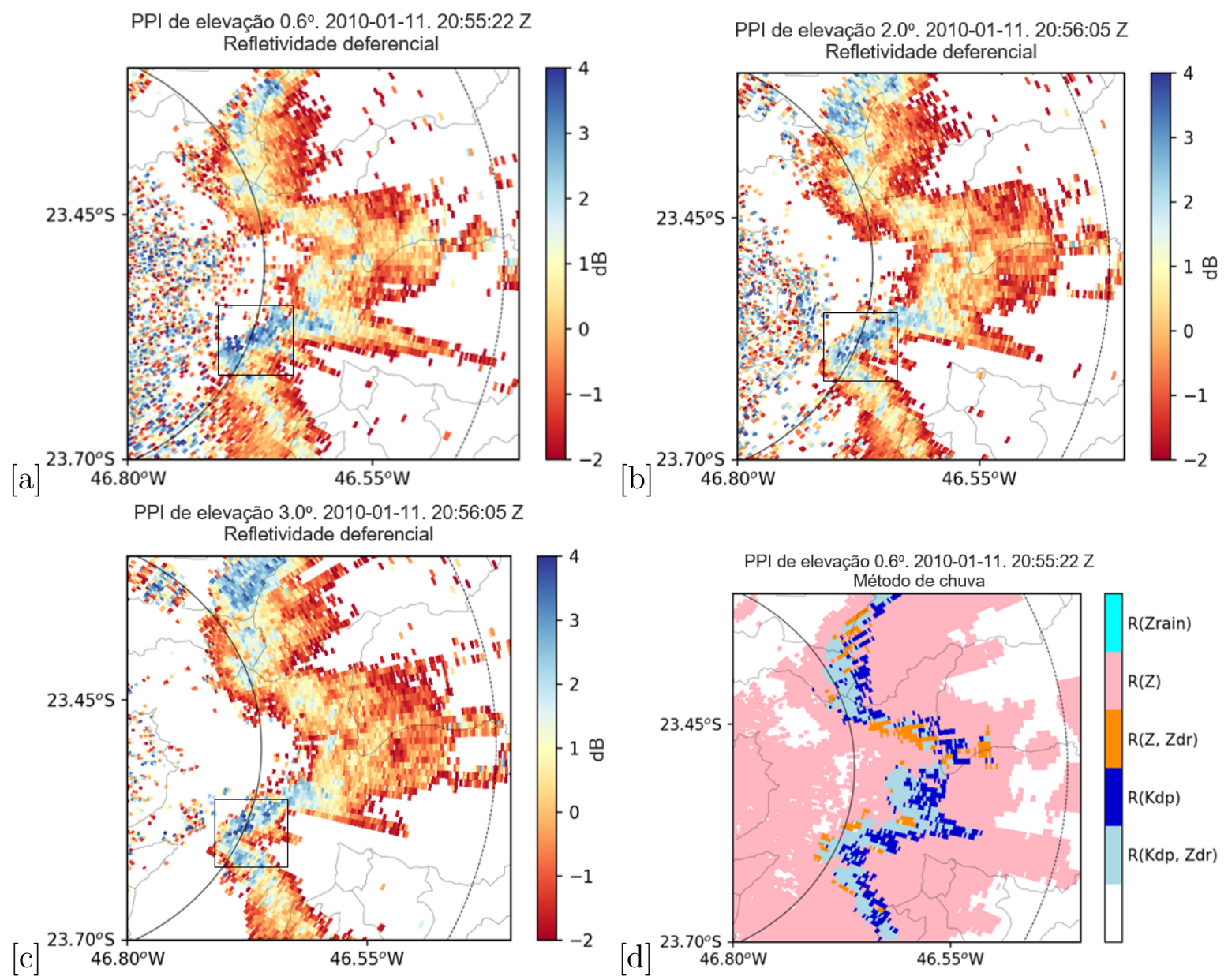

Figura 3.10: PPIs de elevações $0.6^{\circ}, 2.0^{\circ}$ e $3.0^{\circ}$ do radar MXPOL no dia 11 de Janeiro de 2010 entre 2055 a 2056 UTC, (a) refletividade diferencial $\left(\mathrm{Z}_{D R}\right)$, (b) refletividade diferencial $\left(\mathrm{Z}_{D R}\right)$, (c) refletividade diferencial $\left(\mathrm{Z}_{D R}\right)$ e $(\mathrm{d})$ método de chuva. A escala de cores indica a refletividade diferencial $(\mathrm{dB})$. A escala de cores apresenta os 5 métodos de chuva: R(kdp, Zdr), R(Kdp), R(Z, Zdr), R(Z) e R(Zrain). Circunferências concêntricas estão espaçadas a cada $25 \mathrm{~km}$. O radar meteorológico MXPOL está centro da menor circunferência concêntrica ( $23^{\circ} 32.2^{\prime} \mathrm{S} ; 46^{\circ}$ 52.8'W) em Barueri, São Paulo. Longitudes, latitudes, contornos dos municípios são indicados.

De acordo com Rinehart (2010) para o que ocorra o processo de descongelamento, é preciso energia do ar circundante com temperaturas mais quentes. O processo de descongelamento resfria o ar e faz com que o ar frio acelere para baixo na forma de forte corrente descendente. Essas dinâmicas dentro de tempestade causam a downburst.

O método da taxa de chuva mais intensa é representada pela ralação $\mathrm{R}(\mathrm{Kdp})$, cor azul escuro, e menos intensa representada pela relação $\mathrm{R}(\mathrm{Kdp}, \mathrm{Zdr})$, cor azul claro, e seguida pela relação R(Z, Zdr), cor laranja (Fig. 3.10d). Observa-se taxa de chuva correspondentes às $\mathrm{R}(\mathrm{Kdp}, \mathrm{Zdr})$ e $\mathrm{R}(\mathrm{Z}, \mathrm{Zdr})$ nas regiões frontais da tempestade e taxa de chuva 
correspondente $\mathrm{R}(\mathrm{Kdp})$ nas regiões traseiras da tempestade (Fig. 3.10d). Indicativo que a chuva mais intensa ocorre nas regiões traseiras da tempestade liderada pelas correntes descendentes. Enquanto que as regiões fronta da tempestade são lideradas pelas correntes ascendentes.

A predominância da tonalidade rosa correspondente ao método de estimativa $R(Z)$ está relacionada à refletividade de alvos não meteorológicos e, provavelmente, chuvisco.

A Tab. 3.1 mostra o resumo da classificação dos hidrometeoros acima da isoterma $0^{\circ} \mathrm{C}$, dentro da isoterma $0^{\circ} \mathrm{C}$, abaixo da isoterma $0^{\circ} \mathrm{C}$ e na superfície, durante a evolução espaço-temporal da tempestade.

No início da formação das célula primárias a oeste da RMSP, foi observado quantidade alta de graupel de baixa densidade, gelo vertical e agregado acima da isoterma $0^{\circ} \mathrm{C}$, às 1950 UTC (Tab. 3.1). Provavelmente, a corrente ascendente ainda não tinha força suficiente para transportar quantidade alta das gotas recém formadas acima da isoterma $0^{\circ} \mathrm{C}$. Abaixo da isoterma $0^{\circ} \mathrm{C}$ havia presença relativamente significativa de massa de água líquida, que proporcionou a formação de quantidade alta de graupel de alta densidade, gota grande, e início de formação de granizo (Tab. 3.1, às 1950 UTC). Observa-se chuva na parte inferior da célula convectiva.

Nota-se a importância da fase mista da nuvem convectiva acimada da isoterma $0^{\circ} \mathrm{C}$ para a produção de chuva misturada de gotas grandes a partir da base da isoterma $0^{\circ} \mathrm{C}$. Essas mesmas observações foram verificadas por Mason e Ramanadham (1954), onde ocorre processo de acreção (gotículas de nuvem e cristais de gelo) para o riming e formação de granizo acima da isoterma $0^{\circ} \mathrm{C}$, e ocorrência do processo de coalescência entre gotículas e gotas de chuva, e o derretimento de granizo para transformação em gotas grandes logo abaixo da isoterma $0^{\circ} \mathrm{C}$. Harper (1957) descreveu que a contribuição do conteúdo de água líquida em nuvem convectiva para o crescimento de gota de chuva abaixo da isoterma $0^{\circ} \mathrm{C}$ é muito pequena, porque o mecanismo de acreção é insignificante abaixo da isoterma $0^{\circ}$ $\mathrm{C}$, a temperaturas positivas. 
Tabela 3.1 - Resumo de tipos de hidrometeoros identificados nos núcleos das células secundárias acima da isoterma $0^{\circ} \mathrm{C}$, abaixo da isoterma $0^{\circ} \mathrm{C}$, dentro da isoterma $0^{\circ} \mathrm{C}$ e provavelmente atingindo a superfície durante a evolução espaço-temporal sobre o centro geométrico da RMSP entre 1950 e 2135 UTC do dia 11 de Janeiro de 2010 com os dados do radar MXPOL.

\begin{tabular}{|c|c|c|c|c|}
\hline \multirow{3}{*}{ UTC } & \multicolumn{4}{|c|}{ Tipos de hidrometeoros identificados do 11012010} \\
\hline & \multicolumn{3}{|c|}{ Isoterma $0^{\circ} \mathrm{C}$} & \multirow{2}{*}{ Superfície } \\
\hline & Acima & Abaixo & Dentro & \\
\hline 1950 & $\begin{array}{l}\text { Quantidade alta de } \\
\text { graupel } \mathrm{BD} \text {, gelo vertical } \\
\text { e agregados. }\end{array}$ & $\begin{array}{l}\text { Quantidade alta de } \\
\text { graupel AD e gota } \\
\text { grande; quantidade } \\
\text { baixa de granizo. }\end{array}$ & $\begin{array}{l}\text { Chuva; quantidade } \\
\text { alta de neve } \\
\text { molhada e graupel } \\
\text { AD. }\end{array}$ & Chuva. \\
\hline 2010 & $\begin{array}{l}\text { Graupel BD; agregados; } \\
\text { gelo vertical. }\end{array}$ & $\begin{array}{l}\text { Chuva ; graupel AD; } \\
\text { gota grande. }\end{array}$ & $\begin{array}{l}\text { Quantidade alta de } \\
\text { graupel AD e neve } \\
\text { molhada; Chuva; } \\
\text { gota grande. }\end{array}$ & $\begin{array}{l}\text { Chuva; } \\
\text { quantidade alta } \\
\text { de gota grande; } \\
\text { quantidade } \\
\text { baixa de graupel } \\
\text { BD. }\end{array}$ \\
\hline 2035 & $\begin{array}{l}\text { Quantidade alta de } \\
\text { granizo, graupel AD e } \\
\text { graupel BD, agregados, } \\
\text { gelo vertical, cristais de } \\
\text { gelo, graupel BD. }\end{array}$ & $\begin{array}{l}\text { Quantidade alta de } \\
\text { graupel AD e } \\
\text { quantidade baixa de } \\
\text { gota grande; chuva }\end{array}$ & $\begin{array}{l}\text { Quantidade alta de } \\
\text { graupel AD, gota } \\
\text { grande, granizo, e } \\
\text { neve molhada; } \\
\text { chuva. }\end{array}$ & $\begin{array}{l}\text { Quantidade alta } \\
\text { de gota grande, } \\
\text { graupel AD, } \\
\text { granizo; chuva }\end{array}$ \\
\hline 2100 & $\begin{array}{l}\text { Quantidade alta de } \\
\text { granizo, graupel AD, } \\
\text { agregados, gelo vertical, } \\
\text { cristais de gelo, graupel } \\
\text { BD. }\end{array}$ & $\begin{array}{l}\text { Quantidade alta de } \\
\text { gota grande, graupel } \\
\text { AD, granizo; chuva. }\end{array}$ & $\begin{array}{l}\text { Quantidade alta de } \\
\text { gota grande, } \\
\text { granizo, graupel AD; } \\
\text { quantidade baixa } \\
\text { de neve molhada; } \\
\text { chuva. }\end{array}$ & $\begin{array}{l}\text { Quantidade alta } \\
\text { de gota grande, } \\
\text { granizo e } \\
\text { graupel AD; } \\
\text { chuva. }\end{array}$ \\
\hline 2135 & $\begin{array}{l}\text { Agregados, gelo vertical } \\
\text { e cristais de gelo. }\end{array}$ & Chuva. & $\begin{array}{l}\text { Quantidade alta de } \\
\text { neve molhada; } \\
\text { chuva. }\end{array}$ & Chuva. \\
\hline
\end{tabular}

A Tab. 3.1 mostra a variação microfísica acima, dentro e abaixo da isoterma $0^{\circ} \mathrm{C}$, às 2010 UTC sobre o centro geométricos da RMSP. Nota-se uma a diminuição da quantidade de graupel de baixa densidade acima da isoterma $0^{\circ} \mathrm{C}$. Observa-se chuva misturada a graupel de alta densidade e gotas grandes abaixo da isoterma $0^{\circ} \mathrm{C}$. Percebe-se o aumento da quantidade de graupel de alta densidade e o surgimento das gostas grandes dentro 
na isoterma $0^{\circ} \mathrm{C}$. Na parte inferior da nuvem, observa-se o surgimento de concentração alta das gotas grandes, provavelmente, resultante do derretimento das pedras de granizo devido as temperaturas positivas. A tempestade ainda estava, provavelmente, sob correntes ascendentes intensas para sustentar concentração alta de gelo acima da isoterma $0^{\circ} \mathrm{C}$, às 2010 UTC.

Observa-se a variação microfísica acima, dentro e abaixo da isoterma $0^{\circ} \mathrm{C}$ após o disparo da célula convectiva secundária mais intensa sobre o centro geométrico da RMSP, às 2035 UTC, e em seguida, quando integraram-se as células primárias e a célula e secundária. A tempestade integrada sob forte correntes ascendentes, ejetou quantidade alta de conteúdo de água líquida acima da isoterma $0^{\circ} \mathrm{C}$, que favoreceu a produção da quantidade alta de granizo, graupel de alta densidade e a sustentação por muito tempo desses hidrometeoros acima da isoterma $0^{\circ} \mathrm{C}$. Observou-se chuva misturada a graupel de alta densidade em alta quantidade, gotas grandes e granizo dentro e abaixo da isoterma $0^{\circ} \mathrm{C}$. E, chuva misturada a gotas grandes, graupel de alta densidade e granizo, que provavelmente, atingiram a superfície. A tempestade entrou em estágio de dissipação a partir das 2135 UTC.

\subsubsection{Distribuição de tamanho de gota (DTCs)}

A Fig. 3.11 mostra espectros de gotas e distribuição de tamanho de gotas integrados a cada 5 minutos do disdrômetro de impacto Joss-Waldvogel (JWD) durante a passagem da tempestade entre 1830-2045 horário local, no dia 11 de janeiro de 2010. Este evento causou inundação relacionado com a brisa do mar e os efeitos da ilha de calor (Pereira Filho et al., 2013).

A frente de brisa marítima alcança o JWD às 1757 UTC (Fig. 3.4a). Uma das células convectiva secundárias desloca-se em direção a localização do JWD às 2025 UTC (Fig. 3.4d). As medições de JWD da célula convectiva principal começaram às 2050 UTC (Fig. 3.5b). Às 2135 UTC, a pluviosidade dominante era do tipo estratiforme (Fig. 3.5d).

A evolução temporal dos espectros de gota indica claramente as fases convectivas, de transição e estratiformes deste sistema convectivo profundo (Fig. 3.11a) que corrobora com as medições do MXPOL. Nota-se 1000 gotas entre 1.8 e 2.6 mm de diâmetro e 1000 gotas entre 1.0 e $1.5 \mathrm{~mm}$ de diâmetro na fase convectiva (Fig. 3.11a). Isso sugeriu que a tempestade resultante da integração de várias células convectivas intensa, produziu quan- 
tidade alta de granizo acima da isoterma $0^{\circ} \mathrm{C}$ que precipitou na forma de gotas grandes. A poluição urbana e ilha de calor urbano aumentaram a concentração de gotas (Pereira Filho et al., 2013) na tempestade do dia 11 de janeiro de 2010.

A Fig. 3.11b sugere que os efeitos combinados dos mecanismos de coalescência-quebra na distribuição de tamanho de gotas (DTGs) e força de arrasto aerodinâmico, ocorreram à medida que as gotas grandes precipitavam da base da isoterma $0^{\circ} \mathrm{C}$ até à superfície e, modificaram as características microfísicas dos espectros de gotas à medida que esses hidrometeoros precipitavam até à superfície (Tab. 3.1), resultando no aumento da população de gotas de 1.116 e $2 \mathrm{~mm}$ de diâmetro e diminuição gradual das gotas acima de $2 \mathrm{~mm}$ de diâmetro (Fig. 3.11b). Tal como observado por Rosenfeld e Ulbrich (2003) que o mecanismo de quebra é mais importante para gotas grandes e o mecanismo de coalescência para gotículas de nuvem.
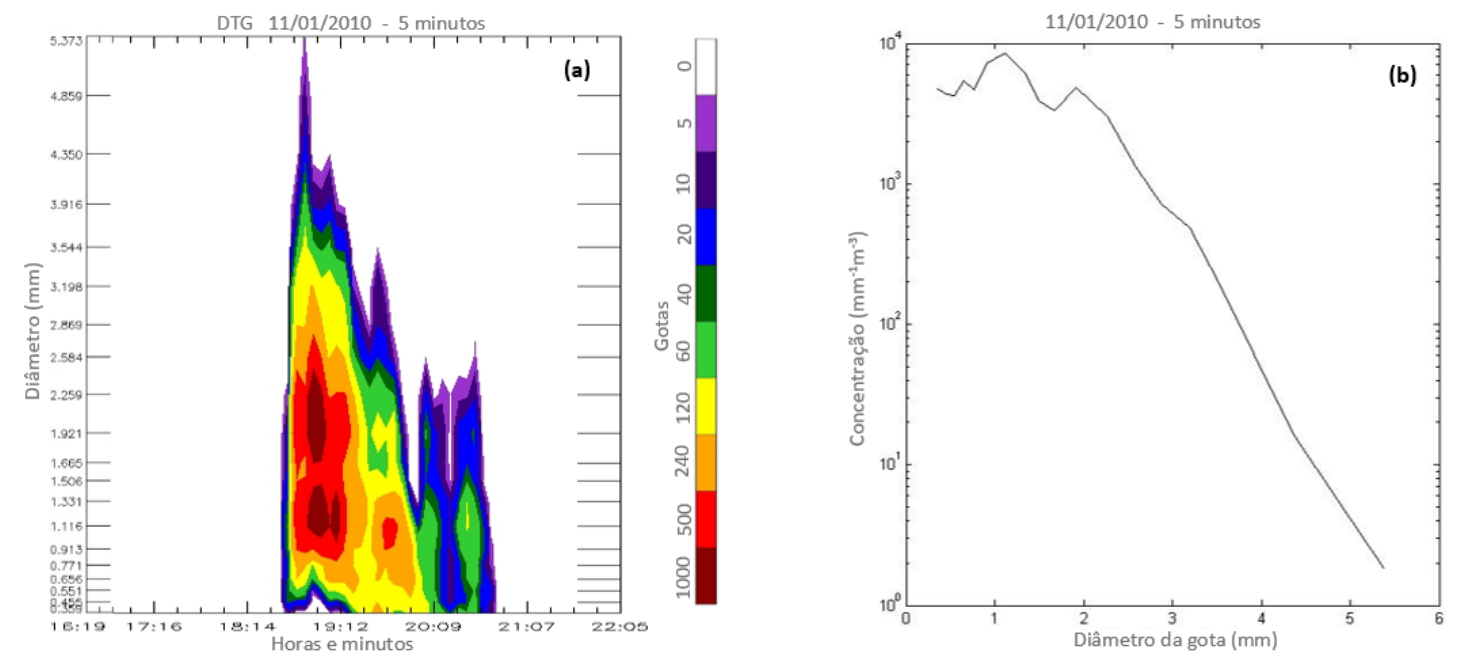

Figura 3.11: (a) Evolução temporal do número total de tamanhos de gotas com diâmetros entre 0,359 e 5,373 mm e, (b) medição da distribuição de tamanho de gotas feitas por um disdrômetro de impacto Joss-Waldvogel no dia 11 Janeiro de 2010 no PEFI da cidade de São Paulo (Fig. 2.2). Números de gotas integrados a cada 5 minutos indicados na escala de cores. Fonte: Pereira Filho et al. (2013).

\subsubsection{Perfis verticais}

Os perfis verticais foram extraídos no núcleo da célula secundária (às 2025 UTC), no núcleo das células primárias e célula secundária integradas (às 2030 UTC) e no núcleo da extremidade sul da tempestade, onde, provavelmente, ocorreu o downburst (às 2055 UTC). 

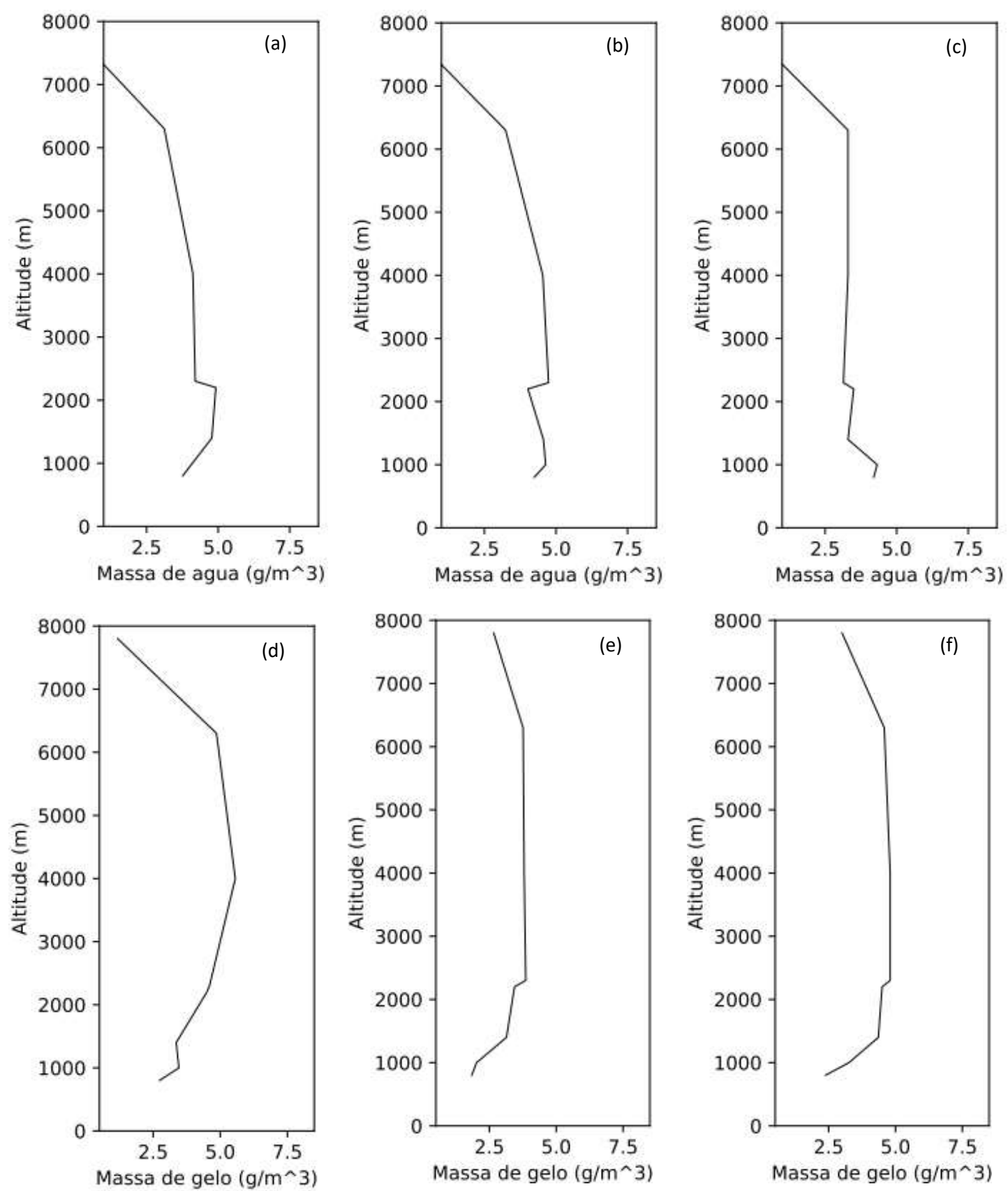

Figura 3.12: Perfis verticais da massa de água (a, b, c, d) e massa de água sólida gelo (e, $\mathrm{f}, \mathrm{g}, \mathrm{h}$ ) nos núcleos das células secundária e célula integradas, no núcleo da extremidade sul da tempestade às 2025 UTC, às 2030 UTC e às 2055 UTC, respectivamente, do dia 11 de Janeiro de 2010.

A Fig. 3.12 mostra os perfis verticais da massa de água líquida e massa de água sólida. Nota-se maior concentração de massa de água sólida no núcleo da célula secundária (Fig 3.12d) do que nos núcleos das células integradas e da extremidade sul da tempestade (Fig. 3.12e, f). A causa microfísica dessa maior concentração de gelo, está na corrente 
ascendente. A célula secundária estava sob corrente ascendente intensa do que as células primárias. De acordo com Korolev et al. (2003), quando há velocidades verticais próximas de zero, o ar em nuvens de fase mista é subsaturada em relação à água. Assim, a mistura isobárica de duas parcelas subsaturadas possuem diferentes temperaturas que resulta em elevada umidade relativa. Sob certas condições, a umidade relativa resultante pode exceder a saturação sobre a água líquida, proporcionando um crescimento simultâneo de gotículas e partículas de gelo (Korolev et al., 2003).

O perfil vertical da massa de água líquida dentro do núcleo da extremidade sul da tempestade, apresenta duas variações bruscas a partir dos $2000 \mathrm{~m}$ de altitude, e observa-se massa de água constante até os $6300 \mathrm{~m}$ de altitude (Fig. 3.12c) diferente de outros perfis (Fig. 3.12a, b). A causa está, provavelmente, no colapso da massa de água das altitudes altas para altitudes baixas, e provável ocorrência de downburst nessa região da tempestade.

Observa-se pico de refletividade alta em 6300 m de altitude, às 2035 UTC (Fig. 3.13b), correspondente ao perfil vertical no núcleo das células secundaria e primárias integradas, tornando a tempestade mais intensa, que favoreceu a produção alta de granizo. Os valores da refletividade diferencial tendem a $0 \mathrm{~dB}$ (Fig. 3.13e), correspondentes a concentração alta de granizo, que corrobora com os valores da refletividade.

Enquanto que no núcleo da célula secundária, observa-se refletividades maiores em altitudes baixas (entre 9900 e $2300 \mathrm{~m}$ de altitude, aproximadamente), e valores constantes de 45 dBZ entre 2300 e $2300 \mathrm{~m}$ de altitude (Fig. 3.13a). Sendo uma célula recém formada de origem da interação da frente de rajadas das células primárias com a frente de brisa marítima estagnada sobre o centro geométrico da RMSP. Provavelmente, há concentração alta de gotas de chuva do que gelo. A Fig. 3.13f mostra valores altos de dB em altitudes elevados, correspondentes as gotas de chuva.

A Fig. 3.13c apresenta um perfil vertical de refletividade com ligeira variação e com aumento significativo nos valores da refletividade em altitudes baixas no núcleo da extremidade sul da tempestade. Enquanto que observa-se aumento brusco nos valores da refletividade diferencial em altitudes baixas, devido o colapso da massa de água e gelo e ocorrência provável de um downburst (Fig. 3.13f).

Em geral, observa-se que quando maior é a concentração de massa de água sólida, menor é a concentração de massa de água líquida nos perfis verticais correspondentes (Fig.3.12). Que está relacionado aos processos de acreção e deposição do vapor de água que convertem 
a massa de água líquida em massa de água sólida a temperaturas $<0^{\circ} \mathrm{C}$.
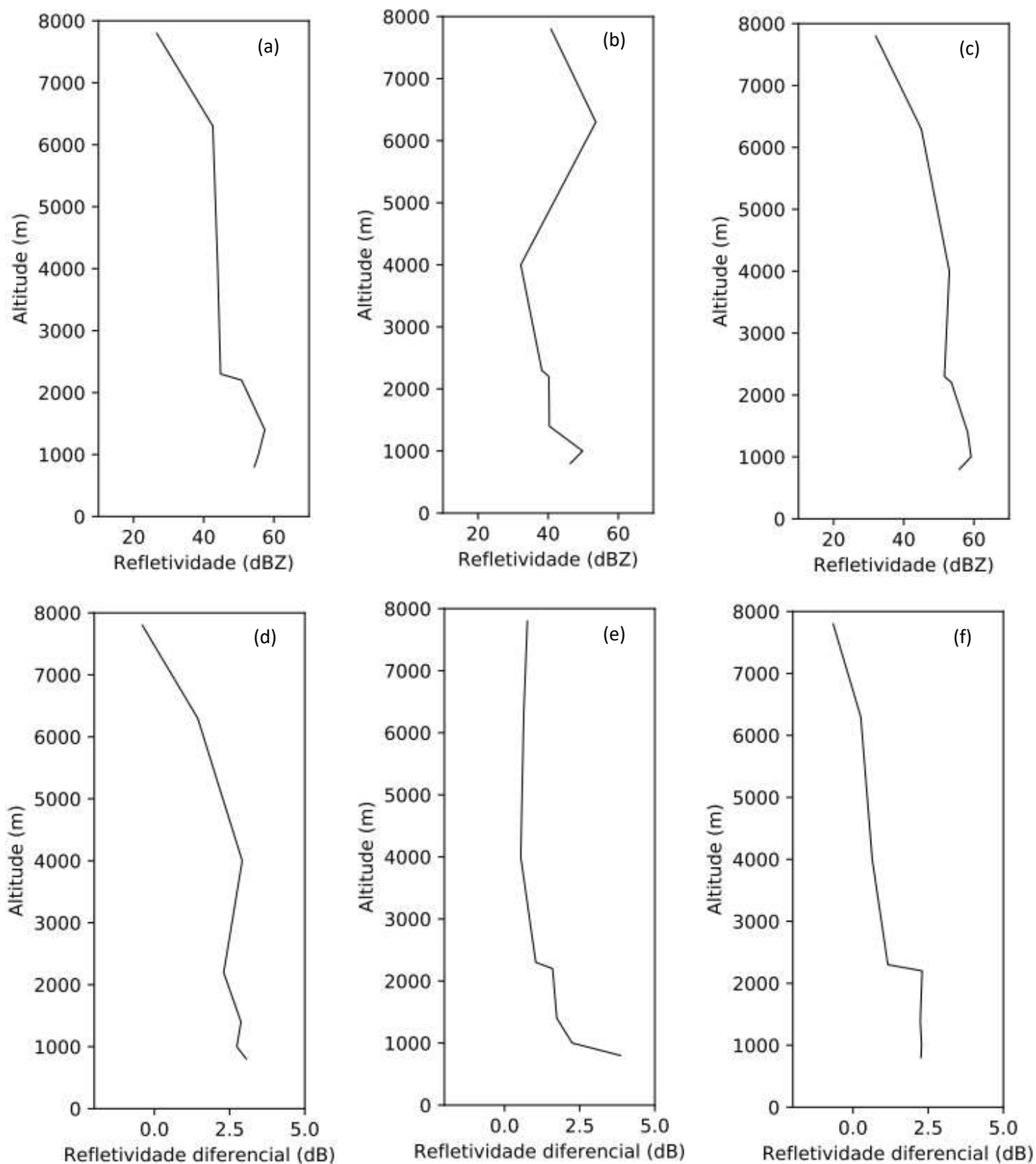

Figura 3.13: Perfis verticais da refletividade horizontal (a, b, c) e refletividade diferencial(e, f, g) nos núcleos das células secundária e integradas, no núcleo da extremidade sul da tempestade às 2025 UTC, às 2030 UTC e às 2055 UTC, respectivamente, no dia 11 de Janeiro de 2010 .

A Fig. 3.14 mostra o perfil vertical do diâmetro da gota de chuva. Nota-se que a gota de chuva aumenta de tamanho à medida que precipita das altitudes altas para altitudes baixas. Em geral, percebe-se o aumento do tamanho da gota de chuva entre 1.8 a $2.2 \mathrm{~mm}$ de diâmetro entre $6300 \mathrm{~m}$ e $4000 \mathrm{~m}$ de altitude, às 2025 UTC (Fig. 3.14a). O tamanho da 
gota de chuva diminui, significativamente, 5 minutos depois, onde no mesmo nível verificase gota de chuva com tamanho $<1,8 \mathrm{~mm}$ de diâmetro, às 2030 UTC (Fig. 3.14b). Mas, nota-se o aumento da gota de chuva $>2 \mathrm{~mm}$ de diâmetro (Fig. 3.14b) abaixo de $1000 \mathrm{~m}$ de altitude quando comparada ao perfil vertical anterior na Fig. 3.14a.
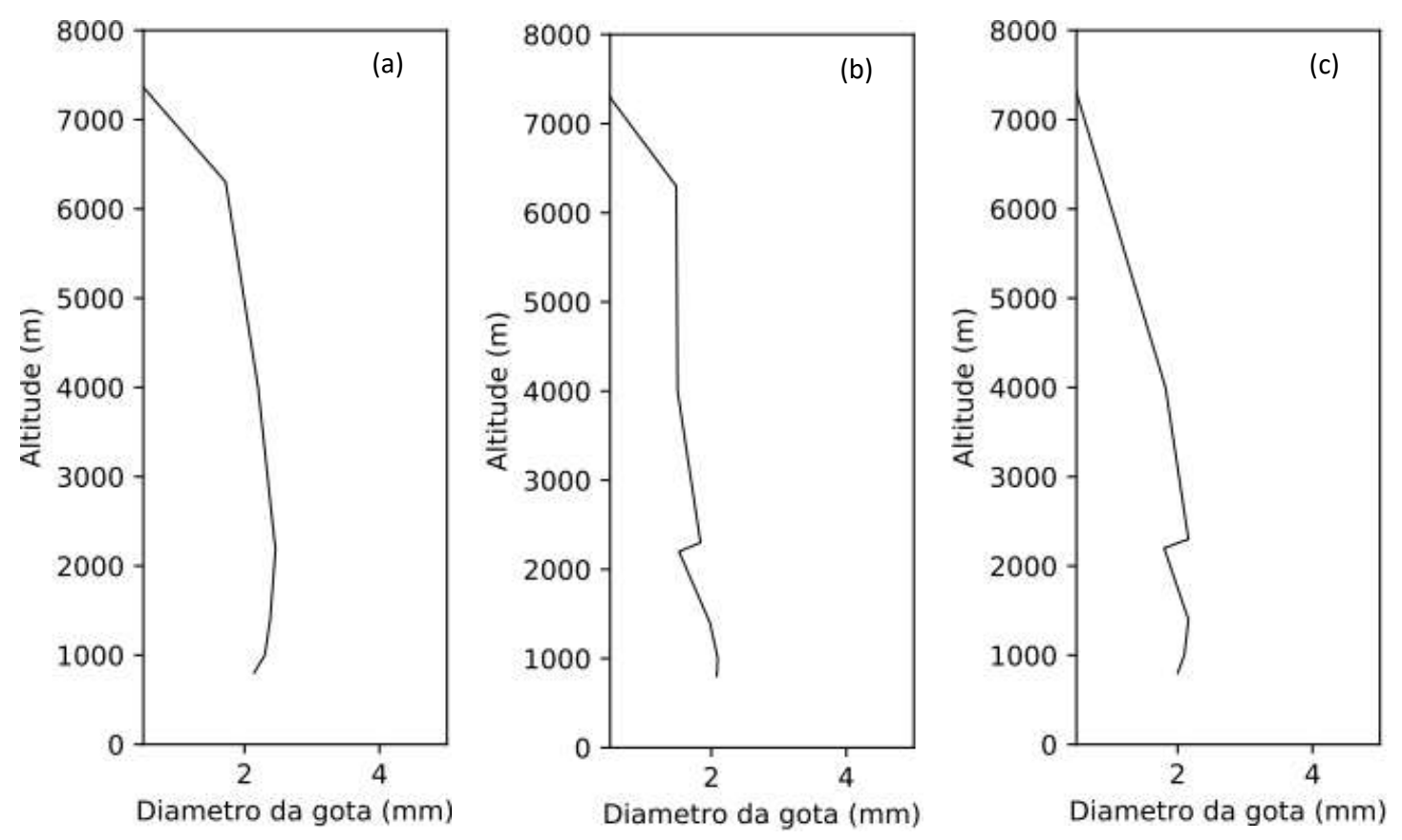

Figura 3.14: Perfis do diâmetro da gota de chuva no núcleo da célula secundária (a), no núcleo das células integradas (b) e no núcleo da extremidade sul da tempestade (c) às 2025 UTC, às 2030 UTC e às 2055 UTC, respectivamente, do dia 11 de Janeiro de 2010.

Nota-se gota grande de chuva ( $\sim 2 \mathrm{~mm}$ de diâmetro) em altitudes altas (Fig. 3.14a) durante o disparo da célula secundária, sob influência da corrente ascendente intensa, transportou as gotas de chuva naquele nível. Enquanto que outros perfis mostram gota grande $\sim 2 \mathrm{~mm}$ de diâmetro em altitude baixas (Fig. 3.14b, c), quando ocorria precipitação de gotas grandes resultante do derretimento de granizo.

As Fig. 3.14b, c mostra diminuição brusca do diâmetro da gota de chuva, não só devido a quebra da gota de chuva causada por força de arrasto aerodinâmica e processo de colisãoquebra. Abaixo da diminuição brusca do diâmetro da gota de chuva, nota-se o aumento do diâmetro da gota de chuva em ambos os perfis, causado por processo de coalescência (Fig. 3.14b, c).

Mas também a variação da diminuição do tamanho da gota está relacionada ao ângulo de visão do radar em relação a variação das altitudes altas para altitude baixas. A gota 
grande na base da isoterma $0^{\circ} \mathrm{C}$ são observadas pela sua base achatada e quase esférica, e à medida que que a gota precipita para altitudes baixas, apresenta orientação horizontal (maior distribuição de massa na horizontal do que na vertical) por ser oblata, dando a impressão que aumentou de tamanho. Essas variações são observadas em perfis verticais de outros eventos analisados a posterior. De acordo com Sauvageot (1992) à medida que gota de chuva cai, aumenta de tamanho com maior eixo orientado na horizontal para ângulos de elevação mais baixos devido o efeito do ângulo de visão do radar em relação a altitude em que se encontra a gota de chuva.

\subsection{Convecção Isolada (CI) associada a um Ciclone Extratropical e}

\section{Sistema de Alta Pressão no dia 18 de maio de 2014}

\subsubsection{Análise Sinótica}

As imagens de satélite na Fig. 3.15 mostram a densa banda de nebulosidade de retocação horária induzida pelo ciclone extra-tropica e outra banda de nebulosidade menos densa associada a um sistema de alta pressão no 18 de maio de 2014. Observa-se uma pequena banda de nebulosidade no leste do estado de São Paulo com ênfase na RMSP (Ficg. 3.15a), mais densa que a nebulosidade associada ao sistema de alta pressão.
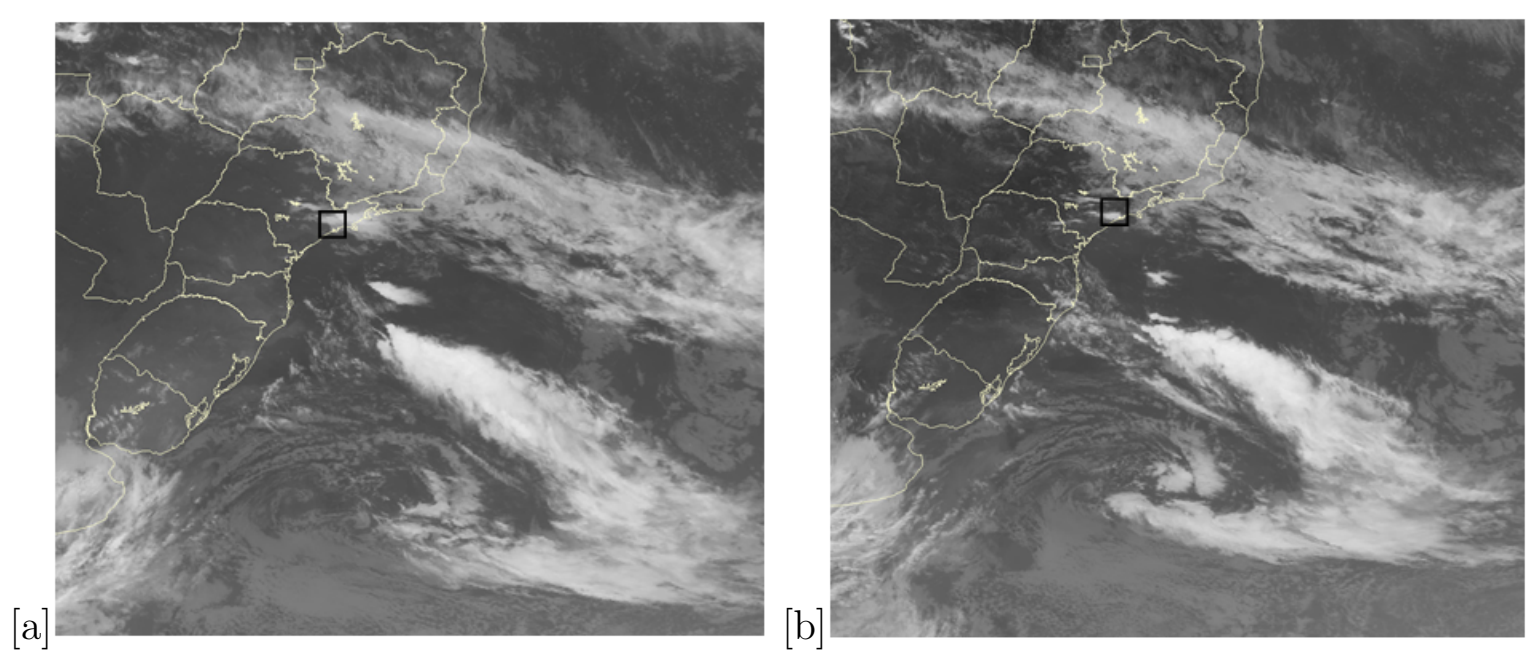

Figura 3.15: Imagens do satélite GOES 10 no canal infravermelho da Amárica do Sul entr $-20^{\circ}$ e $-35^{\circ}$ de latitude e entre $-60^{\circ} \mathrm{S}$ e $-30^{\circ}$ de longitude (a) às 1800 UTC e (b) às 2100 UTC de 18 de maio de 2014. Contornos geográficos dos estados do Brasil e dos países da Argentina, Uruguai e Paraguai são indicados nas imagens. Fonte: DSA-CPTEC.INPE, 2020. 
O relevo, provavelmente, influenciou na intensificação da nebulosidade que se formou a leste de São Paulo, menos densa às 1800 UTC (Fig. 3.15a), e mais densa às 2100 UTC sobre a RMSP (Fig. 3.15b), área destacada. Possivelmente, o aquecimento superficial durante o dia e a ejeção de umidade durante o período da tarde, aumentaram os índices de instabilidade sobre a RMSP, área destacada.
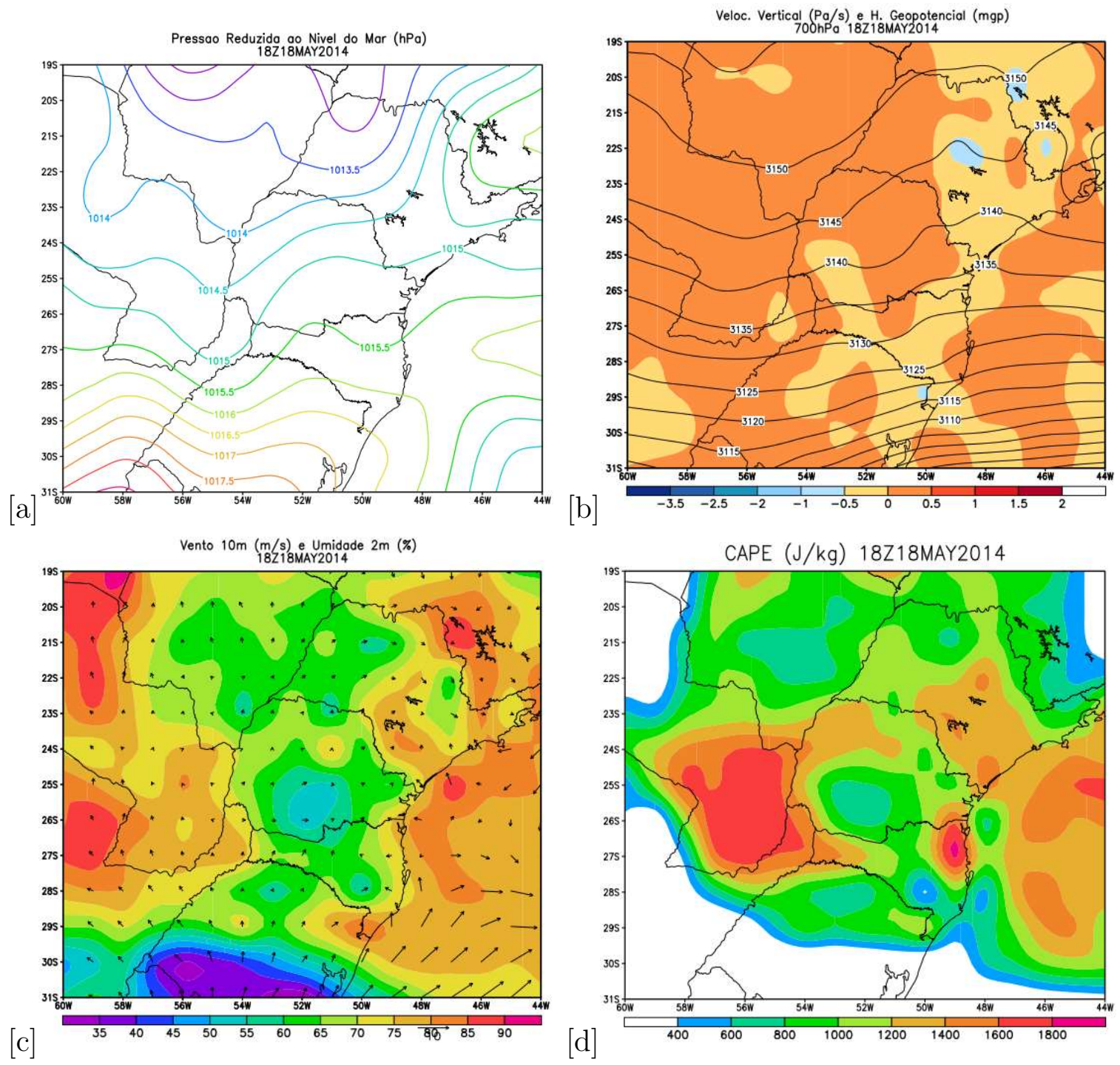

Figura 3.16: (a) Campo de pressão reduzido ao nível do mar (hPa); (b) campo de movimento vertical e altura geopotencial (gpm); (c) Campo de vento $\left(\mathrm{m} . \mathrm{s}^{-1}\right)$ a $10 \mathrm{~m}$ e umidade (\%) a $2 \mathrm{~m}$ acima da superfície e (d) CAPE $\left(\mathrm{J} \mathrm{kg}^{-1}\right)$ do GFS às 1800 UTC do dia dia 18 de Maio de 2014. A faixa de isóbaras é de 1 $\mathrm{hPa}$. Cores frias/quentes indicam valores mais baixos/mais altos. A faixa de isolinhas geopotenciais é de $20 \mathrm{gpm}$ e a barra de cores indica a velocidade vertical em $\mathrm{Pa} \mathrm{s}^{-1}$. As setas indicam a magnitude do vento e a barra de cores indica a umidade. A escala de cores indica os valores do CAPE. Contornos geopolíticos dos estados do Brasil e dos países da Argentina e Paraguai, latitudes, longitudes e horários e datas são indicados nos campos. 
Os dados do GFS foram utilizados para caracterizar a situação sinóptica do ambiente em que a CI se desenvolveu no dia 18 de maio de 2014. A Fig. 3.16)a mostra o campo de pressão ao nível médio do mar, às 1800 UTC. Observa-se um cavado a norte e uma crista a leste do estado de São Paulo.

O campo de geopotencial na Fig. 3.16b, mostra um cavado em 700 mb com inclinação positiva do eixo e observa-se geopotencial intenso no sul e na costa sul do Brasil. No campo de vento a $10 \mathrm{~m}$ de altitude e umidade a $2 \mathrm{~m}$ de altitude, nota-se vento intenso de sudoeste na costa sul do Brasil associado ao ciclone extra-tropical e vento de nordeste na costa estado de São Paulo associado ao sistema de alta pressão (Fig. 3.16)c.

Observa-se a esteira de umidade ejetada pelo sistema de alta pressão, que se estende desde o estado de Minas Gerais até a Bacia do Alto Tietê, no estado de São Paulo, com seu núcleo mais intenso na divisa entre os estados de São Paulo e Minas Gerais (Fig. 3.16)c. A CAPE apresenta valores relativamente altos da costa ao centro do estado de São Paulo (Fig. 3.16d), com valores máximos entre 1400 a $1600 \mathrm{~J} \mathrm{~kg}^{-1}$ às 1800 UTC.

A área ciclogenética da América do Sul ocorrem entre $-45^{\circ}$ e $-15^{\circ}$ de latitude e entre $-60^{\circ}$ e $-20^{\circ}$ de longitude. Os ciclones extratropicais atuam em todas as épocas do ano, com maior frequência no inverno nessa área (Gan e Rao, 1991; Sinclair, 1994; Simmonds e Keay, 2000; Mendes et al., 2010).

\subsubsection{Análises termodinâmica e dinâmica}

Observa-se nos dois perfis das 1200 UTC do dia 18 e 0000 UTC do dia 19 de maio de 2014, que houve diminuição significativa da razão de mistura entre 500-300 mb causado pelo sistema de alta pressão e ligeiro aumento da razão de mistura entre 700-100 mb, que indicou a passagem da CI sobre aeroporto Campo do Marte, Fig. 3.17. 

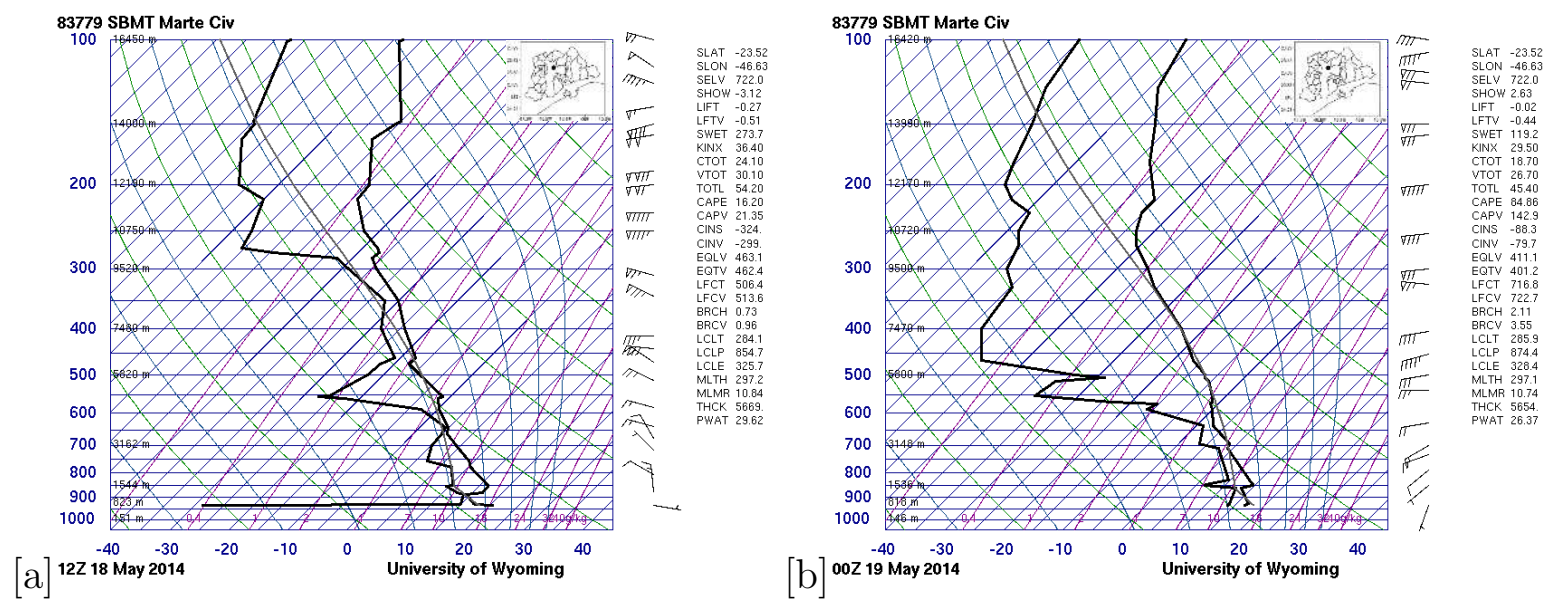

Figura 3.17: Perfis verticais da temperatura do ar $\left({ }^{\circ} \mathrm{C}\right)$, temperatura do ponto do orvalho $\left({ }^{\circ} \mathrm{C}\right)$, velocidade

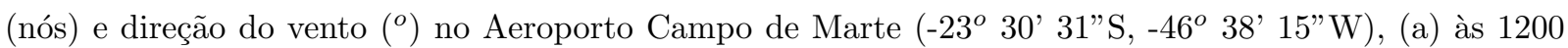
UTC do 18 UTC e (b) à 0000 UTC do dia 19 de maio de 2014. A RMSP, as latitude e longitudes são indicados nos mapas, indicados nos cantos superiores direito dos perfis, e o ponto preto indica a localização de lançamento das sondagens. Fonte: weather.uwyo.edu. Acessada em 14 de julho de 2019.

A Fig. 3.18 mostra duas assinaturas de meso-escala no campo da velocidade radial. No azimute $270^{\circ}$, a oeste do radar SPOL, observa-se uma região de rotação ciclônica da CI (representada pela seta curva vermelha que se afasta do radar e pela seta azul que aproxima em relação ao radar) nos quatro PPIs, Fig. 3.18, indicativo de uma persistente corrente ascendente com forte rotação ciclônica, provavelmente da base até quase ao topo da CI. No azimute $360^{\circ}$, a norte do radar SPOL, observa-se uma região meso-anticiclônica da célula quase-linha de instabilidade (representada pelas setas curvas vermelha e azul) nos quatro PPIs. Nota-se que a tonalidade azul intensifica-se (torna-se mais escuro) com aumento de elevações. 

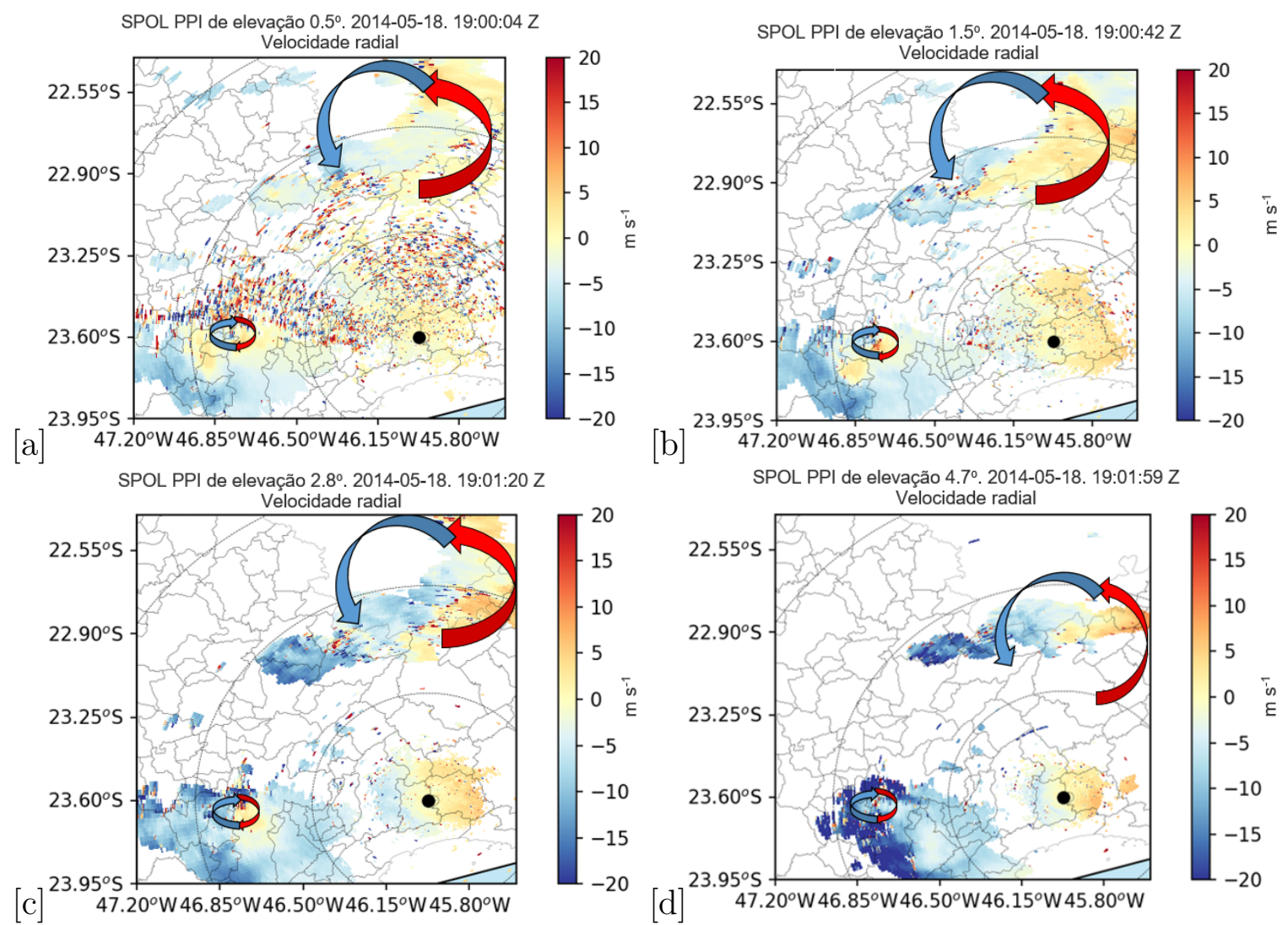

Figura 3.18: Campos da velocidade radial do radar SPOL, (a) PPI de elevação $0.5^{\circ}$, (b) PPI de elevação $1.5^{\circ}$, (c) PPI de elevação $2.8^{\circ}$ e (d) PPI de elevação $4.7^{\circ}$ entre às 1900 e 1901 UTC de 18 de Maio de 2014. A escala de core indica a velocidade $\left(\mathrm{m} \mathrm{s}^{-1}\right)$ de alvos que se aproxima (azul) e se afasta (vermelho) do SPOL. O ponto preto no centro indica posição do radar meteorológico SPOL na cabeceira da Bacia do Alto Tietê. Circunferências concêntricas estão espaçadas a cada $50 \mathrm{~km}$. Longitudes, latitudes, contornos dos municípios são indicados.

De acordo com Johnson et al. (1994), a rotação ciclônica facilita a separação da corrente ascendente da corrente descendente, permitindo que a tempestade persista. A tempestade exibe características dinâmicas e termodinâmicas, incluindo uma intensa e persistente corrente ascendente com forte rotação ciclônica nos inferiores e médio da super-célula (Johnson et al., 1994).

Do ponto de vista Característico, a formação e sobrevivência de tempestades depende de onde cresce, e principalmente estabilidade termodinâmica e perfil vertical do vento. As propriedades de CIs envolvem mecanismos de disparo disponível para a convecção, ou seja, aquecimento diurno, levantamento frontal, ou limite de mesoescala. Tempestade convectiva é uma região de forte corrente ascendente, com extensão horizontal 10-100 km², 
estendo-se na vertical em níveis superiores da troposfera (Houze Jr, 2014). Tempestade de célula única ou isolada consiste em uma única corretante ascendente, que aumenta rapidamente através do troposfera e produz grandes quantidades de água e gelo (Houze Jr, 2014). Quando as gotas de chuva e partículas de gelo tornam-se pesadas para a corrente ascendente suportar, começam a precipitar, criando uma corrente descendente que rapidamente substitui a corrente ascendente (Houze Jr, 2014). A corrente descendente é inicialmente saturada, mas a medida que cai nos níveis baixo da troposfera mistura-se com ar seco ocorrendo forte resfriamento evaporacional (Houze Jr, 2014).
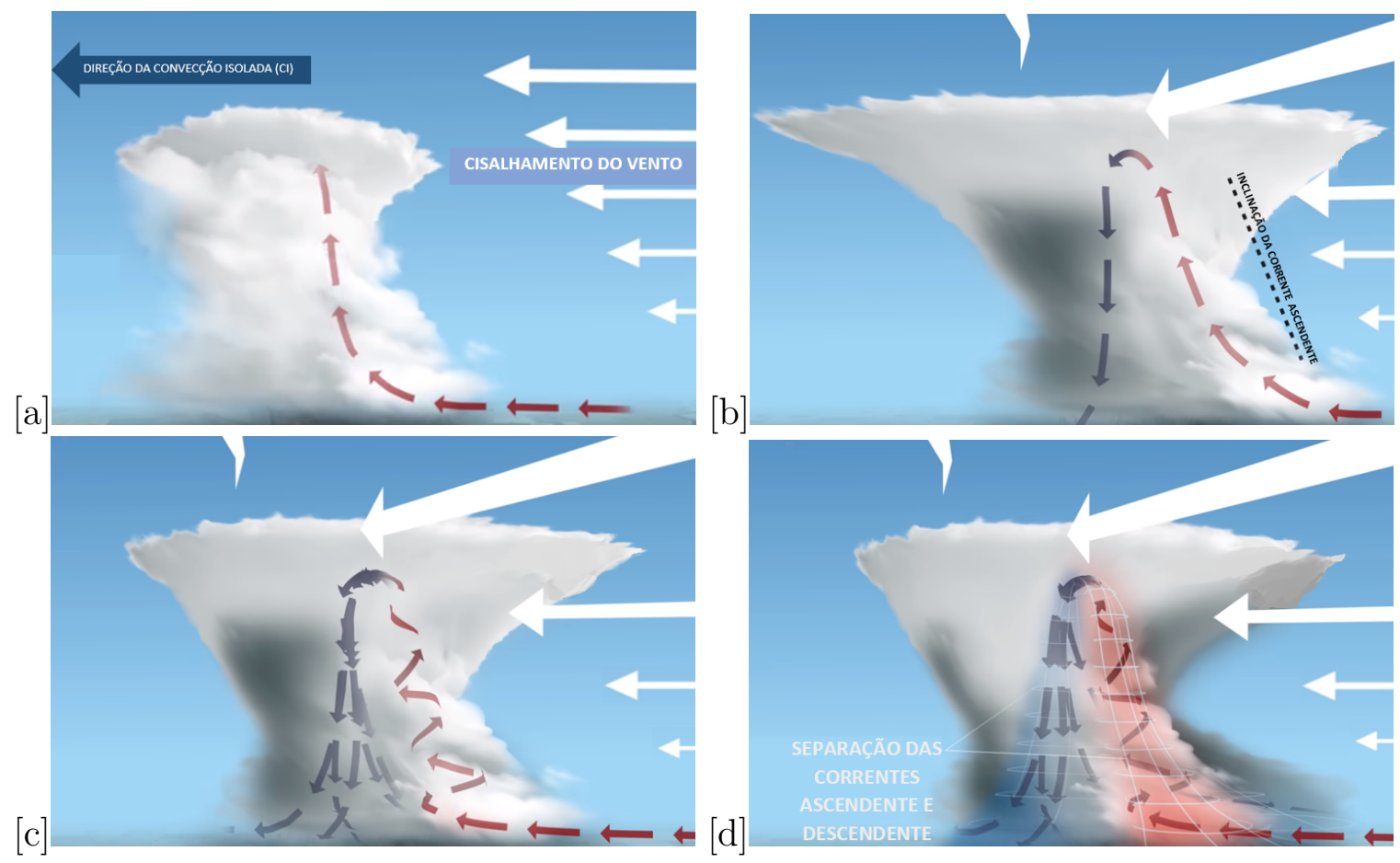

Figura 3.19: Esquema ilustrativo de tempestade severa (convecção isolada-CI) em diferentes estágios de desenvolvimento. (a) estágio sob influência de corrente ascendente. (b) estágio sob influência de correntes ascendente e descendente. (c) estágio inicial sob influência de rotação ciclônica. (d) tempestade severa sob influência de rotação ciclônica. A seta azul-escuro indica a direção de propagação da CI. As setas brancas indicam o gradiente de vento (cisalhamento). As setas vermelhas dentro da nuvem indicam a corrente ascendente. As setas azul-escuro dentro da nuvem indicam a corrente descendente. Fonte: www.bom.gov.au. Acessada em 23 de Outubro de 2020.

Esse resfriamento acelera a corrente descendente por causa da flutuabilidade negativa que se espalha horizontalmente (frente de rajada) como piscina de ar fria sobre a superfície (Ray, 2015). Geralmente esse evento leva geralmente 30-50 minutos para completar. Du- 
rante esse período, o sistema provoca tempe severo como vento forte ou granizo que pode ocorrer em curta duração. E raramente verifica-se ocorrência de tornado (Houze Jr, 2014).

Entretanto, as CIs que se forma na RMSP, geralmente duram mais de 2 horas e podem ocasionaram precipitação de granizo por longo tempo. A título de exemplo, a Fig. 3.19 ilustra características dinâmicas e termodinâmicas de uma convecção isolada (CI) sob influência de cisalhamento de vento (Fig. 3.19a, b) que induziu a inclinação do eixo e rotação ciclônica da corrente ascendente (Fig. 3.19c, d). Sob influência da rotação ciclônica (Fig. 3.19d), a corrente ascendente separa-se da corrente descendente, possibilitando que a tempestade severa dure várias horas percorrendo longas distâncias com a mesma intensidade.

Aproximadamente, 45 minutos depois, as duas células convectivas apresentam as mesmas configurações, à medida que se aproximam ao radar SPOL, às 1945 UTC (Fig. 3.3).
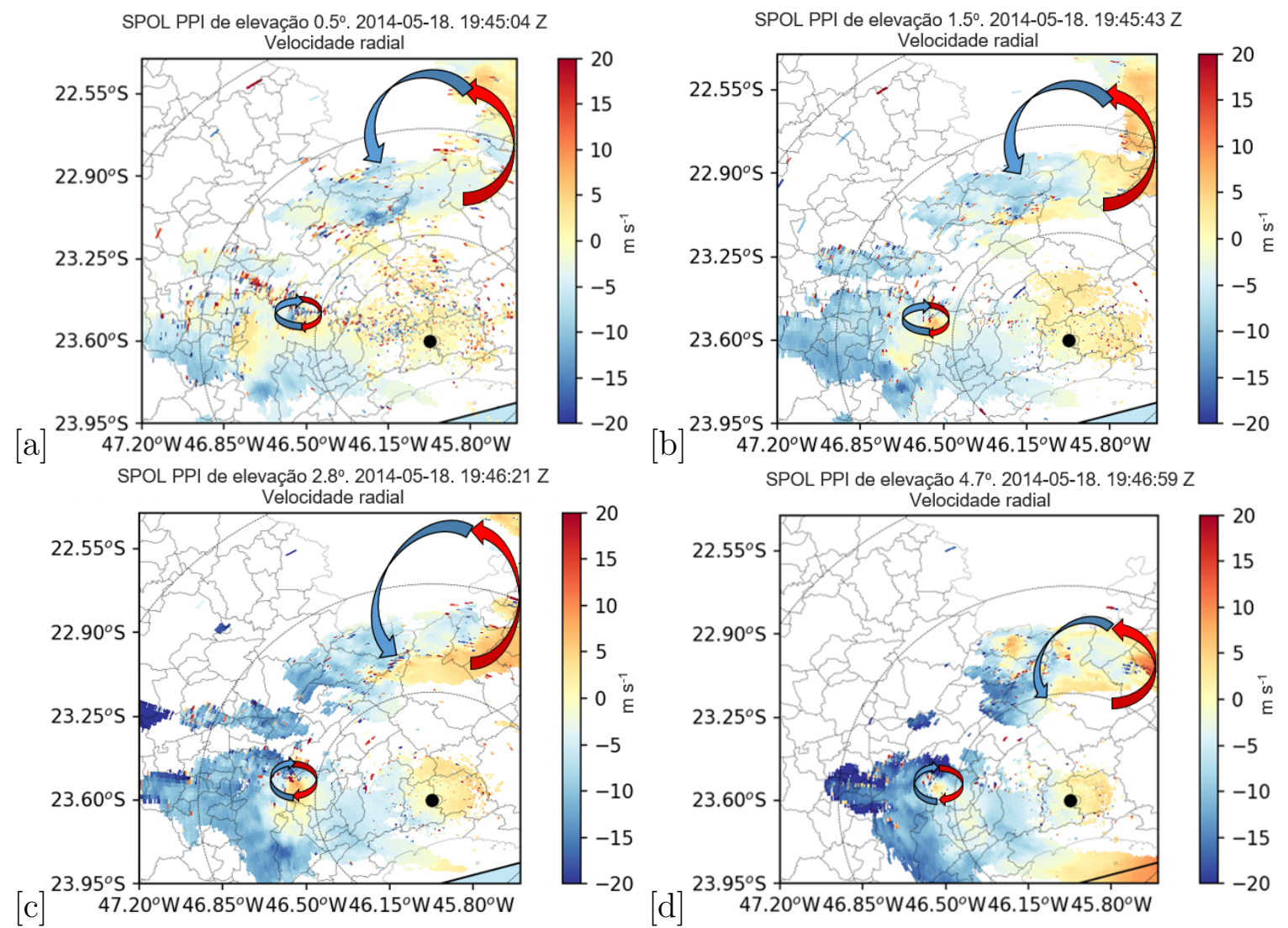

Figura 3.20: Idem Fig. 3.18, mas às 1945 UTC. 


\subsubsection{Evolução Espaço-Temporal da CI e da quase-linha de instabilidade}

Os dados do radar SPOL indicam a formação da célula convectiva nos azimutes $270^{\circ}$ a $100 \mathrm{~km}$ distância a partir das 1755 UTC, área destacada (Fig. 3.21a) e essa foi monitorada até às 2145 UTC (Fig. 3.25h), quando essa integrou-se com a célula quase linha de instabilidade na fase de dissipação.

A célula convectiva de origem urbana (convecção isolada-CI), destacada no retângulo redondo, deslocou-se de oeste à leste-nordeste (azimute $270^{\circ}$ ao azimute $67.5^{\circ}$ ) a uma velocidade média de $5 \mathrm{~m} \mathrm{~s}^{-1}$ (Fig. 3.18). Enquanto que a célula de origem rural(Fig. 3.21f) deslocou-se de norte à sul em diração ao radar SPOL a uma velocidade média de 8 $\mathrm{m} \mathrm{s}^{-1}$. Ambas as células convectivas integraram-se no azimute $337.5^{\circ}$, próximo do radar SPOL, às 2055 UTC (Fig. 3.25c). Posteriormente, essa célula convectiva integrada entra na fase de dissipação.

Durante a propagação CI (área destacada) adentrando no município de São Paulo, às 1845 UTC, ganhou intensidade (> $60 \mathrm{dBZ})$, Fig. 3.21d). A CI propagou-se ao lestenordeste com quase a mesma intensidade (Fig. 3.25d).

A CI mostra uma bigorna saliente para a frente nos campos das variáveis polarimétricas, uma distinta região de fraca densidade, que é característico da presença atuante de cisalhamento do vento na atmosfera, área destacada (Fig. 3.21a, b, c, d; Fig. 3.22a, b, c, d; Fig. 3.23a, b, c, d).

A fig. 3.22 mostra os campos de refletividade diferencial, que são coerentes com os resultados apresentados nos campos de refletividade, onde se observa maiores valores entre 0.5 e 3 dBs nos núcleos das células convectivas, correspondentes a granizo, gota grande e chuva, e valores menores entre 0 e -1 dB correspondentes a cristal de gelo, agregado e gelo vertical nas regiões estratiformes, circunvizinhanças dos núcleos das células, área destacada (fig. 3.22).

Observa-se a mesma coerência nos campos da fase diferencial específica (fig. 3.23), onde a densidade azul correspondente a valores positivos é verificada nos núcleos das células convectivas, e densidade vermelha correspondentes a valores $\sim 0{ }^{\circ} \mathrm{km}^{-1}$ e valores negativos são observados nas circunvizinhanças dos núcleos, área destacada. Os valores acima de $2^{\circ} \mathrm{km}^{-1}$ indicam uma quantidade significativa de água líquida (chuva e gota grande) como descrito por Ruzanski e Chandrasekar (2012). 
SPOL PPI de elevação 0.5․ 2014-05-18. 17:55:05 Z Refletividade
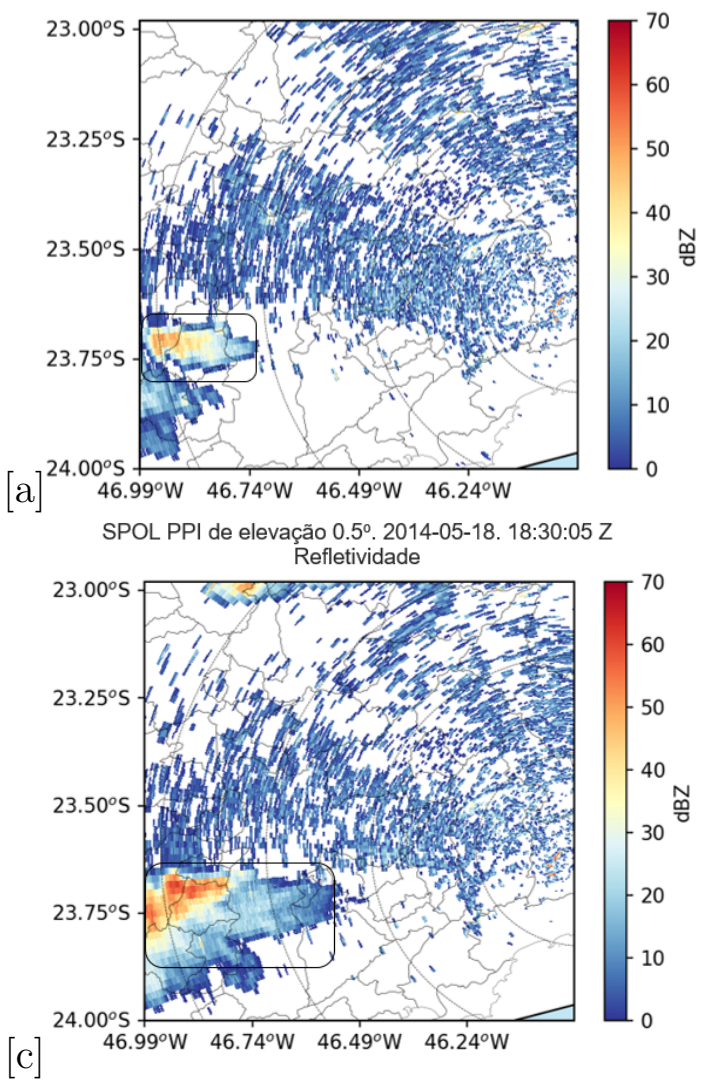

$[\mathrm{C}]$

SPOL PPI de elevação 0.5․ 2014-05-18. 19:10:04 Z
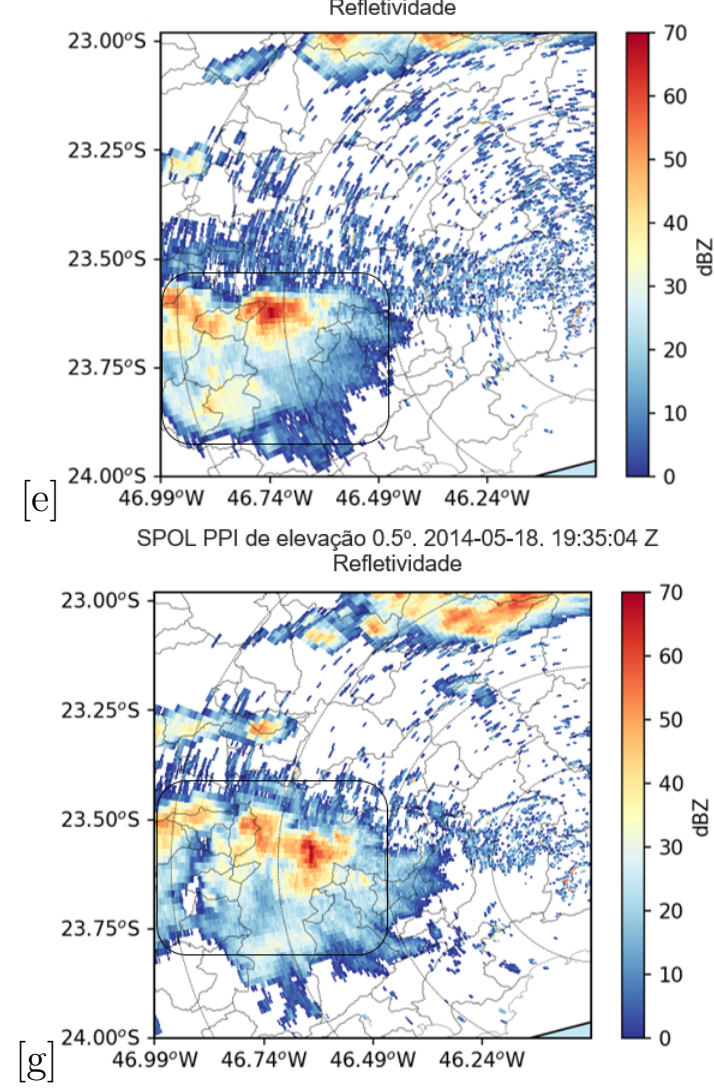

SPOL PPI de elevação 0.5․ 2014-05-18. 18:15:04 Z
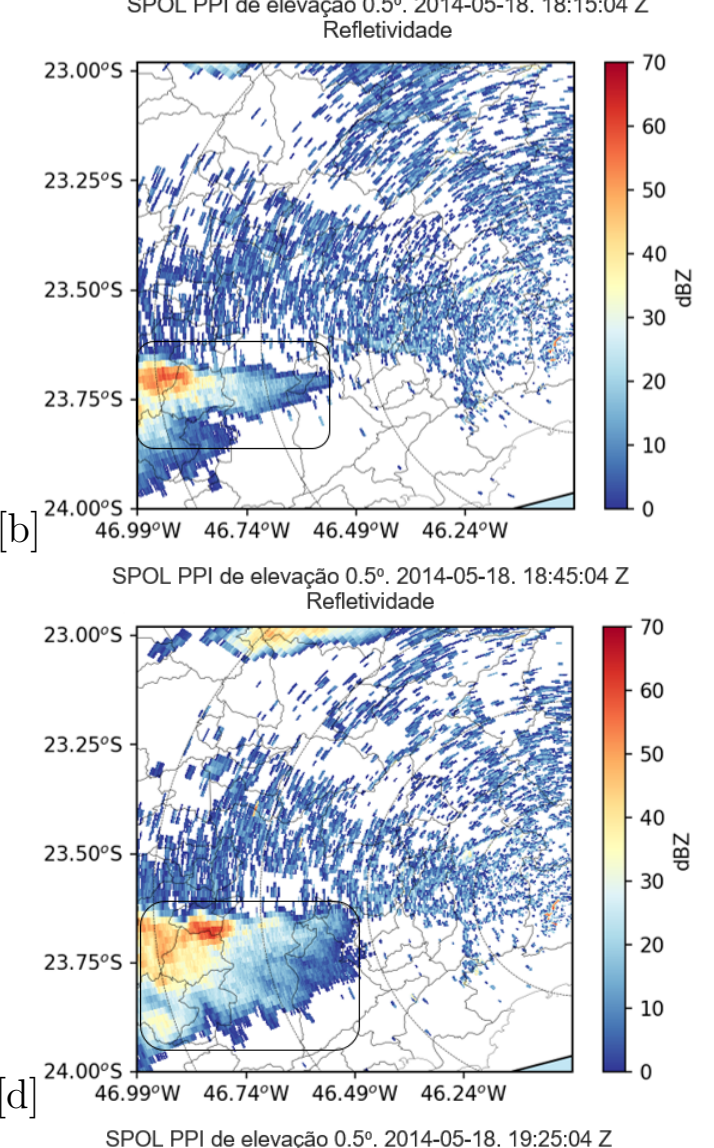

SPOL PPI de elevação 0.5․ 2014-05-18. 19:25:04 Z
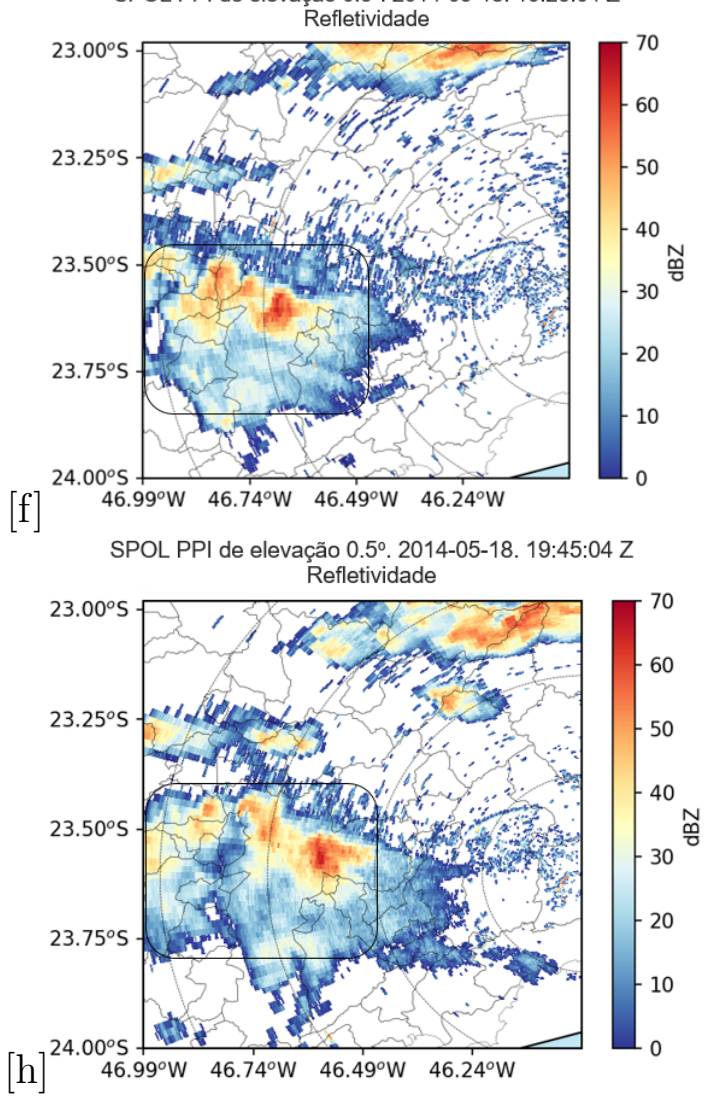

Figura 3.21: PPI de ângulo de elevação de $0.5^{\circ}$ da refletividade $\left(\mathrm{Z}_{H}\right)$ do radar SPOL (a) às 1755 UTC, (b) 1815 UTC, (c) 1830 UTC, (d) 1845 UTC, (e) 1910 UTC, (f) 1925 UTC, (g) 1935 UTC e (h) 1945 UTC do dia 18 de Maio de 2014. A escala de cores indica a refletividade (dBZ). Circunferências concêntricas estão espaçadas a cada $50 \mathrm{~km}$. O radar meteorológico SPOL está centro da menor circunferência concêntrica. Longitudes, latitudes, contornos dos municípios são indicados. 

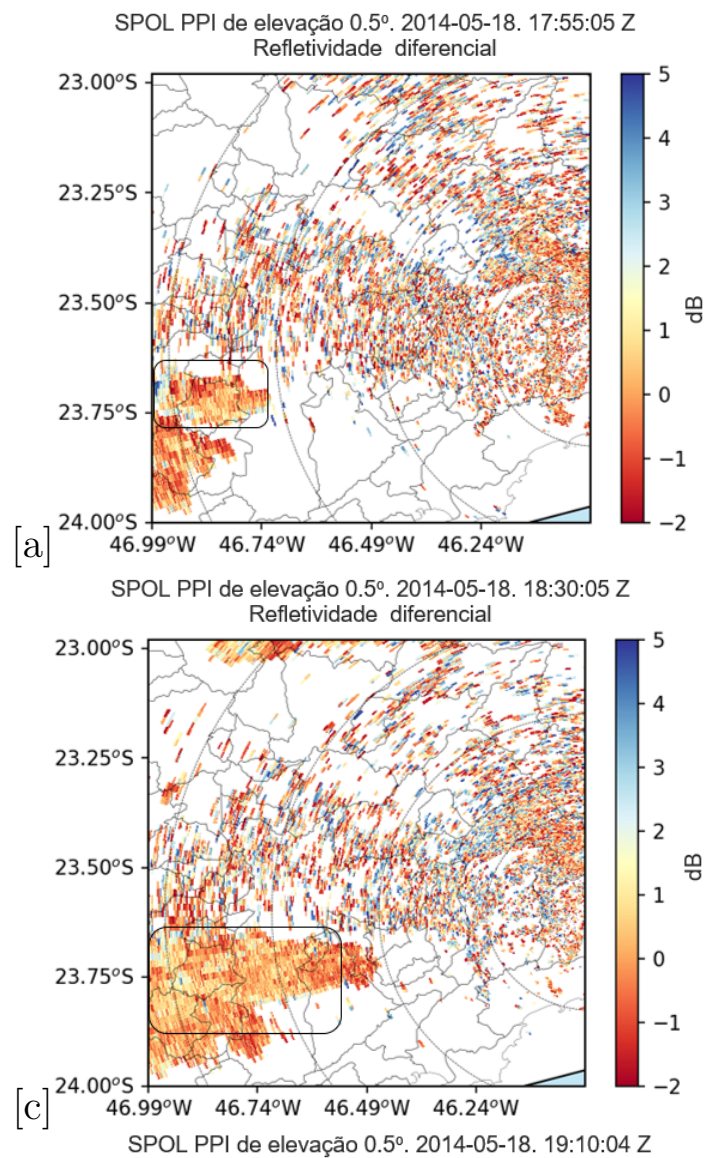

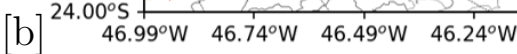
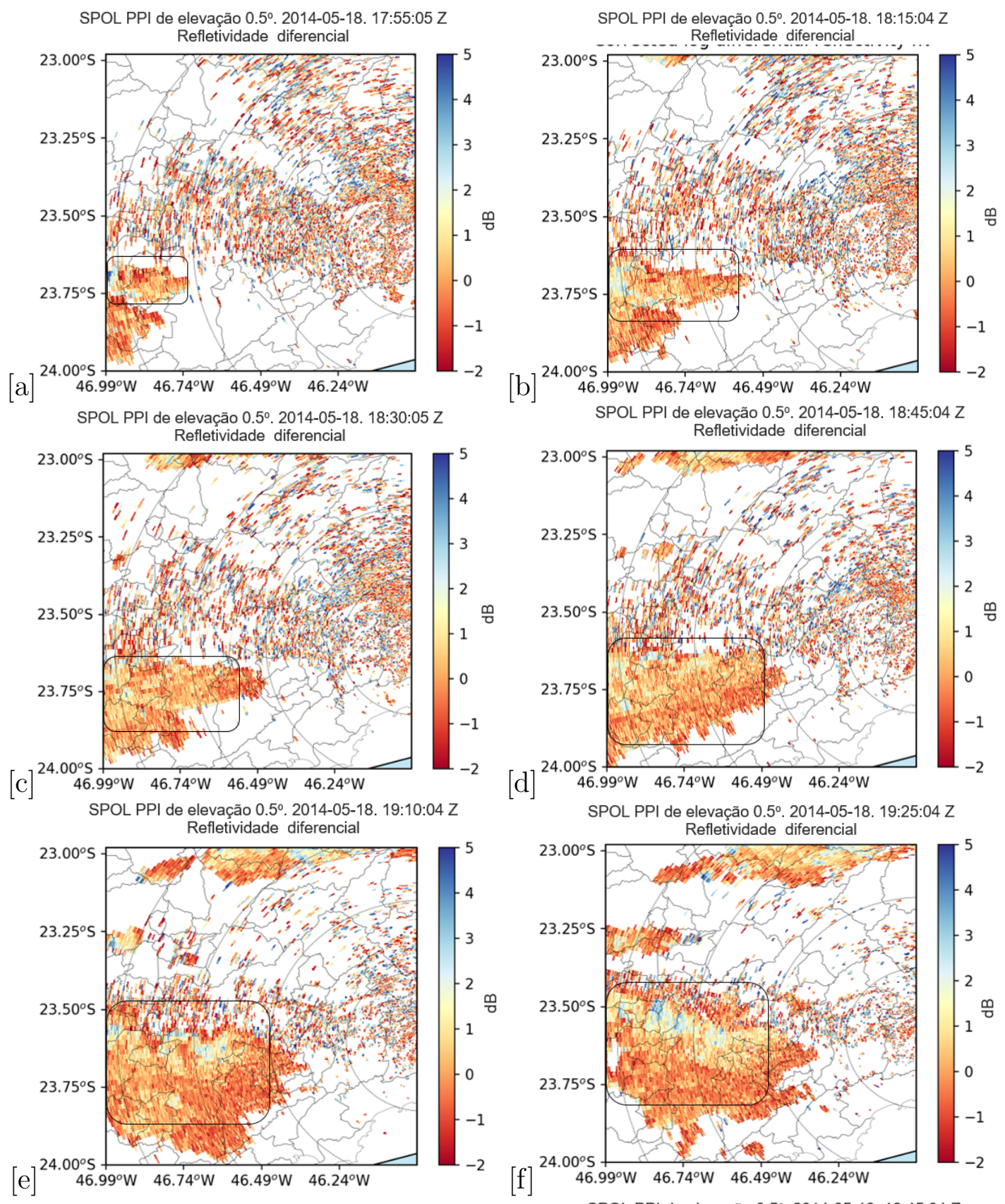

$[\mathrm{d}]$
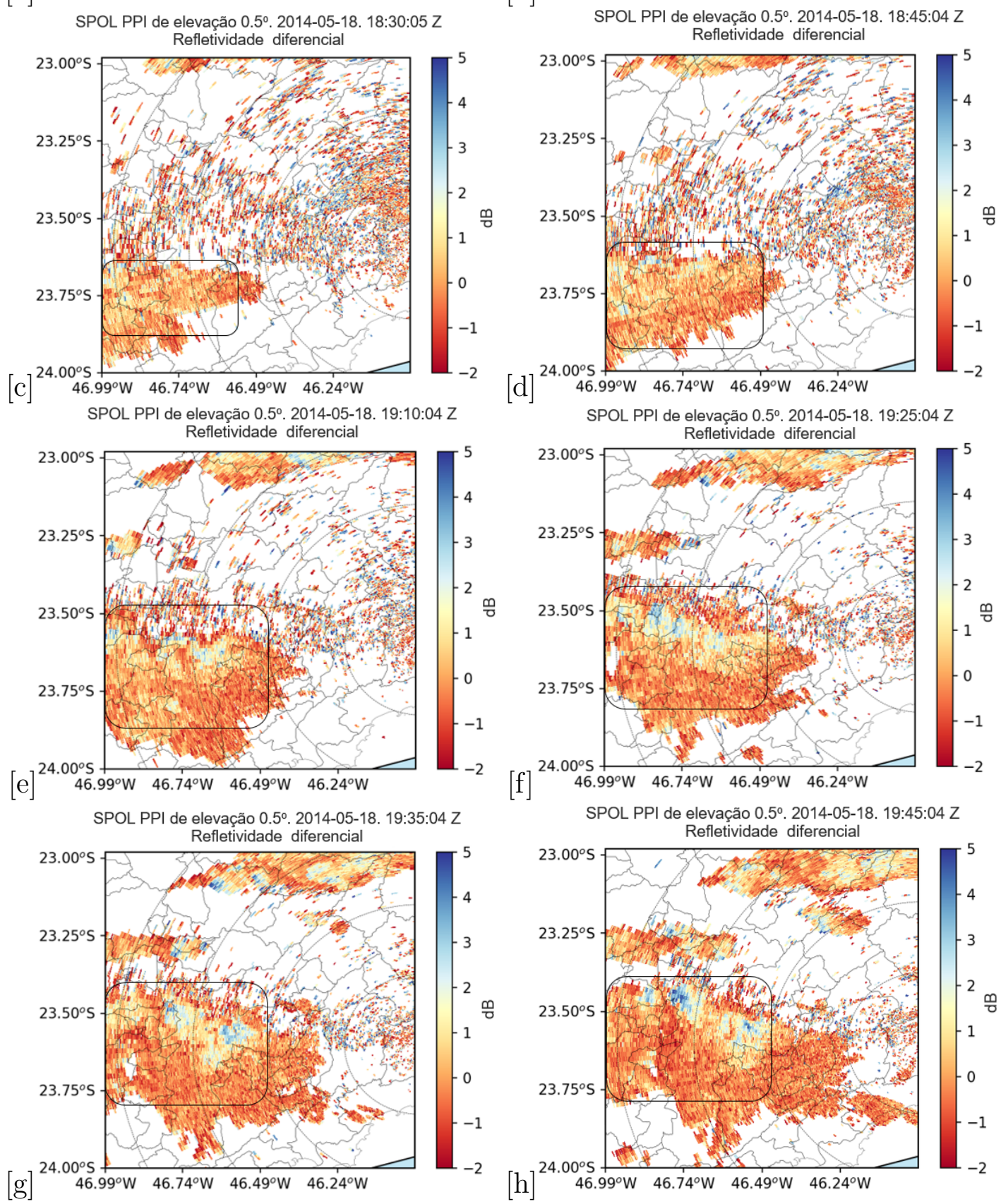

Figura 3.22: Idem Fig. 3.21, mas para Refletividade diferencial $\left(\mathrm{Z}_{D R}\right)$. 
SPOL PPI de elevação 0.50 2014-05-18, 17:55.05 Z Fase diferencial específica

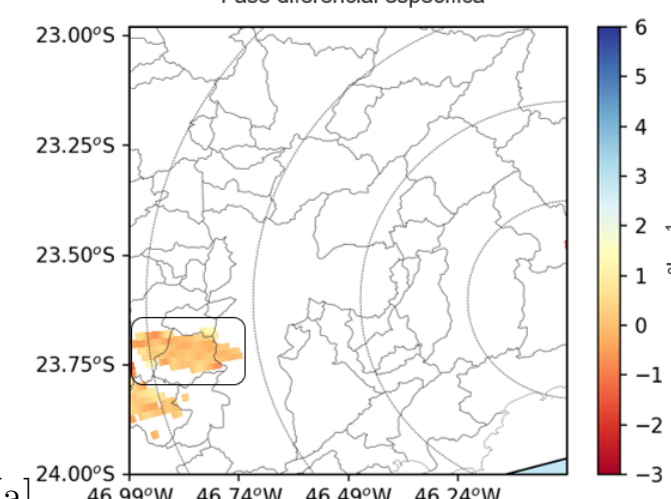

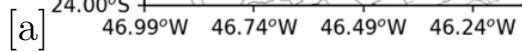
SPOL PPI de elevação $0.5^{\circ}$. 2014-05-18. 18:30:05 Z

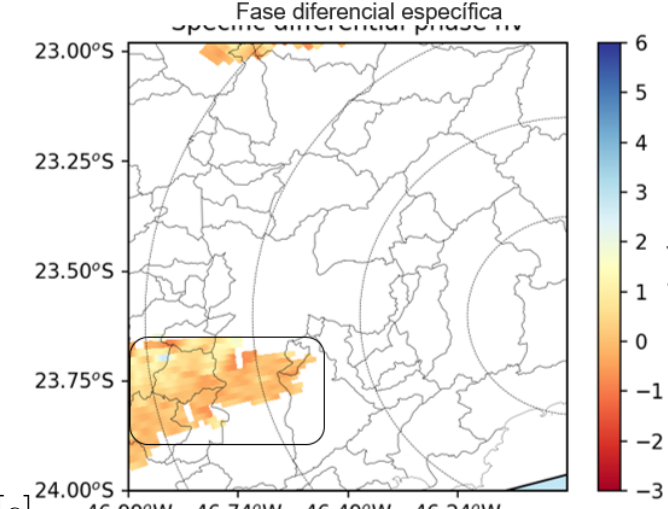

$[\mathrm{C}] \quad 46.99^{\circ} \mathrm{W} \quad 46.74^{\circ} \mathrm{W} \quad 46.49^{\circ} \mathrm{W} \quad 46.24^{\circ} \mathrm{W}$

SPOL PPI de elevação $0.5^{\circ}$. 2014-05-18. 19:10:04 Z Fase diferencial específica

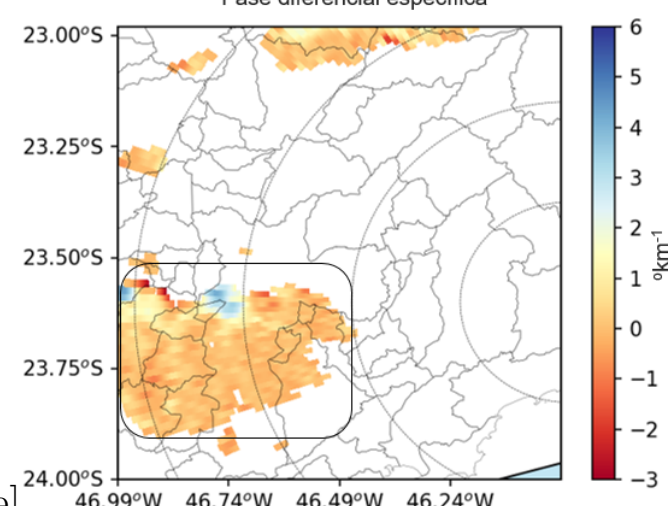

$[\mathrm{e}] \quad 46.99^{\circ} \mathrm{W} \quad 46.74^{\circ} \mathrm{W} \quad 46.49^{\circ} \mathrm{W} \quad 46.24^{\circ} \mathrm{W}$

SPOL PPI de elevacão 0.50.2014-05-18. 19:35:04 Z Fase diferencial específica

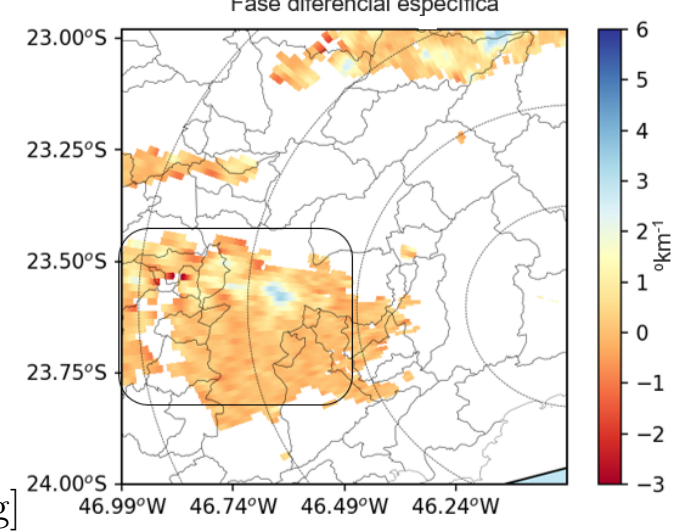

SPOL PPI de elevacão 0.5․ 2014-05-18, 18:15:04 Z Fase diferencial específica

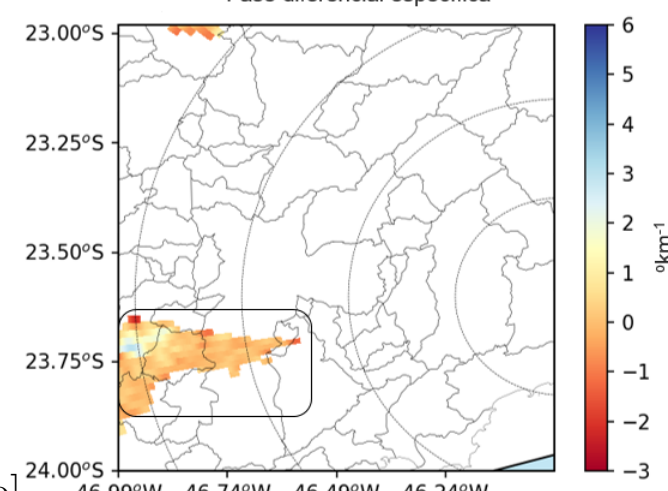

$[\mathrm{b}]^{24.00} 46.99^{\circ} \mathrm{W} \quad 46.74^{\circ} \mathrm{W} \quad 46.49^{\circ} \mathrm{W} \quad 46.24^{\circ} \mathrm{W}$

SPOL PPI de elevação $0.5^{\circ}$. 2014-05-18. 18:45:04 Z Fase diferencial específica

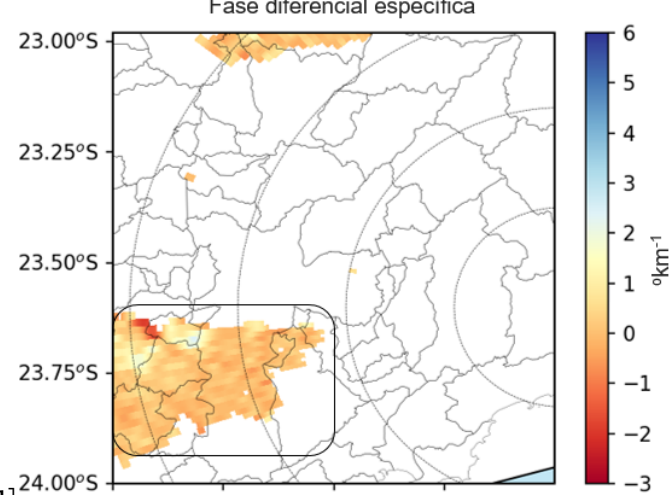

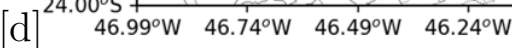

SPOL PPI de elevação 0.5ํ. 2014-05-18. 19:25:04 Z

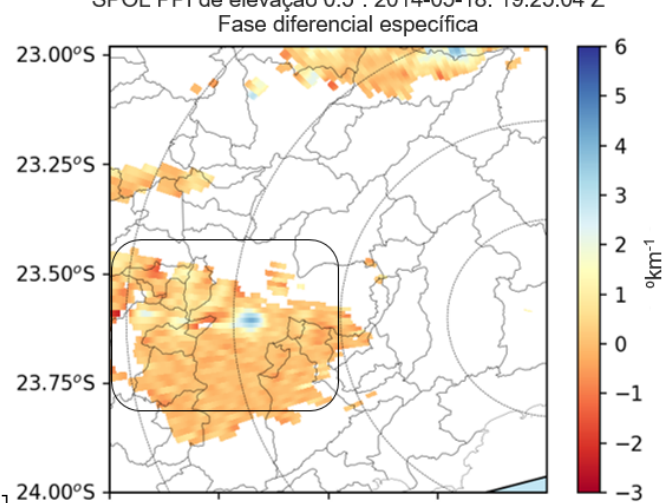

$[f$
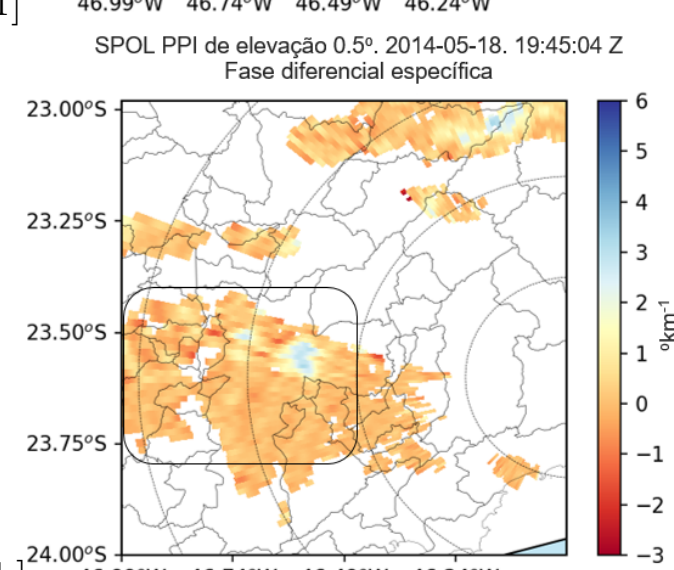

$\left[\begin{array}{lllll}24.00^{\circ} \mathrm{S} & & & & \\ 46.99^{\circ} \mathrm{W} & 46.74^{\circ} \mathrm{W} & 46.49^{\circ} \mathrm{W} & 46.24^{\circ} \mathrm{W}\end{array}\right.$

Figura 3.23: Idem Fig. 3.21, mas para fase diferencial específica $\left(\mathrm{K}_{D P}\right)$. 
SPOL PPI de elevação 0.5․ 2014-05-18. 17:55:05 Z

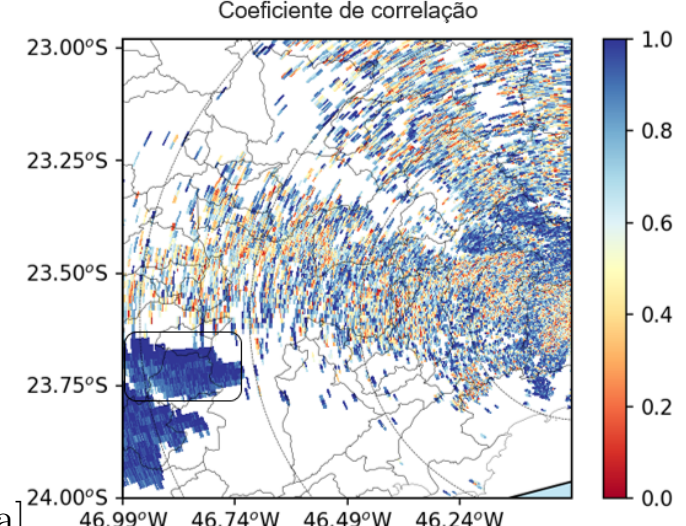

$[\mathrm{a}]^{24.00^{\circ} \mathrm{S}} 46.99^{\circ} \mathrm{W} \quad 46.74^{\circ} \mathrm{W} \quad 46.49^{\circ} \mathrm{W} \quad 46.24^{\circ} \mathrm{W}$

SPOL PPI de elevação 0.5․ 2014-05-18. 18:30:05 Z Coeficiente de correlação

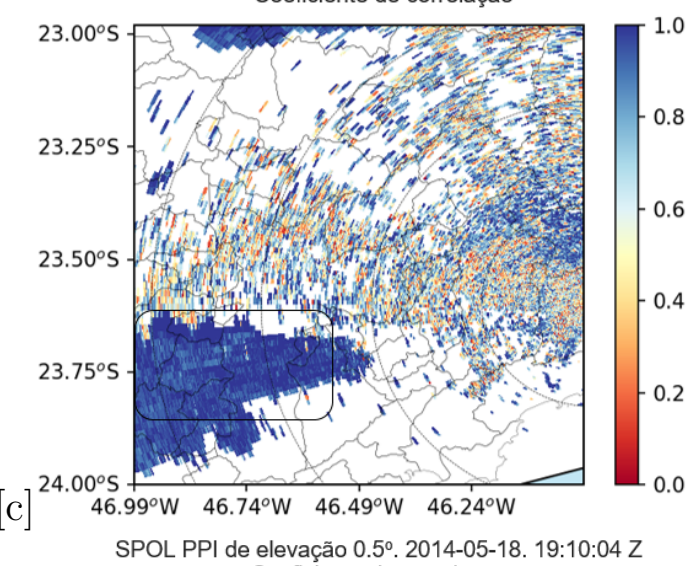

SPOL PPI de elevação 0.5․ 2014-05-18. 19:10:04 Z
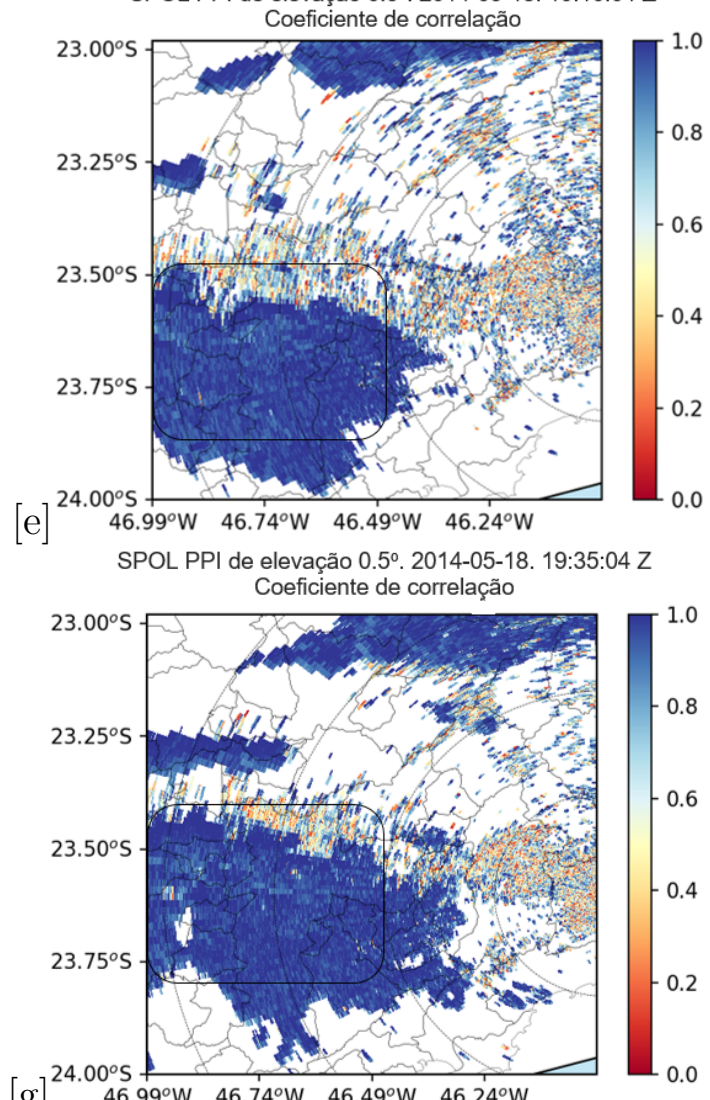

SPOL PPI de elevação 0.5․ 2014-05-18. 18:15:04 Z

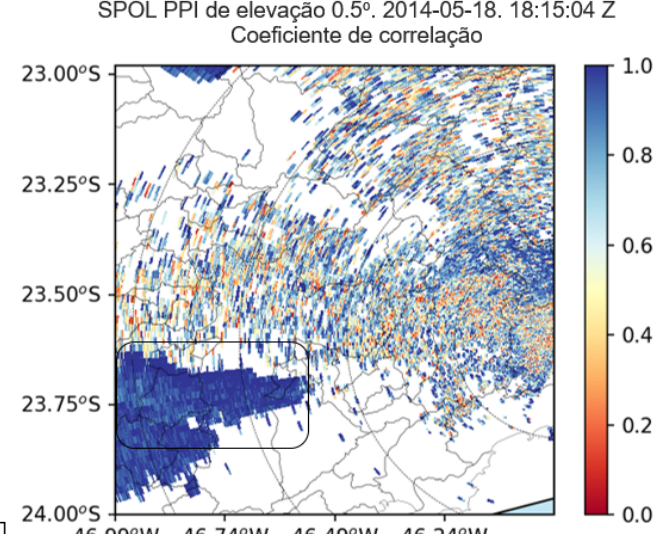

[b] $\quad 46.99^{\circ} \mathrm{W} \quad 46.74^{\circ} \mathrm{W} \quad 46.49^{\circ} \mathrm{W} \quad 46.24^{\circ} \mathrm{W}$

SPOL PPI de elevação $0.5^{\circ}$. 2014-05-18. 18:45:04 Z Coeficiente de correlação

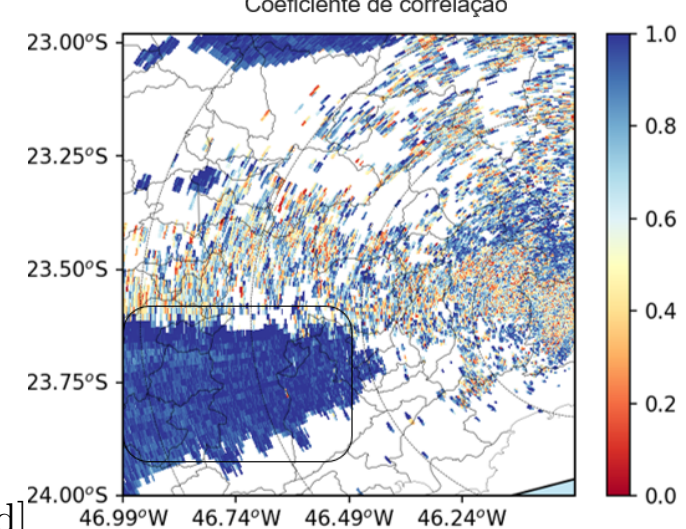

SPOL PPI de elevação 0.5 . 2014-05-18. 19:25:04 Z

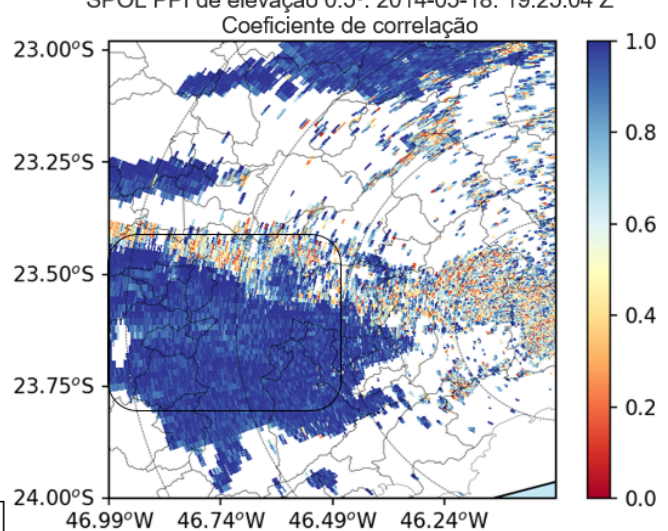

SPOL PPI de elevação 0.5․ 2014-05-18. 19:45:04 Z

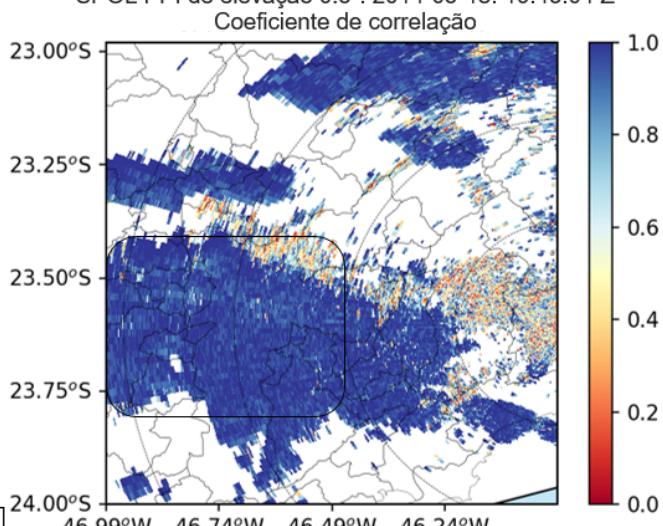

$[\mathrm{h}]^{24.00^{\circ} \mathrm{S}} \begin{array}{llll}46.99^{\circ} \mathrm{W} & 46.74^{\circ} \mathrm{W} & 46.49^{\circ} \mathrm{W} & 46.24^{\circ} \mathrm{W}\end{array}$

Figura 3.24: Idem Fig. 3.21, mas para coeficiente de correlação (sem unidade). 
Em geral, nota-se na Fig. 3.24, os campos de coeficiente de correlação com cor uniforme característico de alvos hidrometeorológicos. Observa-se uma descrição de hidrometeoros mais próximo de 1.0 correspondentes gotas pequenas. Entretanto, repara-se que há valores entre 0.8 e 0.6 nas áreas correspondentes aos núcleos das células convectivas, devido a presença de gotas grandes e presença mista de água e gelo. Nota-se também valores pontuais $<0.6$ correspondentes a gelo com orientação vertical em algumas áreas da região estratiforme na circunvizinhança dos núcleos convectivos (fig. 3.24).

A Fig. 3.25 mostra a CI sobre o centro geométrico da RMSP, i.e, sobre a zona de adensamento urbano do município de são Paulo. Nota-se que o núcleo da célula aumentou de dimensão e está mais intensa (>60 dBZ), área destacada, Fig. 3.25a, b. Nota-se que a célula da quase-linha de instabilidade $(<55 \mathrm{dBZ})$ no azimute $360^{\circ}$, aproxima-se ao radar SPOL (Fig. 3.25a, b). Nota-se que ambas as células estão na mesma radial, a $50 \mathrm{~km}$ do radar SPOL, propagando-se em direção ao SPOL (Fig. 3.25b).

À medida que ambas as células aproximam-se ao SPOL, diminui o ângulo do azimute e a distância do SPOL, que faz varredura dos volumes nas regiões mais baixas das células (Fig. 3.25c, d, e, f, g). Ambas as células aparecem completamente integradas às 2055 UTC (Fig. 3.25c), que muda de direção propagando-se para leste, perdendo intensidade (Fig. $3.25 f, \mathrm{~g}, \mathrm{~h})$.

Contrariamente do que foi observado no núcleo da célula nos campos de refletividade, os valores de refletividade diferencial baixaram no núcleo da CI, que estão entre 2.5 e 0.5 dBs, área destacada (Fig. 3.26a, d), indicativo da presença predominante de granizo e gota grande. A variável refletividade diferencial é amplamente utilizada para diferenciar chuva, granizo, neve, e mesmo objetos não meteorológicos (KUMJIAN, 2013).

Quando o núcleo da célula começa a perder intensidade como observado nos campos da refletividade, observa-se o oposto nos campos de refletividade diferencial (Fig. 3.26c, d) com aumento nos valores (entre 4 e $0.5 \mathrm{dBs}$ ), indicativo da predominância de gotas grandes sobre o granizo. À medida que que célula vai perdendo intensidade como observado nos campos de refletividade, encolhe também a tonalidade azul escuro nos campos de refletividade deferencial (Fig. 3.26e, f, g, h), indicativo da diminuição da população de gota grande e granizo, e predominância de chuva. 

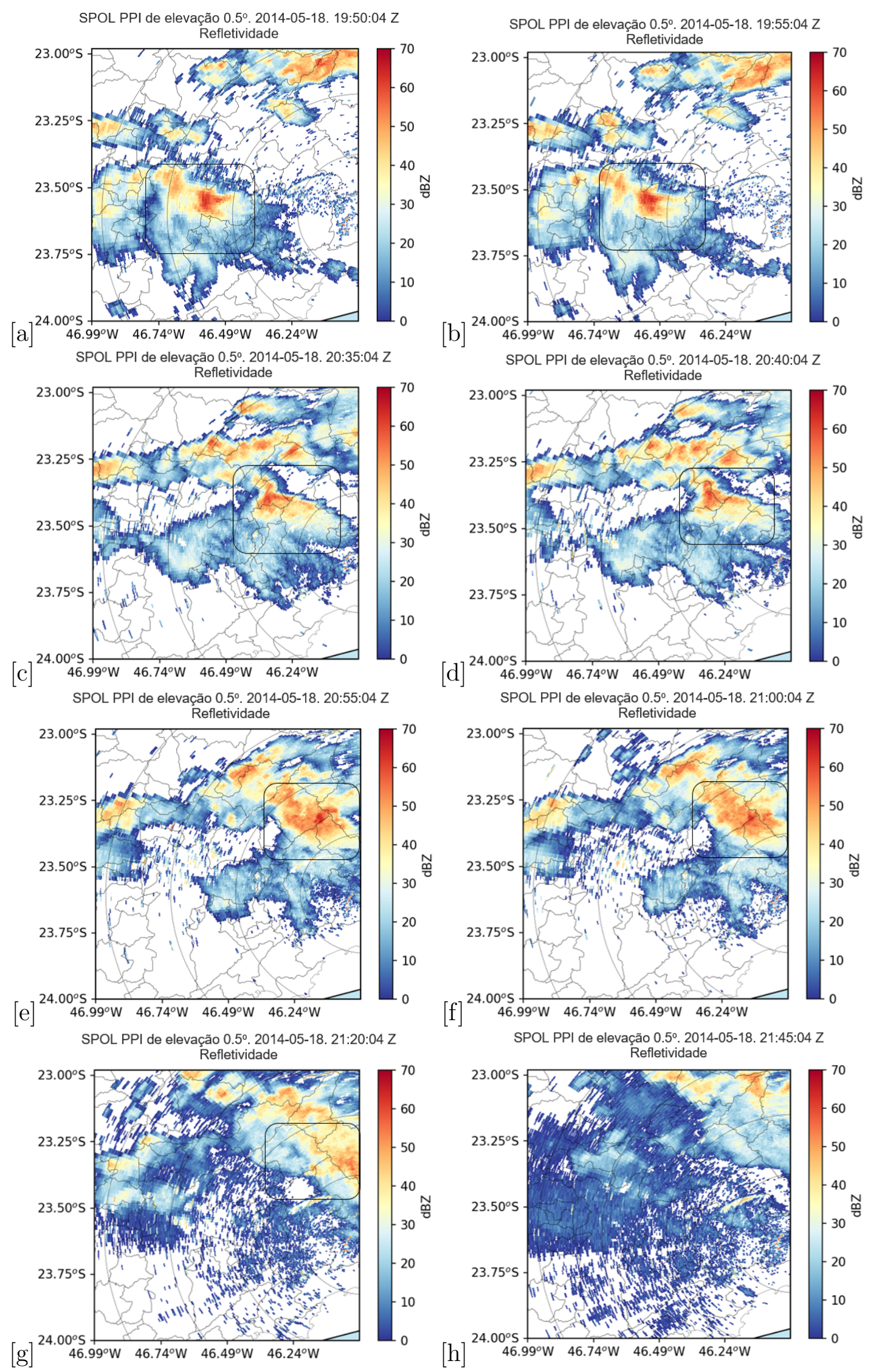

Figura 3.25: PPI de ângulo de elevação de $0.5^{\circ}$ da refletividade $\left(\mathrm{Z}_{H}\right)$ do radar SPOL (a) às 1950 UTC, (b) 1955 UTC, (c) 2035 UTC, (d) 2040 UTC, (e) 2055 UTC, (f) 2100 UTC, (g) 2120 UTC e (h) 2145 UTC do dia 18 de Maio de 2014. A escala de cores indica a refletividade (dBZ). Circunferências concêntricas estão espaçadas a cada $25 \mathrm{~km}$. O radar meteorológico SPOL está centro da menor circunferência concêntrica, a direita das figuras. Longitudes, latitudes, contornos dos municípios são indicados. 
SPOL PPI de elevação 0.5․ 2014-05-18. 19:50:04 Z Refletividade diferencial
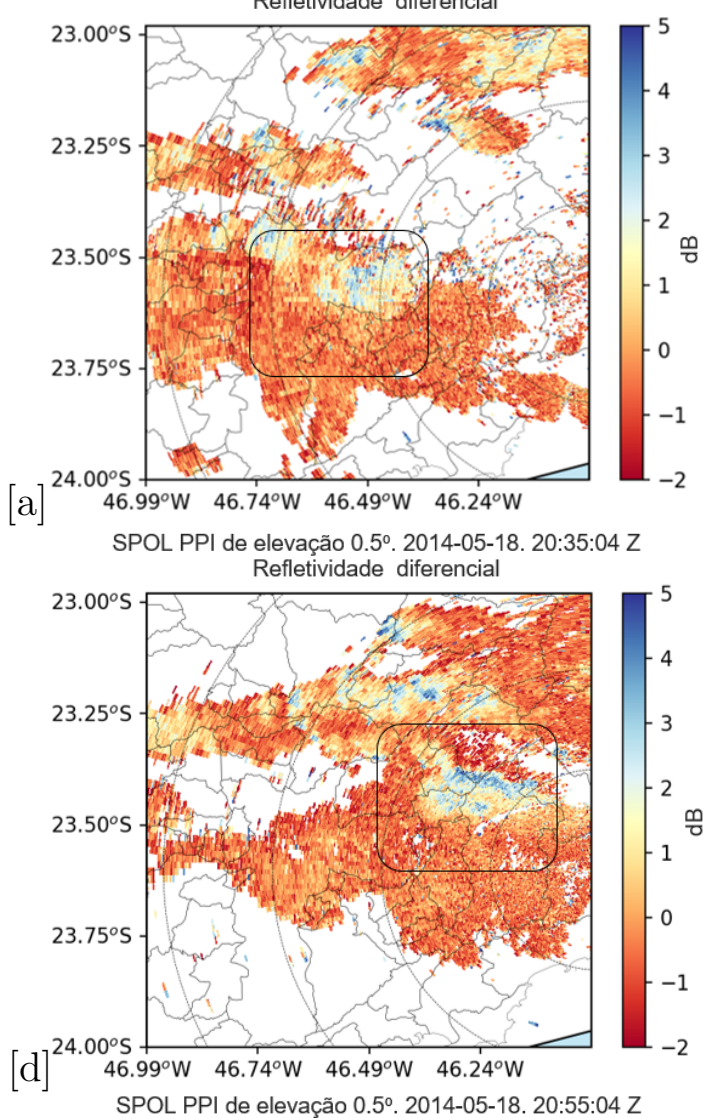

SPOL PPI de elevação 0.50 2014-05-18. 20:55:04 Z
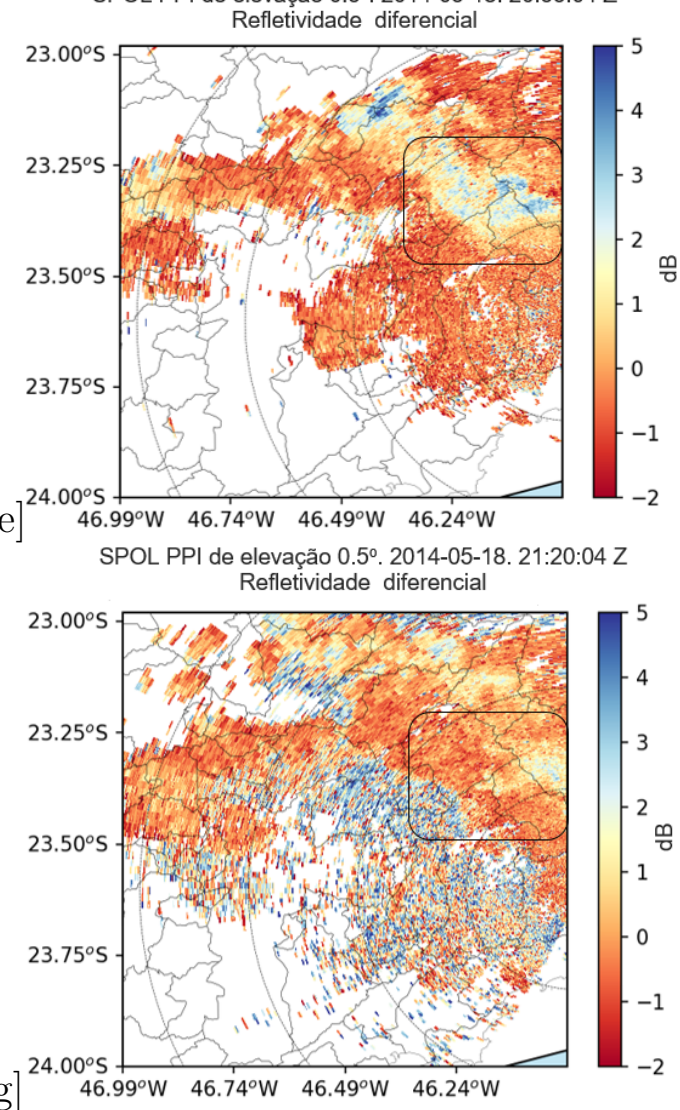

SPOL PPI de elevação $0.5^{\circ}$. 2014-05-18. 19:55:04 Z

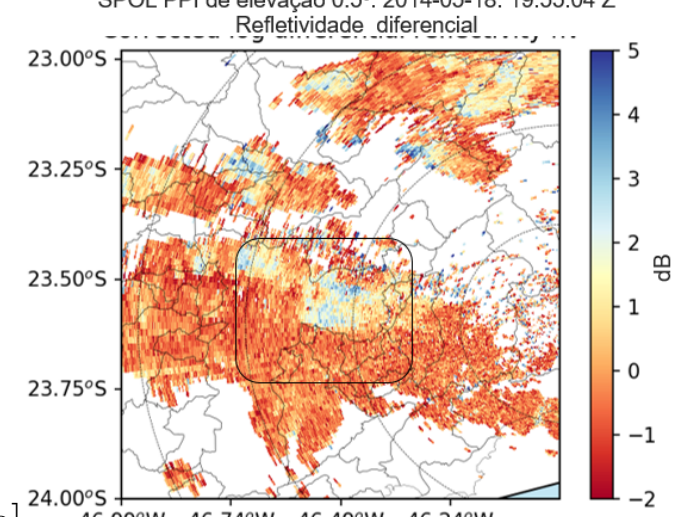

$\left[\mathrm{b}{ }^{24.00^{\circ} \mathrm{S}} \begin{array}{llll}46.99^{\circ} \mathrm{W} & 46.74^{\circ} \mathrm{W} & 46.49^{\circ} \mathrm{W} & 46.24^{\circ} \mathrm{W}\end{array}\right.$

SPOL PPI de elevação 0.5․ 2014-05-18. 20:40:04 Z Refletividade diferencial

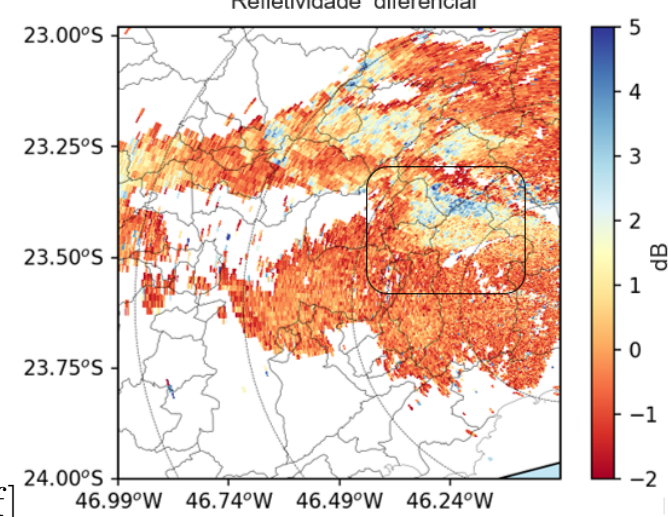

SPOL PPI de elevação 0.5․ 2014-05-18. 21:00:04 Z Refletividade diferencial
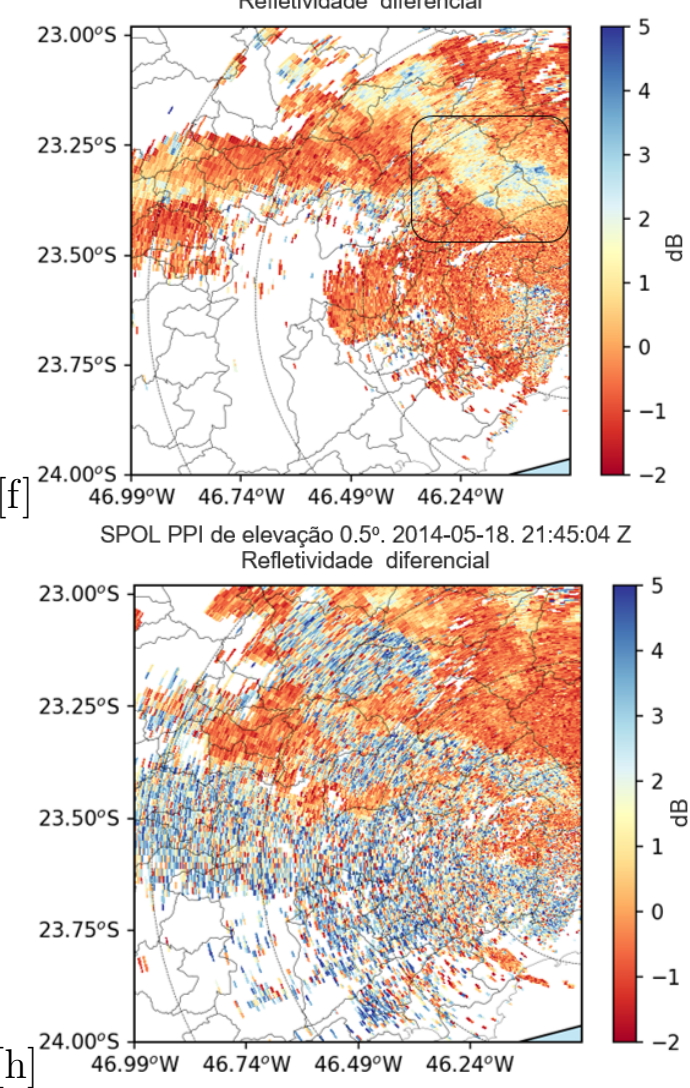

Figura 3.26: Idem Fig. 3.21, mas para Refletividade diferencial $\left(\mathrm{Z}_{D R}\right)$. 
SPOL PPI de elevação 0.5․ 2014-05-18. 19:50:04 Z Fase diferencial específica

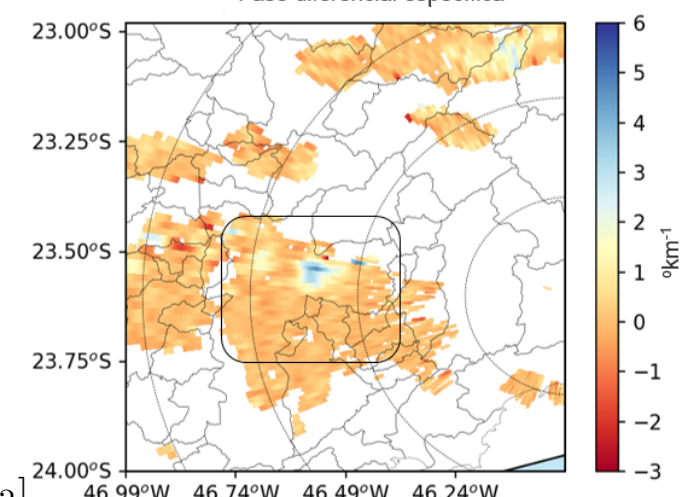

[a]

SPOL PPI de elevação 0.5 . 2014-05-18. 20:35:04 Z

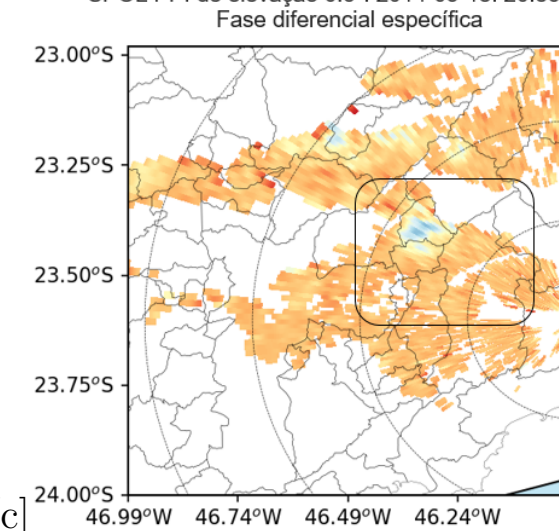

c]

SPOL PPI de elevacão 0.50.2014-05-18. 20:55:04 Z

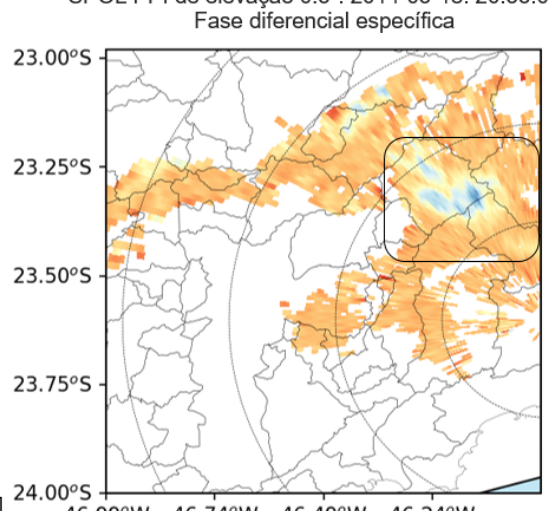

$[\mathrm{e}]$

$46.99^{\circ} \mathrm{W} \quad 46.74^{\circ} \mathrm{W} \quad 46.49^{\circ} \mathrm{W} \quad 46.24^{\circ} \mathrm{W}$

SPOL PPI de elevação 0.5․ 2014-05-18. 21:20:04 Z

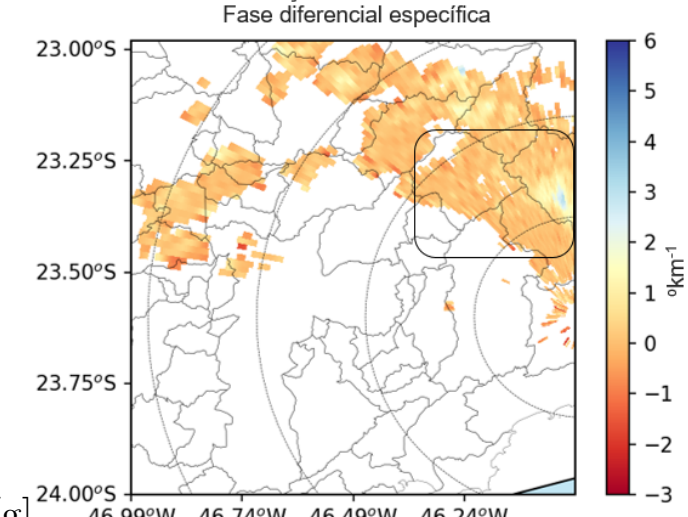

$[\mathrm{g}]$

$46.99^{\circ} \mathrm{W} \quad 46.74^{\circ} \mathrm{W} \quad 46.49^{\circ} \mathrm{W} \quad 46.24^{\circ} \mathrm{W}$
SPOL PPI de elevação $0.5^{\circ}$. 2014-05-18. 19:55:04 Z

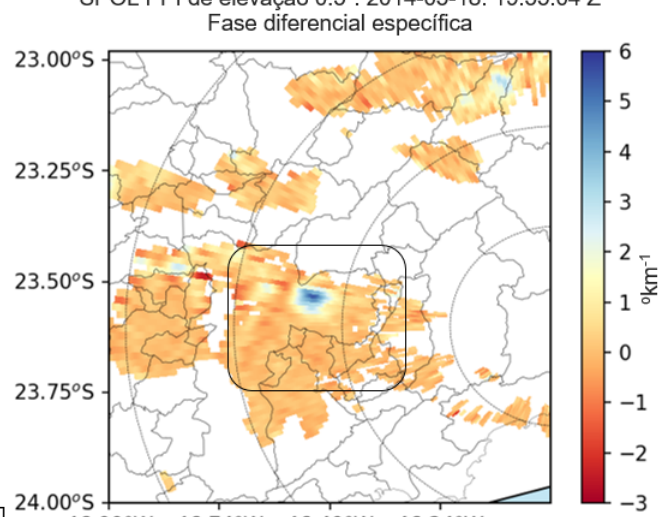

[b]

$46.99^{\circ} \mathrm{W} \quad 46.74^{\circ} \mathrm{W} \quad 46.49^{\circ} \mathrm{W} \quad 46.24^{\circ} \mathrm{W}$

SPOL PPI de elevação $0.5^{\circ}$. 2014-05-18. 20:40:04 Z

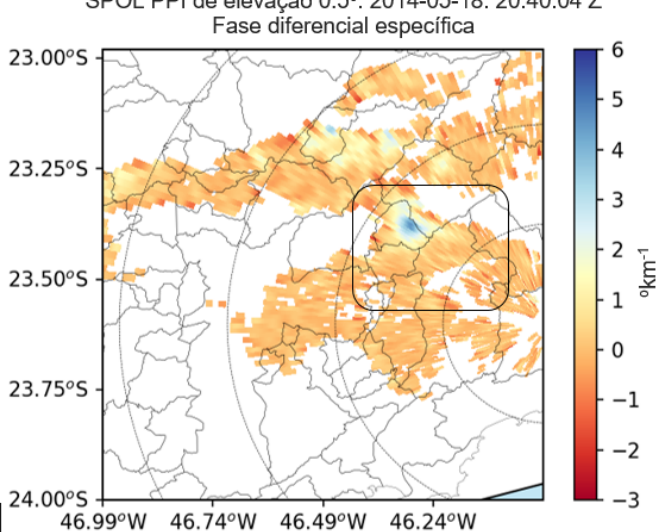

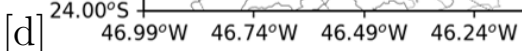

SPOL PPI de elevacão 0.5 . 2014-05-18. 21:00:04 Z

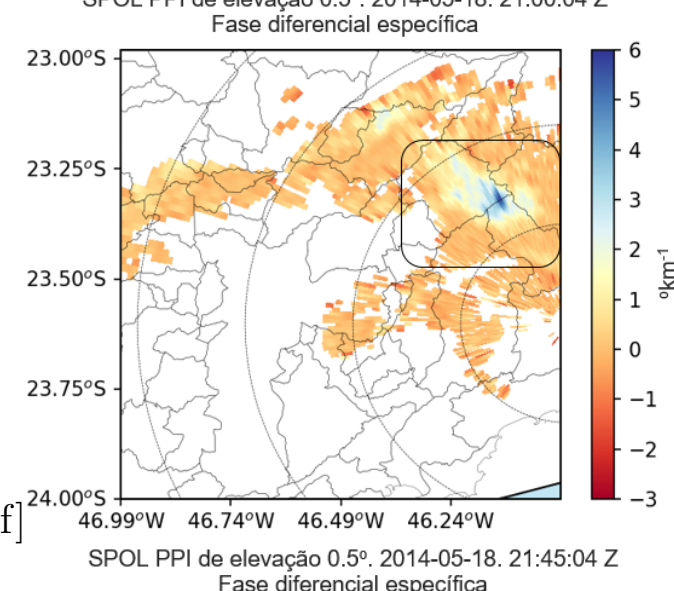

$[\mathrm{h}]^{24}$
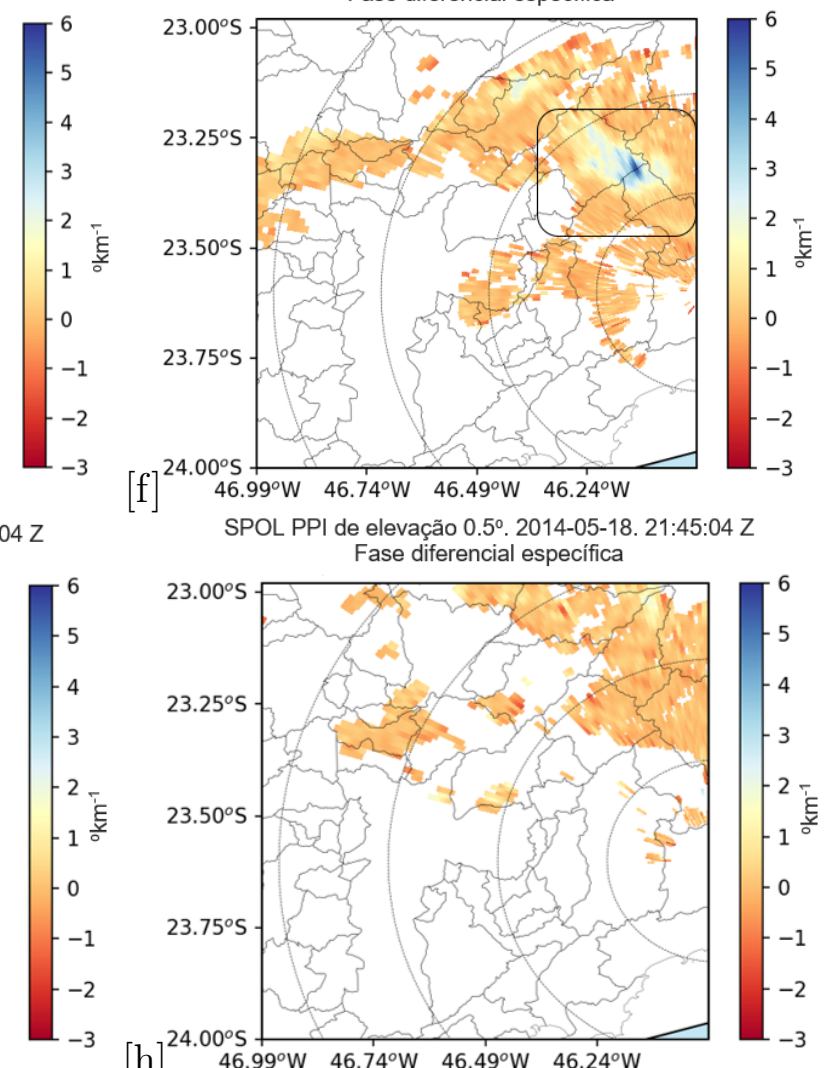$$
\text { [f] }
$$

Figura 3.27: Idem Fig. 3.21, mas para fase diferencial específica $\left(\mathrm{K}_{D P}\right)$. 
SPOL PPI de elevação 0.5․ 2014-05-18. 19:50:04 Z

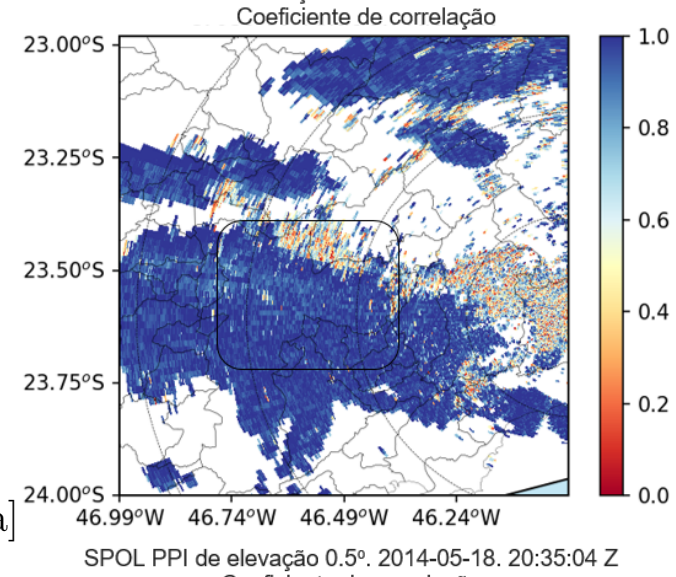

SPOL PPI de elevacão 0.5․ 2014-05-18. 20:35:04 Z Coeficiente de correlação

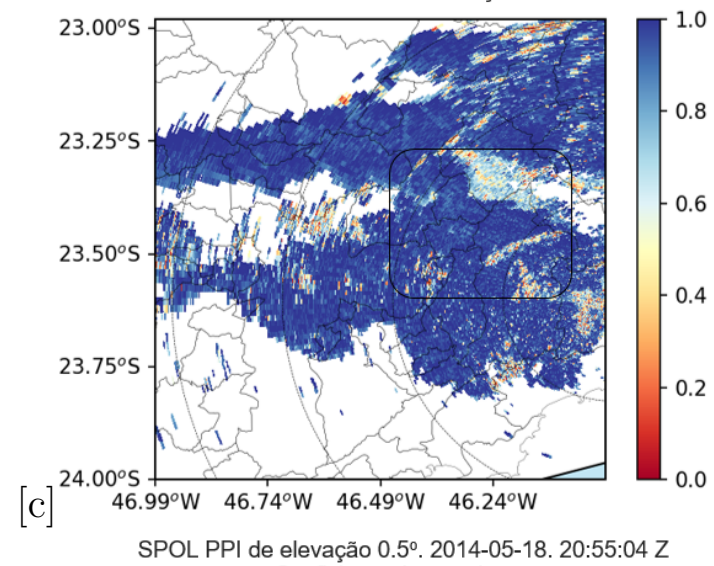

SPOL PPI de elevação 0.5. 2014-05-18. 19:55:04 Z

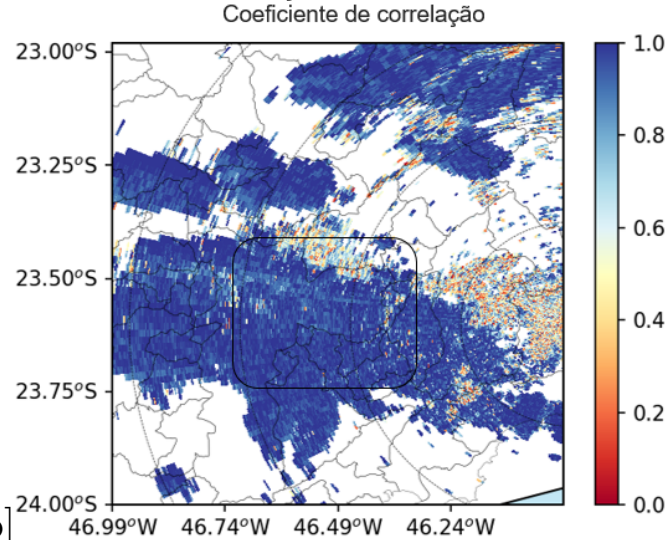

SPOL PPI de elevação 0.5․ 2014-05-18. 20:40:04 Z

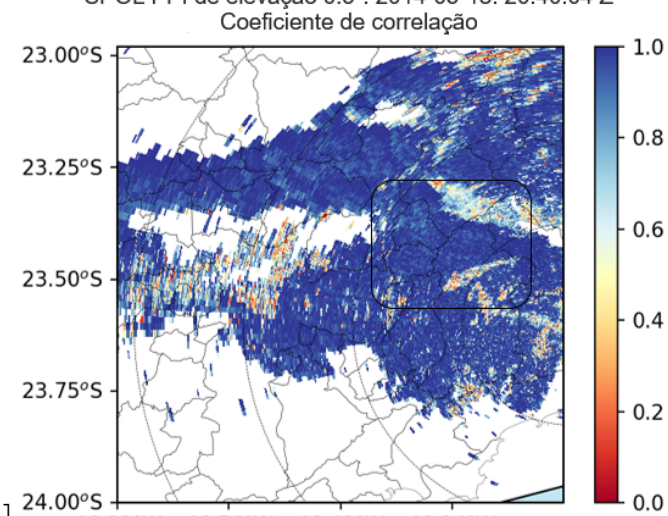

d] $\begin{array}{cccc}24.00^{\circ} \mathrm{S} & & & \\ 46.99^{\circ} \mathrm{W} & 46.74^{\circ} \mathrm{W} & 46.49^{\circ} \mathrm{W} & 46.24^{\circ} \mathrm{W}\end{array}$

SPOL PPI de elevação $0.5^{\circ}$. 2014-05-18. 21:00:04 Z

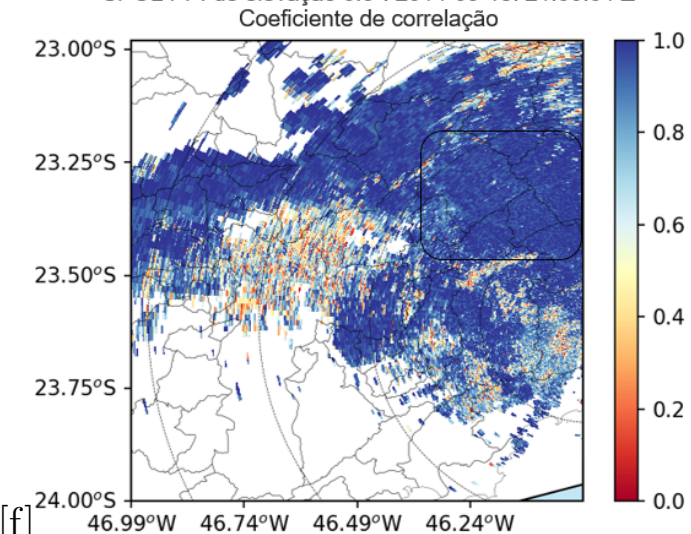

$[f]^{24.005} \quad 46.99^{\circ} \mathrm{W} \quad 46.74^{\circ} \mathrm{W} \quad 46.49^{\circ} \mathrm{W} \quad 46.24^{\circ} \mathrm{W}$

SPOL PPI de elevação 0.5․ 2014-05-18. 21:45:04 Z

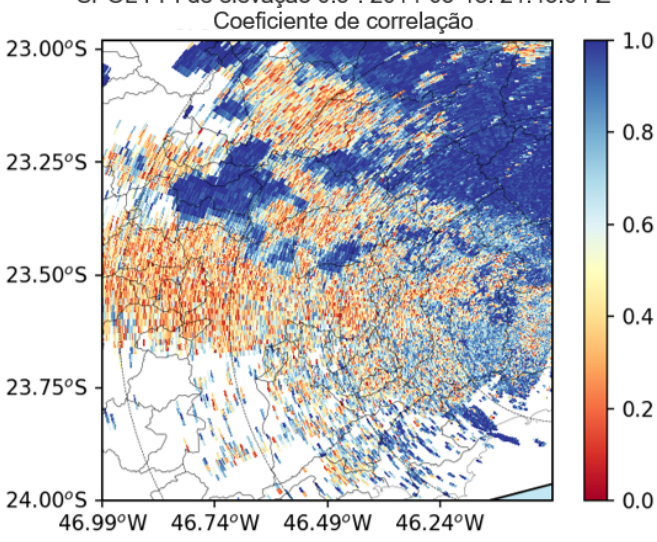

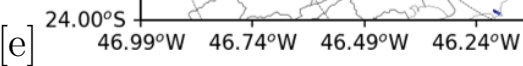

SPOL PPI de elevação $0.5^{\circ}$. 2014-05-18. 21:20:04 Z

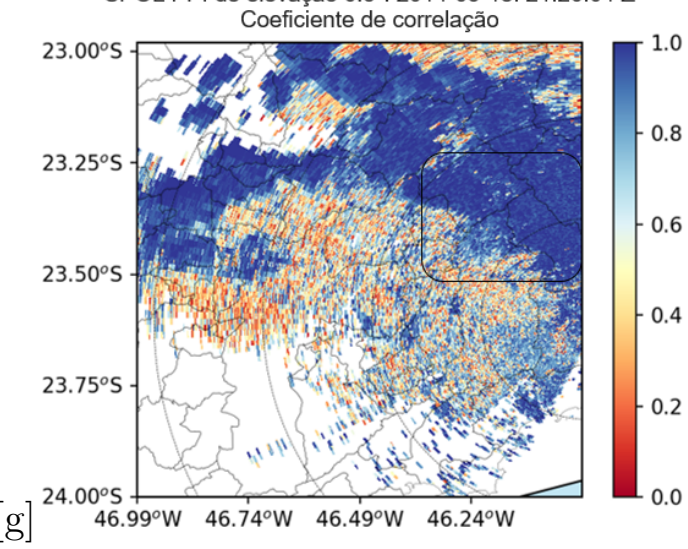

Figura 3.28: Idem Fig. 3.21, mas para coeficiente de correlação (sem unidade). 
A fase diferencial específica é um excelente estimador de precipitação, tal como apresentado por Ruzanski e Chandrasekar (2012) em que os valores acima de $2^{\circ} \mathrm{km}^{-1}$ indicam uma quantidade significativa de água líquida ou gotas oblatas. Nota-se diminuição e aumento intermitente na tonalidade azul escuro no núcleo da célula, área destaca (Fig. 3.27a, b, d, d, e, f). Quando a CI passava sobre área de adensamento urbano, provavelmente mais quente, aumentou a população de granizo, que provavelmente precipitava até à superfície, e diminuição da polução de gota grande no núcleo da célula, área destacada (Fig. 3.27a). A tonalidade azul escuro aumentou $\left(>4^{\circ} \mathrm{km}^{-1}\right)$ após a passagem sobre a área de adensamento urbano, indicativo do aumento da população de gotas oblatas (Fig. 3.27b).

O que observa-se para adiante é aumento e diminuição intermitente na tonalidade azul escuro, quando a CI sobre a região de Guarulhos e sobre as divisas de outros municípios (Fig. 3.27c, d, e, f).

A Fig. 3.28 mostra os campos de coeficiente de correlação, onde os valores variam entre 0.6 e 1.0 com tonalidade homogenia nas células precipitantes, correspondentes a diversidade de tipos de hidrometeoros presentes nas nuvens.

\subsubsection{Classificação dos hidrometeoros}

A Lógica fuzzy foi também aplicada aos dados do radar SPOL para obtenção da classificação dos hidrometeoros presentes nas CIs em todos os PPIs para análise microfísica durante a evolução espaço-temporal, ocorridos nas datas 18 de maio de 2014 e 29 de janeiro de 2019, e das BDs ocorridos nas datas 24 de janeiro de 2016 e 19 de agosto de 2019. Como descrito na metodologia, o método utiliza dados refletividade horizontal, refletividade diferencial, fase diferencial específica, coeficiente de correlação e temperatura como dados de entrada. A Tab. 2.6 mostra a classificação de hidrometeoros para dados do SPOL, ajustados por uma extensa revisão bibliográfica (Straka et al., 2000; Liu e Chandrasekar, 2000; Kessinger et al., 2003; Ryzhkov et al., 2003; Park et al., 2009; Rauber e Nesbitt, 2018; Alberoni et al., 2002; Baldini et al., 2004; Keenan e Carbone, 1992) e entre outros.

A classificação dos hidrometeoros da CI de origem urbana induzida por rotação ciclônica, foi realizada durante sua evolução espaço-temporal sobre a RMSP, i.e, sobre a divisa do município de São Paulo, a oeste da RMSP (Fig. 3.29), sobre o centro geométrico da RMSP (Fig. 3.30), sobre a zona leste do município de São Paulo (Fig. 3.32) e sobre a divisa entre os municípios de São Paulo e Guarulhos (Fig. 3.33). Notou-se uma predominância 
intermitente entre a população de granizo e gota grande em diferentes ângulos de elevação durante a evolução espaço-temporal sobre a RMSP. Observou-se também a precipitação de pedras granizos durante quase 2 horas ininterrupta, provavelmente, atingiram superfície.

A Fig. 3.29 mostra a sequência de quatro PPIs de diferentes ângulos de elevação da classificação dos hidrometeoros da CI sobre a divisa do município de São paulo, a oeste da RMSP. A classificação de hidrometeoros identifica chuva misturada a gotas grandes e granizo no núcleo da célula convectiva, área destacada (Fig. 3.29a). A Fig. 3.29b mostra a classificação de hidrometeoros dentro da isoterma ${ }^{\circ} \mathrm{C}$, onde é identificada a camada neve molhada predominante. Entretanto, observa-se mistura de graupel de alta densidade, granizo, gota grande no núcleo de célula, indicativo da localização da intensa corrente ascendente que ejeta quantidade alta de água líquida na parte superior da nuvem. Nota-se isso acima da isoterma ${ }^{\circ} \mathrm{C}$, onde é identifica quantidade alta de graupel de baixa densidade, a grauple de alta densidade e granizo (Fig. 3.29b). Observa-se a inexistência de gotas grandes acima isoterma ${ }^{\circ} \mathrm{C}$, que têm origem do derretimento do granizo. Do ponto de vista microfísico, é impossível o granizo derreter para originar gota gota grande a temperatura abaixo de $-5^{\circ} \mathrm{C}$ (Fig. 3.29c).

O agregado predomina entorno do núcleo da célula convectiva acima da isoterma ${ }^{\circ} \mathrm{C}$, resultante da aglutinação entre cristais de gelo (Fig. 3.29c), indicativo que o conteúdo de água líquida ejeta pela única corrente ascendente, está concentrada no núcleo da célula convectiva típico de CI . Nas regiões mais frias (Fig. 3.29d), provavelmente entre $-5^{\circ} \mathrm{C}$ e $-10^{\circ} \mathrm{C}$, observa-se a predominância de gelo vertical (conhecidos como agulhas, do grupo prisma pelo diagrama Nakaya), que são típicos a essas temperaturas (Schlichting, 2017).

$\mathrm{Na}$ área destacada, é identificada alta concertação de granizo e graupel BD no seu entorno (Fig. 3.29d), resultante da formação pelo processo de acreção (gotículas superresfriadas e cristais de gelo), e os cristais de gelo formados por deposição da vapor de água. Esse cenário indicativo da única corrente ascendente imperante, que ejeta quantidade significativa de conteúdo de água líquida até a esses níveis da atmosfera. Nesse ambientes as partículas de gelo servem eficientemente como centros de recolha de água líquida superresfriada que atingem rapidamente dimensões de pedras de granizo (Houze Jr, 2014). 

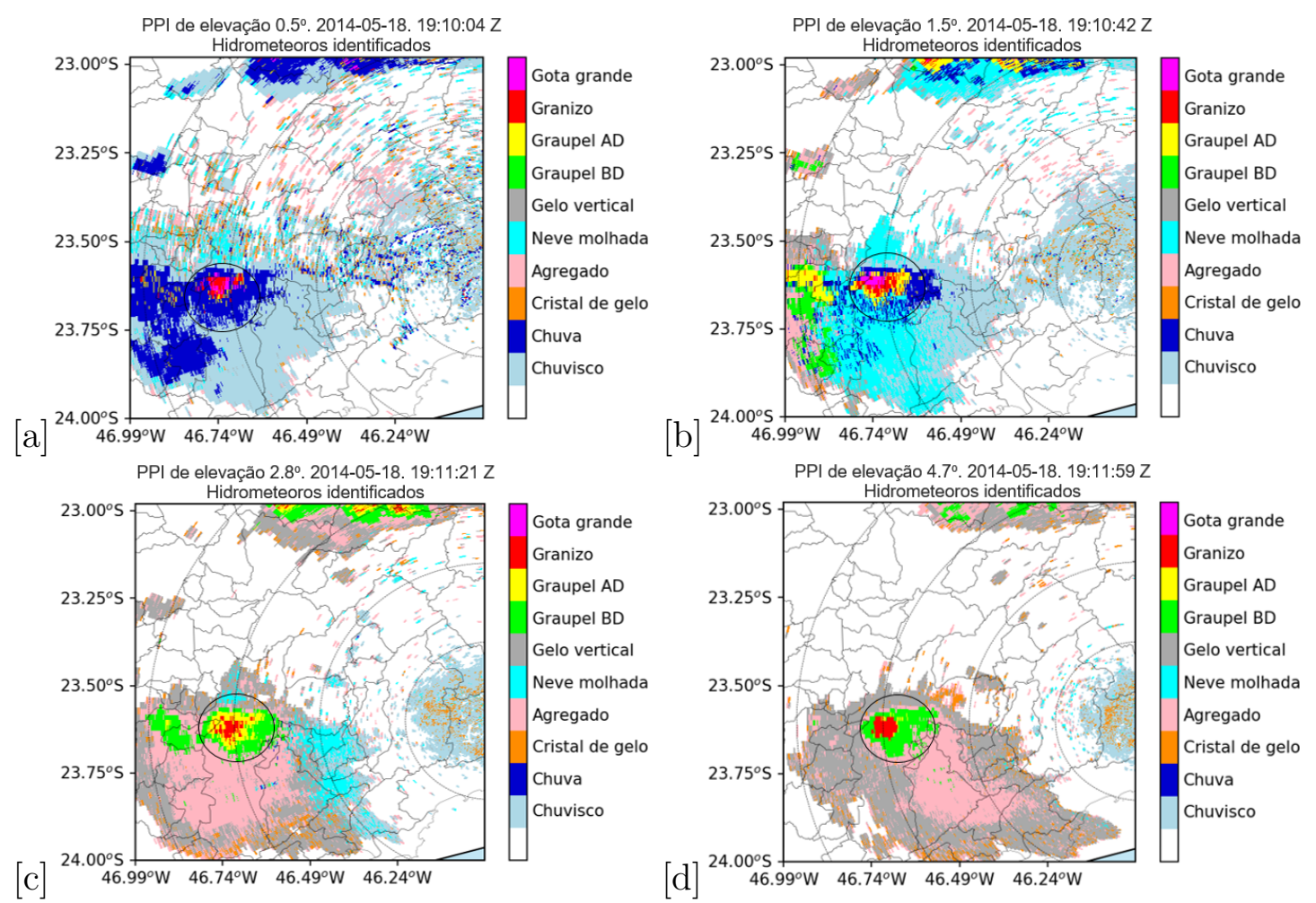

Figura 3.29: PPIs de ângulo de elevação de $0.5^{\circ}$ (a), $1.5^{\circ}$ (b), $2.8^{\circ}$ (c) e $4.7^{\circ}$ (d) da classificação de hidrometeoros do radar SPOL no dia 18 de Maio de 2014, às 1910 UTC. A escala de cores apresenta as 10 classificações dos hidrometeoros: Gota de água, Granizo, Graupel AD, Graupel BD, Gelo vertical, Neve molhada, Agregado, Cristal de gelo, Chuva e Chuvisco. Circunferências concêntricas estão espaçadas a cada $25 \mathrm{~km}$. O radar meteorológico SPOL está centro da menor circunferência concêntrica. Longitudes, latitudes, contornos dos municípios de São Paulo são indicados.

$\mathrm{Na}$ sequência de PPIs, entre o ângulo mais alto $4.7^{\circ}$ de elevação e o ângulo mais baixo $0.5^{\circ}$ de elevação, nota-se a profundidade da coluna vertical da camada de granizo, concentrado no núcleo da célula convectiva, área destacada (Fig. 3.29).

A alta concentração de granizo acima da isoterma $0^{\circ} \mathrm{C}$, permitiu que uma parte precipitasse sem derreter, provavelmente até à superfície, e outra parte que precipitou na forma de gota grande, resultante do derretimento do granizo a partir da isoterma $0^{\circ} \mathrm{C}$, área destacada (Fig. 3.29a).

A Fig. 3.30 mostra a CI sobre o centro geométrico da RMSP (áreas de adensamento urbano) com as mesmas características microfísicas ilustra na Fig. 3.29. Nota-se uma diminuição significativa na concentração de gota de grande, e ligeira diminuição na concentração de graniza, área destacada (Fig. 3.30a). 
Por que a diminuição da concentração desses hidrometeoros? A resposta esta acima da isoterma ${ }^{\circ} \mathrm{C}$ (Fig. 3.30d), onde observa-se que a concentração de graupel BD e granizo diminuiu significativamente. Isso pressupõem que a gota grande tem origem do derretimento do granizo a partir da isoterma $0^{\circ} \mathrm{C}$. À medida que as pedras granizo precipitam da isoterma $0^{\circ} \mathrm{C}$, a temperaturas $>0^{\circ} \mathrm{C}$ até às regiões inferiores da célula convectiva, Uma parte descongela, transformando-se em gotas grandes e outra parte precipita intacta nas condições termodinâmica sob influência de rotação ciclônica. Ou seja, a quantidade de granizo produzida acima da isoterma $0^{\circ} \mathrm{C}$ influi na quantidade de produção de gotas grandes nas regiões inferiores da célula convectiva. Que é consistente com que foi observado por Lin e Wang (1997), afirmaram que quase toda a chuva à superfície durante eventos convectivos, provêm do derretimento de granizo e graupel.
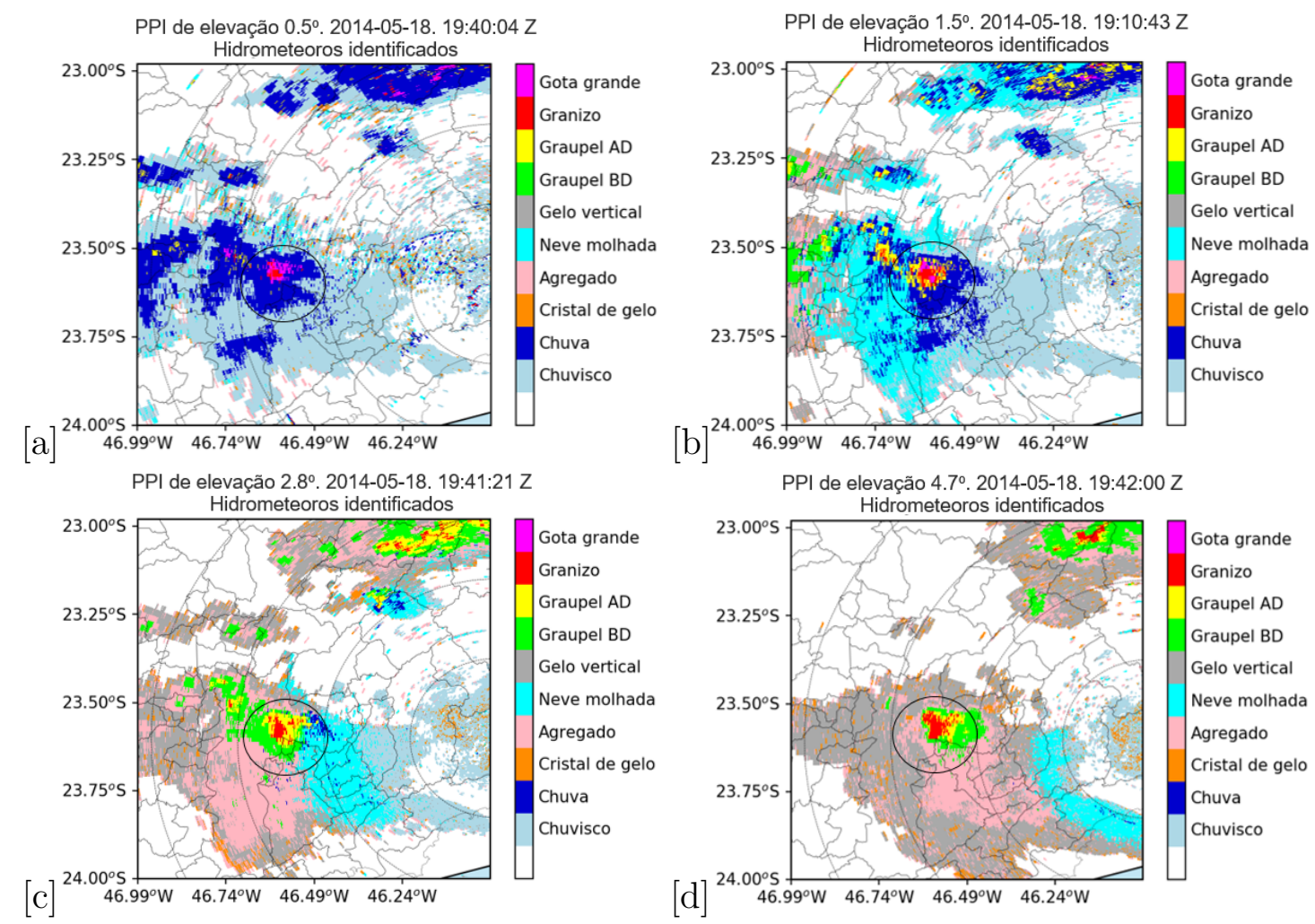

Figura 3.30: Idem Fig. 3.29, mas às 1940 UTC.

Na Fig. 3.31a, b, é possível observar a evidência do rastro da tempestade de granizo na zona oeste do município de São Paulo, centro geométrico da RMSP. Nota-se camada expressiva de pedras de granizo sendo retirada da via pública e transportada por caimões. 
As partículas de gelo também crescem por coleção, seja de gotas de água quanto por outras partículas de gelo. As gotículas super-resfriadas aderem aos cristais de gelo por contato mecânico (acrescimento de graupel ou riming) em que os cristais de gelo crescem por difusão até alcançarem um tamanho em que começam a coletar gotículas de água (Yau e Rogers, 1996). As gotas de água super-resfriadas colidem com o cristal de gelo e congelam. Se a temperatura do cristal de gelo e da gotícula for $>-15^{\circ} \mathrm{C}$, a gotícula tende a espalhar pela superfície antes de congelar completamente, tomando a forma do cristal de gelo (Yau e Rogers, 1996). Se a temperatura for $<-15^{\circ} \mathrm{C}$, a gotícula mantém sua forma e congela imediatamente quando atinge o cristal de gelo, que leva a uma estrutura mais porosa do granizo (Fig. 3.31c, d), cuja densidade é uma função do tamanho da gota, da taxa de acresção e a temperatura ambiente (Yau e Rogers, 1996). Nota-se pelo tipo de granizo de diâmetro relativamente pequeno, característico de tempestade de célula única (Convecção isolada) e apresentando bolhas de ar no seu interior (Fig. 3.31c, d).
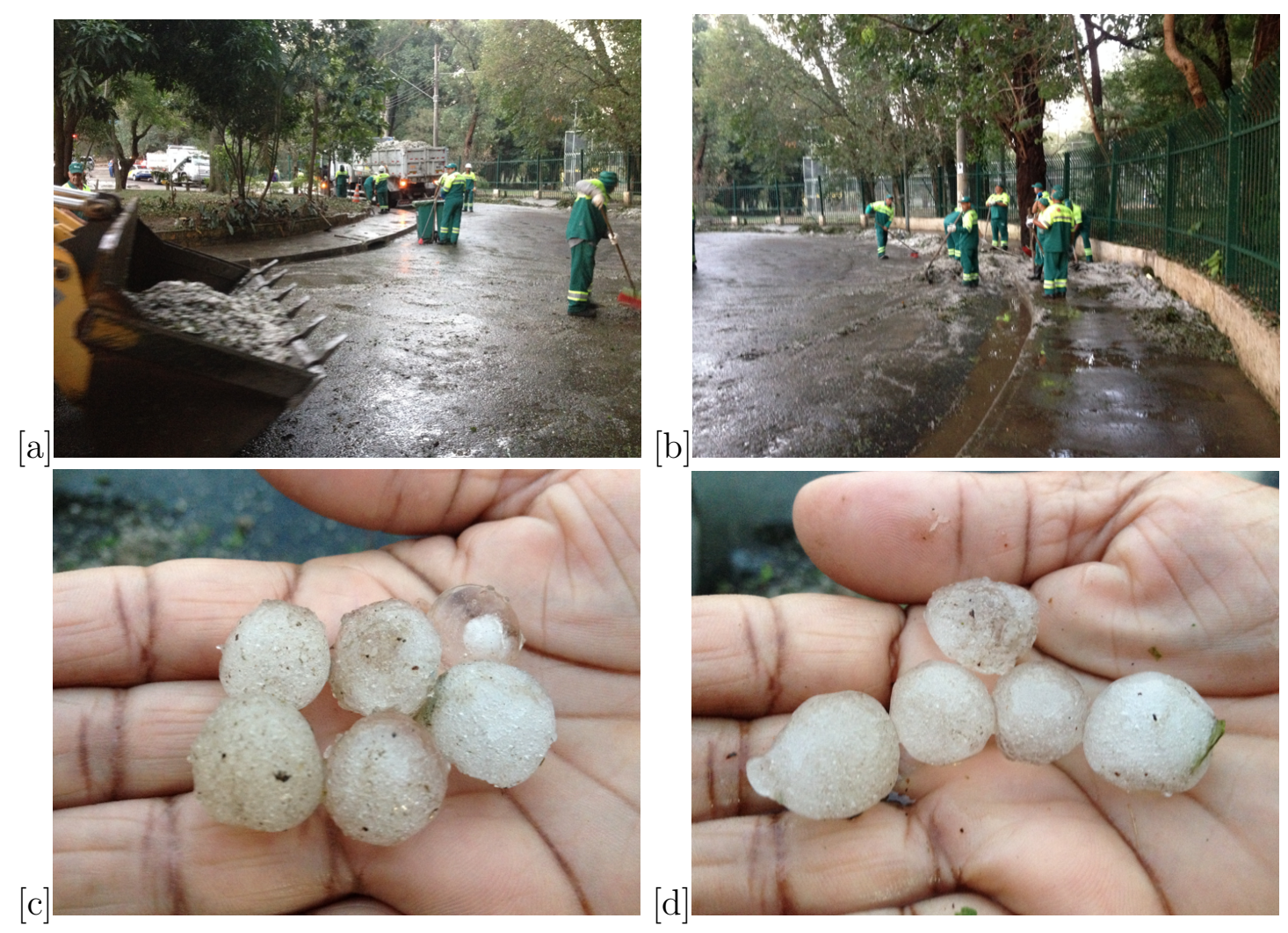

Figura 3.31: Imagens de recolha da camada de gelo no dia seguinte após a passagem da tempestade sobre a zona oeste do município de São paulo, centro geométrico da RMSP (a) e (b). Pedras de granizo com bolhas de ar dentro das mesmas (c) e (d). Crédito: Augusto José Pereira Filho. 
Minutos depois, nota-se diminuição significativa da concentração de granizo acima da isoterma $0^{\circ} \mathrm{C}$, quando a célula convectiva encontrava-se sobre a zona leste do município da São Paulo, aproximando-se do radar SPOL (Fig. 3.32d). O feixe do ângulo de elevação 0.5 ${ }^{o}$ faz varreduras nas regiões mais baixas da célula convectiva, onde observa-se um aumento na concentração de granizo e menor concentração de gota grande (Fig. 3.32a). Entretanto, observa-se maior concentração de gota grande do que do que a concentração de granizo abaixo da isoterma $0^{\circ} \mathrm{C}$ (Fig. 3.32b).

Por que verifica-se maior concentração na base da isoterma $0^{\circ} \mathrm{C}$ e menor concentração de gotas grandes nas regiões mais baixas da célula convectiva? Essa variação na concentração de gota grande é causada pelo mecanismo de quebra causada por força de arrasto aerodinâmica e pelo mecanismo de colisão seguida de quebra das gotas grandes de seus trajetos da base da isoterma $0^{\circ} \mathrm{C}$ para regiões mais baixas da célula convectiva, tal como observado por (Rosenfeld e Ulbrich, 2003).
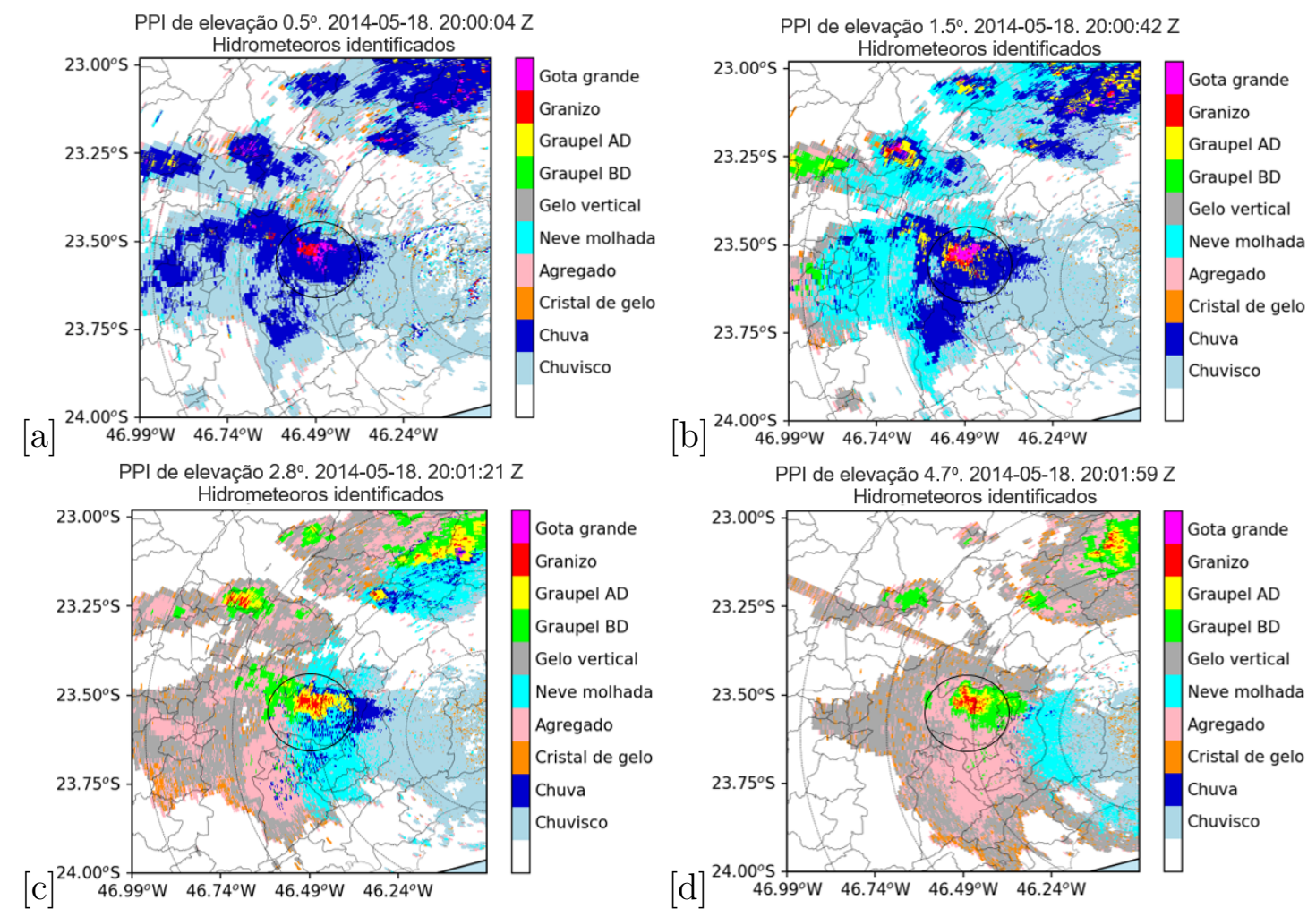

Figura 3.32: Idem Fig. 3.29, mas às 2000 UTC.

A classificação de hidrometeoros (Fig. 3.33d, e) identifica o aumento da concentração 
de granizo acima da isoterma $0^{\circ} \mathrm{C}$ do que no cenário anterior da célula convectiva, quando encontrava-se sobre a divisa dos municípios da RMSP, região de menor adensamento urbano comparada à região central do município de São Paulo.

O adensamento urbano verticalizado influenciou negativamente na dinâmica e termodinâmica da CI induzida por rotação ciclônica? Observou-se que a concentração de granizo acima da isoterma $0^{\circ} \mathrm{C}$ diminuiu, quando a célula convectiva passou sobre a região central do município de São Paulo, área de maior adensamento urbano verticalizado do estado de São Paulo, deslocando-se para zona leste da cidade de São Paulo. Notou-se que a concentração de granizo acima isoterma $0^{\circ} \mathrm{C}$ aumentou, quando a célula convectiva passou sobre a zona leste, área de menor adensamento urbano verticalizado, propagando-se região de Guarulhos.

Nota-se que a concentração de granizo é menor para menores ângulos de elevação, área destacada na Fig. 3.33. Provavelmente, quando a alta concentração de granizo precipitou das regiões mais frias (temperaturas $<0^{\circ} \mathrm{C}$ ) para regiões mais quentes (temperaturas $>$ $0^{\circ} \mathrm{C}$ ). A diminuição da quantidade do granizo deve estar relacionada, provavelmente, com duas possibilidade devido a temperatura ambiente. Primeiro, o derretimento de granizo mudando de fase sólida para fase líquida; segundo, o granizo embebido na água derretida, como observado por Bringi et al. (1984, 1986); Rasmussen e Heymsfield (1987). Esses resultados corroboram com análise de Lin e Wang (1997), que afirmaram que quase toda a chuva à superfície durante eventos convectivos provém do derretimento de granizo e graupel. A segunda possibilidade, provavelmente, induziu o radar SPOL a confundir granizo embebido na água derretida por gota gingante. 


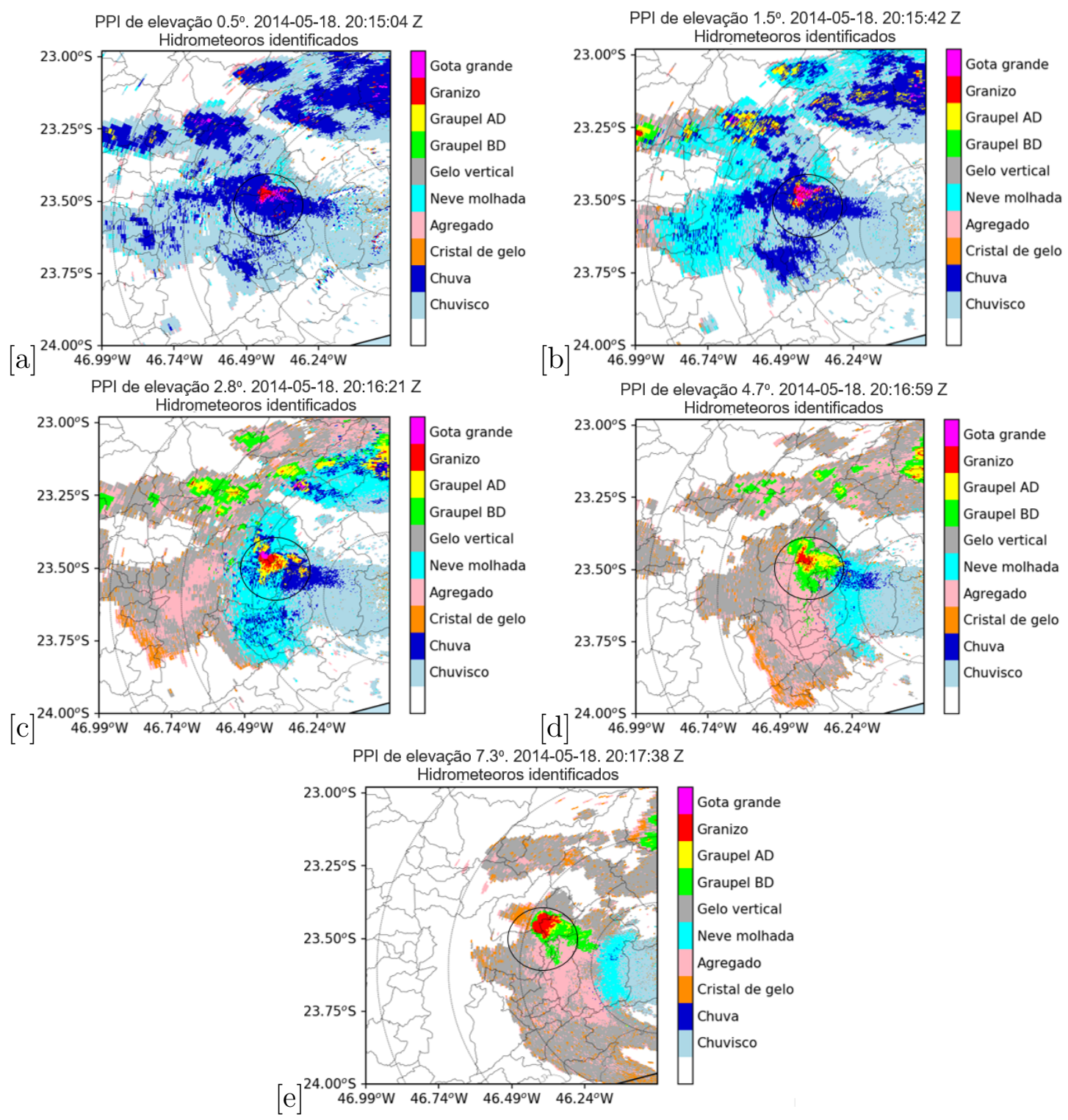

Figura 3.33: PPIs de ângulo de elevação de $0.5^{\circ}$ (a), $1.5^{\circ}$ (b), $2.8^{\circ}$ (c), $4.7^{\circ}$ (d) e $7.3^{\circ}$ (e) da classificação de hidrometeoros do radar SPOL no dia 18 de Maio de 2014, às 2015 UTC. A escala de cores apresenta as 10 classificações dos hidrometeoros: Gota de água, Granizo, Graupel AD, Graupel BD, Gelo vertical, Neve molhada, Agregado, Cristal de gelo, Chuva e Chuvisco. Circunferências concêntricas estão espaçadas a cada $25 \mathrm{~km}$. O radar meteorológico SPOL está centro da menor circunferência concêntrica. Longitudes, latitudes, contornos dos municípios de São Paulo são indicados.

A Fig. 3.34 mostra o método de chuva $\mathrm{R}\left(\mathrm{K}_{D P}\right), \mathrm{R}\left(\mathrm{K}_{D P}, \mathrm{Z}_{D R}\right), \mathrm{R}\left(\mathrm{Z}, \mathrm{Z}_{D R}\right), \mathrm{R}(\mathrm{Z})$ durante a evolução espaço-temporal na sequência de PPI de elevação 0.5º às 1910 UTC, às 1940 UTC, às 2000 UTC e às 2015 UTC da célula convectiva de origem de urbana. O método mostra chuva intensa no núcleo da célula convectiva, áreas destacadas (Fig. 3.34), que corrobora com a classificação dos hidrometeoros. A tonalidade azul $\mathrm{R}\left(\mathrm{K}_{D P}\right)$ 
corresponde a chuva mais intensa, seguidas da $\mathrm{R}\left(\mathrm{K}_{D P}, \mathrm{Z}_{D R}\right)$ na tonalidade cinza e $\mathrm{R}(\mathrm{Z}$, $\mathrm{Z}_{D R}$ ) na tonalidade laranja.
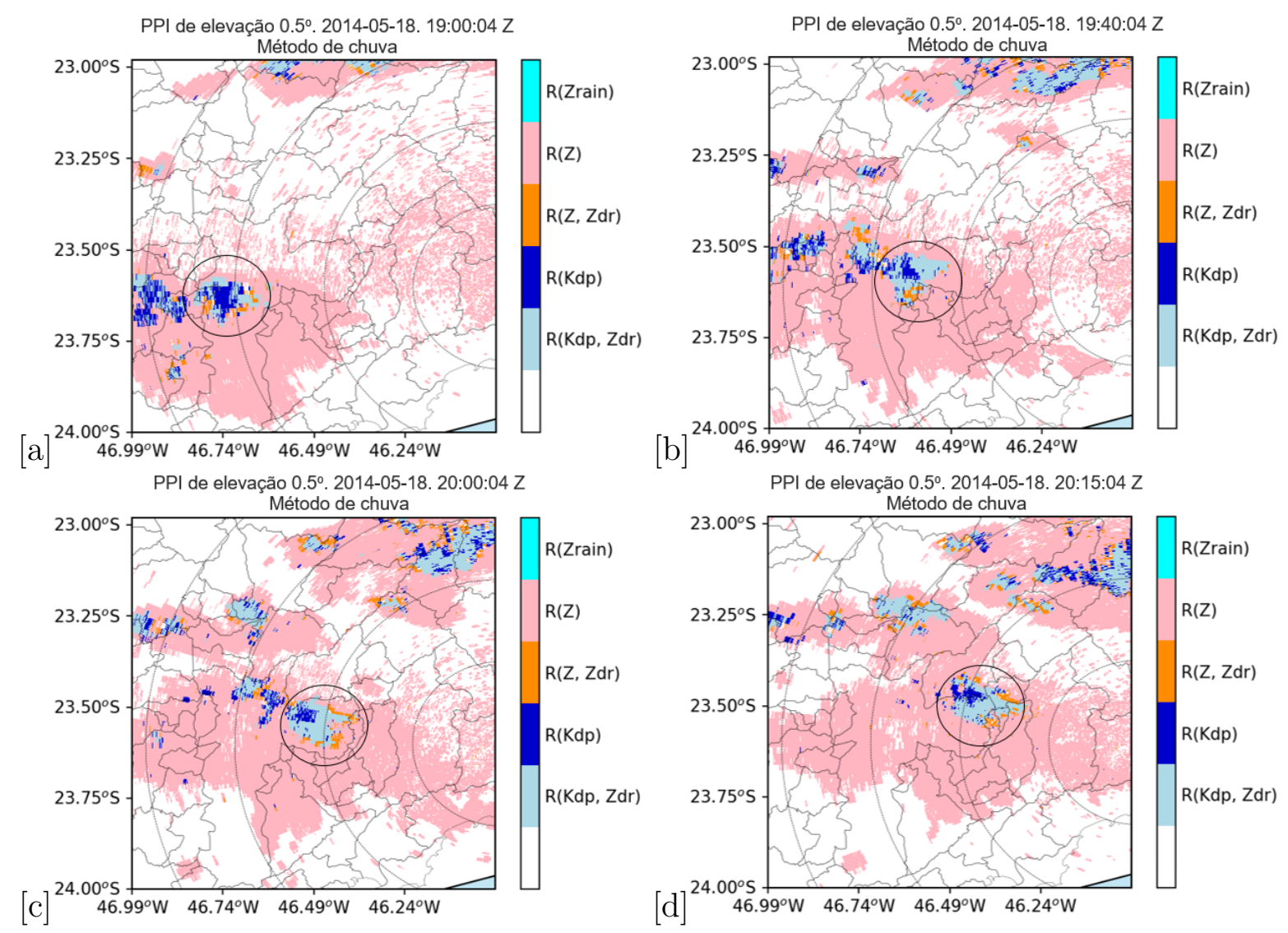

Figura 3.34: PPI de ângulo de elevação de $0.5^{\circ}$ do radar SPOL às 1900 UTC (a), às 1940 UTC (b), às 2000 UTC (c) e às 2015 UTC (d) dos métodos de chuva do dia 18 de Maio de 2014. A escala de cores apresenta os 4 métodos de chuva: $\mathrm{R}\left(\mathrm{K}_{D P}\right), \mathrm{R}\left(\mathrm{K}_{D P}, \mathrm{Z}_{D R}\right), \mathrm{R}\left(\mathrm{Z}, \mathrm{Z}_{D R}\right), \mathrm{R}(\mathrm{Z}) \mathrm{R}\left(\mathrm{K}_{D P}\right), \mathrm{R}\left(\mathrm{K}_{D P}, \mathrm{Z}_{D R}\right), \mathrm{R}(\mathrm{Z}$, $\left.\mathrm{Z}_{D R}\right), \mathrm{R}(\mathrm{Z})$ e $\mathrm{R}($ rain).

A Fig. 3.44 mostra a sequência de PPIs de elevação $0.5^{\circ}$ da massa de água líquida precipitante durante a evolução espaço-temporal da célula convectiva. Nas áreas destacadas, com maior concentração da massa de água líquida, é o núcleo da célula convectiva, onde impera a corrente ascendente (Fig. 3.44). Observa-se aumento da concentração da massa de água líquida com valores $\sim 7 \mathrm{~g} \mathrm{~m}^{-3}$, à medida que a célula convectiva propaga-se à leste da RMSP, aproximando-se do radar SPOL. Nota-se espaços ocos entre as massas de água líquida, causada pela precipitação mista de massa de água sólida. 

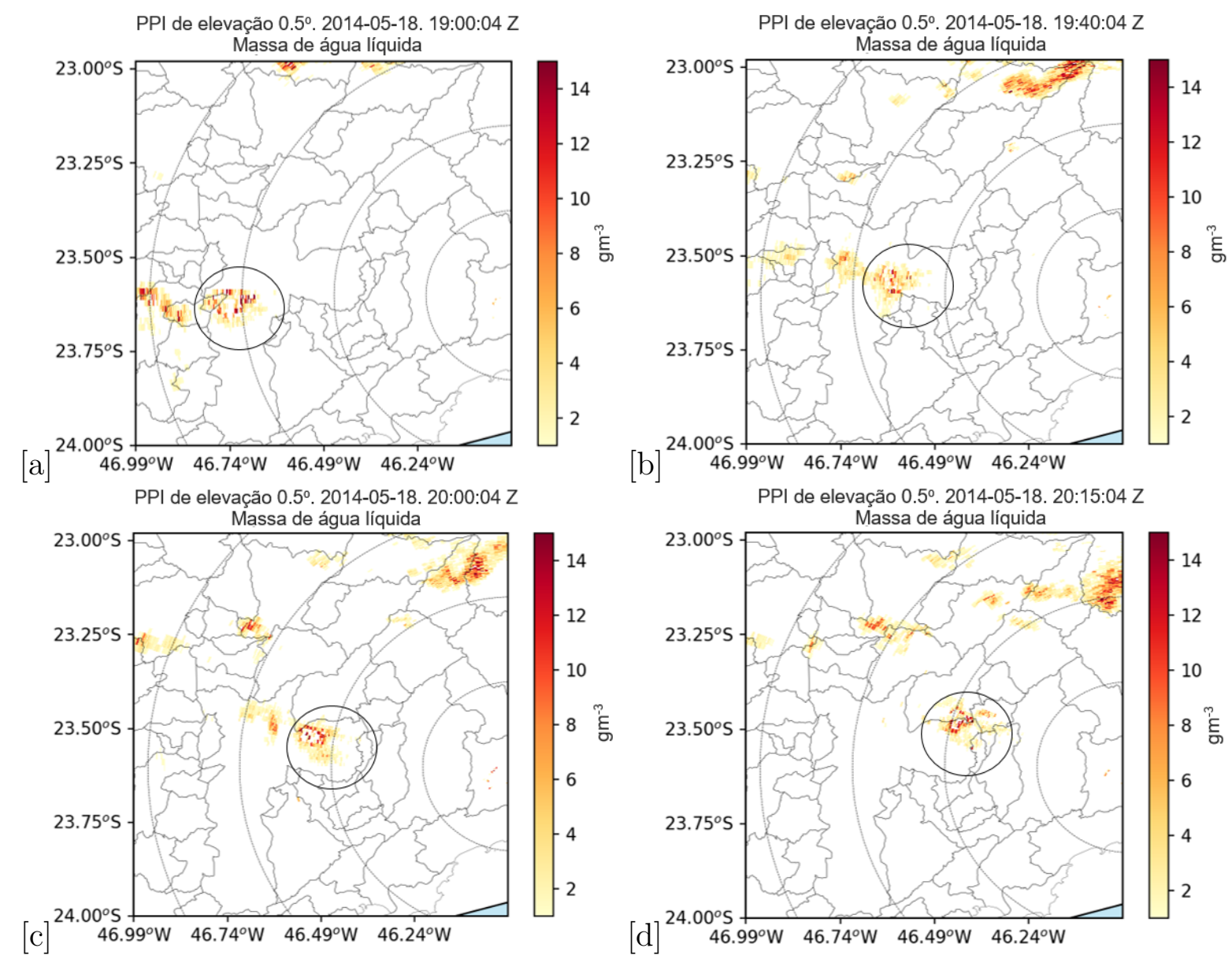

Figura 3.35: PPIs de ângulo de elevação de $0.5^{\circ}$ do radar SPOL às 1900 UTC (a), às 1940 UTC (b), às 2000 UTC (c) e às 2015 UTC (d) da massa de água sólida $\left(\mathrm{g} \mathrm{m}^{-3}\right)$ do dia 18 de Maio de 2014,. As escalas de cores estão indicados. Circunferências concêntricas estão espaçadas a cada $25 \mathrm{~km}$. O radar meteorológico SPOL está centro da menor circunferência concêntrica. Longitudes, latitudes, contornos dos municípios são indicados.

PPI de elevação $0.5^{\circ}$ da massa de água sólida $\left(\mathrm{g} \mathrm{m}^{-3}\right)$ com o radar SPOL no dia 18 de Maio de 2014, (a) às 1900 UTC, (b) às 1940 UTC, (c) às 2000 UTC e (d) às 2015 UTC.

A Fig. 3.36 mostra a sequência de PPIs de elevação $0.5^{\circ}$ da massa de água líquida precipitante durante a evolução espaço-temporal da célula convectiva. Nota-se a diminuição na concentração da massa de água sólida à medida que a célula convectiva aproxima-se do radar, porque o feixe faz varredura nas regiões mais baixas da nuvem. Nota-se também espaços ocos entre as massas de água sólida preenchida por massas de água líquida. 

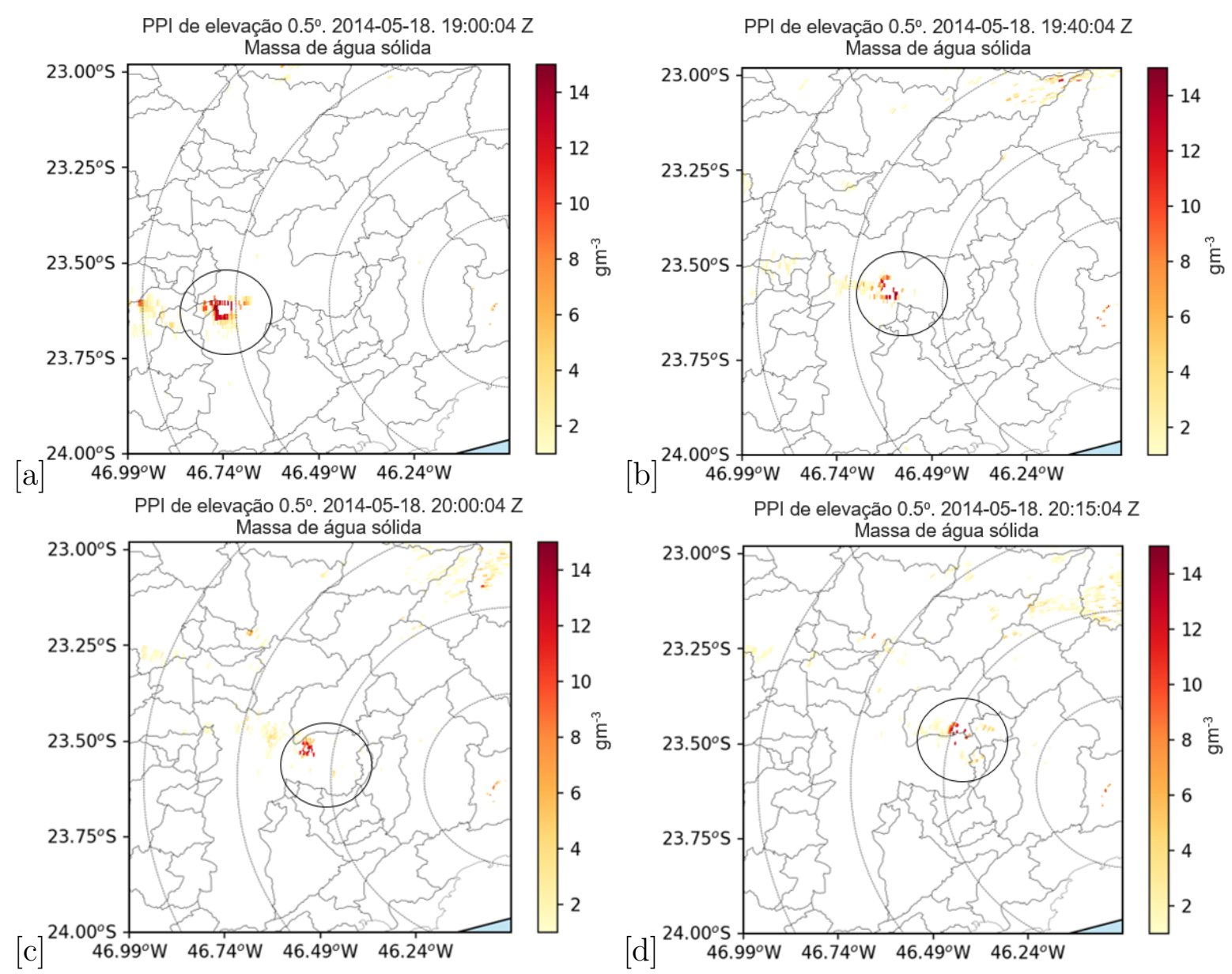

Figura 3.36: Idem Fig. 3.44, mas para massa de água sólida.

A Fig. 3.37 mostra a classificação dos hidrometeoros durante a evolução espaçotemporal da célula convectiva sobre as regiões de Guarulhos, Itaquaquecetuba e Arujá. A região de chuva aumentou, mas ainda é identificada granizos e gotas grandes no núcleo da célula convectiva, ou seja, a célula convectiva apresenta as mesmas características microfísicas no seu núcleo, comparado há 2 horas antes (Fig. 3.37). A classificação de hidrometeoros indica claramente a ligeira diminuição da concentração das gotas grandes e granizos, na sequência dos PPIs, área destacada (Fig. 3.37). 

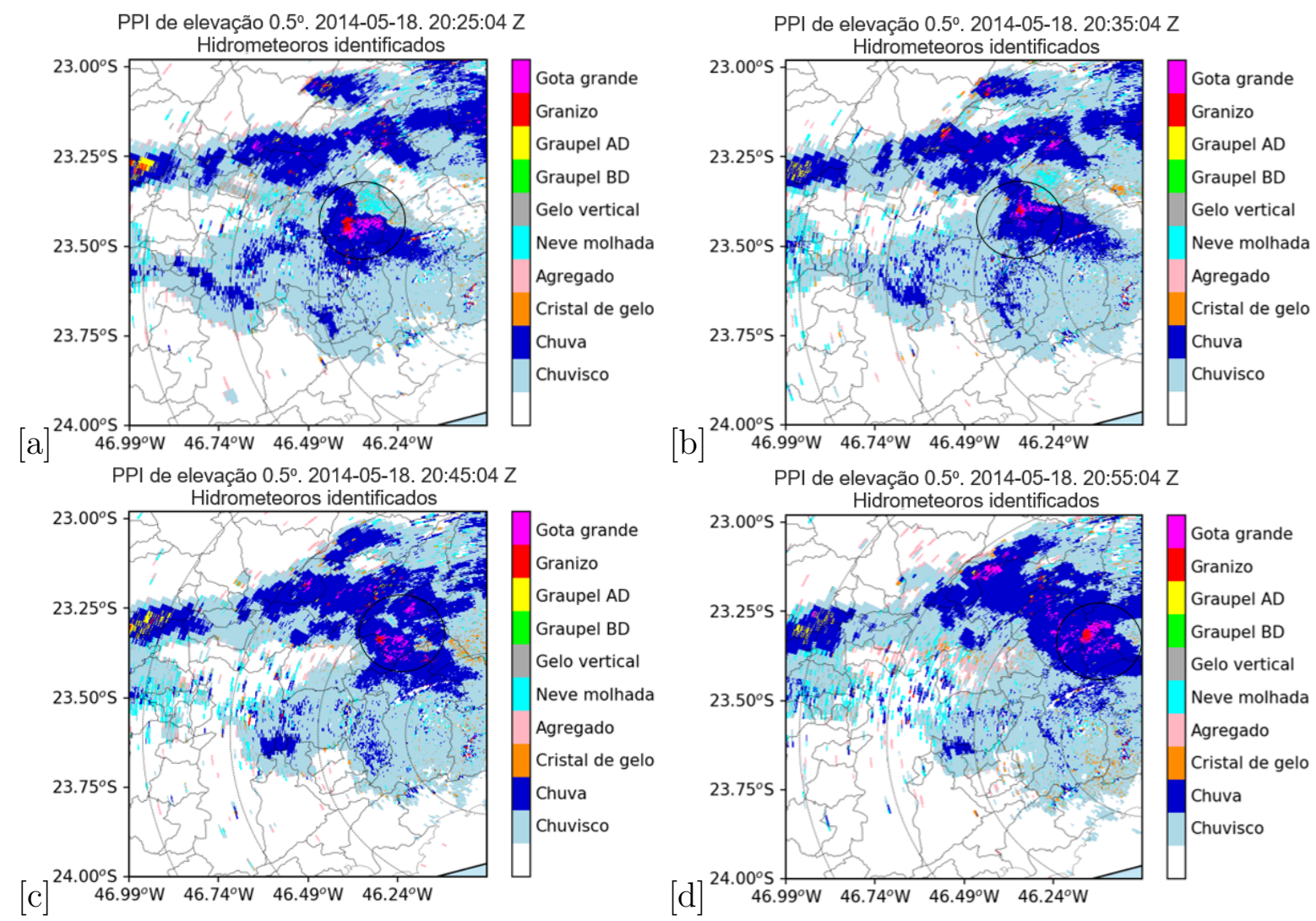

Figura 3.37: PPI de ângulo de elevação de $0.5^{\circ}$ do radar SPOL às 2025 UTC (a), às 2035 UTC (b), às 2045 UTC (c) e às 2055 UTC (d) da classificação dos hidrometeoros presentes na CI do dia 18 de maio de 2014. A escala apresenta as 10 classificações dos hidrometeoros: Gota de água, Granizo, Graupel AD, Graupel BD, Gelo vertical, Neve molhada, Agregados, Cristais de gelo, Chuva e Chuvisco. Circunferências concêntricas estão espaçadas a cada $25 \mathrm{~km}$. O radar meteorológico SPOL está centro da menor circunferência concêntrica. Longitudes, latitudes, contornos dos municípios são indicados.

A diminuição da concentração das gotas grandes e granizos observado na Fig. 3.37, provavelmente esta relacionado com a diminuição da produção de granizo acima da isoterma $0^{\circ} \mathrm{C}$, área destacada (Fig. 3.38). A célula convectiva entrou na fase terminal do ciclo de vida Fig. 3.38d). As correntes ascendentes provavelmente estão enfraquecidas e sem forças o suficiente para ejetar água líquida na parte superior da nuvem, acima da isoterma $0^{\circ}$, essencial para a produção de granizo, onde a água congela tornando-se embriões de cristais de gelo que promovem um crescimento rápido por deposição de vapor de água evaporada, que conduz a graupel e granizo. 

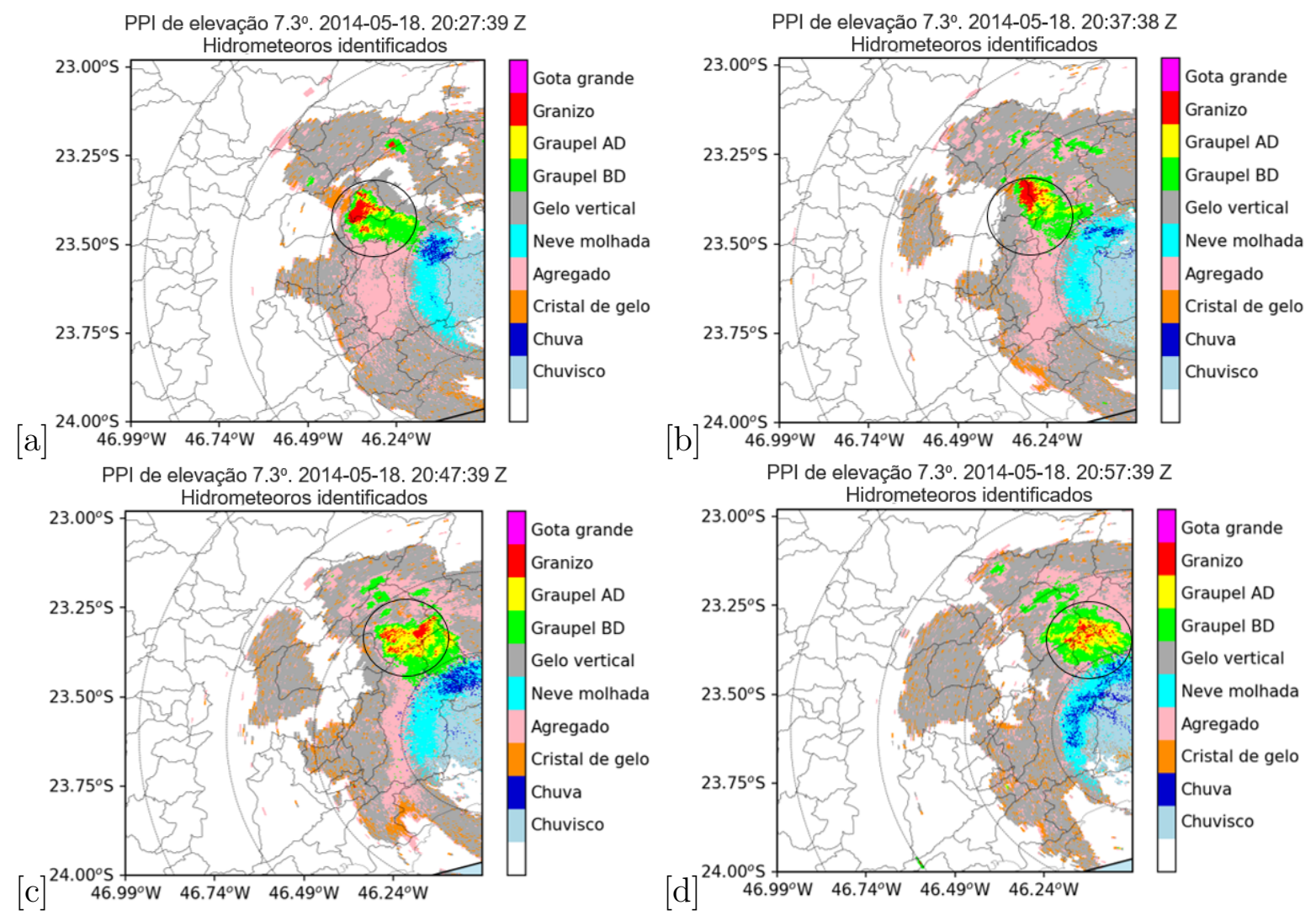

Figura 3.38: Idem Fig. 3.37, mas para $7.3^{\circ}$ de elevação.

A decadência da produção de granizo acima da isoterma $0^{\circ} \mathrm{C}$ impactou na produção chuva intensa. Nota-se uma clara redução da mancha azul escuro do método $\mathrm{R}\left(\mathrm{K}_{D P}\right)$ correspondente a chuva intensa, área destacada (Fig. 3.39). Mas observa-se a extensa mancha azul claro do método $\mathrm{R}\left(\mathrm{K}_{D P}, \mathrm{Z}_{D R}\right)$ correspondente a chuva relativamente intensa, área destacada (Fig. 3.39). Esse cenário mostra que a fase mista da nuvem é indispensável para a produção de chuva na RMSP. 

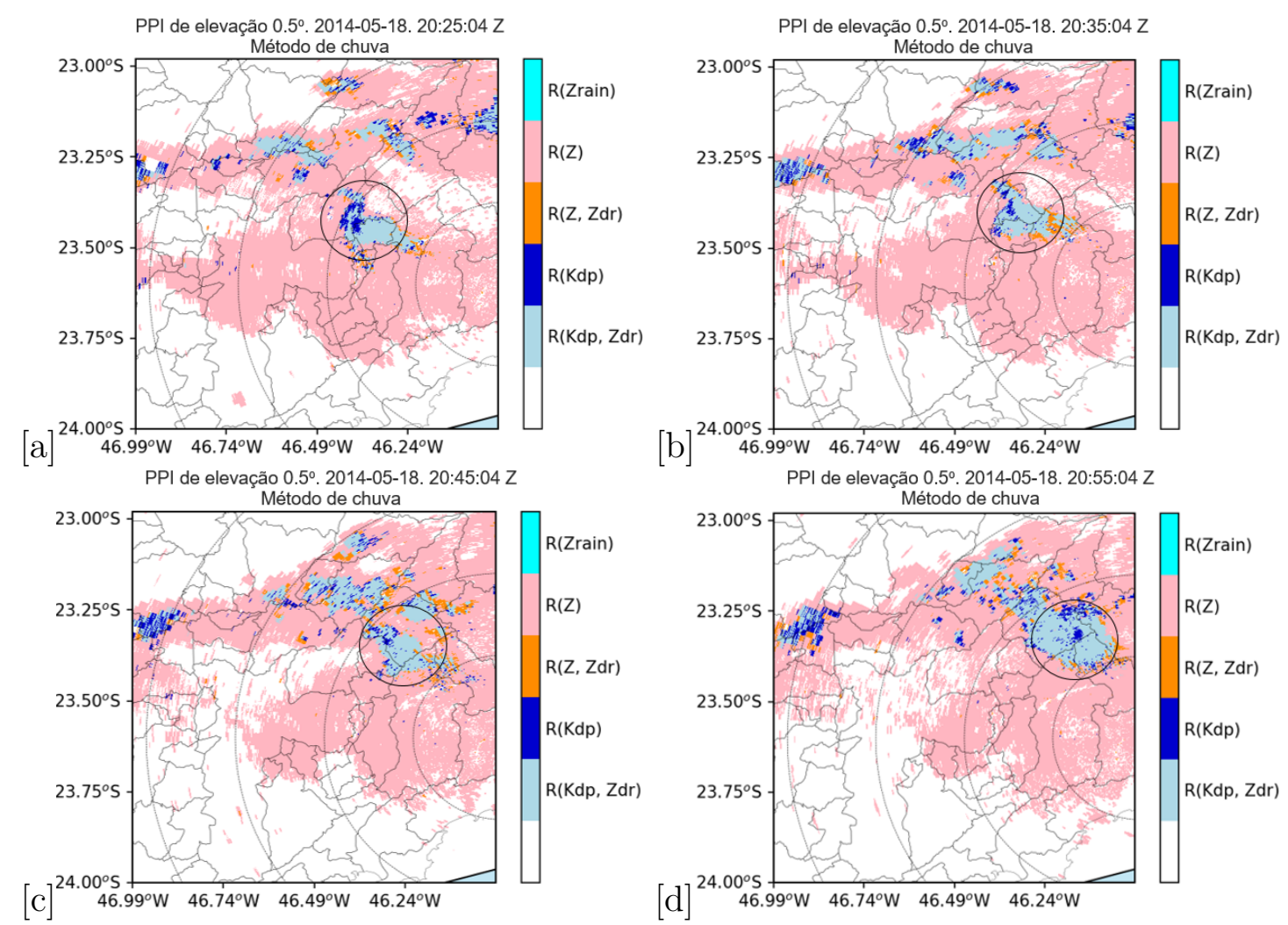

Figura 3.39: Idem Fig. 3.37, mas para método de chuva.

A Fig. 3.40 mostra a sequência de PPIs 0.5 de elevação das 1900 UTC, 1940 UTC, 2000 UTC, e 2015 UTc da quase linha de instabilidade de origem rural. A classificação dos hidrometeoros indicou predominância chuva com resquícios de gotas grandes e granizo. Observa-se pouquíssima precipitação de goras grandes e granizo quando comparada à célula convectiva de origem urbana. Talvez por não ser induzido por rotação ciclônica e não ser de origem urbana. 

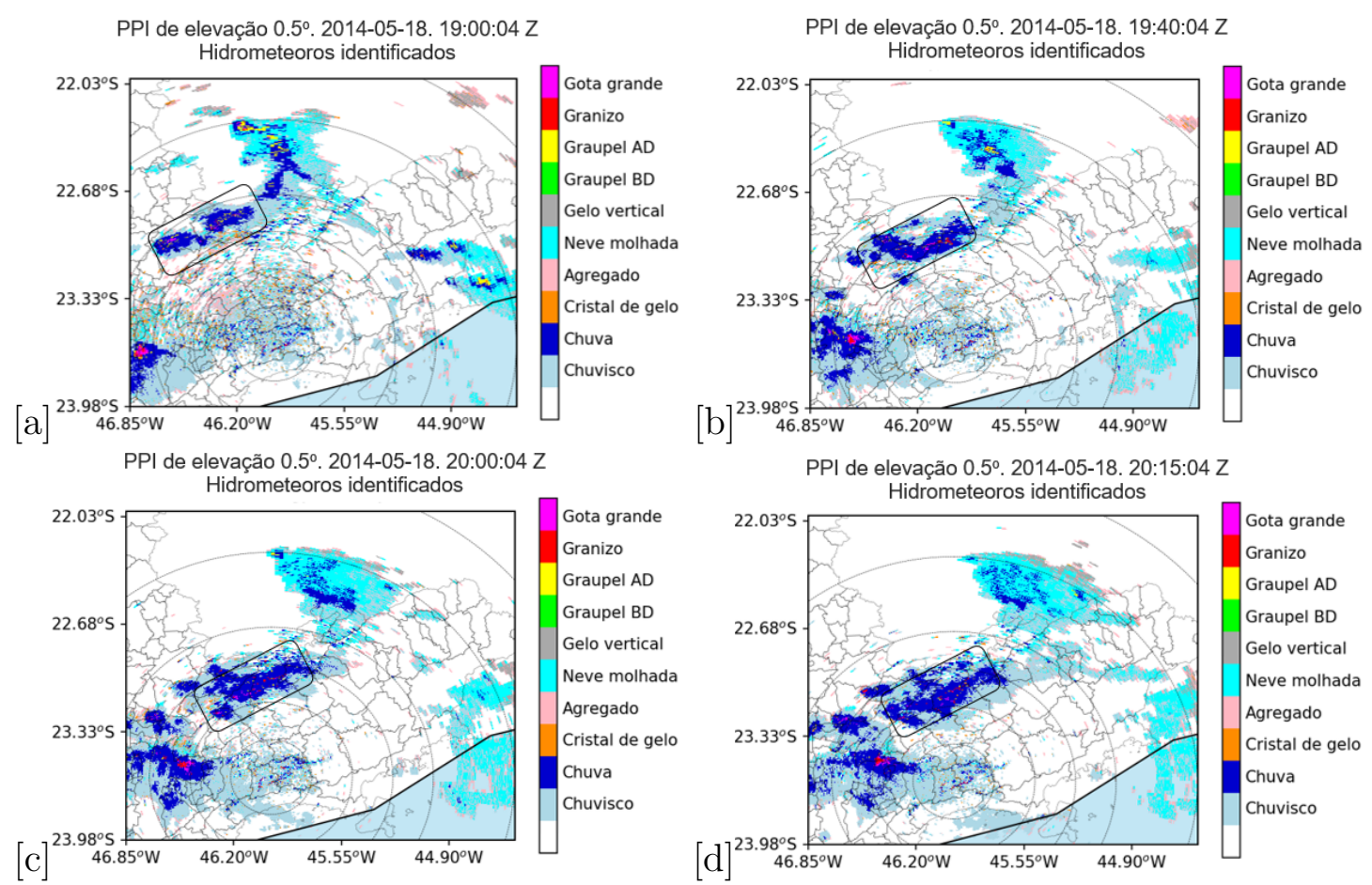

Figura 3.40: PPI de ângulo de elevação de $0.5^{\circ}$ do radar SPOL às 1900 UTC (a), às 1940 UTC (b), às 2000 UTC (c) e 2015 UTC (d) da classificação dos hidrometeoros presentes quase linha de instabilidade formada sobre a região rural do dia 18 de maio de 2014. A escala apresenta as 10 classificações dos hidrometeoros: Gota de água, Granizo, Graupel AD, Graupel BD, Gelo vertical, Neve molhada, Agregados, Cristais de gelo, Chuva e Chuvisco. Circunferências concêntricas estão espaçadas a cada $25 \mathrm{~km}$. O radar meteorológico SPOL está centro da menor circunferência concêntrica. Longitudes, latitudes, contornos dos municípios são indicados.

A quase ausência de hidrometeoros como granizo e gotas grandes nas regiões mais baixas da quase linha de instabilidade de origem rural, está relacionada com a pouca produção de granizo acima da isoterma ${ }^{\circ} \mathrm{C}$ (Fig. 3.41). A classificação de hidrometeoros indica a predominância de gelo vertical na quase linha de instabilidade. 

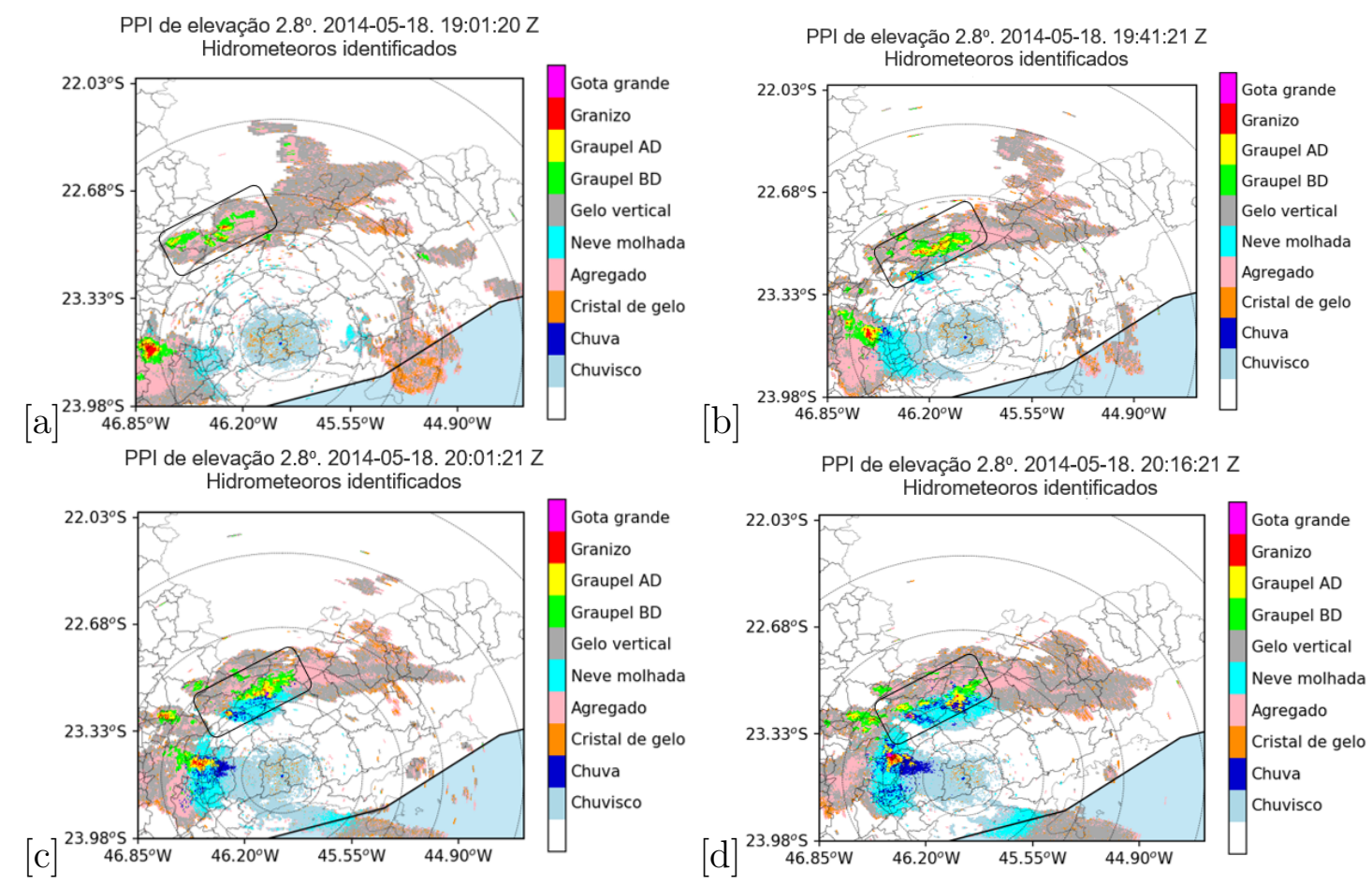

Figura 3.41: Idem Fig. 3.40, mas para PPI de elevação $2.8^{\circ}$.

O granizo é importante para a formação de gotas grandes e na intensidade da chuva. A baixa produção de granizo acima da isoterma $0^{\circ} \mathrm{C}$ impactou na diminuição da intensidade da chuva, nota-se quase a ausência da mancha azul do método $\mathrm{R}\left(\mathrm{K}_{D P}\right)$ relacionada a chuva intensa, área destacada (Fig. 3.42). 

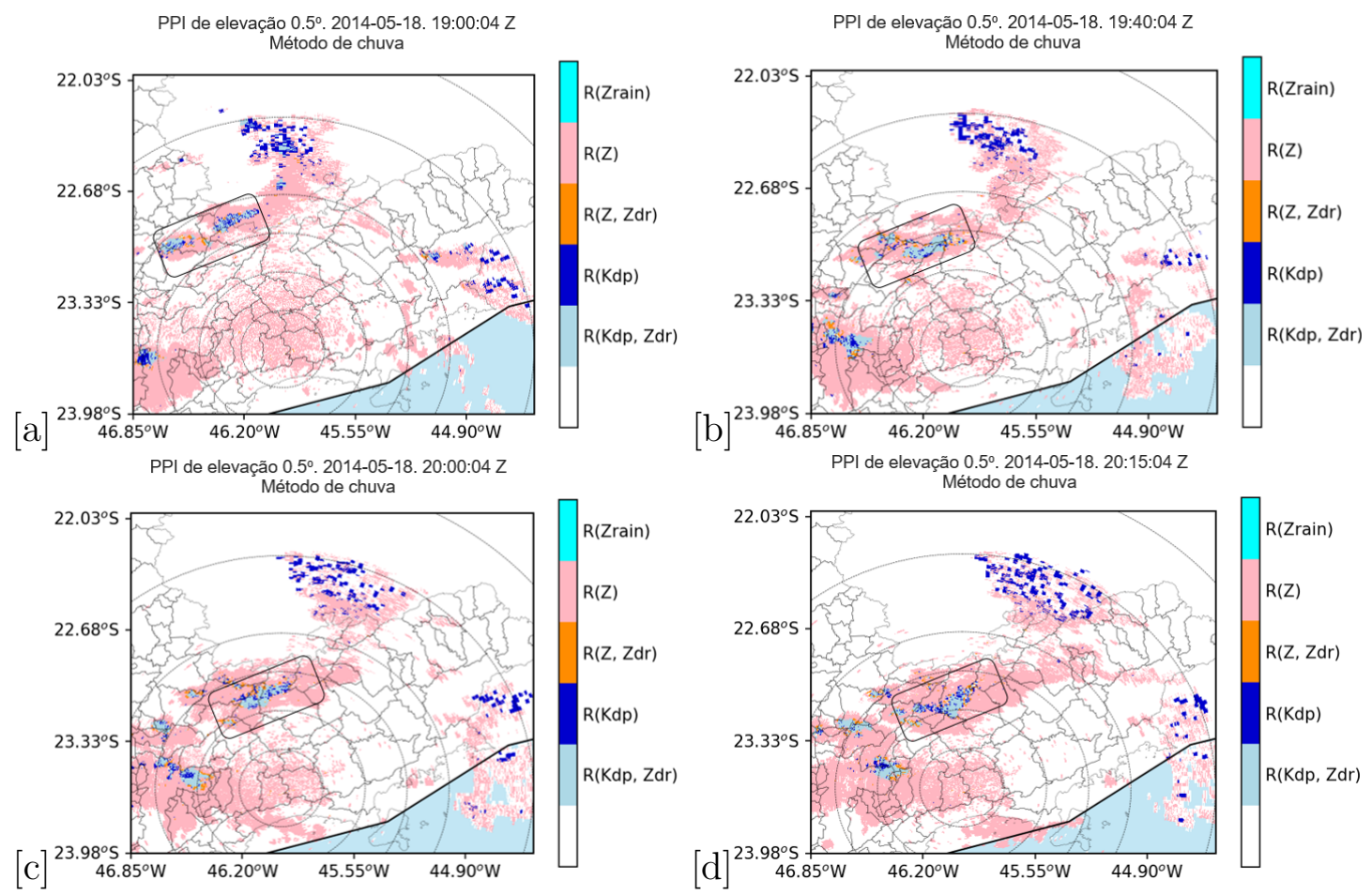

Figura 3.42: Idem Fig. 3.40 para o método de chuva.

A Fig. 3.43 mostra a sequência de PPIs de elevação $0.5^{\circ}$ da distribuição espacial das gotas de chuva durante a evolução espaço-temporal da quase linha de instabilidade de origem rural às 1900 UTC, às 1940 UTC, às 2000 UTC, e às 2015 UTC. Observa-se gotas de chuva com $\sim 2 \mathrm{~mm}$ de diâmetro médio, área destacada. O diâmetro das gotas de chuva dessa célula convectiva são menores comparadas às gotas de chuva da célula convectiva de origem urbana. 

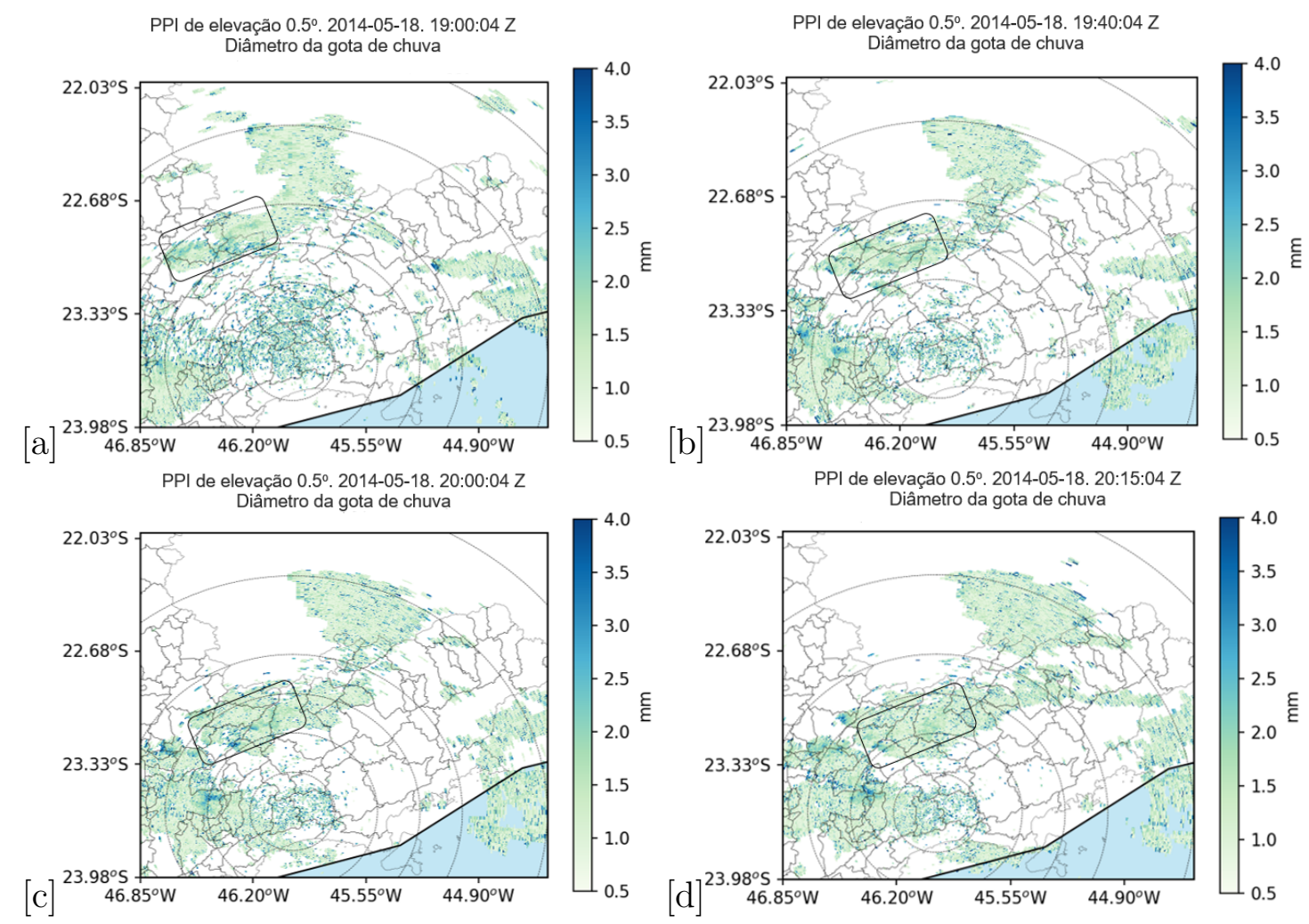

Figura 3.43: Idem Fig. 3.40, mas para gotas de chuva.

A Fig. 3.44 mostra a concentração de massa de água líquida variando entre 4 e $8 \mathrm{~g} \mathrm{~m}^{-3}$. A concentração é mais consistente comparada a da célula convectiva de origem urbana, devido a baixíssima presença de massa de de água sólida. Nota-se que essa não apresenta áreas ocas provocadas por excesso de massa de água sólida como foi observado na célula convectiva de origem urbana. 

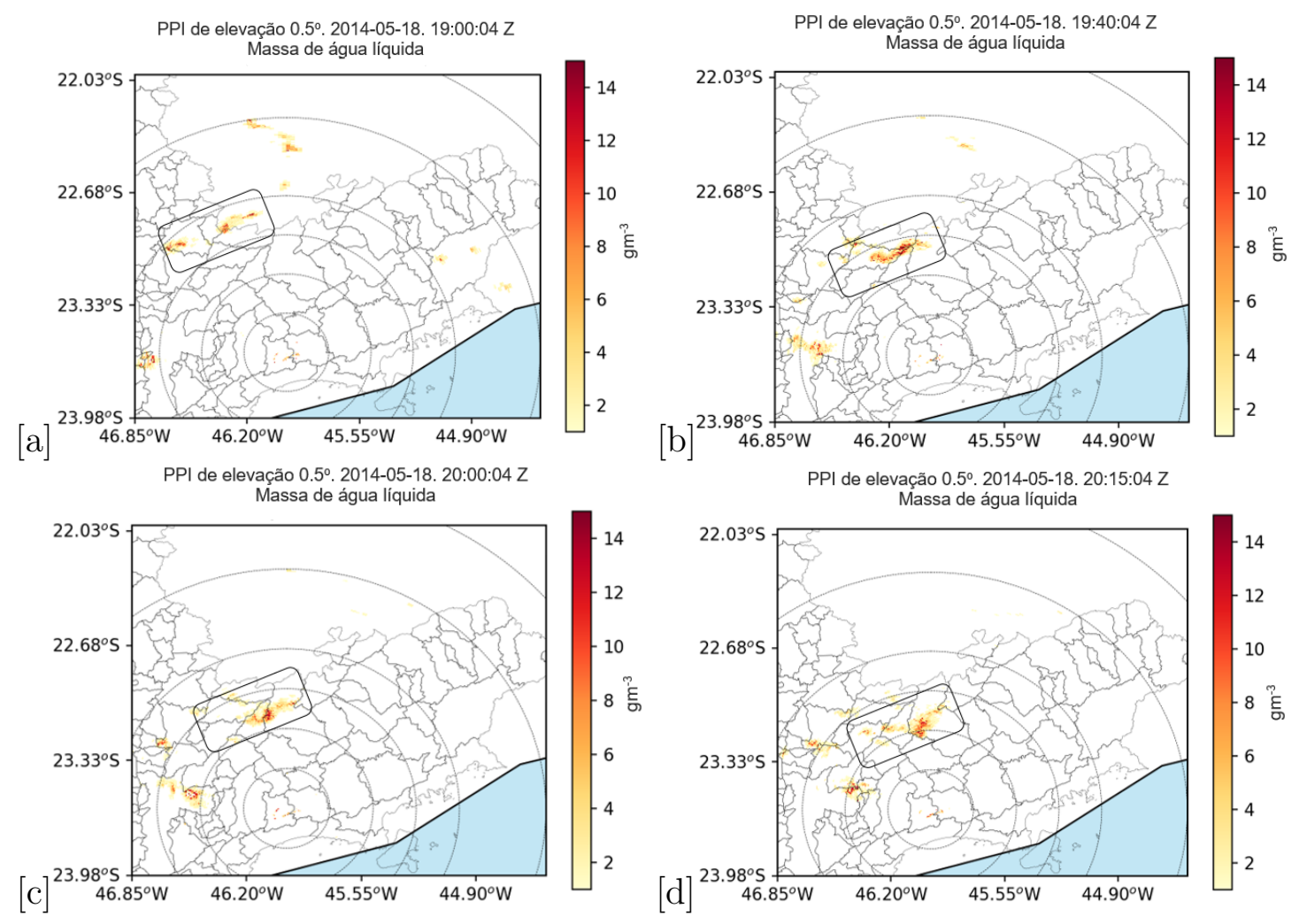

Figura 3.44: Idem Fig. 3.40, mas para a massa de água líquida.

A Fig. 3.45 mostra a baixíssima concentração de massa de água sólida devido a ausência de precipitação de granizo, consequência da baixa produção de graupel de alta densidade e granizo acima da isoterma ${ }^{\circ} \mathrm{C}$. 

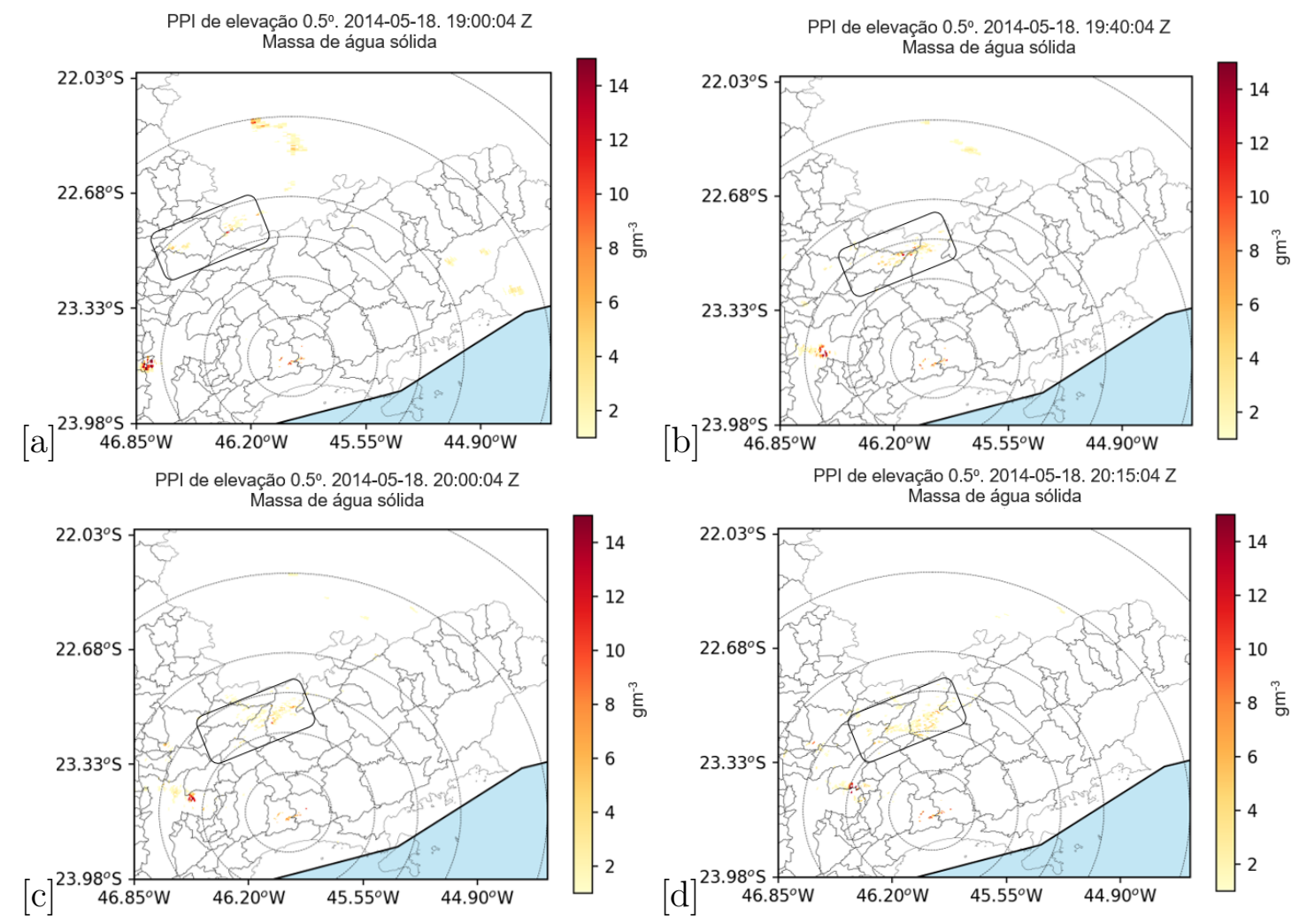

Figura 3.45: Idem Fig. 3.40, mas para a massa de água sólida.

A Fig. 3.46 mostra a sequência de PPIs de elevação $0.5^{o}$ da taxa de chuva $\left(\mathrm{mm} \mathrm{h}^{-1}\right)$ durante a evolução espaço-temporal da célula convectiva de origem urbana e da quase linha de instabilidade de origem rural. Nota-se taxa de chuva superior a $120 \mathrm{~mm} \mathrm{~h}^{-1}$ no núcleo da célula convectiva de origem urbana, área destacada (Fig. 3.46). Após a passagem da célula convectiva sobre o centro geométrico da RMSP, a produção de granizo aumentou acima da isoterma $0^{\circ} \mathrm{C}$ e consequentemente a precipitação de gotas grandes aumentou, que aumentou a taxa de chuva, área destacada (Fig. 3.46c, d) 

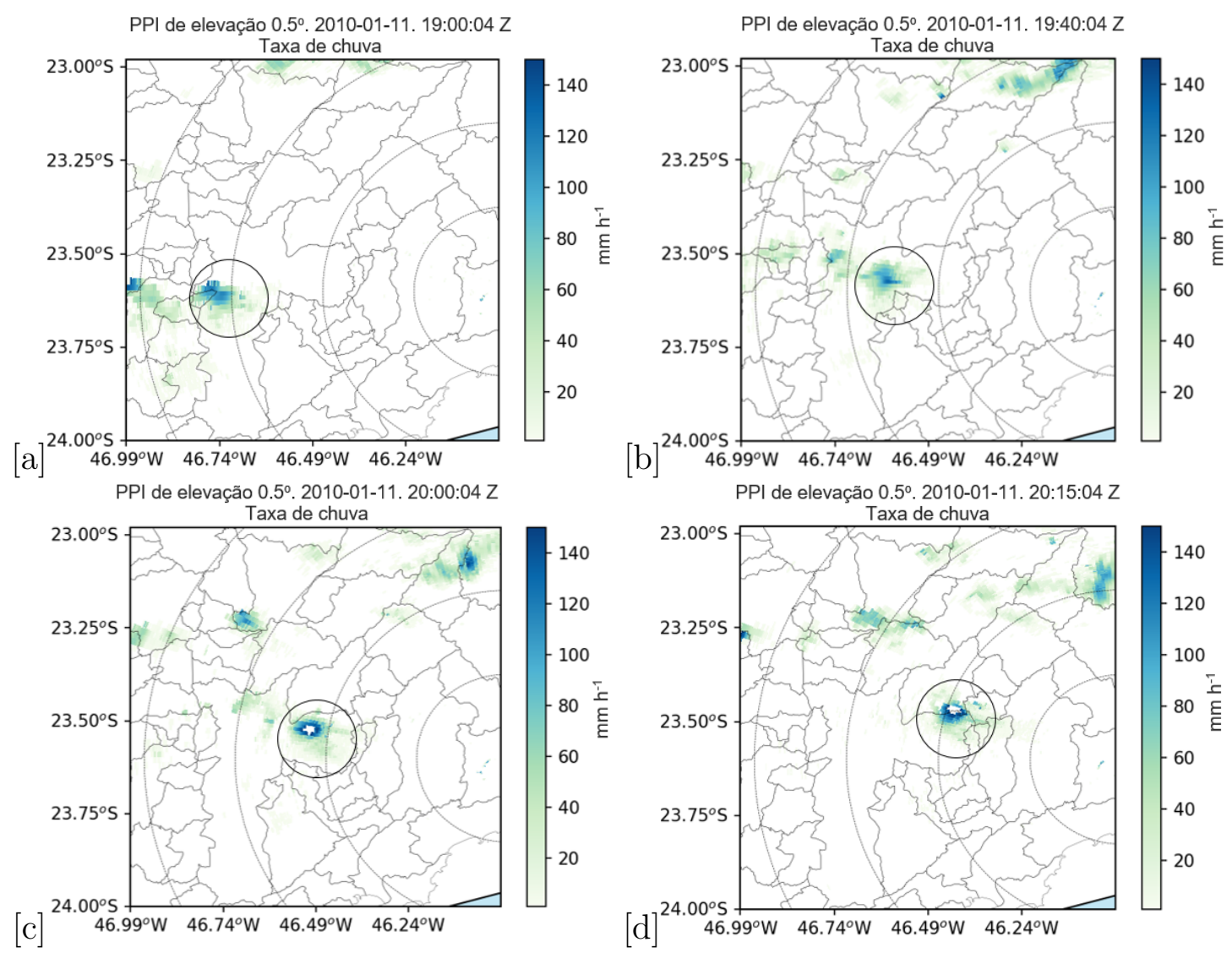

Figura 3.46: PPI de ângulo de elevação de $0.5^{\circ}$ do radar SPOL às 1910 UTC (a), às 1940 UTC (b), às 2000 UTC (c) e às 2015 UTC (d) da da taxa de chuva da CI de origem urbana. A escala de cor indica a taxa de chuva $\left(\mathrm{mm} \mathrm{h}^{-1}\right)$ do 18 de Maio de 2018. Circunferências concêntricas estão espaçadas a cada 25 km. O radar meteorológico SPOL está centro da menor circunferência concêntrica. Longitudes, latitudes, contornos dos municípios são indicados.

A Tab. 3.2 mostra o resumo dos hidrometeoros da célula convectiva de origem urbana durante a evolução espaço-temporal sobre a RMSP. Observa-se que às 1805 UTC, não é identificado granizo que provavelmente atinge a superfície. Mas, 40 minutos depois é identificada granizo, atingindo provavelmente a superfície, às 1905 UTC. Nota-se a predominância de graupel de alta densidade a abaixo da isoterma $0^{\circ} \mathrm{C}$, às 1805 UTC. Entretanto, observa-se a predominância de granizo e gotas grandes, às 1905 UTC.

Observa-se baixa concentração de gotas grandes abaixo da isoterma $0^{\circ} \mathrm{C}$, e baixa quantidade de gotas grandes sem presença de granizo, às 2105 UTC. Em geral, verifica-se a dependência da formação de gotas grandes a partir da basa da isoterma $0^{\circ} \mathrm{C}$ com a precipitação de pedras de granizo acima da isoterma $0^{\circ} \mathrm{C}$. Isso indica a importância da fase mista da nuvem para a produção de chuva intensa sobre a RMSP. 
Tabela 3.2 - Resumo de tipos de hidrometeoros identificados no núcleo da CI acima da isoterma $0^{\circ} \mathrm{C}$, abaixo da isoterma $0^{\circ} \mathrm{C}$, dentro da isoterma $0^{\circ} \mathrm{C}$ e provavelmente atingindo a superfície durante a evolução espaço-temporal sobre o centro geométrico da RMSP entre entre 1825 e 2105 UTC do dia 18 de Maio de 2014 com os dados do radar SPOL.

\begin{tabular}{|c|c|c|c|c|}
\hline \multirow{3}{*}{ UTC } & \multicolumn{4}{|c|}{ Tipos de hidrometeoros identificados do 18052014} \\
\hline & \multicolumn{3}{|c|}{ Isoterma $0^{\circ} \mathrm{C}$} & \multirow{2}{*}{ Superfície } \\
\hline & Acima & Abaixo & Dentro & \\
\hline 1825 & $\begin{array}{l}\text { Quantidade alta de } \\
\text { graupel } B D \text {, graupel } A D, \\
\text { granizo, agregados e gelo } \\
\text { vertical. }\end{array}$ & $\begin{array}{l}\text { Quantidade alta de } \\
\text { graupel AD, granizo e } \\
\text { gota grande; chuva. }\end{array}$ & $\begin{array}{l}\text { Quantidade alta de } \\
\text { neve molhada; } \\
\text { quantidade baixa } \\
\text { de graupel AD e } \\
\text { granizo; chuva. }\end{array}$ & Chuva. \\
\hline 1905 & $\begin{array}{l}\text { Quantidade alta de } \\
\text { granizo, graupel } B D \text {, } \\
\text { graupel } A D \text {, agregados e } \\
\text { gelo vertical. }\end{array}$ & $\begin{array}{l}\text { Quantidade alta de } \\
\text { granizo e gota } \\
\text { grande; quantidade } \\
\text { baixa de graupel AD; } \\
\text { chuva. }\end{array}$ & $\begin{array}{l}\text { Quantidade alta de } \\
\text { graupel AD, granizo, } \\
\text { neve molhada; } \\
\text { chuva }\end{array}$ & $\begin{array}{l}\text { Quantidade alta } \\
\text { de granizo e } \\
\text { gota grande; } \\
\text { chuva. }\end{array}$ \\
\hline 2015 & $\begin{array}{l}\text { Quantidade alta de } \\
\text { granizo, graupel } A D, \\
\text { graupel } B D \text {, cristais de } \\
\text { gelo, gelo vertical e } \\
\text { agregados. }\end{array}$ & $\begin{array}{l}\text { Quantidade alta de } \\
\text { gota grande, granizo; } \\
\text { quantidade baixa de } \\
\text { graupel AD; chuva. }\end{array}$ & $\begin{array}{l}\text { Quantidade alta de } \\
\text { graupel AD, gota } \\
\text { grande, granizo e } \\
\text { neve molhada; } \\
\text { chuva. }\end{array}$ & $\begin{array}{l}\text { Quantidade alta } \\
\text { de gota grande } \\
\text { e granizo; chuva }\end{array}$ \\
\hline 2030 & $\begin{array}{l}\text { Quantidade alta de } \\
\text { granizo, graupel } A D \text {, } \\
\text { graupel } B D \text {, cristais de } \\
\text { gelo, gelo vertical e } \\
\text { agregados. }\end{array}$ & $\begin{array}{l}\text { Quantidade alta de } \\
\text { gota grande, granizo; } \\
\text { chuva. }\end{array}$ & $\begin{array}{l}\text { Quantidade alta de } \\
\text { graupel AD, gota } \\
\text { grande, granizo; } \\
\text { chuva. }\end{array}$ & $\begin{array}{l}\text { Quantidade alta } \\
\text { de gota grande; } \\
\text { quantidade } \\
\text { baixa de } \\
\text { granizo; chuva. }\end{array}$ \\
\hline 2105 & $\begin{array}{l}\text { Quantidade alta de } \\
\text { graupel } B D \text {, graupel } A D, \\
\text { agregados, gelo vertical; } \\
\text { quantidade baixa de } \\
\text { granizo e cristais de gelo. }\end{array}$ & $\begin{array}{l}\text { Quantidade baixa de } \\
\text { gota grande, vestígio } \\
\text { de granizo e graupel } \\
\text { AD; chuva. }\end{array}$ & $\begin{array}{l}\text { Quantidade alta de } \\
\text { graupel AD; } \\
\text { quantidade baixa } \\
\text { de gota grande e } \\
\text { granizo; chuva. }\end{array}$ & $\begin{array}{l}\text { Quantidade } \\
\text { baixa de gota } \\
\text { grande; chuva }\end{array}$ \\
\hline
\end{tabular}




\subsubsection{Perfis verticais}

A seguir são ilustradas os perfis verticais das massas de água líquida e água sólida (Fig. 3.47), refletividade e refletividade diferencial (Fig. 3.48 ) e diâmetro da gota de chuva (Fig. 3.49) no núcleo da célula convectiva de origem urbana durante a evolução espaço-temporal sob influência de rotação ciclônica às 1900 UTC, às 1940 UTC, às 2000 UTC e às 2015 UTC do dia 18 de Maio de 2014.

Os resultados obtidos mostram o aumento da massa de água líquida e diminuição da massa de água sólida para altitudes baixas no núcleo da célula convectiva (Fig. 3.47). Sugere-se que a concentração alta da massa de água sólida em altitudes altas, é causada pelo crescimento de cristais de gelo à custa das gotículas super-resfriadas pelo processo de deposição de vapor de água e processo de acreção para os graupeis. E o aumento da concentração de massa de água líquida em altitudes baixas, é causada pelos processos de derretimentos das pedras de granizo a partir da isoterma $0^{\circ} \mathrm{C}$.

De acordo com o Korolev (2007), a conversão de fase e a formação de precipitação em nuvens de fase mista está associada ao processo Wegener-Bergeron-Findeisen, no qual os cristais de gelo crescem à custa das gotículas líquidas superesfriadas. O gelo precipita e derrete, transformados em gotas grandes.

Nota-se das altitudes baixas para altitudes altas, que a massa de água sólida aumenta com altitude a temperaturas negativas até um determinado nível. Enquanto que a massa de água líquida diminui com aumento da altitude a temperaturas positivas (Fig. 3.47). Essas observações corroboram com as análises feitas por Korolev et al. (2003), onde verificou que a concentração das gotículas líquidas em nuvens, diminuiu com a diminuição da temperatura (aumento da altura), e a concentração das partículas de gelo aumentou com a diminuição da temperatura até um determinado nível, que depois diminuiu por falta de água líquida, responsável para o crescimento dos partículas de gelo.

Observa-se também que durante a evolução espaço-temporal da CI, diminuiu de profundidade às 2000 UTC (Fig. 3.47c, g), quando esta passa sobre a região de adensamento urbano verticalizado, e aumentou de profundidade quando saiu dessa região, às 2015 UTC (Fig. 3.47d, h). 

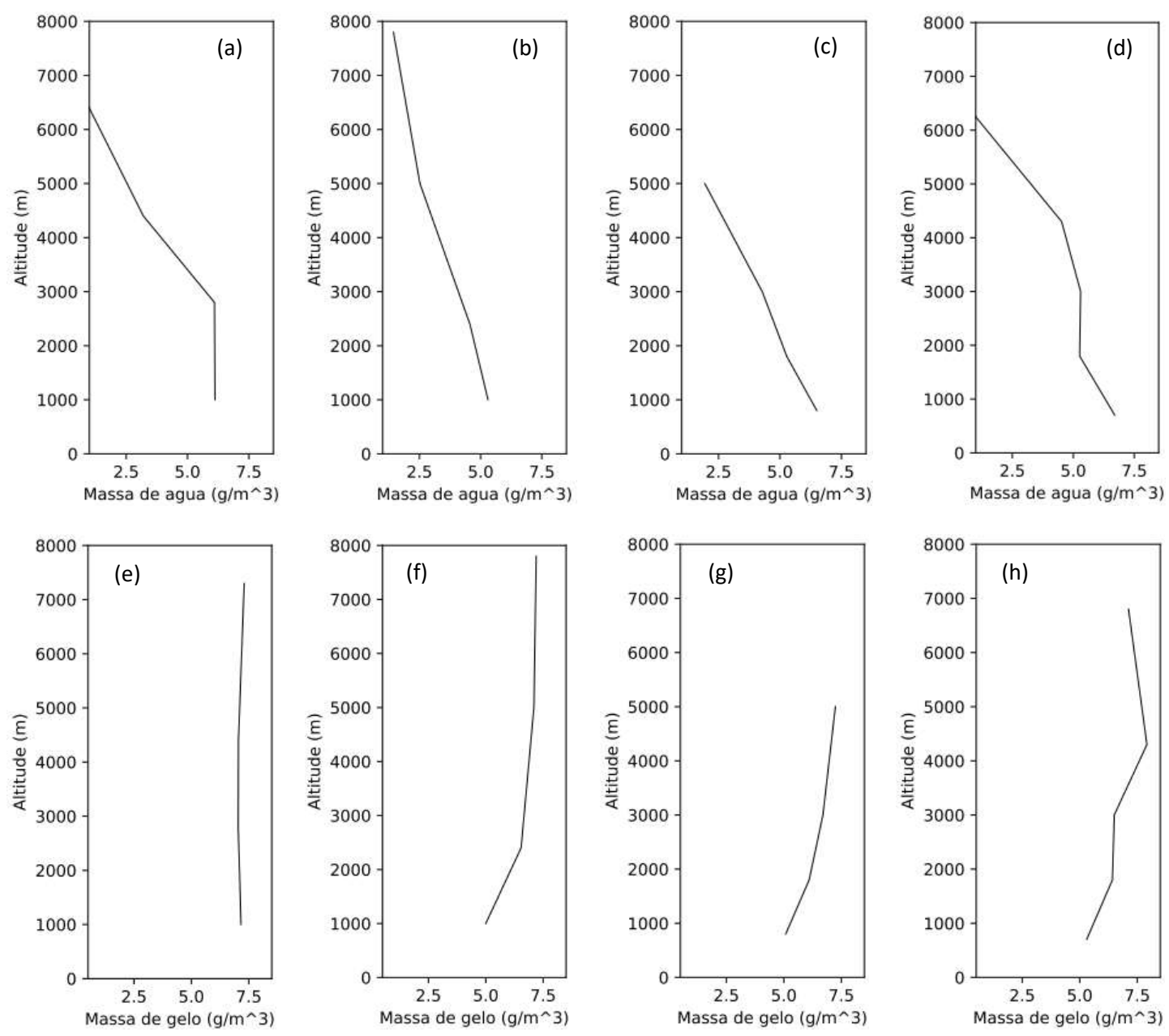

Figura 3.47: Perfis verticais da massa de água (a, b, c, d) e massa de gelo (e, f, g, h) no núcleo da CI, durante a evolução espaço-temporal às 1900 UTC, 1940 UTC, 2000 UTC e 2015 UTC, respectivamente, do dia 18 de Maio de 2014.

A Fig. 3.48 mostra os perfis verticais da refletividade e refletividade diferencial no núcleo da célula convectiva de origem urbana. O gradiente de reflectividade entre 800 a $7500 \mathrm{~m}$ de altitude, é menor comparado à tempestade ocorrido no do dia 11 de Janeiro de 2010. Observa-se valores de refletividade acima de $60 \mathrm{dBZ}$ entre os 800 e $7500 \mathrm{~m}$ de altitude (Fig. 3.48a, b, c, d), enquanto que os valores de refletividade diferencial tendem próximo de $0 \mathrm{~dB}$ (Fig. 3.48e, f, g, h), indicativo da presença de quantidade alta de granizo. 

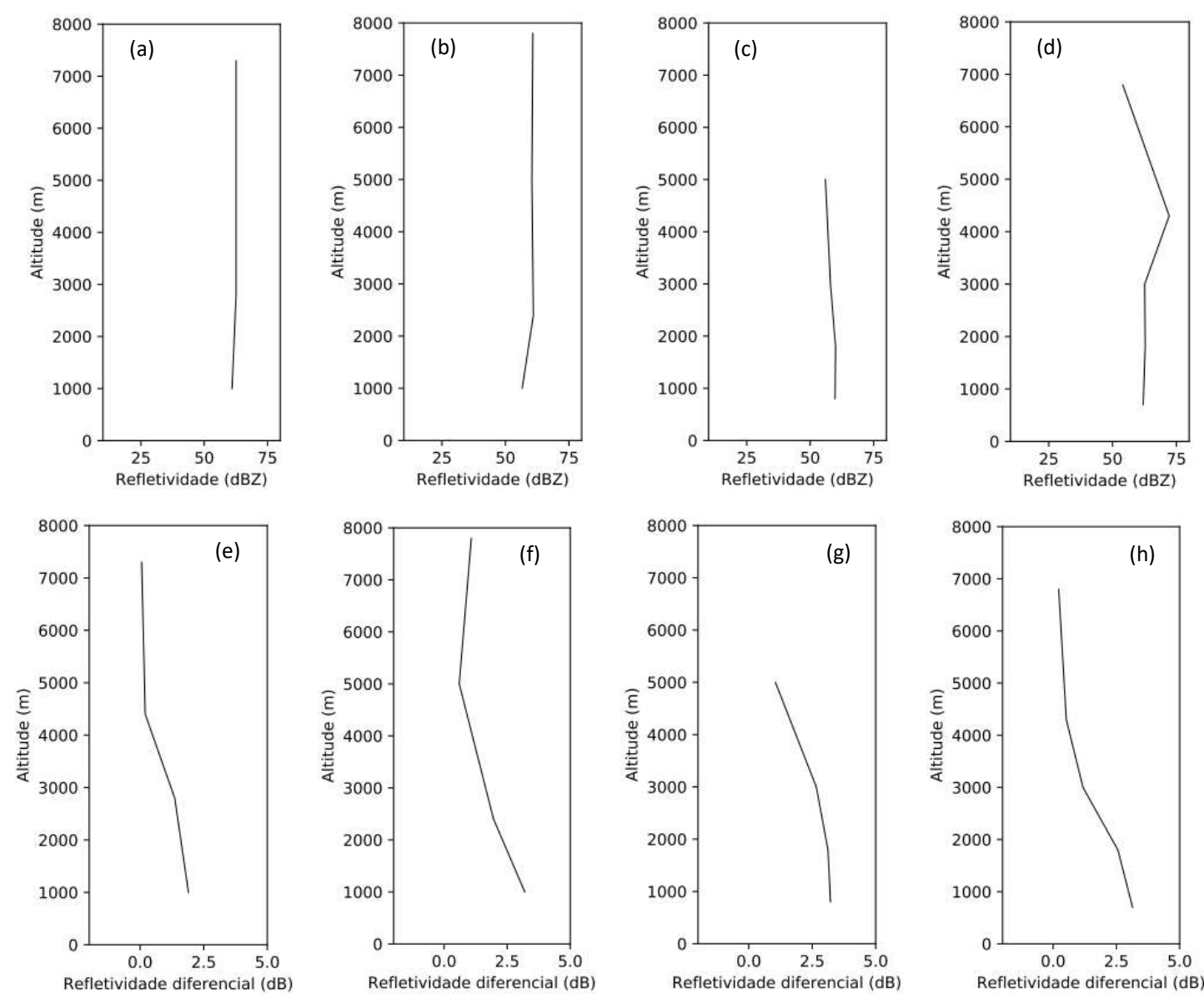

Figura 3.48: Perfis verticais da refletividade horizontal (a, b, c, d) e refletividade diferencial(e, f, g, h) no núcleo da CI, durante a evolução espaço-temporal às 1900 UTC, 1940 UTC, 2000 UTC e 2015 UTC, respectivamente, do dia 18 de Maio de 2014.

O valores altos de refletividade diferencial $(>2.5 \mathrm{~dB})$ a baixo de $2000 \mathrm{~m}$ de altitude, indica precipitação de gotas grandes (Fig. 3.48e, f, g, h), resultante do derretimento de uma parte da quantidade de granizo devido à medida que precipita da isoterma $0^{\circ} \mathrm{C}$ para temperaturas positivas. 

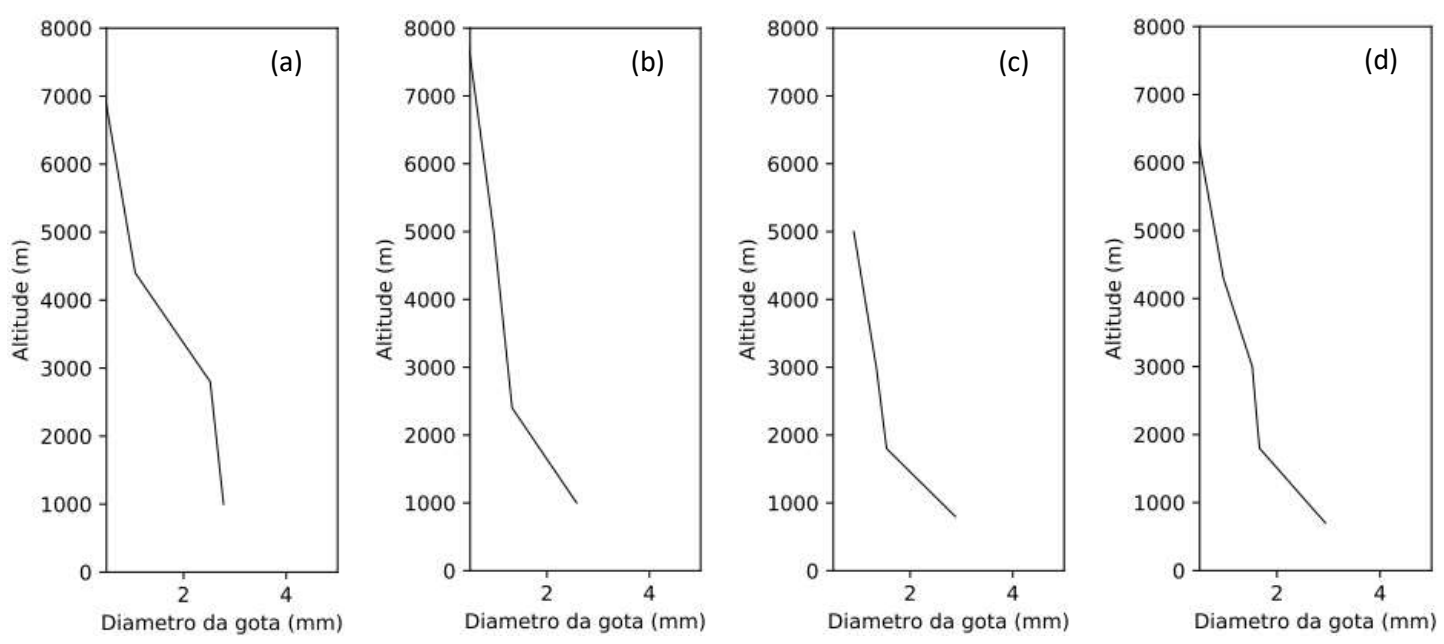

Figura 3.49: Perfis verticais do diâmetro da gota de chuva no núcleo da CI, durante a evolução espaço-temporal (a) às 1900 UTC, (b) às 1940 UTC, (c) às 2000 UTC e (d) às 2015 UTC do dia 18 de Maio de 2014.

A Fig. 3.49 mostra os perfis verticais do diâmetro da gotas de chuva no núcleo da célula convectiva, durante a evolução espaço-temporal. Nota-se gotas de chuva com diâmetro de 0,9 $\mathrm{mm}$ entre 4500 e $7000 \mathrm{~m}$ de altitude, e o valor triplica para 3,3 $\mathrm{mm}$ de diâmetro em altitudes mais baixos, devido o derretimento da pedra de granizo durante a precipitação da isoterma $0^{\circ} \mathrm{C}$ para temperaturas positivas, e provavelmente devido o mecanismo de colisãocoalescência entre a gota de chuva que precipita e coalescendo as gotículas encontradas no seu trajeto.

\subsection{Bandas dispersas (BDs) induzidas por frente fria no dia 24 de}

\section{Janeiro de 2016}

\subsubsection{Análise sinótica, termodinâmica e dinâmica}

As imagens de satélite na Fig. 3.50 mostram o deslocamento de uma frente fria sobre a região sudeste, onde as BDs desenvolveram-se sobre o leste da São Paulo. Observa-se nas imagens a extensa área de nebulosidade com orientação noroeste-sudeste. Às 1600 UTC, observa-se a primeira banda de nebulosidade dentro da área destacada (Fig. 3.50a). Às 1730 UTC, verifica-se a segunda banda de nebulosidade adentrando na área destacada, enquanto que a premeria sai da área destacada em direção ao oceano (Fig. 3.50b). Nota-se 
as bandas de nebulosidade agregadas e mais intensas na área destacada, às 2000 UTC (Fig. 3.50c), e às 2100 UTC a banda agregada perde intensidade (Fig. 3.50d).
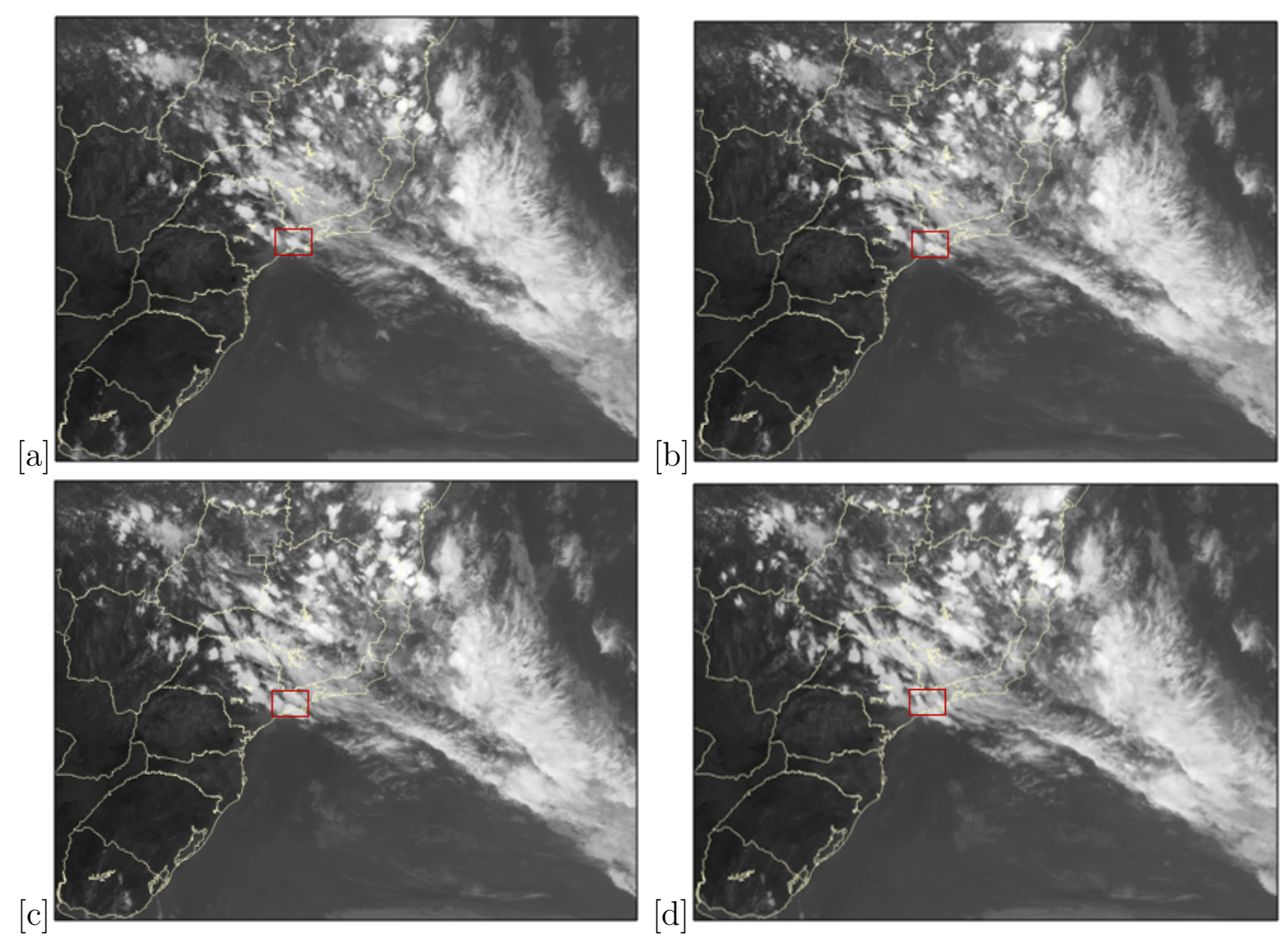

Figura 3.50: Imagens do satélite GOES 12 no canal infravermelho (a) 1600 UTC, (b) 1730 UTC, (c) 2000 UTC e (d) 2100 UTC de 24 de Janeiro de 2016. A RMSP destacada no quadrado vermelho. Fonte: DSA-CPTEC.INPE, 2020.

A Fig.3.51 mostra os perfis de temperatura, umidade de vento medidos com a radiossonda no Aeroporto Campo de Marte (23⒊4'S; 46²44.1'W) às 1200 UTC do dia 24 antes da passagem da FF e 0000 UTC do dia 25 de Janeiro de 2016 após a passagem. A razão de mistura estava relativamente alta em baixos níveis e baixa em médios e altos níveis antes da passagem da FF (Fig.3.51a). Observa-se razão de mistura alta em todos os níveis da atmosfera após a passagem da FF sobre a região (Fig.3.51b). 

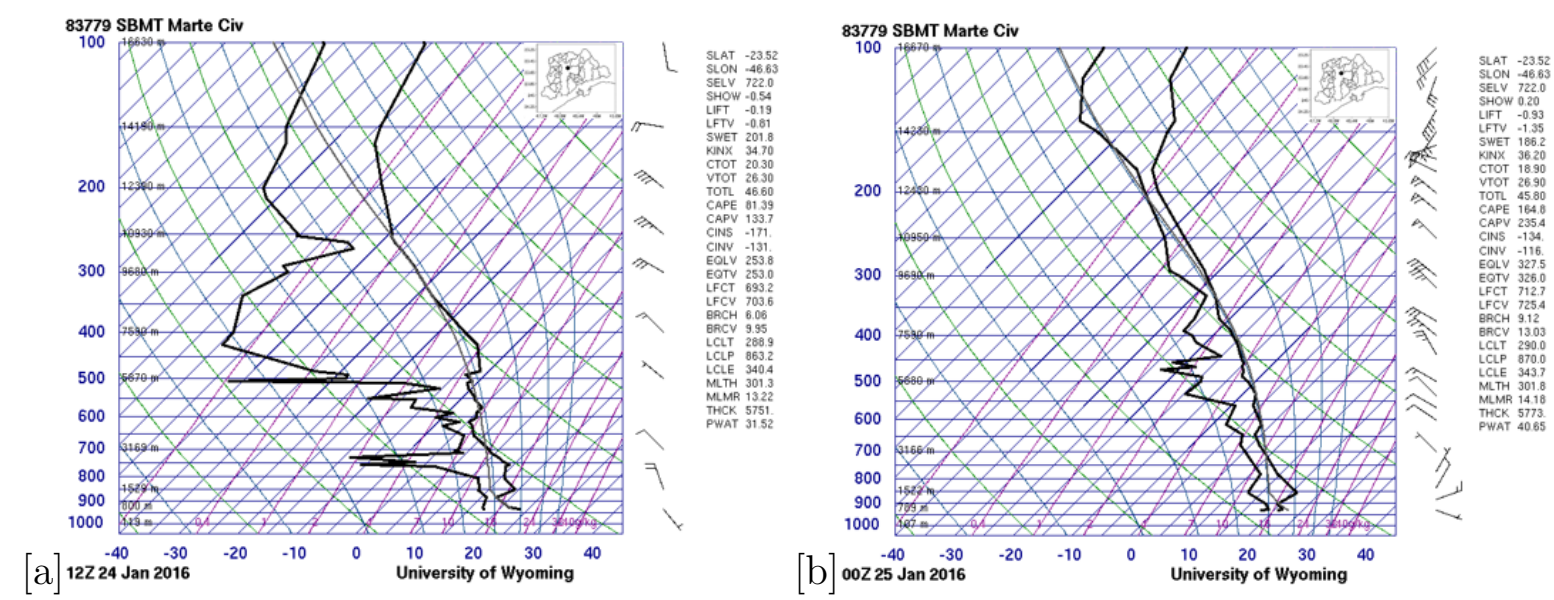

Figura 3.51: [Perfil vertical da temperatura do ar $\left({ }^{\circ} \mathrm{C}\right)$, temperatura do ponto do orvalho $\left({ }^{\circ} \mathrm{C}\right)$, velocidade (nós) e direção do vento $\left(^{\circ}\right)$ no Aeroporto Campo de Marte (-23 $33^{\prime} 31^{\prime \prime} \mathrm{S},-46^{\circ} 38^{\prime} 15^{\prime \prime} \mathrm{W}$ ), onde a) 1200 UTC do dia 24 de Janeiro de 2016 e b) 0000 UTC do dia 24 de Janeiro de 2016. Fonte: University of Wyoming.

As barbelas mostram ventos intensos de noroeste que diminui de intensidade com a diminuição de altitude, característico de cisalhamento de vento, às 1200 UTC do dia 24 antes da passagem. Após a passagem da FF, observa-se ventos intensos de sudoeste, de noroeste-sudeste em médios níveis e de nordeste em baixos níveis.

A Fig. 3.52 mostra campos da velocidade radial em diferentes níveis de elevação, às 1705 UTC. Observa-se o escoamento de noroeste para sudeste, típico de sistemas de BDs como desctrito por Silva et al. (2009).

Nota-se uma linha fina de tonalidade vermelha $\left(4 \mathrm{~m} \mathrm{~s}^{-1}\right)$, que penetrou na área predominante de cor azul em todas as elevações, até a $65 \mathrm{~km}$ do radar SPOL, a oeste-noroeste (Fig. 3.52). Nessa região convergência de massas de ar, que transportou umidade de baixo níveis para altos níveis da atmosfera. 

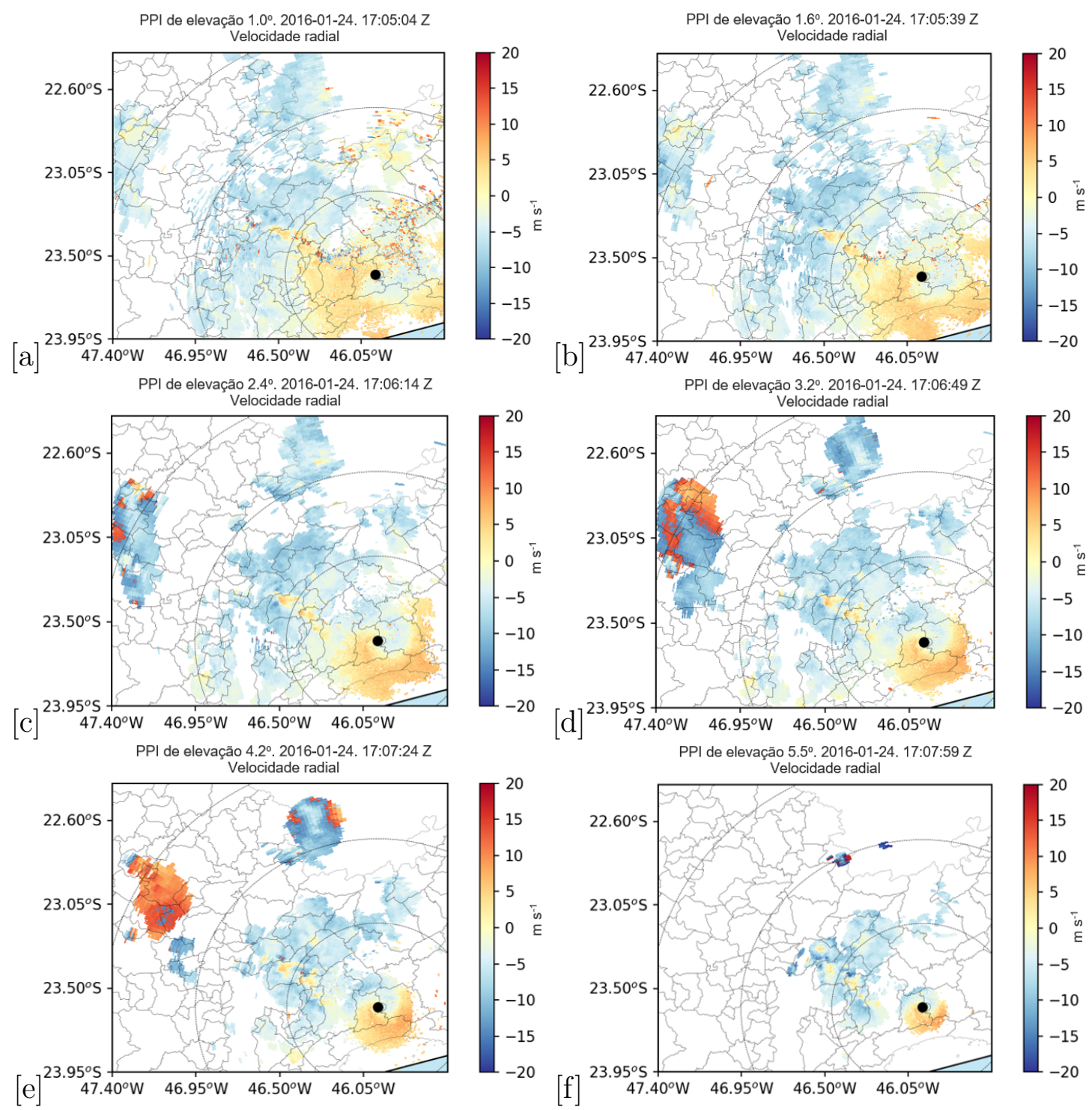

Figura 3.52: PPI de ângulo de elevação da velocidade radial do radar SPOL às 1705 UTC (a) $1.0^{\circ}$, (b) $1.6^{\circ}$, (c) $2.4^{\circ}$, (d) $3.2^{\circ}$, (e) $4.2^{\circ}$, (f) $5.50^{\circ}$ do dia 24 de Janeiro de 2016. A escala de cores indica a velocidade radial $\left(\mathrm{m} \mathrm{s}^{-1}\right)$. As cores azul e vermelho representam o conjunto de hidrometeoros que se aproxima e se afasta do radar SPOL. Circunferências concêntricas estão espaçadas a cada $50 \mathrm{~km}$. O ponto preto indica a localização do radar meteorológico SPOL, no centro da menor circunferência concêntrica. Longitudes, latitudes, contornos dos municípios são indicados.

\subsubsection{Evolução espaço-temporal}

Os dados do radar SPOL indicaram formação típica de BDs e foram monitorados a partir das 1510 UTC (Fig. 3.53a) até às 1955 UTC (Fig. 3.53g). Durante esse intervalo, observa-se o surgimento de várias pequenas células convectivas. 
Os campos da refletividade mostra que as BDs não apresentam organização espacial e, estão associadas a um sistema de frente fria, que corrobora com as observações feitas por Silva et al. (2009).
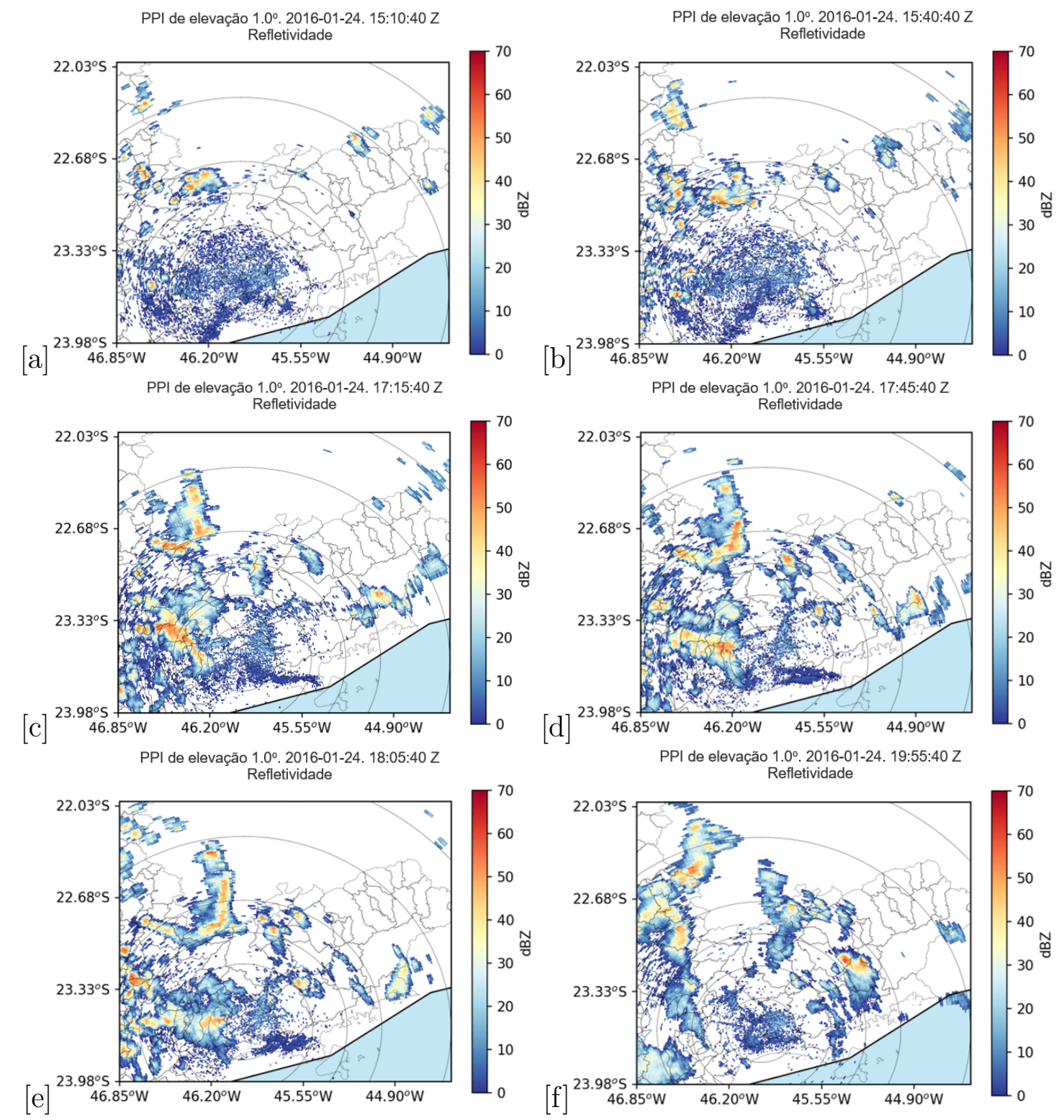

Figura 3.53: PPI de ângulo de elevação de $1.0^{\circ}$ da refletividade $\left(\mathrm{Z}_{H}\right)$ do radar SPOL às 1510 UTC (a), 1540 UTC (b), 1715 UTC (c), 1745 UTC (d), 1805 UTC (e) e 1945 UTC (f) do dia 24 de Janeiro de 2016. A escala de cores indica a refletividade (dBZ). Circunferências concêntricas estão espaçadas a cada 25 km. O radar meteorológico SPOL está centro da menor circunferência concêntrica. Longitudes, latitudes, contornos dos municípios são indicados.

Durante a evolução espaço-temporal das BDs, as pequenas células convectivas são embebidas por sistema estratiformes, com tendência de integrarem-se uma das outras. Os 
núcleos apresentam refletividades que variam entre 45 e $60 \mathrm{dBZ}$ (Fig. 3.53g).

Os campos do coeficiente de correlação (Fig. 3.54) apresentam as características físicas dos hidrometeoros, estando mais próximo de 1,0 por serem quase uniformes, uma vez que as os sinais verticais e horizontais que retornam ao radar SPOL, tendem a ser os mesmos na generalidade, e com algumas áreas pontuais com valores próximos de 0.8 correspondentes aos pequenos núcleos.
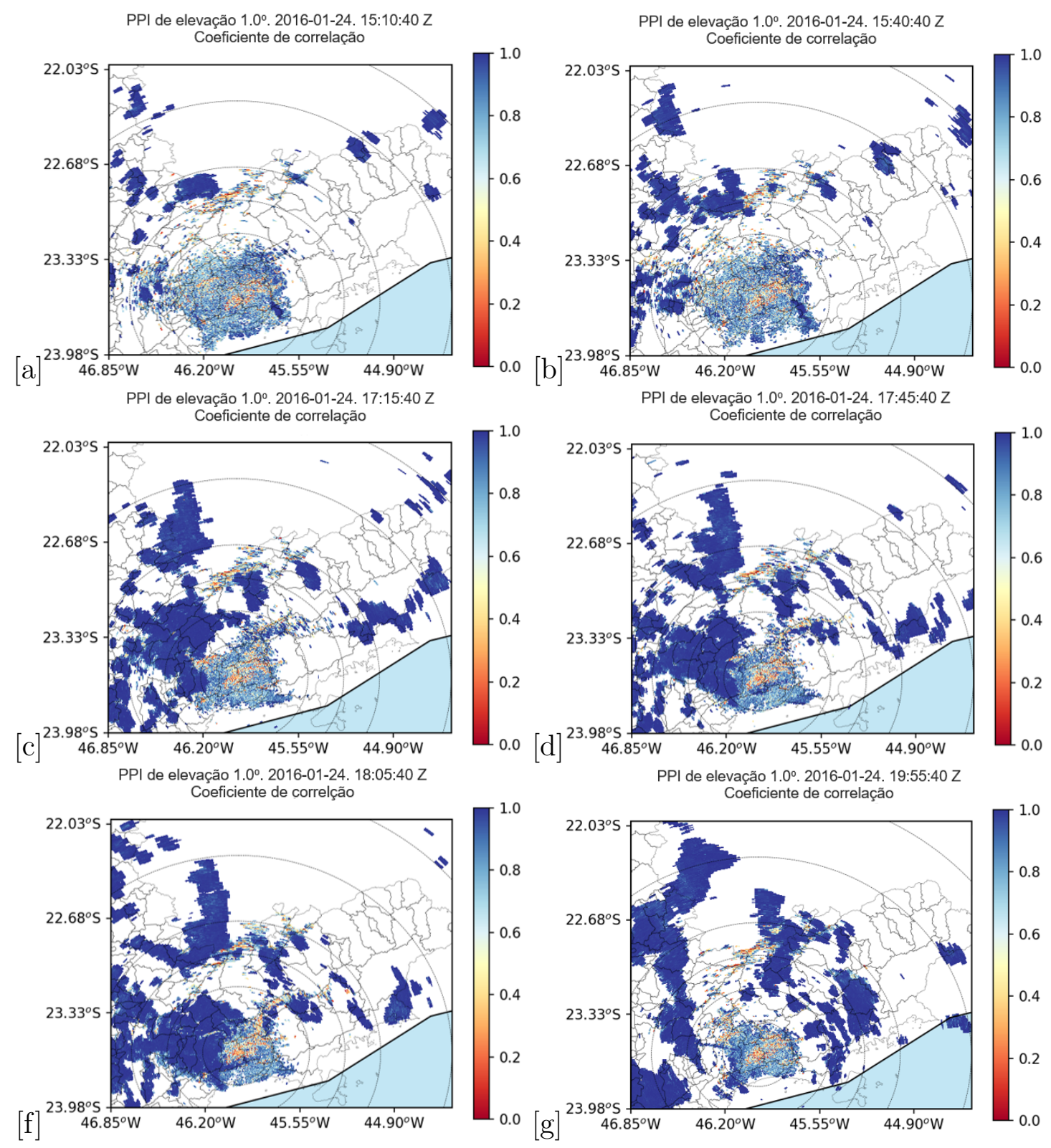

Figura 3.54: Idem Fig. 3.53, mas para coeficiente de correlação (sem unidade).

Os campos da refletividade diferencial (Fig. 3.55) apresentam valores que variam entre 
-1 e 4 dB. Nas áreas de refletividades mais intensas, correspondentes aos pequenos núcleos convectivos, observa-se valores entre 2 e $4 \mathrm{~dB}$, e valores entre 1 e $-1 \mathrm{~dB}$ entorno dessas áreas.
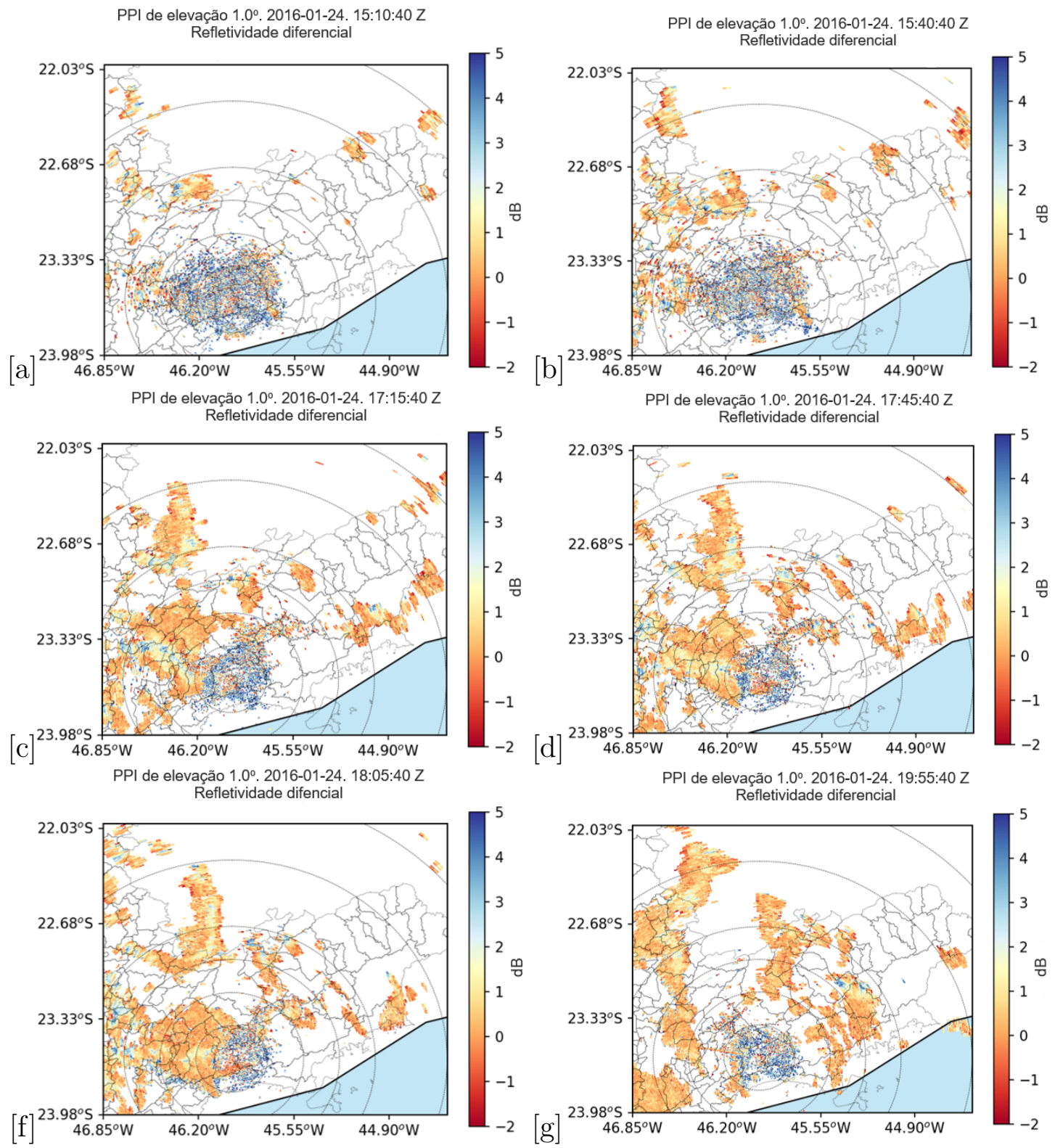

Figura 3.55: Idem Fig. 3.53, mas para refletividade diferencial $\left(\mathrm{Z}_{D R}\right)$.

A fase diferencial especifica é um excelente estimador de precipitação, tal como apresentado por Ruzanski e Chandrasekar (2012), valores acima de $2{ }^{\circ} \mathrm{km}^{-1}$ indicam uma quantidade significativa de água líquida ou oblate. Os campos da fase diferencial especifica (Fig. $3.56 \mathrm{c}$, d) mostram valores acima de $2^{\circ} \mathrm{km}^{-1}$ em algumas áreas pontuais correspondentes 
a pequenos núcleos, às 1715 UTC e 1745 UTC.
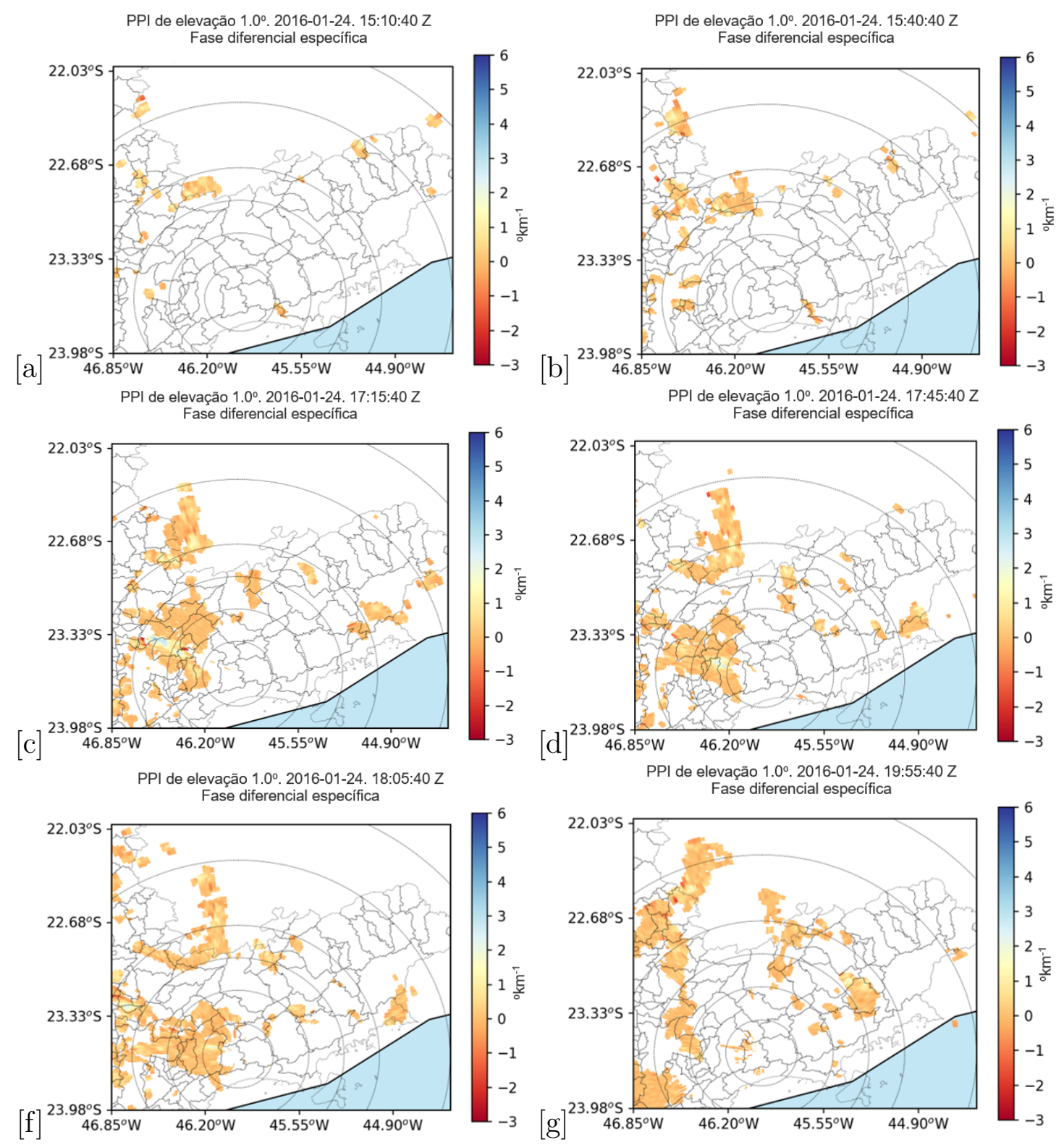

Figura 3.56: Idem Fig. 3.53, mas para fase diferencial especifica $\left(\mathrm{Z}_{D P}\right)$.

\subsubsection{Classificação dos hidrometeoros}

A Fig. 3.57 apresenta a classificação dos hidrometeoros nas nuvens das BDs que está de acordo com o esperado para este tipo de sistema. 

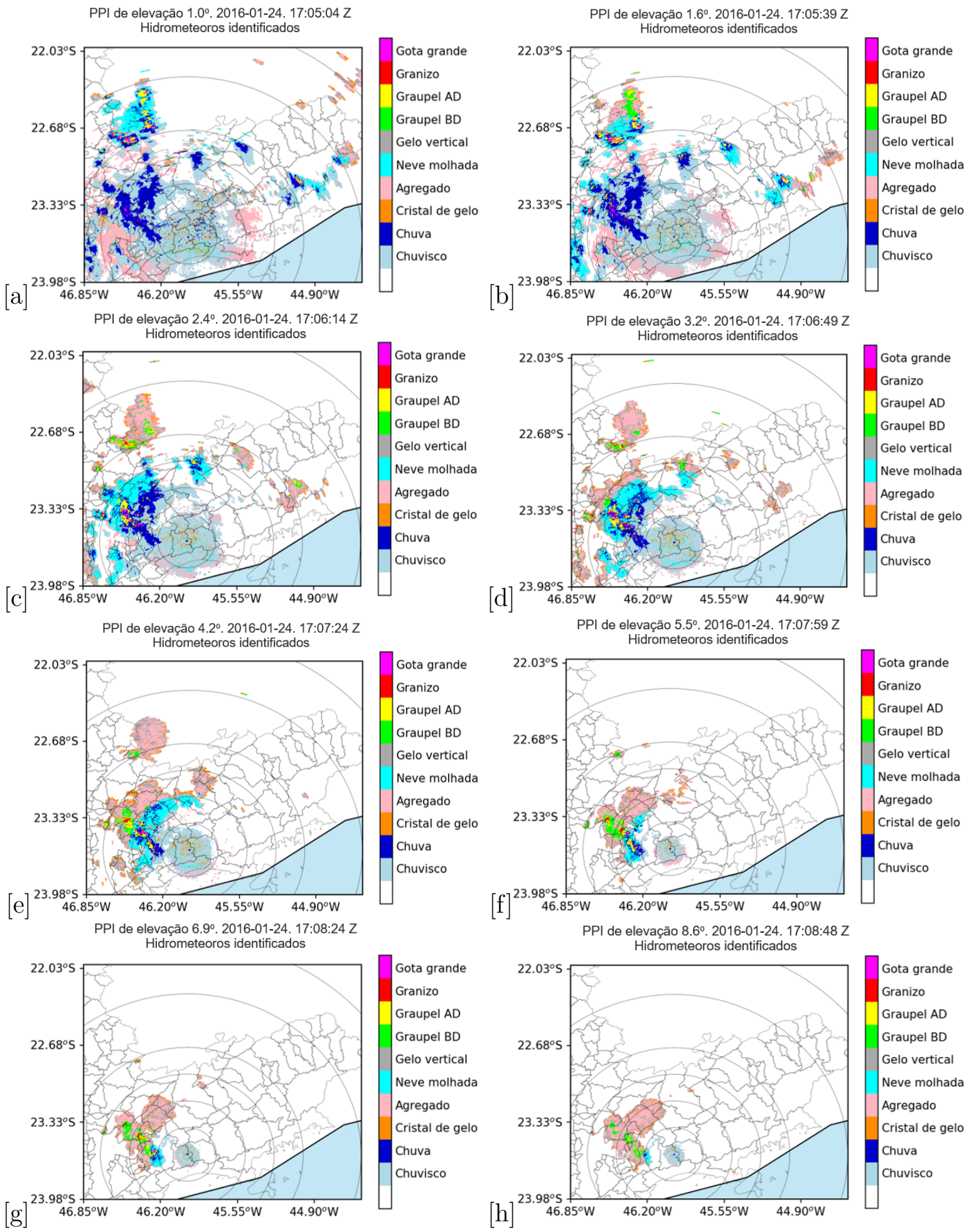

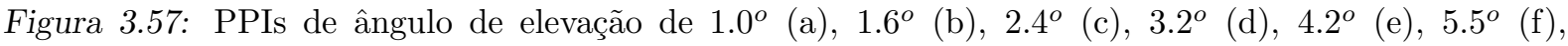
$6.9^{\circ}(\mathrm{g})$ e $8.6^{\circ}(\mathrm{h})$ da classificação de hidrometeoros do radar SPOL no dia 24 de Janeiro de 2016, às 1705 UTC. A escala de cores apresenta as 10 classificações dos hidrometeoros: Gota de água, Granizo, Graupel AD, Graupel BD, Gelo vertical, Neve molhada, Agregado, Cristal de gelo, Chuva e Chuvisco. Circunferências concêntricas estão espaçadas a cada $25 \mathrm{~km}$. O radar meteorológico SPOL está centro da menor circunferência concêntrica. Longitudes, latitudes, contornos dos municípios de São Paulo são indicados. 
A classificação de hidrometeoros indica chuva com resquício de gotas grandes, a $65 \mathrm{~km}$ do radar SPOL, a oeste-noroeste (Fig. 3.57a), áreas onde foram identificadas valores de fase diferencial específica acima de $2^{\circ} \mathrm{km}^{-1}$, e convergência pelos campos da velocidade radial. A classificação de hidrometeoros indica pequenos núcleos de granizo nas elevações $4.2^{\circ}$ e $5.5^{\circ}$ (Fig. 3.57e, f), acima das áreas identificadas chuva com gotas grandes.

A classificação de hidrometeoros corrobora com análise (Lin e Wang, 1997), que afirmaram que quase toda a chuva à superfície durante eventos convectivos provém do derretimento do granizo e graupel.

Em geral, observa-se predominância e agregados acima da camada de neve molhada (Fig. 3.57c, d, e, f, g, h) por serem sistemas estratiformes embebidos de pequenos núcleos. A presença predominante de agregados é devido não presença de conteúdo de água líquida (gotículas super-resfriadas), onde só atua o processo de agregação.
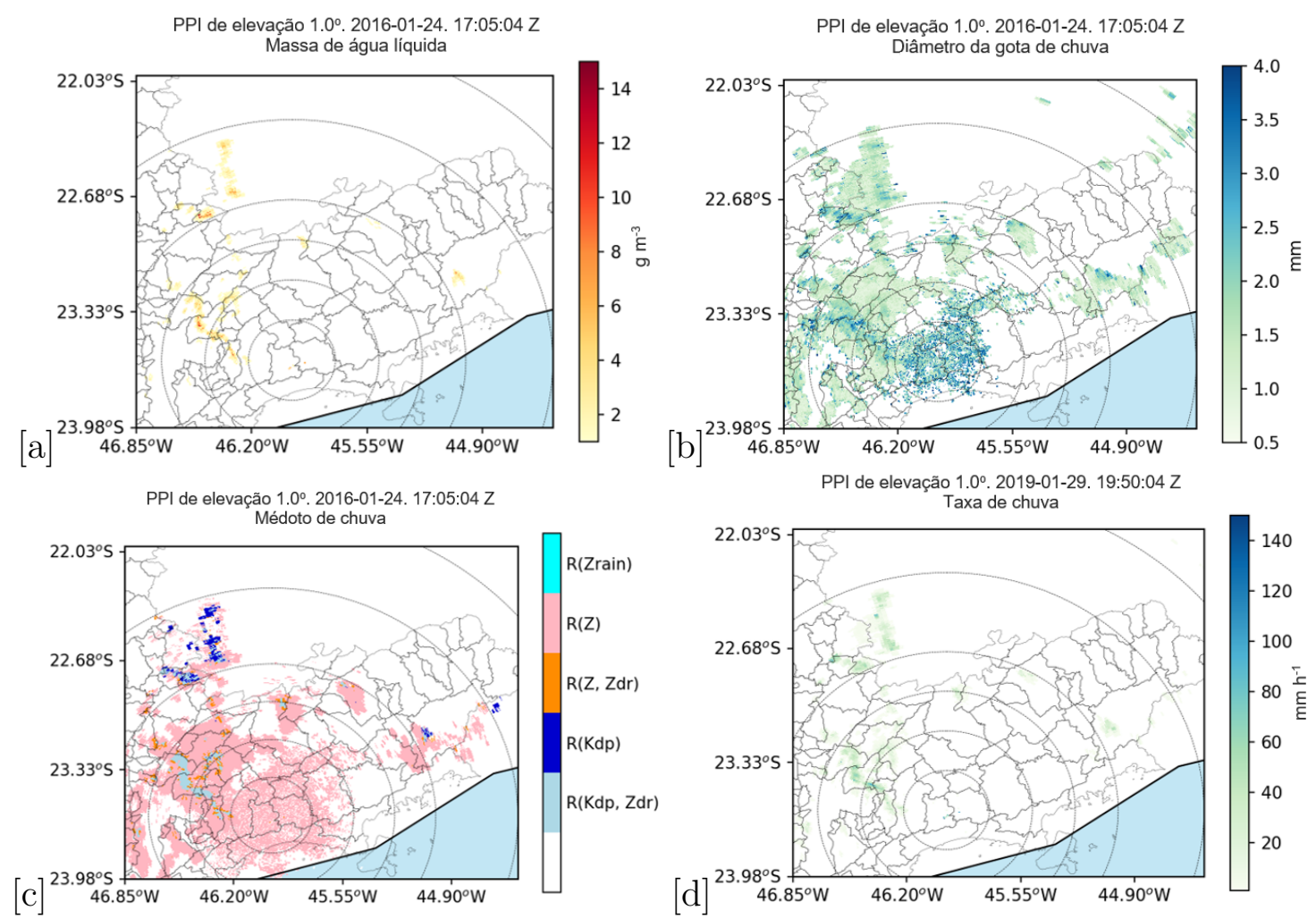

Figura 3.58: PPIs de ângulo de elevação de $1.0^{\circ}$ do radar SPOL às 1705 UTC, (a) massa de água líquida, (b) diâmetro da gota de chuva, (c) método de chuva, e (d) taxa de chuva no dia 24 de Janeiro de 2016. As escalas de cores estão indicadas. Circunferências concêntricas estão espaçadas a cada $25 \mathrm{~km}$. O radar meteorológico SPOL está centro da menor circunferência concêntrica. Longitudes, latitudes, contornos dos municípios de São Paulo são indicados. 
A Fig. 3.58 campos de massa de água líquida, diâmetro da gota de chuva e taxa de chuva no PPI de elevação $1.0^{\circ}$ do radar SPOL, às 1705 UTC. Observa-se tonalidade azul claro corresponde ao método $\mathrm{R}(\mathrm{kdp}, \mathrm{Zdr})$, nas áreas onde foram observadas chuva com gotas grandes pelo método de classificação de hidrometeoros, e valores acima de $2{ }^{\circ} \mathrm{km}^{-1}$ da fase diferencial específica (Fig. 3.58c).

Nota-se que nessas mesmas áreas são observadas taxas de chuva que atingem valores $\sim 60 \mathrm{~mm} \mathrm{~h}^{-1}$ (Fig. 3.58d), gotas de chuva de $\sim 2 \mathrm{~mm}$ de diâmetro (Fig. 3.58b) e concentração de água líquida $\sim 6 \mathrm{~g} \mathrm{~m}^{-3}$ (Fig. 3.58a).

A Tab. 3.3 mostra o resumo da classificação dos hidrometeoros identificados durante a evolução espaço-temporal das BDs sobre o LSP. As quantidades altas de graupel de alta densidade e granizo acima da isoterma $0^{\circ} \mathrm{C}$ em áreas pontuais e chuva misturada a resquícios de gotas grandes na superfície foram observadas nos dois primeiros horários durante a evolução espaço-temporal das BDs. Das 1730 UTC para adiante não observa-se graupel de alta densidade e granizo acima da isoterma $0^{\circ} \mathrm{C}$, e na parte inferior do sistema é identificada chuva e chuvisco. 
Tabela 3.3 - Resumo de tipos de hidrometeoros identificados nos núcleos das BDs acima da isoterma $0^{\circ} \mathrm{C}$, abaixo da isoterma $0^{\circ} \mathrm{C}$, dentro da isoterma $0^{\circ} \mathrm{C}$ e provavelmente atingindo a superfície durante a evolução espaço-temporal sobre o LSP entre 1640 e 1850 UTC do dia 24 de Janeiro de 2016 com os dados do radar SPOL.

\begin{tabular}{|c|c|c|c|c|}
\hline \multirow{3}{*}{ UTC } & \multicolumn{4}{|c|}{ Tipos de hidrometeoros identificados do 24012016} \\
\hline & \multicolumn{3}{|c|}{ Isoterma $0^{\circ} \mathrm{C}$} & \multirow{2}{*}{ Superfície } \\
\hline & Acima & Abaixo & Dentro & \\
\hline 1640 & $\begin{array}{l}\text { Quantidade alta de } \\
\text { graupel } \mathrm{BD} \text {, graupel AD, } \\
\text { agregados e gelo vertical; } \\
\text { quantidade baixa de } \\
\text { granizo e cristais de gelo. }\end{array}$ & $\begin{array}{l}\text { Quantidade baixa de } \\
\text { gota grande; chuva. }\end{array}$ & $\begin{array}{l}\text { Quantidade alta de } \\
\text { neve molahda, gota } \\
\text { grande, garupel AD; } \\
\text { vestígio de granizo; } \\
\text { chuva. }\end{array}$ & $\begin{array}{l}\text { Vestígio de gota } \\
\text { grande; Chuva. }\end{array}$ \\
\hline 1705 & $\begin{array}{l}\text { Quantidade alta de } \\
\text { graupel } B D \text {, graupel AD, } \\
\text { granizo, agregados e gelo } \\
\text { vertical; quantidade } \\
\text { baixa de cristais de gelo. }\end{array}$ & $\begin{array}{l}\text { Quantidade alta de } \\
\text { gota grande; vestígio } \\
\text { de graupel AD; chuva. }\end{array}$ & $\begin{array}{l}\text { Quantidade alta de } \\
\text { gota grande, } \\
\text { garupel AD, neve } \\
\text { molhada; chuva. }\end{array}$ & $\begin{array}{l}\text { Quantidade } \\
\text { baixa de gota } \\
\text { grande; chuva. }\end{array}$ \\
\hline 1730 & $\begin{array}{l}\text { Quantidade alta de } \\
\text { graupel } \mathrm{BD} \text {, gelo vertical, } \\
\text { agregados e cristais de } \\
\text { gelo. }\end{array}$ & $\begin{array}{l}\text { Quantidade baixa de } \\
\text { gota grande e graupel } \\
\text { AD; chuva. }\end{array}$ & $\begin{array}{l}\text { Quantidade alta de } \\
\text { graupel AD, neve } \\
\text { molhada; vestígio } \\
\text { de gota grande e } \\
\text { granizo; chuva. }\end{array}$ & $\begin{array}{l}\text { Quantidade } \\
\text { baixa de gota } \\
\text { grande; chuva. }\end{array}$ \\
\hline 1745 & $\begin{array}{l}\text { Quantidade alta de } \\
\text { graupel BD, agregados, } \\
\text { gelo verticale; } \\
\text { quantidade baixa de } \\
\text { cristais de gelo. }\end{array}$ & $\begin{array}{l}\text { Quantidade baixa de } \\
\text { gota grande; chuva. }\end{array}$ & $\begin{array}{l}\text { Quantidade alta de } \\
\text { neve molhada; } \\
\text { quantidade baixa } \\
\text { de graupel AD; } \\
\text { chuva. }\end{array}$ & $\begin{array}{l}\text { Quantidade } \\
\text { baixa de gota } \\
\text { grande; chuva. }\end{array}$ \\
\hline 1800 & $\begin{array}{l}\text { Quantidade baixa de } \\
\text { graupel } \mathrm{BD} \text {, graupel } \mathrm{AD} \text {, } \\
\text { agregados, gelo vertical e } \\
\text { cristais de gelo. }\end{array}$ & Chuva. & $\begin{array}{l}\text { Quantidade alta de } \\
\text { neve molhada; } \\
\text { quantidade baixa } \\
\text { de graupel AD; } \\
\text { chuva. }\end{array}$ & Chuva, chuvisco. \\
\hline 1820 & $\begin{array}{l}\text { Quantidade alta de } \\
\text { graupel } \mathrm{BD} \text {, agregados e } \\
\text { gelo vertical; quantidade } \\
\text { baixa de graupel AD, } \\
\text { granizo e cristais de gelo. }\end{array}$ & Chuva. & $\begin{array}{l}\text { Quantidade alta de } \\
\text { neve molhada; } \\
\text { quantidade baixa } \\
\text { de graupel AD; } \\
\text { chuva. }\end{array}$ & Chuva, chuvisco \\
\hline 1850 & $\begin{array}{l}\text { Quantidade alta de } \\
\text { graupel } \mathrm{BD} \text {, agregados e } \\
\text { gelo vertical. }\end{array}$ & Chuva. & $\begin{array}{l}\text { Quantidade alta de } \\
\text { neve molhada; } \\
\text { quantidade baixa } \\
\text { de graupel AD; } \\
\text { chuva. }\end{array}$ & Chuva, chuvisco. \\
\hline
\end{tabular}


3.4 Convecção isolada (CI) associada a um sistema de alta pressão no dia 29 de Janeiro de 2019

\subsubsection{Análise sinótica}

As imagens de satélite na Fig. 3.59 mostram a evolução da célula convectiva na RMSP, área destacada. Observa-se nebulosidade com topo frio entre -50 a $-60^{\circ} \mathrm{C}$ nas imagens das 1730 UTC, 2000 UTC e 2100 UTC (Fig. 3.59b, c, d).
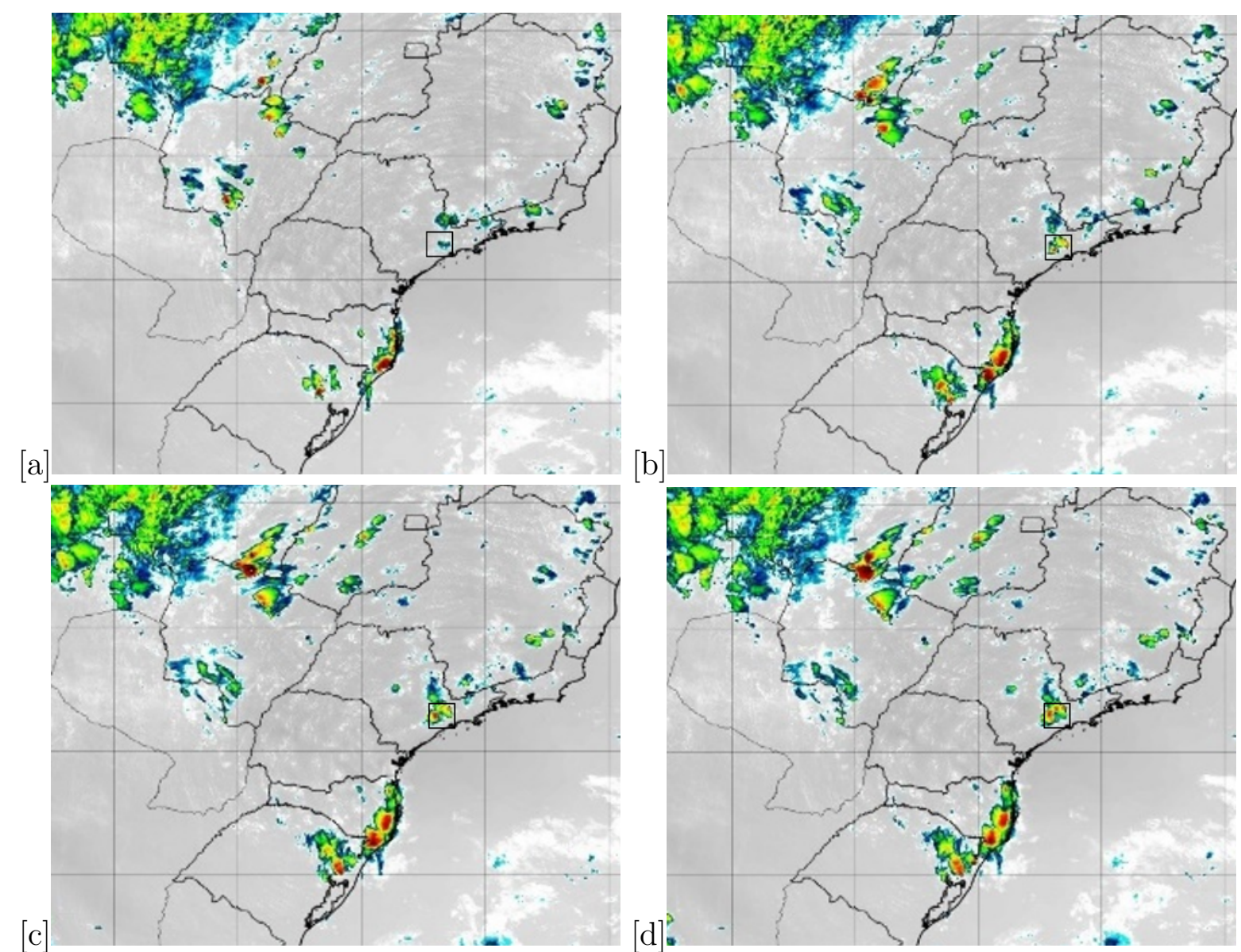

Figura 3.59: Imagens do satélite GOES 16 (a) 1600 UTC, (b) 1730 UTC, (c) 2000 UTC e (d) 2100 UTC de 29 de Janeiro de 2019. A escala de cores represta a temperatura do topo da nuvem. A RMSP destacada no quadrado vermelho. Fonte: DSA-CPTEC. INPE, 2020.

A Fig. 3.60a mostra o campo de pressão no nível médio do mar do dia 29 de janeiro de 2020, às 1800 UTC. Observa-se dois sistemas de alta pressão sobre o estado de Minas Gerais e Paraná. O campo geopotencial mostra um centro de alta pressão em 700 mb e 
com fraco movimentos ascendentes de $0.5 \mathrm{~Pa} \mathrm{~s}^{-1}$ sobre a RMSP, às 1800 UTC (Fig. 3.60b).

A análise do campo de vento em $10 \mathrm{~m}$ e umidade em $2 \mathrm{~m}$ mostra vento intenso de leste associado ao sistema de alta pressão com escoamento paralelo à costa do estado de São Paulo e menos intenso no interior do estado (Fig. 3.60c). Observa-se valores de CAPE variando entre 600 a $900 \mathrm{~J} \mathrm{~K}^{-1}$ sobre a RMSP, às $1800 \mathrm{UTC}$ (Fig. 3.60d).
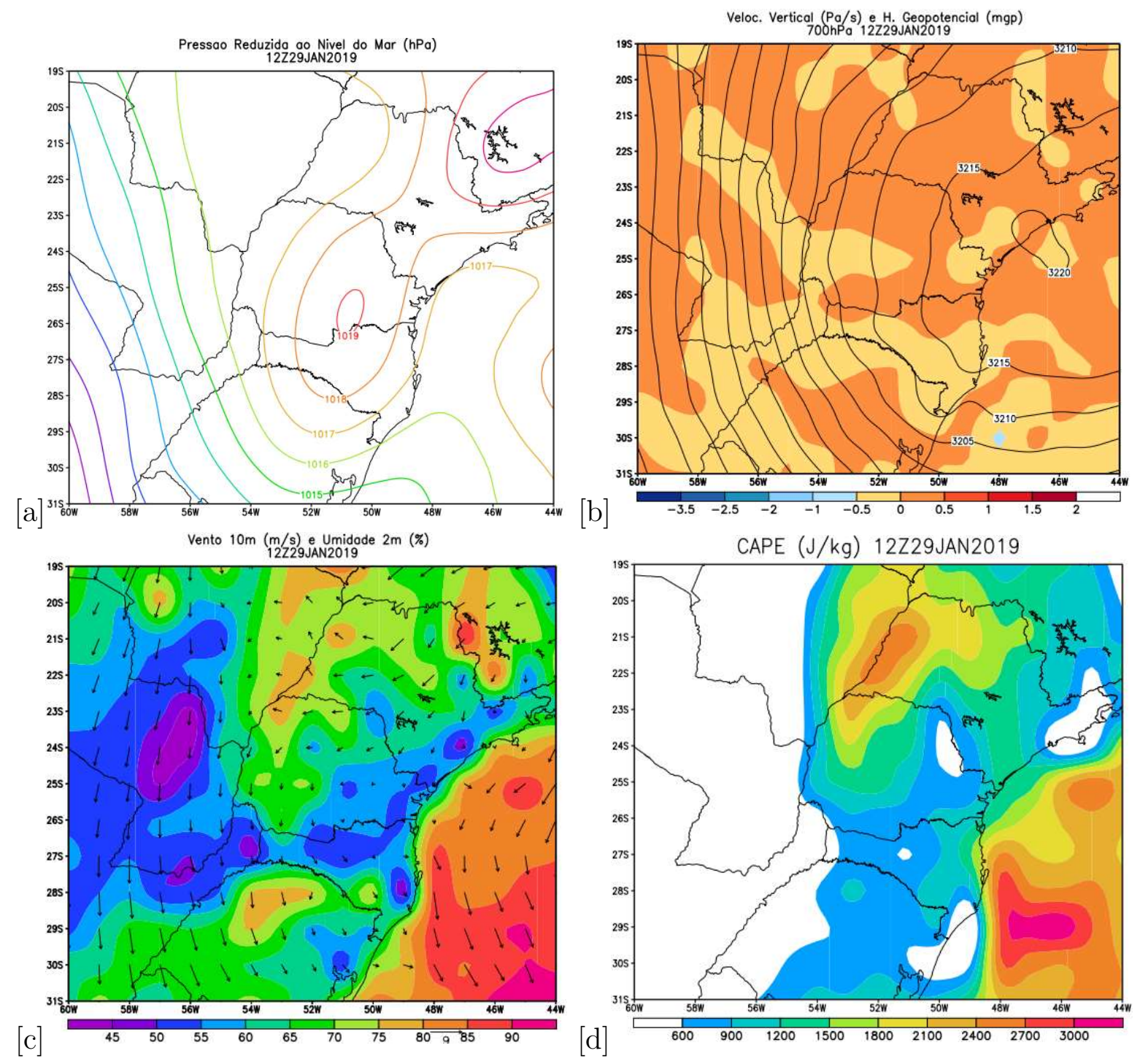

Figura 3.60: (a) Campo de pressão reduzido ao nível do mar (hPa); (b) campo de movimento vertical e altura geopotencial (gpm); (c) Campo de vento $\left(\mathrm{m}^{-1}{ }^{-1}\right.$ ) em $10 \mathrm{~m}$ e umidade (\%) em $2 \mathrm{~m}$ acima da superfície; e (d) CAPE $\left(\mathrm{J} \mathrm{kg}^{-1}\right)$ obtido a partir GFS do dia 29 de Janeiro de 2019. A faixa de isóbaras é de $1 \mathrm{hPa}$. Cores frias/quentes indicam valores mais baixos/mais altos. A faixa de isolinhas geopotenciais é de $20 \mathrm{gpm}$ e a barra de cores indica a velocidade vertical em $\mathrm{Pa} \mathrm{s}^{-1}$. As setas indicam a magnitude do vento e a barra de cores indica a umidade. A escala de cores indica os valores do CAPE. Contornos geopolíticos, latitudes, longitudes e tempos são indicados. 


\subsubsection{Análise termodinâmica e dinâmica}

A Fig.3.61 mostra os perfis de temperatura, umidade de vento medidos com a radiossonda no aeroporto Campo de Marte (23⒊4'S; $\left.46^{\circ} 44.1^{\prime} \mathrm{W}\right)$ às 1200 UTC do dia 29 antes da passagem da CI sobre a RMSP e 0000 UTC do dia 30 de Janeiro de 2019 após a passagem da CI. A razão de mistura estava muito baixa em todos os níveis da atmosfera antes da passagem da célula convectiva sobre a região, às 1200 UTC. Observa-se pelas barbelas o cisalhamento do vento com direções de sudeste e leste (Fig.3.61a). Nota-se que razão de mistura aumentou entre 700 e 800 mb e em 400 mb após a passagem da célula convectiva sobre a região (Fig.3.61b).
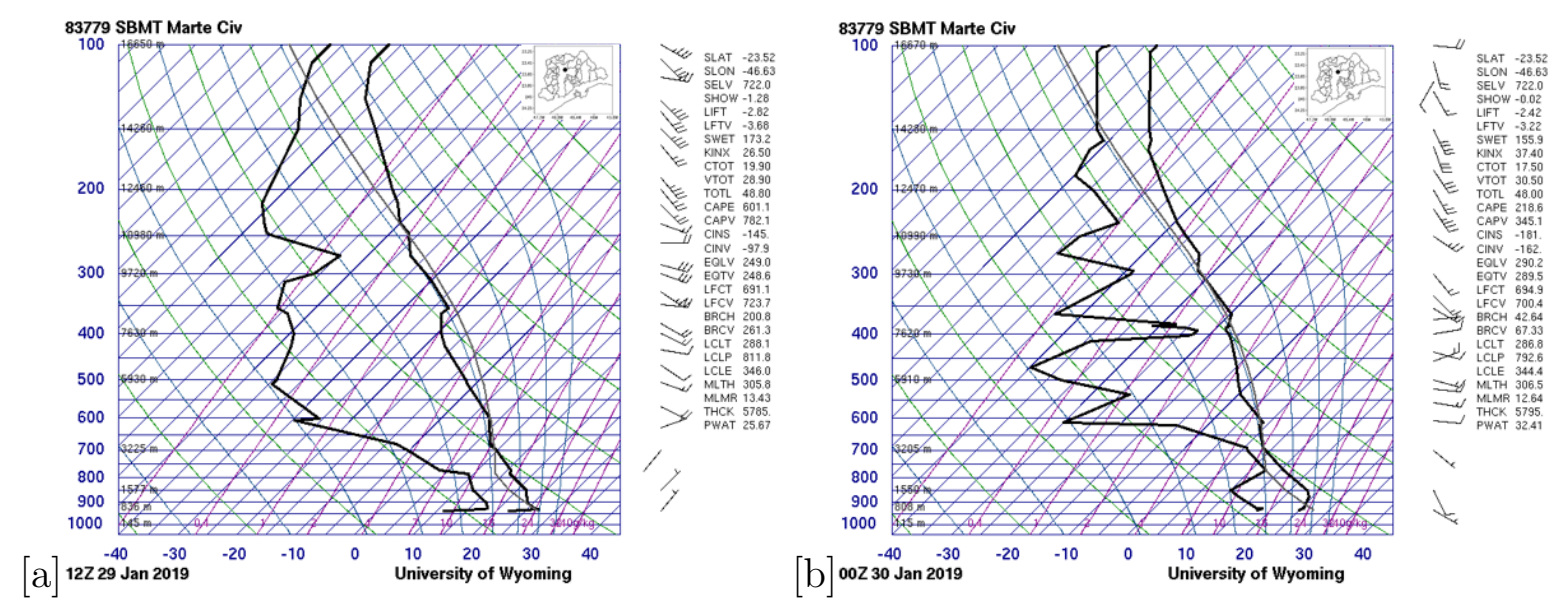

Figura 3.61: [Perfis verticais da temperatura do ar $\left({ }^{\circ} \mathrm{C}\right)$, temperatura do ponto do orvalho $\left({ }^{\circ} \mathrm{C}\right)$, velocidade (nós) e direção do vento $\left(^{\circ}\right)$ no Aeroporto Campo de Marte (-23 30' 31"S, -46 38' 15"W), (a) às 1200 UTC do dia 29 e (b) à 0000 UTC do dia 30 de Janeiro de 2019. A RMSP, as latitude e longitudes são indicados nos mapas, estão indicados nos cantos superiores direito dos perfis, o ponto preto indica a localização de lançamento das sondagens. Fonte: weather.uwyo.edu. Acessada em 14 de julho de 2019.

A Fig. 3.62 mostra campos da velocidade radial durante a evolução espaço-temporal da CI sobre a região entre 1700 e 1910 UTC do dia 29 de Janeiro de 2019. As Fig. 3.62a, b, indicam regiões de convergências a $70 \mathrm{~km}$ do radar SPOL, aproximadamente, onde as setas azul/vermelha indicam os fluxos de ar que se aproxima/afasta do radar SPOL, áreas destacadas, às 1700 UTC e às 1755 UTC.

A partir das 1805 UTC (Fig. 3.62c) até às 1910 UTC (Fig. 3.62f), observa-se que a CI está sob influência de rotação ciclônica. A seta azul (fluxo que se aproxima ao radar SPOL) apresenta curvatura para direita e a seta vermelha (fluxo que se afasta do radar 
SPOL) apresenta curvatura para esquerda, indicam rotação ciclônica .
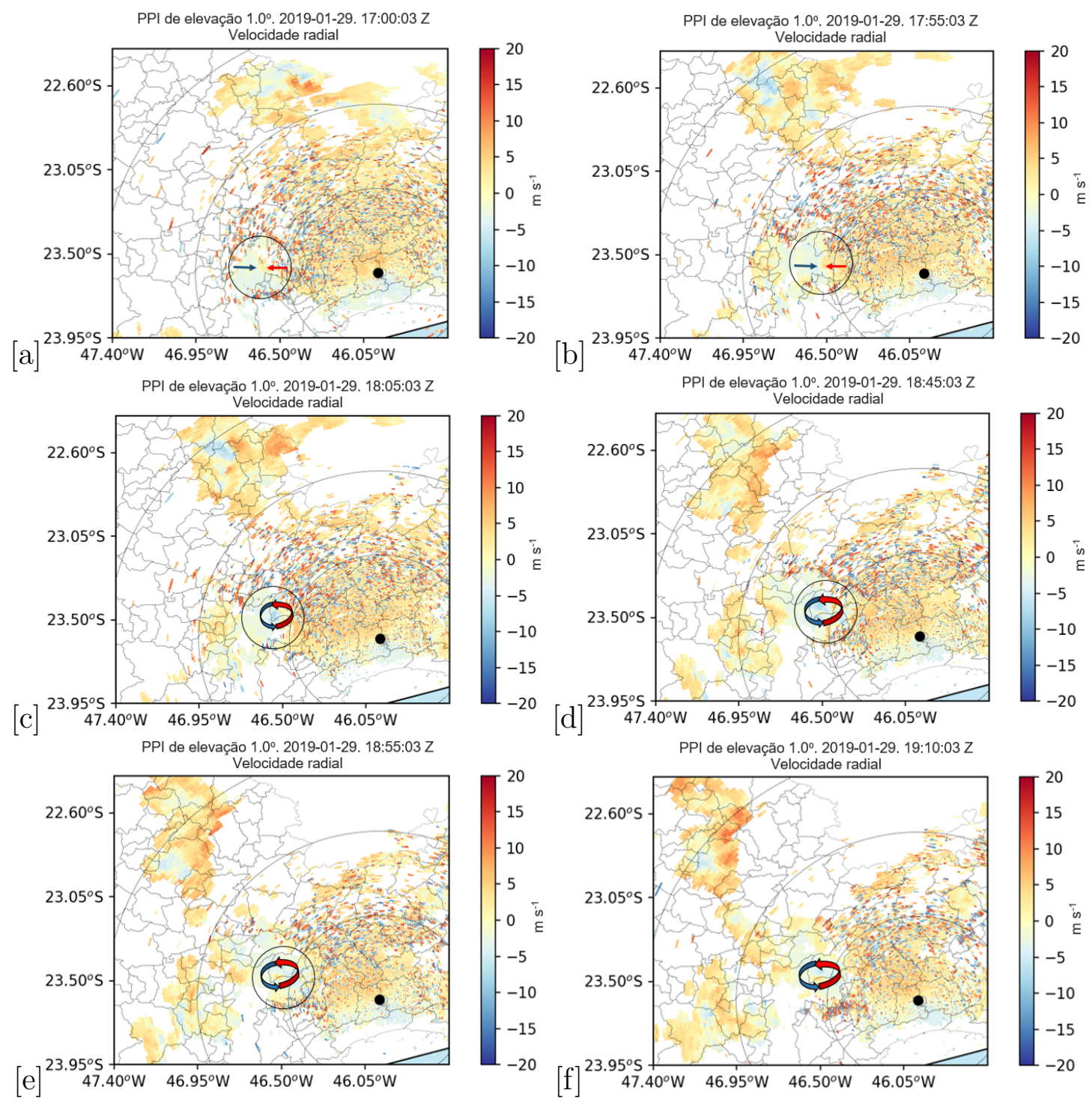

Figura 3.62: PPIs de ângulo de elevação de $1.0^{\circ}$ da velocidade radial do radar SPOL às 1700 UTC (a), às 1755 UTC (b), às 1805 UTC (c), às 1845 UTC (d), às 1855 UTC (d) e às 1910 UTC (e) do dia 29 de Janeiro de 2019. A escala de core indica a velocidade $\left(\mathrm{m} \mathrm{s}^{-1}\right)$ de alvos que se aproxima (azul) e se afasta (vermelho) do SPOL. O ponto preto no centro indica posição do radar meteorológico SPOL, na cabeceira da Bacia do Alto Tietê. Circunferências concêntricas estão espaçadas a cada $50 \mathrm{~km}$. Longitudes, latitudes, contornos dos municípios são indicados.

A CI tornou-se mais profunda sob influência de rotação ciclônica. A Fig. 3.63 mostra a profundidade da célula convectiva em vários PPIs sobre o centro geométrico da RMSP, região de adensamento urbano. 

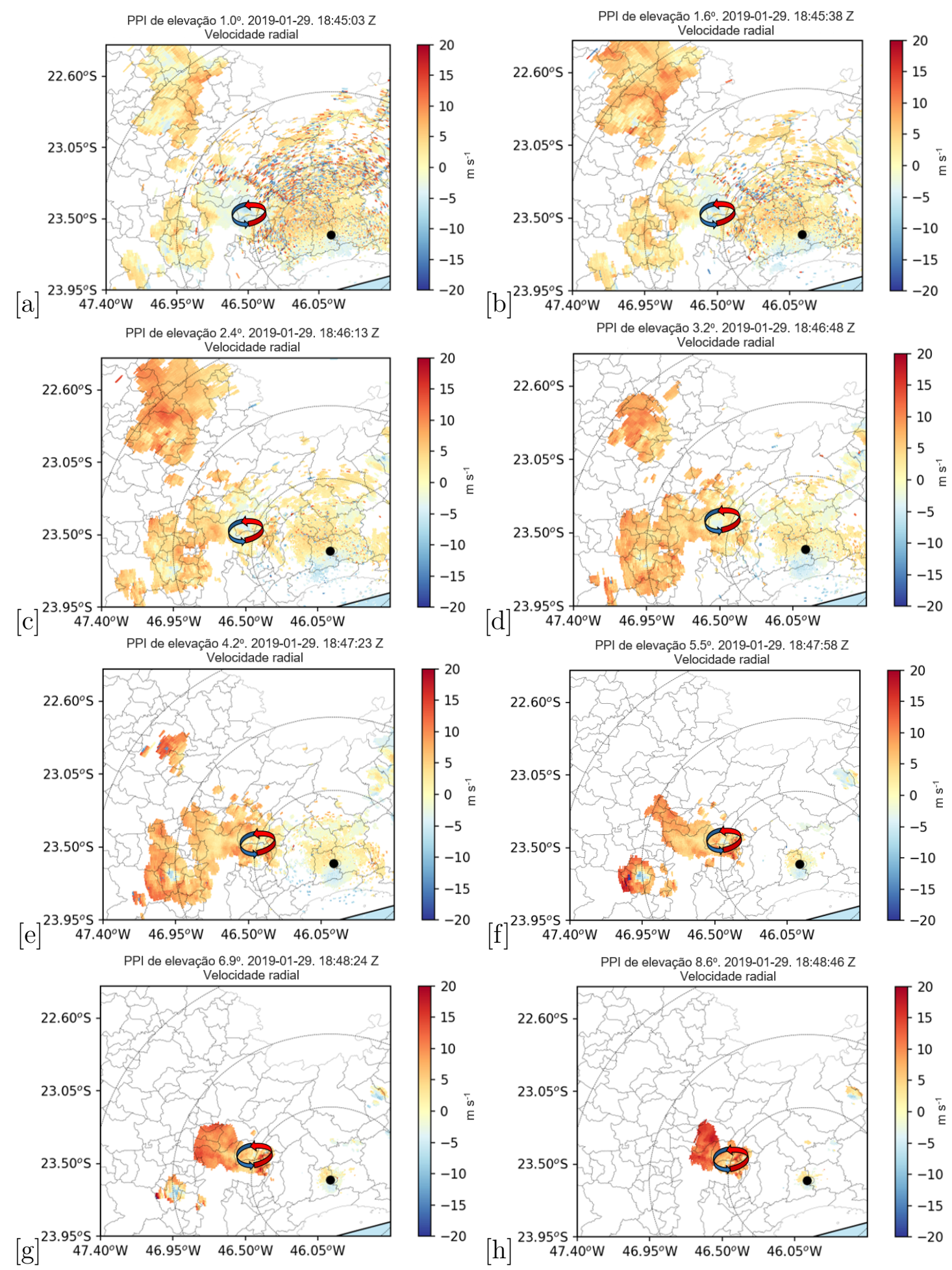

Figura 3.63: Campos da velocidade radial do radar SPOL nos PPIs de ângulo de elevação de $1.0^{\circ}$ (a), $1.6^{\circ}(\mathrm{b}), 2.4^{\circ}(\mathrm{c}), 3.2^{\circ}$ (d), $4.2^{\circ}$ (e), $5.5^{\circ}$ (f), $6.9^{\circ}$ (g) e 8.6.2 (h) entre às 1845 e 1848 UTC do dia 29 de Janeiro de 2019. A escala de core indica a velocidade $\left(\mathrm{m} \mathrm{s}^{-1}\right)$ de alvos que se aproxima (azul) e se afasta (vermelho) do SPOL. O ponto preto no centro indica posição do radar meteorológico SPOL, na cabeceira da Bacia do Alto Tietê. Circunferências concêntricas estão espaçadas a cada 50 km. Longitudes, latitudes, contornos dos municípios são indicados. 
De acordo com Johnson et al. (1994), uma tempestade sob rotação anticiclônica facilita a separação da corrente ascendente da corrente descendente, permitindo que a tempestade persista. A tempestade exibiu características dinâmicas e termodinâmicas, incluindo uma intensa e persistente corrente ascendente com forte rotação anticiclônica em baixo e médios níveis Johnson et al. (1994).

A CI está a $50 \mathrm{~km}$ do radar SPOL e é exibido nos PPIs de elevação $1.0^{\circ}$, (b) $1.6^{\circ}$, (c) $2.4^{\circ}$, (d) $3.2^{\circ}$, (e) $4.2^{\circ}$, (f) $5.5^{\circ}$, (g) $6.9^{\circ}$ e (h) 8.6.2. Com base na Fig. 2.1, o PPI de elevação $1.0^{\circ}$ fez varredura a $0,9 \mathrm{~km}$ de altura, aproximadamente, e o PPI de elevação 8.6.2 $2^{\circ}$ fez varredura a $8 \mathrm{~km}$ de altura, aproximadamente. A CI apresenta $9 \mathrm{~km}$ de profundidade (Fig. 3.63), provavelmente, com mesmas características dinâmicas e termodinâmicas, incluindo uma intensa e persistente corrente ascendente com forte rotação clônica em baixo e médios níveis.

\subsubsection{Evolução espaço-temporal}

Os dados do radar SPOL indicaram a formação típica de CI, aproximadamente a 70 $\mathrm{km}$, no azimute $247.5^{\circ}$, área destacada (Fig. 3.64a) e essa foi monitorada até às 1950 UTC (Fig. 3.68h), quando perdeu intensidade. O disparo da CI ocorreu sobre a divisa do município de São Paulo, a leste-sudeste, deslocou-se da zona oeste para zona oeste, posteriormente, para zona leste do município de São Paulo e para divisa do município de São Paulo com Guarulhos. Às 1700 UTC, a célula convectiva aumentou de dimensão e de intensidade, e à medida que essa propagou-se para regiões de adensamento urbano, sobre o centro geométrico da RMSP, área destacada (Fig. 3.64b). A Fig. 3.64e mostra o núcleo da CI com refletividade > $65 \mathrm{dBZ}$, quando estava sob influência de rotação ciclônica sobre a divisa dos dois municípios, às 1805 UTC. A partir desse horário, a CI ficou sob influência de rotação ciclônica. Aproximadamente, 40 minutos depois, a CI encontra-se sobre sobre a divisa dos dois municípios, e observa-se o disparo de célula convectiva menor na sua retaguarda, às 1845 UTC (Fig. 3.64f). A célula convectiva menor integra-se à célula convectiva maior (CI), que a intensificou, às 1855 UTC, área destacada (Fig. 3.64g). A Fig. 3.64h mostra uma única célula convectiva completamente integrada e com dimensão maior, às 1905 UTC, área destacada. 

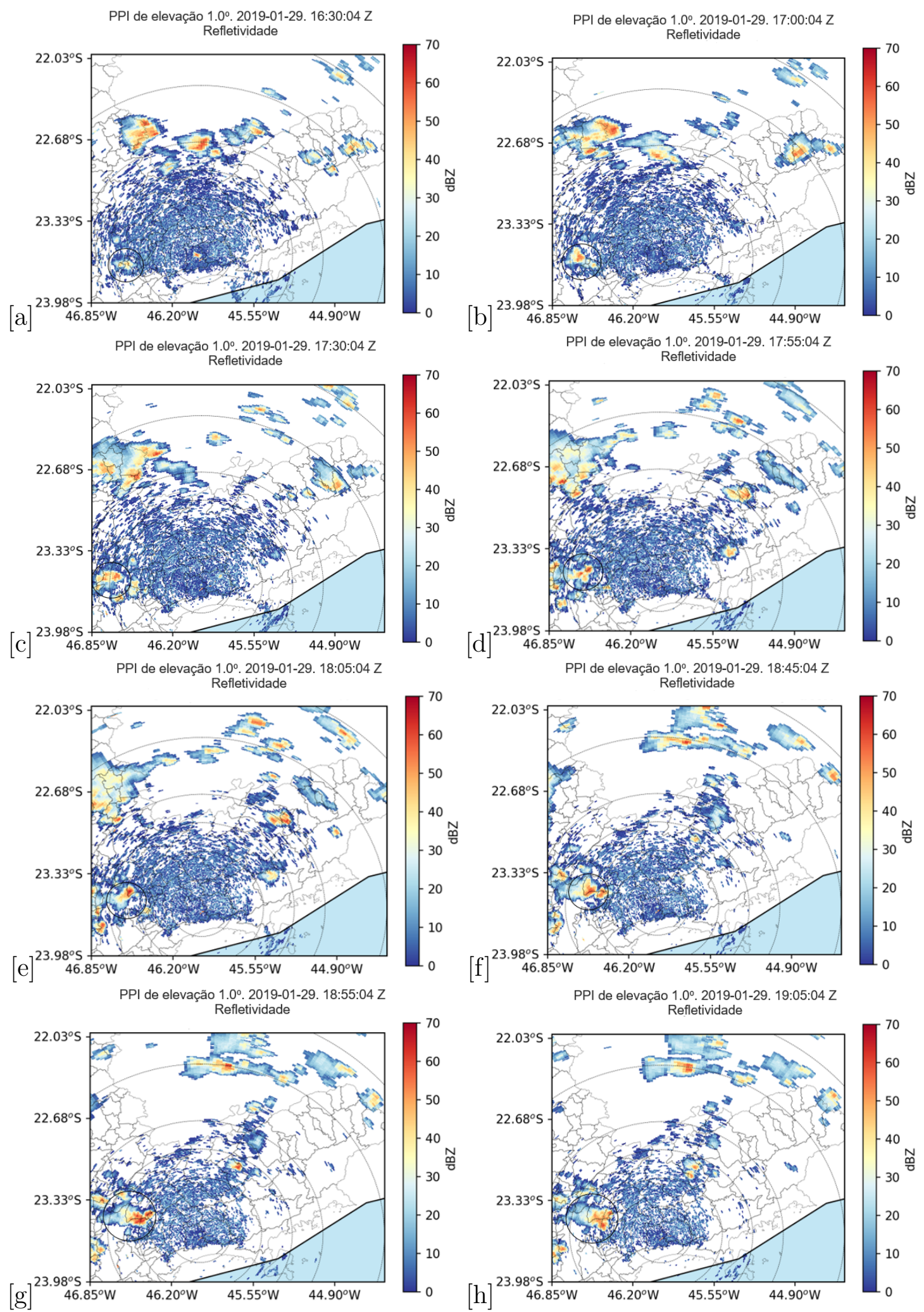

Figura 3.64: PPI de ângulo de elevação de $1.0^{\circ}$ da refletividade $\left(\mathrm{Z}_{H}\right)$ do radar SPOL às 1630 UTC (a), 1700 UTC (b), 1730 UTC (c), 1755 UTC (d), 1805 UTC (e), 1845 UTC (f), 1855 UTC (g) e 1905 UTC (h) do dia 29 de Janeiro de 2019. A escala de cores indica a refletividade (dBZ). Circunferências concêntricas estão espaçadas a cada $25 \mathrm{~km}$ até aos $100 \mathrm{~km}$ e espaçadas a cada $50 \mathrm{~km}$ até aos $200 \mathrm{~km}$. O radar meteorológico SPOL está centro da menor circunferência concêntrica. Longitudes, latitudes, contornos dos municípios são indicados. 

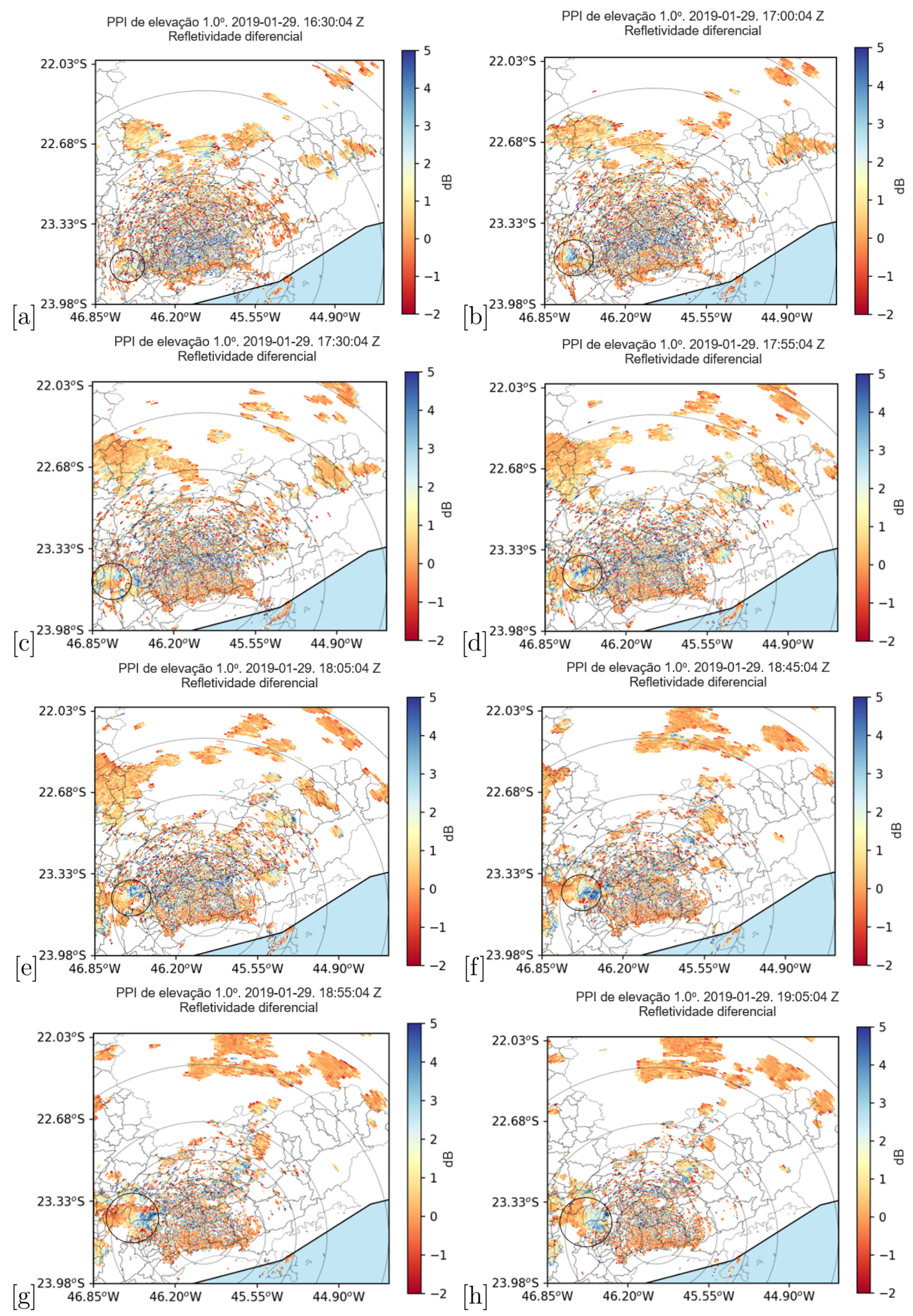

Figura 3.65: Idem Fig. 3.64, mas para refletividade diferencial. A escala de cores indica refletividade diferencial $(\mathrm{dB})$. 

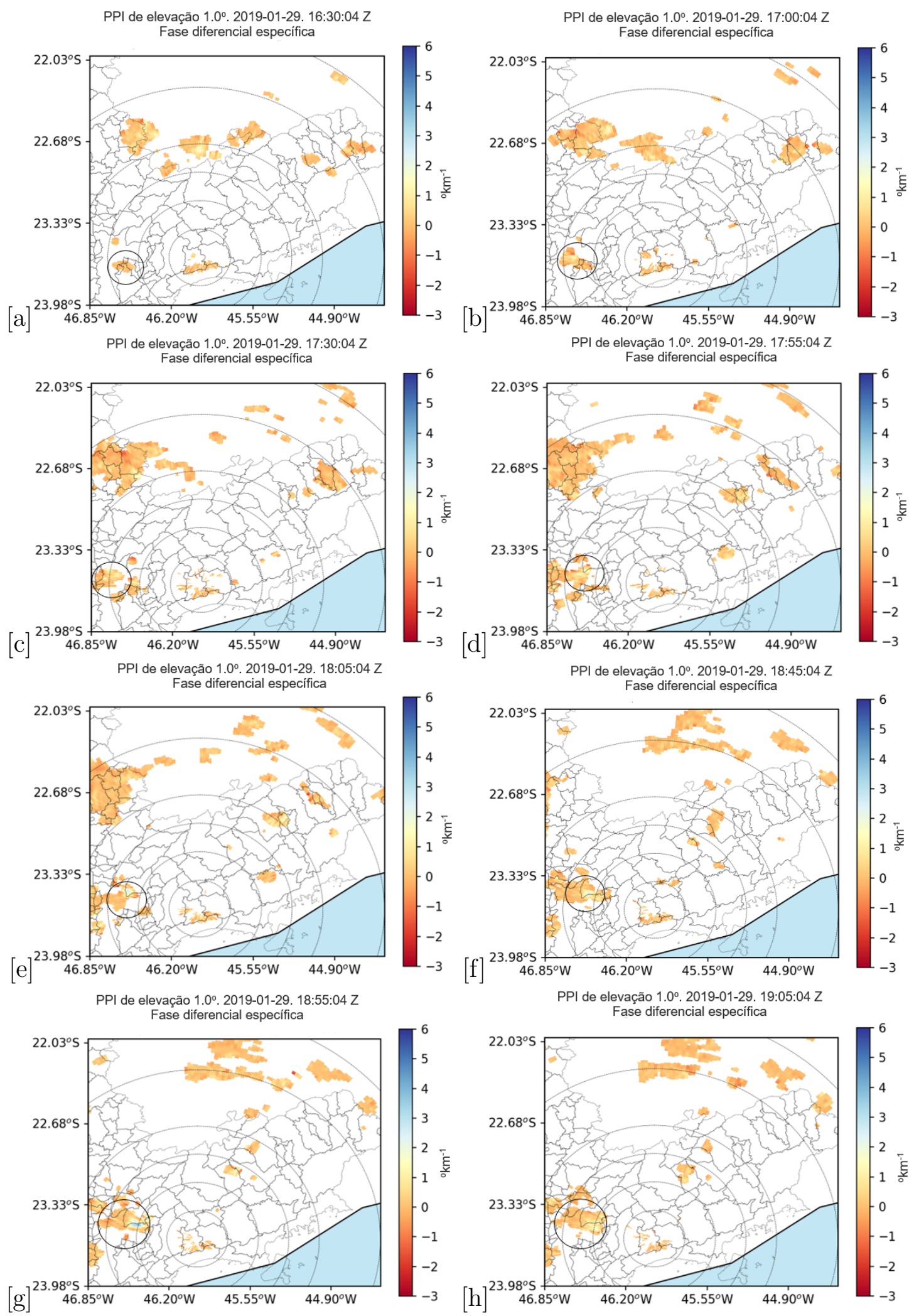

Figura 3.66: Idem Fig. 3.64, mas para fase diferencial específica. A escala de cores indica a fase diferencial específica $\left({ }^{\circ} \mathrm{km}^{-1}\right)$. 

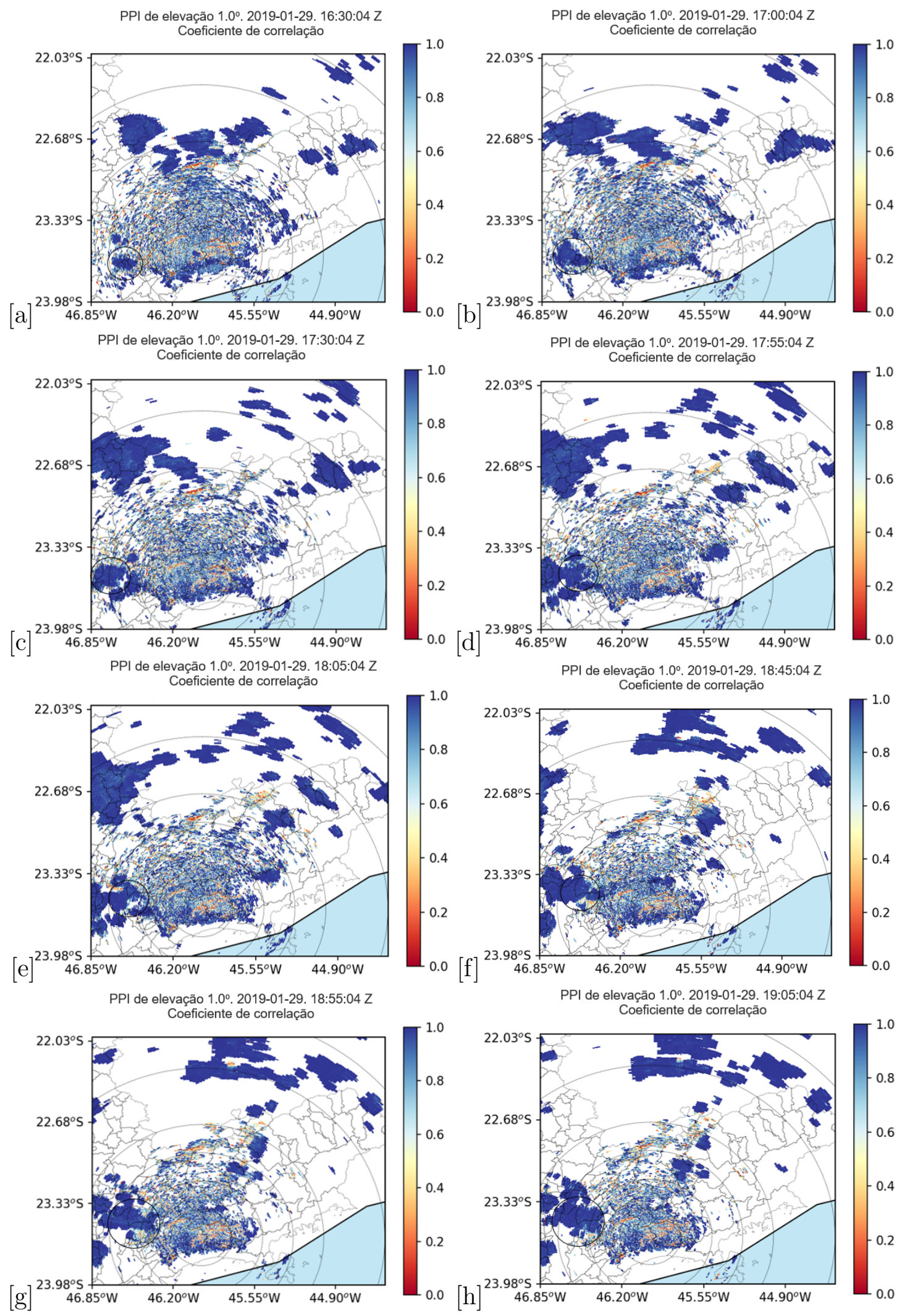

Figura 3.67: Idem Fig. 3.64, mas para coeficiente de correlação. A escala de cores indica o coeficiente de correlação (sem unidade). 
Os campos de refletividade diferencial são observados valores muitos baixos no núcleo da CI, área destacada (Fig. 3.65a). Às 1700 UTC, o núcleo da CI apresenta valores altos entre 2 e $5 \mathrm{~dB}$, área destacada (Fig. 3.65b). Nota-se que o núcleo com alores altos entre 2 e 5 dB, expandiu-se às 1805 UTC, área destacada (Fig. 3.65c). O núcleo da célula convectiva menor apresenta valores altos entre 4 e $5 \mathrm{~dB}$ enquanto a célula convectiva maior (CI) apresente valores altos entre 2 e $5 \mathrm{~dB}$, às 1845 UTC, área destacada (Fig. 3.65f). A célula convectiva completamente integrada exibe núcleo com valores predominante de 5 $\mathrm{dB}$, às $1855 \mathrm{~dB}$ (Fig. 3.65g), e 10 minutos depois, essa apresenta valores predominantes de $3 \mathrm{~dB}$, área destacada (Fig. 3.65h).
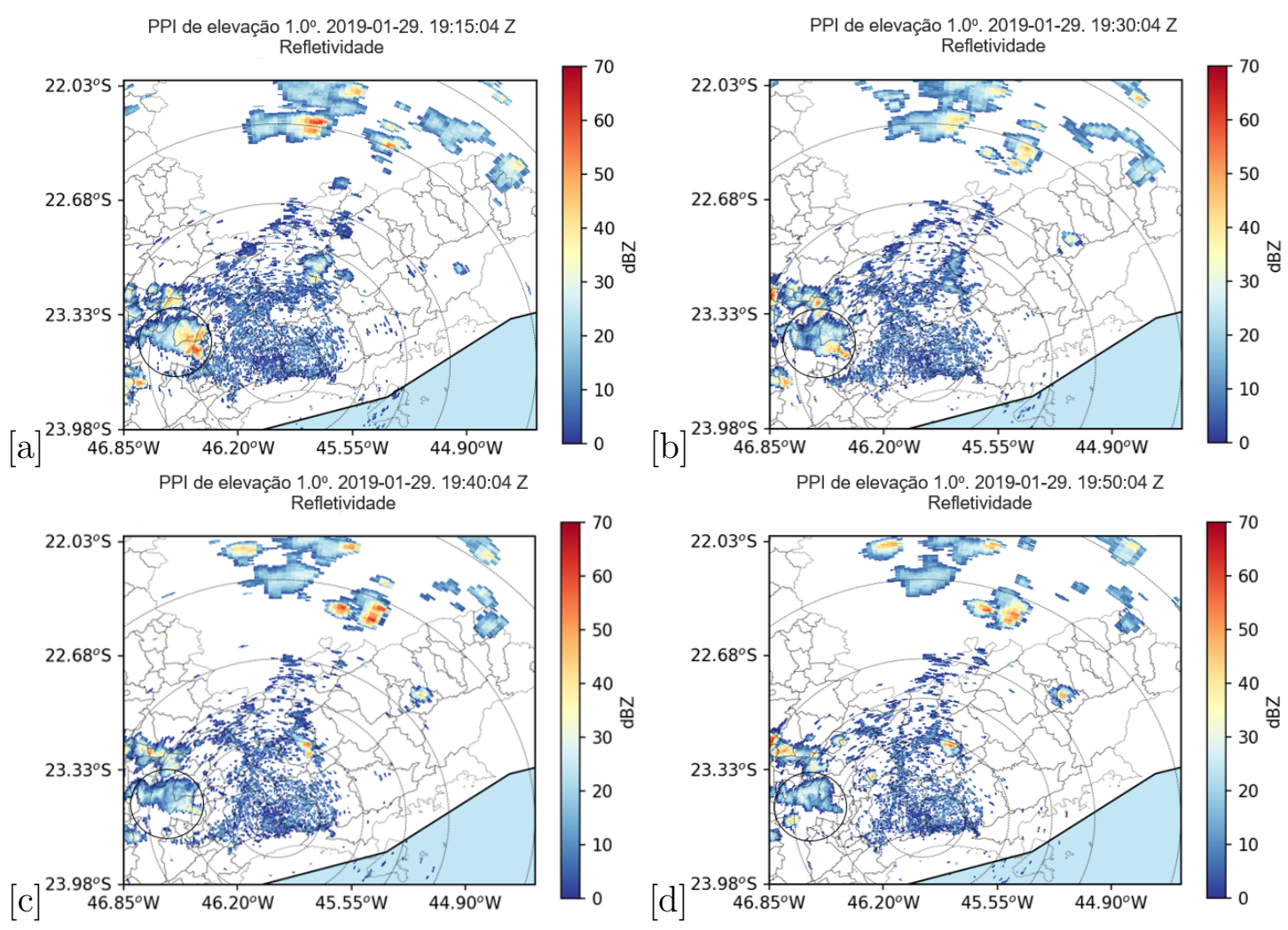

Figura 3.68: PPI de ângulo de elevação de $1.0^{\circ}$ da refletividade $\left(\mathrm{Z}_{H}\right)$ do radar SPOL às 1915 UTC (a), 1930 UTC (b), 1940 UTC (c), 1950 UTC (d) do dia 29 de Janeiro de 2019. A escala de cores indica a refletividade (dBZ). Circunferências concêntricas estão espaçadas a cada $25 \mathrm{~km}$ até aos $100 \mathrm{~km}$ e espaçadas a cada $50 \mathrm{~km}$ até aos $200 \mathrm{~km}$. O radar meteorológico SPOL está centro da menor circunferência concêntrica. Longitudes, latitudes, contornos dos municípios são indicados.

Nota-se que o aumento dos valores para $2^{o} \mathrm{~km}^{-1}$ da fase diferencial específica no núcleo da CI a partir das 1805 UTC, área destacada (Fig. 3.66c), quando essa está sob influência 
de rotação ciclônica. Os valores aumentaram $>2^{\circ} \mathrm{km}^{-1}$ depois da célula convectiva menor integrar-se à célula convectiva maior (Fig. 3.66g).

A Fig. 3.67 mostra os campos do coeficiente de correlação durante a evolução espaçotemporal da CI. Nota-se coloração homogenia nas áreas com hidrometeoros. Observa-se valor mais próximo de 1,0 generalizado. Mas no núcleo da CI é possível observar valores que variam entre 1,0 e 0,8, quando essa tornou-se mais intensa.
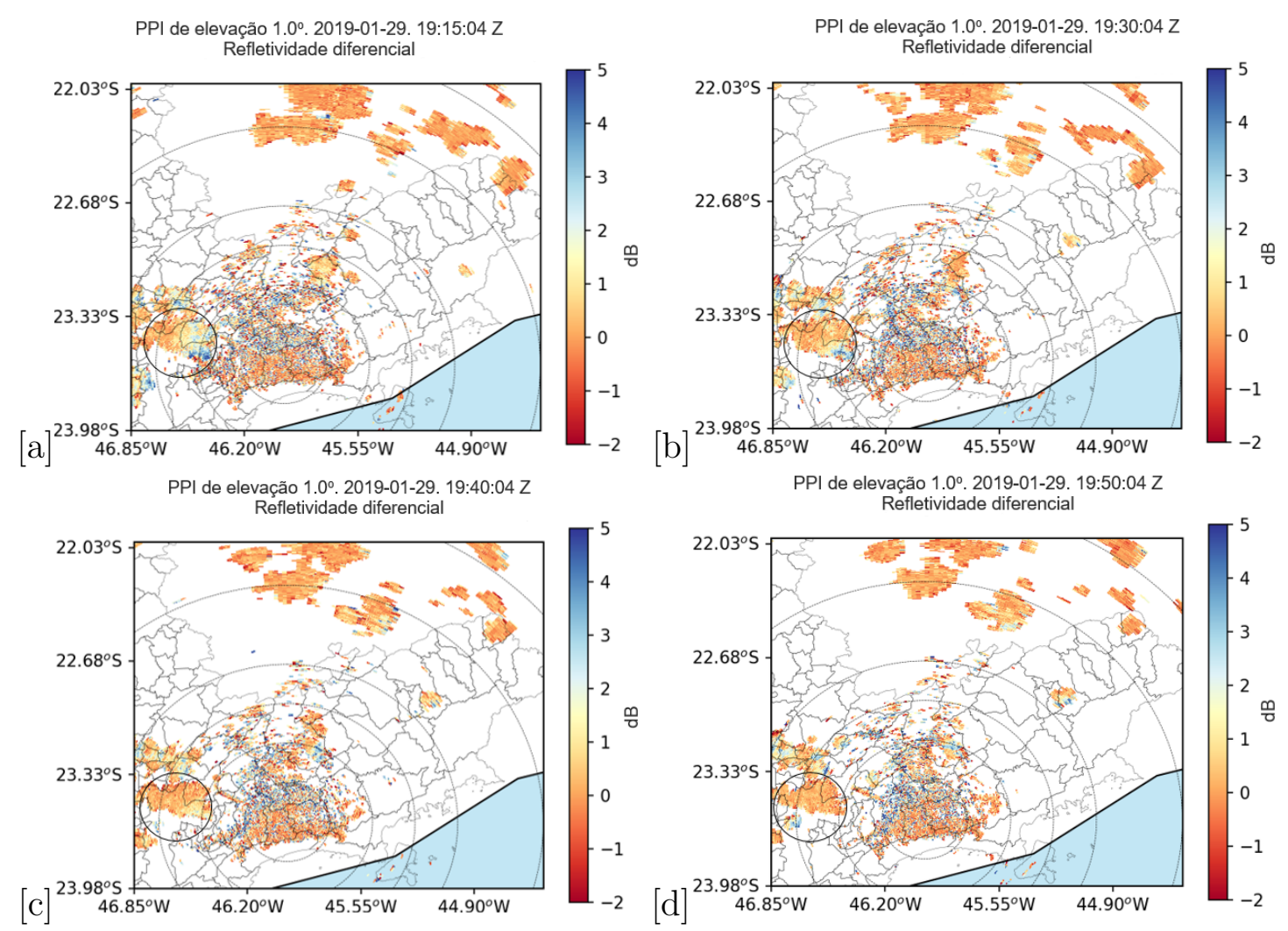

Figura 3.69: Idem Fig. 3.68, mas para refletividade diferencial. A escala de cores indica refletividade diferencial $(\mathrm{dB})$.

A Fig. 3.68 mostra que a CI entrou na fase de dissipação, quando essa passa a exibir refletividade com valores $<35$ dBZ no seu núcleo a partir das 1940 UTC, área destacada. Os valores de refletividade diferencial ficaram $<1.5 \mathrm{~dB}$ (Fig. 3.69). 

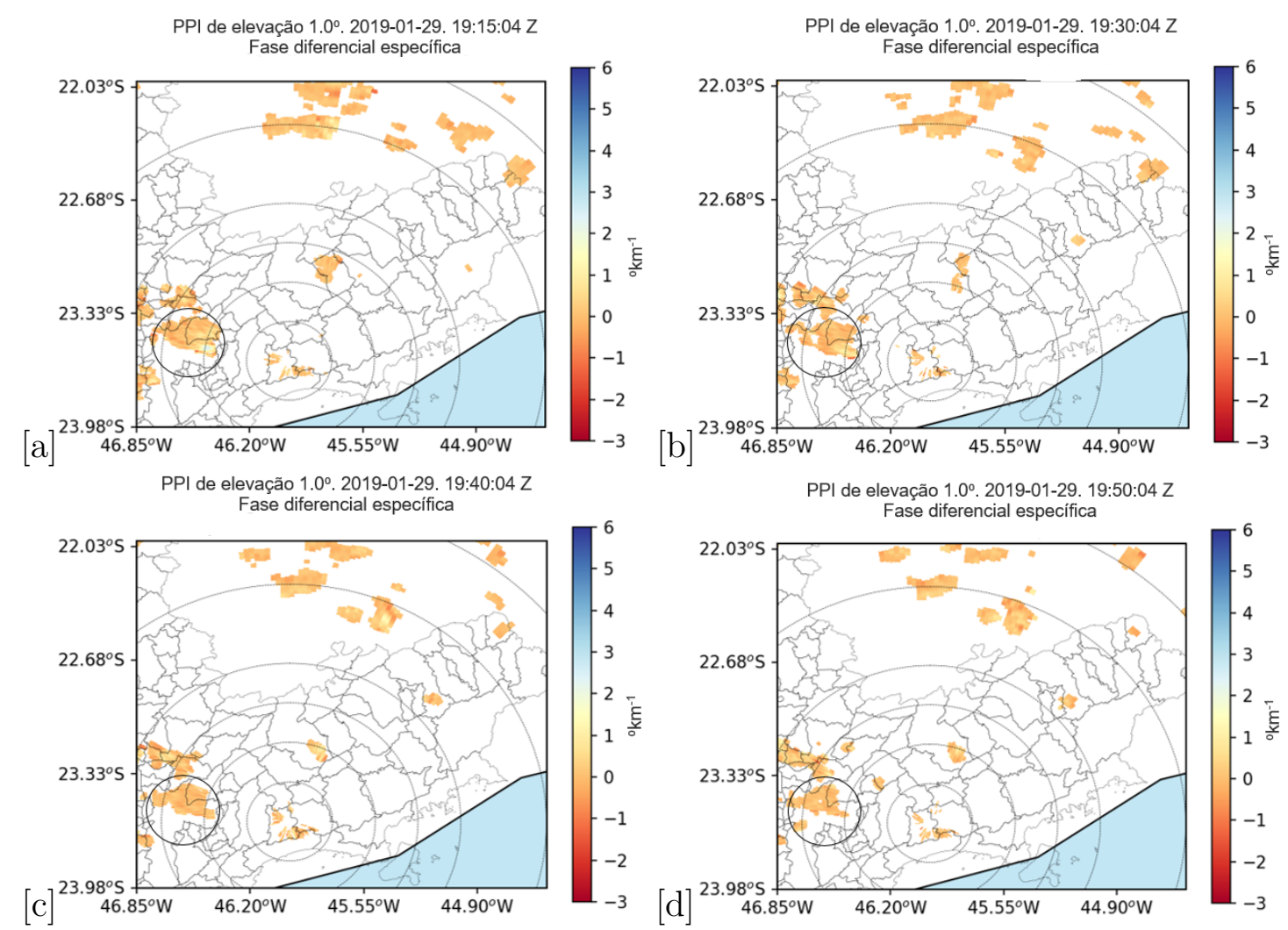

Figura 3.70: Idem Fig. 3.68, mas para fase diferencial específica. A escala de cores indica a fase diferencial específica $\left({ }^{\circ} \mathrm{km}^{-1}\right)$.

Nota-se que os valores da fase diferencial específica estão abaixo de $2^{o} \mathrm{~km}^{-1}$ no núcleo da CI, às 1915 UTC, área destacada (Fig. 3.70a), e a partir das 1930 UTC para adiante os valores ficaram $<1.5^{\circ} \mathrm{km}^{-1}$ (Fig. 3.70b). Isso indica que a partir das 1930 UTC não existe gotas oblatas na célula decadente. E o que se observa nos campos do coeficiente de correlação, são alvos meteorológicos estando mais próximo de 1,0, por serem mais uniforme, uma vez que os sinais verticais e horizontais tendem a ser os mesmos (Fig. 3.71). 

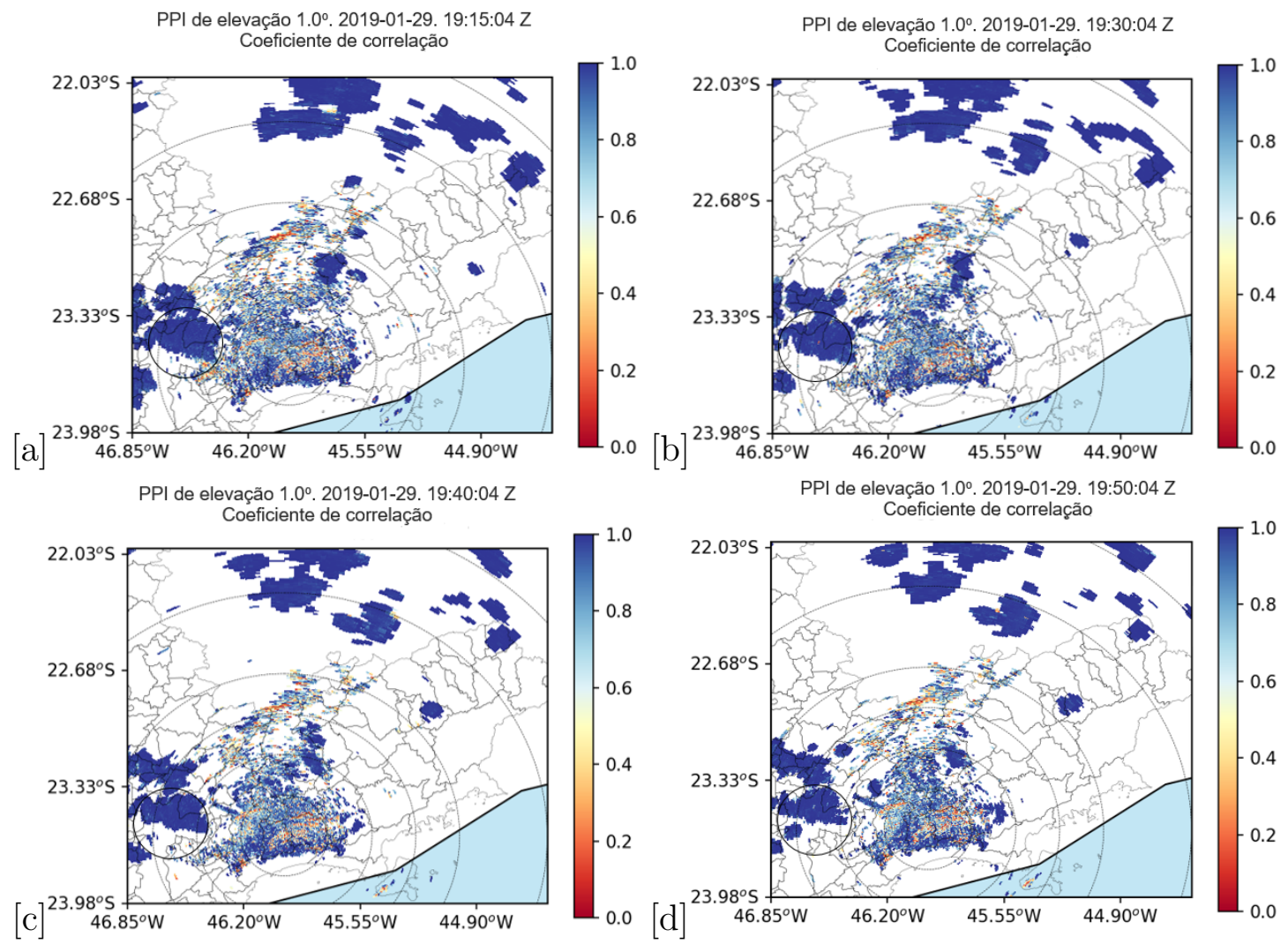

Figura 3.71: Idem Fig. 3.68, mas para coeficiente de correlação. A escala de cores indica o coeficiente de correlação (sem unidade).

\subsubsection{Classificação dos hidrometeoros}

A Fig. 3.72 apresenta a classificação dos hidrometeoros da CI, quando estava sobre o centro geométrico da RMSP. A classificação dos hidrometeoros indica chuva forte associada a gotas grandes na parte inferior da CI, quando estava sob convergência de massa de ar, área destacada (Fig. 3.72a). A classificação de hidrometeoros indica quantidade baixa de granizo acima da isoterma $0^{\circ} \mathrm{C}$, onde observa-se predominância de granizo de baixa densidade, área destacada (Fig. 3.72a) Envolvendo essa região de chuva misturada a gotas grandes, encontra-se chuvisco que compõe a região estratiforme (Fig. 3.72c). Provavelmente, a convergência em baixos níveis não transportaram conteúdo de água líquida suficiente, para que o mecanismo de acreção seja eficiente, responsável para a produção de granizo. O granizo é responsável para a produção de gotas grandes a partir da isoterma $0^{\circ} \mathrm{C}$. 

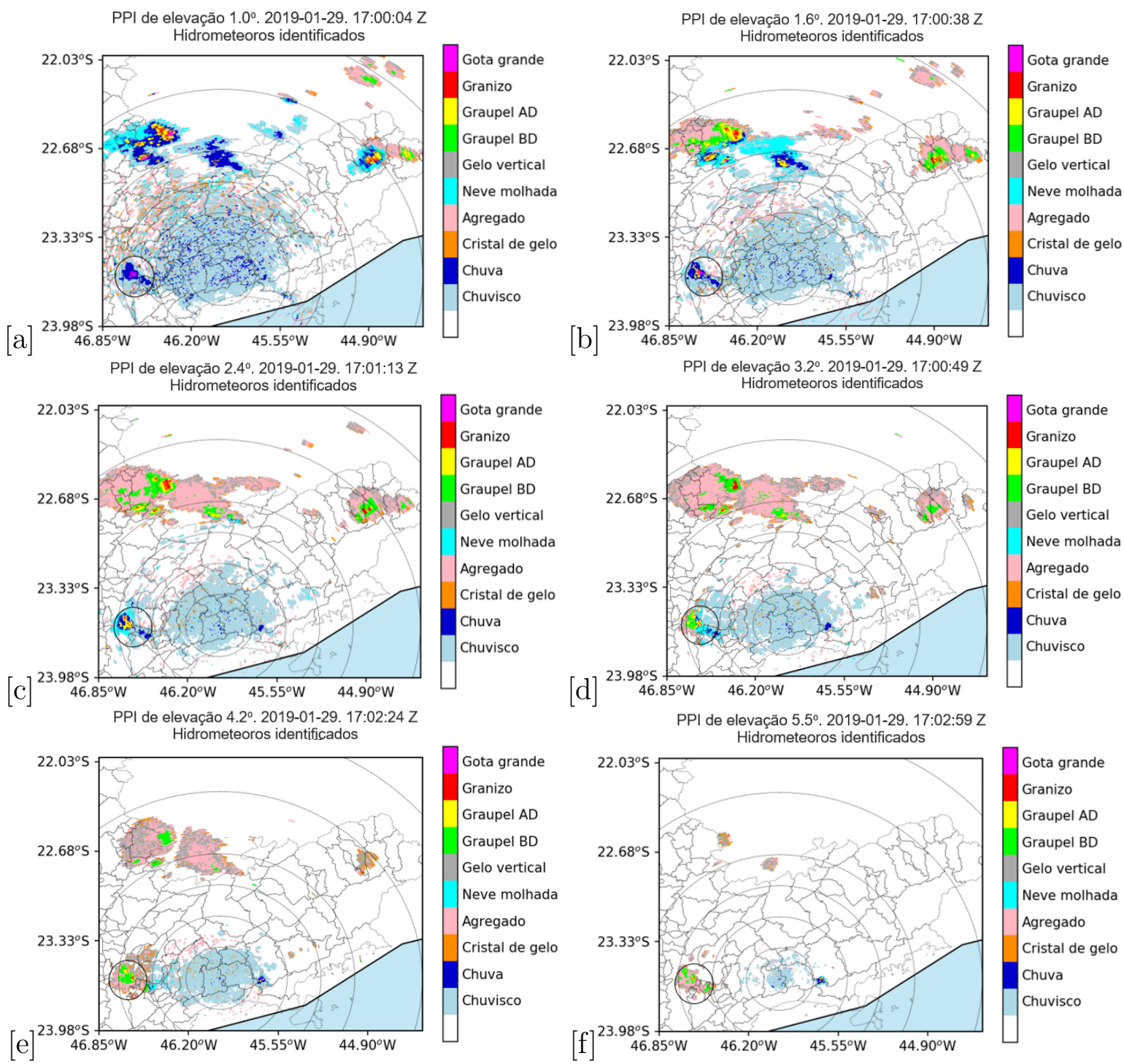

Figura 3.72: PPIs de ângulo de elevação de $1.0^{\circ}$ (a), $1.6^{\circ}$ (b), $2.4^{\circ}$ (c), $3.2^{\circ}$ (d), $4.2^{\circ}$ (e) e $5.5^{\circ}$ (f) da classificação de hidrometeoros do radar SPOL no dia 29 de Janeiro de 2019, às 1700 UTC. A escala de cores apresenta as 10 classificações dos hidrometeoros: Gota de água, Granizo, Graupel AD, Graupel BD, Gelo vertical, Neve molhada, Agregado, Cristal de gelo, Chuva e Chuvisco. Circunferências concêntricas estão espaçadas a cada $25 \mathrm{~km}$. O radar meteorológico SPOL está centro da menor circunferência concêntrica. Longitudes, latitudes, contornos dos municípios de São Paulo são indicados.

Provavelmente, quando a corrente ascendente começa a ser induzida rotacionalmente pelo gradiente do vento, A CI se intensificou e tornou-se profunda. Por que isso ocorreu? Por que a rotação ciclônica da corrente ascendente é mais intensa, que ejeta quantidade alta de umidade para a atmosfera, que condensa liberando quantidade alta de energia (calor latente). Isso aumenta a flutuabilidade da corrente ascendente e ejeta quantidade 
alta de conteúdo de água líquida.
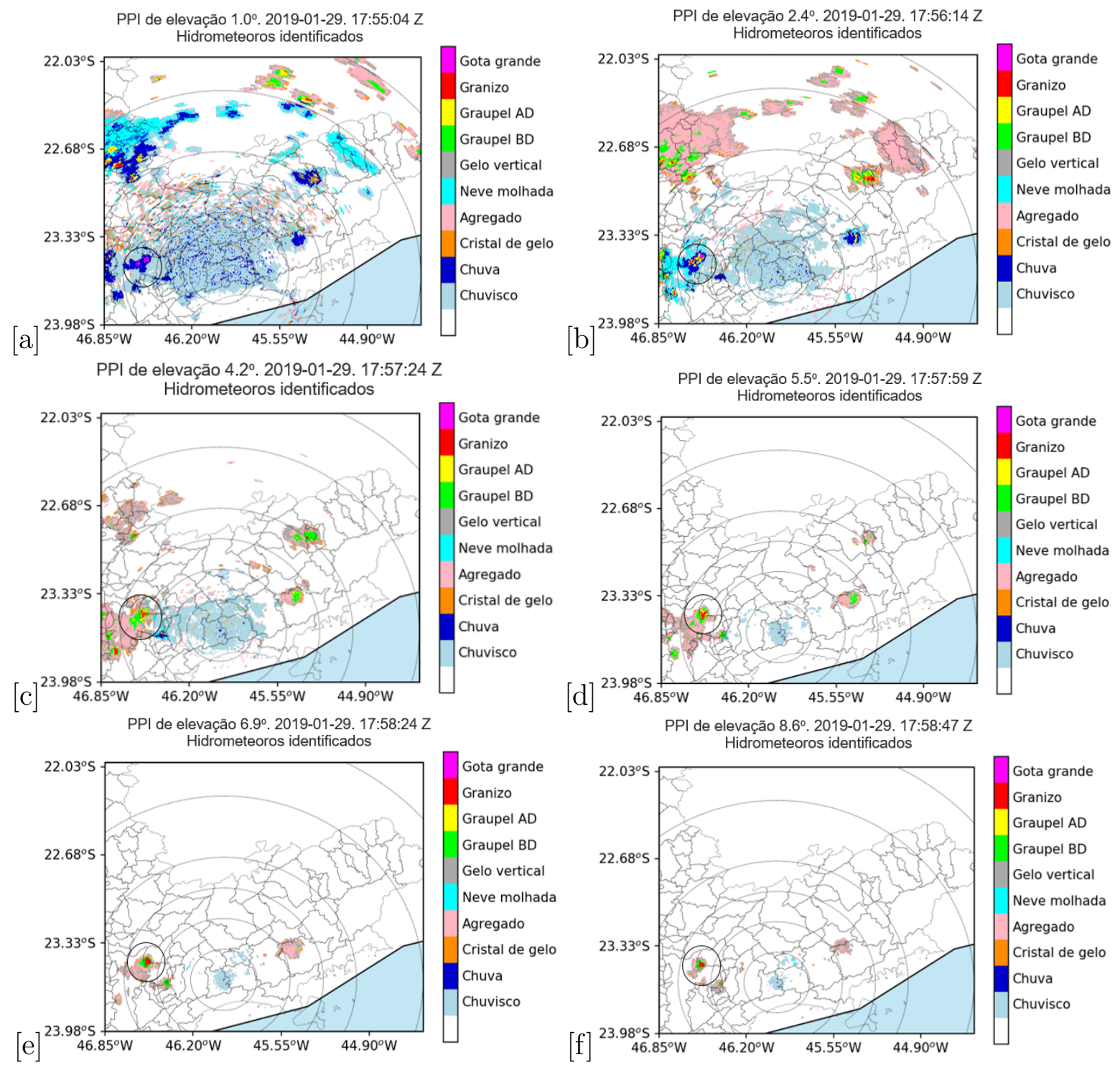

Figura 3.73: PPIs de ângulo de elevação de $1.0^{\circ}$ (a), $1.6^{\circ}$ (b), $2.4^{\circ}$ (c), $3.2^{\circ}$ (d), $4.2^{\circ}$ (e), $5.5^{\circ}$ (f), $6.9^{\circ}(\mathrm{g})$ e $8.6^{\circ}(\mathrm{h})$ da classificação de hidrometeoros do radar SPOL no dia 29 de Janeiro de 2019 , às 1755 UTC. A escala de cores apresenta as 10 classificações dos hidrometeoros: Gota de água, Granizo, Graupel AD, Graupel BD, Gelo vertical, Neve molhada, Agregado, Cristal de gelo, Chuva e Chuvisco. Circunferências concêntricas estão espaçadas a cada $25 \mathrm{~km}$. O radar meteorológico SPOL está centro da menor circunferência concêntrica. Longitudes, latitudes, contornos dos municípios de São Paulo são indicados.

A Fig. 3.73 mostra claramente que a convecção é profunda. Observa-se o aumento da concentração de gotas grandes na parte inferior da CI, área destacada (Fig. 3.73a). Esse aumento da quantidade de gotas grandes na parte inferior da CI, justifica-se fato 
da corrente ascendente ser intensa o suficiente para carregar as gotículas de água para a região superior da nuvem a temperaturas abaixo de $0^{\circ} \mathrm{C}$, onde essas congelam tornando-se em cristais de gelo. Esses cristais de gelo coabitam com gotículas supres-resfriadas, que torna eficiente o processo de acreção, responsável para de granizo, como indicado pela classificação de hidrometeoros, quantidade alta de granizo acima da isoterma ${ }^{\circ} \mathrm{C}$, área destacada (Fig. 3.73c, f).

A Fig. 3.74 mostra a CI sobre a divisa dos municípios de São Paulo e Guarulhos, quando estava sob influência de rotação ciclônica, área destacada, às 1805 UTC. A classificação de hidrometeoros indica quantidade alta de gotas grandes e no seu núcleo quantidade quantidade alta de granizo, provavelmente que precipitou até à superfície, área destacada (Fig. 3.74a).

De acordo com Johnson et al. (1994), a rotação anticiclônica facilita a separação da corrente ascendente da corrente descendente, permitindo que a tempestade persista. Provavelmente, CI com as correntes ascendente e descendente separadas devido as condições dinâmicas e termodinâmicas, permitiu que quantidade alta de precipitasse até à superfície sem descongelar (Fig. 3.74a).

Nota que dentro da isoterma $0^{\circ} \mathrm{C}$ a concentração de granizo, é mais alta (Fig. 3.74c) que nos níveis mais baixas da célula convectiva. Não obstante da separação das correntes ascendente e descendente, parte das pedras de granizo descongela ao precipitar a temperaturas acima de $0^{\circ} \mathrm{C}$, justificando a diminuição da concentração das pedras de granizo que chega à superfície. Bringi et al. (1986) observaram variações microfísicas um graupel de tamanho típico de $2,3 \mathrm{~mm}$, que ao precipitar, derrete transformando-se numa gota de chuva de 3,6 mm sob temperatura alta e umidade relativa alta dentro do núcleo da célula convectiva isolada.

As Fig. 3.74d, e, f da classificação de hidrometeoros, indica que a produção de granizo aumentou acima da isoterma $0^{\circ} \mathrm{C}$, áreas destacadas, devido as condições termodinâmica e dinâmica associadas a rotação ciclônica. Essa foi a única ocasião que a classificação de hidrometeoros indicou pedras de granizo, que provavelmente precipitaram até à superfície. 

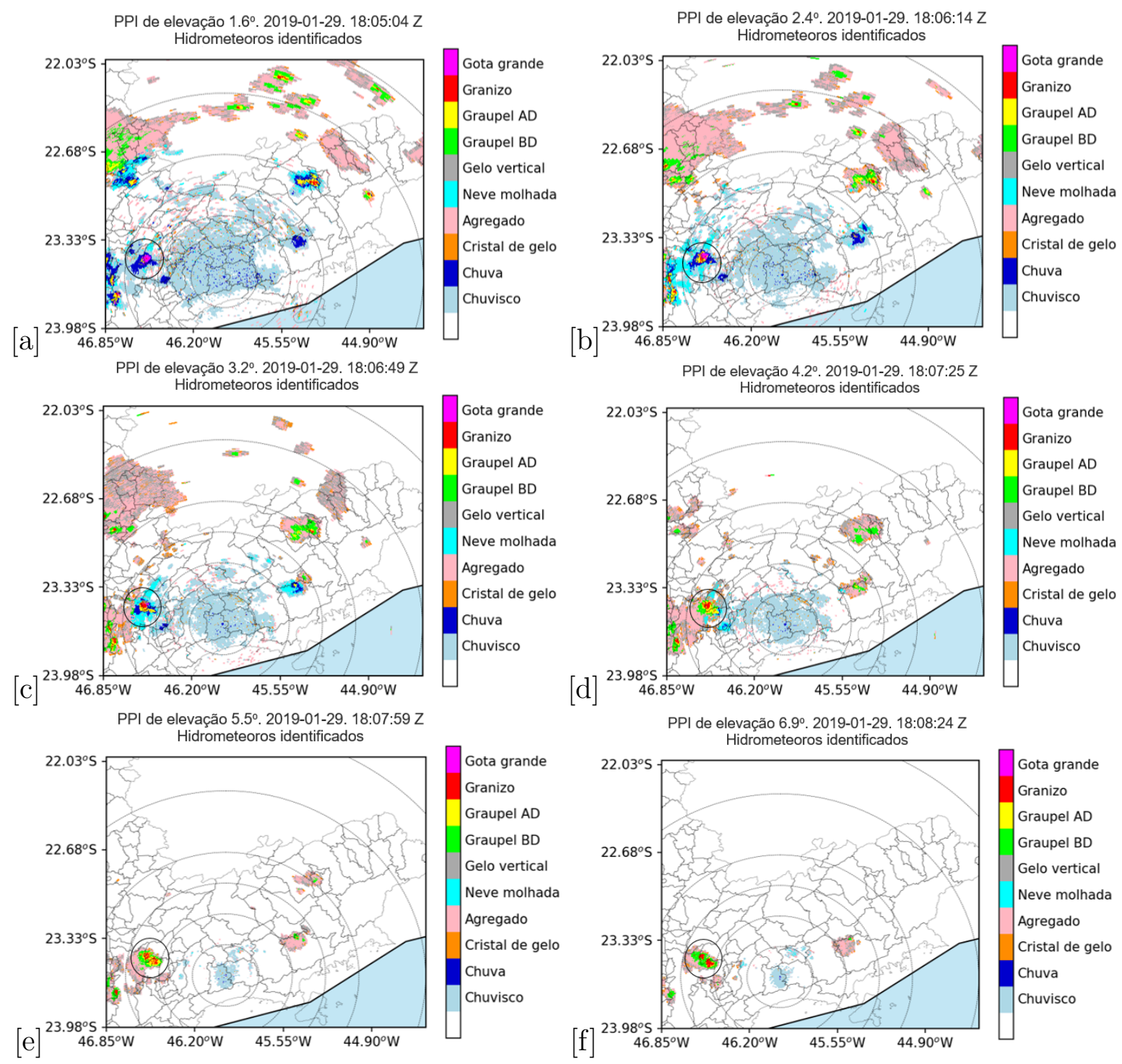

Figura 3.74: PPIs de ângulo de elevação de $1.0^{\circ}$ (a), $1.6^{\circ}$ (b), $2.4^{\circ}$ (c), $3.2^{\circ}$ (d), $4.2^{\circ}$ (e) $6.9^{\circ}$ (f) da classificação de hidrometeoros do radar SPOL no dia 29 de Janeiro de 2019, às 1805 UTC. A escala de cores apresenta as 10 classificações dos hidrometeoros: Gota de água, Granizo, Graupel AD, Graupel BD, Gelo vertical, Neve molhada, Agregado, Cristal de gelo, Chuva e Chuvisco. Circunferências concêntricas estão espaçadas a cada $25 \mathrm{~km}$. O radar meteorológico SPOL está centro da menor circunferência concêntrica. Longitudes, latitudes, contornos dos municípios de São Paulo são indicados.

Mas não se sabe o porquê a precipitação de pedras de granizo até à superfície não foi observada nos horários subsequentes, pois ainda a CI está sob influência da rotação ciclônica! 

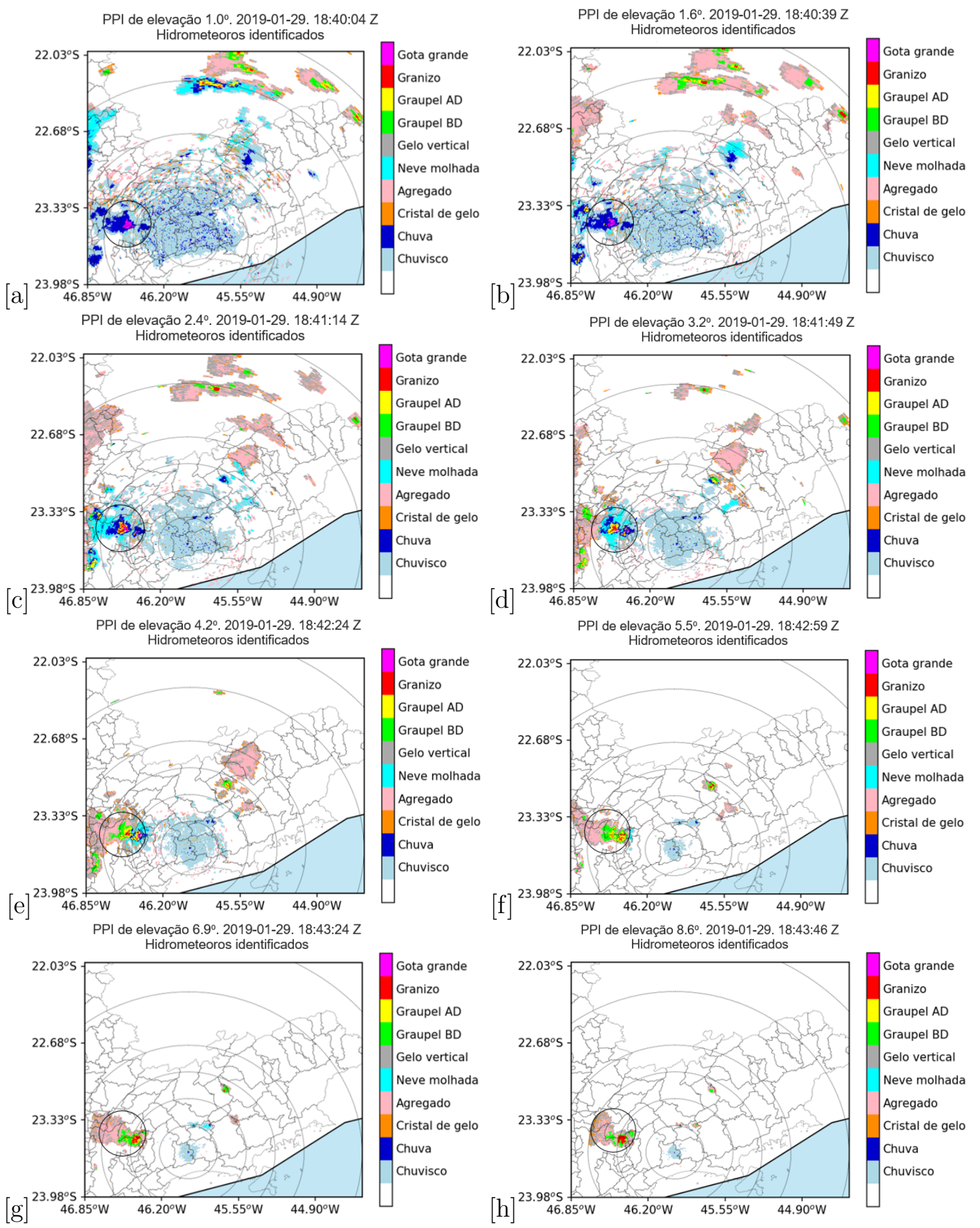

Figura 3.75: PPIs de ângulo de elevação de $1.0^{\circ}$ (a), $1.6^{\circ}$ (b), $2.4^{\circ}$ (c), 3.2 $2^{\circ}$ (d), $4.2^{\circ}$ (e), $5.5^{\circ}$ (f), $6.9^{\circ}(\mathrm{g})$ e $8.6^{\circ}(\mathrm{h})$ da classificação de hidrometeoros do radar SPOL no dia 29 de Janeiro de 2019, às 1840 UTC. A escala de cores apresenta as 10 classificações dos hidrometeoros: Gota de água, Granizo, Graupel AD, Graupel BD, Gelo vertical, Neve molhada, Agregado, Cristal de gelo, Chuva e Chuvisco. Circunferências concêntricas estão espaçadas a cada $25 \mathrm{~km}$. O radar meteorológico SPOL está centro da menor circunferência concêntrica. Longitudes, latitudes, contornos dos municípios de São Paulo são indicados. 
A classificação de hidrometeoros indica quantidade alta de gotas grandes sem pedras de granizo na parte inferior da célula convectiva, área destacada (Fig. 3.75a). Não obstante da CI produzir quantidade alta de granizo acima da isoterma ${ }^{\circ} \mathrm{C}$, área destacada Fig. $3.75 \mathrm{~g}, \mathrm{~h})$.

O adensamento vertical urbano favorece na precipitação de granizo até à superfície? Sabe-se que o centro geométrico da RMSP é mais quente e poluído do que na circunvizinhança! Provavelmente, o centro geométrico da RMSP mais quente e poluído do que as regiões adjacentes, intensificou a CI, que proporcionou a precipitação de granizo sobre a divisa dos municípios de São Paulo e Guarulhos!?

Foi observado dinamicamente que a CI sobre a divisa dos municípios de São Paulo e Guarulhos, tendia a propagar-se sobre Guarulhos. Porém, a CI retornou lentamente para zona leste do munício de São Paulo. Há um fator físico que serviu de barreira para a CI não continuasse a se propagar em direção à Guarulhos? E que isso influenciou na não precipitação de pedras de granizo até à superfície? não obstante da CI ainda estar sob influência de rotação ciclônica, área destacada (Fig. 3.75)!

A Fig. 3.76a mostra o aumento da concentração de gotas grandes da parte inferior da CI, e redução significativa da concentração de granizo dentro e acima da isoterma ${ }^{\circ} \mathrm{C}$ (Fig. $3.76 \mathrm{e}, \mathrm{f}, \mathrm{g}, \mathrm{h})$.

O aumento da quantidade de gotas grandes na parte inferior da célula convectiva está associada a alta produção de granizo há pouco minutos anteriores, às 1840 UTC. Provavelmente, a rotação ciclônica começa a perder intensidade minutos depois, às 1855 UTC. O principal mecanismo da rotação ciclônica é de facilitar a separação da corrente ascendente da corrente descendente, permitindo que a tempestade persista na produção de granizo acima da isoterma ${ }^{\circ} \mathrm{C}$ (Johnson et al., 1994). Provavelmente, a rotação ciclônica perdendo intensidade, a corrente descendente sobrepõem-se à corrente ascendente, que impede a ejeção de conteúdo de água líquida acima da isoterma ${ }^{\circ} \mathrm{C}$, a temperaturas abaixo de ${ }^{\circ} \mathrm{C}$, útil para o processo de acreção para a produção de granizo.

Entretanto, 25 minutos depois, observou-se o aumenta da produção de granizo acima da isoterma ${ }^{\circ} \mathrm{C}$, às 1910 UTC (Fig. 3.77f, g, h), à medida que a CI propagou-se sobre zona leste do município de São Paulo. Quando observa-se pelo campo da velocidade radial (Fig. 3.62f), nota-se que a rotação ciclônica intensificou-se ligeiramente. E verifica-se a presença de pequeno núcleo de granizo na parte inferior da célula convectiva (Fig. 3.77a). 

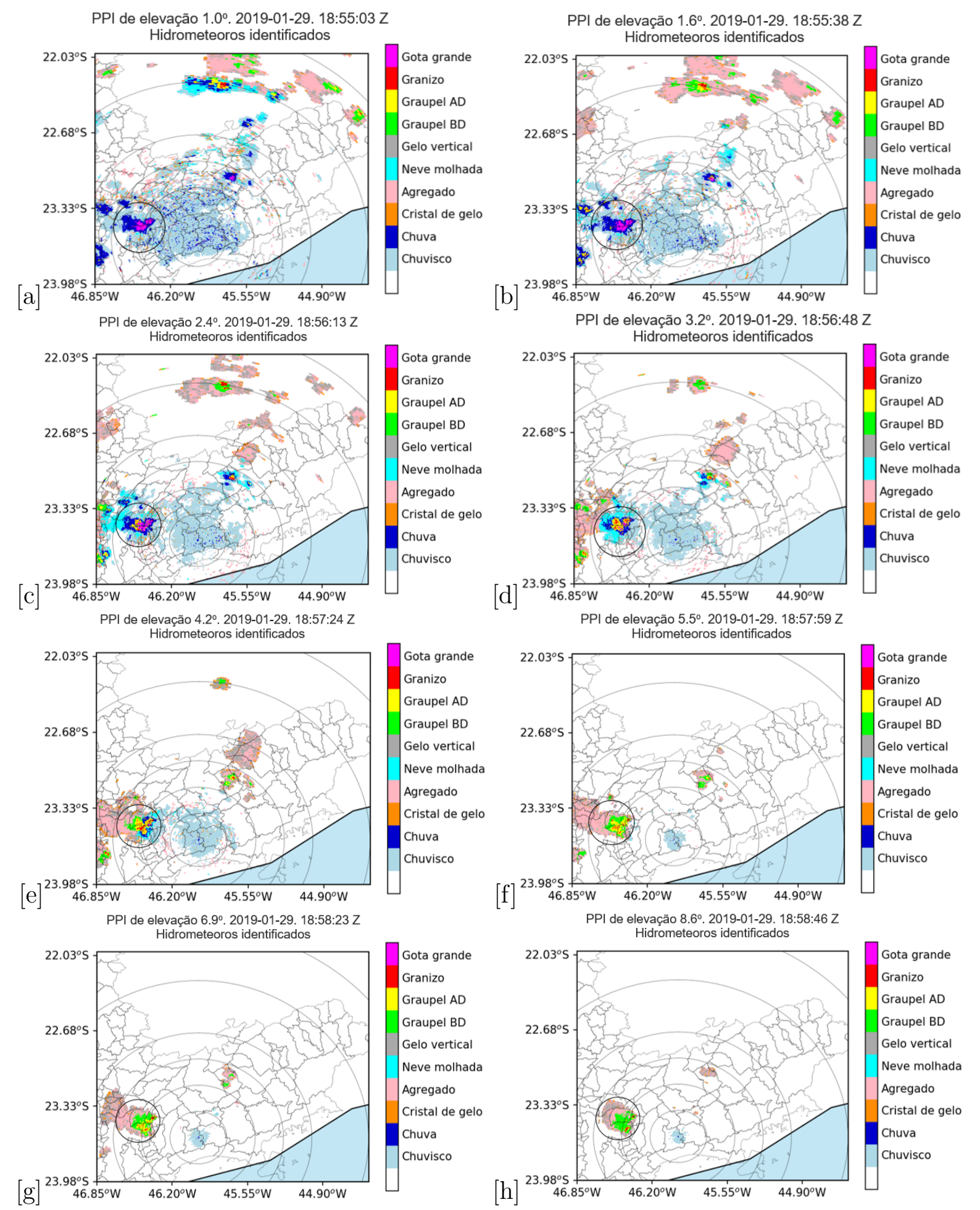

Figura 3.76: PPIs de ângulo de elevação de $1.0^{\circ}$ (a), $1.6^{\circ}$ (b), $2.4^{\circ}$ (c), 3.2 $(\mathrm{d}), 4.2^{\circ}$ (e), $5.5^{\circ}$ (f), $6.9^{\circ}(\mathrm{g})$ e $8.6^{\circ}(\mathrm{h})$ da classificação de hidrometeoros do radar SPOL no dia 29 de Janeiro de 2019, às 1855 UTC. A escala de cores apresenta as 10 classificações dos hidrometeoros: Gota de água, Granizo, Graupel AD, Graupel BD, Gelo vertical, Neve molhada, Agregado, Cristal de gelo, Chuva e Chuvisco. Circunferências concêntricas estão espaçadas a cada $25 \mathrm{~km}$. O radar meteorológico SPOL está centro da menor circunferência concêntrica. Longitudes, latitudes, contornos dos municípios de São Paulo são indicados. 

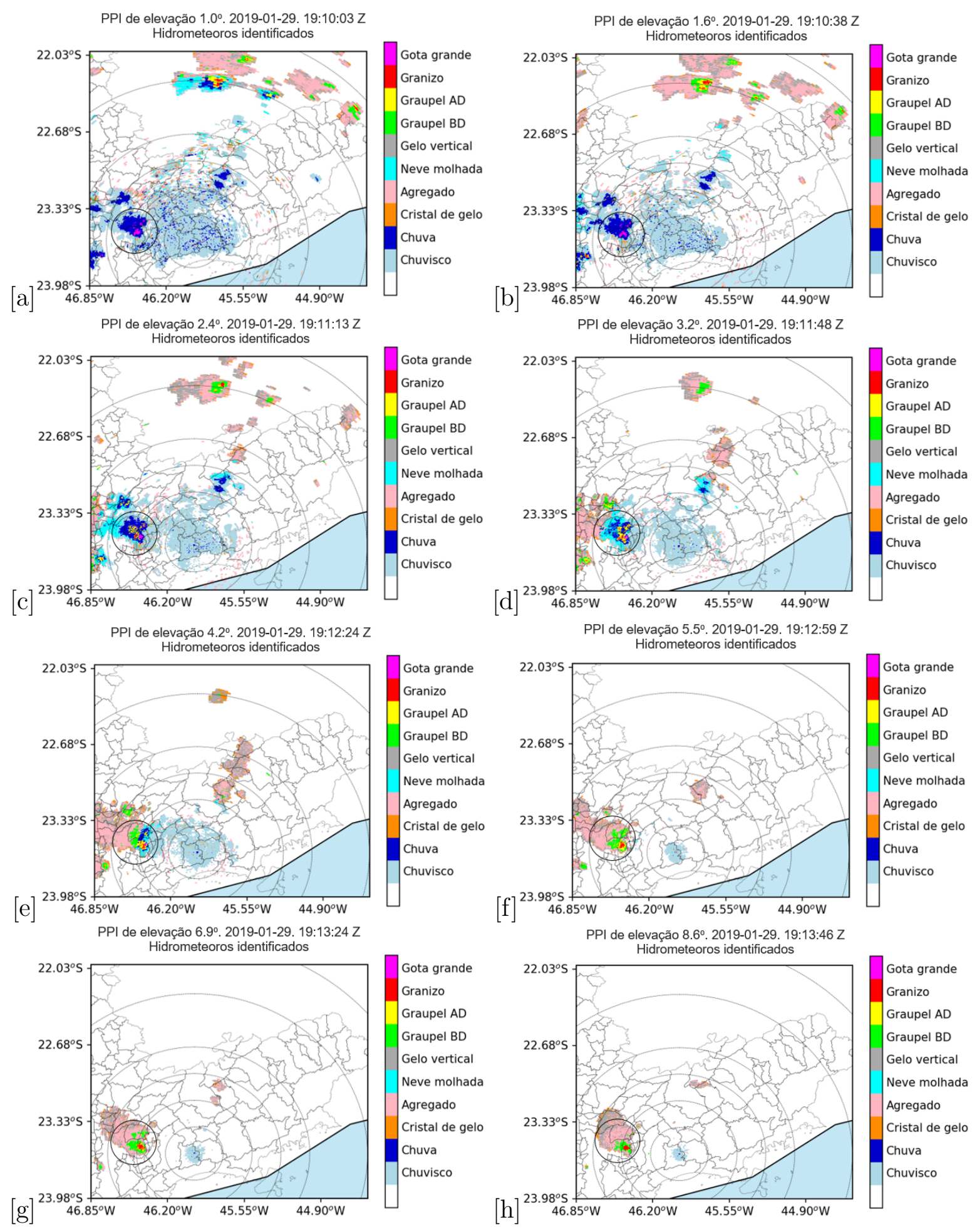

Figura 3.77: PPIs de ângulo de elevação de $1.0^{\circ}$ (a), $1.6^{\circ}$ (b), $2.4^{\circ}$ (c), $3.2^{\circ}$ (d), $4.2^{\circ}$ (e), $5.5^{\circ}$ (f), $6.9^{\circ}(\mathrm{g})$ e $8.6^{\circ}(\mathrm{h})$ da classificação de hidrometeoros do radar SPOL no dia 29 de Janeiro de 2019, às 1910 UTC. A escala de cores apresenta as 10 classificações dos hidrometeoros: Gota de água, Granizo, Graupel AD, Graupel BD, Gelo vertical, Neve molhada, Agregado, Cristal de gelo, Chuva e Chuvisco. Circunferências concêntricas estão espaçadas a cada $25 \mathrm{~km}$. O radar meteorológico SPOL está centro da menor circunferência concêntrica. Longitudes, latitudes, contornos dos municípios de São Paulo são indicados. 
A classificação de hidrometeoros indica redução drástica da quantidade de gotas grandes, 20 minutos depois, área destacada (Fig. 3.78a). A classificação de hidrometeoros indica pequena quantidade de graupel de baixa densidade e predominância de agregados acima da isoterma ${ }^{\circ} \mathrm{C}$ (Fig. 3.78e, f, g, h). Isso mostra que a precipitação de gotas grandes à superfície, depende da produção de granizo acima da isoterma ${ }^{\circ} \mathrm{C}$.

Portanto, a célula convectiva está em dissipação sobre a zona leste do município de São paulo, às 1930 UTC, área destacada (Fig. 3.78). A predominância de agregados e gelo vertical na parte superior da célula convectiva (Fig. 3.78f, g, h), é característico de sistema estratiforme, com a região da bigorna ocupando áreas maiores representandos esses hidrometeoros leves. Liu et al. (1997) afirmaram que a velocidade terminal lenta dos hidrometeoros como gelo e neve, é a principal razão para a formação de bigornas largamente disseminadas, porque são transportadas mais horizontalmente durante a queda. 

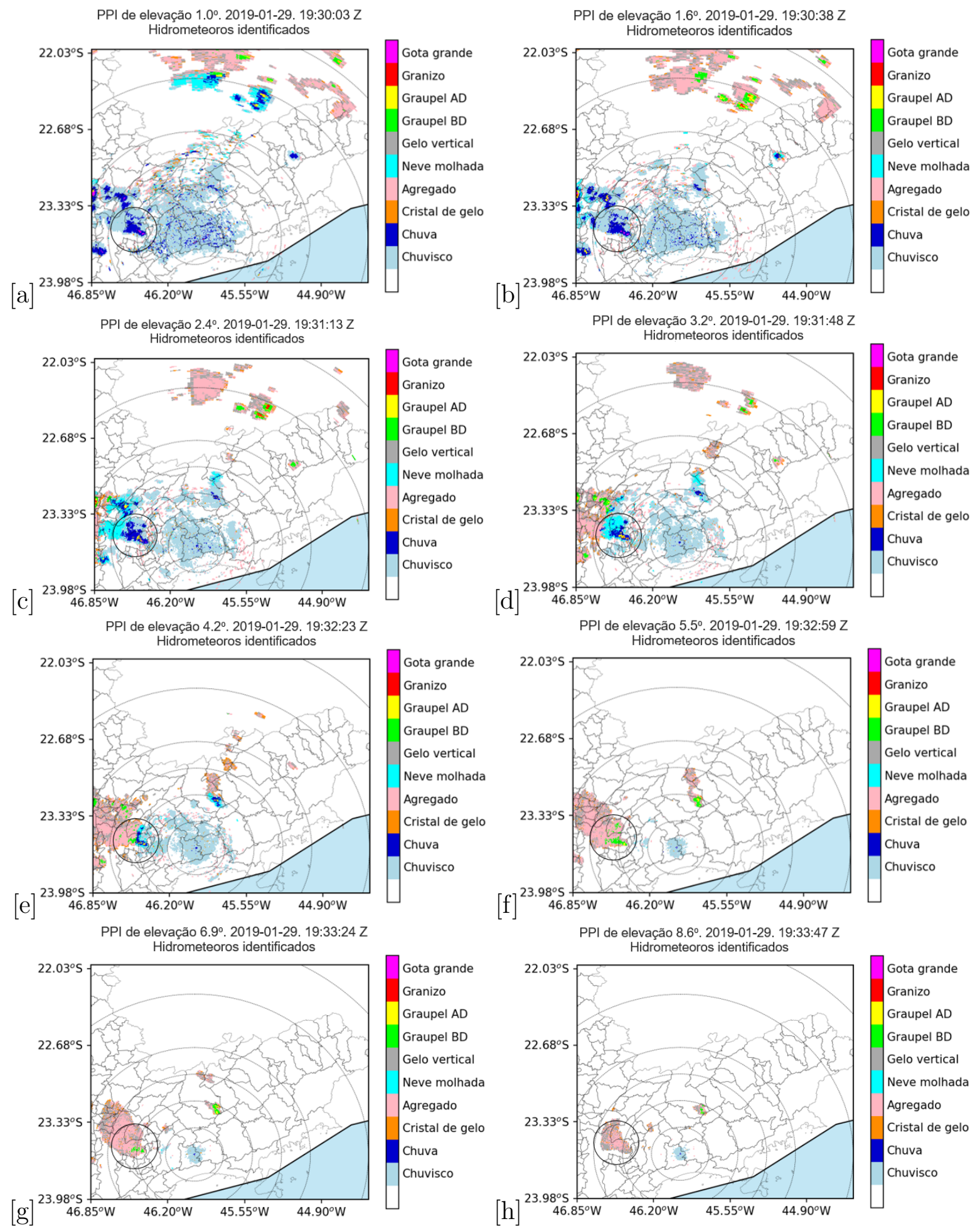

Figura 3.78: PPIs de ângulo de elevação de $1.0^{\circ}$ (a), $1.6^{\circ}$ (b), $2.4^{\circ}$ (c), 3.2 $(\mathrm{d}), 4.2^{\circ}$ (e), $5.5^{\circ}$ (f), $6.9^{\circ}(\mathrm{g})$ e $8.6^{\circ}(\mathrm{h})$ da classificação de hidrometeoros do radar SPOL no dia 29 de Janeiro de 2019, às 1930 UTC. A escala de cores apresenta as 10 classificações dos hidrometeoros: Gota de água, Granizo, Graupel AD, Graupel BD, Gelo vertical, Neve molhada, Agregado, Cristal de gelo, Chuva e Chuvisco. Circunferências concêntricas estão espaçadas a cada $25 \mathrm{~km}$. O radar meteorológico SPOL está centro da menor circunferência concêntrica. Longitudes, latitudes, contornos dos municípios de São Paulo são indicados. 


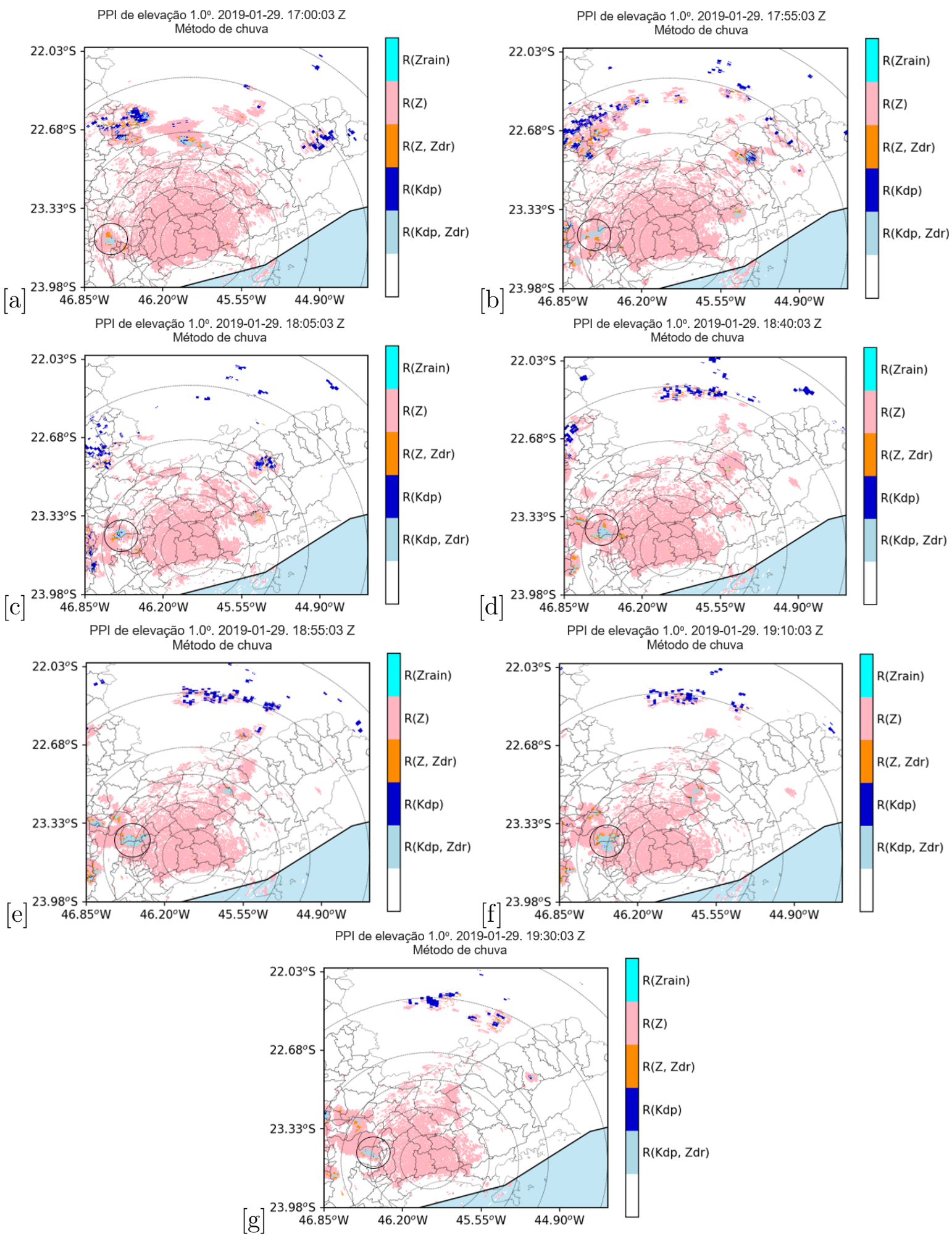

Figura 3.79: PPIs de ângulo de elevação de $1.0^{\circ}$ do radar SPOL para o método de chuva às 1700 UTC (a), às 1755 UTC (b), às 1805 UTC (c), às 1840 UTC (d), às 1855 UTC (e), às 1910 UTC (f), e 1930 UTC (g) do dia 29 de Janeiro de 2019. A escala de cores indica a relação $\mathrm{R}\left(\mathrm{mm} \mathrm{h}^{-1}\right)$ com as variáveis polarimétricas. Circunferências concêntricas estão espaçadas a cada $25 \mathrm{~km}$. O radar meteorológico SPOL está centro da menor circunferência concêntrica. Longitudes, latitudes, contornos dos municípios de São Paulo são indicados. 
A Fig. 3.79 mostra o método de chuva da relação das taxas de chuva com as variáveis polarimétricas durante a evolução espaço temporal da CI. A relação $\mathrm{R}\left(\mathrm{K}_{D P}\right)$ e relação $\mathrm{R}\left(\mathrm{K}_{D P}, \mathrm{Z}_{D R}\right)$ são para estimativa de chuvas intensas.

Nota-se que a relação $\mathrm{R}\left(\mathrm{K}_{D P}\right)$ representada pela cor azul de chuva mais intensa, foi estimada no núcleo da célula convectiva às 1805 UTC, área destacada (Fig. 3.79c). Nesse horário foi observado nos campos da velocidade radial, o início em que a célula convectiva é induzida por rotação ciclônica.

Não obstante da estimativa representada pela relação $\mathrm{R}\left(\mathrm{K}_{D P}\right)$ ser observado em uma única ocasião durante a evolução espaço-temporal da CI, a chuva foi intensa, representada pela relação $\mathrm{R}\left(\mathrm{K}_{D P}, \mathrm{Z}_{D R}\right)$ cor azul claro no núcleo célula, áreas destacadas (Fig. 3.79). Nota-se que a cor azul claro encolheu no núcleo da CI durante a evolução espaço-temporal, áreas destacadas. A menor mancha azul claro é observado na Fig. 3.79g, quando a célula convectiva estava se dissipando.

A Fig. 3.80 mostra a taxa de chuva $\left(\mathrm{mm} \mathrm{h}^{-1}\right)$ durante a evolução espaço-temporal da CI. Observa-se que a taxa de chuva é $<40 \mathrm{~mm} \mathrm{~h}^{-1}$, quando a CI estava sob influência convergência de massa de ar, áreas destacada (Fig. 3.80a, b). Quando a CI era induzida por rotação ciclônica, observa-se taxa de chuva $>80 \mathrm{~mm} \mathrm{~h}^{-1}$, áreas destacadas (Fig. 3.80c, d, e). As Fig. 3.80f, g, mostram as taxas de chuva $<50 \mathrm{~mm} \mathrm{~h}^{-1} \mathrm{e}<30 \mathrm{~mm} \mathrm{~h}^{-1}$, quando a célula convectiva entrou na fase de dissipação. Em geral, a taxa de chuva corrobora com o método de chuva durante a evolução espaço-temporal da CI. 


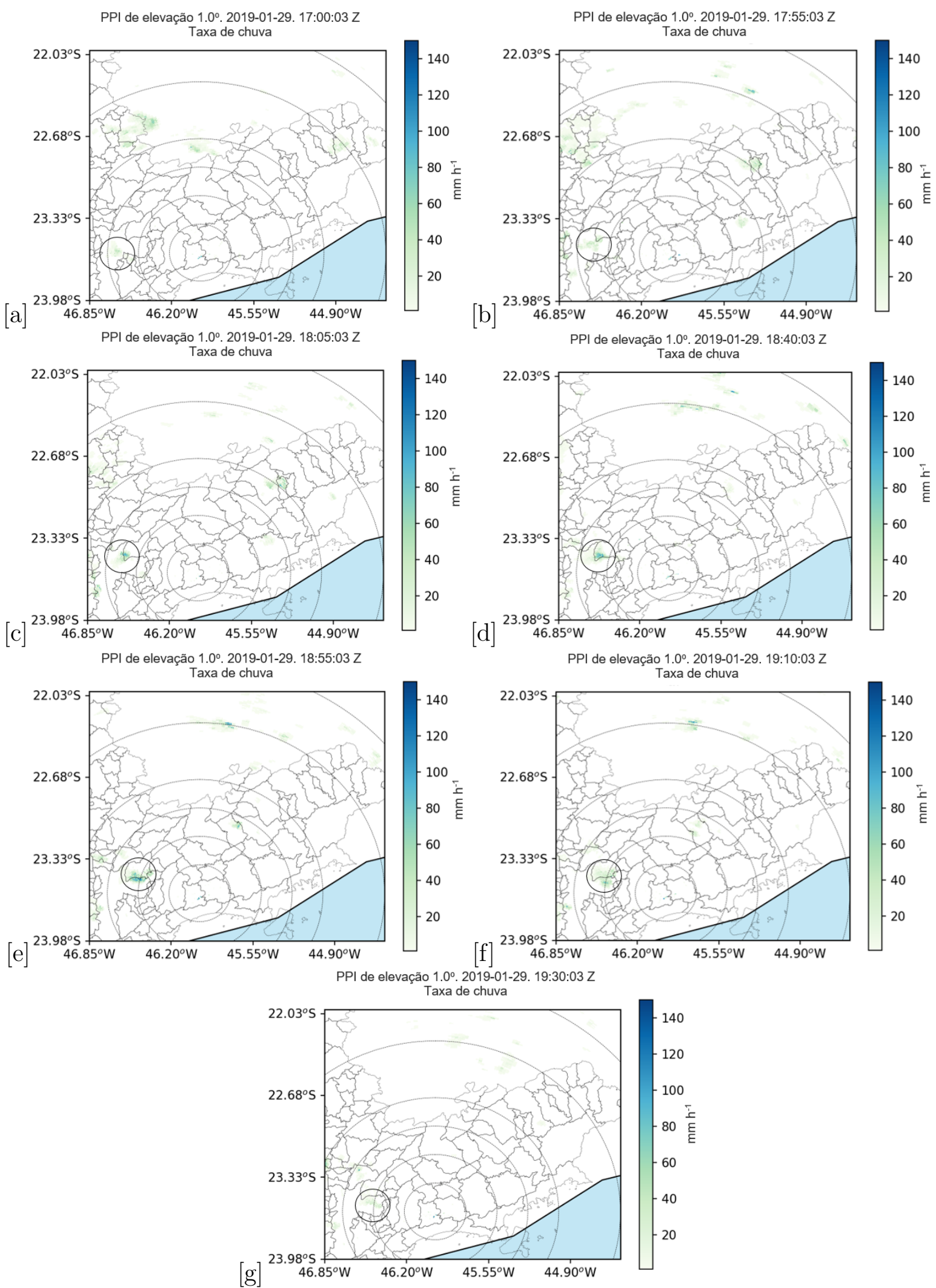

Figura 3.80: PPIs de ângulo de elevação de $1.0^{\circ}$ do radar SPOL para a taxa de chuva às 1700 UTC (a), às 1755 UTC (b), às 1805 UTC (c), às 1840 UTC 9d), às 1855 UTC (e), às 1910 UTC (f), e 1930 UTC (g) do dia 29 de Janeiro de 2019. A escala de cores indica a taxa de chuva $\left(\mathrm{mm} \mathrm{h}^{-1}\right)$. Circunferências concêntricas estão espaçadas a cada $25 \mathrm{~km}$. O radar meteorológico SPOL está centro da menor circunferência concêntrica. Longitudes, latitudes, contornos dos municípios de São Paulo são indicados. 
Tabela 3.4 - Resumo de tipos de hidrometeoros identificados no núcleo da CI acima da isoterma $0^{\circ} \mathrm{C}$, abaixo da isoterma $0^{\circ} \mathrm{C}$, dentro da isoterma $0^{\circ} \mathrm{C}$ e provavelmente atingindo a superfície durante a evolução espaço-temporal sobre o centro geométrico da RMSP entre entre 1700 e 2005 UTC do dia 29 de Janeiro de 2019 com os dados do radar SPOL.

\begin{tabular}{|c|c|c|c|c|}
\hline \multirow{3}{*}{ UTC } & \multicolumn{4}{|c|}{ Tipos de hidrometeoros identificados do 21012019} \\
\hline & \multicolumn{3}{|c|}{ Isoterma $0^{\circ} \mathrm{C}$} & \multirow{2}{*}{ Superfície } \\
\hline & Acima & Abaixo & Dentro & \\
\hline 1700 & $\begin{array}{l}\text { Quantidade alta de } \\
\text { graupel BD, agregados e } \\
\text { gelo vertical; quantidade } \\
\text { baixa de graupel AD e } \\
\text { cristais de gelo. }\end{array}$ & $\begin{array}{l}\text { Quantidade alta de } \\
\text { graupel AD; } \\
\text { quantidade baixa de } \\
\text { gota grande e } \\
\text { granizo; chuva. }\end{array}$ & $\begin{array}{l}\text { Quantidade alta de } \\
\text { garupel AD, neve } \\
\text { molhada; } \\
\text { quantidade baixa } \\
\text { de granizo; chuva. }\end{array}$ & $\begin{array}{l}\text { Quantidade alta } \\
\text { de gota grande; } \\
\text { Chuva. }\end{array}$ \\
\hline 1730 & $\begin{array}{l}\text { Quantidade alta de } \\
\text { graupel } B D \text {, agregados; } \\
\text { quantidade baixa de } \\
\text { graupel AD, granizo, } \\
\text { cristais de gelo e gelo } \\
\text { vertical. }\end{array}$ & $\begin{array}{l}\text { Quantidade alta de } \\
\text { graupel AD; } \\
\text { quantidade baixa de } \\
\text { granizo; chuva. }\end{array}$ & $\begin{array}{l}\text { Quantidade alta de } \\
\text { neve molhada; } \\
\text { quantidade baixa } \\
\text { de graupel AD e } \\
\text { granizo; chuva. }\end{array}$ & $\begin{array}{l}\text { Quantidade alta } \\
\text { de gota grande; } \\
\text { chuva. }\end{array}$ \\
\hline 1755 & $\begin{array}{l}\text { Quantidade alta de } \\
\text { graupel BD, graupel AD, } \\
\text { granizo, agregados, } \\
\text { cristais de gelo e gelo } \\
\text { vertical. }\end{array}$ & $\begin{array}{l}\text { Quantidade alta de } \\
\text { gota grande, graupel } \\
\text { AD, granizo; chuva. }\end{array}$ & $\begin{array}{l}\text { Quantidade alta de } \\
\text { graupel } A D \text {, gota } \\
\text { grande, granizo e } \\
\text { neve molhada; } \\
\text { chuva. }\end{array}$ & $\begin{array}{l}\text { Quantidade alta } \\
\text { de gota grande; } \\
\text { chuva }\end{array}$ \\
\hline 1825 & $\begin{array}{l}\text { Quantidade alta de } \\
\text { graupel BD, graupel AD, } \\
\text { granizo, agregados, gelo } \\
\text { vertical e cristais de } \\
\text { gelo. }\end{array}$ & $\begin{array}{l}\text { Quantidade alta de } \\
\text { granizo, gota grande, } \\
\text { graupel AD; chuva. }\end{array}$ & $\begin{array}{l}\text { Quantidade alta de } \\
\text { graupel AD, granizo, } \\
\text { gota grande e neve } \\
\text { molhada; chuva. }\end{array}$ & $\begin{array}{l}\text { Quantidade alta } \\
\text { de gota grande; } \\
\text { chuva. }\end{array}$ \\
\hline 1845 & $\begin{array}{l}\text { Quantidade alta de } \\
\text { graupel BD, graupel AD, } \\
\text { granizo, agregados e gelo } \\
\text { vertical; quantidade } \\
\text { baixa de cristais de gelo. }\end{array}$ & $\begin{array}{l}\text { Quantidade alta de } \\
\text { graupel AD, gota } \\
\text { grande, granizo; } \\
\text { chuva. }\end{array}$ & $\begin{array}{l}\text { Quantidade alta de } \\
\text { graupel AD, gota } \\
\text { grande, granizo, } \\
\text { neve molhada; } \\
\text { chuva. }\end{array}$ & $\begin{array}{l}\text { Quantidade alta } \\
\text { de gota grande; } \\
\text { quantidade } \\
\text { baixa de } \\
\text { granizo; Chuva. }\end{array}$ \\
\hline 1915 & $\begin{array}{l}\text { Quantidade alta de } \\
\text { graupel BD, graupel AD, } \\
\text { granizo, agregados, gelo } \\
\text { vertical; quantidade } \\
\text { baixa de cristais de gelo. }\end{array}$ & $\begin{array}{l}\text { Quantidade alta de } \\
\text { gota grande, granizo } \\
\text { e graupel AD; chuva. }\end{array}$ & $\begin{array}{l}\text { Quantidade alta de } \\
\text { graupel AD, granizo, } \\
\text { gota grande e neve } \\
\text { molhada. }\end{array}$ & $\begin{array}{l}\text { Quantidade alta } \\
\text { de gota grande; } \\
\text { chuva. }\end{array}$ \\
\hline 1945 & $\begin{array}{l}\text { Quantidade alta de } \\
\text { agregados e gelo vertical; } \\
\text { quantidade baixa de } \\
\text { graupel BD e cristaisl de } \\
\text { gelo. }\end{array}$ & Chuva. & $\begin{array}{l}\text { Quantidade alta de } \\
\text { neve molhada; } \\
\text { chuva. }\end{array}$ & $\begin{array}{c}\text { Chuvisco; chuva } \\
\text { localizada. }\end{array}$ \\
\hline 2005 & $\begin{array}{l}\text { Quantidade alta de } \\
\text { agregados e gelo vertical; } \\
\text { quantidade baixa de } \\
\text { graupel BD e cristaisl de } \\
\text { gelo }\end{array}$ & Chuvisco. & $\begin{array}{l}\text { Quantidade alta de } \\
\text { neve molhada. }\end{array}$ & Chuvisco. \\
\hline
\end{tabular}


A Tab.3.4 mostra o resumo dos hidrometeoros identificados por meio do método lógica fuzzy no núcleo da célula convectiva durante a evolução espaço-temporal. Observa-se a variação da quantidade de tipos de hidrometeoros durante as fases de convergência de massas de ar, rotação ciclônica e dissipação da célula convectiva.

A classificação de hidrometeoros indicou chuvisco na superfície, neve molhada dentro da isoterma $0^{\circ} \mathrm{C}$, chuvisco abaixo na isoterma $0^{\circ} \mathrm{C}$, e agregados, gelo vertical acima da isoterma $0^{\circ} \mathrm{C}$ na fase de dissipação, às 2005 UTC. A classificação de hidrometeoros indicou variedades de hidrometeoros na superfície, abaixo da isoterma $0^{\circ} \mathrm{C}$, dentro da isoterma $0^{\circ} \mathrm{C}$ e acima da isoterma $0^{\circ} \mathrm{C}$ na fase de convergência às 1700 UTC e 1730 UTC, e na fase de rotação ciclônica às 1825 UTC, 1845 UTC e 1915 UTC (Tab.3.4).

A classificação de hidrometeoros indicou pedras de granizo na superfície, às 1845 UTC, horário em que a rotação ciclônica estava bem configurada e intensa (Tab.3.4).

\subsubsection{Perfis verticais}

A seguir são ilustradas os perfis verticais das massas de água líquida e água sólida (Fig. 3.81), refletividade e refletividade diferencial (Fig. 3.82 ) e diâmetro da gota de chuva (Fig. 3.83) no núcleo da célula convectiva sob convergência às 1720 UTC, sob rotação ciclônica às 1805 UTC e às 1815 UTC do dia 29 de Janeiro de 2019.

A CI era menos profunda quando estava sob influência de convergência. No início da influência da rotação ciclônica (às 1805 UTC) e 10 mintus depois (1815 UTC), a CI tornou-se mais profunda (Fig. 3.81, Fig. 3.82 e Fig. 3.83).

Os valores máximos da concentração de massa de água líquida e massa de água sólida no núcleo da célula convectiva, são $<6 \mathrm{~g} \mathrm{~m}^{-3}$, quando a célula convectiva estada sob influência de convergência, e $>6 \mathrm{~g} \mathrm{~m}^{-3}$ quando estava sob influência de rotação ciclônica (Fig. 3.81).

Durante a fase de influência de rotação ciclônica, foi ejeta quantidade alta de umidade convertido em água líquida pelo processo de condensação, que foi transportado a temperaturas $<-5{ }^{\circ} \mathrm{C}$, e parte dessa água líquida foi convertido em cristais de gelo pelo processo solidificação, outra parte evapora por força de tensão de vapor e outra parte coabita com os cristais de gelo. A coabitação dos cristais de gelo com gotículas superes-resfriadas, proporcionou a formação de graupel e granizo pelo processo de acreção. Por isso, nota-se que a massa de água líquida diminui com altitude (Fig. 3.81b, c), e massa de água sólida 
aumenta com altitude até um certo nível (Fig. 3.81e, f).
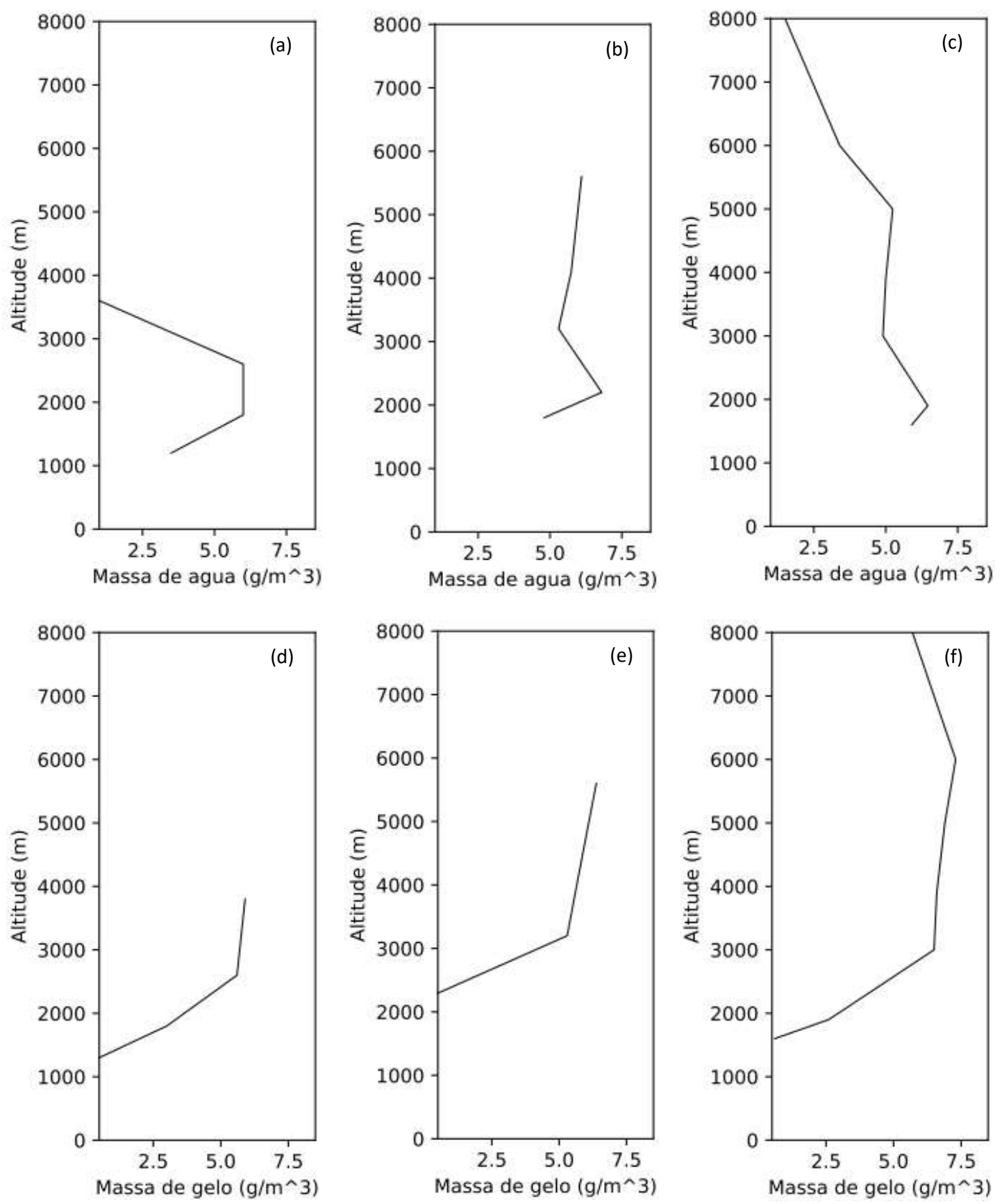

Figura 3.81: Perfis verticais da massa de água $(\mathrm{a}, \mathrm{b}, \mathrm{c})$ e massa de gelo $(\mathrm{d}, \mathrm{e}, \mathrm{f})$ no núcleo da CI às 1700 UTC, 1805 UTC e 1815 UTC, respectivamente, no dia 29 de Janeiro de 2019.

Nota-se que a concentração alta da massa de água sólida é proporcional à concentração alta da água líquida (Fig. 3.81). A massa de água sólida crescem à custa do vapor água fornecido pela massa de água líquida evaporada em consequência da pressão de vapor de equilíbrio menor sobre os cristais de gelo do que a pressão sobre as gota de água (Rogers e 
Yau, 1989). De acordo com Korolev et al. (2003) a concentração de gotículas líquidas em nuvens convectivas diminuiu com a diminuição da temperatura. Tanto o gelo como a água líquida diminuíram com a temperatura decrescente.
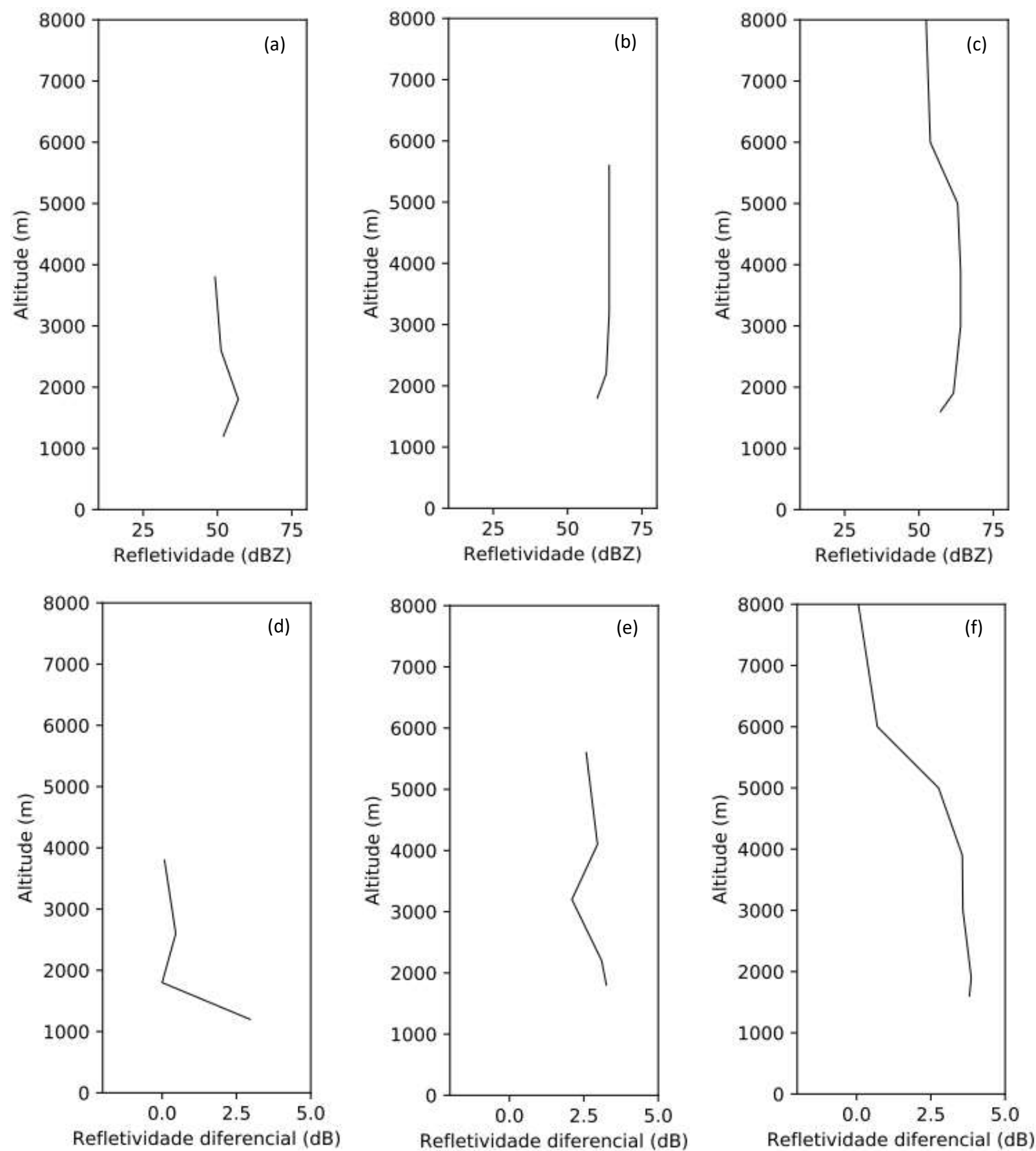

Figura 3.82: Perfis verticais da refletividade horizontal (a, b, c) e refletividade diferencial(d, e, f) no núcleo da CI às 1700 UTC, 1805 UTC e 1815 UTC, respectivamente, no dia 29 de Janeiro de 2019. 
Os perfis verticais de refletividade (Fig. 3.82b, c) e refletividade diferencial (Fig. 3.82e, f), mostram valores altos no núcleo da CI sob influência da rotação ciclônica do que sob influência de convergência (Fig. 3.82a, d). Os valores altos da refletividade e refletividade diferencial no núcleo da CI. quando estava sob influência de rotação ciclônica, está na produção da quantidade alta de granizo acima da isoterma $0^{\circ} \mathrm{C}$. Quando as pedras de granizo precipitavam da base da isoterma $0{ }^{\circ} \mathrm{C}$, parte delas descongelavam e transformavam-se em gotas grandes, outras pedras de granizo precipitavam intactas, provavelmente até à superfície.
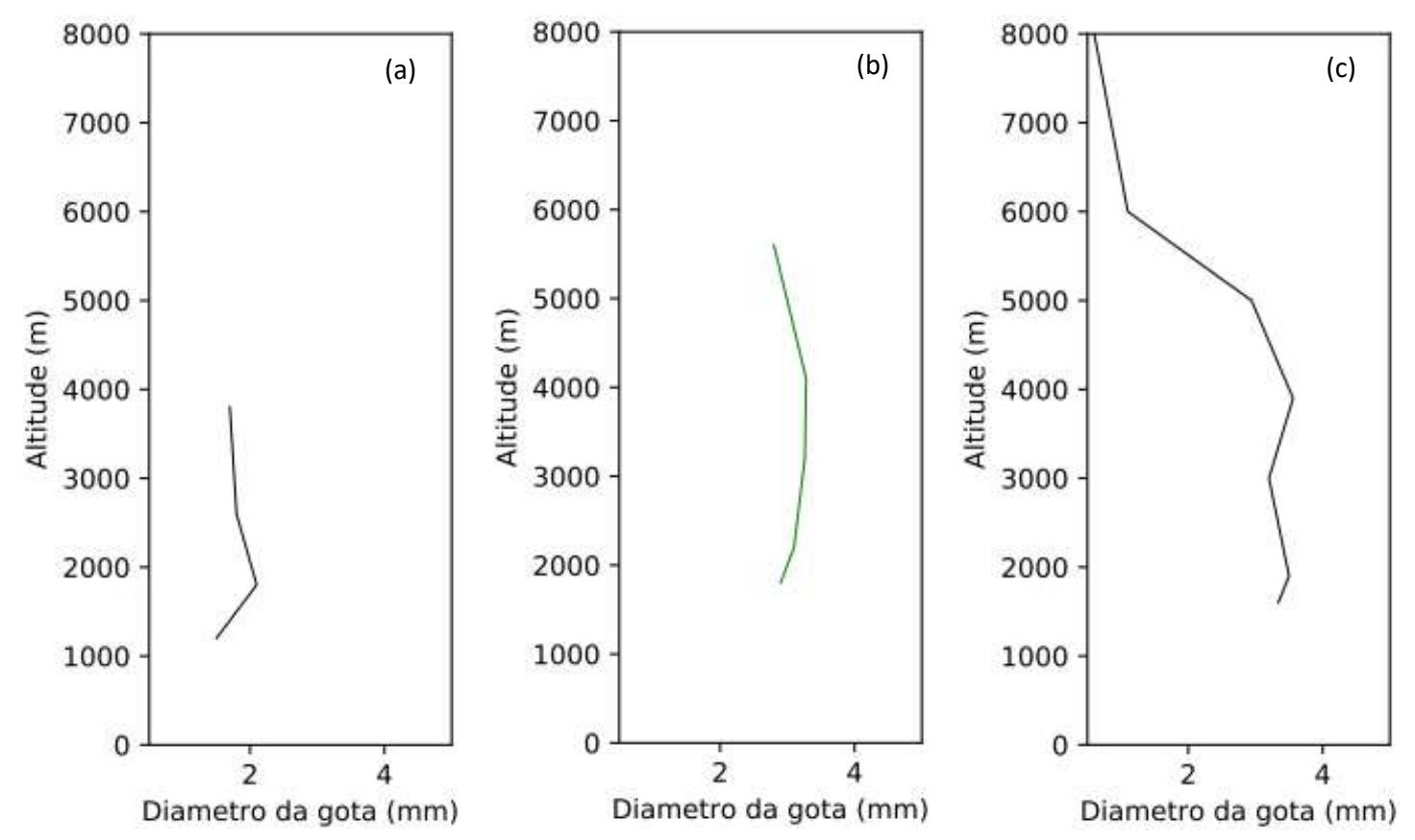

Figura 3.83: Perfis verticais do diâmetro da gota de chuva no núcleo da CI (a) às 1700 UTC, (b) às 1805 UTC e (c) às 1815 UTC do dia 29 de Janeiro de 2019.

Nota-se nos perfis verticais do diâmetro das gotas de chuva (Fig. 3.83c), a variação do aumento e diminuição do tamanho da gota com a diminuição da altitude, coerente com os perfis verticais de massa de água líquida (Fig. 3.81c), de refletividade (Fig. 3.82c) e de refletividade diferencial (Fig. 3.82f), provavelmente devido o mecanismo de quebra por influência da força de arrasto aerodinâmica, o processo de colisão seguida de quebra e processo de colisão-coalescência das gotas de chuva durante precipitação, coerente com as análises de Rosenfeld e Ulbrich (2003). 


\subsection{BDs associadas a fumaça de incêndios na Amazônia induzidas por uma FF}

\subsubsection{Análise sinótica}

A Fig. 3.84 mostram a sequência de imagens de satélites, onde observa-se uma banda de nebulosidade associada a uma FF, com orientação noroeste-sudoeste. Nota-se que o sistema frontal tende a afastar-se da costa do estado de São Paulo. A área destacada é a RMSP, observa-se nuvem densa (Nimbustratus) de topo relativamente fria com temperatura variando entre $-20^{\circ} \mathrm{C}$ a $-10^{\circ} \mathrm{C}$, às $1440 \mathrm{UTC}$ (Fig. 3.84a).

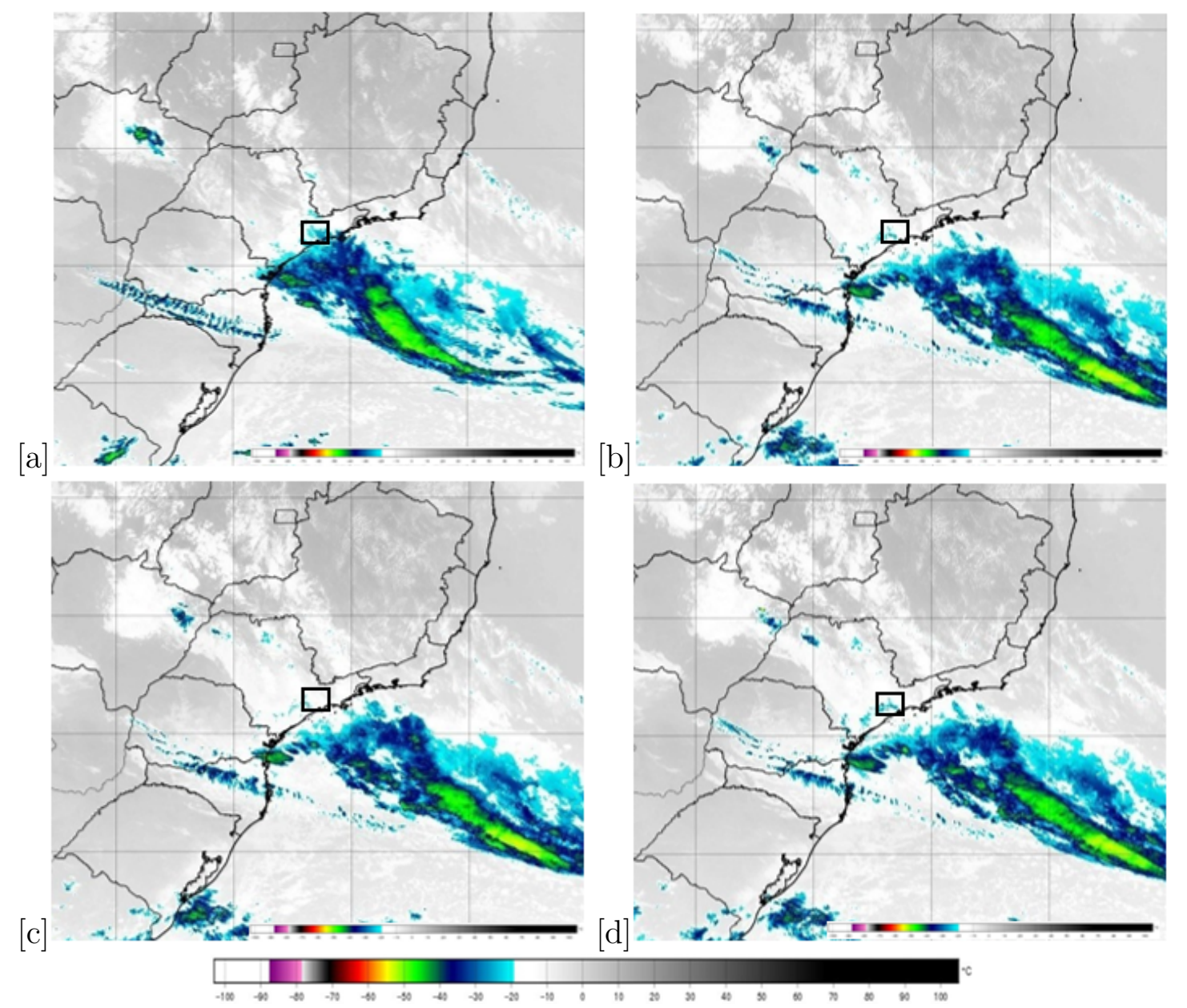

Figura 3.84: Imagens GOES16 - Canal $_{16}$ (13.30 microns) da banda de nebulosidade associada a frente fria ocorrido às 1440 UTC (a), 1715 UTC (b), 1750 UTC (c) e 1800 UTC (d) dia 19 de Agosto de 2019. A escala de cores indica temperatura no topo da nuvem em graus célcius.

Posteriormente, a RMSP é coberta por nuvem relativamente menos densa (Fig. 3.84b, 
c). Às 1800 UTC, a nuvem tornou-se densa e baixa (Nimbustratus) em plena estacão de inverno, que causou o escurecimento do céu sobre a cidade de São Paulo às 1530 HL (hora local), devido o fastamento do sistema frontal da região, onde encontrou uma área alongada de cavada sobre o estado do Paraná, associada baixa pressão a sobre norte do estado de São Paulo, e uma área alongada da crista sobre a costa de Santa Catarina, Paraná e São Paulo (Fig. 3.85a), com as condições de umidade muito alta (Fig. 3.85b). Nota-se que o percentual de umidade é muito alta (90\%) desde o litoral e toda região sul do estado de São paulo (Fig. 3.85b). A CAPE apresenta valores significativos sobre a região de atuação do cavado, CAPE nulo sobre a região de atuação da crista (Fig. 3.85c) às 1800 UTC.

O campo geopotencial a $700 \mathrm{hPa}$ mostra a geopotencial forte com movimentos ascendentes e descendentes fortes de $2 \mathrm{~Pa} \mathrm{~s}^{-1}$ e $-3.5 \mathrm{~Pa} \mathrm{~s}^{-1}$, respectivamente, associados ao centro da baixa pressão sobre a região norte do estado de São Paulo (Fig. 3.85d). Nota-se que sobre a região de estudo (RMSP), há um núcleo de movimento ascendente fraco de 1 $\mathrm{Pa} \mathrm{s}^{-1}$.

Em geral, observa-se umidade relativa muito alta sobre a região de estudo, mas sem correntes ascendente intensa para o transporte dessa umidade para ambientes de temperaturas negativas, provavelmente devido a presença da crista. 

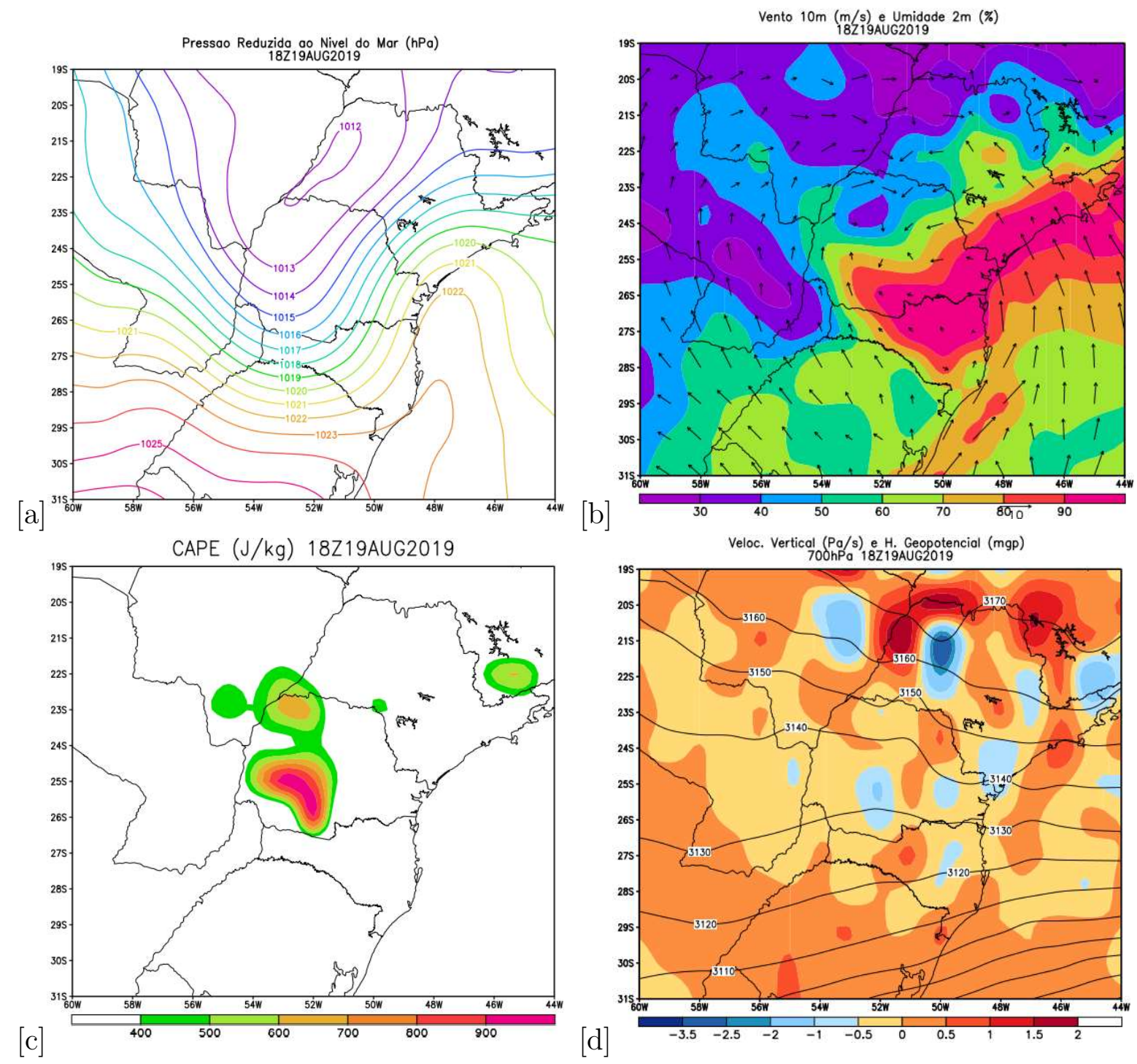

Figura 3.85: (a) Recorte do campo de pressão reduzido ao nível do mar (hPa), (b) Campo de vento $\left(\mathrm{m} . \mathrm{s}^{-1}\right)$ a $10 \mathrm{~m}$ e umidade (\%) a $2 \mathrm{~m}$ acima da superfície; e (c) CAPE $\left(\mathrm{J} \mathrm{kg}^{-1}\right)$ e (d) campo de movimento vertical e altura geopotencial (gpm) obtidos a partir da análise de modelo de circulação global-GFS às 1800 UTC 19 de Agosto de 2019. As setas indicam a magnitude do vento e a barra de cores indica a umidade. A escala de cores indica os valores do CAPE. Contornos geopolíticos, latitudes, longitudes e tempos são indicados.

\subsubsection{Análise termodinâmica e dinâmica}

Tem-se o perfil vertical da radiossondagem feita no aeroporto Campo de Marte, durante a chegada do sistema frontal às 1200 UTC do dia 19 e, durante a passagem do sistema frontal, à 0000 UTC do dia 20 de agosto de 2019 (Fig. 3.86). A razão de mistura está muito muito alta em baixos níveis entre 550 e 900 mb, típico da influência de um sistema 
frontal. Destaca-se (barbelas de vento) ventos de sudeste em baixos níveis e ventos intensos de leste em médios e altos níveis durante a chegada do sistema frontal (Fig. 3.86a). Notase que durante a passagem do sistema frontal, que os ventos são de sudeste tanto em baixos como em médios níveis níveos (Fig. 3.86b). Os CAPEs são praticamente nulos em ambas as radiossondagens (Fig. 3.86), tal como observados na Fig. 3.85c). Os índices de levantamento estão fracos apresentando atmosfera estável em ambos as radiossondagens, devido provavelmente a influência da crista sobre a região.
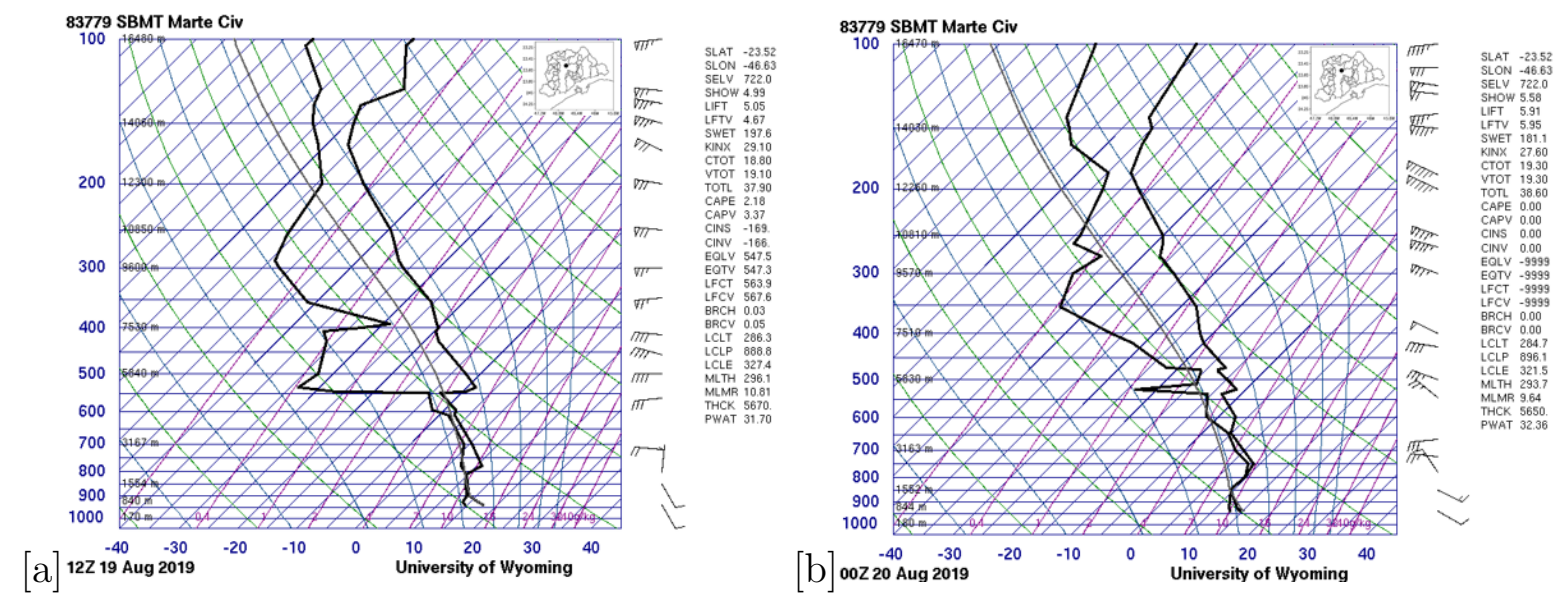

Figura 3.86: [Perfis verticais da temperatura do ar $\left({ }^{\circ} \mathrm{C}\right)$, temperatura do ponto do orvalho $\left({ }^{\circ} \mathrm{C}\right)$, velocidade

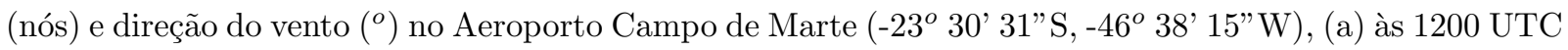
do dia 19 e (b) à 0000 UTC do dia 20 de Agosto de 2019. A RMSP, as latitude e longitudes são indicados nos mapas, estão indicados nos cantos superiores direito dos perfis, o ponto preto indica a localização de lançamento das sondagens. Fonte: weather.uwyo.edu. Acessada em 22 de julho de 2020.

A Fig. 3.87 mostra campos a velocidade radial para o PPI $1.0^{\circ}$ de elevação em diferentes horários. As tonalidades vermelha/azul indicam fluxos de massa de ar que que se afasta/aproxima do radar SPOL. O ponto preto centro da menor correferência concêntrica, indica a localização radar SPOL.

Observa-se fluxo de massa de ar de sul-sudeste perto do radar, em baixos níveis, e fluxos intensos de massas de ar de leste e oeste-sudoeste em médios e altos níveis (Fig. 3.87). A oeste do radar SPOL nota-se tonalidades de cores não homogênea, indicativo de áreas com turbulências (Fig. 3.87). 

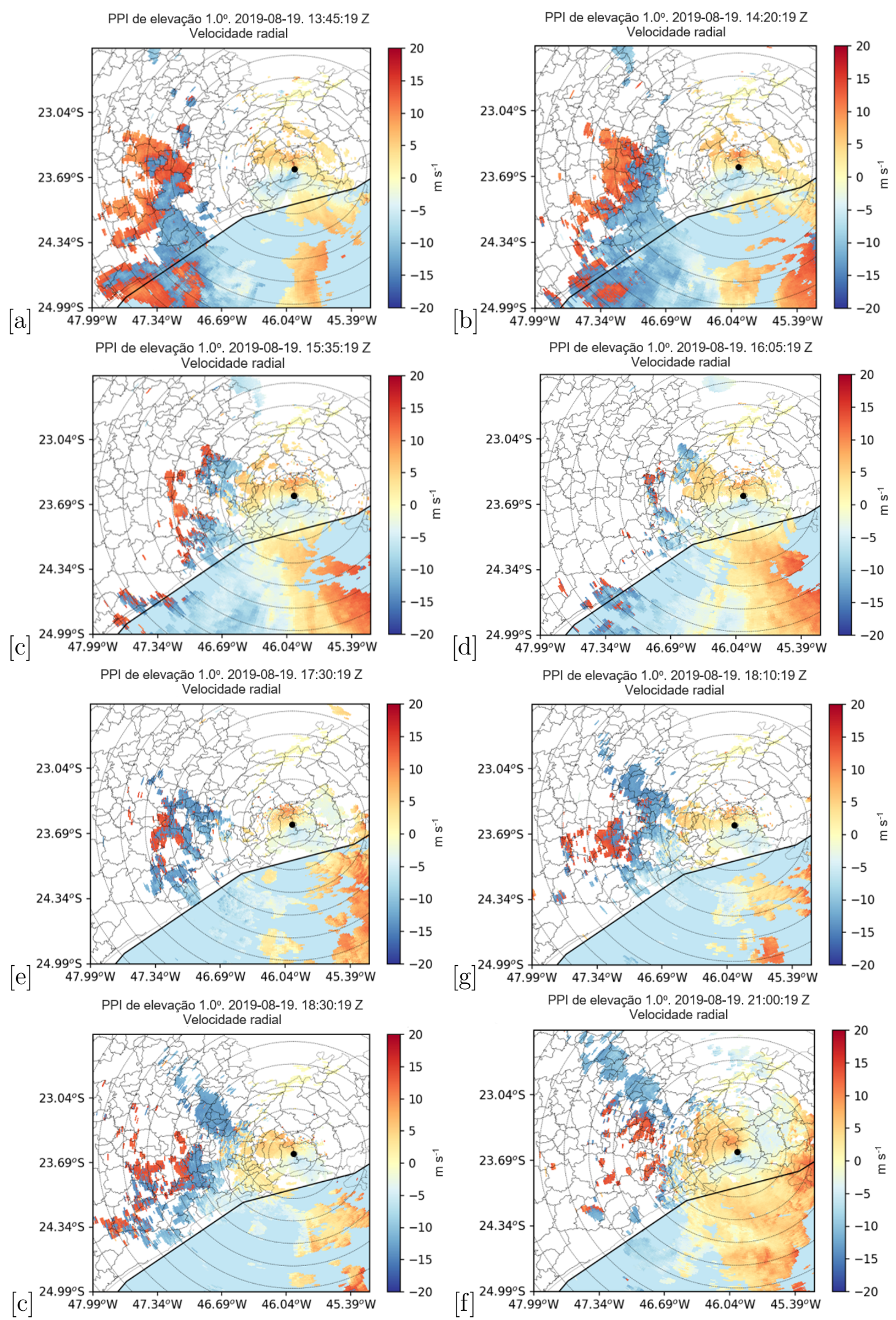

Figura 3.87: Campos da velocidade radial do radar SPOL no PPI de ângulo de elevação $1.0^{\circ}$, (a) às 1345 UTC, (b) às 1420 UTC, (c) às 1535 UTC, (d) às 1605 UTC, (e) às 1730 UTC, (f) às 1810 UTC, (g) às 1830 UTC e (h) às 2100 UTC do dia 19 de Agosto de 2019. A escala de core indica a velocidade $\left(\mathrm{m} \mathrm{s}^{-1}\right)$ de alvos que se aproxima (azul) e se afasta (vermelho) do SPOL. O ponto preto no centro indica posição do radar meteorológico SPOL, na cabeceira da Bacia do Alto Tietê. Circunferências concêntricas estão espaçadas a cada $25 \mathrm{~km}$. Longitudes, latitudes, contornos dos municípios são indicados. 


\subsubsection{Evolução espaço-temporal}

A Fig. 3.88 mostra campos de refletividades no PPI $1.0^{\circ} \mathrm{C}$ entre 1345 e 1755 UTC. Nota-se que a refletividade mais intensa é de $\sim 40$ dBZ (Fig. 3.88b). Em geral, os campos da refletividade mostras valores baixíssimos generalizados, e valores de de $\sim 30 \mathrm{dBZ}$ correspondente a banda brilhante.

Nota-se não só refletividade de baixa intensidade, mas também fragmentos de nuvens, dissipando-se rapidamente nas bordas (Fig. 3.88). Koren et al. (2004) observou que a poluição do ar urbano e o fumo dos incêndios da floresta da Amazônia modulam, reduzindo a formação de nuvens através da absorção da luz solar, arrefecendo assim a superfície e aquecendo a atmosfera. Dados de satélite sobre a região amazônica durante a época de queima de biomassa, mostraram que a cobertura dispersa de nuvens de cúmulo foi reduzida de 38\% em condições limpas para 0\% com a concentração alta de fumo (Koren et al., 2004).

Observa-se valores generalizados entre $<1$ e -1 dB nos campos de refletividade diferencial, indicativo da presença de gotículas e partículas de gelo. Excepto em algumas áreas pontuais sobre o oceano, onde observa-se núcleos com valores máximos de $\sim 4 \mathrm{~dB}$ (Fig. 3.89c), indicativo da presença de gotas de chuva. Nota-se entre os círculos concêntricos de 100 e 150 km, que a tonalidade da refletividade diferencial não é homogenia, devido a presença da banda brilhante, na isoterma $0^{\circ} \mathrm{C}$ (Fig. 3.89). O círculos concêntricos estão espaçadas a cada $25 \mathrm{~km}$ até aos $100 \mathrm{~km}, 50 \mathrm{~km}$ entre 100 e $150 \mathrm{~km}$ e, novamente $24 \mathrm{~km}$ entre 150 e $200 \mathrm{~km}$.

Os campos da fase diferencial específica mostram valores que variam entre 1 e $0{ }^{\circ} \mathrm{km}^{-1}$, indicativos da presença da população de gotículas (Fig. 3.90). Os campos de coeficiente de correlação mostra homogeneidade (Fig. 3.91), indicativos que as refletividades observadas, correspondem a hidrometeoros. Nota-se que os valores de coeficiente de correlação decaem, variando entre 0.6 e 0.8, na região da banda brilhante, típico de presença da mistura de água e gelo (Fig. 3.91). 

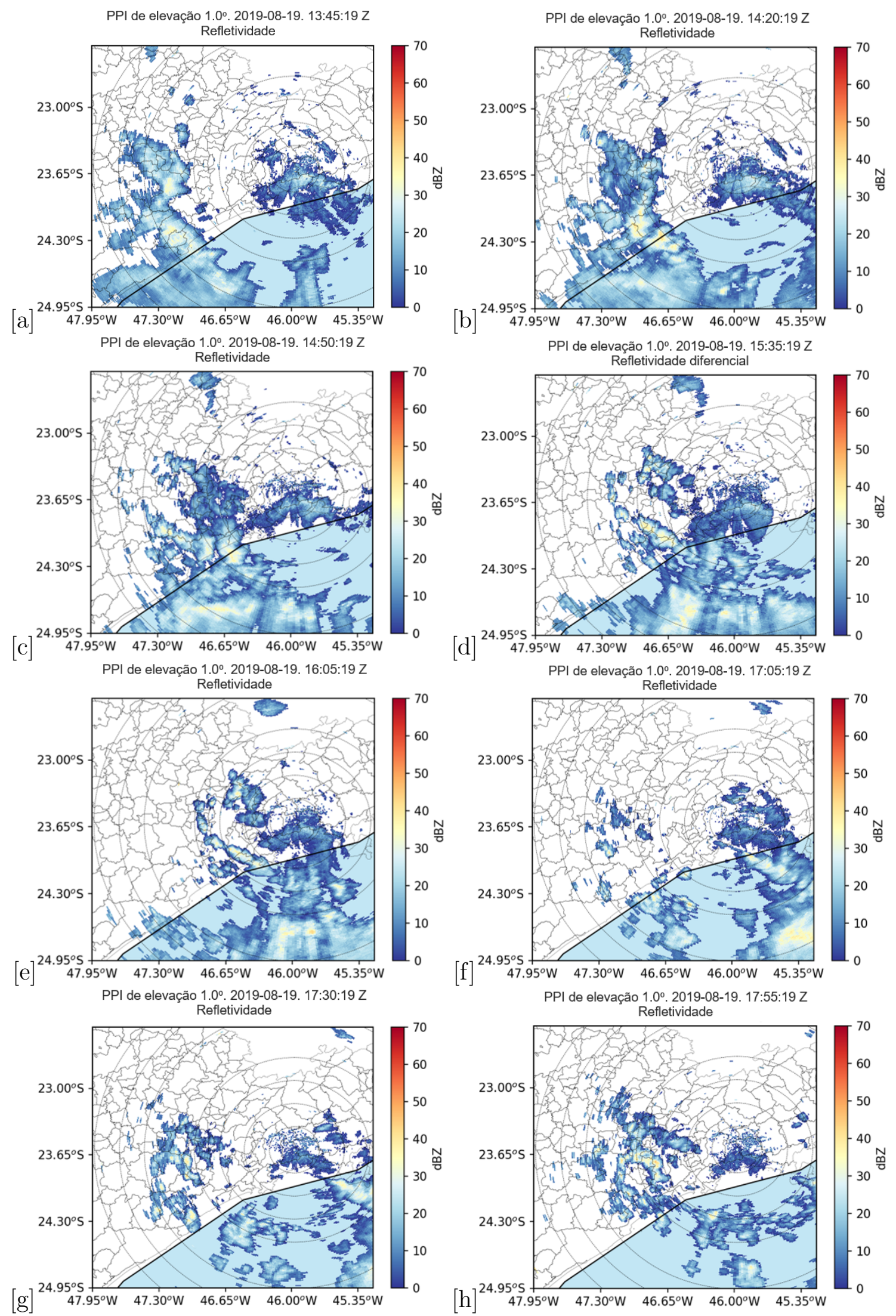

Figura 3.88: Campos da refletividade $\left(\mathrm{Z}_{H}\right)$ do radar SPOL no PPI de ângulo de elevação $1.0^{\circ}$, (a) às 1345 UTC, (b) 1420 UTC, (c) 1450 UTC, (d) 1535 UTC, (e) 1605 UTC, (f) 1705 UTC, (g) 1730 UTC e (h) 1755 UTC do dia 19 de Agosto de 2019. A escala de cores indica a refletividade (dBZ). O círculos concêntricos estão espaçadas a cada $25 \mathrm{~km}$ até aos $100 \mathrm{~km}, 50 \mathrm{~km}$ entre 100 e $150 \mathrm{~km}$ e, novamente 24 $\mathrm{km}$ entre 150 e $200 \mathrm{~km}$. O radar meteorológico SPOL está centro da menor circunferência concêntrica. Longitudes, latitudes, contornos dos municípios são indicados. 

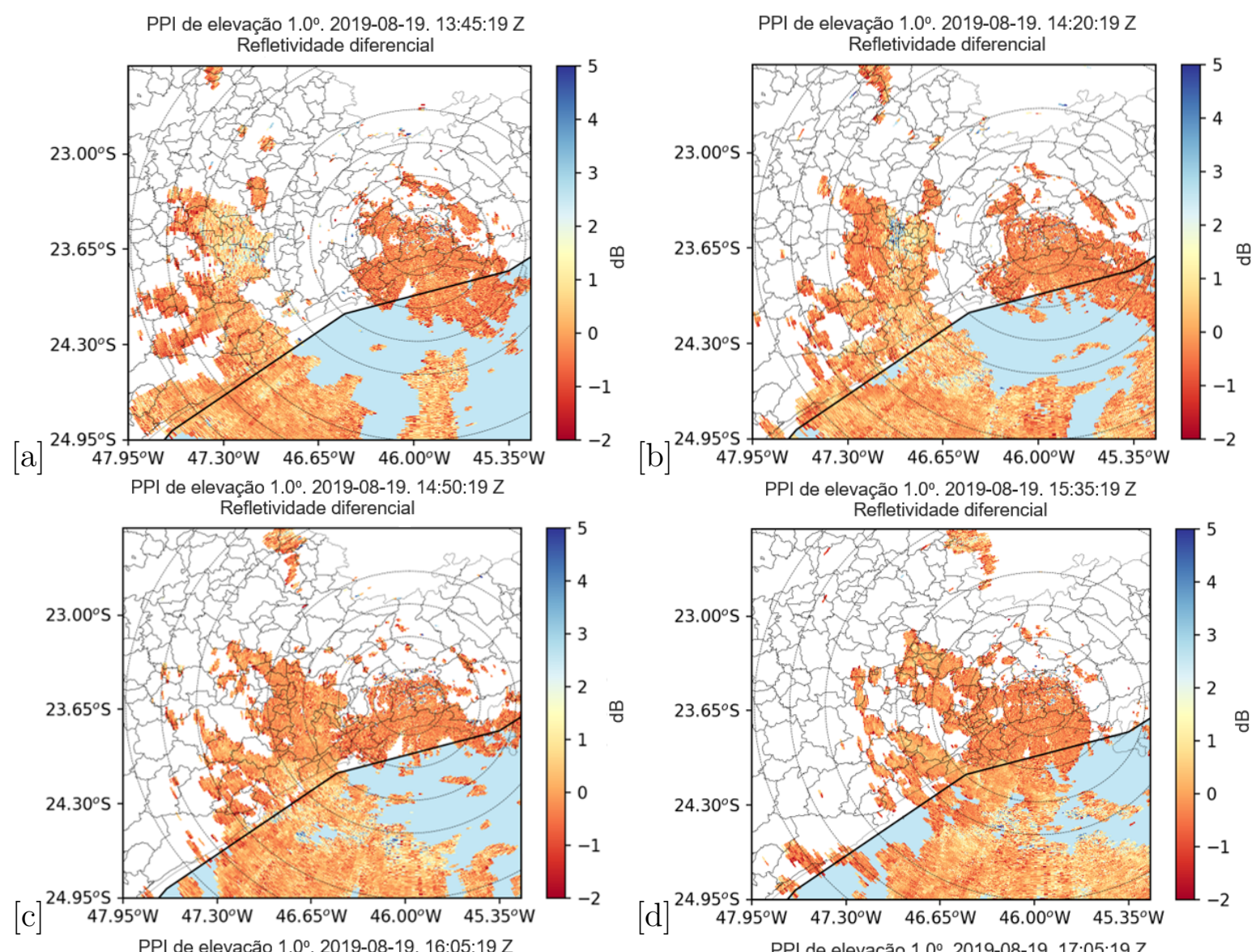

PPI de elevação $1.0^{\circ}$. 2019-08-19. 16:05:19 Z

PPI de elevação $1.0^{\circ}$. 2019-08-19.17:05:19 Z
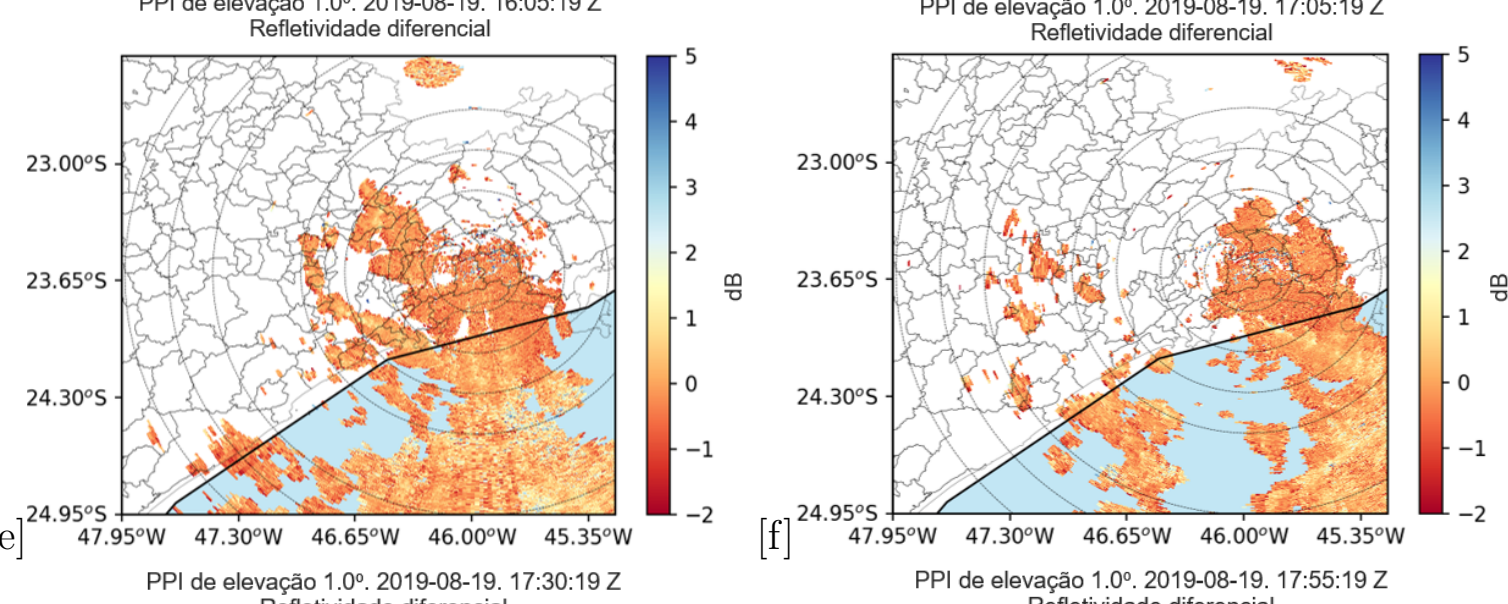

$[f]^{24.95} 47.95^{\circ} \mathrm{W} \quad 47.30^{\circ} \mathrm{W} \quad 46.65^{\circ} \mathrm{W} \quad 46.00^{\circ} \mathrm{W} \quad 45.35^{\circ} \mathrm{W}$

PPI de elevação $1.0^{\circ}$. 2019-08-19. 17:55:19 Z Refletividade diferencial
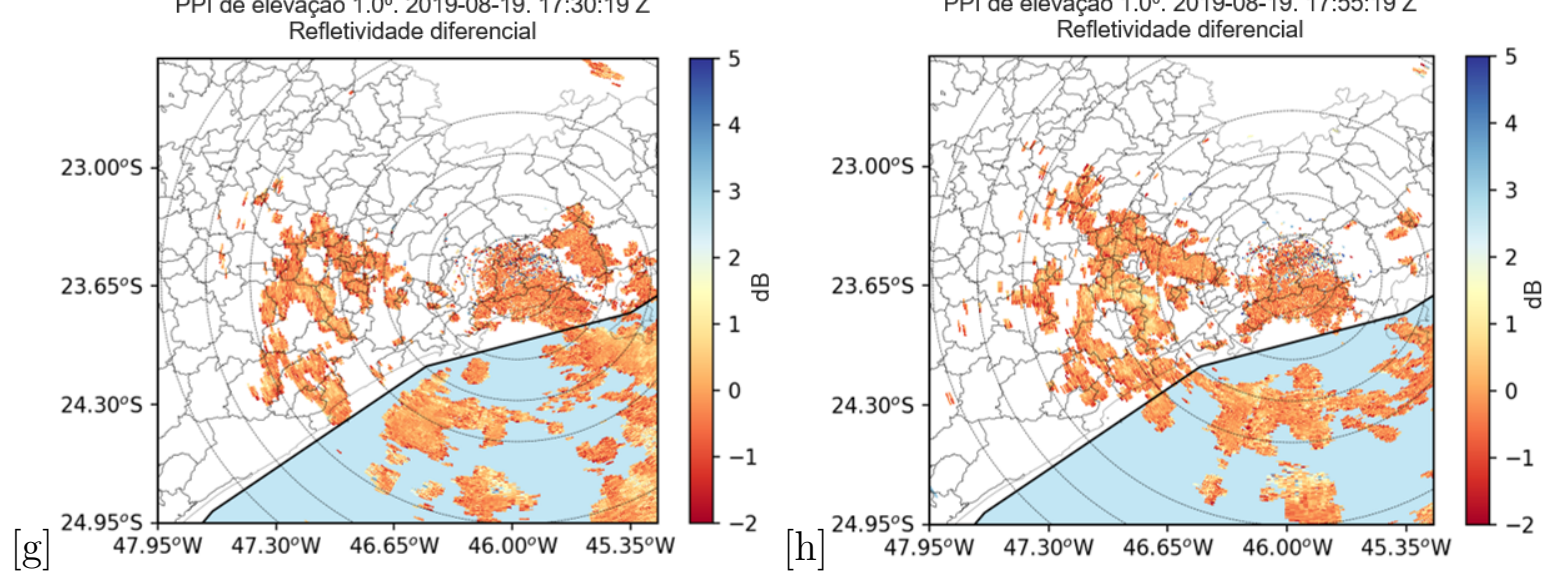

Figura 3.89: Idem Fig. 3.88, mas para refletividade diferencial. A escala de cores indica refletividade diferencial $(\mathrm{dB})$. 

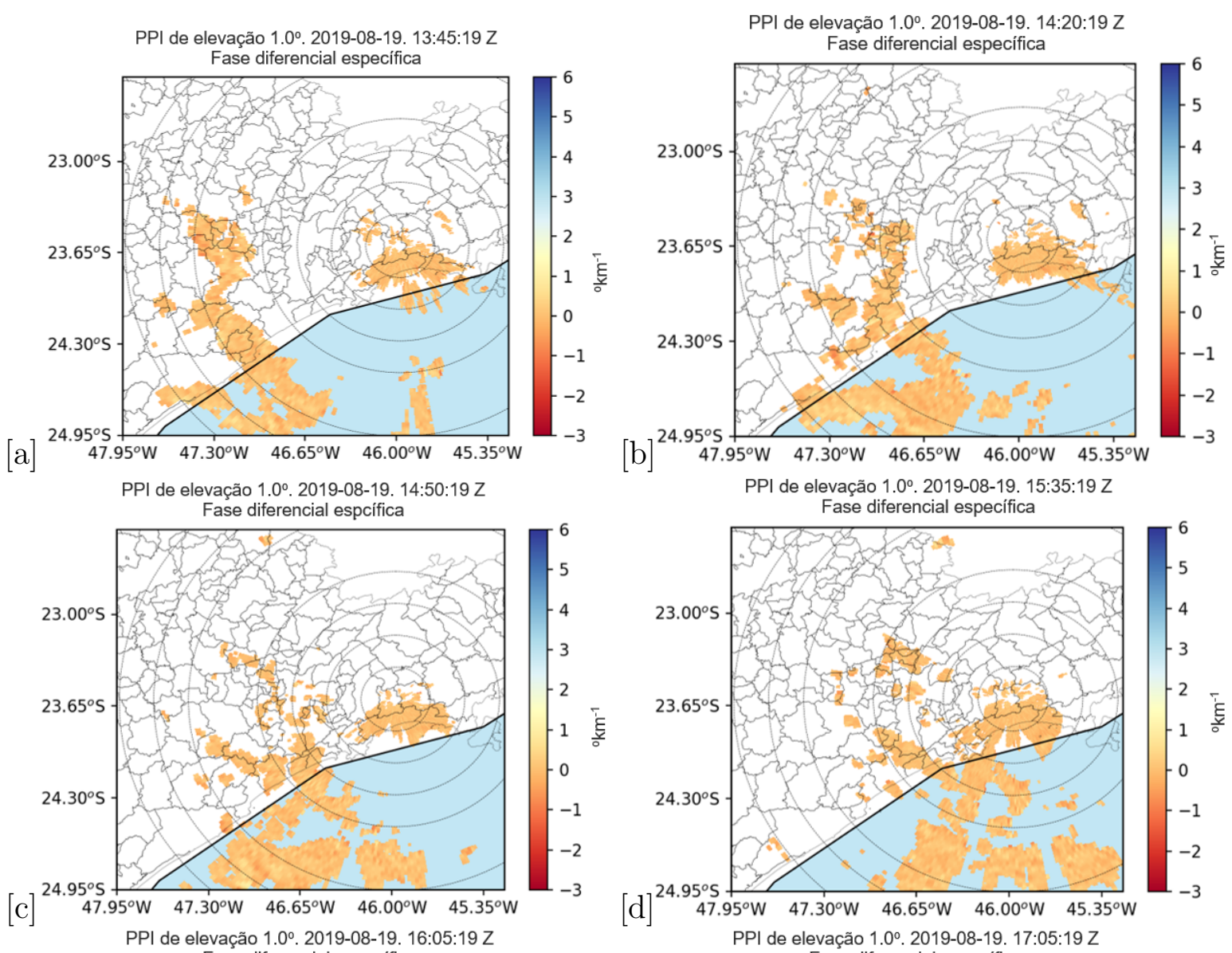

$[\mathrm{d}]^{24.95^{\circ} \mathrm{S}} 47.95$

PPI de elevač̃o $1.0^{\circ} \cdot 2010-08-19 \cdot 15 \cdot 35: 19$ Z

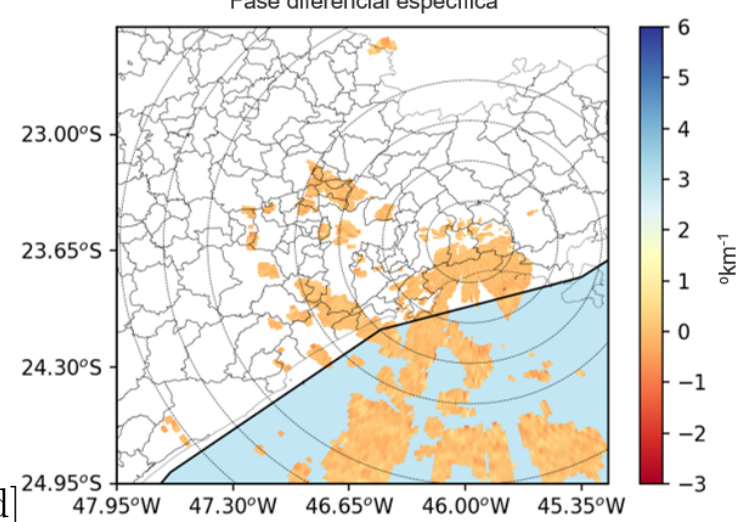

PPI de

PPI de elevação 1.0 . 2019-08-19, 17:05:19Z

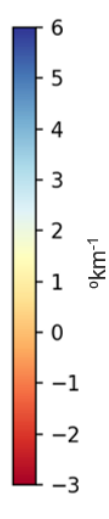

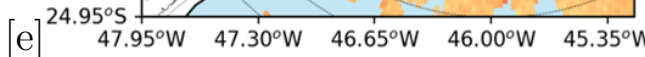

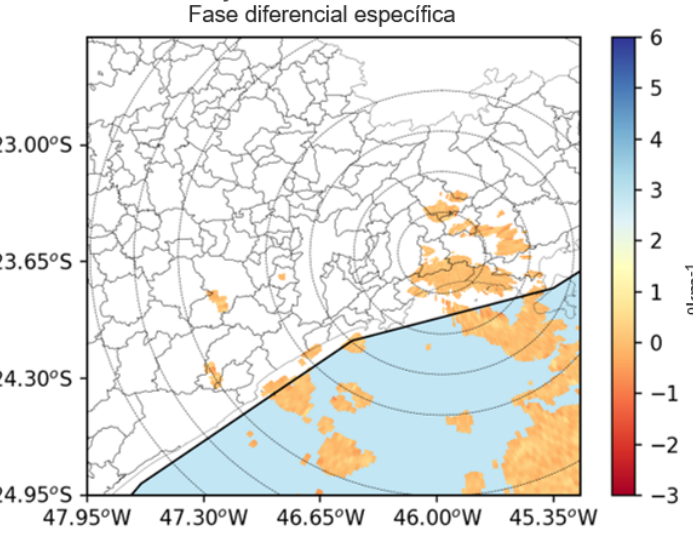

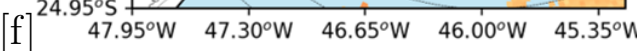

PPI de elevação $1.0^{\circ}$. 2019-08-19. 17:55:19 Z

PPI de elevação 1.0.2019-08-19.17:30:19 Z Fase diferencial específica
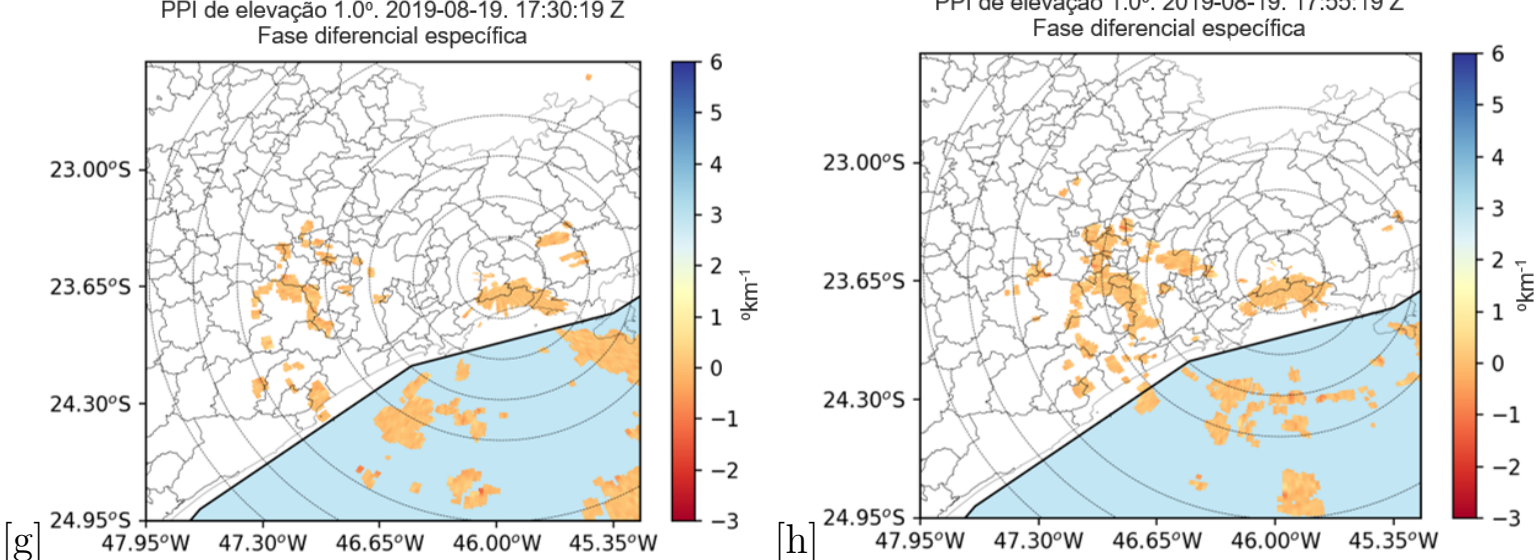

Figura 3.90: Idem Fig. 3.88, mas para fase diferencial específica. A escala de cores indica fase diferencial específica $\left({ }^{\circ} \mathrm{km}^{-1}\right)$. 

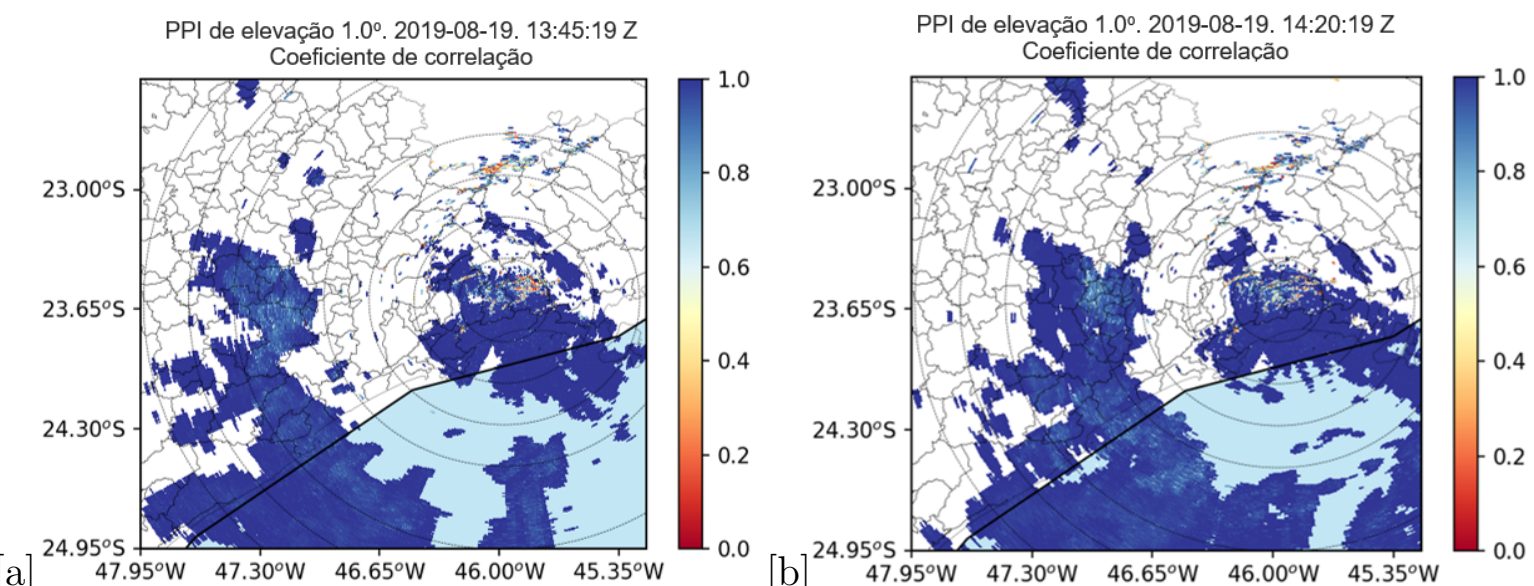

$[a] \quad 47.95^{\circ} \mathrm{W} \quad 47.30^{\circ} \mathrm{W} \quad 46.65^{\circ} \mathrm{W} \quad 46.00^{\circ} \mathrm{W} \quad 45.35^{\circ} \mathrm{W}$

PPI de elevação 1.0 $2019-08-19.14: 50: 19 Z$

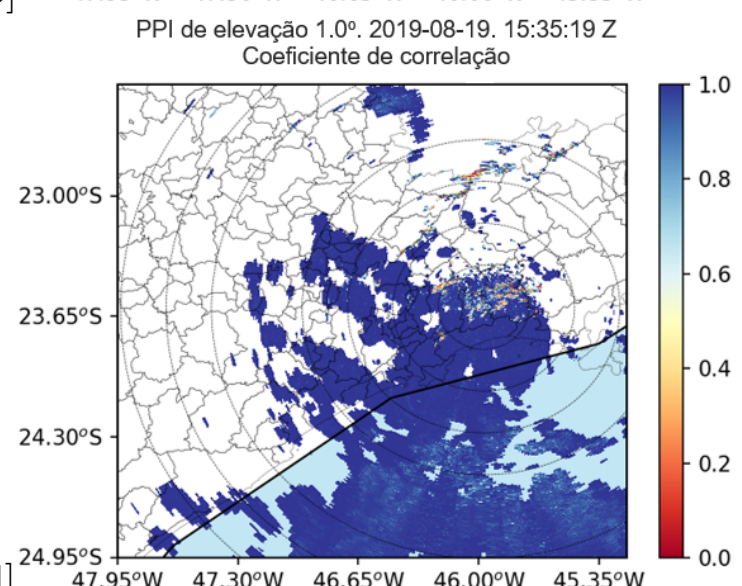

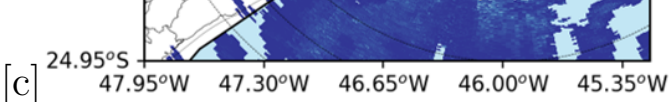

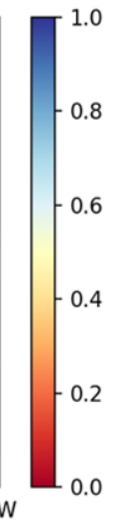

PPI de elevação 1.0 $0^{\circ}$. 2019-08-19. 16:05:19 Z

$47.95^{\circ} \mathrm{W} \quad 47.30^{\circ} \mathrm{W} \quad 46.65^{\circ} \mathrm{W} \quad 46.00^{\circ} \mathrm{W} \quad 45.35^{\circ} \mathrm{W}$

PPI de elevação 1.0 . 2019-08-19.17:05:19 Z

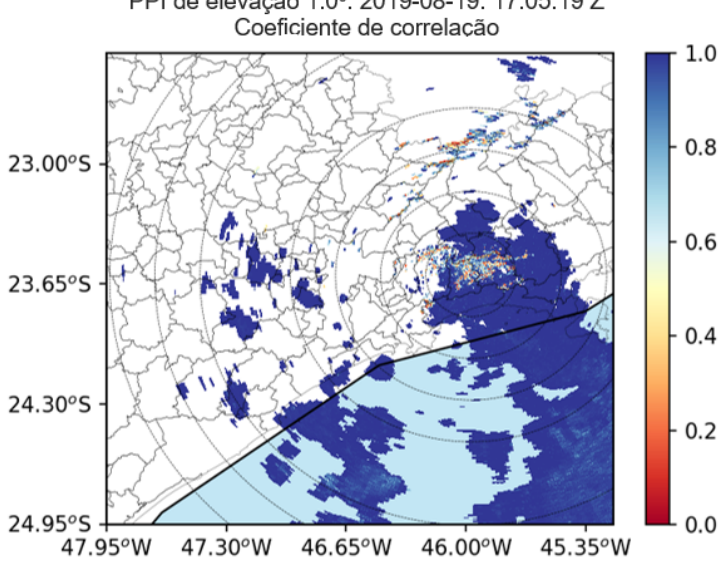

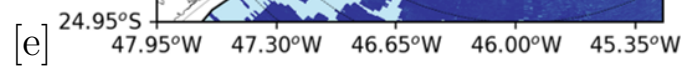

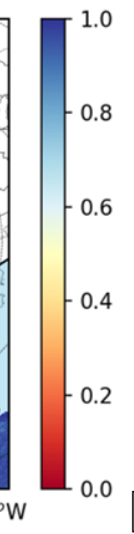

PPI de elevação 1.0 $0^{\circ}$. 2019-08-19.17:30:19 Z

Coeficiente de correlação

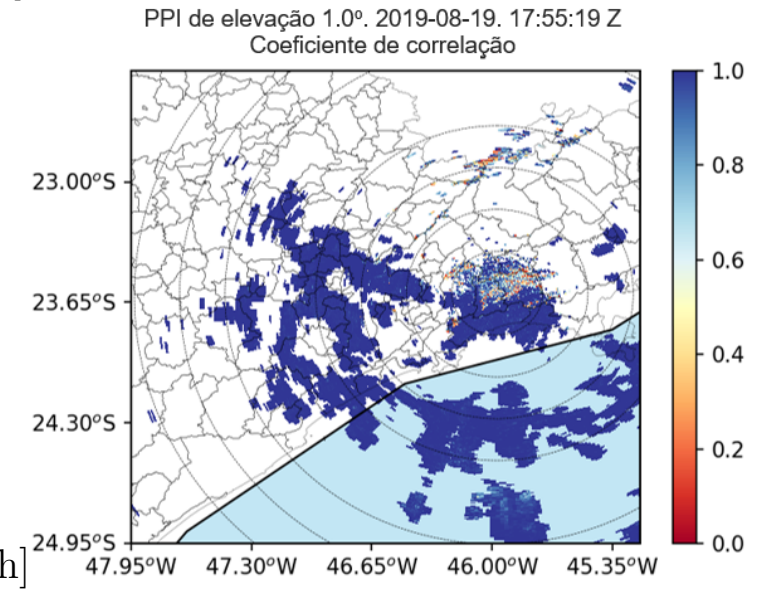

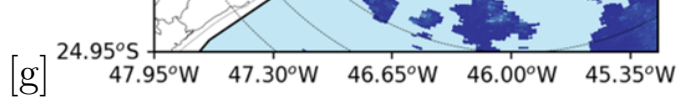

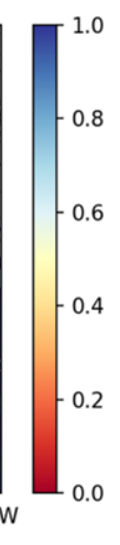

Figura 3.91: Idem Fig. 3.88, mas para coeficiente de correlação. A escala de cores indica coeficiente de correlação (sem unidade). 
Às 1800 UTC, correspondente a 1500 HL (horário local) para adiante, que foi observado o escurecimento aparente do céu sobre algumas regiões da RMSP, observa-se que as BDs ganharam intensidade (Fig. 3.92), com núcleos relativamente intensos (entre 40 e $50 \mathrm{dBZ}$ ). Os campos de refletividade diferencial indicaram valores de $1.5 \mathrm{~dB}$ nos núcleos das BDs, correspondentes a gotas de chuva aos núcleos (Fig. 3.93). Nos campos da fase diferencial específica, os valores chegam $1^{\circ} \mathrm{km}^{-1}$ as gotas de chuva nos núcleos das BDs (Fig. 3.94). Nos campos de coeficiente de correlação não houve alteração, observa-se valores generalizados próximo de 1.0 a gotas de chuva, e 0.8 entre os círculos concêntricos 100 e 150 km correspondente a banda brilhante (Fig. 3.95).

Entretanto, observa-se ainda nuvens fragmentadas, aparentemente com suas bordas em dissipação rápida (Fig. 3.92). 

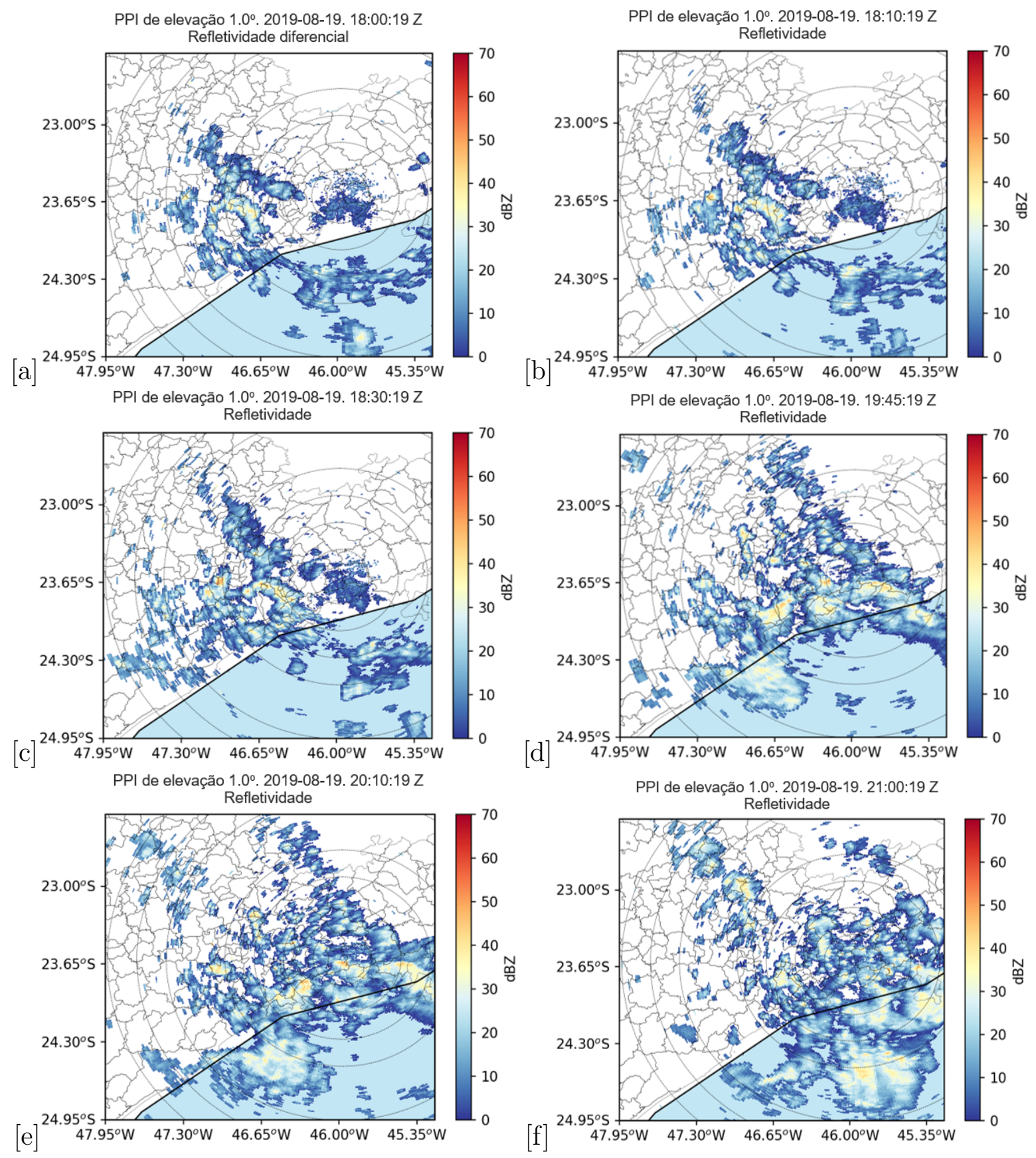

Figura 3.92: Campos da refletividade $\left(\mathrm{Z}_{H}\right)$ do radar SPOL no PPI de ângulo de elevação $1.0^{\circ}$, (a) às 1800 UTC, (b) 1810 UTC, (c) 1830 UTC, (d) 1945 UTC, (e) 2010 UTC e (f) 2100 UTC do dia 19 de Agosto de 2019. A escala de cores indica a refletividade (dBZ). O círculos concêntricos estão espaçadas a cada $25 \mathrm{~km}$ até aos $100 \mathrm{~km}, 50 \mathrm{~km}$ entre 100 e $150 \mathrm{~km}$ e, novamente $24 \mathrm{~km}$ entre 150 e $200 \mathrm{~km}$. O radar meteorológico SPOL está centro da menor circunferência concêntrica. Longitudes, latitudes, contornos dos municípios são indicados. 

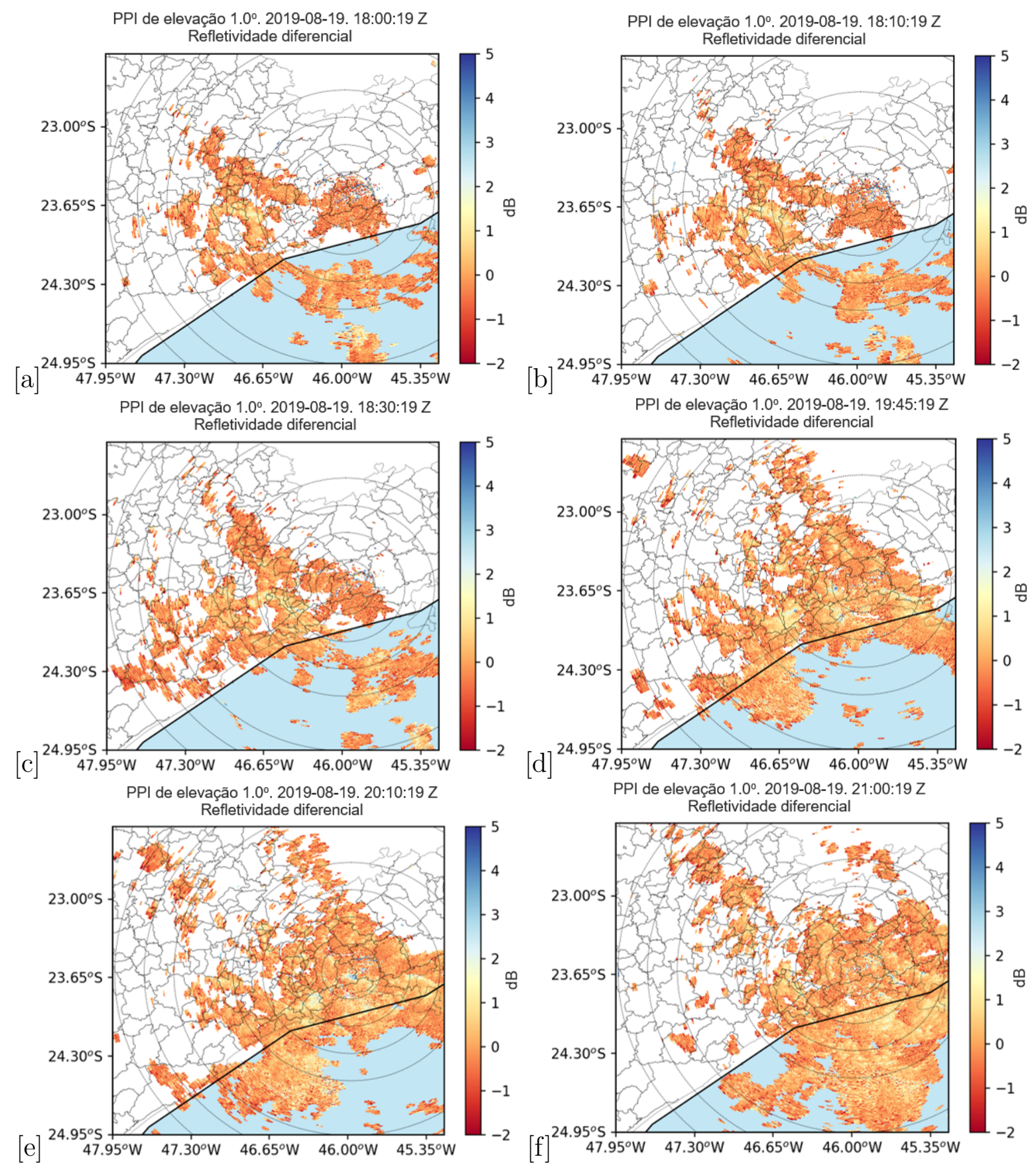

Figura 3.93: Idem Fig. 3.92, mas para refletividade diferencial. A escala de cores indica refletividade diferencial $(\mathrm{dB})$. 

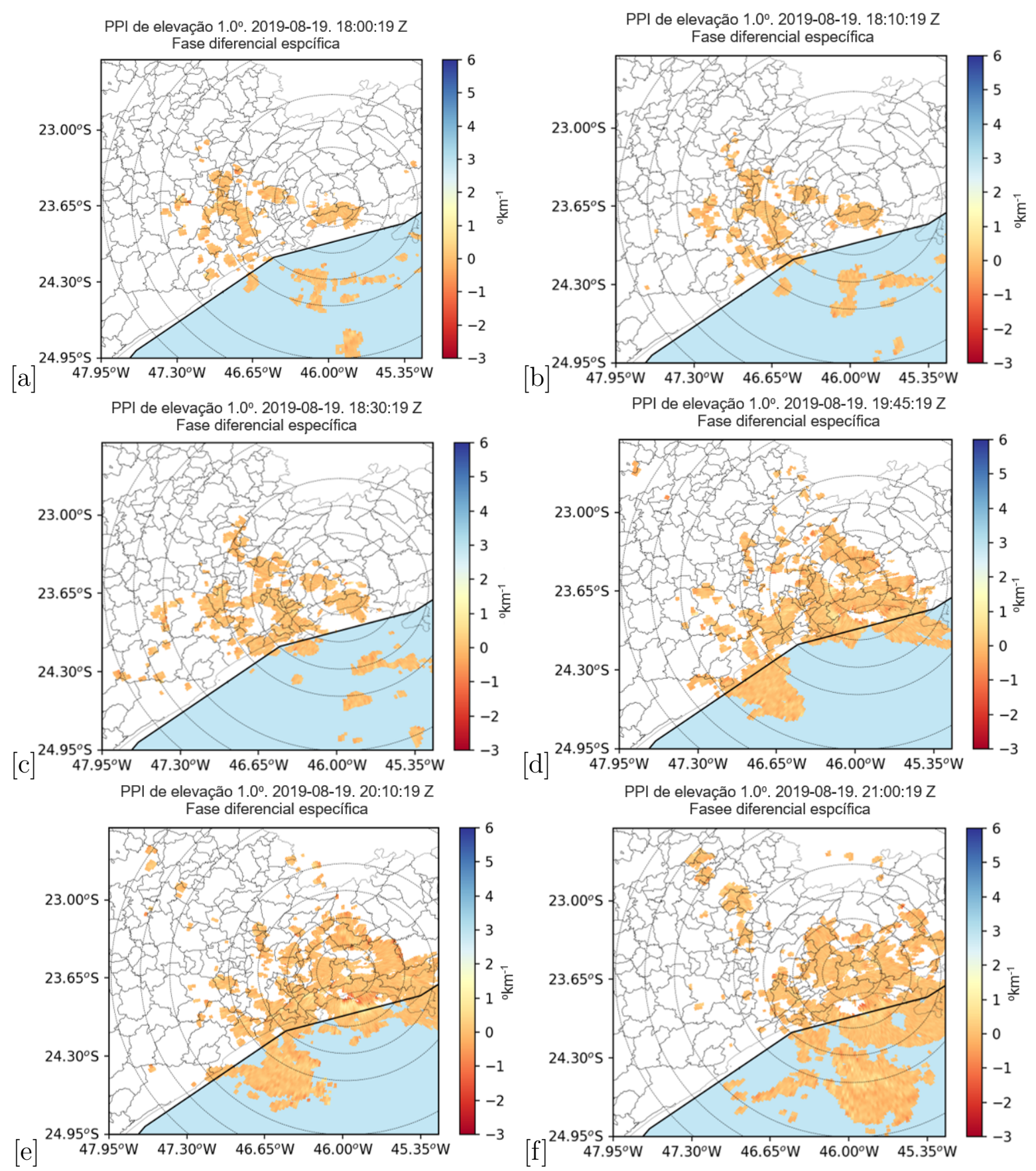

Figura 3.94: Idem Fig. 3.92, mas para fase diferencial específica. A escala de cores indica fase diferencial específica $\left({ }^{\circ} \mathrm{km}^{-1}\right)$. 


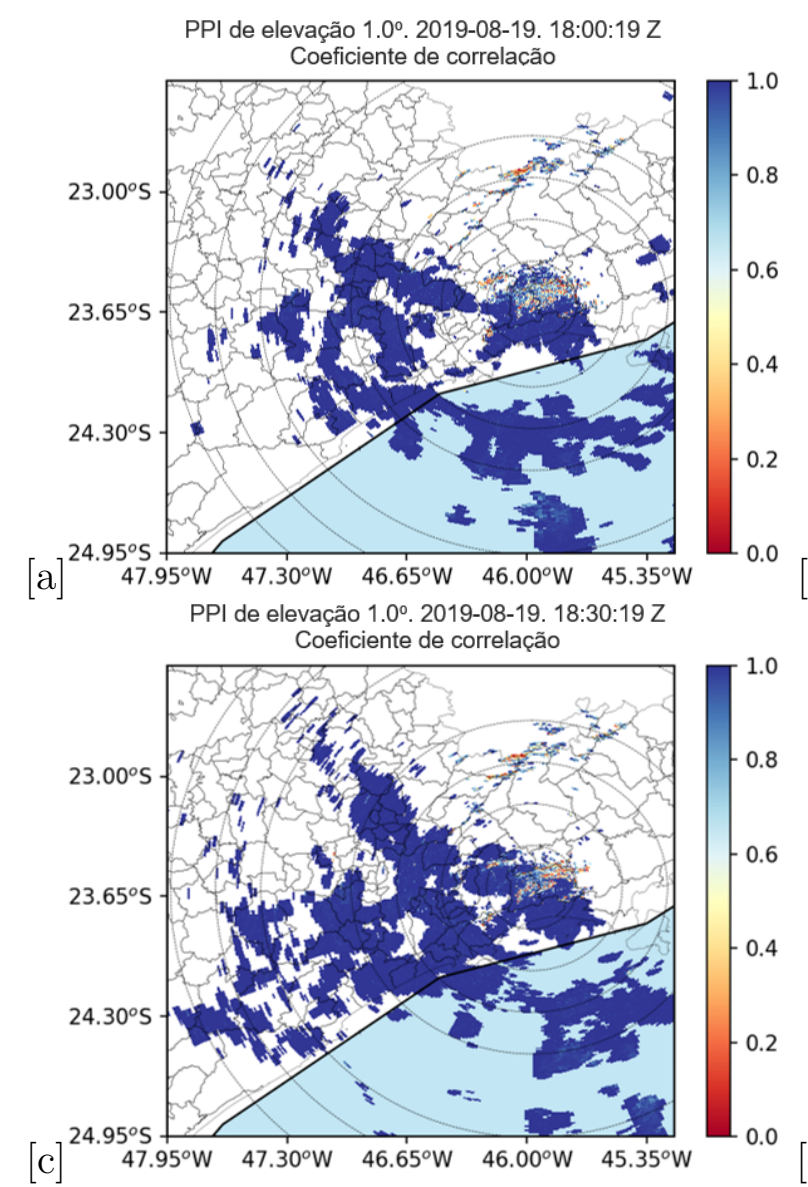

PPI de elevação 1.0. 2019-08-19. 20:10:19 Z

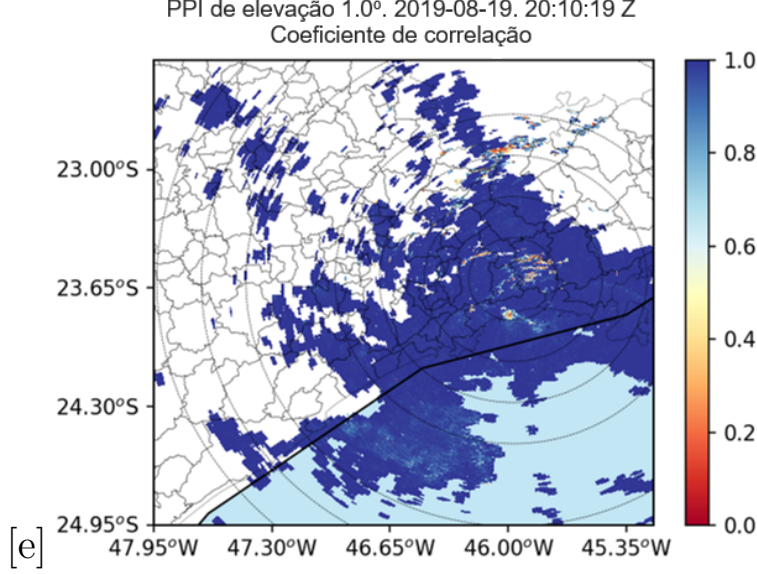

PPI de elevação 1.0². 2019-08-19. 18:10:19 Z

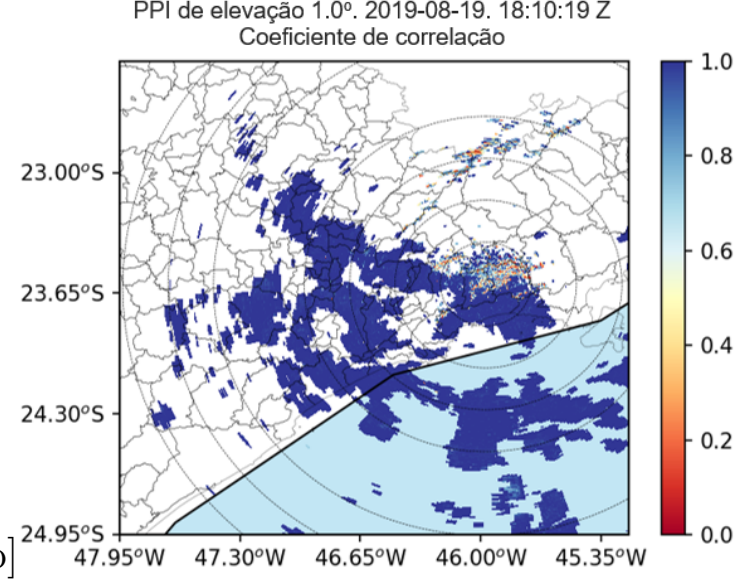

PPI de elevação 1.0. 2019-08-19. 19:45:19 Z

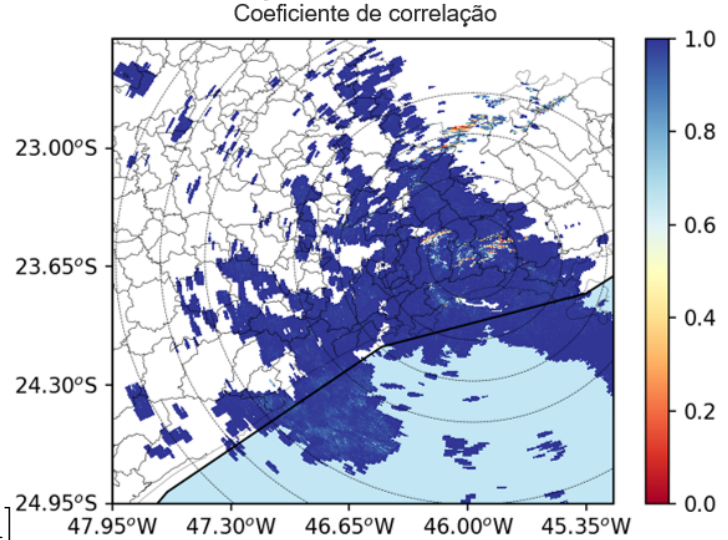

PPI de elevação $1.0^{\circ}$. 2019-08-19. 21:00:19 Z Coeficiente de correlação

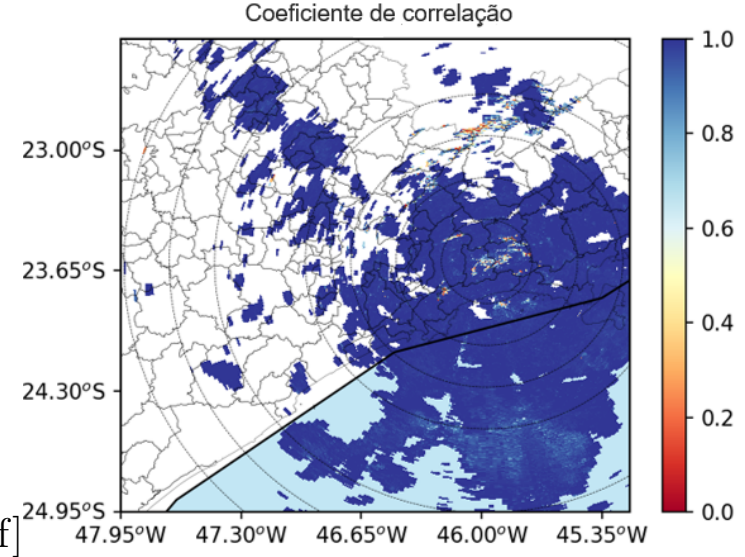

Figura 3.95: [Idem Fig. 3.92, mas para coeficiente de correlação. A escala de cores indica coeficiente de correlação (sem unidade).

\subsubsection{Classificação de hidrometeoros}

A Fig. 3.96 mostra a sequência de PPIs de $1.0^{\circ}$ de elevação da classificação de hidrometeoros. Destaca-se a camada de neve molhada entre os círculos concêntricos 100 e 
$150 \mathrm{~km}$, agregados e gelo vertical acima da camada de neve molhada (Fig. 3.96a, b). A classificação de hidrometeoros indica chuva em áreas pontuais, e predominância de chuvisco abaixo da camada de neve molhada (Fig. 3.96). Pesquisadores sugerem que dependendo das condições meteorológicas, o efeito de aerossóis pode desencadear ou restringir a ocorrência de precipitação (Rosenfeld e Ulbrich, 2003).

O conceito de dissipação de nuvens pela semeadura é muito parecido com o de aumento da precipitação. Grandes partículas ou núcleos de gelo são introduzidos para varrer as gotículas de nuvens baixas e nevoeiros ao redor do aeroporto, limpando assim a temporalidade de uma área (Yau e Rogers, 1996). Provavelmente a alta concentração de fumaça de incêndios na Amazônia serviu sumidouro das gotículas das nuvens que afetou na redução de precipitação sobre a região (Fig. 3.96 e Fig. 3.97).

Nas análises sinótica, seção 3.5.1 e termodinâmica, seção 3.86, não obstante de umidade relativa alta, observou-se que a atmosfera estava estável com CAPE, praticamente nulo, que não favoreceu o transporte da água líquida e de material particulado para níveis superiores, que proporcionaria a produção de granizo e chuva generalizada. Nessas condições, a alta concentração de material particulado de queimada de biomassa amazônica, provavelmente alterou os processos microfísicos de formação e desenvolvimento da gotas de chuva, suprimindo a precipitação generalizada durante a evolução espaço-temporal das BDs (Fig. 3.96). Esse efeito é conhecido como hipótese do aerossol, devido a alta concentração de aerossóis que disputam pelo vapor de água para a formação de gotículas de nuvem, que precisam ser carregadas para temperaturas a baixos de $0^{\circ} \mathrm{C}$, onde transformam-se em cristais de gelo e crescem por difusão de vapor de água (Williams et al., 2002).

Andreae et al. (2004) observou que o fumo intenso dos incêndios florestais na Amazônia reduziu o tamanho das gotas de nuvens, que retarda o início da precipitação. Entretanto, as condições atmosféricas eram instáveis sobre a região de estudo, que favoreceu o transporte da água líquida e de material particulado para níveis superiores, revigorando as correntes de ar liberando o calor latente, que proporcionam a produção de granizo, causando descargas atmosféricas intensas. As tempestades revigoradas mais alto na atmosfera (Andreae et al., 2004). 


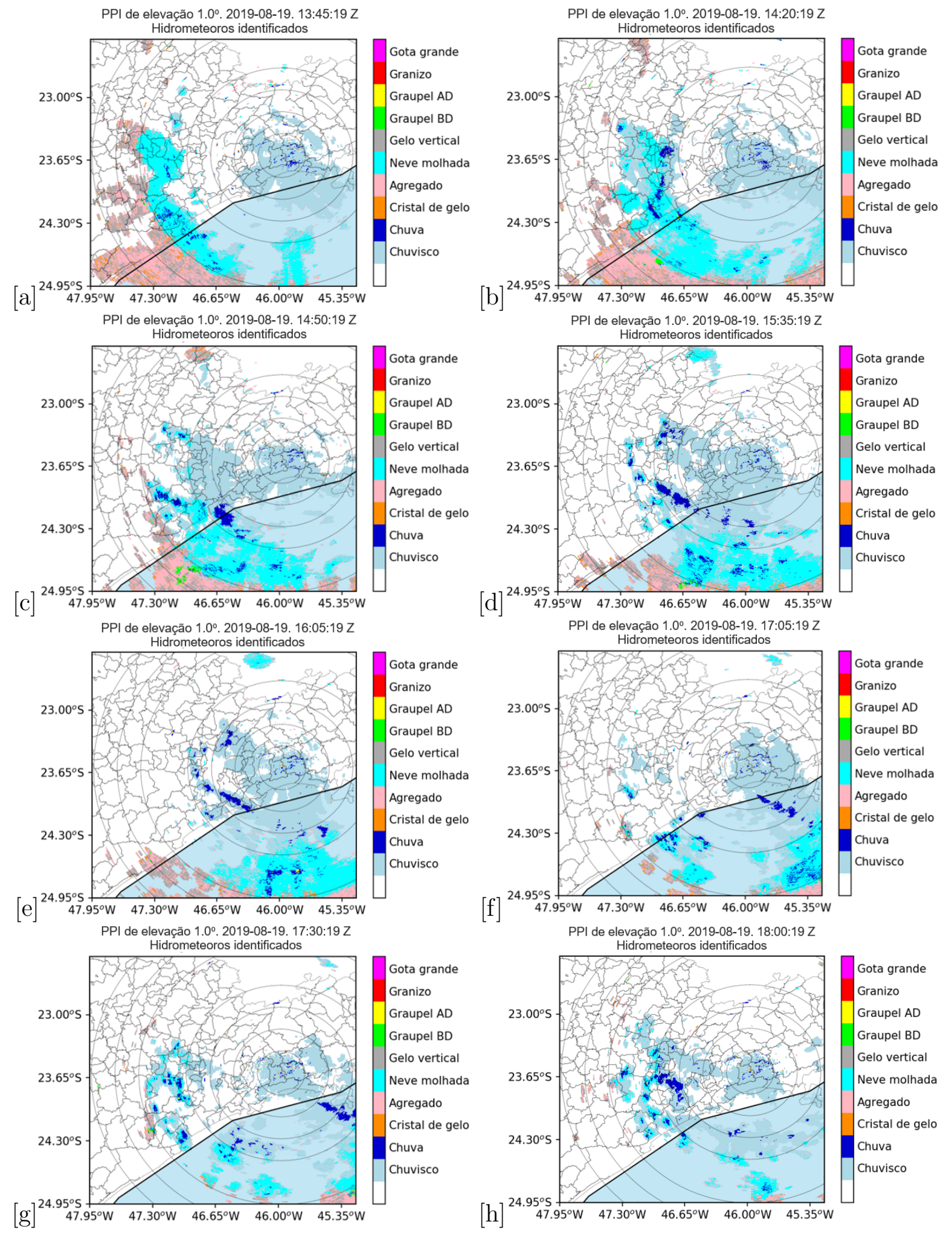

Figura 3.96: PPI de ângulo de elevação de $1.0^{\circ}$ às 1430 UTC (a), 1435 UTC (b), 1440 UTC (c) e 1450 UTC (d) do dia 19 de Agosto de 2019, apresentando a classificação dos hidrometeoros presentes na tempestade. A escala apresenta as 10 classificações dos hidrometeoros: Gota de água, Granizo, Graupel AD, Graupel BD, Gelo vertical, Neve molhada, Agregados, Cristais de gelo, Chuva e Chuvisco. 
No estágio inicial, durante os primeiros segundos, as gotículas que possuem raio menor que $10 \mu_{m}$ crescem por condensação e difusão do vapor de água com taxa de crescimento sendo dominada pela supersaturação do ambiente, temperatura e efeito soluto (Pruppacher e Klett, 1996). Com os raios menor que $50 \mu_{m}$, as gotículas estão suspensas ou precipitam a uma velocidade terminal em que o fluxo de ar ao seu redor pouco afeta, e ainda se isenta na interação entre os campos de vapor de gotículas próximas devido à distância das gotas vizinhas serem da ordem cem vezes o raio das gotículas na fase quente da (Pruppacher e Klett, 1996).

Não obstante da grande disponibilidade de vapor de água nessas condições, o crescimento por condensação é insuficiente para que ocorresse a transformação rápida do conteúdo de água líquida em gota de chuva ou ocorresse o processo microfísico de colisãocoalescência (raio menor a $50 \mu_{m}$ ), que permitiria que as gotículas continuassem crescendo interagindo entre elas abaixo da isoterma $0^{\circ} \mathrm{C}$.
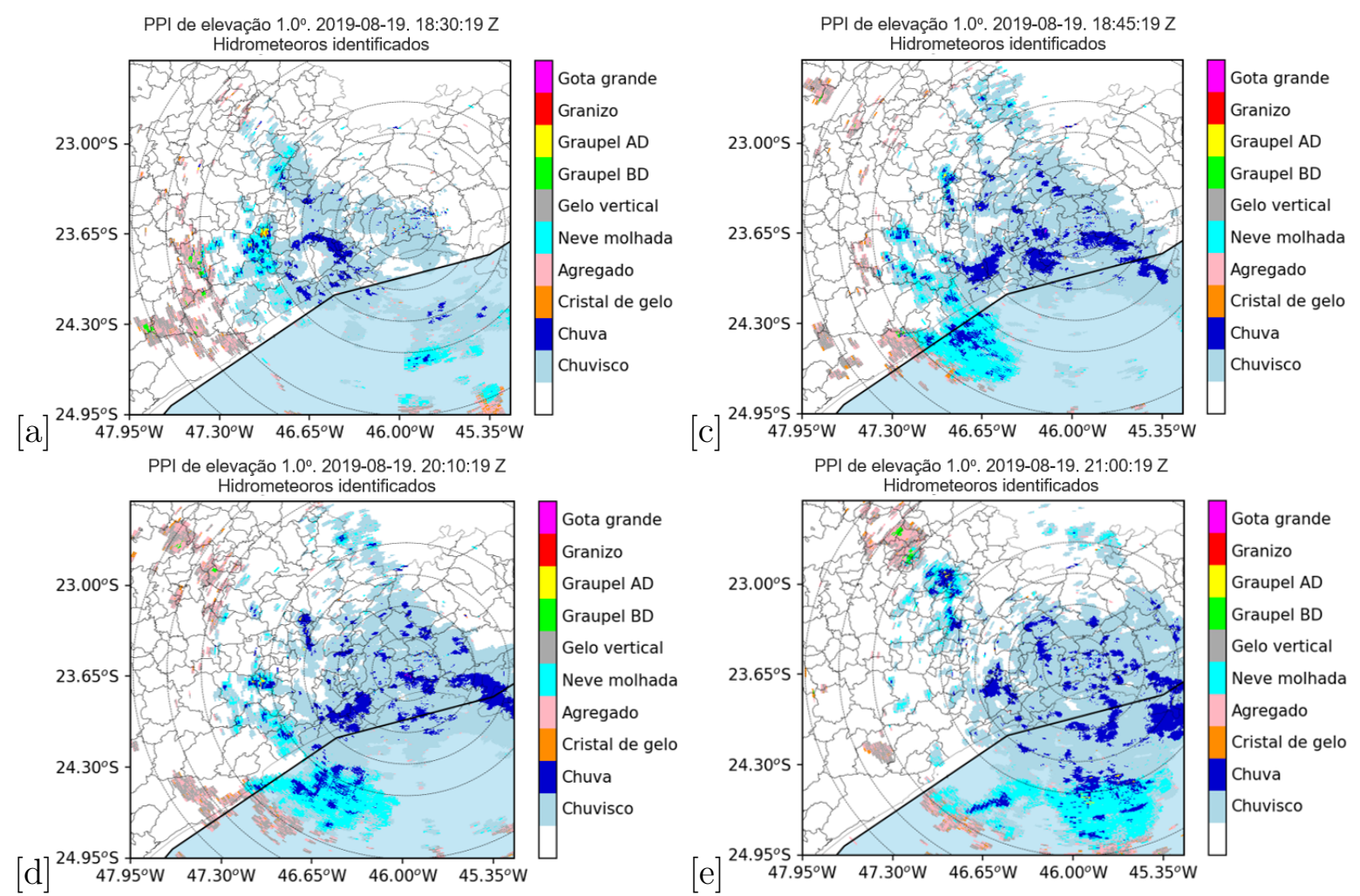

Figura 3.97: PPI de ângulo de elevação de $1.0^{\circ}$ às 1830 UTC (a), 1845 UTC (b), 2010 UTC (c) e 2100 UTC (c) do dia 19 de Agosto de 2019, apresentando a classificação dos hidrometeoros presentes na tempestade. A escala apresenta as 10 classificações dos hidrometeoros: Gota de água, Granizo, Graupel AD, Graupel BD, Gelo vertical, Neve molhada, Agregados, Cristais de gelo, Chuva e Chuvisco. 
Porem, devido as condições atmosféricas estáveis, o processo microfísico de colisãocoalescência, provavelmente foi ineficiente para quase todo sistema, limitando o crescimento das gotículas, que foram identificadas chuviscos generalizado, excepto em algumas áreas pontuais, onde são identificadas chuvas durante a evolução espaço-temporal das BDs (Fig. 3.96 e Fig. 3.97).

A Fig. 3.98 mostra sequência de PPIs em diferentes ângulos de elevação $\left(1.0^{\circ}, 1.6^{\circ}\right.$, $2.4^{\circ}$ e $3.2^{\circ}$ ) às 1755 UTC. Nota-se que não há presença de graupel e granizo acima da camada de neve molhada, devido ausência de água a temperaturas a baixo de $0^{\circ} \mathrm{C}$ que proporcionaria o crescimento das partículas de gelo para graupel e granizo pelo processo de acreção, que ocasionaria chuva generalizada com gotas grandes (Fig. 3.98).
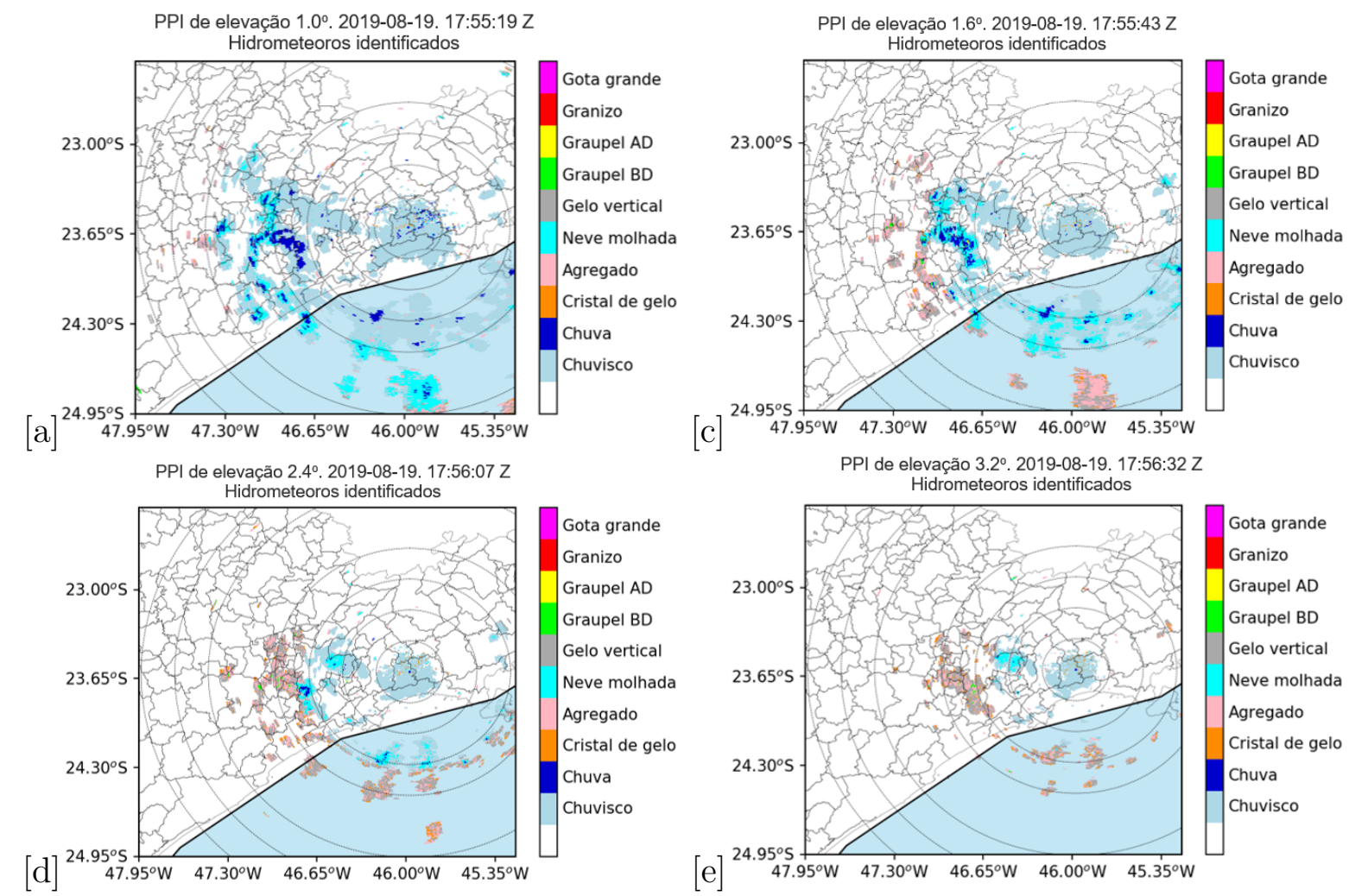

Figura 3.98: PPIs de ângulos de elevação de $1.0^{\circ}$ (a), $2.4^{\circ}$ (b), $3.2^{\circ}$ (c) e $4.2^{\circ}$ (d) de classificação de hidrometeoros, às 1755 UTC do dia 19 de Agosto de 2019. A escala de cores indica os hidrometeoros identificados. 
Capítulo 4

\section{Conclusões e Recomendações}

\subsection{Conclusões}

Este trabalho analisou a microfísica, dinâmica e termodinâmica de cinco eventos dos principais sistemas precipitantes atuantes no LSP, com ênfase na RMSP, ocorridos nas datas 11 de Janeiro de 2010, 18 de Maio de 2014, 24 de Janeiro de 2016, 29 de Janeiro de 2019 e 19 de Agosto de 2019. Utilizou-se medidas de variáveis polarimétricas dos radares meteorológicos Doppler de dupla polarização banda X e banda S e dados de temperaturas e altitude das radiossondagens como dados de entrada no método lógica fuzzy para a classificação dos hidrometeoros. Calculou-se a massa de água líquida, a massa de água sólida, o diâmetro da gota e a taxa da chuva a partir de medidas de variáveis polarimétricas e de radiossondagens para análise do espectro das gotas de chuva. Os hidrometeoros classificados foram consistentes com as variáveis polarimétricas e medidas de radiossondagens, excepto o evento medido pelo radar MXPOL. O método permitiu obter bom refinamento dos diferentes tipos de hidrometeoros para a análise microfísica durante a evolução espaçotemporal dos eventos.

Os resultados mais importantes encontrados nas análises microfísicas de cada caso de estudo são pontuados a seguir:

Primeiro caso (11-01-2010) - a combinação de sistemas de frente de BM, FF e ICU desencadeou disparos de várias células convectivas secundárias intensas que agregaram-se para formar uma única tempestade extensa sobre o centro geométrico da RMSP. A forte convergência de fluxos de massas de ar induzida pela intensa ICU no centro geométrico da RMSP, impediu a propagação da frente de BM e da tempestade por aproximadamente $2 \mathrm{~h}$. A tempestade produziu mais granizo acima da isoterma $0^{\circ} \mathrm{C}$ sobre o centro da cidade de 
São Paulo. A concentração máxima da massa de água líquida ocorreu nos níveis inferiores da tempestade e diminuiu com aumento de altitude. A concentração máxima da massa de água sólida ocorreu acima da isoterma $0^{\circ} \mathrm{C}$ e reduziu com a diminuição da altitude.

Segundo caso (18-05-2014) - a CI foi induzida por rotação ciclônica intensa causada pelo cisalhamento de vento associado a dois sistemas de escala sinótica, um ciclone extratropical e uma de alta pressão. O evento produziu precipitação de pedras de granizo com gotas grandes que atingiram a superfície por cerca de $2 \mathrm{~h}$ interrupto à medida que propagou-se sobre o centro geométrico da RMSP. As gotas de chuva apresentaram $\sim 2.8$ mm de diâmetros nos níveis inferiores do núcleo da célula convectiva. A concentração máxima da massa de água líquida de $\sim 5.8 \mathrm{~g} \mathrm{~m}^{-3}$ ocorreu no núcleo dos níveis inferiores da célula convectiva e o valor decresceu com aumento da altitude. A concentração máxima da massa de água sólida de de $\sim 6.8 \mathrm{~g} \mathrm{~m}^{-3}$ ocorreu no núcleo da célula convectiva acima da isoterma $0^{\circ} \mathrm{C}$ e o valor decresceu com a diminuição da altitude.

Terceiro caso (29-01-2019) - a CI foi induzida inicialmente por convergência de massas de ar e posteriormente por rotação ciclônica causada por cisalhamento de vento associado a um sistema de alta pressão. A precipitação de gotas grandes sem pedras de granizo até à superfície, ocorreu quando a CI estava sob influência de convergência e apresentou menos profundidade. A precipitação de pedras granizo com gotas grandes até à superfície, ocorreu quando a CI estava sob influência de rotação ciclônica e apresentou mais profundidade, quando propagou-se sobre as regiões adjacentes do centro da cidade de São Paulo. As gotas de chuva apresentaram $\sim 3 \mathrm{~mm}$ de diâmetros nos níveis inferiores do núcleo da célula convectiva. A concentração máxima da massa de água líquida nos níveis inferiores do núcleo da célula convectiva, atingiu valores de $\sim 6.5 \mathrm{~g} \mathrm{~m}^{-3}$ e decresceu com aumento da altitude. A concentração máxima da massa de água sólida no núcleo da célula convectiva acima da isoterma $0^{\circ} \mathrm{C}$, atingiu valores de $\sim 6.4 \mathrm{~g} \mathrm{~m}^{-3}$ e decresceu com a diminuição da altitude.

Ambas CIs apresentaram um padrão de deslocamento. Os disparos das CIs ocorreram na parte sul do centro geométrico da RMSP e deslocaram-se para regiões adjacentes ao centro da cidade de São paulo em direção Guarulhos. 
A quantidade de graupel de alta densidade nos níveis superiores do núcleo das CIs, foi sendo substituída pela quantidade de pedras de granizo que aumentou até ao topo da isoterma $0^{\circ} \mathrm{C}$. A quantidade de pedras de granizo no núcleo das CIs dentro da camada de neve molhada, foi sendo substituído por concentração alta de gotas grandes que aumentou até nos níveis inferiores das CIs, à medidas que as pedras granizo descongelavam quando precipitavam às temperaturas elevadas.

As variedades de hidrometeoros são distribuídas por densidade acima da isoterma $0^{\circ} \mathrm{C}$, os cristais de gelo acima, em seguida os graupel de baixa densidade, os graupel de alta densidade e as pedras de granizo por baixo. Alta concentração de gelo vertical e agregados concentram-se a temperaturas abaixo de $-20^{\circ} \mathrm{C}$.

A alta concentração de gotas grandes nos núcleos das CIs na base da isoterma $0^{\circ} \mathrm{C}$, resultam do derretimento das pedras de granizo. A quantidade de gotas grandes no núcleo das CIs, diminuem com a diminuição da altitude até aos níveis inferiores das células convectivas, provavelmente devido os mecanismos da força de arrasto aerodinâmico que resultam na quebra das gotas grandes à medida que essas precipitaram e proporcionou taxas altas de chuva.

Quarto caso (29-01-2019) - BDs induzidas por um sistema frontal sem de fumaça de incêndios da Amazônia. As BDs produziram chuva generalizada, e algumas células produziram pedras de granizo e graupel nos núcleos acima da isoterma $0^{\circ} \mathrm{C}$ e gotas grandes na base da isoterma $0^{\circ} \mathrm{C}$.

Quinto caso (19-08-2019) - BDs induzidas por um sistema frontal com fumaça de incêndios da Amazônia. Não obstante da alta concentração de umidade, a fumaça impactou na microfísica das nuvens, suprimindo chuva devido a redução do tamanho das gotas sobre a RMSP, que predominou chuvisco da base da isoterma $0^{\circ} \mathrm{C}$ até nos níveis inferiores das nuvens. O evento ocorreu no inverno e sem mecanismo de levantamento para a produção de graupel e granizo acima da isoterma $0^{\circ} \mathrm{C}$.

Os resultados microfísico, dinâmico e termodinâmico obtidos principalmente das CIs, são inéditos, e são indispensáveis na previsão de curto prazo de perigo de precipitação de pedras de granizo com aproximadamente uma hora (1h) de antecedência sobre o centro 
geométrico da RMSP que pode ajudar no planeamento e a mitigar ou mesmo evitar os danos.

\subsection{Recomendações}

Esta pesquisa inédita de análise microfísica e dinâmica na região leste do Estado de São Paulo (LSP) serve como ponto de partida para mais análises e simulações microfísicas das células convectivas que se desenvolvem na RMSP, uma vez que as células convectivas variam de local para local e no mesmo local. Serão pautadas a seguir recomendações consideradas mais relevantes, a fim de complementar e dar continuidade a este trabalho. Entretanto, não deve ficar limitada ao sugerido abaixo.

- Aumentar a série de análise microfísica da evolução espaço-temporal dos principais sistemas precipitantes para que seja possível fazer novas comparações e avaliar os resultados;

- Instalar disdrômetros em diferentes pontos da RMSP para que seja possível fazer comparações entre os espectros de gotas em superfície e em altitude;

- Efetuar sondagens em horários antes, durante e após a ocorrência dos sistemas precipitantes. A temperatura ambiente em diferentes níveis da atmosfera é uma variável indispensável por servir como fator determinante na classificação de diferentes tipos de hidrometeoros.

- Medir e analisar a variação das concentrações de tipos de aerossóis e seus efeitos diretos na microfísica da nuvem antes, durante e após as passagens dos sistemas precipitantes;

- Aplicar os resultados microfísicos nas parametrizações microfísicas das nuvens ao modelo Advanced Research and Weather Research and Forecasting (WRF-ARW), com uma resolução de $1 \mathrm{~km}$ da grade.

- Realizar várias simulações microfísicas para cada sistema precipitante e analisar a sensibilidade do modelo às parametrizações microfísicas das nuvens para acurácia da previsão de perigo de granizo e de chuvas fortes. 
E para finalizar as recomendações, aconselho paciência e dedicação nos futuros trabalhos. 


\section{Referências Bibliográficas}

Alberoni P., Zrnic D., Ryzhkov A., Guerrieri L., Use of a fuzzy logic classification scheme with a C-band polarimetric radar: first results. In Proceedings of ERAD , vol. 324, 2002

Andreae M. O., Rosenfeld D., Artaxo P., Costa A., Frank G., Longo K., Silva-Dias M. d., Smoking rain clouds over the Amazon, science, 2004, vol. 303, p. 1337

Atlas D., Drop size and radar structure of a precipitation streamer, Journal of Meteorology, 1957, vol. 14, p. 261

Baldini L., Gorgucci E., Chandrasekar V., Hydrometeor classification methodology for C-band polarimetric radars. In Proceedings of ERAD , vol. 62, 2004

Barry R. G., Chorley R. J., Atmosfera, tempo e clima. Bookman Editora, 2009

Battan L. J., Radar observation of the atmosphere, 1973

Bauer P., Thorpe A., Brunet G., The quiet revolution of numerical weather prediction, Nature, 2015, vol. 525, p. 47

Bhattacharjee S., DLS and zeta potential--what they are and what they are not?, Journal of controlled release, 2016, vol. 235, p. 337

Bringi V., Seliga T., Cooper W., Analysis of aircraft hydrometeor spectra and differential reflectivity (ZDR) radar measurements during the Cooperative Convective Precipitation Experiment, Radio Science, 1984, vol. 19, p. 157

Bringi V., Seliga T. A., Aydin K., Hail detection with a differential reflectivity radar, Science, 1984, vol. 225, p. 1145 
Bringi V., Vivekanandan J., Tuttle J., Multiparameter radar measurements in Colorado convective storms. Part II: Hail detection studies, Journal of the atmospheric sciences, 1986, vol. 43, p. 2564

Bringi V. N., Chandrasekar V., Polarimetric Doppler weather radar: principles and applications. Cambridge university press, 2001

Carey L. D., Rutledge S. A., The relationship between precipitation and lightning in tropical island convection: A C-band polarimetric radar study, Monthly weather review, 2000, vol. 128 , p. 2687

Cifelli R., Petersen W. A., Carey L. D., Rutledge S. A., da Silva Dias M. A., Radar observations of the kinematic, microphysical, and precipitation characteristics of two MCSs in TRMM LBA, Journal of Geophysical Research: Atmospheres, 2002, vol. 107

Dolan B., Rutledge S. A., A theory-based hydrometeor identification algorithm for X-band polarimetric radars, Journal of Atmospheric and Oceanic Technology, 2009, vol. 26, p. 2071

Doviak R., Zrnic D., Doppler Radar and Weather Observations. Academic Press, San Diego, 1993

Doviak R. J., et al., Doppler radar and weather observations. Courier Corporation, 2006

Fabry F., Radar meteorology: principles and practice. Cambridge University Press, 2015

Fernández-González S., Valero F., Sánchez J., Gascón E., López L., García-Ortega E., Merino A., Analysis of a seeder-feeder and freezing drizzle event, Journal of Geophysical Research: Atmospheres, 2015, vol. 120, p. 3984

Fernández-González S., Wang P., Gascón E., Valero F., Sánchez J., Latent cooling and microphysics effects in deep convection, Atmospheric Research, 2016, vol. 180, p. 189

Ferreira T. A., Análise dinâmica, termodinâmica e microfísica de uma linha de instabilidade com o radar meteorológico móvel mxpol., Tese (Mestradoo em Meteorologia)(IAG-USP). São, SP, 2010, Dissertação de Mestrado

Fisher E. L., An observational study of the sea breeze, Journal of Meteorology, 1960, vol. 17, p. 645 
Freitas E. D., Rozoff C. M., Cotton W. R., Dias P. L. S., Interactions of an urban heat island and sea-breeze circulations during winter over the metropolitan area of São Paulo, Brazil, Boundary-Layer Meteorology, 2007, vol. 122, p. 43

Fujita T. T., McCarthy J., , 1990 in , Radar in meteorology. Springer pp 657-681

Fukao S., Hamazu K., Doviak R. J., Radar for meteorological and atmospheric observations. Springer, 2014

Gan M. A., Rao V. B., Surface cyclogenesis over South America, Monthly Weather Review, 1991, vol. 119, p. 1293

García-Ortega E., Hermida L., Hierro R., Merino A., Gascón E., Fernández-González S., Sánchez J., López L., Anomalies, trends and variability in atmospheric fields related to hailstorms in north-eastern Spain, International Journal of Climatology, 2014, vol. 34, p. 3251

Gochis D. J., Shuttleworth W. J., Yang Z.-L., Sensitivity of the modeled North American monsoon regional climate to convective parameterization, Monthly Weather Review, 2002, vol. 130, p. 1282

Hallak R., Simulações numéricas de tempestades severas na RMSP., Tese (Doutorado em Meteorologia)-(IAG-USP). São Paulo, SP, 2007, Tese de Doutorado

Harper W., Variation with height of rainfall below the melting level, Quarterly Journal of the Royal Meteorological Society, 1957, vol. 83, p. 368

He G.-X., Yu C. W. F., Lu C., Deng Q.-H., The influence of synoptic pattern and atmospheric boundary layer on PM10 and urban heat island, Indoor and Built Environment, 2013, vol. 22 , p. 796

Helmus J. J., Collis S. M., The Python ARM Radar Toolkit (Py-ART), a library for working with weather radar data in the Python programming language, Journal of Open Research Software, 2016, vol. 4

Holton J. R., An introduction to dynamic meteorology, American Journal of Physics, 1973, vol. 41, p. 752 
Holton J. R., Curry J. A., Pyle J., Preface, Encyclopedia of Atmospheric Sciences, SixVolume Set, 2003

Houze Jr R. A., Cloud dynamics. vol. 104, Academic press, 2014

Houze Jr R. A., Smull B. F., Dodge P., Mesoscale organization of springtime rainstorms in Oklahoma, Monthly Weather Review, 1990, vol. 118, p. 613

Ihadua I. M. T. J., et al., Estabelecimento de critérios inovadores para a quantificação da precipitação para a região coberta pelo radar meteorológico de Maceió, 2016

Johnson D. E., Wang P. K., Straka J. M., A study of microphysical processes in the 2 August 1981 CCOPE supercell storm, Atmospheric research, 1994, vol. 33, p. 93

Keenan T., Carbone R., A preliminary morphology of precipitation systems in tropical northern Australia, Quarterly Journal of the Royal Meteorological Society, 1992, vol. 118, p. 283

Kessinger C., Ellis S., Vanandel J., Yee J., The AP clutter mitigation scheme for the WSR88D. In Preprints, 31st Conf. on Radar Meteorology, Seattle, WA, Amer. Meteor. Soc, 2003, p. 526

Khain A., Rosenfeld D., Pokrovsky A., Aerosol impact on the dynamics and microphysics of deep convective clouds, Quarterly Journal of the Royal Meteorological Society: A journal of the atmospheric sciences, applied meteorology and physical oceanography, 2005, vol. 131, p. 2639

Koren I., Kaufman Y. J., Remer L. A., Martins J. V., Measurement of the effect of Amazon smoke on inhibition of cloud formation, Science, 2004, vol. 303, p. 1342

Korolev A., Limitations of the Wegener-Bergeron-Findeisen mechanism in the evolution of mixed-phase clouds, Journal of the Atmospheric Sciences, 2007, vol. 64, p. 3372

Korolev A. V., Isaac G. A., Cober S. G., Strapp J. W., Hallett J., Microphysical characterization of mixed-phase clouds, Quarterly Journal of the Royal Meteorological Society: A journal of the atmospheric sciences, applied meteorology and physical oceanography, 2003, vol. 129, p. 39 
Korolev A. V., Mazin I. P., Supersaturation of water vapor in clouds, Journal of the atmospheric sciences, 2003, vol. 60, p. 2957

Kouketsu T., Uyeda H., Ohigashi T., Oue M., Takeuchi H., Shinoda T., Tsuboki K., Kubo M., Muramoto K.-i., A hydrometeor classification method for X-band polarimetric radar: Construction and validation focusing on solid hydrometeors under moist environments, Journal of Atmospheric and Oceanic Technology, 2015, vol. 32, p. 2052

Kraut I., Separating the Aerosol Effect in Case of a"Medicane". vol. 68, KIT Scientific Publishing, 2015

KUMJIAN M. R., Principles and Applications of Dual-Polarization Weather Radar. Part II: Warm-and Cold-Season Applications., Journal of Operational Meteorology, 2013, vol. 1

Lang T., Dolan B., Guy N., Gerlach C., Hardin J., , 2019 CSURadarmet/CSU_RadarTools: CSU_RadarTools v1.3

Lawson R. P., Woods S., Morrison H., The microphysics of ice and precipitation development in tropical cumulus clouds, Journal of the Atmospheric Sciences, 2015, vol. 72, p. 2429

Lee S.-S., Feingold G., Precipitating cloud-system response to aerosol perturbations, Geophysical Research Letters, 2010, vol. 37

Li R., Min Q., Wu X., Fu Y., Retrieving latent heating vertical structure from cloud and precipitation profiles-Part II: Deep convective and stratiform rain processes, Journal of Quantitative Spectroscopy and Radiative Transfer, 2013, vol. 122, p. 47

Lin H.-M., Wang P. K., A numerical study of microphysical processes in the 21 June 1991 northern Taiwan mesoscale precipitation system, Terrestrial, Atmospheric and Oceanic Sciences, 1997, vol. 8, p. 385

Liu C., Moncrieff M. W., Zipser E. J., Dynamical influence of microphysics in tropical squall lines: A numerical study, Monthly weather review, 1997, vol. 125, p. 2193 
Liu H., Chandrasekar V., Classification of hydrometeors based on polarimetric radar measurements: Development of fuzzy logic and neuro-fuzzy systems, and in situ verification, Journal of Atmospheric and Oceanic Technology, 2000, vol. 17, p. 140

Martinez V. M., Sistema baseado em regras fuzzy do tipo Takagi-Sugeno aplicado a ecos de radares meteorológicos, 2016

Marzano F. S., Botta G., Montopoli M., Iterative Bayesian retrieval of hydrometeor content from X-band polarimetric weather radar, IEEE Transactions on Geoscience and Remote Sensing, 2010, vol. 48, p. 3059

Mason B., Ramanadham R., Modification of the size distribution of falling raindrops by coalescence, Quarterly Journal of the Royal Meteorological Society, 1954, vol. 80, p. 388

Matrosov S. Y., Cifelli R., Kennedy P. C., Nesbitt S. W., Rutledge S. A., Bringi V., Martner B. E., A comparative study of rainfall retrievals based on specific differential phase shifts at X-and S-band radar frequencies, Journal of Atmospheric and Oceanic Technology, 2006, vol. 23, p. 952

Mendes D., Souza E. P., Marengo J. A., Mendes M. C., Climatology of extratropical cyclones over the South American-southern oceans sector, Theoretical and applied climatology, 2010, vol. 100, p. 239

Mie G., Contribution to the optics of suspended media, specifically colloidal metal suspensions, Ann. Phys, 1908, vol. 25, p. 377

Mohan P. R., Srinivas C., Yesubabu V., Baskaran R., Venkatraman B., Simulation of a heavy rainfall event over Chennai in Southeast India using WRF: Sensitivity to microphysics parameterization, Atmospheric Research, 2018, vol. 210, p. 83

Morrison H., Milbrandt J. A., Parameterization of cloud microphysics based on the prediction of bulk ice particle properties. Part I: Scheme description and idealized tests, Journal of the Atmospheric Sciences, 2015, vol. 72, p. 287

Nesbitt S. W., Cifelli R., Rutledge S. A., Storm morphology and rainfall characteristics of TRMM precipitation features, Monthly Weather Review, 2006, vol. 134, p. 2702 
Oliveira A. P. d., Dias S., et al., Aspectos observacionais da brisa marítima em São Paulo, II CBM: Anais 1980-2006, 1982

Oziel M., Korenstein R., Rubinsky B., Radar based technology for non-contact monitoring of accumulation of blood in the head: A numerical study, Plos one, 2017, vol. 12, p. $\mathrm{e} 0186381$

Park H. S., Ryzhkov A., Zrnić D., Kim K.-E., The hydrometeor classification algorithm for the polarimetric WSR-88D: Description and application to an MCS, Weather and forecasting, 2009, vol. 24, p. 730

Parker S. P., Andersen P. H., Mcgraw-Hill Science Reference Series, Physics Today, 1988, vol. 41 , p. 97

Pereira Filho A. J., Chuvas de verão e as enchentes na Grande São Paulo: El Niño, Brisa marítima e ilha de calor. In XI Congresso Brasileiro de Meteorologia, Rio de Janeiro, RJ. Anais... Soc. Bras. Meteorologia , 2000

Pereira Filho A. J., Barros M., Hallak R., Gandú A. W., Enchentes na região metropolitana de São Paulo: aspectos de mesoescala e avaliação de impactos. In XIII CONGRESSO BRASILEIRO DE METEOROLOGIA , 2004

Pereira Filho A. J., Massambani O., Martins P., Cazenave F., An operational mobile XPOL for hydrometeorological applications in Brazil. In 33rd Conference on Radar Meteorology. Paper P , vol. 10, 2007

Pereira Filho A. J., SILVA F. D. S., The morphology of tropical rainfall systems and their hydrological significance. In 32nd conference on radar meteorology, Albuquerque. Boston: American Meteorological Society , 2005

Pereira Filho A. J., Vemado F., Peres J. R., Silva Jr I. W. d., Tanaka K., Measurements of drop size distribution in a megacity, 2013

PEREIRA FILHO A. J., VEMADO F., SAITO K., SEKO H., ROJAS J. L. F., KARAM H. A., ARPS Simulations of Convection during TOMACS, Journal of the Meteorological Society of Japan. Ser. II, 2018 
Probert-Jones J., The radar equation in meteorology, Quarterly Journal of the Royal Meteorological Society, 1962, vol. 88, p. 485

Pruppacher H., Klett J., , 1996 Microphysics of clouds and precipitation, 2nd rev. and enl. ed., Atmospheric and oceanographic sciences library; v. 18

Qin Y., Gong J., Li Z., Sheng R., Assimilation of Doppler radar observations with an ensemble square root filter: A squall line case study, Journal of Meteorological Research, 2014, vol. 28 , p. 230

Raghavan S., Radar meteorology. vol. 27, Springer Science \& Business Media, 2013

Rasmussen R. M., Heymsfield A. J., Melting and shedding of graupel and hail. Part II: Sensitivity study, Journal of the atmospheric sciences, 1987, vol. 44, p. 2764

Rauber R. M., Nesbitt S. W., Radar Meteorology: A First Course. John Wiley \& Sons, 2018

Ray P., Mesoscale meteorology and forecasting. Springer, 2015

Rinehart R. E., Radar for meteorologists. University of North Dakota, Office of the President, 1991

Rinehart R. E., Radar for meteorologists: or you, too, can be a radar meteorologist. Rinehart Publications, 2010

Rogers R., Yau M., , 1989 A short course of cloud physics. Pregamon

Rojas J. L. F., Pereira Filho A. J., Karam H. A., Vemado F., Masson V., Effects of explicit urban-canopy representation on local circulations above a tropical mega-city, Boundarylayer meteorology, 2018, vol. 166, p. 83

Rosenfeld D., Ulbrich C. W., Cloud microphysical properties, processes, and rainfall estimation opportunities, Radar and Atmospheric Science: A Collection of Essays in Honor of David Atlas, 2003, vol. 52, p. 237

Ruzanski E., Chandrasekar V., Nowcasting rainfall fields derived from specific differential phase, Journal of applied Meteorology and Climatology, 2012, vol. 51, p. 1950 
Ryzhkov A., Zrnić D., Comparison of dual-polarization radar estimators of rain, Journal of Atmospheric and Oceanic Technology, 1995, vol. 12, p. 249

Ryzhkov A., Zrnic D., Radar polarimetry at S, C, and X bands: Comparative analysis and operational implications, paper presented at 32nd Conference on Radar Meteorology, Am. Meteorol. Soc., Norman, Okla, 2005

Ryzhkov A., Zrnic D., Doviak R., Zhang P., Development of a classification algorithm for operational polarimetric NEXRAD radar. In IGARSS 2003. 2003 IEEE International Geoscience and Remote Sensing Symposium. Proceedings (IEEE Cat. No. 03CH37477) , vol. 2, 2003, p. 869

Sauvageot H., Radar meteorology. Artech House Publishers, 1992

Schlichting H. J., La belleza cristalina de los copos de nieve, Investigación y ciencia, 2017

Serafin R. J., Meteorological radar, Skolnik, M., Radar Handbook, 2nd Edition, McGrawHill, 1990

Silva F. D. D. S., Pereira Filho A. J., Hallak R., et al., Classificação de sistemas meteorológicos e comparação da precipitação estimada pelo radar e medida pela rede telemétrica na Bacia Hidrográfica do Alto Tietê, Revista Brasileira de Meteorologia, 2009, vol. 24 , p. 292

Simmonds I., Keay K., Mean Southern Hemisphere extratropical cyclone behavior in the 40-year NCEP-NCAR reanalysis, Journal of Climate, 2000, vol. 13, p. 873

Simpson J. E., Sea breeze and local winds. Cambridge University Press, 1994

Sinclair M. R., An objective cyclone climatology for the Southern Hemisphere, Monthly Weather Review, 1994, vol. 122, p. 2239

Snyder J. C., Bluestein H. B., Zhang G., Frasier S. J., Attenuation correction and hydrometeor classification of high-resolution, X-band, dual-polarized mobile radar measurements in severe convective storms, Journal of Atmospheric and Oceanic Technology, 2010, vol. 27, p. 1979

Stephens G. L., Cloud feedbacks in the climate system: A critical review, Journal of climate, 2005, vol. 18, p. 237 
Straka J. M., Zrnić D. S., Ryzhkov A. V., Bulk hydrometeor classification and quantification using polarimetric radar data: Synthesis of relations, Journal of Applied Meteorology, 2000, vol. 39, p. 1341

Szeto K., Stewart R., Effects of melting on frontogenesis, Journal of the atmospheric sciences, 1997, vol. 54, p. 689

Tessendorf S. A., Miller L. J., Wiens K. C., Rutledge S. A., The 29 June 2000 supercell observed during STEPS. Part I: Kinematics and microphysics, Journal of the atmospheric sciences, 2005, vol. 62, p. 4127

Vemado F., Pereira Filho A. J., Severe weather caused by heat island and sea breeze effects in the metropolitan area of São Paulo, Brazil, Advances in Meteorology, 2016, vol. 2016

Vivekanandan J., Adams W., Bringi V., Rigorous approach to polarimetric radar modeling of hydrometeor orientation distributions, Journal of Applied Meteorology, 1991, vol. 30, p. 1053

Vivekanandan J., Ellis S., Oye R., Zrnic D., Ryzhkov A., Straka J., Cloud microphysics retrieval using S-band dual-polarization radar measurements, Bulletin of the american meteorological society, 1999, vol. 80, p. 381

Wang D., Yin J., Zhai G., In-situ measurements of cloud-precipitation microphysics in the East Asian monsoon region since 1960, Journal of Meteorological Research, 2015, vol. 29 , p. 155

Williams E., Rosenfeld D., Madden N., Gerlach J., Gears N., Atkinson L., Dunnemann N., Frostrom G., Antonio M., Biazon B., et al., Contrasting convective regimes over the Amazon: Implications for cloud electrification, Journal of Geophysical Research: Atmospheres, 2002, vol. 107

Yau M. K., Rogers R. R., A short course in cloud physics. Elsevier, 1996

Zrnic D., Balakrishnan N., Ziegler C., Bringi V., Aydin K., Matejka T., Polarimetric signatures in the stratiform region of a mesoscale convective system, Journal of applied meteorology, 1993, vol. 32, p. 678 